\title{
Beyond Greenwash: Environmental Discourses of Appropriation and Resistance
}

\author{
By Keely Kidner
}

A thesis

submitted to the Victoria University of Wellington in fulfillment of the requirement for the degree of Doctor of Philosophy

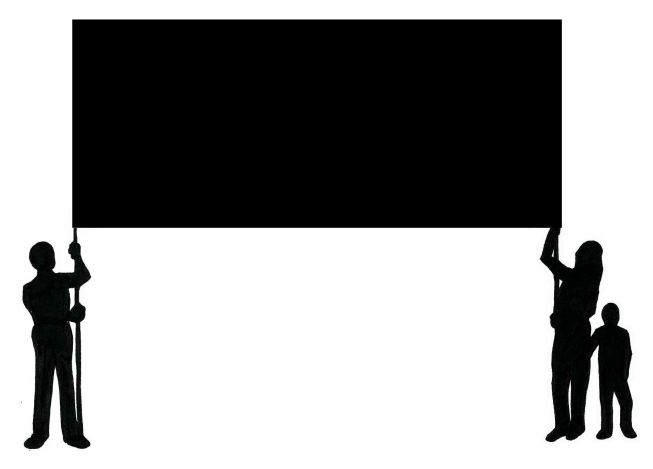

Victoria University of Wellington

(2015) 
For Joyce, Fred, Liam, Allie, Elaine, and Nathanael
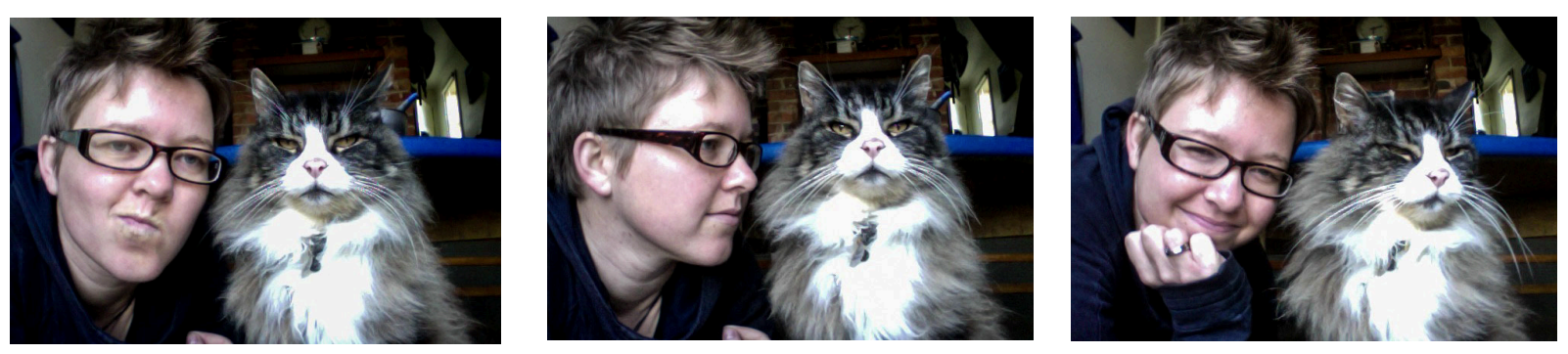


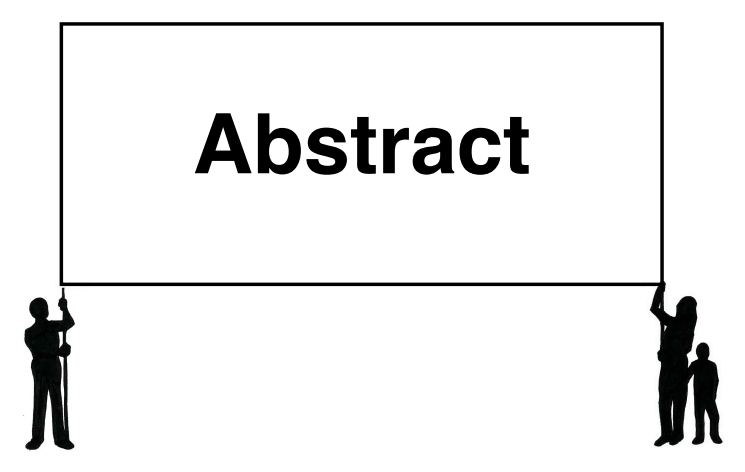

\section{multimodal, critical approach to Discourse allows us to understand contemporary environmental debates in a nuanced way. Fossil fuel mining} has become especially controversial due to the environmental, health, and social impacts, as well as the substantial economic dependence on such development. Wider discussions surrounding mining projects tend to diverge into two major oppositions: that of the industry itself, and that of local activists protesting development on their lands. Research in these areas has leaned towards a focus on the use of environmental language by polluting industries, termed 'greenwash', missing to some degree the ways in which these and other Discourses are articulated multimodally through interaction. This thesis brings a critical, multimodal analysis to controversial mining debates which go 'beyond greenwash', in order to track how Discourses are appropriated, resisted, and re-entextualised.

In this thesis I adopt overlapping critical, multimodal, and ethnographic theoretical lenses to view interaction surrounding two controversial mining case studies: the Athabasca tar sands in Alberta, Canada and a lignite coal mine expansion in Southland, Aotearoa/New Zealand. Drawing upon an understanding of human communication as inherently multimodal, I include video-recorded interviews with both activists and industry representatives, as well as relevant artefacts (such as pamphlets, photographs, signs, etc) in my dataset. Using mediated action as the unit of analysis, I employ Multimodal Interaction Analysis to examine interview interaction, coupled with methods from Social Semiotics to interrogate designed artefacts. These analytical frameworks, viewed through 
combined theoretical lenses, provide a unique perspective on the way Discourses are appropriated and creatively resisted in debates about resource development.

In both case studies, Discourses of the environment and the economy are appropriated by activists and industry actors, forming the basic 'Environment $\mathrm{v}$. Economy' Discourse. This dichotomy is expanded through the appropriation of additional Discourses, such as regional identity in both Southland and Alberta. Activist groups subsequently resist and re-appropriate these regional Discourses by multimodally re-contextualising them. In Alberta, additional Discourses of Indigenous and LGBTQ+ identities are appropriated by industry actors in attempts to legitimise mining expansion. While some of these appropriations draw upon ideas of intersecting oppressions, mining industries fail to adequately address the ways in which resource extraction contributes to those oppressions. However, these actions are both recognised and resisted by local anti-tar sands activists, who use public events and designed artefacts to display their opposition and reappropriate Discourses.

Although both case studies are concerned with similar types of fossil fuel extraction, there are notable differences. Whereas Discourses of the environment, the economy, and regional identity are both appropriated and resisted in Southland and Alberta, it appears that in Alberta, industry actors draw upon a wider variety of Discourses. This may be due, in part, to the fact that the Athabasca tar sands controversy has had a longer development period and more international resistance, meaning there is more pressure to legitimise new and ongoing projects. This has led to a type of 'discursive arms race', where wider Discourses are appropriated as other, more directly-linked, Discourses are exhausted (e.g. the environment). In response, activists in both Southland and Alberta make use of creativity and humour in mundane performances to enact satirical representations of powerful industry actors. While these performances occur regularly in many of my interviews, activists in Alberta also tend to stage elaborate and humorous theatrics in order to criticise government and industry approaches to fossil fuel development. 
The unique framework employed in this thesis has resulted in a number of research implications. These include the combination of Critical Discourse Analysis with a multimodal, ethnographic approach, and the coupling of Multimodal Interaction Analysis with Social Semiotics to expand my analytical reach. Additionally, I have made use of a variety of modes in this thesis' presentation, in order to exploit each mode's affordances and better represent the complexity of my dataset. Finally, from a critical perspective, this research offers an agenda of empowerment for environmental justice activist groups struggling to protect their lands. 


\section{Acknowledgements}

I would like to acknowledge Victoria University of Wellington and the Social Sciences and Humanities Research Council of Canada for the financial support provided by way of scholarships during the researching and writing of this thesis. I am also grateful for the Faculty Research Grants provided by the Faculty of Humanities and Social Sciences which allowed me to both conduct and present this research abroad.

Massive gratitude goes also to my 'officemates' from VZ406 and beyond: Brian, Nick, Ewa, Kieran, Anna, Jenn, Khadij, Emily, Evan, Diego, TJ, Matt, and Jay. Whether it was discussions over beers, cookies, or a hot curry on the Milford track, you've all helped me learn and grow and understand this thesis. And a special shout out to my Big Buddy for your mentorship and for always getting the next round.

Thanks as well to the many fantastic people involved in creating research networks at Vic: to the LALS Thesis Group in all its incarnations, to the various Shut Up \& Write groups, to RNWOD, to the STSP discussion group, to those with whom I worked in SACL, to the many conference delegates who discussed these issues with me, and of course to the DAGgers for our conversation and data sessions. A special thanks to everyone in LALS: I feel very lucky to have landed in this school at this time, as there is an atmosphere of collegiality here that is indeed rare to find.

I would especially like to thank my co-researcher Dr. Nicole Nolette for her help in conducting interviews for this project. It has been wonderful to go through this thesis experience with you as a supportive and understanding friend.

Of course I have also been lucky enough to have had an incredible team of supervisors. As scholars, Professor Janet Holmes and Dr Meredith Marra have been genuine role models and a source of inspiration. The way that they work 
together to lead, challenge, encourage, and care for students is truly impressive. Thank you so much for your time and commitment to your students and this school. Your work is appreciated by many.

Thanks to my family (scattered all over the globe) for accepting my need for work hours during holiday times. I also wish to thank my husband Nathanael for his support throughout this entire process. Thank you for not only putting up with, but continuously encouraging and supporting all the travel, and time l've spent involved in my writing and analysis. As always, you have been a pillar of patience and reassurance.

And finally, I owe a debt of gratitude to my participants in Southland and Alberta. After so much time spent on ferries, trains, and buses, l've been touched by the genuine hospitality I experienced at my destinations. Thank you especially to the Southland farming community for making me feel included and lending me a pair of gumboots and a hammer, and to the people of Treaty 6 and 8 Territories, for giving me a safe place to rest both physically (Bern) and emotionally. I reserve a special acknowledgement for those on the frontlines of tar sands expansion: your perseverance and strength is an inspiration. 


\section{Table of contents}

\begin{tabular}{|l|r|}
\hline List of Figures and Tables & $\mathbf{x i}$ \\
\hline Glossary & $\mathbf{x v i}$ \\
\hline 1 Why Research Mining? & $\mathbf{1}$ \\
\hline 1.2 Why a Critical Perspective? & 4 \\
\hline 1.3 Why a Multimodal Perspective? & 5 \\
\hline 1.4 Why an Ethnographic Perspective? & 6 \\
\hline 1.5 The Canadian Case Study & 7 \\
\hline 1.5.1 The Athabasca Tar Sands & 10 \\
\hline 1.6 The Aotearoa/New Zealand Case Study & 16 \\
\hline 1.7 Discourses of Appropriation and Resistance & 18 \\
\hline 1.8 Resource Extraction and Climate Justice & 21 \\
\hline 1.9 Thesis Structure & 23 \\
\hline 2 Theoretical Approaches & $\mathbf{2 5}$ \\
\hline 2.1 Critical Approaches & 25 \\
\hline 2.1.1 A Critical Approach to Discourse & 25 \\
\hline 2.1.2 Critical Approaches and the Focus on Context & 29 \\
\hline 2.1.3 Empowerment Agendas & 31 \\
\hline 2.1.4 CDA and Subjectivity & 32 \\
\hline 2.2 Appropriation and Resistance & 34 \\
\hline 2.3 Multimodality & 39 \\
\hline 2.3.1 Gesture & 52 \\
\hline 2.4 Ethnography & 54 \\
\hline 2.4.1 Linguistic Ethnography & 42 \\
\hline
\end{tabular}




\begin{tabular}{|l|r|}
\hline 2.5 Conclusion & 55 \\
\hline 3 Methodological Tools & 59 \\
\hline 3.1 Ethnography: Giving Voice to Participants & 59 \\
\hline 3.2 Becoming an Ethnographer & 63 \\
\hline 3.3 Multimodal Interaction Analysis & 67 \\
\hline 3.4 Social Semiotics & 71 \\
\hline 3.5 Conceptualising the Interview & 84 \\
\hline 3.5.1 Conducting Interviews & 87 \\
\hline 3.5.2 Processing Interviews & 94 \\
\hline 3.6 Summary & 97 \\
\hline 3.7 Analytical Design & 100 \\
\hline 4 Environment v. Economy: An Embodied Discourse & 103 \\
\hline 4.1 Environment v. Economy in Interviews & 105 \\
\hline 4.2 Conclusion & 117 \\
\hline 5 Regional Identities in Focus & 119 \\
\hline 5.1 Alberta is Oil & 121 \\
\hline 5.2 Resistance to 'Alberta is Oil' & 131 \\
\hline 5.2.1 Alternatives to 'Alberta is Oil' & 133 \\
\hline 5.3 Multimodal Entextualisation: Purely Albertan & 141 \\
\hline 5.4 Southland Identities: Close-knit, Rural Farmers & 176 \\
\hline 5.5 Multimodal Entextualisation: Wolves in Sheep's Clothing & 164 \\
\hline 5.6 Appropriation, Resistance, and Entextualisation & 167 \\
\hline Indigenous Discourses in Focus & 170 \\
\hline 6.1 Discourse Appropriation & 178 \\
\hline 6.1.1 Appropriating Bison & 169 \\
\hline 6.1.2 Appropriating Language & 16 \\
\hline
\end{tabular}




\begin{tabular}{|c|c|}
\hline 6.2 Aboriginal 'Opportunities' & 183 \\
\hline 6.3 Aboriginal Opportunities: Another View & 190 \\
\hline 6.4 Multimodal Resistance: Alternative Economies in Fort Chip & 208 \\
\hline 6.5 Public Relations & 216 \\
\hline 6.6 Conclusion & 225 \\
\hline 7 LGBTQ+ Discourses in Focus & 229 \\
\hline 7.1 Intersectionality: A Theory From the Grassroots & 229 \\
\hline 7.2 Pinkwashing the Tar Sands & 232 \\
\hline 7.2.1 EQUAIA & 234 \\
\hline 7.3 Complicated Intersections: Pride, Palestine and the Tar Sands & 242 \\
\hline 7.4 Multimodal Entextualisations & 251 \\
\hline 7.5 Conclusion & 263 \\
\hline 8 Representing the Opposition & 267 \\
\hline 8.1 Play and Creativity as Strategic Resources & 283 \\
\hline $\begin{array}{l}\text { 8.2 The Discursive Arms Race in Canada and Aotearoa/New } \\
\text { Zealand }\end{array}$ & 298 \\
\hline 9. Reflexive Reflections at the Intersections & 305 \\
\hline 9.1 Becoming a Participant: Reconsidering the Researcher & 306 \\
\hline 9.1.2 The Toilet Lady: Becoming an Organiser & 308 \\
\hline 9.1.3 The Note-taker: Forced Positionings and Resistance & 310 \\
\hline 9.1.4 The Student: Claiming Control & 312 \\
\hline 9.1.5 Returning Home & 316 \\
\hline 9.1.6 The Researcher: Stepping Back & 318 \\
\hline 9.1.7 The Activist: Going Undercover & 320 \\
\hline 9.2 Resources for Positioning & 322 \\
\hline 10: Conclusions and Implications & 325 \\
\hline
\end{tabular}




\begin{tabular}{|l|r|}
\hline 10.2 Theoretical Implications & 328 \\
\hline 10.3 Analytical Implications & 329 \\
\hline 10.4 Implications for Data Collection and Presentation & 330 \\
\hline 10.5 Implications for Activists & 331 \\
\hline 10.6 Further Research & 332 \\
\hline 10.7 Closing Remarks & 333 \\
\hline References & 335 \\
\hline Appendix A: Cast of Actors & 356 \\
\hline Appendix B: Interviewing Confidentiality Agreement & 359 \\
\hline Appendix C: Information Sheet & 360 \\
\hline Appendix D: Consent Form & 361 \\
\hline Appendix E: Ethics Approval & 362 \\
\hline Appendix F: Transcription Conventions & 363 \\
\hline
\end{tabular}




\section{List of Figures and Tables}

Figures

\begin{tabular}{|c|c|}
\hline 1.1: Numbered Treaties & 8 \\
\hline 1.2: Bitumen & 11 \\
\hline 1.3: Tailings Pond & 12 \\
\hline 1.4: Alberta & 13 \\
\hline 1.5: Southland & 17 \\
\hline 1.6: Ethical Oil & 19 \\
\hline 1.7: $100 \%$ Pure & 20 \\
\hline 2.1: Iconic Gesture & 44 \\
\hline 2.2: Metaphoric Gesture & 45 \\
\hline 2.3: Beats & 46 \\
\hline 2.4: Cohesive Gesture & 47 \\
\hline 2.5: Performative Gesture & 49 \\
\hline 2.6: Modal Gesture & 50 \\
\hline 2.7: Interactive Gesture & 51 \\
\hline 2.8: Theoretical Lenses & 55 \\
\hline 3.1: Layout and Modal Density & 68 \\
\hline 3.2: Layout and Multimodal Configuration & 70 \\
\hline 3.3: Mining Diagram & 73 \\
\hline 3.4 Lignite Marketing Image & 75 \\
\hline 3.5: Approaches Conceptualized as Lenses and Reversed & 78 \\
\hline 3.6: Protest Button & 79 \\
\hline 3.7: Bitumen Painting & 82 \\
\hline 3.8: Equipment Set-up & 89 \\
\hline
\end{tabular}




\begin{tabular}{|l|r|}
\hline 3.9: Interview Description and Notation & 95 \\
\hline 3.10: ELAN Transcription Software & 96 \\
\hline 3.11: Methodologies and Theoretical Approaches & 99 \\
\hline 4.1 'Environment v. Economy' Artefacts & 105 \\
\hline 4.2: Alanis & 107 \\
\hline 4.3: Alanis & 108 \\
\hline 4.4: Alanis & 110 \\
\hline 4.5: Christina & 112 \\
\hline 4.6: Christina & 114 \\
\hline 4.7: Christina & 115 \\
\hline 5.1: 'Alberta is Oil' & 124 \\
\hline 5.2: Piece of Alberta & 125 \\
\hline 5.3: Fort McMurray Postcards & 126 \\
\hline 5.4: Alberta's Oil Sands & 127 \\
\hline 5.5: Greenpeace Artefact & 135 \\
\hline 5.6: Tom & 137 \\
\hline 5.7: Tom & 138 \\
\hline 5.8: Tom & 139 \\
\hline 5.9: Tom & 141 \\
\hline 5.10: Andrea & 143 \\
\hline 5.11: Andrea & 146 \\
\hline 5.12: Andrea & 152 \\
\hline 5.13: Justin & 156 \\
\hline 5.14: Mining Footprint & 147 \\
\hline 5.15: Mining Process & 139 \\
\hline 5.16: Field Days & 139 \\
\hline
\end{tabular}




\begin{tabular}{|l|r|}
\hline 5.17: Southland Pamphlet & 160 \\
\hline 5.18: Southland Pamphlet & 162 \\
\hline 6.1: Wood Bison Toy & 168 \\
\hline 6.2: Wood Bison Viewpoint & 170 \\
\hline 6.3: Wood Bison Viewpoint & 171 \\
\hline 6.4: Wood Bison Viewpoint & 172 \\
\hline 6.5: Wood Bison Viewpoint & 173 \\
\hline 6.6: Wood Bison Viewpoint & 174 \\
\hline 6.7: Wood Bison Viewpoint & 175 \\
\hline 6.8: Matcheetawin & 177 \\
\hline 6.9: Matcheetawin & 178 \\
\hline 6.10: Sagow Pematosowin & 179 \\
\hline 6.11: Sagow Pematosowin & 181 \\
\hline 6.12: Brandon & 184 \\
\hline 6.13: Brandon & 185 \\
\hline 6.14: Brandon & 188 \\
\hline 6.15: CAPP Booklet & 189 \\
\hline 6.16: Quotative Gesture & 192 \\
\hline 6.17: Denise & 194 \\
\hline 6.18: Denise & 209 \\
\hline 6.19: Denise & 205 \\
\hline 6.20: Denise & 204 \\
\hline 6.21: Brainwash Gesture & 196 \\
\hline 6.22: Denise & 201 \\
\hline 6.23: Denise & 195 \\
\hline 6.24: Denise & 17 \\
\hline
\end{tabular}




\begin{tabular}{|c|c|}
\hline 6.25: Denise & 213 \\
\hline 6.26: Denise & 214 \\
\hline 6.27: Denise & 217 \\
\hline 6.28: Denise & 219 \\
\hline 6.29: Denise & 221 \\
\hline 6.30: Healing Walk & 222 \\
\hline 6.31: Cowboys and Indians Alliance & 224 \\
\hline 7.1: Terminology & 233 \\
\hline 7.2: EQUAIA & 235 \\
\hline 7.3: 'Ethical Oil' & 236 \\
\hline 7.4: William & 239 \\
\hline 7.5: Our Pride is Political & 243 \\
\hline 7.6 Parade Signs & 245 \\
\hline 7.7: Pamphlet & 246 \\
\hline 7.8: Pamphlet & 247 \\
\hline 7.9: Pamphlet & 248 \\
\hline 7.10: Pamphlet & 250 \\
\hline 7.11: T-shirt & 255 \\
\hline 7.12: William & 256 \\
\hline 7.13: William & 259 \\
\hline 8.1: $\mathrm{Al}$ & 269 \\
\hline 8.2: Al & 272 \\
\hline 8.3: Brandon & 273 \\
\hline 8.4: Brandon & 275 \\
\hline 8.5: Greenpeace Booklet & 278 \\
\hline 8.6: EQUAIA Banner & 279 \\
\hline
\end{tabular}




\begin{tabular}{|l|r|}
\hline 8.7: Southland Coal Bags & 280 \\
\hline 8.8: Industry Artefacts & 281 \\
\hline 8.9: Field Days Stalls & 282 \\
\hline 8.10: Denise & 285 \\
\hline 8.11: Denise & 287 \\
\hline 8.12: Denise & 289 \\
\hline 8.13: Jill & 291 \\
\hline 8.14: Jill & 293 \\
\hline 8.15: Discursive Arms Race & 300 \\
\hline
\end{tabular}

\section{Tables}

\begin{tabular}{|l|r|}
\hline 3.1: Data Collection Trips & 64 \\
\hline 7.1: EQUAIA Timeline & 252 \\
\hline
\end{tabular}




\section{Glossary}

\begin{tabular}{|c|c|}
\hline Artefact & $\begin{array}{l}\text { Designed item such as pamphlet, information sheet, button, } \\
\text { etc. }\end{array}$ \\
\hline $\begin{array}{l}\text { Athabasca tar } \\
\text { sands }\end{array}$ & $\begin{array}{l}\text { A deposit of bitumen-rich sand located in northeastern } \\
\text { Alberta. }\end{array}$ \\
\hline ACFN & Athabasca Chipewyan First Nation. \\
\hline AYTF & $\begin{array}{l}\text { Aboriginal Youth Task Force, industry-supported groups } \\
\text { which visit Indigenous community schools. }\end{array}$ \\
\hline Bitumen & $\begin{array}{l}\text { Petroleum-like substance found in the Athabasca tar sands } \\
\text { which can be refined into oil and oil-based products. }\end{array}$ \\
\hline $\mathrm{BH}, \mathrm{RH}, \mathrm{LH}$ & Both hands, right hand, left hand. \\
\hline CAPP & $\begin{array}{l}\text { Canadian Association of Petroleum Producers, an } \\
\text { organisation representing oil and gas extraction companies } \\
\text { operating in Canada. }\end{array}$ \\
\hline CDA & Critical Discourse Analysis. \\
\hline CRT & Critical Race Theory \\
\hline Dene & Indigenous language used in Treaty 8 Territory \\
\hline DIY & $\begin{array}{l}\text { Do-it-yourself, a cultural movement characterised by values } \\
\text { of sustainability, accessibility, and self-sufficiency. }\end{array}$ \\
\hline EQUAIA & Edmonton Queers Against Israeli Apartheid. \\
\hline Field Days & $\begin{array}{l}\text { Annual rural farming expo, consisting of events and stalls } \\
\text { representing businesses and organisations. }\end{array}$ \\
\hline $\begin{array}{l}\text { Fort } \\
\text { Chipewyan }\end{array}$ & $\begin{array}{l}\text { First Nations community located downstream from the } \\
\text { Athabasca tar sands in Treaty } 8 \text { Territory (northern Alberta). }\end{array}$ \\
\hline Fort McKay & $\begin{array}{l}\text { First Nations community located just north of Fort } \\
\text { McMurray, surrounded by Athabasca tar sands mines. }\end{array}$ \\
\hline
\end{tabular}




\begin{tabular}{|c|c|}
\hline Fort McMurray & $\begin{array}{l}\text { City in northern Alberta, located closest to the Athabasca } \\
\text { tar sands. }\end{array}$ \\
\hline Greenwash & $\begin{array}{l}\text { The use of environmental Discourses to appear } \\
\text { environmentally friendly, while continuing unsustainable } \\
\text { practices. }\end{array}$ \\
\hline Iwi & Māori nations or tribes. \\
\hline Lignite & $\begin{array}{l}\text { Brown/low-grade form of coal, characterised by low energy } \\
\text { density and high water content. }\end{array}$ \\
\hline LGBTQ+ & $\begin{array}{l}\text { Lesbian, Gay, Bisexual, Trans*, Queer, (Intersex, } \\
\text { Questioning, 2-Spirit, Asexual, Ally) identities }\end{array}$ \\
\hline MIA & Multimodal Interaction Analysis. \\
\hline $\begin{array}{l}\text { Oil Sands } \\
\text { Discovery } \\
\text { Centre }\end{array}$ & $\begin{array}{l}\text { A government-run, interactive museum located in Fort } \\
\text { McMurray. }\end{array}$ \\
\hline Pākeha & New Zealander of European descent. \\
\hline Pinkwash & $\begin{array}{l}\text { The use of LGBTQ+ rights to cover/distract from human } \\
\text { rights abuses. }\end{array}$ \\
\hline Pride Parade & $\begin{array}{l}\text { Annual celebration of LGBTQ+ identities in many large } \\
\text { cities around the world. }\end{array}$ \\
\hline Southland & $\begin{array}{l}\text { Area in the south of the South Island in Aotearoa/New } \\
\text { Zealand where the proposed lignite mine expansion is } \\
\text { located. }\end{array}$ \\
\hline Turtle Island & $\begin{array}{l}\text { Indigenous name for North America (Canada, USA, } \\
\text { Mexico). }\end{array}$ \\
\hline $\begin{array}{l}\text { Treaty } 8 \\
\text { Territory }\end{array}$ & $\begin{array}{l}\text { Area encompassing parts of northern BC, Alberta and } \\
\text { Saskatchewan and part of southern Northwest Territories. }\end{array}$ \\
\hline SAGD & $\begin{array}{l}\text { Steam-assisted Gravity Drainage, a form of tar sands } \\
\text { extraction using super-heated water to melt bitumen into } \\
\text { horizontally-drilled pipes. }\end{array}$ \\
\hline
\end{tabular}


Tailings ponds Massive lakes built with earthen dykes to hold leftover water, chemicals, and residual bitumen after extraction. 


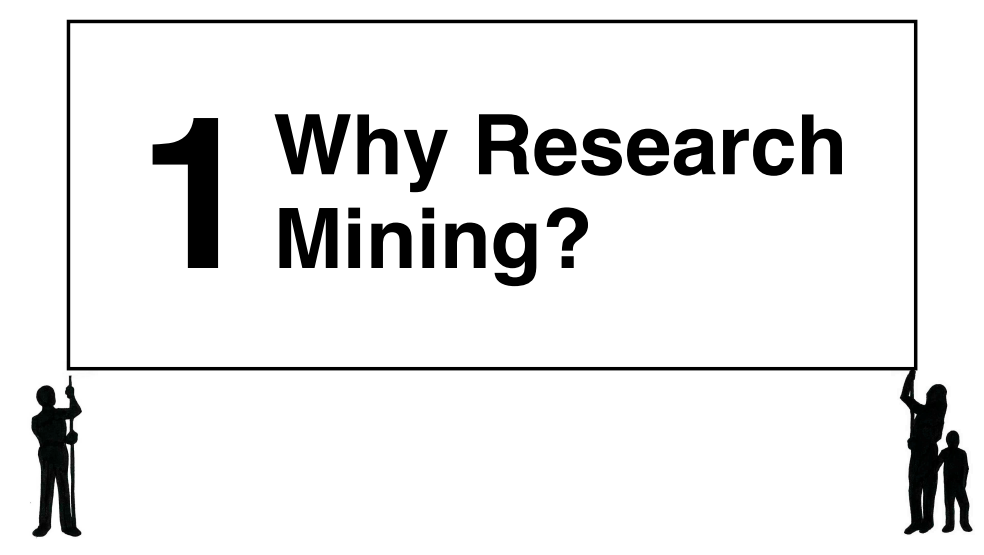

The ways in which Discourses affect our lives, and the power that they hold, became clear to me through a massive hole in the Earth. The first time I visited the Athabasca tar sands, I had already been living in Alberta for a number of years. As a newcomer from neighbouring British Columbia, I was at first struck by my new provincial home's emphasis on oil. Oil was everywhere: in the news, in dinner conversations, in the names of buildings, streets, and even hockey teams. Discussions about the 'tar sands' or 'oil sands' dominated my social circles as I befriended locals who were concerned with the rate of development and the impact on their communities. It wasn't long before a visit to the source of Alberta's oil wealth became a personal goal and, in the summer of 2007, I traveled Highway 63 to Fort McMurray along with a small cohort of student organisers. I was struck by the rugged beauty of the boreal forest, the long summer days, and the vastness of northern Alberta. I was also struck by the surprising size of the city as it suddenly emerged from the greenery, the unending tailings lakes to the north, and the constant stench of tar. A week after my trip, a delayed and gloomy melancholy overcame me as I struggled to come to terms with what I had seen. This, it turns out, was a common feeling amongst those of us who had viewed the mines. After so many years spent seeing photographs and reading testimonies, the tar sands were suddenly and horribly real.

Over the next few years, I became more interested in how the mines were talked about, portrayed, and argued over in the public sphere. In private conversation, nuanced issues could be brought to the fore while in public, 
dichotomies became more and more entrenched. It seemed practically impossible to discuss oil without adopting a 'pro' or 'anti' mining position. In fact, the very practice of naming either tar or oil sands brings with it a pre-determined political stance (Katz-Rosene, 2012; Kidner, 2012). As the tar sands have grown, so have environmental concerns. Many companies have since made use of environmental language in their marketing strategies, also known as 'greenwash' (e.g. Devauld \& Green, 2010). In response, those who question the pace of development have been met with accusations of radicalism and extremism (Payton, 2012), antiCanadian sentiment (EthicalOil.org, 2014), and questionable ethics (Levant, 2010). It is this divided space in which my thesis found its genesis.

As climate change continues unabated, mining proposals all over the world are met with increasing resistance. It is important to stress, however, that these projects have always been met with resistance from land-based peoples who have historically benefited little from development (e.g. IEN, 2011). The cases explored in this thesis provide a useful comparison of two nation states in which locals struggle against industrial development. In Canada, I examine the Athabasca tar sands and in Aotearoa/New Zealand, I examine a proposed lignite coal mine in Southland. As these struggles come to the forefront of environmental debates, the discursive situation surrounding them becomes increasingly polarised and ideological. In this atmosphere, multimodal actions at the micro level are crucial to how such projects move forward, or not, at a macro level.

Due to the ideological nature of mining, I choose to approach environmental debates as sites of community struggle and inequality ${ }^{1}$. Considering the various social and environmental issues surrounding the tar sands and the lignite project, I aim to conduct my research in ways that do not continue to harm already

\footnotetext{
${ }^{1}$ As I recognise that many terms used to describe these communities are problematic in the way they position them as disempowered (i.e. Graham, 2009), I use the terms communities of struggle and communities of resistance. In using these terms, I wish to acknowledge not only historical and ongoing power imbalances, but also the fact that these communities continue to confront and resist the oppressions they face.
} 
vulnerable communities. This alignment locates each case within the framework of climate justice, orienting to the inequalities that characterise many mining projects.

Within sociolinguistics, there are approaches to discourse analysis which provide affordances for such inequalities. Discourse Theory engages with larger societal and structural Discourses (Gee, 1999) in instances of social struggle but in this tradition text is considered unbounded (i.e. everything can be "text"), a rather nebulous concept (Fairclough, 1995). At the other extreme, Conversation Analysis occupies itself with everyday language use and, in its focus on the micro interactions of interlocutors, tends to ignore the wider sociocultural context that brings power differences into interaction (Billig, 1999). Critical Discourse Analysis (CDA) on the other hand, brings power and inequality to the fore as a crucial element of analysis and even seeks to empower the communities with which it works (Billig, 1999; Blommaert, 2005; Van Dijk, 1993). CDA is also consistent with an ethnographic approach to community engagement and data collection. Above all, CDA recognises that actions on a micro level lead to social change and that Discourse is therefore powerful and thus "worth struggling over" (Wodak \& Fairclough, 2010, p. 103).

In this thesis, I employ a number of tools to temporarily unravel the threads which make up the complicated tapestry of environmental struggles. These threads consist of micro interactions, in the form of video-recorded interviews, collected artefacts (e.g. pamphlets, signs, photographs), and detailed ethnographic notes. By teasing apart and examining the actions used by various social actors, I aim to illuminate the complexity of the positions people take up in order to negotiate the mining proposals. In this way, I metaphorically step back to see the larger patterns on a macro level, as they are made apparent through mediated action on a micro level.

When examining controversial mining projects, an understanding of the background of each case (in Canada and Aotearoa/New Zealand) is crucial. My research questions raise a number of issues, from the need for critical, multimodal, 
and ethnographic approaches, to the history and development of resource extraction and resistance Discourses by locals and international actors alike. In the following discussion, I will outline the aims and motivations for my research framework, as well as provide a brief background to help contextualise the mining projects on which I will focus.

\subsection{Why a Critical Perspective?}

Because this research considers case studies as sites of inequality and struggle, I adopt a framework that allows me to examine power. Power, in this case, is approached from a Foucauldian perspective as something which "only exists in action" as opposed to something which can be given or exchanged (Foucault, 1980b, p. 89). Considered within a multimodal framework, these actions enact, reflect, and reproduce wider Discourses in the form of higher-level action units (Norris, 2004b, p. 102). Power then circulates through society in the form of Discourse-in-action, creating and legitimising forms of knowledge and truth (Foucault, 1980b, p. 93; Foucault, 1980a 119). This thesis therefore focuses on power-infused action as the basic unit of analysis, whether it be speech, gesture, gaze, or other modes.

Individuals as well as Discourses are naturally entangled in the workings of power, being constituted through it while at the same time acting as its vehicle (Foucault, 1980b, p. 98, Wodak \& Fairclough 2010, p. 103). Power through Discourse can emerge in various ways: as the ability to control and change basic discursive practice and structures, as the ability to produce knowledge, and even as a way of upholding or creating institutionalised practices (Bäckstrand \& Lövbrand, 2007, p. 125; Van Dijk, 1996; Wodak \& Fairclough, 2010, p. 103). In this orientation, language becomes a non-neutral medium that can be used to construct social relations that are characterised by inequalities but which also reflect and contribute to social processes and structures (Hansen \& Machin, 2008, p. 780). 
Yet, these abilities do not go unchallenged: the exercise of power is very much a dialectal, negotiated, and contested process (Wodak \& Fairclough 2010, p. 103). Because of this dialogic relationship between the communicative and the sociological, it is important to analyse not just text, but also its interpretations, reception, and effects (Wodak \& Fairclough, 2010, p. 105). Foucault suggests examining the workings of power in action as opposed to the motivations behind it (1980b, p. 97). He calls for a focus on the micro, the processes of power at its lowest level, and then extension to a macro analysis (1980, p. 100). This means that an analysis of power should be an analysis of "the techniques and tactics of domination" (Foucault, 1980b, p. 102). Ultimately, power produces inequality by stratifying, categorising, and dividing people and so a versatile discourse analysis "takes difference and inequality as points of departure" ${ }^{2}$ (Blommaert, 2005, pp. $154,236)$. My preoccupation with discursive sites of inequality such as controversial mining projects, positions this research within a critical tradition. This thesis will explore power-in-action by examining how texts are interpreted and reinterpreted through processes of entextualisation.

Additionally, in keeping within a critical tradition, this thesis will aim to "have effects on society" (Blommaert, 2005, p. 25). Because of this, the primary aim of this thesis is to "contribute to a specific discipline, paradigm, school or discourse theory" by engaging with "pressing social issues, which it hopes to better understand through discourse analysis" (Van Dijk, 1993, p. 252).

\subsection{Why a Multimodal Perspective?}

Contemporary communication practices are characterised by interconnecting, globalised diversities and mobile technologies (Blommaert, 2012; Cresse \& Blackledge, 2010). As researchers of language, Discourse analysts are recognising the need to develop their approaches in order to reflect these complexities in their analyses (Blommaert, 2005; Van Dijk, 1993). Many scholars have therefore called

\footnotetext{
2 Blommaert makes extensive use of italics and, throughout this thesis, all italics quoted are in the original unless otherwise noted.
} 
for a wider multimodal approach within critical research (Fairclough, 1995; Machin, 2013; Van Leeuwen, 2005); this thesis takes up this call.

Like other contemporary discussion topics (e.g. Vestergaard, 2013), mining debates are characterised multimodally through the use of visual productions (such as pamphlets, information sheets, protest buttons, etc.), which I refer to as 'artefacts' (cf. Kress \& Van Leeuwen, 2001). These artefacts play an important role in the marketing of and resistance to mining expansion and will therefore be incorporated into the analysis of wider Discourses in this thesis ${ }^{3}$.

In much the same way that considerations about layout, colour, and other aspects of design are meaningful (see Kress \& Van Leeuwen, 2006), interactive actions such as gesture, gaze, and others, create meaning beyond spoken language (Jewitt, 2009; Norris, 2011). I will therefore also extend my analytic lens to include multimodal action in interaction (cf. Norris, 2011).

By combining multimodal interaction analysis (MIA) (e.g. Norris, 2004b) and Social Semiotics (e.g. Kress \& Van Leeuwen, 2006) into an integrated framework, I am able to analyse and track the various Discourses which are made relevant by each side in the mining debates. This will give a broader contextual picture of Discourse as action, that is made visible through interaction. To do so, I conduct video-recorded interviews with individuals involved on either side of the debate: industry representatives and activists in both Canada and Aotearoa/New Zealand. Additionally, I collect any relevant artefacts to form my multimodal dataset.

\subsection{Why an Ethnographic Perspective?}

Ethnography embraces and utilises multiple analytical methods to examine the complexity of social interaction within communities (Blommaert \& Jie, 2010).

\footnotetext{
${ }^{3}$ All artefacts reproduced in this thesis are done so with permission. In cases where I did not obtain permission, I have removed the image after the examination of the thesis. When possible, I have also included links to online versions of the removed images, however, I have not done this for images belonging to specific companies so as to maintain their anonymity.
} 
Such an approach aims to present a "longitudinal, contextualised, sociocultural "perspective"...even if the research design itself is not longitudinal" (Duff, 2008, p. 113). Additionally, ethnographers have examined communities of which they are part (Duff, 2008), creating an inside-out stance, where researchers seek "to get analytic distance on what's close-at-hand, rather than a move from the outside inwards, trying to get familiar with the strange," (Rampton, 2007, p. 591). Following such precedents, I examine two communities of which I am a part as an active participant. Like Scollon and Scollon, I recognise that my own actions as an analyst have consequences as I take an engaged stance (2007, p. 615) but I also recognise that this is to be expected and therefore necessitates reflexivity of ethnographic knowledge itself (Blommaert, 2007a, p. 682). Such reflexivity is also important to critical and Indigenous methodologies as the history of research work with such communities has been fraught with colonial tendencies (Jones \& Jenkins, 2008; Smith, 1999).

An ethnographic approach also helps researchers gain trust with communities of struggle (Emihovich, 2005) and to develop deeper analytical understandings (Blommaert \& Jie, 2010). Because I am a part of the activist communities presented in this thesis, I will also consider the various positionings and impacts of my own role as a critical scholar through reflexivity (Sarangi \& Candlin, 2003). In sum, adopting an ethnographic approach allows me to gain access and trust with vulnerable communities, interpret and analyse data, and problematise my own role(s). My positionings are therefore made relevant to my project, especially as a researcher who brings a history working with tar sands activism in Canada.

\subsection{The Canadian Case Study}

As this thesis takes a critical perspective which examines the workings of power, it is appropriate to discuss the historical, colonial context of Turtle Island and the nation state of Canada. Canada's relationship with Indigenous nations was formerly recognised through a series of numbered treaties (Figure 1.1). As settlers arrived, the Canadian government signed treaties with Native groups which 
relinquished land to the Crown in exchange for cash, hunting rights, and 'reserves': non-indigenous territories subsequently governed by the Indian Act (Usher, Tough, \& Galois, 1992, p. 115). However, many treaties were problematic in that they did not reflect the full negotiations, or there existed differences between versions (Usher et al., 1992). As a result, contemporary understandings of what the treaties entailed differ.

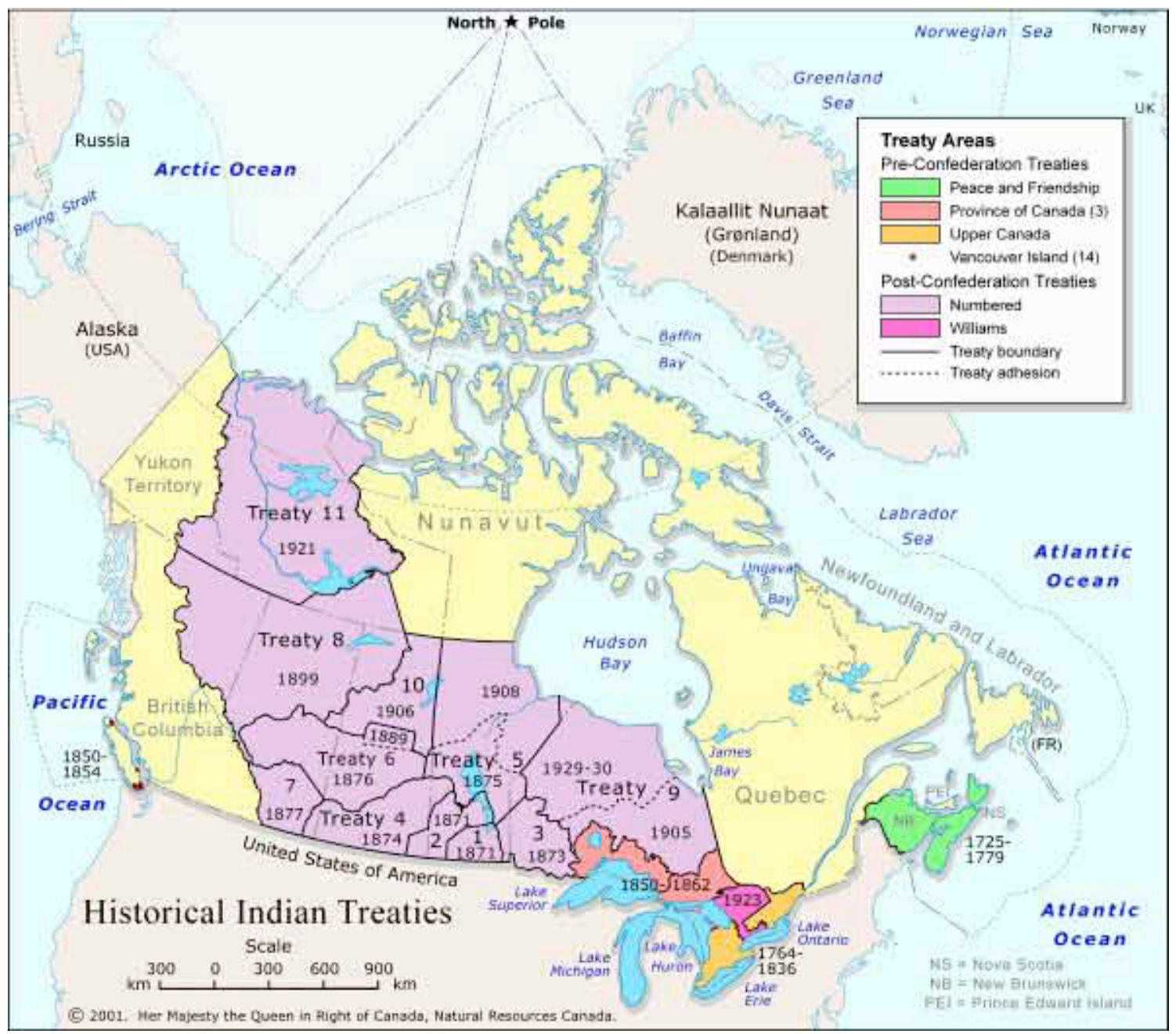

Figure 1.1: Numbered Treaties ${ }^{4}$

The tar sands is located within Treaty 8 territory, which spans across the subarctic range of northern Saskatchewan, Alberta, and BC (with British Columbia being

${ }^{4}$ Image used with permission from http://firstpeoplesofcanada.com/fp treaties/ fp treaties confedandtreatieswest.html 
joined later), and Indigenous communities living within this area include the Woodland Cree, Dunneza, and Chipewyan. Like many treaties, Treaty 8 was prompted by resource development (the Yukon gold rush), and local Nations signed, ensuring them hunting and fishing rights (Fumoleau, 2004). More specifically, the treaties established aboriginal rights, which are "basic rights of existence as distinct peoples or 'nations', including the right to selfgovernment" (Usher et al., 1992, p. 112). The right to land, known as aboriginal title, was established based on evidence of "continuous use and occupancy by native peoples prior to the effective assertion of European sovereignty" (Usher et al., 1992, p. 113). In contemporary land claim negotiations, the Canadian government has attempted to extinguish these rights, "in exchange for a limited but defined set of benefits" (Usher et al., 1992, p. 113).

After treaties were signed, the Indian Act was established to govern Indigenous communities. In the late 1800 s, the act was amended, forcing around 150,000 Indigenous children into residential schools (Gwiazda, 2014), many of whom were stolen from their families. Scattered throughout the country, these schools imposed Christian doctrine and outlawed Native languages, cultural practices, and clothing (Hill, 2009). The schools were also sites of sexual, physical, and emotional abuse, resulting in a generation of traumatised children (Hill, 2009). In 2008, the Truth and Reconciliation Commission was created to investigate the stories of survivors and create a final report documenting the extent of abuse (Gwiazda, 2014).

It is important to note that Indigenous peoples have staged resistance to the attacks on their communities and the mismanagement of treaties from their very inception. Usher et al. argue that Native leaders approached the treaty process with a well-reasoned set of demands and negotiations in order to ensure an economic future for their people (1992, p. 118). While the Canadian government has developed various initiatives to extinguish rights and title (e.g. outlawing fundraising for land claims), native groups have resisted through protest, litigation, 
and blockades (Usher et al., 1992, p. 119). First Nations groups seek to retain sovereign control of their livelihoods and access to their original land systems throughout contemporary land discussions (Usher et al., 1992, p. 129). Despite ongoing attempts at eradication, Indigenous people remain on their lands and have engaged in continued resistance.

This is the case for communities in northern Alberta, where individuals continue to hunt and fish traditionally as guaranteed under Treaty 8. However, these practices are increasingly threatened by resource activities encroaching further onto their territory, and many are left in a situation where they are unable to utilise the land due to oil and gas development (Davidson \& Gismondi, 2011, p. 99). This creates a difficult position where communities are in desperate need of economic opportunities and must resort to working for the very companies who are destroying their ancestral lands (Davidson \& Gismondi, 2011, p. 99). Despite recent work in land reclamation, the traditional lifestyle guaranteed under treaty is at risk.

\subsubsection{The Athabasca Tar Sands}

The Athabasca tar sands, which form one of the controversial mining cases studied in this thesis, are deposits of bitumen-rich ${ }^{5}$ sand beneath the boreal forest in Northern Alberta (Figure 1.2). Once extracted and separated from the sand, bitumen can be upgraded and refined into crude oil and other fuel products. The tar sands are characterised as an unconventional oil resource (Humphries, 2008), due to the relatively high amount of energy input needed for extraction and refinement.

\footnotetext{
${ }^{5}$ Bitumen is a petroleum-like substance which, in its natural state, has very low viscosity.
} 

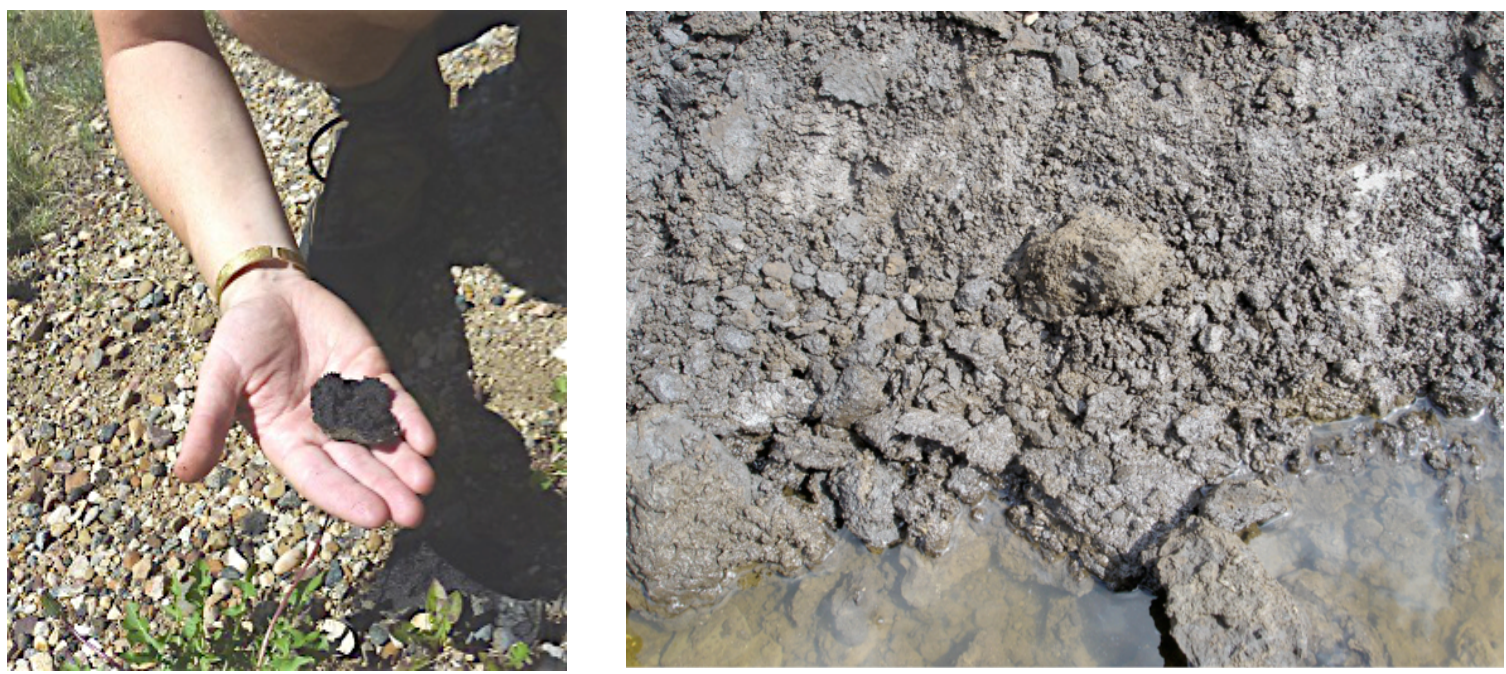

Figure 1.2: Bitumen ${ }^{6}$

Local First Nations had been using the sticky, tar-like substance for patching canoes and introduced it to settlers in the 1700 s. Techniques for extracting bitumen were already being developed in the early 1920 s and by the 1970s, large-scale mining operations had become economically feasible (Humphries, 2008) ${ }^{7}$. Today, there are a growing number of international mining companies operating in the Athabasca tar sands, making it one of the largest industrial projects on the planet. Both open-pit traditional truck and shovel methods as well as steam assisted gravity drainage (SAGD) are used ${ }^{8}$. Once the sand is removed from the ground, hot water is added to separate the bitumen which is then piped onwards for upgrading and export. The residual sand, water, and bitumen is pumped into massive tailings reservoirs, built with earthen berms. These 'tailings ponds' have marked the landscape since the first mass extraction development (see Figure

${ }^{6}$ Unless otherwise noted, all images reproduced in this thesis are my own.

7 Due to the political nature of tar sands development, I make use of a single fact sheet (Humphries, 2008) in order to avoid contradicting information.

${ }^{8}$ SAGD involves pumping super-heated steam through horizontal piping, which melts the bitumen and allows it to flow into a second set of piping, bringing it to the surface. For more information, see Humphries, 2008. 
1.3) and, besides a few fledgling technologies such as Suncor's $\mathrm{TRO}^{9}$, there has been no reduction in their size. In fact, they are expected to grow to 1 billion cubic meters by the year 2020 (Humphries, 2008, p. 22).

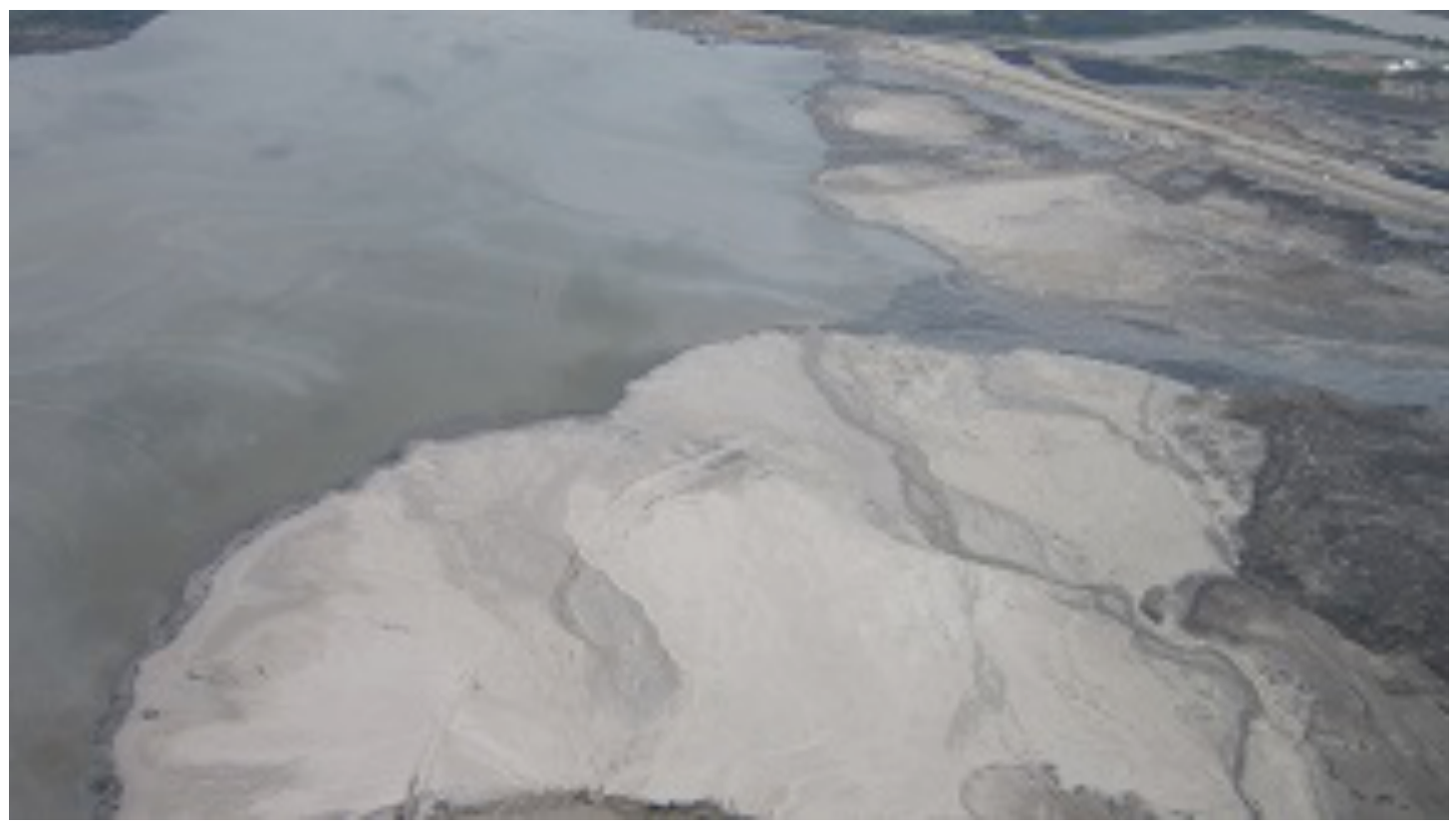

Figure 1.3: Tailings Pond

As the largest supplier of oil to the United States (Humphries, 2008), the Athabasca tar sands drive both the Albertan and increasingly the Canadian economy. With massive numbers of people employed in work camps throughout the boreal region, the closest city, Fort McMurray, has experienced exponential growth in the last decade. This has led to many social issues common to resource boom towns, such as increased crime, infrastructure stress, and instability and mobility (Dorow \& O'Shaughnessy, 2013). Fort McMurray is thus a complicated community, and has been subject to a multitude of social science research (i.e. Dorow \& O'Shaughnessy, 2013; Taylor, McGray, \& Watt-Malcolm, 2007).

There are many environmental concerns relating to such development, which include the loss of the boreal landscape, the efficacy of reclamation, and

9 TRO stands for "Tailings Reduction Operation" and involves a process of "dry tailings". More information can be found at www.suncor.com 
C02 emissions in both extraction and end use. Additionally, many of the tailings reservoirs are located along the Athabasca River, which itself flows into the McKenzie Basin and forms part of the largest watershed in the country (see Figure 1.4).

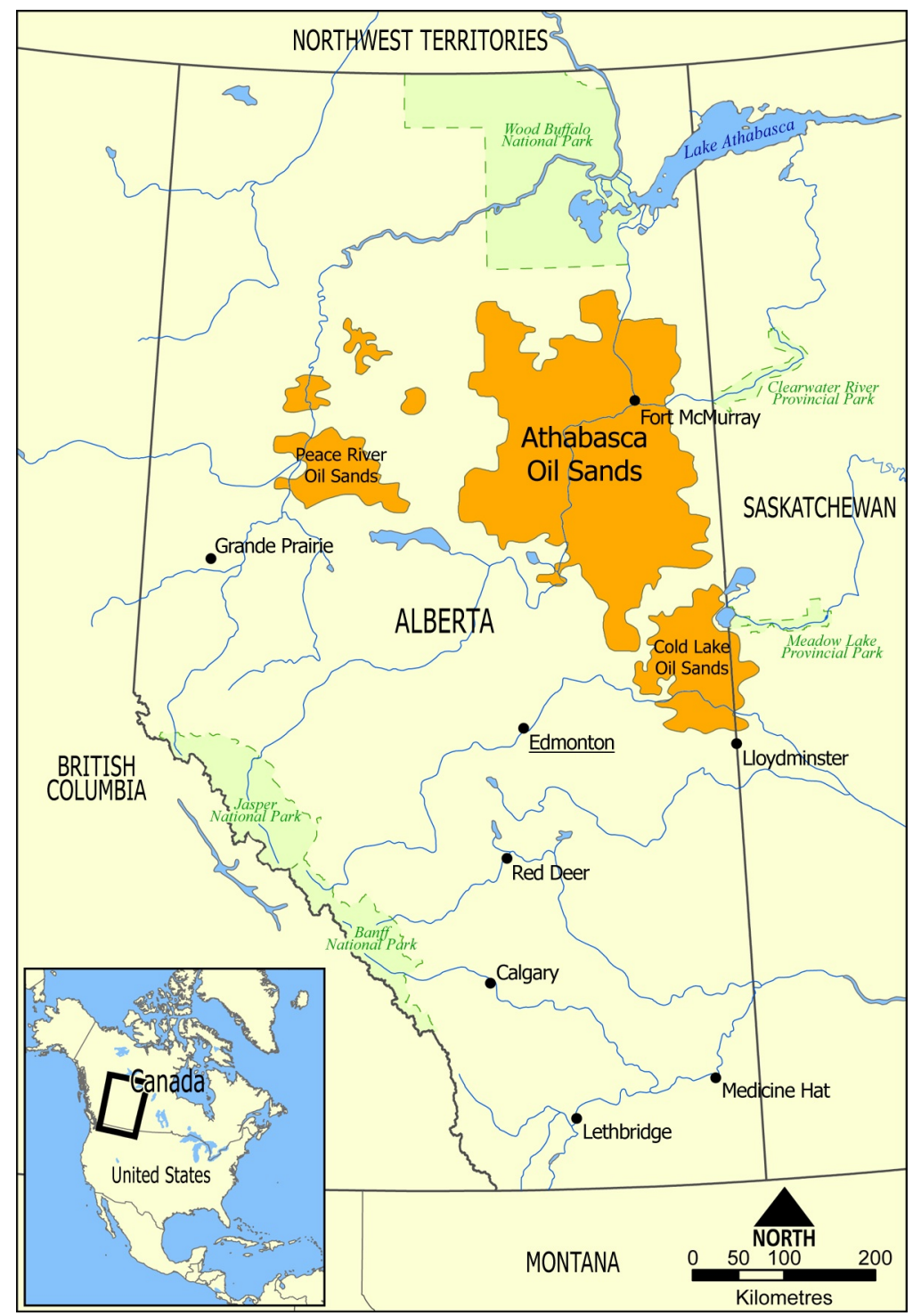

Figure 1.4: Alberta $^{10}$

${ }^{10}$ This image has been released into the public domain, more information can be found here: http://en.wikipedia.org/wiki/Athabasca_oil_sands 
Indigenous communities located along these rivers downstream from the mines, such as Fort Chipewyan, are experiencing the effects of years of development. These include changes to community rates of cancer and reports of malformed, tumorous wildlife ${ }^{11}$ (Timoney \& Lee, 2009). A staple of the traditional diet guaranteed under treaty, the Woodland Caribou, is now endangered due to habitat loss (Blay, 2011). Local communities have long complained of Treaty violations and some are issuing constitutional challenges around these issues (McDermott, 2012). For these reasons, I approach my analysis of Discourses surrounding the tar sands with special attention to First Nations issues.

The oil industry, supported by the Canadian Association of Petroleum Producers (CAPP), has also done work and research in 'land reclamation'. At its most basic, reclaimed land is land that has been restored after mining has finished. The land is leased from the province by mining companies with the expectation it will be returned to a productive state and given back to the Crown. To date there is one certified reclaimed site that has been returned to Alberta (Gateway Hill). However, reclamation success in the tar sands is contested. Rooney, Bayley \& Schindler take issue with the destruction of peatland that is consequently reclaimed as upland forest, resulting in the loss of carbon sinks (2012). Other critics, like Andrew Nikiforuk, describe reclamation as amounting "to little more than putting lipstick on a corpse" (2008, p. 102). The Government of Alberta's own definition of reclamation requires that sites be "returned to a productive state" (Government of Alberta, 2014). However, this does not mean it must be replaced as it was originally found: in other words, wetlands may become forests or even parks. Here, 'productive' is open for interpretation as to who will use the land in what way, and reclaimed areas have even been opened for recreational activities and tourism (see Davidson \& Gismondi, 2011, p. 124).

\footnotetext{
11 Many of these reports have been disputed by government officials but I refer the reader here to the following work for an analysis of downstream effects: Kelly et al., 2009; Rooney, Bayley, \& Schindler, 2012.
} 
Additionally, the province of Alberta is politically aligned with the oil industry through a distinct sociocultural identity. Known as Canada's energy province (Vanderklippe, 2013), Alberta has a long history with oil exploration and development (Chastko, 2004). It is this relationship that has helped create a provincial identity Discourse centred around oil and gas. As Haluza-Delay so aptly puts it, "Homo alberticus becomes homo energeticus" (2012, p. 2). The development of this Discourse has been tracked through Albertan literature (Gordon, 2012, p. 15), through narratives told by locals resisting development on their lands (Evans \& Garvin, 2009), through provincial discussions in legislature (Davidson \& Gismondi, 2011), and of course through analysis of industry media productions themselves (Haluza-Delay, 2012; Kowalsky \& Haluza-DeLay, 2013). Despite this popular identity Discourse, many Albertans have never seen the tar sands. This is perhaps due to its relative remoteness (Fort McMurray is a five hour drive north of Edmonton along Highway 63, also known as 'the Highway of Death'), although 'oil sands tourism' is on the rise. The province also hosts the main Calgary office of the Canadian Association of Petroleum Producers (CAPP), an organisation which represents companies involved in extraction ${ }^{12}$. CAPP acts as a public relations group, producing advertisements which promote the developments and even designing petroleum-inspired energy curricula for use in public primary schools (Uechi, 2013). Such projects are decidedly multimodal, and partly inspired my decision to include collected artefacts for analysis in this thesis.

Discussion about the Athabasca tar sands has become extremely polarised due to the intersecting issues of land disturbance, social issues, and economic need. Linguistic difficulties often arise where speakers are positioned on either side of the debate with little hope for neutral ground (Kidner, 2012). Most problematic, is the choice of words used to describe the sands: 'tar' implies a position against development whereas 'oil' implies a position for development. Although 'tar sands' was the original label, the term 'oil sands' was introduced by the Alberta government and today is cultivated as the dominant, so-called 'neutral' term (Katz-

12 It is worth noting that many of these companies are foreign-owned. 
Rosene, 2012; Uechi, 2013). Proponents on both sides of the debate claim either 'tar' or 'oil' to be the most accurate (e.g. Nikiforuk, 2008, p. 10; Uechi, 2013), but textual analysis of environmental debates in the region has found both terms to be problematic for speakers and notes that they are sometimes avoided altogether (Kidner, 2012). The choice of terms becomes crucial to perceptions about the resource, as "the name used for the place in question carries an underlying meaning that relates to intended perceptions of the location", conjuring up "beliefs about what is and what ought to be happening in Northern Alberta" (Katz-Rosene, 2012, p. 10).

In light of this issue, I use the term 'tar sands' to refer to the Northern Alberta geographical place in which bituminous sands are found. This term is not used as a statement regarding the chemical makeup of the substance, nor its intended use, but rather as a sociolinguistic alignment with communities of struggle in the region.

\subsection{The Aotearoa/New Zealand Case Study}

Similar to Canada, Aotearoa ${ }^{13} / \mathrm{New}$ Zealand is based on a treaty between European settlers and the Māori people. Signed in 1840, the Treaty of Waitangi represents a founding document for the nation state of New Zealand. Similar to the situation in Canada, treaty issues in Aotearoa are contested and many iwi ${ }^{14}$ continue the struggle for access to land bases which were taken (Smith, 1999). Resource development has threatened the traditional livelihood of many, and Māori have resisted projects on their land. Contemporary fossil fuel expansion all around the country has been met with resistance from iwi and Pākehā'15 alike, including fracking in Taranaki (Climate Justice Taranaki, n.d.), and deep sea oil drilling on the East Cape (ONE News, 2012b), Wellington, Kaikoura, and Dunedin (Lewis, 2014).

\footnotetext{
${ }_{13}$ Meaning "land of the long white cloud", Aotearoa is the name given to the land by the Māori people and I use it interchangeably throughout this thesis with the more commonly known New Zealand.

14 Tribes.

15 Descendants of European settlers to Aotearoa.
} 
The case explored in this thesis is located in Southland (see Figure 1.5), and consists of an operational lignite mine that the company (Terra Resources ${ }^{16}$ ) is seeking to expand.

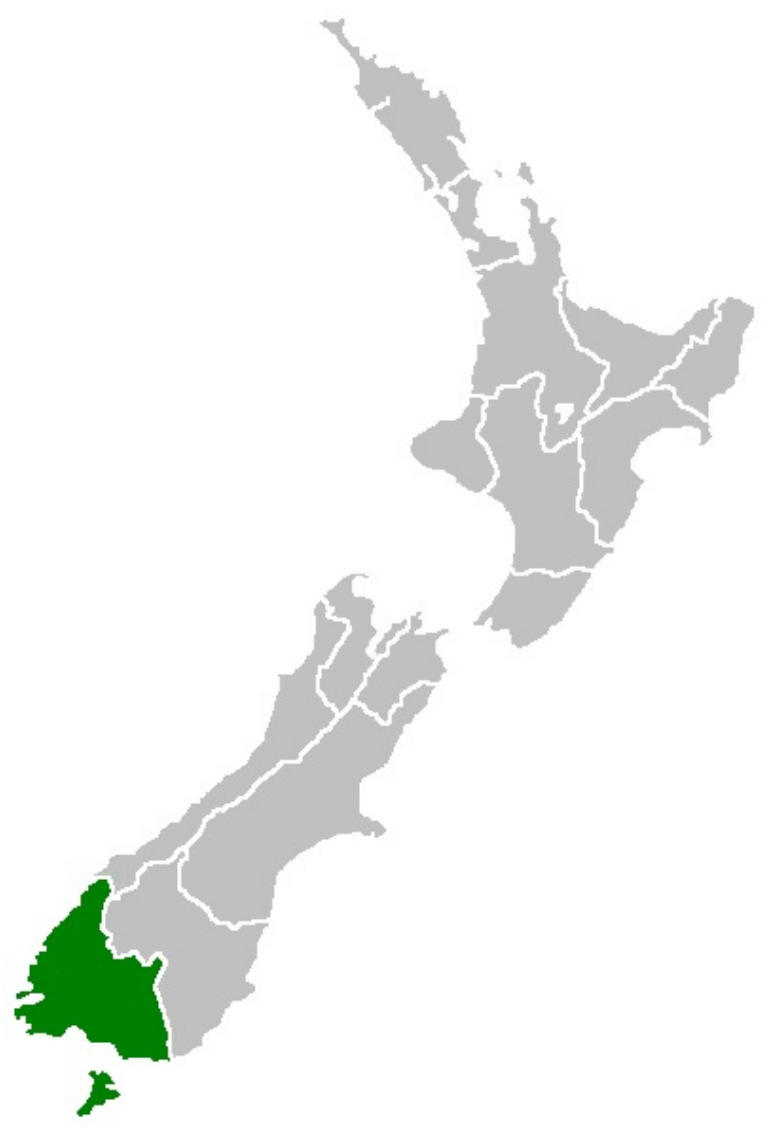

Figure 1.5: Southland 17

Lignite is a low grade form of brown coal characterised by low calorific content and high moisture (Parliamentary Commissioner for the Environment, 2010, p. 11). In a way similar to the Athabasca tar sands, the mining of this product can be considered unconventional (Parliamentary Commissioner for the Environment, 2010), as many of the final products (e.g. fuel 'briquettes' which would be exported) require extensive upgrading to be made usable. Due to the many environmental

\footnotetext{
${ }^{16}$ All company names are pseudonyms.

${ }_{17}$ This image has been released into the public domain, more information can be found here: http://en.wikipedia.org/wiki/Southland_Region
} 
issues involved with developing lignite (including $\mathrm{C0} 2$ emissions and destruction of land), the proposed expansion of the mine has been met with wide resistance. Most notably, many local farmers are concerned about the impact on land and soil, despite industry assurances that reclamation technologies will return land to its original state (ONE News, 2012a). Terra Resources has bought farmland under the requirement that farmers sign non-disclosure agreements, leading to an atmosphere of silence and distrust amongst neighbours. Local iwi have supported the mine to an extent, although there are concerns amongst Māori in the wider area.

With the help of a national anti-coal organisation, small, isolated pockets of resistance to the mine have begun to unite into a local group. It is this local antimining group, as well as organisers involved in the wider national group, which contribute to this thesis through a study of the debate's initiation and development. However, during the course of this research, Terra Resources experienced a number of economic difficulties due to the falling price of coal and so the proposed

lignite mine expansion and briquetting facility were cancelled. The local anti-mining group has since disbanded; however, it presented a compelling case study during my fieldwork in the region.

\subsection{Discourses of Appropriation and Resistance}

Both the mining cases studied in this thesis are embedded within wider national Discourses of environmental identity. The multimodal entextualisation of these Discourses are exemplified through the 'Ethical Oil' campaign in Canada and the ' $100 \%$ Pure NZ' campaign in Aotearoa/New Zealand.

As debates about the development of the tar sands in Alberta have progressed, new campaigns to market Albertan oil have been initiated. A recent example is the 'Ethical Oil' campaign, which began with the publication of a book by the same title (Levant, 2010). The campaign features a series of advertisements depicting tar sands oil as an 'ethical choice' compared to oil produced in other 
nations (Figure 1.6).

Images removed after examination

Figure 1.6: Ethical Oil ${ }^{18}$

The ads form a cohesively designed interpretation of Canadian oil as 'ethical' by drawing upon Discourses of women's rights, Aboriginal rights, and environmental stewardship, among others. These images were met with protest by many (e.g. Pullman, 2011), but the term ethical oil was soon heard in political discussions in Canada (Chase, 2011). The Ethical Oil campaign partly inspired this

18 Images can be viewed at http://www.theguardian.com/environment/blog/2011/jul/28/oiltar-sands-canada-ethical 
thesis' aim to explore the appropriation and resistance of Discourses in mining debates.

Similarly, in Aotearoa/New Zealand, resource development in the country is encouraged under the current National Government, with Prime Minister John Key supporting extensive exploration and mining both on and offshore (John Key Exploring Our Resource Potential, 2013). This includes coal mining development on the South Island, and there have been several high profile cases of national resistance along the West Coast (NZPA, 2006). These developments have been especially contentious in light of New Zealand's clean green, 100\% pure marketing image (see Tady, 2006), which is highly valued in various sectors, including tourism (Ministry for the Environment, 2001). Resistance to development (most notably offshore oil drilling) has made reference to the $100 \%$ pure brand in multimodal ways (Figure 1.7).

Images removed after examination

Figure 1.7: $100 \%$ Pure $^{19}$

Here, the $100 \%$ pure ad is recreated in full, but is accompanied by a multimodal metacomment (left). The image depicts a poster from the TV series The $X$-Files, which has since become commonly used "for a variety of mythical

19 Images can be viewed at http://thedailyblog.co.nz/2013/08/13/100-pure-is-like-ufos-weall-want-to-believe-it-exists/\#!prettyPhoto 
subjects and issues that remain debatable, such as the existence of Santa Claus" (Know Your Meme, 2010). Appearing before the $100 \%$ pure ad, I want to believe suggests the claim of $100 \%$ is imaginary or untrue, calling into question the idea of a sustainable, green New Zealand. It thus helps to multimodally recontextualise a powerful Discourse of national identity by re-orienting the frame for interpretation. It is against this backdrop of negotiated identity Discourses that the Southland lignite mining case study explored in this thesis is situated.

\subsection{Resource Extraction and Climate Justice}

Environmental Discourses are constantly evolving, leaving many areas to be explored. It seems that two competing and continuously polarising Discourses have arisen: one that sees the environmental crisis as symptom of a larger and unequal structural problem, and one that sees the environmental crisis as a capitalist opportunity to be reframed and packaged for profit (see Bäckstrand \& Lövbrand, 2007). It is within this dialectal context that I position my research, asking, as Blommaert encourages, "why do we investigate this now?" (2005, p. $65)$.

Because environmental Discourses cover so many aspects of modern interaction (e.g. economy, conservation, social justice), there has been much research from interdisciplinary perspectives. Studies have been conducted in the fields of gender (Berman, 2006; Di Chiro, 2011), business (Ählström, Macquet, \& Richter, 2009; Djonov, 2007), activism (Long, Roberts, \& Dehm, 2010), and outside of academia (Biofuelwatch, 2011; Rising Tide North America \& Carbon Trade Watch, n.d.). Additionally, since the release of Al Gore's influential film An Inconvenient Truth (2006), the focus on climate change has caused a proliferation of environmental Discourses. Current dominant Discourses tend to view the management of the ecological crisis as compatible with economic growth (Bäckstrand \& Lövbrand, 2007, p. 129), assuming solutions to the crisis can come out of the neoliberal market itself (Bäckstrand \& Lövbrand, 2007, p. 129). However, discursive space has recently opened to "a struggle over meaning in the climate 
domain" (Bäckstrand \& Lövbrand, 2007, p. 124), allowing for more radical Discourses that call for solutions which acknowledge and seek to transform the power relations inherent in the climate crisis (Bäckstrand \& Lövbrand, 2007, p. 132).

The emerging Discourse is evident in the rise of the climate justice movement, which demands community-based as opposed to market-based solutions and a re-evaluation of the fundamental political and economic systems upon which society is based (Bäckstrand \& Lövbrand, 2007). Advocates call for new analyses of intersectionality (Di Chiro, 2011), global actions of solidarity (Long et al., 2010), and a redefinition of human rights relating to ecological space (Hayward, 2007).

In direct opposition to the climate justice movement is a reinvigorated Discourse of market-based solutions, which still dominates much environmental debate (Di Chiro, 2011, p. 233; Hansen, 2011). There is ongoing appropriation of environmental arguments by for-profit interests through new technologies (Biofuelwatch, 2011; Hayward, 2007; Rising Tide North America \& Carbon Trade Watch, n.d.) and corporate interests have even been accused of co-opting specific climate justice Discourse through the use of front groups (Morningstar, 2010). High tech solutions are also being proposed by the fossil fuel industry as methods to offset harmful practices and make fossil fuel extraction part of the solution to climate change (e.g. Biofuelwatch, 2011). In this way, the marketing strategies apparent in the mining industry's expansion projects are part of a larger Discourse of 'green' mining, which is itself part of an even larger Discourse of neoliberal, 'business as usual' environmental practices. The constant appropriation and resistance of these Discourses by both the fossil fuel industry and the climate justice movement form the focus for this project. Through my analysis, I aim to examine how these mining debates go 'beyond greenwash' and incorporate a variety of intersecting Discourses which are continuously recontextualised. 
I should also emphasise that my involvement with communities of resistance in Canada and Aotearoa/New Zealand was not solely for the purpose of writing this thesis. As an educated, white woman born and raised on colonised land, I recognise that I have privileges which must be continually navigated. The reflexivity inherent to this thesis is also relevant to my everyday work with the environmental justice movement, which has continued after data collection. Had I chosen a different topic to examine for this thesis, I would still be involved with these resistance communities in some capacity.

\subsection{Thesis Structure}

In this chapter, I have introduced the rationale and aims of the thesis, and situated it within a critical tradition. Additionally, I have introduced and provided background on the case studies and the climate justice movement. In Chapter 2, I introduce and discuss the theoretical approaches I use, which I conceptualise as overlapping critical, ethnographic, and multimodal lenses. In Chapter 3, I discuss my methodological framework, incorporating Multimodal Interaction Analysis, Social Semiotics, and Linguistic Ethnography for data collection and analysis. My analysis begins in Chapter 4 with an examination of Discourses of environment and economy in the two case studies. Then, in Chapter 5, I explore how Discourses of regional identity in both Canada and Aotearoa/New Zealand are appropriated and resisted multimodally. Chapters 6-7 extend this analysis in the Canadian case study to consider other relevant Discourses of appropriation and resistance, including Indigenous identity (Chapter 6), and LGBTQ+ identity (Chapter 7). Chapter 7 also introduces the wider concept of 'intersectionality' and how it relates to grassroots activism and Discourses in mining debates. In Chapter 8 , I broaden the discussion with an examination of the ways that social actors on either side of the debate discuss their opposition, and the roles that creativity and humour play as resources in activist resistance. Finally, I present an overarching comparative analysis of the two case studies and conclude with a discussion of the ways in which Discourses are continuously appropriated and resisted, resulting in a 
'discursive arms race'. In Chapter 9, I interrogate my own positionings throughout the fieldwork and writing of this thesis as a reflexive, critical scholar. Chapter 10 presents the implications of this research for critical scholarship, multimodality, ethnography, and environmental activism, and outlines possibilities for future research. 


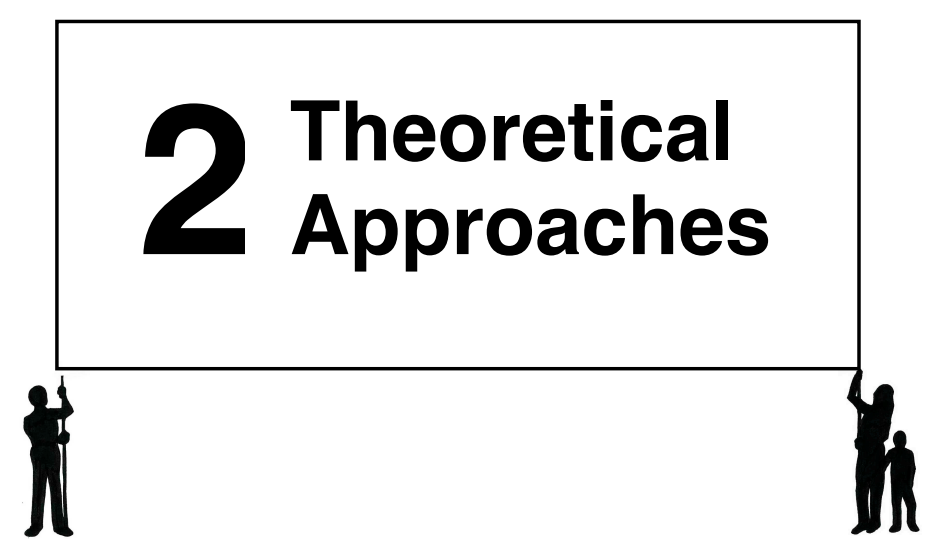

$\mathrm{n}$ this thesis, I adopt a number of theoretical perspectives. Taken together, these critical, multimodal, and ethnographic approaches construct a unique framework through which I examine Discourses in controversial mining debates.

\subsection{Critical Approaches}

Adopting a critical approach highlights a number of methodological and theoretical issues. First, it encourages the researcher to consider wider contexts, most notably the socio-political dimensions of language use. Second, critical research challenges assumptions of scholarly neutrality and objectivity in general, and highlights the power dynamics and inequalities inherent in social interaction. This perspective also acknowledges and engages with the researcher's own subjectivities through practices of reflexivity. Finally, a critical approach promotes the idea that scholars have a responsibility as privileged members of society to make their research accessible and meaningful to the communities with which they work. In this section, I outline the critical perspective I take as well as discuss the concepts of appropriation and recontextualistion of Discourses ${ }^{1}$.

\subsubsection{A critical approach to Discourse}

Adopting a critical approach to this research allows me to recognise powerful forces of domination, consider wider contexts, question neutrality, practice

\footnotetext{
1 In this thesis, I make an orthographic distinction between 'big D' Discourses and 'little d' discourse as text (see Gee, 1999). However, I maintain the original spelling in citations from other authors.
} 
reflexivity, and consider ways in which I might empower communities and make my research accessible. Based on a critical discourse analysis (CDA) stance, I therefore bring some basic assumptions into this project. First, I recognise that communication occurs in a wider context which must be considered for its analytical potential (Blommaert, 2005; Wodak \& Fairclough, 2010). Second, contextualised language use which is embedded within social structures of inequality, is subject to power in action and therefore not neutral. In the context of environmental debates that are characterised by inequalities and that involve communities of struggle, ignoring the role of power as central to the analysis is to commit an injustice as a researcher. Finally, as a crucial part of this wider context, I must negotiate my own role within my research through reflexivity (Blommaert, 2005; Cameron, Frazer, Harvey, Rampton, \& Richardson, 1993; Wodak, 2006). An ethnographic approach, discussed in section 2.4, provides an ideal framework for such practice.

At its core, my theoretical perspective attempts to account for various readings of a text, interpret them, and subsequently find new meanings through critique (Wodak, 2006, pp. 6, 9). Critical approaches take "a 'pejorative' view of ideology as a means through which social relations of power are reproduced" (Fairclough, 1995, p. 17) and, because ideologies are often hidden, endeavour to 'denaturalise' what seems common sense (Fairclough, 1995, p. 36). As such, critical analysts seek to understand how "discourse cumulatively contributes to the reproduction of macro structures" (Fairclough, 1995, p. 43) and the relationships between text, ideology, and struggles over power (Blommaert, 2005; Fairclough, 1995; Van Dijk, 1993; Wodak \& Fairclough, 2010).

However, due to its nebulous nature, "there can be no theory of the critical analysis of discourse - but there can, and should, be a permanent will to think theoretically while we work practically" (Blommaert, 2005, p. 235). This means we must adopt "an eclectic register of approaches and methods"; interdisciplinary toolkits which can be adapted for specific and contextualised problems (Blommaert, 2005, pp. 233, 235). In this thesis, I utilise a number of methodological 
tools but I also conceptualise my critical approach as a lens through which I may view my case studies. This lens highlights the subjective, power-laden nature of mining projects and brings its wider context to the fore.

In examining wider contexts, work with Indigenous communities warrants special attention (Battiste, 2008; Smith, 1999). This project concerns itself partly with Indigenous sovereignty issues in the sense that resource extraction can be viewed within the frame of ongoing colonialism (Davidson \& Gismondi, 2011, p. 99). Both case studies in Canada and Aotearoa/New Zealand are occurring in and around Indigenous lands and traditional territories. Near Fort McMurray and Fort Chip, First Nations people are already experiencing first hand the land and health effects of industrial development (CBC, 2009a). Similarly, in Southland where lignite mining expansions are proposed in Aotearoa/New Zealand, development plans leave some locals worried about their continued ability to harvest from land and sea.

In light of this, special consideration should be given to the role of both research and researcher within a context of academic exploitation and colonisation. There are various issues that have made research "probably one of the dirtiest words in the indigenous world's vocabulary" (Smith, 1999, p. 1). Problematising Indigenous Peoples themselves and using research practices determined by Western imperialist ideals, creates an intellectual forcefield against other ways of knowing (Dunbar Jr., 2008, p. 8692; Smith, 1999, pp. 92, 47). Even within universities, academic knowledge is insulated in disciplines and management structures which work to keep privilege in place, and many scholars fail to recognise the power dynamics within their research (Battiste, 2008, pp. 500501; Smith, 1999, pp. 133, 176). Above all:

Researchers are in receipt of privileged information. They may interpret it within an overt theoretical framework, but also in terms of a covert ideological framework. They have the power to distort, to make invisible, to overlook, to exaggerate and to draw 
conclusions, based not on factual data, but on assumptions, hidden value judgements, and often downright misunderstandings.

They have the potential to extend knowledge or to perpetuate ignorance (Smith, 1999, p. 176).

New research approaches, such as reflexivity and incorporating schedules of empowerment, have been suggested to minimise the power structures inherent in scholarly work (Cameron et al., 1993; Smith, 1999). Many scholars claim that research (and activism) is necessary that acknowledges "intersecting oppressions within a contemporary hypercapitalist patriarchal context" and new methodologies are emerging out of this activist research space (Cannella \& Manuelito, 2008, p. 56). For example, 'Kaupapa Māori' research involves historical and critical analyses which incorporate cultural protocols as well as consensual, healthy relationships and ongoing community input (Smith, 1999). Practitioners of Indigenous methodologies recognise that research "should set out to make a positive difference for the researched" (Smith, 1999, p. 191), and that researchers are required to share control of their work with those who are affected (Battiste, 2008, pp. 501, 503; Denzin \& Lincoln, 2008, p. 2; Smith, 1999, p. 191).

Although this project may only engage peripherally with Indigenous issues, it does draw upon critical and indigenous research orientations. Because I don't identify as Indigenous to either Canada or Aotearoa/New Zealand (I consider myself a Settler to both, (see Adam J. Barker, 2009)), I am restricted in my ability to ethically use Indigenous approaches such as Kaupapa Māori or others, such as Red Pedagogy (Grande, 2008, p. 241; Smith, 1999, p. 187). Yet, recognising the uncomfortable, historical legacy of research as a tool of oppression is necessary if we are to change its effects in the present day. This thesis sits within this colonial history and I recognise both its limitations as a genre and its power to legitimise certain forms of knowledge. Many of my aims align with critical Indigenous methodologies as I seek to explore inequalities, problematise 'objective' academic spaces, and empower communities of struggle (Denzin \& Lincoln, 2008, p. 4). 


\subsubsection{Critical Approaches and the Focus on Context}

A critical approach to discourse seeks to make connections between social, economic and political processes on the one hand and language on the other (Blommaert, 2005, p. 66; Van Dijk, 1996, p. 84; Wodak \& Fairclough, 2010, p. 107) by looking at how language both effects and is determined by social structures (Fairclough, 1995). It is text, argues Fairclough, that provides evidence of these social structures, relations, and processes and it is text that can indicate social change (Fairclough, 1995, p. 209). Increasingly, it is also text which forms the medium through which social control and domination are constructed, negotiated, and resisted (Fairclough, 1995, p. 209). However, analysis must also focus on "the actual and densely contextualised forms in which language occurs in society", bringing context into the foreground of any language study (Blommaert, 2005, p. 15). As such, "context is not something we can just 'add' to text - it is text, it defines its meanings and conditions of use" and is reflective of social characteristics and domains (Blommaert, 2005, pp. 45, 10-11). Critical analysis should consider both culture and language within their own specific environments as opposed to any universal standard (Blommaert, 2005, p. 8): an idea which recognises that "language operates differently in different environments" (Blommaert, 2005, p. 14). It makes little sense to analyse language use according to contexts that differ from the real spaces in which such language practices develop (Blommaert, 2005, p. 43). I therefore take seriously the role of situated context in meaning-making, and will expand the analytical landscape to encompass multimodal action as well as spoken and written language (see section 2.3.1 ). By taking contextualisation seriously as a component of analysis, "we shall be forced to develop a linguistics that ceases to be linguistic from a certain point onwards, and becomes a social science of language-in-society" (Blommaert, 2005, p. 235). Such adaptability is crucial, as a critical sociolinguistics must remain responsive to ongoing societal transformations (Blommaert, 2005, p. 235). Additionally, Blommaert calls for an enhanced view of Discourse itself as any form of "meaningful semiotic conduct" (2005, p. 236). This means we must analyse 
"more things in more ways", and go beyond our comfort zones and outside welldefined boundaries of what constitutes discourse (2005, p. 236). This prospect brings opportunities of different data, and new combinations of tools, to bring us a "richer and more interesting field to dwell in than rigidly defined habitual orthodoxies of scientific exploration" (2005, pp. 236-237).By embracing this orientation, this thesis examines social interactions through communication practices, embedded in wider contexts (Eades, 2004). ${ }^{2}$

\section{Dawn}

@ThisPhD

\section{I study people first, and language second.}

This is an important distinction.

Because critical analysts concern themselves with inequalities, they must also consider the responsibilities they have as scholars. In fact, linguists, much like scholars of critical and indigenous methodologies, are encouraged to do more with their knowledge, by building better connections between research and applications that have real effects in society and even intervene if necessary (Alexander, 2008, pp. 20, 3, 5; Blommaert, 2005, p. 25; Eades, 2004; O'Connor, 2007, p. 233). CDA is about "empowering the powerless, giving voices to the voiceless, exposing power abuse, and mobilising people to remedy social wrongs"(Blommaert, 2005, p. 25). If we choose to examine sites of inequality as a detached outsider whilst doing nothing to benefit those who struggle, we risk behaving in an ethically irresponsible way. As such, CDA approaches often incorporate an empowerment agenda.

\footnotetext{
${ }^{2}$ As a component of ethnographic methodology, I make use of 'tweets' which present some of my personal reflections at various stages of my research.
} 


\subsubsection{Empowerment Agendas}

Empowering research may seem "a contradiction in terms" (Cameron et al., 1993, p. 89) because social sciences often contribute to oppressive structures of knowledge. Often, analysts consider their participants for only one aspect of the research and then they are "pushed out of the analysis", leaving the sole voice of the analyst at the fore (Blommaert, 2005, p. 33). Researchers must then consider how they position themselves and their participants throughout the entire research process, from fieldwork to written word. Yet, the more the various relational complexities of researcher and researched are recognised and problematised, the more difficult it becomes to to create a straightforward empowerment agenda (Cameron et al., 1993, p. 90). At this stage, empowerment can mean sharing knowledge as opposed to information, where the theory and analyses used to construct the research findings are transparently presented to the community (Smith, 1999, p. 16). By making research practices accessible to non-academic communities, we can share analytical tools and theories which may prove beneficial in understanding social situations. Textual analysis, and text itself, can be a crucial political resource and critical discourse analysts play an important role in providing such resources (Fairclough, 1995, pp. 209, 221). This orientation also recognises the privileged nature of scholarly work which for so long has been, and continues to be, dominated by a distinct sociocultural class (Van Dijk, 1996). It is arrogant and at best irresponsible to simply assume that community groups will not be concerned with the theoretical underpinnings of our work (Smith, 1999, p. 16). As a critical approach aims to work in service of those who struggle against oppressive Discourses, it makes sense to give to them all the tools necessary for their discursive resistance. This includes maintaining a theoretical transparency that can aide them in re-interpreting our initial interpretations. By demystifying and making accessible the research process, we can also begin the process of decolonisation, bringing the academic world into the reach of those who do not inhabit it (Smith, 1999, p. 16). For example, scholars may consider adding an educational workshop component to their research programme to engage with 
those who will benefit from a more academic understanding of their social situations (e.g. Fairclough, 1995). Above all, when working with communities of struggle it is important to recognise that problems of power are best tackled by those directly involved (Fairclough, 1995, p. 221).

\subsubsection{CDA and Subjectivity}

While a CDA approach seeks to extend the lens of analysis beyond the immediate interaction, it must also include the researcher him/herself. In practice, this means that interaction with participants is inevitably considered a crucial part of the broader research practice, from fieldwork to analysis and onward to writing. Whereas some may consider such researcher involvement to be "misleading as to the nature of 'reality"(Cameron et al., 1993, p. 87), it should in fact be considered normal communication amongst social beings. Locating participants and researchers within the same social world also positions them as interactive subjects rather than objects (Cameron et al., 1993, p. 86). This has ethical implications in that it discourages researchers from objectifying the people with whom they work, presenting participants as individuals with their own social realities outside of research. Such an orientation flies against traditional régimes of academic objectivity where researchers seek 'truth', which is itself a powerful Discourse of legitimising knowledge ${ }^{3}$ (Foucault, 1980a, pp. 131, 133, 1980b, p. 83). Positivist ideals may discourage scholars from developing relationships which they feel could render their work less 'valid' (Cameron et al., 1993, pp. 84, 86).

However, some researchers are embracing a more subjective stance, building trust and solidarity and even attempting to decolonise their work and position themselves as an advocate for their participants (Denzin \& Lincoln, 2008, p. 4; Khasnabish \& Haiven, 2012, pp. 409-410; Smith, 1999). They acknowledge bias as a fundamental part of the research paradigm and work with it (Billig, 1999), recognising their research as an "activity that has something at stake and that

\footnotetext{
3 Because "human researchers are not robots", the question remains whether any research paradigm can be truly objective (Baker 2010, p. 143).
} 
occurs in a set of political and social conditions" (Smith, 1999, p. 5). Unfortunately, as this stance develops, scholars who embrace it are forced to justify their work to those who distrust any research which highlights its own inherent political nature (Denzin \& Lincoln, 2008, p. 4; Khasnabish \& Haiven, 2012, pp. 409-410). This is an even riskier endeavour for new scholars such as myself, who have relatively little academic experience to draw upon (Emihovich, 2005, p. 310). A CDA approach calls attention to and problematises bias by encouraging scholars to acknowledge and reflect upon the stances they may adopt during the research process (Baker, 2010, pp. 122, 143). This approach allows for research not on participants, but with participants, that can exploit, instead of deny, the multiple roles of the researcher (Cameron et al., 1993, pp. 87, 91). These myriad roles, or "positionings" (Harré \& Langenhove, 1991), are expanded upon and discussed in this thesis (see Chapter 9).

One method in managing neutrality and bias is the practice of reflexivity, where researchers become visible in their own work as it unfolds (Mann, 2011, p. 11). Considered a crucial element of contextualised discourse, the researcher's motivations and positionings help situate the work and avoid overly simplistic, onesided analyses (Blommaert, 2005, p. 65; Sarangi \& Candlin, 2003; Wodak \& Fairclough, 2010, p. 108; Wodak, 2006, p. 9). In other words, many researchers approach their analyses as objective observers, despite tendencies towards subjectivities; a critical analyst will instead acknowledge and reflect upon these tendencies in an accountable way. Failing this, we risk ignoring or obscuring "the workings of social and subjective factors" that may affect both the researcher and the research (Bucholtz, 2000, p. 1446). Exactly how this reflexivity looks in practice is described more in the next section and exemplified in the methodology discussion (see sections 3.1 and 3.2). Bias and subjectivity are thus part of this thesis' analysis, which I will discuss throughout. Using my fieldnotes, Twitter reflections, and interviews, I bring myself as a researcher into the foreground of my research and acknowledge my own subjectivities. 


\subsection{Appropriation and Resistance}

CDA recognises the wider intertextuality of context, where Discourses are connected and referenced over time and space (Bakhtin, 1981; Wodak \& Fairclough, 2010, p. 106). Intertextuality can be conceptualised as the way in which texts reference each other within larger discourses, for example in-text quotations or reported speech where the words of others are represented (Fairclough, 2003). Alternately, intertextuality can be approached from a much wider angle, where all utterances are built upon what has come before and what is expected to come after (Bakhtin, 1981, p. 280; Blommaert, 2005, p. 46). In this view, Discourses are entangled in dialogic relationships which are in turn embedded within social contexts. In other words, utterances are stratified into wider contextual dimensions, be they linguistic, sociological, ideological, and so on, in what Bakhtin terms "heteroglossia" (Bakhtin, 1981, pp. 271-272). It follows that an utterance is then tainted with its past use: "it exists in other people's mouths, in other people's contexts, serving other people's intentions: it is from there that one must take the word, and make it one's own" (Bakhtin, 1981, pp. 293-294). By recognising the wider context in which utterances are used and from which they are taken, an intertextual perspective also highlights the inherent power of words; their ideological saturation (Bakhtin, 1981, p. 271).

This idea has implications for how words are borrowed or appropriated from one context to another. Entextualisation refers to the process by which a Discourse is de-contextualised and simultaneously re-contextualised, thereby associating with a new context, new actors, and new meanings (Blommaert, 2005, p. 47). There is power in the "interplay between ideology of fixedness and practices of reentextualisation", as the space for new interpretations are managed by those who control the reformulation (Blommaert, 2005, pp. 196, 202). This is apparent in the case of mining where Discourses of environmentalism are appropriated by industry actors and recontextualised to make them appear eco-friendly (Devauld \& Green, 2010; Howlett \& Raglon, 2006): a process known as "greenwash". Devauld and Green trace the history of the term from "ecopornography" in the 1960s through to 
the coining of the term in 1986 (2010, p. 1) and its subsequent entrance into the Oxford English Dictionary. Through greenwash, the words of the environmental movement (e.g. "green", "sustainable", "renewable", etc.) are recontextualised to serve the interests of environmentally destructive businesses (Schulz, Berth, 2006).

Within sociolinguistics, greenwashing has been examined from various angles. Howlett and Raglon conducted a longitudinal analysis of advertising from the last 100 years (1910-1990), finding that the use of nature in advertising is not new, although it has shifted to be used more strongly since the 1970s (2006, p. 246). Greenwashing research has examined corporate motives (Biloslavo \& Trnavcevic, 2009), strategies (Devauld \& Green, 2010; Reynolds, 2004), and political speeches about the environment (Alexander, 2008; Carvalho, 2005). Studies have found that greenwashing allows social actors to shift blame and blur agency (Alexander, 2008, p. 29; Carvalho, 2005, p. 15). Industry actors also recontextualise environmental problems to be in harmony with marketing opportunities in order to maintain and increase consumption (Hansen \& Machin, 2008, p. 792). Ultimately, greenwash allows corporations to appropriate environmental Discourses and thus reframe their identities as corporate environmental stewards who are leading the charge in environmental protection (Alexander, 2008, p. 67).

Discussions about the environment are constantly evolving, leaving many areas to be explored. This thesis is situated within the rise of two competing and continuously polarising Discourses: one that sees the environmental crisis as symptom of a larger and unequal structural problem (i.e. the climate justice movement), and one that sees the environmental crisis as a capitalist opportunity to be reframed and packaged for profit (Long, Roberts, \& Dehm, 2010). Within this context, the tensions around controversial mining projects encourage the constant entextualisation of Discourses. For example, the 'Ethical Oil' campaign (see Chapter 1), draws upon larger social issues and appropriates wider Discourses in order to position oil industry actors as both profitable and socially responsible. The 
first of my three research questions will explore this phenomenon in detail:

\section{What types of Discourses are appropriated in the marketing of the fossil fuel industry and how is this accomplished?}

Negotiation is, however, available to those who wish to resist the appropriation of their Discourses and industry constructions of reality are often responded to by activists of the climate justice movement. These responses tend to involve creative re-contextualisations of industry messages in a sort of 'throwing back' of appropriated Discourses. For example, in 2010 Greenpeace ${ }^{4}$ Alberta ran a retaliation campaign against an advertisement series by the Canadian Association of Petroleum Producers (CAPP). The campaign encouraged users to "construct the funniest or edgiest mash-ups, image swaps, collages, rewrites, or remixes" in order to "fix these greenwashes with the truth about the tar sands" (Hudema, 2010). In the response to appropriated Discourses of environmentalism produced by CAPP, Greenpeace encouraged a further entextualisation (or, perhaps more appropriately in this case, re-entextualisation, see Blommaert, 2005, p. 202), of these Discourses to portray the industry in a new light. Entextualisation thus becomes "a userfriendly concept, open to manipulation by groups or individuals who want to impose their own agenda on it, and who find ammunition in the reformulations of the concept given by authoritative actors" (Blommaert, 2005, p. 189). The process of entextualisation thus also represents a way to take back control through reinterpreting powerful Discourses, and allows an analysis of the negotiation of this power using CDA.

Evident in the Greenpeace example is the encouraged use of creativity and the wish to "have fun with it" (Hudema, 2010). This creative edge is common to social movements and has been commented upon in past research. In his account of the use of play in activism in late 1990s Northeastern United States, Shepard

\footnotetext{
4 Although Greenpeace's approach has been considered problematic in its use of climate justice principles in other areas (see Inuit Tapiriit Kanatami, 2013), Greenpeace Alberta has maintained a close working relationship with local Indigenous activist groups.
} 
discusses various functions of play which are summarised below (Shepard, 2011). Playfulness and ludic protest, he argues, can act as a form of subversion, a coping mechanism, and finally as a way to build community. Play spaces can invert social hierarchies and challenge rules while drawing the attention of authority figures (cf. Holmes, 2000). However, "jesters carry no weapons; thus they apparently offer less of a threat to the powers-that-be" (Shepard, 2011, p. 21) and can often get away with more than their serious political counterparts. Similarly, civil disobedience can be used to challenge legitimacy and authority but also simultaneously creates a new vision of social change. It is this authentic and unregulated play that poses the biggest challenge to authority in that it advances alternative narratives of social life. Play also serves as a coping mechanism for activist groups dealing with difficult and oppressive situations. At a most basic level, laughter can lighten a heavy mood and act as an escape from hostility, while allowing activists to laugh at themselves. Perhaps most importantly, play "offers a generally - but not always - nonviolent way of engaging and playing with power while creating communities" (Shepard, 2011, p. 261). By imagining the world they want as opposed to rallying against the world they don't want, activists create a joyous, carnival atmosphere which encourages others to become engaged. Thus, play creates a space for people to meet and interact, while helping construct an ideal, imagined world.

Within sociolinguistics, Jones (2010) proposes a novel approach to analysing creativity and language which he calls the discourse and creativity perspective. He stresses that pragmatic value (as opposed to aesthetic) is central in how "so called 'creative' uses of language actually help us to accomplish things in the material world and in our relationships with others" (2010, p. 471). In this way, the creativity of language does not reside simply in its linguistic product, but in its strategic use, generating "a new way of dealing with a situation or a new set of social relationships." (Jones, 2010, p. 472). Creativity, then, is not just novel text but novel Discourses and "new ways of speaking, thinking and being" (Jones, 2010, p. 477) where people create spaces for identities and actions. This practice 
of discursive play, in effect, allows us to open up spaces and to find "our way around constraints or limitations placed on us" by large Discourses (Jones, 2010, p. 477). It then follows that a methodology must be developed which could unpack the intended and unintended uses of creative Discourse and follow it through time. As Jones puts it, "in order to really understand if, why and how this piece of discourse is 'creative', the analyst needs to go beyond just looking at the discourse itself" (2010, p. 475) and instead read "around the text" (2010, p. 477).

Similar to a CDA approach, Jones advocates for a wider contextual lens, drawing upon ethnographic knowledge to track the creative appropriations of texts. These creative activities can affect social change on two levels: first, in the immediate interaction by shifting power relations, reframing activities, or creating new space for social actions and second, by negotiating conventional Discourses and imagining new possibilities for seeing the world (Jones, 2010). Jones cautions, however, that social change can only really come through an accumulation of the uses of the appropriated text across situations and domains, where they then become part of larger Discourses, eventually supplanting the original text. In this way, people can use text to become agents of change: "we are not just talking about changing language in some clever or inventive way - we are talking about changing the world." (Jones, 2010, p. 473). In this light, the playful appropriation and entextualisation of Discourses by industry and activists alike take on a powerful dimension.

Even the temporal rise and fall of discursive possibilities can give us interesting insights into the sociocultural dimensions of our societies (Blommaert, 2005 , p. 66). In other words, the ability to use language at any one time cannot be assumed and we must recognise that people are restricted in what they can say, to whom, and when (Blommaert, 2005, p. 67; Van Dijk, 1996). Such access, or lack of access, becomes relevant in all aspects of communicative events, from planning and setting to language choice and genre (Van Dijk, 1996). Drawing on this intertextual orientation, analysts should consider the situation before "people open their mouths" as well as continue after that (Bakhtin, 1981; Blommaert, 2005, pp. 
$67,234)$. In this thesis, I recognise the 'pretextual impossibility' of certain discourses and therefore consider the ways in which whole perspectives are silenced, whether it is through constructed opposition or outright dismissal.

The struggle over mining practices then becomes a struggle over words and contexts, as who controls the Discourse may ultimately control the direction of social change. This thesis thus examines the process of entexualisation by activists with a focus on creativity:

\section{How is Discourse appropriation by the fossil fuel industry creatively resisted by the climate justice movement?}

However, as is evidenced in the Greenpeace example described above, the entextualisation of Discourses often occurs in multimodal ways (consider the call to construct collages, image mash-ups, etc.). Many CDA scholars have called for more research which includes other modes such as gaze, colour, gesture, etc. (Fairclough, 1995; Van Leeuwen, 2004). In this thesis I extend my analytical lens beyond spoken and written discourse to consider the ways in which various modes may create meaning.

\subsection{Multimodality}

It is useful to discuss the concept of 'mode' in multimodal research. In attempting a definition, Kress notes that mode is "a socially shaped and culturally given resource for making meaning" (Kress, 2009, p. 54). Drawing upon Kress and Van Leeuwen (2001), Norris defines modes as "systems of representation or semiotic systems with rules and regularities attached to them" and highlights that all action is mediated (2009, p. 79). In moving from a Social Semiotic to a Mediated Interaction Analysis (MIA) approach, Norris thus brings the focus from the system of rules itself to such systems as they are being used by social actors (italics mine) (2009, p. 80). More precise definitions can be drawn from different social and theoretical perspectives (Kress, 2009, p. 59), however, as this thesis' aim is to examine social justice problems surrounding mining projects and not to develop 
multimodal theories, it is sufficient to consider modes as they become relevant through action in the interactions presented (see Norris, 2004a).

Modes have varying affordances and reach which allow different modes to do specific things and express specific information: for example, image depicts, while speech names, and layout organises (Kress, 2009, pp. 56, 57; Norris, 2009, p. 80). Meaning can become 'fixed' in certain modes and here Kress gives the example of formal reports in writing, which then make it seem as if the world as represented in this way comes about naturally (Kress, 2009, p. 66). Each mode also has its own way of framing information, which is "essential to make meaning" (Kress, 2009, p. 66). Frames not only hold together but also segment information into parts and demand that people "attend to the entities within the frame as connected, as having unity and coherence" while regarding "what is outside the frame as different from what is inside, and, if to be connected, then differently connected" (Kress, 2009, p. 67).

Multimodality can be considered less a theoretical framework and more a "domain of inquiry" that is embedded within other approaches (Kress, 2009, p. 54). However, common to all approaches is an agreement that communicators make use of a variety of modes and that these modes are used together to co-construct meaning in complex ways (Norris, 2004b; Scollon \& Scollon, 2009). Even 'language', traditionally considered one mode, is "constructed across multiple modes of communication, including speech and gesture" (Scollon \& LeVine, 2004, pp. 1-2). Considering this information, many scholars have called for a multimodal view of language in sociolinguistics research that considers how different modes might interact in creating meaning (Kendon, 2004; McNeill, 1992; Norris, 2004b; Scollon \& Scollon, 2009; Van Leeuwen, 2004).

Although multimodal research has a long history in other disciplines (Machin, 2013), within sociolinguistics there has been a recent multimodal turn encompassing three different approaches: multimodal discourse analysis, social semiotic multimodality, and multimodal interaction analysis. 
Growing out of Halliday's systemic functional linguistics, multimodal discourse analysis (MDA) emphasises the metafunctional systems which underlay semiotic choices (Jewitt, 2009, p. 32). The approach aims to both develop and subsequently utilise a theory of semiotic systems, as well as to develop systemic grammars which can map available semiotic resources (Jewitt, 2009, p. 33; see also Norris, 2004b). MDA focuses on exploration of the "system in use" as well as its social context, making the multimodal phenomenon itself, as opposed to the social actor, the focus (Jewitt, 2009, p. 33).

Like MDA, social semiotic multimodality (SSM) has drawn from Halliday's work, but also incorporated theoretical ideas from interactional sociolinguistics and non-linguistic disciplines. SSM focuses on mapping the use of modal resources and views semiotics as a decidedly social process which emphasises the social actor and their choice of semiotic resources (Jewitt, 2009, p. 30; Kress, 2011). SSM is concerned with how a sign-maker decides which resources to use and how these resources make meaning, placing the social actor at the centre of analysis (Jewitt, 2009, p. 31; Kress, 2011; Van Leeuwen, 2005).

Finally, a multimodal interaction analysis (MIA) approach bases its theoretical framework primarily on interactional sociolinguistics and mediated interaction (e.g. Scollon, 1999) and is further influenced by social semiotics (e.g. Kress \& Van Leeuwen 2001). MIA has arisen out of an ethnographic analysis of identity across modes (e.g. Norris, 2011) with a heavy focus on context and coconstruction. Because it does not consider the modal system to exist outside of interaction, MIA does not seek to map semiotic resources or create a theory of their use (Jewitt 2009). Instead, MIA seeks to understand how modes are made and understood through action that is taken by a social actor through mediational means (Jewitt 2009, pg. 34). MIA has arisen out of the work of mediated discourse analysis, which broadly seeks to bridge an analysis of discourse and social action (Scollon, 2001, p. 1). As such, mediated discourse theory views Discourse as social action that is communicated through shared meaning (Scollon, 2001, pp. 78). It is this latter theoretical approach which informs the methodological tools used 
in this thesis, drawn from MIA and Social Semiotics. Exactly how I develop an analytical framework incorporating these two approaches is described in detail in Chapter 3.

In this thesis, I approach mining debates from a multimodal perspective as a domain of inquiry (Kress, 2009). Approaching Discourse as action, I aim to illuminate how social actors may further entextualise Discourses of appropriation and resistance in multimodal ways:

\section{Within environmental Discourses, how do the dialectics of appropriation, recontextualisation, and resistance play out multimodally?}

In taking a multimodal view, this thesis considers the combination of a variety of modes (such as gaze, colour, layout, speech, etc.). In particular, gesture represents a crucial resource for social actors to create meaning in cohort with other modes in interaction (see Kuśmierczyk, 2013). For this reason, I discuss some of the previous research and ways of approaching gesture in discourse analysis.

\subsubsection{Gesture}

The mode of gesture in particular, has had a long history of study, dating back to Classical Antiquity and through the $18^{\text {th }}$ Century to the present day (Kendon, 2004). Research in gesture has often moved in tangent with developments in linguistics, especially signed languages (Kendon, 2004; McNeill, 1992; Scollon \& Scollon, 2009). Contemporary gesture research has been led by McNeill and Kendon (2004; 1992), and I make considerable use of their work here. Both recognise that gestures are expressive and symbolic, where the hand and/or arm becomes "something other than itself" (McNeill, 1992, p. 105): a character in motion, which utilises narrative space in ways very different from symbolic speech (McNeill, 1992, p. 20). Gestures differ from formal language in that they are noncombinatoric, meaning they cannot be combined like spoken utterances to form larger hierarchical structures (McNeill, 1992, p. 21). Through his experimental 
research, McNeill has found that, although gestures do not conform to a standardised form, speakers of different languages and abilities nonetheless may gesture in ways which carry similar meaning (1992, p. 22). That is, when gestures of different speakers are similar, this is due to meaning and content as opposed to any standardised system (1992, p. 22).

Much recent work in gesture studies has been preoccupied with the relationship between gesture and speech. Kendon believes this relationship to be dialogic and part of thinking processes (2004, p. 359) and McNeill describes gesture and speech as "bound to each other in time" (1992, p. 23). Gestures accompanying speech also tend to present closely-related semantic meanings and similar pragmatic functions (McNeill, 1992, p. 23). Because gesture tends to anticipate speech, McNeill argues that it is therefore an utterance in its "primitive form" and the gesture helps form a linguistic utterance from a "global-synthetic image" (1992, p. 26). In fact, speech and gesture are so closely tied, speakers will pause or hold speech or hand movements in order to maintain semantic, phonological, or pragmatic synchrony (McNeill, 1992, pp. 26-29). This means that the gestural stroke occurs with the "phonological peak" of an utterance, alongside the "idea unit" of an utterance, or functions together on the same pragmatic level (e.g. to deliver a narrative) (McNeill, 1992, pp. 26-29). Synchrony can also be achieved across speakers by mirroring gestures (Kuśmierczyk, 2013, p. 105).

Scholars have identified various 'movement phases' common to gestural action: the preparation phase is when the hands move from quiescence, the stroke is the nucleus of the action which brings the main meaning and may include a poststroke hold (Kendon, 2004, p. 112), and the retraction phase is when the hands move back to quiescence (McNeill, 1992, p. 83). A gesture phrase contains the preparation, the stroke, and the post-stroke hold if present (Kendon, 2004, p. 112; McNeill, 1992, p. 83). Various gesture phrases make up a gesture unit or G-unit, which can be identified as the period from the onset of limb movement to final rest (Kendon, 2004, p. 111; McNeill, 1992, p. 83). 
Because gestures are a form of human expression and may therefore vary, it is not helpful to create a single essential, universal categorical system but rather to use proposed typologies as "provisional working instruments which may be useful within a certain research perspective or interest" (Kendon, 2004, p. 107). In keeping with this idea, McNeill (1992) has suggested a number of influential broad categories which are useful for this thesis as tools for analysis and are thus summarised below. First, iconic gestures are those which "bear a close formal relationship to the semantic content of speech" (McNeill, 1992, p. 12), determined by how closely it relates to the scene described in speech and not necessarily the speech itself. There is variation in the complexity and timing of iconic gestures, which add salience and relevance to the utterance and allow speakers to highlight the exact moment when features become relevant. For example, drawing upon my own data in Figure 2.1, Al is talking about a specific group of people while his hands repeatedly enclose and delineate a closed circle. Through this gesture, Al depicts the group about which he is speaking.

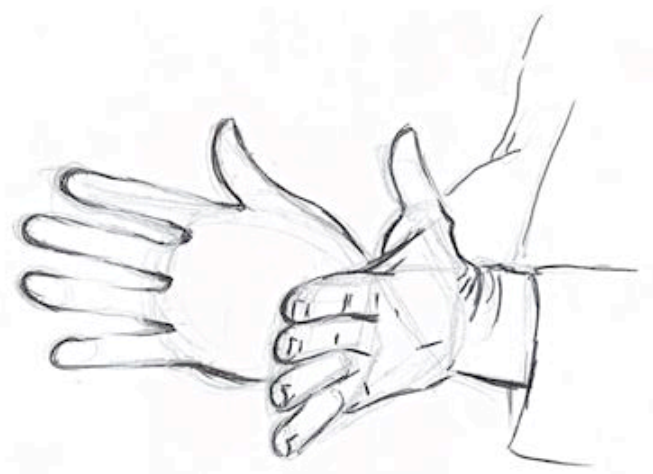

a

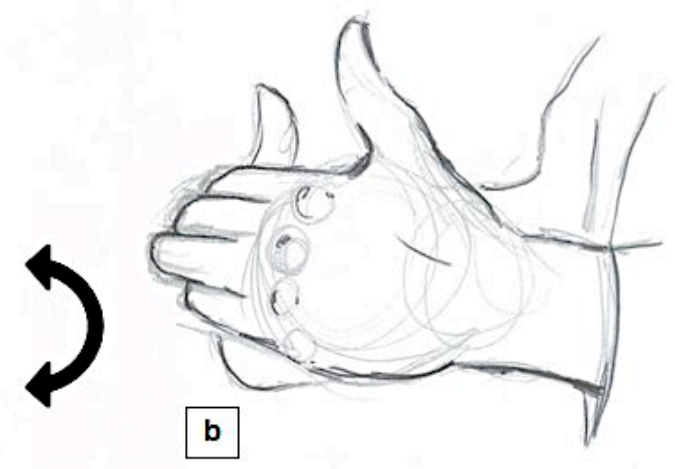

b

Al: "nobody outside that very specialist group"

Figure 2.1: Iconic Gesture

Like iconic gestures, metaphoric gestures are pictorial, although, in an abstract sense: the basic difference is that iconics depict something from the world, whereas metaphorics depict something from the mind (McNeill, 1992). These gestures imagine abstractions by depicting metaphors which are felt to be similar to the concept they describe. For example, in Figure 2.2, Al utilises the common 
"conduit" metaphor where information is a contained substance that is then transferred to a recipient (McNeill, 1992, p. 147). His speech indicates he is about to share information about New Zealand and he conceptualises this information through his hands as something that can be framed, held, and contained.

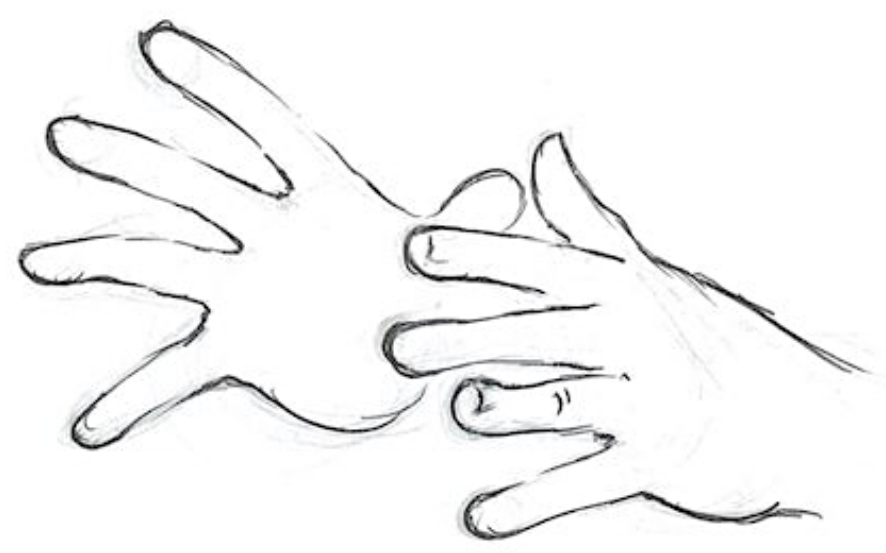

Al: "because one of the things about new zealand is"

Figure 2.2: Metaphoric Gesture

Beats are another important and common gesture type which tend to consist of two movement phases, usually an up/down, in/out, etc. They are so named because "they look like beating musical time", and are used pragmatically to mark certain words or phrases as significant (McNeill, 1992, p. 15). With low pictorial content, beats can be likened to a highlighter in written text and tend to be emphatic, signifying relationships to the larger discourse. Other researchers see beats as interactive gestures, or gestures that are only "made for the other person to see" (Bavelas, Chovil, Lawrie, \& Wade, 1992, p. 483). Bavelas et. al claim that such gestures give no information about the topic of discussion, but are rather meant to involve the interlocutor (1992, p. 472). However, because in this thesis I vew action as inseparable from the social actor in interaction (see Norris, 2004b on mediated action), I consider beats to be fundamentally interactive as well. Words or phrases which are accompanied by beats are thus signaled to the interlocutor as belonging to some other context, usually the larger discourse itself. In Figure 2.3, 
Al uses beats by pointing to the table as he says the words don't and go. These words are then given emphasis within the context of the entire utterance (bold text indicates the utterance with which the gestural stroke coincides).
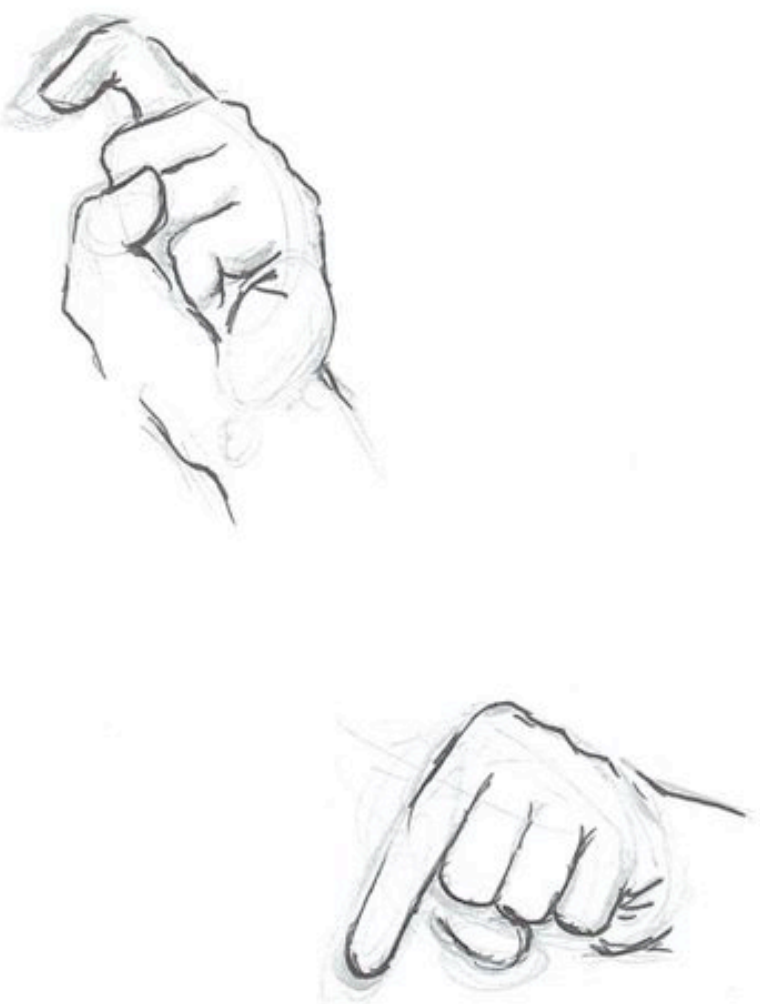

\section{Al: "new zealand isn't clean and green + don't go there"}

Figure 2.3: Beats

Deictic, or pointing, gestures can be used to indicate concrete objects in the real world or they can also be used abstractly, to point to an "empty" space that is nonetheless filled with "conceptual significance" (McNeill, 1992, pp. 18, 173). When this occurs, speakers assign metaphorical meaning to a space which is later referenced throughout the interaction. Referring back to Figure 2.3, we can see how Al uses deictic gestures to refer to a space that can be interpreted as representing New Zealand.

Finally, cohesive gestures are gestures which "tie together thematically 
related but temporally separated parts of the discourse", often as repeated forms or movements (McNeill, 1992, p. 16). Repeated gestures may be changed to signify contrast or diminished to imply non-contrast and shapes may be maintained with one hand while the other continues gesturing along with speech in order to provide cohesive links. In Figure 2.4, Al uses his hands to list off various parts of his utterance.

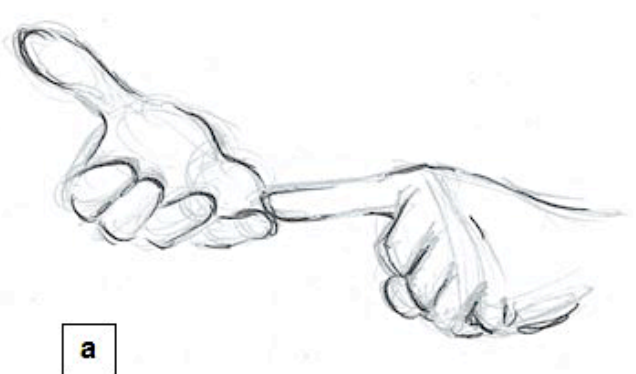

Al: "there's two things they care about + money"
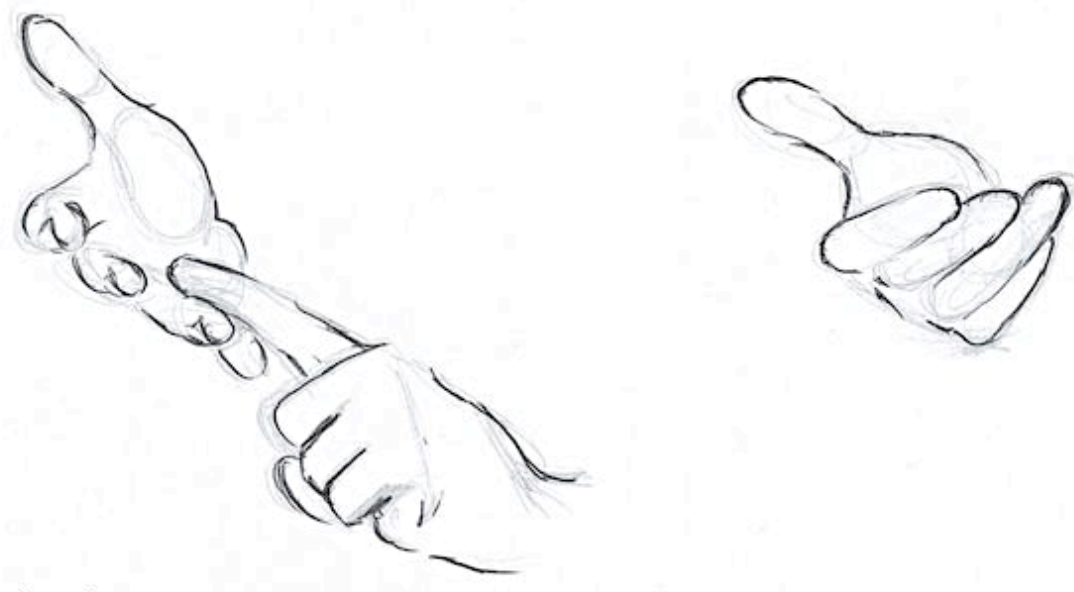

b
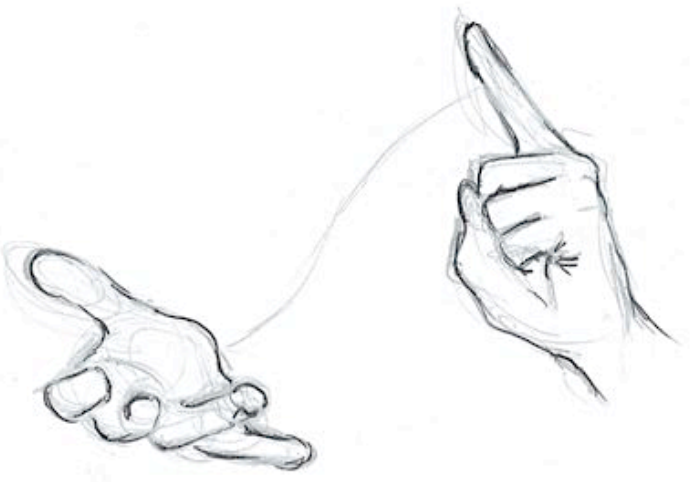

a

$$
\text { Al: "and power + you gotta" }
$$

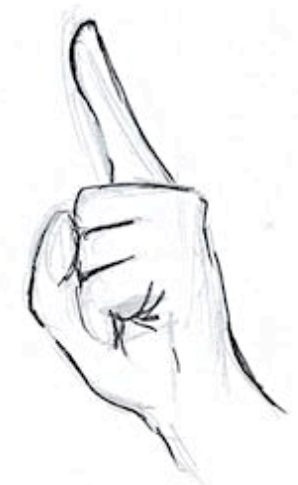




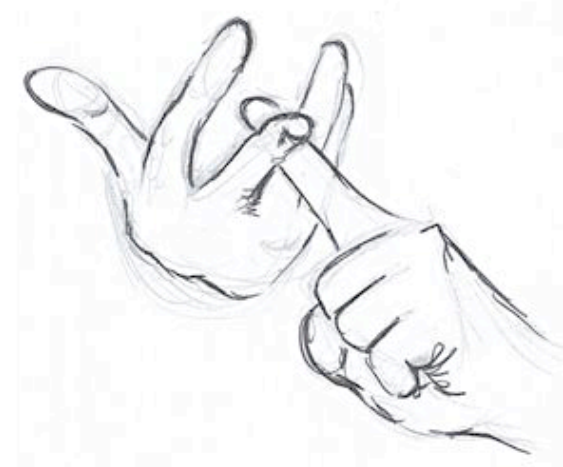

c
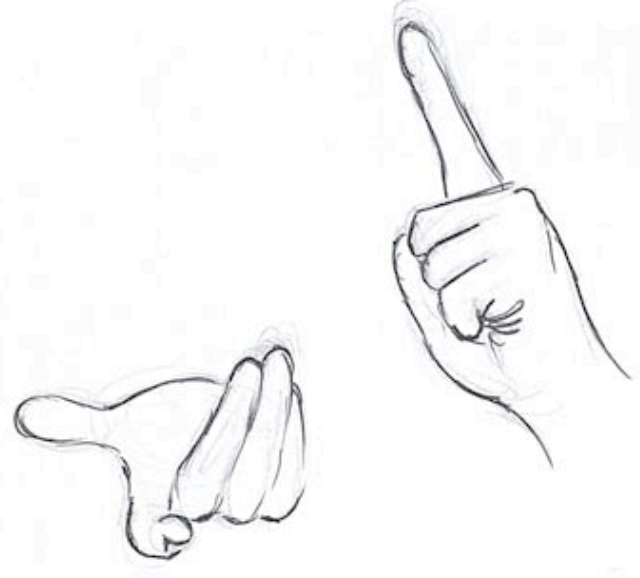

Al: "hit them on"

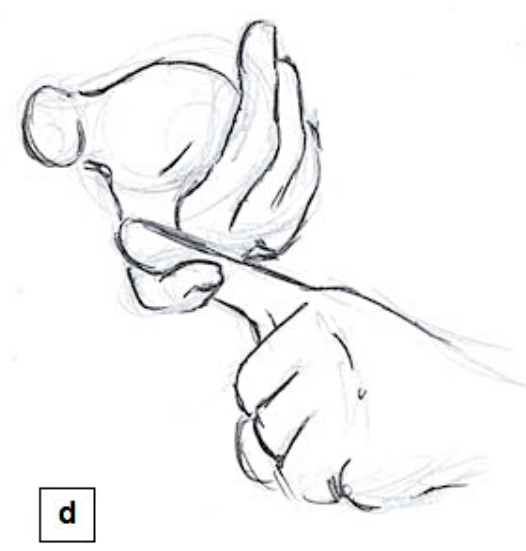

Al: "one of those two things"

Figure 2.4: Cohesive Gesture

He touches his fingers to indicate money and power. After a brief hold, he then continues up his hand, touching the other two fingers to emphasise hit and one. By repeating this movement, and maintaining the moving hand's shape throughout, Al ties the two utterances together.

These gesture types, included alongside considerations about gaze, posture, and other embodied actions, inform my multimodal analysis of interviews 
with activists and industry actors. By including a combination of modes, such as gesture, in my analytical scope, I am able to say more about how various Discourses are shared, negotiated, or appropriated through interaction.

Kendon (2004) outlines a number of gestural functions which can be carried out by any of the gestures found in the previous typography. Referential gestures make reference to speech content through representation and pointing and may be much more efficient than spoken language to depict objects (shape/size) or actions. Figure 2.1 is an example of a gesture acting referentially to depict the "group" which Al is discussing. Pragmatic gestures contribute to or constitute acts accomplished through an utterance, and are further divided into three categories. Performative gestures show a move or speech act, such as offering through open hands with the palms up. In Figure 2.5, Al uses a gesture to show his speech act: he makes quotation marks out of his fingers to show he is quoting a common opinion.
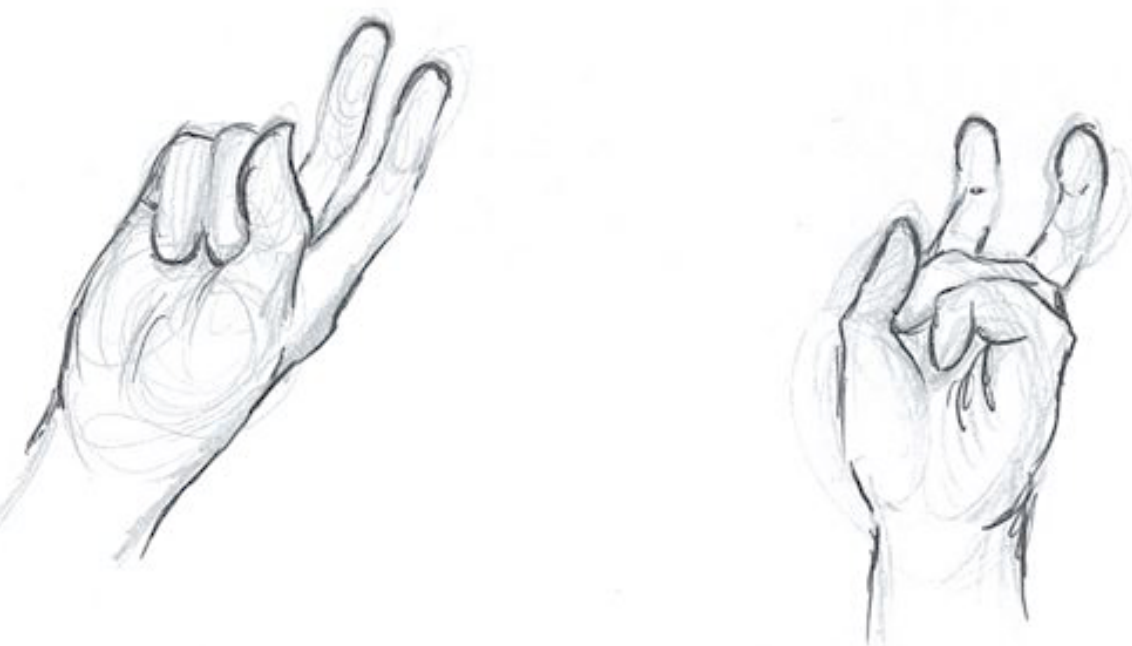

$\mathrm{Al}$ : "new zealand likes to think of itself as a first world country"

Figure 2.5: Performative Gesture 
Modal gestures show how an utterance should be interpreted, as in Figure 2.6 where Al holds his hands vertically with the palms out. According to Kendon (2004), this is a common gesture to indicate that something is stopping or being halted and he interprets it in some instances as serving to stop other objections or interpretations about what is being said.

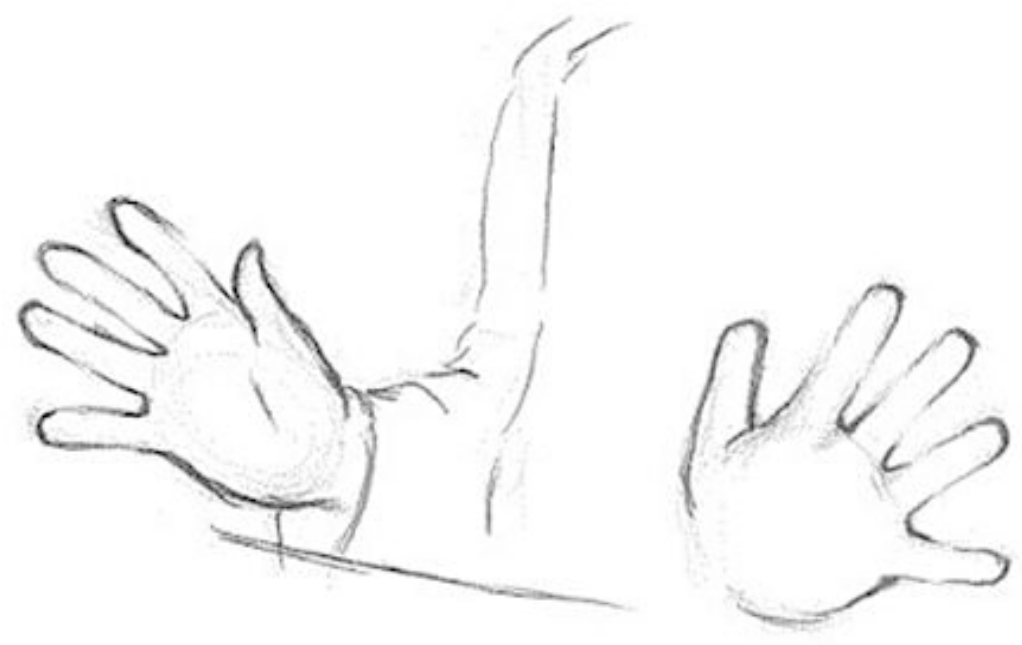

Al: "frankly + so what?"

Figure 2.6: Modal Gesture

Finally, parsing gestures mark aspects of spoken discourse, making them salient or relevant. Beats function commonly as parsing gestures, and in Figures 2.3, 2.4, and 2.5, we can see how each gesture serves to mark or emphasise an aspect of the accompanying utterance (indicated in bold). Kendon also notes Interactive/interpersonal functions of gestures which relate explicitly to interlocutors (i.e. regulating turn-taking, claiming speaker role, etc.) (see also Bavelas et al., 1992). Figure 2.7 shows such a gesture. 


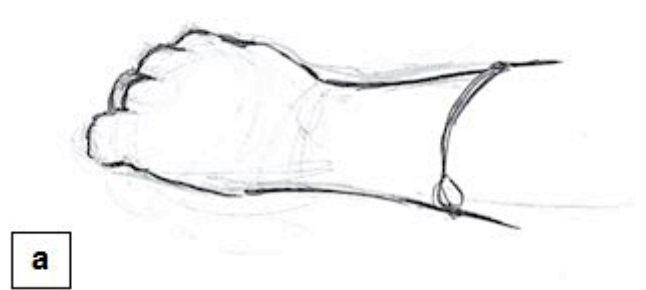

William: "that + that our pride is political and what we believe has + political decisions"

Keely: " $+"$

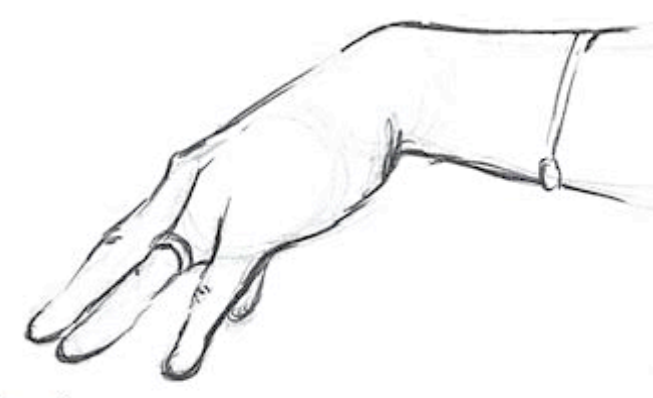

b

William: "and just because + we don't feel like we need to $+u m+i$ forgot what $i$ was gonna say"

Keely: " $+"$

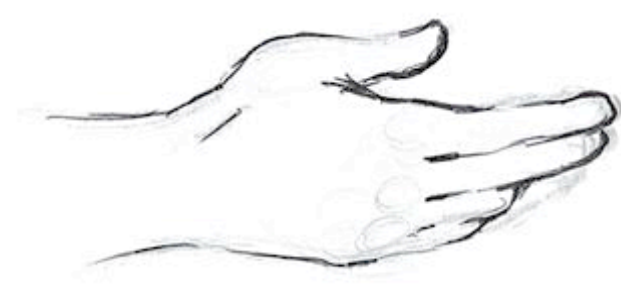

c

William: "sorry go ahead"

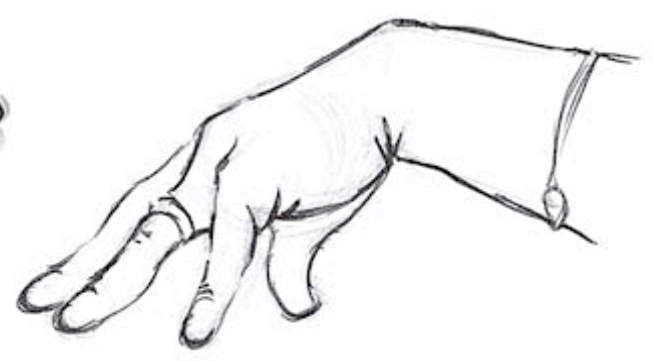

Keely: "oh I was just gonna say"

Figure 2.7: Interactive Gesture

When interacting with William, my hand remains at rest until it moves onto the table when I wish to begin speaking. William continues his turn but then trails off and gestures in my direction, giving me the floor to speak. Here, both speakers' gestures help regulate turn-taking by indicating the wish to speak without verbal interruption and by passing the turn to the next speaker.

In sum, gestures are controlled and orchestrated by speakers and will vary according to their communicative aims (Kendon, 2004, pp. 127, 358). Tied intimately to speech, gestures are used coherently alongside spoken language in expressive communication (Kendon, 2004, p. 360; McNeill, 1992). Echoing many other multimodal scholars, gesture researchers argue for gesture to be included alongside linguistic analysis, "for a truly inclusive view of human 
language" (Kendon, 2004, p. 361; McNeill, 1992). This thesis takes up that call and approaches communication as a multimodal phenomenon which includes gesture. As a multimodal analyst, I also recognise that communication is a complex combination of actions which I seek to represent as opposed to diminish (Blommaert, 2007a). In order to better understand and show the ways that Discourses move amongst various social actors, I therefore combine a critical, multimodal approach with ethnography. I thus draw heavily upon the ideas of Blommaert (2010; 2005, 2007a, 2010), whose work is especially valuable to this discussion.

\subsection{Ethnography}

Within the social sciences, ethnography can be conceptualised as a broad approach to research characterised by subjectivity. Ethnographers share a concern for interpretive and hypothetical knowledge that avoids positivism, and which views social events as inherently contextualised (Blommaert, 2007a, p. 684). Blommaert warns that ethnography is best viewed as "a general theoretical outlook, while things that are often (wrongly) metonymically seen as 'ethnography', such as fieldwork with participant observation and interviews, are just methods." (Blommaert, 2007a, p. 684). As such, ethnography embraces and utilises multiple analytical methods to examine the complexity of social interaction within communities. It allows for a "longitudinal, contextualized, sociocultural 'perspective'...even if the research design itself is not longitudinal" (Duff, 2008, p. 113).

Ethnography stems from anthropological disciplines, where researchers would live amongst and interact with communities in order to develop an insider perspective and ultimately produce a detailed account of social life through 'thick descriptions'(Geertz, 1973). There is, however, an emerging approach which encourages researchers to gain distance from, and understanding of, more familiar situations instead of a constant orientation to the 'Other' (Hammersley, 2007, p. 689). By examining communities of which they are part, ethnographers engage in a 
kind of "reporting out" to other academic groups (Scollon \& Scollon, 2007, p. 612). Rampton refers to such a perspective as an inside-out stance, "from the inside moving outwards, trying to get analytic distance on what's close-at-hand, rather than a move from the outside inwards, trying to get familiar with the strange," (2007, p. 591). Such a trajectory casts doubt on the idea of a traditional, comprehensive ethnography and may have effects on the ethnographer herself (e.g. making her sensitive to the limitations of ethnographic research in exotic lands) (Rampton, 2007, p. 591).

Ethnography ultimately addresses complexity: "It does not, unlike many other approaches, try to reduce the complexity of social events by focusing a priori on a selected range of relevant features, but it tries to describe and analyze the complexity of social events comprehensively" (Blommaert, 2007a, p. 682).

Critical Discourse Analysis also connects with an ethnographic approach. Both perspectives highlight and investigate wider contexts to the immediate interaction, something which approaches like Conversation Analysis do not do (Billig, 1999). In the case of environmental debates, this wider context provides crucial interpretive information, especially when we consider the ways in which Discourses may be appropriated and entextualised. Additionally, Rampton notes that CDA can provide a way of "stepping back from the taken-for-granted in order to uncover the ideological" and that this "de-familiarization" aligns with an ethnographic commitment to making the familiar seem strange (2007, p. 591). However, he warns that CDA has often ignored nontextual practices and may move too quickly from text to grand theory (Rampton, 2007, p. 588). Here, ethnography can provide a more nuanced trajectory, "working one step at a time from the data bottom-up" (Rampton, 2007, p. 588).

There are various approaches to ethnography within social sciences (e.g. microethnography) and within sociolinguistics the most common is linguistic ethnography, described below. 


\section{Dawn}

\section{How do I simplify all this complexity without, well, simplifying it?}

\subsubsection{Linguistic Ethnography}

In his attempt to carve out a theoretical space for linguistic ethnography, Rampton outlines two basic tenets that linguistic ethnographers hold: that context must be investigated and not assumed and that analysis of semiotic data yields great understanding of the social world (Rampton, 2007a, p. 585). This ties the linguistic to the wider context, and provides a a way to do so that draws upon an established methodological and theoretical background. Blommaert notes that linguistic ethnography sits upon a veritable research foundation and indeed is backed by some fairly heavy "benchmarks of recognizability" (2007a, p. 685). Additionally, as opposed to purely linguistic approaches, linguistic ethnography creates a "bridge between language structure and socio-cultural patterns" (Blommaert, 2007a, p. 687). In a way, ethnography can open linguistics up to a more reflexive and sensitive process and "to the potential importance of what gets left out" (Rampton, 2007, p. 596). At the same time however, linguistics can anchor ethnography through analysis of systematic linguistic processes and by introducing robust outside frameworks (Rampton, 2007, p. 596). In other words, ethnography can humanise linguistics while linguistics can help produce more detailed ethnographies (Rampton, 2007, pp. 596-597). The two approaches can also be used to complement each other, "problematising their outputs and turning the spotlight back onto the researchers and methods" (Rampton, 2007, pp. 596597). It is through turning this spotlight that ethnography brings a reflexive practice to linguistic analysis, allowing researchers to consider the values and choices they 
bring to their research projects. These ethnographic ideas are further discussed in the next chapter.

\subsection{Conclusion}

In the preceding sections, I have briefly described the previous literature in the theoretical areas of CDA, ethnography, and multimodality. In this section, I will explain how these different approaches can be woven together to accommodate the strengths and weaknesses of each.

Taken together, CDA, ethnography, and multimodality can be conceptualised as overlapping lenses through which I, as a researcher, view the social world of my research participants (see Figure 2.8).

\section{Environmental Debates}

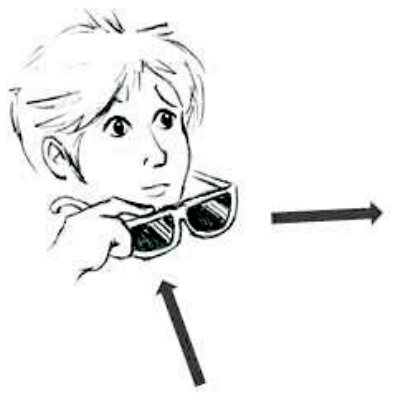

Critical, ethnographic, multimodal lenses

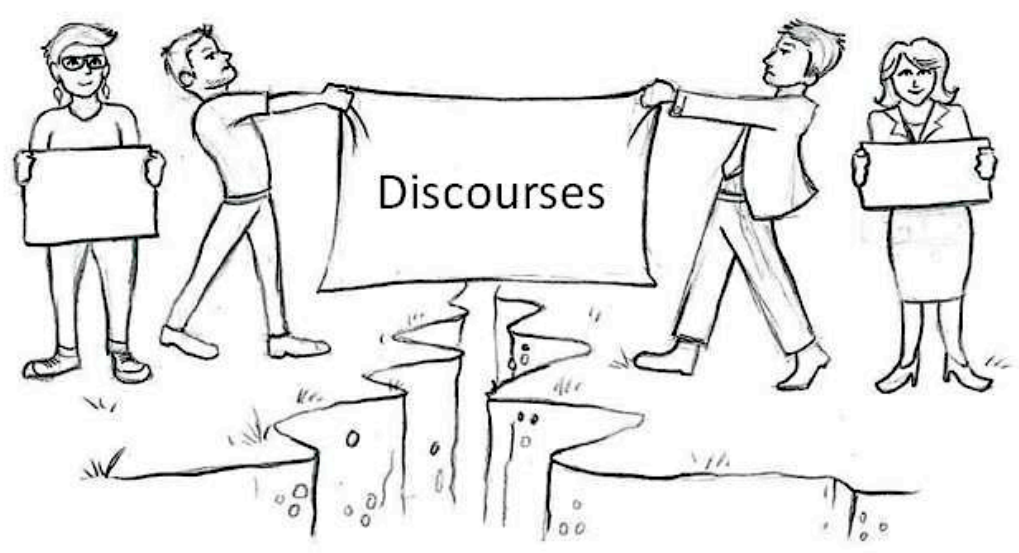

Activist actors

Industry actors

Figure 2.8: Theoretical Lenses

These lenses are tools with which I can focus on certain issues deemed relevant when viewing sites of environmental struggle (e.g. inequality and power, Discourse, gesture, reflexivity, etc.). From here, methodologies such as textual analysis, coupled with Multimodal Interaction Analysis and Social Semiotics, are informed by an intimate ethnographic knowledge of community practices. These 
methodological tools, which are expanded upon in the next chapter, allow me to tease out larger patterns from the complex and intertwined social fabric of these environmental debates.

As has previously been stated (Blommaert, 2005, p. 233), CDA and ethnographic approaches can be combined to draw upon the strengths and combat the weaknesses inherent in each. There is a fairly recent and rich history of critical ethnographic work in sociolinguistics from which my research orientation has been drawn (Blommaert, 2005; Kwon, Clarke, \& Wodak, 2009; Miles, 2010; Wodak \& Fairclough, 2010). As an interpretive approach, CDA may bear issues of validity and objectivity which ethnography can help combat by encouraging the researcher to develop a more emic perspective. CDA has also been criticised for its apparent lack of attention to the micro, textual characteristics of interaction and for making large leaps to the macro level of theory (Rampton, 2007, p. 588). As an approach quite literally grounded in the field, ethnography can anchor CDA to real world situations while providing a way to move between the micro of everyday interaction to the macro of social structure (Rampton 2007, p. 588, drawing on Hammersley \& Atkinson 1995, Blommaert \& Bulcaen 2000, Blommaert et al. 2001). Additionally, ethnographic approaches draw upon a rich history of reflexive practice on the part of the scholar, which can be used to negotiate the inherent positionings brought to research when using a critical perspective (Blommaert \& Jie, 2010). On the other hand, a critical discourse approach can infuse ethnographies with wider linguistic and Discoursal analyses, which help bring more robust and systematic analytical programmes to bear upon ethnographic fieldwork (Rampton, 2007). The CDA commitment to engaging with research participants and challenging powerful social structures also tackles some of the concerns of problematic ethnographic 'Othering' (Barnard, 2006; Denzin \& Lincoln, 2008).

As a "domain of inquiry" (Kress, 2009, p. 54), multimodality is also embedded within the critical ethnographic approach. This allows for a response to calls from CDA for a larger focus on multi-semiotic data (Kress \& Van Leeuwen, 2006; Van Leeuwen, 2004; Wodak \& Fairclough, 2010) while expanding the data 
potential for detailed ethnographic fieldwork. Like the combination of CDA and ethnography, multimodal concerns have been paired with both critical and ethnographic perspectives in past research (Machin, 2013; Norris, 2011).

In sum, the combination of approaches outlined in this chapter provide this thesis with a unique perspective. Including a critical approach which draws upon the work of CDA and Indigenous research programmes helps me to present an agenda of empowerment for communities of resistance. It also helps to challenge the assumed objectivity of research practices, embracing and interrogating the researcher's own subjectivities. At its core, CDA includes an analysis of domination and power as well as a concern for wider contextual issues beyond the immediate text or interaction. In this view, Discourse is a situated action that effects and also reproduces social structures. This makes CDA an ideal perspective from which to examine concepts crucial to my research questions, such as Discourse appropriation, resistance, and entextualisation. I have further integrated my critical approach with a multimodal perspective in order to expand the contextual landscape to include multiple modes of interaction, including gesture. To help me understand and present the complexities of Discourses in action, I also employ ethnography. Conceptualised as lenses, my critical, multimodal, and ethnographic approaches can be integrated to take advantage of the strengths of each, while mitigating their weaknesses. Utilising these lenses, I am able to adopt a perspective in this thesis which is truly unique. In the next chapter, I introduce and discuss the ways in which I plan to operationalise my research questions through these theoretical lenses. 


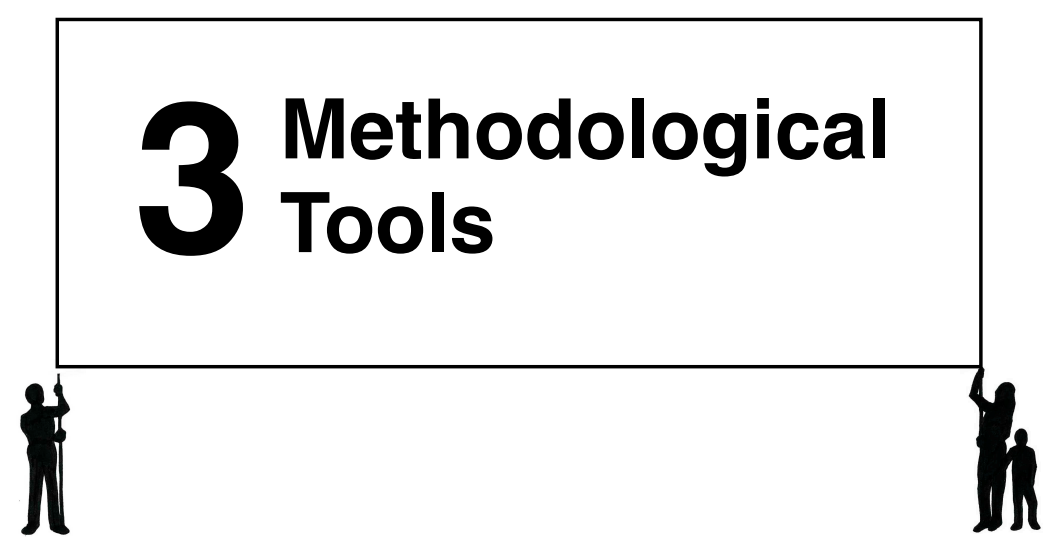

\begin{abstract}
A discussed in Chapter 2, in this thesis I employ critical, multimodal, and ethnographic theoretical lenses. In order to examine the appropriation and resistance of Discourses, I utilise a number of methodological tools, including ethnographic fieldwork, video recording and transcription, as well as Multimodal Interaction Analysis and Social Semiotics.
\end{abstract}

\title{
3.1 Ethnography: Giving Voice to Participants
}

Because this thesis is oriented towards sites of inequality, the research inevitably engages with vulnerable communities. Within the context of environmental debates, this vulnerability tends to be found in the ranks of activists who struggle against powerful corporations, lobbyists, and sometimes governments to resist damaging projects. Both the Athabasca tar sands and the Southland lignite cases are complex and continuously evolving situations which involve various actors and Discourses. Like many other ethnographers, I choose to examine communities of which I am a part, (Duff, 2008; Scollon \& Scollon, 2007), and so I am an involved member of each community, playing a role in their development and complexity as a researcher and activist. Moreover, I recognise that my own actions as an analyst will have consequences as I take an engaged stance (Scollon \& Scollon, 2007, p. 615) but I also recognise that this is to be expected and therefore necessitates reflexivity of ethnographic knowledge itself (Blommaert, 2007a, p. 682). Ethnography then, is an approach that allows me to 
embrace and utilise my own involvement as a member of the groups I wish to examine, as well as providing a framework for reflexivity.

During the eight years I spent living in Edmonton, my organising work with local activists allowed me to become a core member of a very strong community of struggle, allowing me to re-integrate upon my return a year later. In this way, the years of training and organisation put me in a unique position to approach my community as a researcher. However, this new role also brought interaction issues in the field (see Chapter 9).

My arrival in Aotearoa/New Zealand posed the challenge of gaining trust and access to activist groups. Shortly after landing in the country, I began to seek out communities of struggle before l'd officially begun my research schedule. I actually did this without my research in mind, and simply sought interaction with those who were working in anti-oppression activist circles.

When we moved here, one day we went to the library for information on housing. We stumbled across a demonstration in Civic Square - it was the International Day of Action Against Extraction. Te Whanau Apanui were there to protest the deep sea oil drilling (which eventually led to the GP flotilla event). I chatted with a Maori woman, inquiring about the protest...that was my first experience with activism in Aotearoa. (Jan. 16, 2012, FN1)

I quickly became involved in the local cycling advocacy community, as well as a Wellington-based climate justice group. With this group, I helped organise various events, including a tar sands solidarity event. I also traveled to Parihaka and Waitara in Taranaki to discuss networking with locals who were resisting hydraulic fracturing on their land. When the Rena cargo ship ran aground in October 2011, I traveled to Tauranga with a number of activist colleagues and helped clean beaches along the East Cape.

\footnotetext{
1 Field Notes.
} 
We spent a couple days cleaning beaches. We found mostly oil-soaked styrofoam from the inside of shipping containers. We also found rotting bags of milk powder and butter, dead seabirds, and the most disgusting deer hide l've ever come across. But the worst was the oil. It gets everywhere. It was just horrifying to see it all over the rocks and incredibly difficult to get off. I spent so much time trying to clean as best I could and when I turned around or climbed over to the next part there were even bigger globs of it. And it reeked. I dreamed of cleaning oil off rocks for the next couple nights. (Oct. 24, 2011, FN)

Later, I participated in Forest \& Bird's Bioblitz at the Denniston Plateau. Described as a scientific treasure hunt, volunteers were grouped with biologists to survey the organisms living on the plateau.

Even though the Denniston wasn't the campaign I will focus on, it is still very good to attend these sorts of events to gain an understanding of the NZ activist culture and atmosphere. The bioblitz seems a very useful tactic (and one that l've not seen before) to gain some legitimacy for the conservation/environmental movement. There was talk during the weekend of the bioblitz being a way to create an arsenal against industry interests. People were hoping for a big and exciting new find that would mean the Plateau cannot be mined. People also expressed frustration that a big new find was necessary to save the place - "isn't this enough to save it already?" was a common sentiment I heard. (March 6, 2012, FN)

All of these activities gave me access to spaces and people and allowed me to develop an understanding of Kiwi environmental culture. My participation and leadership also positioned me as a core member of these groups and cemented trust and mutual respect. However, these positionings had implications for my interactions with industry representatives (see Chapter 9).

By adopting a dedicated ethnographic approach which includes laying the groundwork for involvement, living amongst and working with activist communities, academics may gain the trust of individuals (over and above a 'consent form'), while also gaining access to spaces otherwise off limits (Fincham, 2006). Due to a 
history of media manipulation and even covert surveillance, many in activist circles are distrustful of outsiders suddenly appearing in their lives, hoping to observe them (Smith, 1999). This makes ethnographic work important in navigating the legitimate concerns of individuals and indeed, there is a great deal of groundwork which must be laid before approaching a community. However, researchers must also recognise that their academic practice lies within a history of colonisation and 'othering' and that there is especially a distrust of research which does nothing to further the activist cause and instead takes precious time and energy away from community groups (Smith, 1999). Additionally, research has been critiqued for extracting community information that has resulted in misrepresentation (Smith, 1999). An ethnographic approach to activist research encourages ethnographers to become part of the community and research with rather than on (Cameron, Frazer, Harvey, Rampton, \& Richardson, 1993; Smith, 1999) while continuously examining their own role. This is one way to approach vulnerable communities of struggle while maintaining an analytical perspective as well as respectful engagement.

Although I was able to approach and work with these groups, such access brings with it issues of alignment and neutrality (Blommaert \& Jie, 2010). In the highly charged, political situations where activism is found, there is a danger of becoming more advocate than observer (Khasnabish \& Haiven, 2012). At the same time however, critical approaches encourage research which engages with instances of inequality, and some researchers have called for more alignment with communities, even demanding academics join the cause (Khasnabish \& Haiven, 2012). Ethnography itself has been problematised as an academic practice that upholds basic power structures by analysing the less powerful from a place of privilege; i.e. the academy (Barnard, 2006). However, for many social scientists, and especially young researchers, aligning with activist communities can be a risky move, as such alternative models of scholarship often lie outside of mainstream social science (Emihovich, 2005). Finding academic space to work with activist communities of struggle can be difficult, but scholars suggest utilising reflexivity as a method for negotiating the various positions we find ourselves taking up (Sarangi 
\& Candlin, 2003). Such reflexivity is also important to critical approaches (Jones \& Jenkins, 2008; Smith, 1999), bringing the author's presence into the research and laying bare the various perspectives and lenses used in interpretation. An ethnographic approach allows for reflexive practice as outlined in section 2.4 , as well as providing scholarly space for academics to negotiate their positioning in the field.

An ethnographic approach also assists in the qualitative interpretation of data. Because recordings, and therefore accompanying transcripts, are selective, additional data collection methods - such as interviews, field notes, and other documents - may be necessary (Flewitt, Hampel, Hauck, \& Lancaster, 2009; Kress, 2011). In order to lend an extra layer of analytical triangulation (Duff, 2008; Norris, 2011; Rampton, 2007), I make use of detailed field notes and experiential knowledge gained with community groups in the field. Because this research involves multiple actors, contexts, and Discourses, such an approach is ideal as it can engage with complexity (Blommaert \& Jie, 2010; Scollon \& Scollon, 2007). Additionally, ethnographic practice provides a grounded, micro-level of engagement with language and action which can then be used to theorise up towards the macro-level Discourses typical of CDA (Rampton, 2007). In sum, the experiences I gained living amongst and working with communities of struggle helped me make sense of the data I collected.

Finally, an ethnographic approach does not cease to be relevant after data collection has ended. I thus seek to give voice to the participants who have made this research possible by including their own utterances (albeit in transcribed form) whenever possible. I also foreground my reflexivity by presenting my fieldnotes where appropriate.

\subsection{Becoming an Ethnographer}

Keeping in mind the need to develop trust with, and understanding of, communities of resistance, I engaged in a number of activities within the 
environmental justice communities around the North Island of Aotearoa/New Zealand. This involved gaining a deeper understanding of the "field" of environmental resistance and conservation in my new home (Blommaert \& Jie, 2010, p. 20). Additionally, this work helped me to develop my own background as a climate justice advocate in Aotearoa/New Zealand, something which would become crucial to developing trust later on (cf. Fincham, 2006). This preparation involved travel throughout the country, visiting communities, participating in, and sometimes organising, events. This work is summarised in Table 3.1.

\section{Dawn}

(1)ThisPhD

\section{From Whangarei to Invercargill in less than 2 weeks \#researchtrips \#wearytraveler}

\begin{tabular}{|l|l|l|l|}
\hline Date & Location & Data collected & $\begin{array}{l}\text { Contextual } \\
\text { Groundwork }\end{array}$ \\
\hline April, 2011 & Wellington & $\begin{array}{l}\text { Integration with local } \\
\text { climate justice } \\
\text { community, }\end{array}$ \\
\hline $\begin{array}{l}\text { August, } \\
2011\end{array}$ & Taranaki & Fieldnotes & $\begin{array}{l}\text { First contact with } \\
\text { activists outside of } \\
\text { Wellington, }\end{array}$ \\
\hline $\begin{array}{l}\text { October, } \\
2011\end{array}$ & East Cape & Fieldnotes & Rena oil spill \\
\hline $\begin{array}{l}\text { January, } \\
2012\end{array}$ & Southland & Fieldnotes, artefacts & Anti-mining festival \\
\hline $\begin{array}{l}\text { February, } \\
2012\end{array}$ & $\begin{array}{l}\text { Taranaki, Southland, } \\
\text { Wellington }\end{array}$ & $\begin{array}{l}\text { Fieldnotes, artefacts, pilot } \\
\text { interviews }\end{array}$ & $\begin{array}{l}\text { First contact with } \\
\text { industry, Southland } \\
\text { Field Days }\end{array}$ \\
\hline $\begin{array}{l}\text { March, } \\
2012\end{array}$ & $\begin{array}{l}\text { West Coast, } \\
\text { Canterbury }\end{array}$ & $\begin{array}{l}\text { Fieldnotes, interview, } \\
\text { artefacts }\end{array}$ & $\begin{array}{l}\text { Interactions with } \\
\text { industry actors and } \\
\text { activist community }\end{array}$ \\
\hline April, 2012 & $\begin{array}{l}\text { Whangerei, } \\
\text { Canterbury }\end{array}$ & $\begin{array}{l}\text { Fieldnotes, interviews, } \\
\text { artefacts }\end{array}$ & Activist interviews \\
\hline May, 2012 & Wellington & $\begin{array}{l}\text { Fieldnotes, artefacts, } \\
\text { interview }\end{array}$ & Activist interview \\
\hline
\end{tabular}




\begin{tabular}{|l|l|l|l|}
\hline June, 2012 & $\begin{array}{l}\text { Calgary, Fort } \\
\text { McMurray, } \\
\text { Edmonton }\end{array}$ & $\begin{array}{l}\text { Fieldnotes, interviews, } \\
\text { artefacts }\end{array}$ & $\begin{array}{l}\text { Industry and activist } \\
\text { interviews, mining } \\
\text { tours }\end{array}$ \\
\hline July, 2012 & Calgary & $\begin{array}{l}\text { Fieldnotes, interview, } \\
\text { artefacts }\end{array}$ & Activist interview \\
\hline
\end{tabular}

Table 3.1: Data Collection Trips

By the end of 2011, I had chosen a community with which to work who were resisting 'fracking'2 on their land in Taranaki. Later, I came across an anti-coal mining festival in Southland which I attended for its networking possibilities but, upon my return to Wellington, I considered its potential as a more relevant case study. I was aware that choosing case studies for ethnographic research is a crucial first step that must consider access, resources, trust, and the potential for comparison (Blommaert \& Jie, 2010; Scollon \& Scollon, 2009, p. 621). As such, my selection was carefully weighed against my previously chosen community of study. Ultimately, what swayed my decision was the experience I had becoming an insider during the festival, outlined below. This, compared with the Taranaki experience, gave me a much higher level of access and comfort with the community, and allowed me to build trust as a researcher (Fincham, 2006). At the time of data collection, the anti-fracking movement was still in its infancy in Aotearoa/New Zealand and did not become a national issue until a few months into my fieldwork.

It is worth describing the circumstances of my initial involvement with the community finally selected as my Aotearoa/New Zealand case study, as my preparation helped me to gain access almost immediately (Blommaert \& Jie, 2010). While planning my trip to the festival, I posted a message on a social media site and found a ride to the venue. I discovered that I was traveling with the festival organisers and, over the next few days, I helped set up the outdoor village, including food stations, tents, stages, and waste facilities. I devoted myself to the construction of the site's composting toilets and was assigned creative control on

${ }^{2} \mathrm{~A}$ controversial technique for removing gas from bedrock. 
the basis that I was the only person present who had used a composting toilet system before. My role was formalised when I was put in charge of everything toilet-related: from organizing a cleaning roster to giving an orientation to over one hundred attendees on the first night of the festival. My enthusiasm for the project earned me the title of 'the toilet lady' (discussed further in Chapter 9), and I even gave an interview about the toilets' construction to a local radio station. In a matter of days, I had become a composting toilet expert and a festival organiser: I had moved from the classic participant 'outsider' to 'insider' in a most unexpected fashion:

There's a strange paradox: I feel like because I went into the festival more pure, without the intention of being a researcher, I'm in the position where I can enter very effectively as a researcher. That role is now much more open to me. (Jan. 25, 2012, FN)

The playful nature of my role as 'the toilet lady' came at a crucial period of getting to know my participants and gaining acceptance. The adoption of my 'toilet lady' duties meant that I had a legitimate reason to be at the festival, and this role also, in turn, "legitimized my enquiry" (Fincham, 2006, p. 192). As the first interaction with those involved in the struggle, my experience was decidedly positive and fortunate.

\section{Dawn} @ThisPhD

\section{I never really expected to be building composting toilets as part of this phd \#yaylinguistics}

12:39 AM - 19 Jan 2012

Ultimately, an ethnographic approach to analyzing Discourses in environmental debates allowed me to gain access and develop trust with communities who are wary of outsiders. The work I undertook to become part of the Southland activist 
community, and my re-integration into my own Edmonton activist community, provide me with a unique perspective in both cases. As a member of these communities, I have privileged insights into their values and practices but I have also been able to gain analytical distance by approaching from the 'outside'. Thus, by adopting an ethnographic approach, I was able to interact with my activist participants in a more genuine way while maintaining the fresh eyes and ears of a researcher. This, in turn, helped me to interpret some of the multimodal meanings as they became relevant in interaction.

\subsection{Multimodal Interaction Analysis}

As outlined in Chapter 2, in this thesis I utilise Multimodal Interaction Analysis (MIA), coupled with Social Semiotics (Kress \& Van Leeuwen, 2006), to examine multimodal action in environmental debates. Arising out of interactional sociolinguistics, mediated discourse analysis (e.g. Ronald Scollon, 2001), and multimodal semiotics (e.g. Kress \& van Leeuwen, 1999) (see section 2.3), MIA focuses the analysis on interaction through multimodal action. This includes and expands upon an analysis of language through textual analysis (Fairclough, 2003). Because MIA is concerned with modes in interaction, it is ideal for analysing the interview components of my thesis in order to understand how Discourses may be appropriated and resisted through embodied action.

MIA focuses on three necessary components of multimodality: the social actor, the action, and the mediational means (Norris, 2009). As tools for communicating action, mediational means are always situated in a specific environment which includes any other social actors present, and cannot be separated from the action of the social actor (Norris, 2009, p. 80; Scollon, 2001, p. 4). This means that context becomes crucial to meaning and it is thus the "mediated action" (Scollon, 2001) taken by a social actor which forms the basic unit of analysis in MIA. This analytical tool has been recently developed by Sigrid Norris and expanded upon by Ewa Kusmierczyk, and I draw heavily upon their work here (Kuśmierczyk, 2013; Norris, 2004b, 2009, 2011). 
In examining actions taken by social actors, Norris differentiates between lower-level (smallest unit of meaning, e.g. a gesture) and higher-level actions (a chain of lower-level actions, e.g. a conversation) (Norris, 2011, p. 39). Higher-level actions are described as "constructed through the employment of numerous lowerlevel actions, drawing on a multiplicity of communicative modes" (Norris, 2004b, p. 102). A social actor may, in fact, be focused on a higher level action while simultaneously engaging in lower level actions, creating what Norris terms modal density: "the intricate interplay of various modes of communication or the intensity of a certain mode that a social actor employs" (Norris, 2004b, p. 102). The social actor may attend to different actions by building up the modal density, which can be interpreted as operating at different levels of awareness (Norris, 2004b, p. 114). Norris asserts, however, that it is not the number of modes which is important, but rather the complexity of the interlinked modes used (Norris, 2004b, p. 104). Through their actions, social actors may use various interactive modes to move certain identity elements to the (metaphorical) foreground, middleground, and background of awareness (Norris, 2011, p. 141). For example, in Figure 3.1, Bernadette and I are engaging in conversation about the local mine and the group that has formed to protest its expansion.

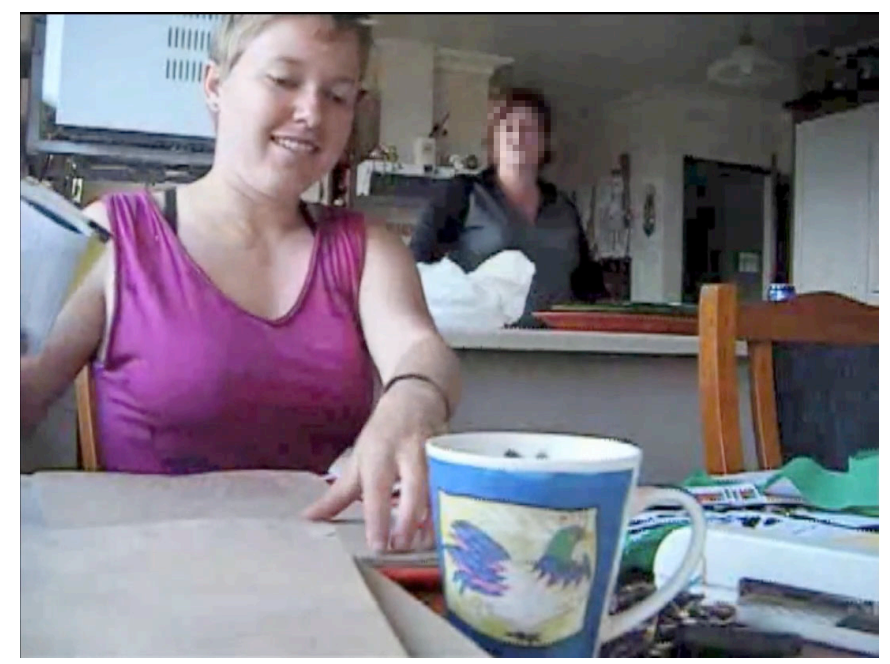

Figure 3.1: Layout and Modal Density (I am on the left and Bernadette is on the right) 
While conversing, both she and I are also engaging in other actions such as folding papers and stuffing envelopes, packing up wine, cleaning, and organising for the event. Additionally, Bernadette is interacting with her family as they come into view and another friend Molly, who has come over to use the shower. At various times, both of us use actions to bring different identities forward:

Bernadette may gaze at and begin speaking to her son, foregrounding her identity as a mother and backgrounding her identity as an activist organiser. I may focus on my work or look back and engage with Bernadette, shifting between my identities as interviewer and activist organiser. These actions are fluid and dynamic and it is the combination of modes which bring focus onto one identity or the other at a moment in time (Norris, 2011).

A related concept, modal configuration, "refers to the hierarchical, equal, or connected relationships among the modes that are at play in a given moment of a higher-level action" (Norris, 2009, p. 78). Using this concept, researchers can analyse the hierarchical positions of different modes that are used in a higher-level action, which allows an analysis of how modes might relate to each other in interaction (Norris, 2009, p. 78). However, this is situated and constrained, as multimodal configurations in one context may not translate directly to another (Norris, 2009, p. 84). To examine another layer of meaning in the above example, we might consider how my gaze towards Bernadette is more deliberate, thus taking on a very meaningful dimension because of the way it is configured in relation to the spatial layout. The fact that I cannot look at Bernadette without turning my head (see Figure 3.2) means my gaze becomes more significant in my engagement with Bernadette than other actions, such as vocal backchanneling, might. 


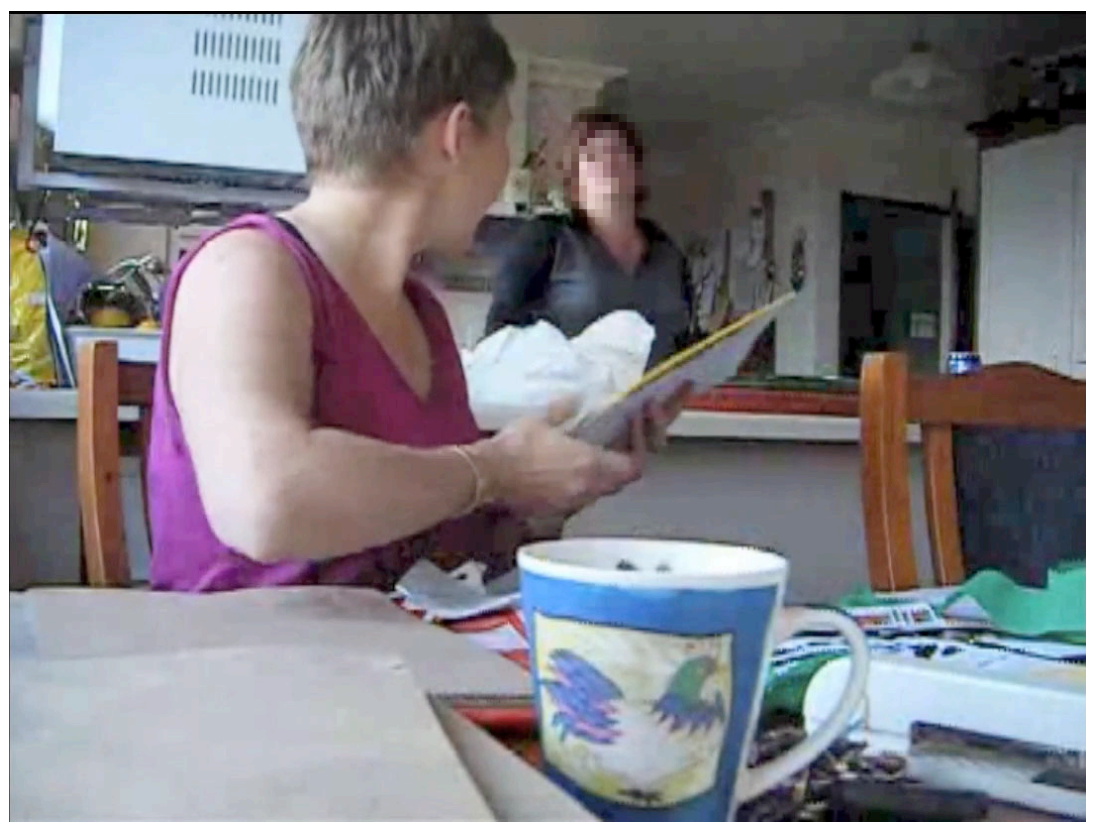

Figure. 3.2: Layout and Multimodal Configuration

Taken together, modal density and modal configuration are useful concepts for identifying meaning constructed through the use of structured, higher-level actions which, in turn, are made up of lower-level actions (see Kuśmierczyk, 2013).

Another useful concept is a social actor's social-time-place which encompasses the broader social, historical, and environmental context that mediates identity production (Norris, 2011, p. 31; Scollon, 2001, p. 4). A social actor's social-time-place informs how "the social actor lives within particular social structures, within a particular historical moment, and in a particular place" (Norris, 2011, pp. 30-31). This leads naturally to sites of engagement, which encompass the physical spaces, times, and psychological and historical make-up of an interaction. In other words, sites of engagement are "the window opened to make the (inter)action possible" (Norris, 2011, p. 51) which cannot be repeated exactly the same way again. Both a social actor's social-time-place and the site of engagement are useful concepts for examining the wider context of an interaction. To build upon the aforementioned example we can see once again, how the socialtime-place and site of engagement add information: these particular activists, and 
researcher, are preparing for an imminent event and so must conduct an interview while simultaneously engaging in other work.

Finally, Norris also describes the concept of frozen action, or "actions that were performed by social actors at the prior moment [and] are frozen in time" (Norris, 2009, p. 82). These actions are visible in the form of artefacts, as objects which are "infused with prior actions" (Norris, 2011, p. 41). Artefacts may be made relevant in interaction, for example when social actors orient to a pamphlet or use a wall map to explain something. Consider once again how artefacts might add another layer of analysis to the above example: I foreground my attention for most of the interaction upon the papers I am folding, while Bernadette organises event items in the kitchen behind me. This need to work with artefacts is partly the reason for the specific spatial layout, which in turn affects the modal hierarchies and therefore the various ways in which modal density can be achieved. In this thesis, artefacts are considered under the wider umbrella of MIA as frozen actions,

however I recognise that they bring meaning in and of themselves. Therefore, I will also analyse artefacts for relevant meaning using concepts drawn from Social Semiotics (Kress \& Van Leeuwen, 2006), summarised in the next section.

\subsection{Social Semiotics}

Modern communication practices are characterised in part by visual actions (see Blommaert, 2012). Social actors on all sides of environmental debates make extensive use of artefacts such as pamphlets, flyers, buttons, and other designed items. To connect macro and micro actions by interrogating how both industry actors and activists construct Discourses, I will thus collect and analyse a variety of relevant artefacts. These will be collected as they are made available throughout my fieldwork and interactions with participants (e.g. displayed in offices, used during interviews, etc.). MIA, although ideal for analysing interaction, is insufficient in this regard, as it tends to focus on embodied, spontaneous interaction in real time (e.g. Norris, 2011). Social Semiotics, on the other hand, provides a useful framework for understanding how Discourses might be constructed and 
entextualised using various principles of design. Although Social Semiotics is a theoretical approach (see section 2.3), its accompanying methodology is useful for analysing visual communication, especially where social actors have made premeditated design decisions (e.g. posters, film, and even sculpture). It encompasses a broad field of research, analysing actions such as musical performance (McDonald, 2013), websites (Harvey, 2013), and even transcription practices (Bezemer \& Mavers, 2011). The brief discussion below draws heavily upon Kress and van Leeuwen's seminal book Reading Images (2006), which is an important reference text for Social Semiotics research.

Like MIA, Social Semiotics views communication as mediated expression within a vast multimodal system and seeks to expand analysis to include other modes $^{3}$ (Kress \& Van Leeuwen, 2006; Norris, 2011, see Chapter 2 for more discussion of multimodal theories). Including visual modes is especially important for critical analysts, to "be able to 'read between the lines', in order to get a sense of what discursive/ideological position, what 'interest', may have given rise to a particular text, and maybe to glimpse at least the possibility of an alternative view" (Kress \& Van Leeuwen, 2006, p. 14). Like other critical discourse analysts who have since begun exploring the possibilities of visual communication (Machin \& Mayr, 2013; Machin, 2013; Vestergaard, 2013), I seek to illuminate this potential 'alternative view' throughout my analysis by asking the reader to imagine how meaning might change if actions are done differently.

Kress and Van Leeuwen argue that mages are used as narrative structures in their own right. Vectors, which may be represented through lines, create relationships between elements, similar to verbs and nouns in verbal language (2006). The Actor is the participant from which a vector emanates and is often the most salient through their size, colour, composition and so on. In a similar fashion, triangles (sometimes symbolising a fusion of participant and vector) can convey

\footnotetext{
3 Even written language, often considered a single mode, involves a variety of modes such as materials and tools, as well as the visual aspect of lettering and layout (Kress \& Van Leeuwen, 2006; Van Leeuwen, 2004).
} 
directionality or process. Other objects may indicate vectorality through a process of tilting, which creates oblique lines. Vectors may be strongly implied through a combination of line and triangle forming arrows, which in turn can be amplified through boldness, curves, and other variants. Vectors have quite generalised meanings and so can be used to "represent fundamentally different processes as though they were the same" (Kress \& Van Leeuwen, 2006, p. 62). In this way, different meanings can become conflated as metaphors: "movement, transport is transformation; mobility is the cause of, and condition for, change, growth, evolution, progress" (Kress \& Van Leeuwen, 2006, p. 62).

Drawing on my own data, we can see how vectors might guide the reader in a trajectory from one image to another, which in turn represent the various steps in the mining process (Figure 3.3, circled in red).

Image removed after examination

Figure 3.3: Mining Diagram

Other elements besides vectors play a role in visual narratives. For example, curved forms may represent organic and natural growth as opposed to 
rectangular, mechanical representations. In Figure 3.3, our interpretation of the mining process as mechanical and precise may be affected by the rectangular boxes encompassing the drawings. Additionally, the various elements that make up such a narrative visual structure are not neutral depictions of reality: "they produce images of reality which are bound up with the interests of the social institutions within which the images are produced, circulated and read. They are ideological" (Kress \& Van Leeuwen, 2006, p. 47). For example, Actors may be barely visible and therefore anonymous, possibly rendering the image as in 'passive agent deletion', where agency is linguistically altered or omitted. This is the case with Figure 3.3 where we do not see any actors. This absence is mirrored in the text which is presented in the passive voice: Lignite is mined, transferred, uploaded etc, without reference to who completes these actions. Even the windows of the trucks seem to be drawn depicting reflective material that does not allow us to see any human agents inside.

Visual processes may also position social agents in various ways. For example, classification processes can create relations between participants (Kress \& Van Leeuwen, 2006; Martinec \& Van Leeuwen, 2009). Here again, conflation is possible, where the more general idea may be represented as more powerful or certain identities may be represented as subordinate to others. Analytical processes, on the other hand, "relate participants in terms of a part-whole structure" (Kress \& Van Leeuwen, 2006, p. 97). Kress and van Leeuwen divide these further into topographical structures, which accurately represent the "physical spatial relations and the relative location" and topological structures, which accurately represent the "way in which participants are connected to each other" (2006, pp. 98-99). Finally, symbolic processes represent "what a participant means or is" (Kress \& Van Leeuwen, 2006, p. 105). They are objects usually associated with symbolism, they may possess characteristics of salience, they may be pointed at, or look out of place. For example, in Figure 3.4 it is apparent that the lignite pictured is the most salient feature: it is much darker than the rest of the image. 
Image removed after examination

Figure 3.4: Lignite Marketing Image

Additionally, it seems out of place in what appears to be a ceramic bowl and in the way it is handled with well-manicured, clean hands. Arguably, the lignite is presented here as a substance of technological value which demands care and consideration. These interpretations are supported in the way the (presumably female) hands seem to cradle it and the lab coat-like attire the person is wearing.

In this framework, participants may be those who are represented (i.e. depicted) or inter-active (real people who engage with the communication). Due to the disjunction of production and reception (where the producer is not physically present and the viewer cannot reciprocate), social relations are represented only, as opposed to enacted. Kress and van Leeuwen argue that the viewer has agency in how they react: interactive participants may or may not identify with such imagined relations (2006). This idea has implications for designs which seek to manipulate viewers into performing actions, such as marketing texts. For example, Vestergaard (2013) analyses humanitarian appeal ads in a Dutch newspaper to 
see how agency and affinity are constructed. She describes how donors have been positioned as individuals who can interact with and gain returns from their humanitarian investment, thus drawing upon a neoliberal Discourse of dependence on market forces. Similarly, activists may respond negatively to an ad and refuse to identify with its contents (consider the Greenpeace call to manipulate the tar sands ad discussed in Chapter 1).

Additionally, visual distance can create different relationships between participants, as people, objects, the environment, landscapes, etc. can all be portrayed "as though they are friends, or as though they are strangers" (Kress \& Van Leeuwen, 2006, p. 126). Frame size, perspective and angles might influence involvement between the representations and the viewer. For example, a high angle may depict the represented participant as having power over the interactive participant and vice versa. Frontal angles seem to orient to action whereas topdown angles arguably orient to power and theoretical, objective knowledge. This can be taken to extremes where top-down angles may present images as viewed "from the satellite, that modern tool of the production of visual knowledge and symbol of informational power" (Kress \& Van Leeuwen, 2006, p. 146). Returning once more to Figure 3.4, we can see that the viewer is placed at a higher angle and looks down upon the lignite sample, possibly presenting it in an objective light. In this case, the viewer seems to be located with the person holding the sample as if they are standing on equal footing. We can imagine how this may be interpreted differently if the lignite were presented straight on, or even at an angle which forced the viewer to gaze up at it.

Visual communication may also make claims to truth through modality, which is a system of cues representing objects as though they are real or not. These judgments are social and dependent on social groups but there are a number of typical, or common ways in which modality can be altered. For example, Kress and van Leeuwen describe how colour photography tends to have high modality in Western culture, depicting something as naturalistic or true. Even within this mode, however, details such as sharpness or colour can be amplified or 
reduced with the possible effect of lowering modality. We might consider once more how Figure 3.3 uses drawings to present the mining process while Figure 3.4 utilises photography in presenting the product. By showing lignite through photography it seems to become real and tangible. It is through a "complex interplay of visual cues" that a general impression of reality, naturalness, or truth is created (Kress \& Van Leeuwen, 2006, p. 163).

An additional visual element, composition, can encode culturally-specific information which leads readers towards specific interpretations. Thus the margin, centre, left, right, top, and bottom of a composition may take on meanings because of "deeply embedded cultural value systems" (such as reading directionality) (Kress \& Van Leeuwen, 2006, p. 192). Hierarchies of layout tend to encourage trajectories through different salient elements, drawing upon compositional meanings to create reading paths. For example, items in the centre often form the nucleus upon which the surrounding elements depend. In more polarised layouts, elements on the left of the horizontal axis are presented as Given: "a wellestablished point of departure" (Kress \& Van Leeuwen, 2006, pp. 183-184). In this case, elements on the right take on the New, presented as the items which draw attention or demand action. To illustrate, we might once again consider Figure 2.8: Approaches Conceptualised as Lenses (see Figure 3.5, top). 


\section{Environmental Debates}

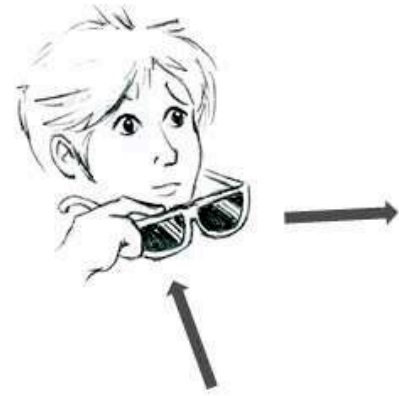

Critical, ethnographic, multimodal lenses

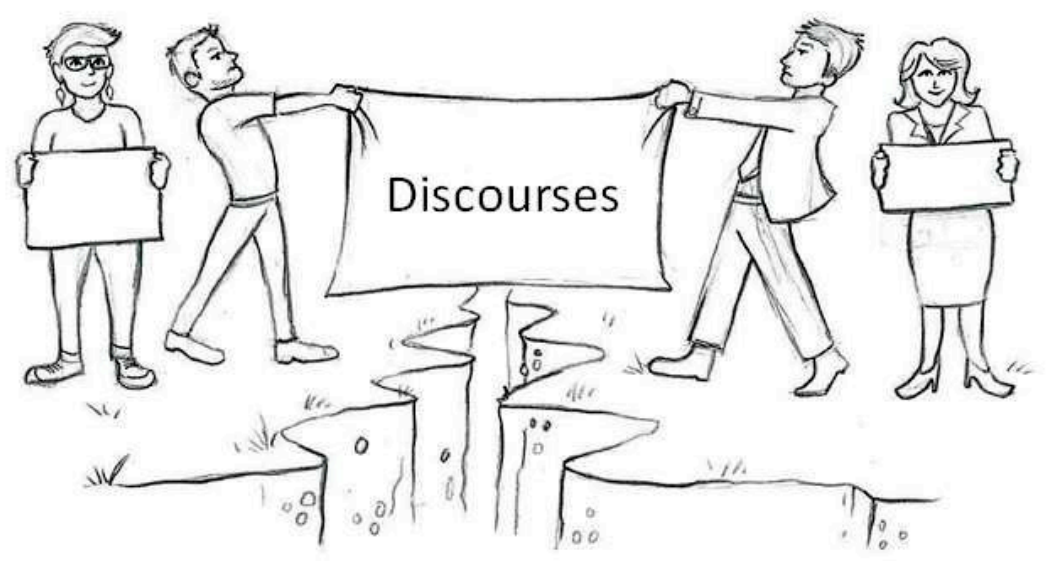

Activist actors

Industry actors

\section{Environmental Debates}

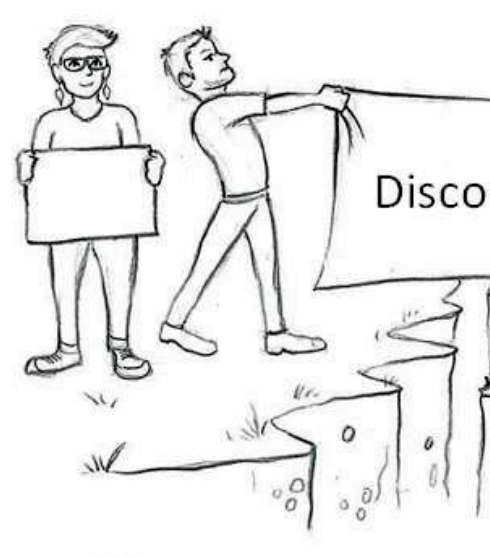

Activist actors

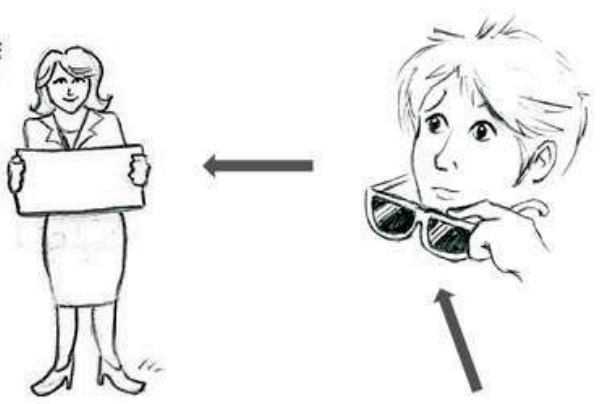

Critical, ethnographic, multimodal lenses

Figure 3.5: Approaches Conceptualised as Lenses and Reversed

In this diagram, I have drawn myself in the Given space and the social actors in the New space. By drawing it thus, I position myself, the researcher, as Given or normalised while presenting the social actors as worthy of further exploration. For an audience of academics, this composition makes sense. However, we can imagine that for an audience of environmental activists, the opposite layout may 
provide a more sensical reading path. Consider how a reversal of these elements might alter our interpretation of the diagram (Figure 3.5, bottom). For example, if I am positioned on the right as New, we may interpret that the social actors are doing something which is considered 'normal' (i.e. debating the development of a mine), but that it is the presence of the researcher which demands attention. In other words, the researcher's role becomes problematised as the New element which deserves explanation. As an example of how composition can subtly create meanings, this exercise also highlights how we as researchers may reflect on the meanings we create in our own work.

The use of this concept is also illustrated in Figure 3.6, which depicts a button developed by farming activists in the Southland case study.

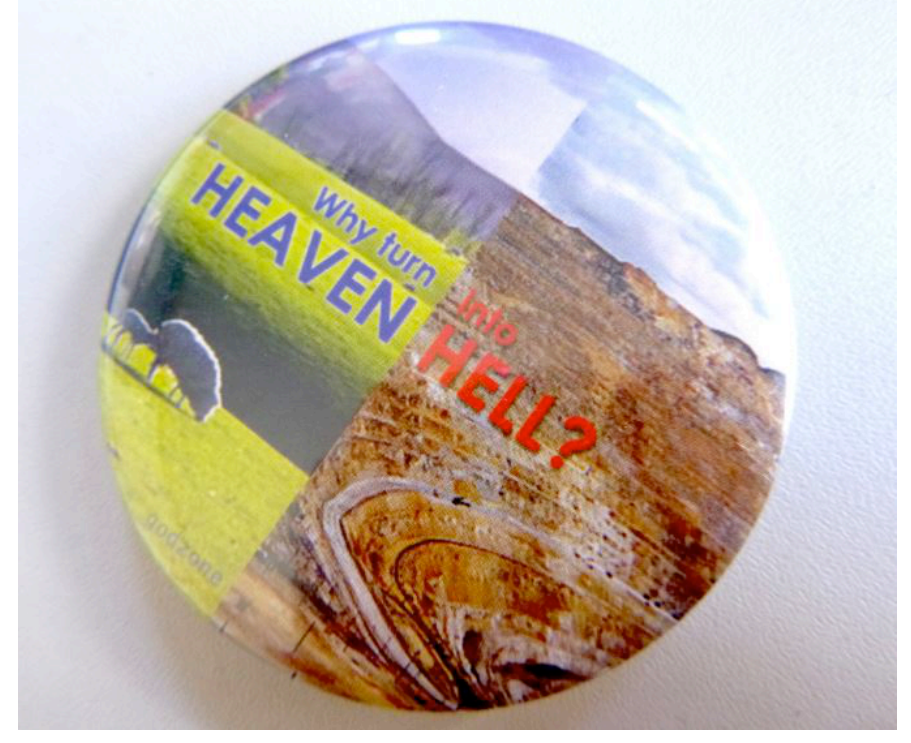

Figure 3.6: Protest Button ${ }^{4}$

The button depicts two contrasting views of the landscape: one featuring sheep grazing peacefully in green fields and one presenting an open pit mine. The text accompanying the images also follows the same layout and utilises colour to differentiate the two spaces. The logic of Given and New becomes evident where Heaven represents Southland as it is, while Hell depicts a possible future that is

\footnotetext{
${ }^{4}$ Artefact reproduced with permission.
} 
problematic and demands attention. The question why turn heaven into hell? further juxtaposes these two options as polar opposites and invites the reader to engage with the issue of open-pit mining as a controversial idea. Thus, by utilising a left/right composition, the producers of this artefact create additional guides to interpretation.

This practice can also be compounded, where the previous New becomes Given for the next element. This draws heavily upon Halliday's discussion of English syntax and information units (Halliday, 1967).

In addition to the horizontal axis, layouts may also utilise the vertical axis, meaning the "upper section tends to make some kind of emotive appeal and to show us 'what might be'; the lower section tends to be more informative and practical, showing us 'what is"' (Kress \& Van Leeuwen, 2006, p. 186). In other words, the top is the Ideal whereas the bottom is the Real. The Ideal tends to be the most salient and generalised while the Real often provides specific and practical information. These elements may be distinctly framed through sharp edges, making them separate, or they may be connected via blurred edges or even vectors, creating connections between the ideas. This is known as framing, and Kress and van Leeuwen argue that the stronger the frame, the "more it is presented as a separate unit of information" (2006, p. 203). For example, in Figure 3.6 (Protest Button) the two elements are separated through a sharp edge as well as contrasting colours. This frame is further strengthened in the blue and red of the text accompanying each side. The authors also note that this can be emphasised through repetition (e.g. of colours, shapes) to draw elements together or apart, which they term visual 'rhymes' (Kress \& Van Leeuwen, 2006, p. 204). Similarly, salient elements draw attention due to their size, sharpness, colour contrast, placement, perspective or their use as symbols. All these factors may contribute to what will draw the eye and therefore can guide readers in a certain trajectory through the text. 
Colour is a special case in that it carries with it an entire history of deeply rooted cultural meanings (Van Leeuwen, 2011). Consider once again Figure 3.6 where heaven and hell are alternately associated with blue and red, possibly referencing cultural connotations such as fire, blood, or sky. Furthermore, colour can be used to create salience, contrast, etc. (van Leeuwen, 2011) as is evident in Figure 3.6 above (e.g. compare the salience of the blue heaven over light green, which could have been placed lower over the grass' shadow). Thus, colour "has meaning potentials (or metaphor potentials) rather than specific meanings" (Van Leeuwen, 2011, p. 68).

The last element of visual communication that will be discussed is the issue of materiality, a "crucial semiotic feature" (Kress \& Van Leeuwen, 2006, p. 216). Both the site of production and the surface on which texts are received matter to meaning, as production involves the "interrelated semiotic resources of surface, substance and tools of production" (Kress \& Van Leeuwen, 2006, p. 225). Because each element carries meaning on its own, their interaction creates complex webs which are culturally and bodily constrained. For example, in my interview with Andrea, she discusses an idea for an art exhibition fundraiser where local artists are asked to create paintings using oil that has been collected from spills throughout Alberta. In this case, it is essentially the materiality of the object which would give it the most salient meaning and, in fact, the exhibition would lose most of its impact without this aspect. Inspired by this prospect, and curious to see how possible it would be to paint with collected oil, I attempted my own painting on canvas with bitumen I had taken from the tar sands, reproduced as Figure 3.7. 


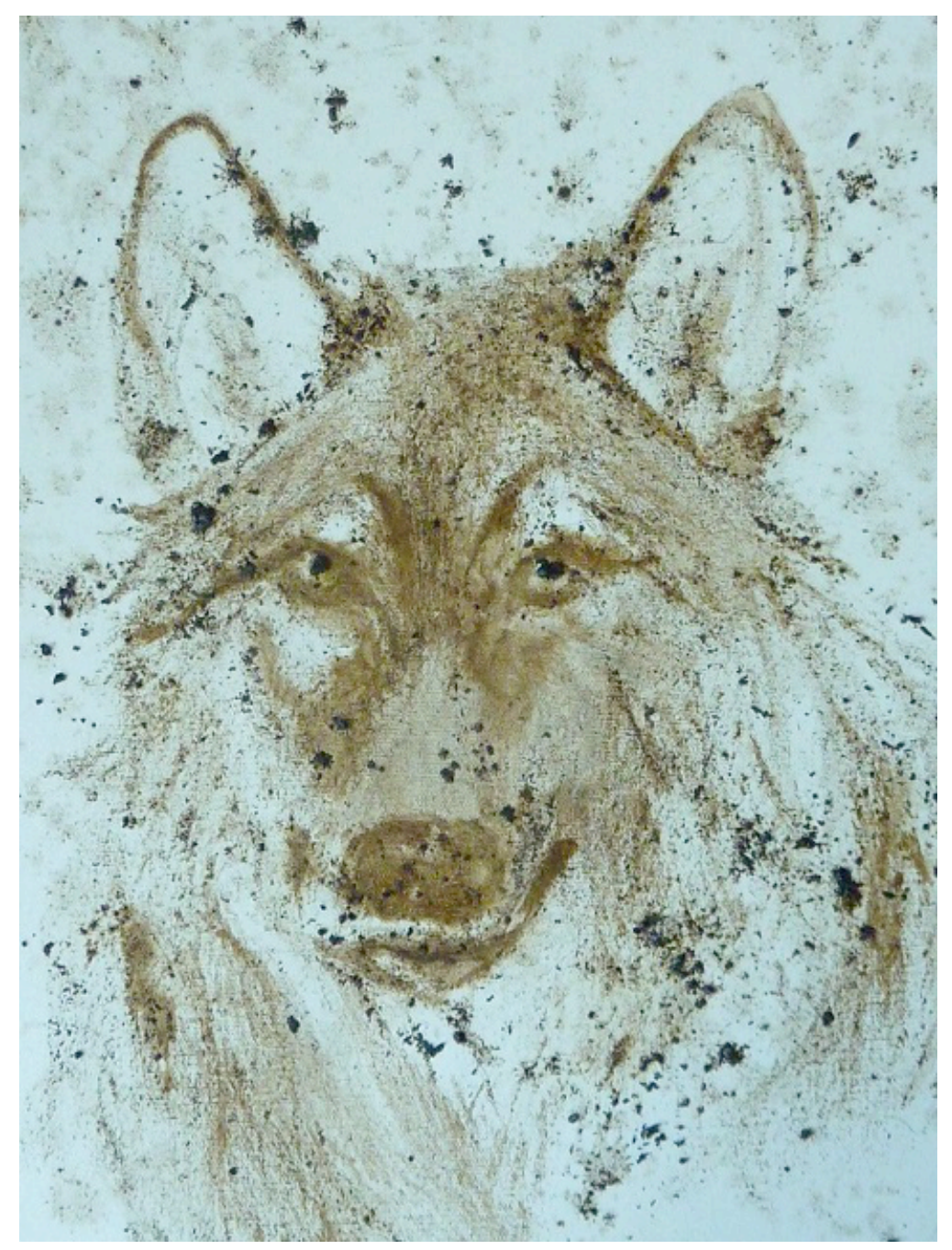

Figure 3.7: Bitumen Painting

In order to better understand this painting, we might recognise it was painted during media discussion about the Government of Alberta's wolf cull. As a proposed solution to the plight of the endangered woodland caribou, many environmentalists and First Nations activists criticised the Alberta government for scapegoating wolves while failing to recognise the impacts of industry itself on caribou habitat. This work in Figure 3.7 might appear to be a simple painting of a wolf, until we consider its material focus (i.e. the way I have allowed large clumps of tar sand to remain on the canvas). Once the viewer knows that it is painted with oil taken from the tar sands, new meanings might be made: this is no longer just a wolf but rather a statement about the impacts of tar sands development on the 
wilderness of Northern Alberta, and possibly a reference to the controversial wolf cull. Much as the place-naming of the tar sands has an impact on how it is perceived (Katz-Rosene, 2012), the materiality of the painting informs its subjectivity and can encode meaning.

As an analytical tool, Social Semiotics lends itself well to visual texts and images, illuminating design strategies such as those outlined above. However, it has also been criticised for not engaging adequately with the embodiment of communication (McDonald, 2013). For this reason, I will use Social Semiotics to analyse visual texts and also employ MIA to analyse embodied interaction in my interview data. I will make use of the concepts outlined above to identify different meanings and meaning potentials in the artefacts I have collected. These will be used in tangent with interviews to illuminate some of the larger Discourses which circulate about the mining projects I will study.

In using artefacts for this research, I should also consider copyright issues and designer consent. After developing a consent form to use when collecting artefacts, its implementation became difficult as it was often unclear who the artefacts 'belonged to' and therefore from whom I should seek consent. To resolve this problem, all artefacts referred to in this thesis are publicly available either through websites or public events (e.g. Southland Field Days). In instances where the reproduction of artefacts was restricted, I have refrained from reproducing some items and instead described or drawn them. For artefacts that are reproduced in this thesis, any distinguishing features have been blurred in order to protect the anonymity of both companies and individuals.

In order to operationalise my theoretical perspective and research questions, I interviewed industry actors and activists in both Canada and Aotearoa/ New Zealand. Because of my multimodal perspective, I used both video and audio devices to record these interviews. 


\subsection{Conceptualising the Interview}

The interview genre has been revisited by many scholars calling for a move away from traditionally structured interviews which impose communicative norms on participants and towards conceptualising interviews as co-constructed, unique, social interactions (Blommaert \& Jie, 2010; Briggs, 1986; Fontana \& Frey, 2005; Pietikainen \& Dufva, 2006). Traditional question and answer interview techniques have even been likened to "communicative hegemony" (Briggs, 1986, p. 121) and less structured, more conversational approaches which help build rapport and allow for a closer relationship between participants have been proposed (Fontana \& Frey, 2005). Blommaert and Jie also warn that behaving "like an interviewer" will encourage people to "behave like interviewees" (2010, p. 44) and thus limit our ability to inspire naturally occurring conversation. They advise interview schedules based on topics as opposed to set questions in order to maintain conversational flow and allow participants to form opinions (Blommaert \& Jie, 2010, pp. 47, 3; Holmes, Bell, \& Boyce, 1991). Being a 'sympathetic interviewer' involves creating an environment of safety and comfort and approaching your interlocutor with an interest that is both respectful and genuine.

Precisely because the positions within interviews are negotiated and dynamic, the role of the interviewer must also be recognised and problematised. Essentially a conversation, the interview is a site of interaction and is therefore collaboratively co-constructed by all participants (Blommaert \& Jie, 2010, 49; Mann, 2011, 8; Pietikainen \& Dufva, 2006, 211). Additionally, because participants and contexts differ, "each interview is a unique social interaction that involves a negotiation of social roles and frames of reference" (Briggs, 1986, pp. 24-25). Approaching interviews as co-constructed, unique social events allows for a deeper analysis than if they are analysed simply for the "answers" (Briggs, 1986, p. 103).

Additionally, I also consider the ways in which power and access have manifested the interview as a uniquely-situated interaction (Van Dijk, 1996). For 
example, who decides when and where the interview will occur, the topics to be discussed, and when it is over? In this sense, my own contributions extend beyond what I say in the interview because meaning is made pretextually before the interaction even begins (Blommaert, 2005, p. 77).

Each interview has had different feeling power dynamics - sometimes my prestige as "researcher"' was very palpable, for example when Al kept bringing up my work and how the research was going...At other times I was very much a "seeker of information", as when I interviewed Justin who is a top level organiser. My interviews with Molly, Mark, and Bernadette were a little different still, as I was staying with them and working for/with them to make events happen or just get things done around the farm. (May 10, 2012, FN)

Interviewers are encouraged to challenge hierarchical roles in which they may enact the same patterns of inequality that occur on a wider societal level (Briggs, 1986, pp. 123-124). Hidden ideological assumptions (mainly that the interviewer has a right to knowledge without offering her own) should be examined, precisely because of the strong "desire to hold on to a rather comfortable position in a number of unequal relationships" (Briggs, 1986, pp. 123-124). By considering the interviewer's contributions alongside those of the interviewee, we recognise that the interviewer tends to maintain control of the conversational topics and flow. However, there is also the possibility that the interviewer's contributions can have a much more dramatic effect in that they shape what may happen next. For example, contributing my own stories and perspectives will most likely lead to different stories and perspectives from my interlocutor: I, in part, determine what is said. But content is not the only thing of interest in such data: more attention should be paid to how the interaction takes place rather than simply what is said (Mann, 2011, p. 11).

Because I aimed for a multimodal analysis going beyond the content of speech, it was crucial that I engaged in natural interactions with my interlocutors. However, I also recognise that the presence of my recording equipment frames the interaction as one that is observed (Holmes \& Bell, 1988; Yakura, 2004). Recording 
with video cameras brings further concerns for confidentiality and anonymity (Yakura, 2004) and is also more intrusive and obvious. In order to counteract these issues, it is important to cultivate an atmosphere of safety and comfort so the participants feel at ease. Creating a trusting and safe environment is especially important in research with activists, where covert surveillance is an all too common threat (Hager \& Mussen, 2007).

In light of these issues, ethical concerns are recognised and respected in this thesis. This study was granted human ethics approval by the VUW Human Ethics Committee before fieldwork began. In keeping with traditional ethical guidelines, I sought prior and informed consent from participants through a formal letter and accompanying information sheet (see Appendix). I also informed interviewees that their participation was voluntary and that their identities would remain anonymous and confidential. Participants were assured that they could withdraw from the study should they wish and during our interviews I turned off the recorders when requested and excluded from analysis any utterances which my participants indicated they felt uncomfortable saying on camera. This is an important factor to highlight, considering the vulnerable positions which many individuals (both community activists and industry representatives) hold. ${ }^{5}$ Consequently, my co-interviewer, Nicole Nolette (discussed in the next section), signed a confidentiality agreement for the interviews she conducted (see Appendix). I have also used carefully chosen pseudonyms for all participants and refrained from mentioning individuals or groups (e.g. companies) in my online Twitter feed. Additionally, I have maintained contact with activist participants and sought to present them with my analyses for feedback when possible (Cameron et al., 1993). In this way, I have attempted to engage with all interviewees with respect and concern as my research programme has developed.

\footnotetext{
5 Many industry actors I approached were unable to participate due to confidentiality clauses in their contracts.
} 


\subsubsection{Conducting Interviews}

When meeting with my participants, I sought to employ a semi-structured interview technique which allowed for topic divergence and therefore more naturally occurring, conversational data (Milroy, 1987). Quite typically, I experienced a number of recording issues, including instances where cameras failed to operate and where footage could not be synchronised. Despite these somewhat common technological challenges (Blommaert \& Jie, 2010; Kuśmierczyk, 2013; Wilson, 2011), and considering the complexity of my recording situations (i.e. the various locations in which I found myself), as well as the number of technological variables out of my control, my data collection was very successful.

Before beginning my interviews, I conducted a pilot study with two activists in Wellington. These were necessary to work through my interview schedule as well as test my recording methods (Holmes et al., 1991; Holmes \& Bell, 1988; Wilson, 2011). The interviews were both held in locations which regrettably had a great deal of ambient noise. However, this was an ideal test of my equipment, as I could not be sure that my field recordings would occur in quiet environments. While recording the first interview, I was quickly aware that my actions (e.g. checking my list of questions, engaging in typical interview turn-taking) were negatively affecting my interlocutor's comfort level. Although I had brought my interview schedule with me, I decided to ignore it and orient instead to my conversation partner, thus changing my own behaviour to ease his discomfort (Blommaert \& Jie, 2010; Holmes \& Bell, 1988). Throughout the discussion I attempted to make him feel as comfortable as possible and continued to ask questions while giving my own answers and refrained from orienting to my interview schedule. Drawing upon this experience, I approached the second interview in a similarly informal way. These pilot experiences, informed by previous literature in interview techniques, helped me develop an interviewing style during fieldwork. Because of the uniqueness of each interview (Briggs, 1986), I was free to negotiate interview topics with my interactants during our discussions. In practice, this meant that I approached each 
interview with the same general questions but maintained the comfort and interest of my interlocutor as my primary goal (Holmes \& Bell, 1988).

\section{Dawn}

@ThisPhD

\section{Pilot studies done! Some technical issues with cameras shutting off but hopefully I can fix that., \#hnope}

For each interview, I set up two small point and shoot cameras, placed so as to capture the face of each participant (or a group of participants depending on the interview) (following Kuśmierczyk, 2013). I used a Zoom H2 recorder with directional microphones as a back-up for the cameras' audio (see Figure 3.8), which was then synched with the footage. This audio recorder proved indispensable, as many of the spaces in which I interviewed were characterised by a high level of ambient noise and the directional microphones allowed me to adapt my recording abilities to the specific audio environments in which I found myself. 


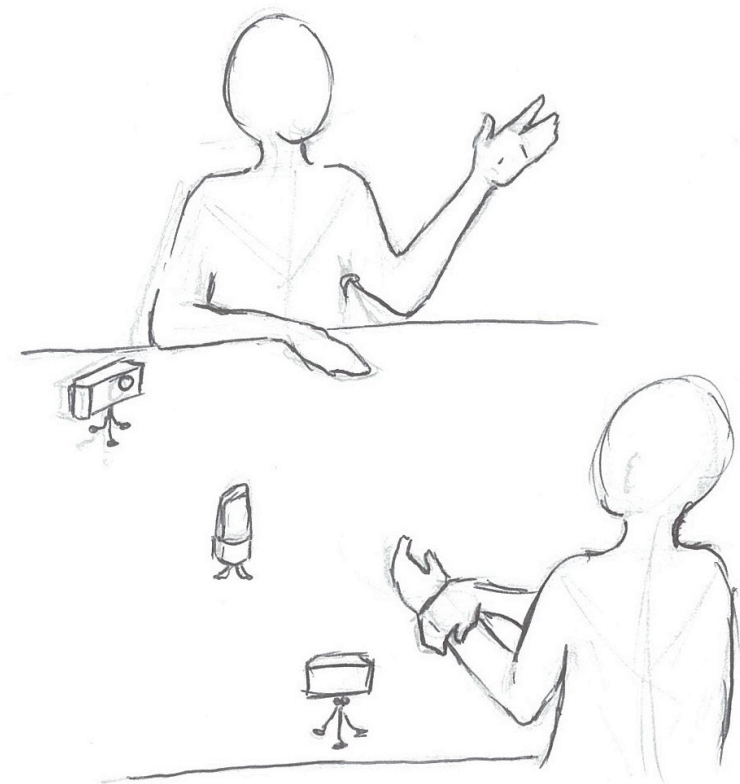

Figure 3.8: Equipment Set-up

I discovered during my pilot study that the Fuji camera I was using automatically stops recording when the video reaches $2 \mathrm{~GB}$ in size:

There is a countdown which one can follow and I needed only to keep an eye on it and press the record button again. However, this leaves a small break in the conversation (which I dealt with by repeating the latest utterance so the camera would catch it again). This is obviously not ideal but at the moment is the only option I have short of buying another camera. I considered other recording options (most notably having two laptops facing each person and recording, but I rejected this idea because of the obvious distraction it would cause and not to mention the interference with gesture). (Feb. 29, 2012, FN)

As this would negatively affect my interactions with participants by drawing attention to the recording device (cf. Labov, 1972), I borrowed small point and shoot cameras from other researchers for my New Zealand and Canadian data collection. Therefore, in total, I used the Sony camera, the Zoom H2 audio recorder, and a number of other cameras, improvising depending on my location 
and recording needs (see Kress, 2011). All data was promptly labeled and loaded onto my laptop computer as well as an external hard drive and then subsequently backed up once more upon my arrival in Wellington.

Dawn

@ThisPhD

So now I have a total of 16 rechargeable

batteries. Un, yeah. \#lastminutepanic

\#fieldworkchaos

12:13 PM - 15 Mar 2012

\section{Dawn}

(2ThisPhD

\section{Hoping with all my heart the cameras all work \#technology \#researchwoes}

3:16 PM - 18 Mar 2012

In order to represent a variety of activist and industry voices, while collecting a manageable amount of video data, I sought to interview five to ten participants from each community (i.e. industry actors and activists each in Canada and Aotearoa/New Zealand). Most of my attempts to gain access to industry representatives raised problems, and I discuss this issue in Chapter 9. However, I was able to draw upon my ethnographic knowledge and the relationships I developed through fieldwork, to interview many of the inner-circle activist organisers in both cases. This resulted in a cross section of individuals representing a variety of backgrounds, including rural and urban. The interviews each lasted from twenty minutes to a couple of hours and took place in a variety of 
locations, including parks, kitchen tables, offices, and even on a sailboat. In sum, I have two pilot interviews, six activist interviews in Aotearoa/New Zealand, eleven activist interviews in Canada, and one industry interview in each of Canada and Aotearoa/New Zealand giving a total of approximately 18 hours of footage.

Interestingly, I found that during many of these recorded interactions, participants (like Al in Excerpt 3.1) would ask aloud when the interview would start.

\section{Excerpt $3.1 \mathrm{Al}^{6}$}

1 A should i suppose we should () + unless you've been recording the

$2 \quad$ whole thing and this IS the interview

$3 \mathrm{~K}$ oh yeah no we're fine

4 A oh this //is fine?

$5 \mathrm{~K} \quad$ /yeahll yeah

6 A i sort of thought there'd be you know <deep voice > carefully //

7 structured sequences $\backslash$

$8 \mathrm{~K}$

/oh no <laughing $>11$

Like many of my participants, Al assumes the official interview has not started yet (unless you've been recording the whole thing and this is the interview, 1-2)7. It seems that, to Al, the term 'interview' implies a set of carefully structured sequences (6-7), something he expresses with a deeper voice, possibly marking it as more formal. It is likely that by using the term interview when organising the meetings, I triggered a behavioural expectation which was not followed through. The type of loosely structured, recorded interaction in which I have engaged is difficult to characterise (i.e. more formal than a 'conversation', less formal than an 'interview'), and this was possibly reflected by my participants' frequent comments

6 In this thesis, I use transcription conventions based on the Wellington Archive of New Zealand English Transcriber's Manual, available at http://www.victoria.ac.nz/lals/centresand-institutes/language-in-the-workplace/publications/occasional-papers. See Appendix F. Additionally, excerpts are used primarily to provide further content although they may receive some textual analysis.

7 It should be noted that, at the time of this comment, Al had already signed the consent form and watched me start the recording devices. 
indicating confusion. I suggest that these comments in fact illustrate the high level of comfort my participants felt during our interactions (i.e. our discussions did not feel so 'formal' as to be an interview, as Al describes in lines 6-7).

In addition to 'showing my human side' (Fontana \& Frey, 2005, p. 370) and proposing discussion topics instead of direct questions, my interviews often involved food and drink which help to frame the interaction as an informal conversation and tied into culturally conditioned ideas about hosting and hospitality (see Marra, King, \& Holmes, 2014).

Sometimes the participants and I cooked together and sometimes we ate at cafes. When there is no food, there is usually a drink of some sort (even if it's just a water bottle). It may be useful to keep in mind the role of food in these kinds of interactions, whether it provides a focal point, an indication of hospitality, or simply a reason to be using a café's space. (Feb. 13, 2012, FN)

Additionally, because I wished to consider location and layout in my analysis (Norris 2004, p. 65), I also encouraged my participants to choose when and where we would meet. If I arrived on site early, at a cafe for example, I would select a table but be sure to give my participants the option of moving to another if they so chose. Requesting that my participants choose the details of the interview also helped to flatten the hierarchy of 'researcher' and 'researched', granting agency and relinquishing some control back to the interviewee.

Because I asked my participants to choose the location, I have interviews in very different areas. These include outdoor parks, boats, cafes, and people's houses. I also requested that my participants choose the location within the location (e.g. which table to sit at in a café) as much as possible. This may have had an impact on the quality of my recordings (mostly lighting) but I felt very strongly that my participants should have the power to choose, even if it meant I had to travel longer distances. Looking back, I know I originally 
did this for methodological reasons ${ }^{8}$, but I also feel it helped the relationship and the negotiation of the interview by abdicating some of the power. (Feb. 13, 2012, FN)

It is worth noting that, despite my best intentions, the process of doing research, and especially of interviewing, positions me in the powerful subjective position of 'researcher'. My participants are then positioned through the very nature of academic practice as subject to surveillance, analysis, and representation by my hand (Smith, 1999). At the same time, however, it is useful to recognise that this constellation was not always assumed and that positions of power were contested and negotiated through various means (for example, see my interview attempts with industry actors discussed in Chapter 9).

Because interviews are collaborative interactions between multiple participants (Mann, 2011), my own actions as interviewer will necessarily impact on how the conversation unfolds (Briggs, 1986). As a researcher who has worked previously with environmental justice communities, I was aware the discussions might be fraught with difficulty had I attempted to interview industry actors myself. Given the political nature of the debates, and my own positioning in alignment with communities of resistance, it would be difficult to conceal my own perspective (e.g. see Van Leeuwen, 2014 on how even listening conveys attitudes). I therefore enlisted the assistance of Dr. Nicole Nolette, a PhD researcher from Canada who traveled with me to Southland and Alberta. Having grown up in Northern Alberta, Nicole was familiar with the issues surrounding large mines but was not directly involved with activist groups in either case. Additionally, as a relative outsider, Nicole was able to ask questions about basic operations and issues that would seem misleading or disingenuous had I, as someone already familiar with the mine and the ensuing controversies, asked them myself (cf. Holmes \& Bell, 1988).

\footnotetext{
8 With the interviewee in control of the location, I am able to infer meaning from surroundings and/or layout (see Norris, 2011). For example, an interview in someone's kitchen might suggest a more comfortable relationship between us than interviews where my conversation partner chose a cafe or park.
} 
In our interactions with industry interviewees, I acted as the point of contact for the project, accompanying Nicole to each interview. Additionally, Nicole and I role-played the interaction beforehand so she would become familiar with my approach and the general topics in which I was interested (Fontana \& Frey, 2005, p. 367; Holmes et al., 1991). Because Nicole's interview style is less interactive than my own, she was able to convey an academic authority throughout the interactions which counterbalanced the implicit institutional authority (Blommaert, 2005) of the participants who represented the industry perspective. Additionally, Nicole maintained a conversational structure through the use of focused questions when needed, while also encouraging her interlocutors to lead the discussion. Although we only managed to secure two industry interviews (discussed more in Chapter 9), Nicole's contributions are vital to this thesis. Her inclusion underlines my approach to interviews as unique interactions that are situated within diverse constellations of participants and contexts (cf. Briggs, 1986). Although we both change and adapt our interaction styles to suit our interlocutors (Mann, 2011), I act as a common thread throughout the interviews with activists and she with industry representatives.

\subsubsection{Processing Interviews}

Transcription is a necessary part of sociolinguistic discourse analysis and should be discussed as a functional, if somewhat problematic, tool. Transcripts are used to represent interactions, assist in analysis, and to disseminate and verify data (Jenks, 2011, p. 5). As a situated practice (Mondada, 2007), transcription can be considered a process (Bezemer \& Mavers, 2011; Coates \& Thornborrow, 1999) that changes depending on function. It has been described as "a never-ending process" (Coates \& Thornborrow, 1999, p. 596) where "selected parts of the world... are held still for a while" (Kress, 2011, p. 255). At a most basic level, transcription allows the researcher to develop insights by working with the data as well as to "provide evidence in developing an argument" in the analysis (Bezemer \& Mavers, 2011, p. 191). It also demands that crucial decisions be made and defended. As researchers the goal is to responsibly represent our data, while 
understanding many of the pitfalls and difficulties (Jenks, 2011, pp. 91-92). The controversy in transcription practices often lies with the assumption that transcripts are objective reports of what was said and done. In fact, "transcription is inevitably a creative, authorial act that has political effects" (Bucholtz, 2000, p. 1461) and "a manifestation of theoretical commitments" (Erickson, 2010, p. 247). Even choices regarding layout have direct consequences: transcriptions featuring a top to bottom and left to right orientation may favour certain types of information over others (Kress \& Van Leeuwen, 2006; Ochs, 1999, p. 169). The choices made in transcribing (how, what, and who) will always create a representation of the data, necessarily excluding some things and foregrounding others (Bucholtz, 2000; Coates \& Thornborrow, 1999; Edelsky, 1981; Erickson, 2010; Flewitt et al., 2009; Jenks, 2011; Ochs, 1999).

I have transcribed my interview data for various analytical and representational functions. I first synched the recorded interviews with the audio recording and formatted the video footage using Macintosh iMovie. This allowed me to view the conversations and create a descriptive transcript (Figure 3.9) which informed the analytical themes explored (Kuśmierczyk, 2013).

\begin{tabular}{|l|l} 
5:15 & Will: more explicit with intersectionality \\
\hline $5: 43$ & Will: "all struggles are the same struggle" \\
\hline $5: 50$ & Mirror gesture \\
\hline $6: 00$ & Green bloc \\
\hline $6: 11$ & Will: Groups manipulating language \\
\hline $6: 30$ & Will: word manipulation, 'ethical oil' \\
\hline $6: 45$ & "pinkwashing" \\
\hline $7: 15$ & Will: pinkwashing more subtle, more history than greenwashing \\
\hline $7: 45$ & Will: pride is no longer political \\
\hline $8: 08$ & Will: good definition of greenwashing \\
\hline $8: 22$ & Will: queer movement "we are nothing more than a commodity now" \\
\hline $8: 36$ & Will: pinkwashing is empowering, based in queer theory \\
\hline $8: 58$ & Keely: white washing?
\end{tabular}

Figure 3.9: Interview Description and Notation

Short clips related to those themes were then chosen and transcribed focusing on spoken utterance and basic multimodal features. Finally, relevant 
sections of each clip were transcribed using ELAN which allowed me to create various tiers for different modes in order to analyse their interaction (see Figure 3.10).

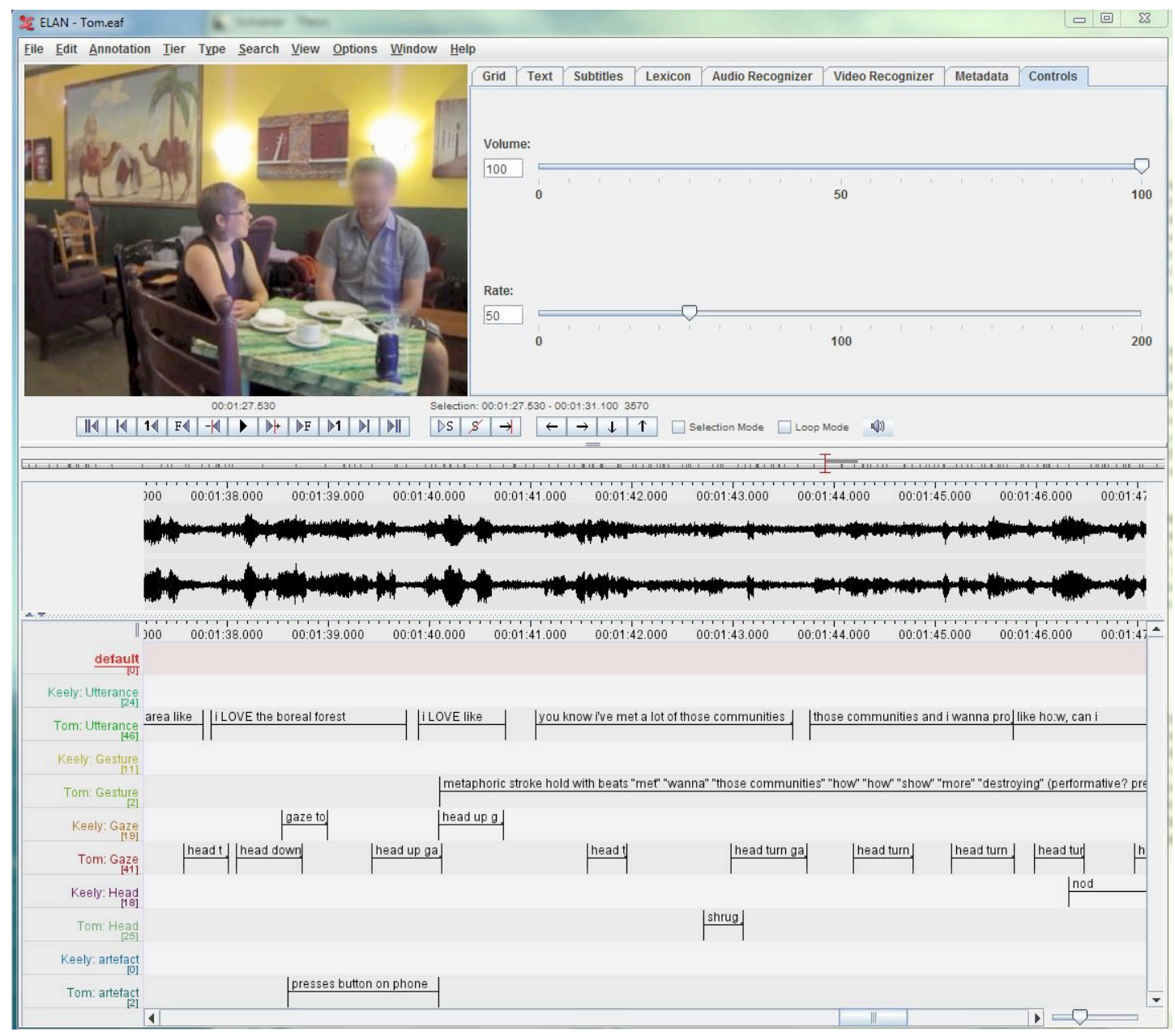

Figure 3.10: ELAN Transcription Software

Used simultaneously with the data recordings, these transcripts function as an aide to my analysis (Bezemer \& Mavers, 2011; Jenks, 2011; Norris, 2004a), presenting areas of greater and lesser modal density (Kuśmierczyk, 2013; Norris, 2011). From there, I utilised aspects of Norris' MIA transcription guideline (Norris, 2004a) to create the final transcripts for presentation in this thesis. This involved layering modes into screenshots as they become relevant, in order to create a 
clear and readily understandable transcript (Ochs, 1999, p. 173).

Ultimately, like research itself, transcription is an act of power (Ochs, 1999). In this thesis, I utilise a number of transcription techniques for my data types which include interviews, collected artefacts, field notes and even Twitter updates where appropriate. Due to the need for anonymity, I have blurred participants' faces, which has allowed me to maintain a level of multimodal legibility, as body movements remain visible (e.g. Figure 3.2) (cf. Kuśmierczyk, 2013). In cases where the multimodal legibility is compromised, or to draw attention to certain features, I have instead created illustrations (cf Kendon, 2004; McNeill, 1992). By using a variety of multimodal representations, I aim to make movement more legible, draw attention to specific actions, and accommodate for many of the "losses" inherent in any transcription practice (Bezemer \& Mavers, 2011, p. 196). I recognise that these are subjective, partial representations (Bezemer \& Mavers, 2011), and that these practices further entextualise the discourse, changing it "from oral to written, from unremarkable to spectacular sometimes, or vise versa" (Blommaert \& Jie, 2010, p. 68).

Because I approach my interviews as a conversation between two or more people (in short, as an interaction), I will consider my own contributions to the unfolding event as an essential part of my analysis (Briggs, 1986). In this way, interview transcripts can then be approached using the same standards of discursive analysis as in other instances of spoken interaction, precisely because interviews are recognised as such (Mann, 2011, p. 10).

\subsection{Summary}

In this chapter I have presented a variety of methodological and analytical tools that will be used in this thesis. However, many of these tools have their own theoretical and analytical issues. For example, my ethnographic methods are folded into a wider approach that sees communication as embodied and complex, occurring in wider social contexts (Blommaert \& Jie, 2010; Dicks, Soyinka, \& 
Coffey, 2006; Kress, 2011). These theoretical implications consequently infuse how I behave and work in the field as well as how I analyse my findings. In fact, even choosing when and what to record can already be considered a step in my analysis (Norris, 2004b), and these decisions must be made on the ground, often through interaction (Blommaert \& Jie, 2010).

Similarly, by using MIA and Social Semiotics, I apply a multimodal theoretical lens which sees communication as occurring through more than one mode (Jewitt, 2009). Yet, in recording interviews and collecting data, I must already make analytical decisions. For example, when setting up recording devices, I am aware that "the camera angle is limited, and the positioning of the camera always focuses on a certain section of the interaction, to the exclusion of others" (Norris, 2004a, p. 62). In deciding where to focus my recorder, I decide what will be important, keeping in mind what aspects of interaction I would like to capture (e.g. gesture and gaze between participants, the background layout, etc.). In a similar way, deciding when and where to gather artefacts is also an analytical choice.

Transcription, although traditionally considered an objective rendering of spoken communication, is highly theoretical and analytical. Much like how I have chosen what to record, I must also choose what to represent (Bucholtz, 2000). Recognising that transcripts are partial and reflective of researcher decisions (Norris, 2011) is a crucial step in my multimodal analysis. Additionally, different transcripts can be used for different aims: from those which aid in systematic analysis (e.g. Figure 3.10) to those which strive to represent interaction. Understanding what a particular transcript is trying to do will influence how it is subsequently manifested.

In this way, my theoretical, methodological, and analytical approaches overlap and influence each other. This reflects a multidisciplinary approach to CDA based on complex social problems, where "distinctions between theory, description and 'application' become less relevant" (Van Dijk, 1993, p. 252). The ways in which my methodological and analytical tools relate to each other and to my theoretical 
lenses is presented in Figure 3.11.

Critical, ethnographic, multimodal lenses

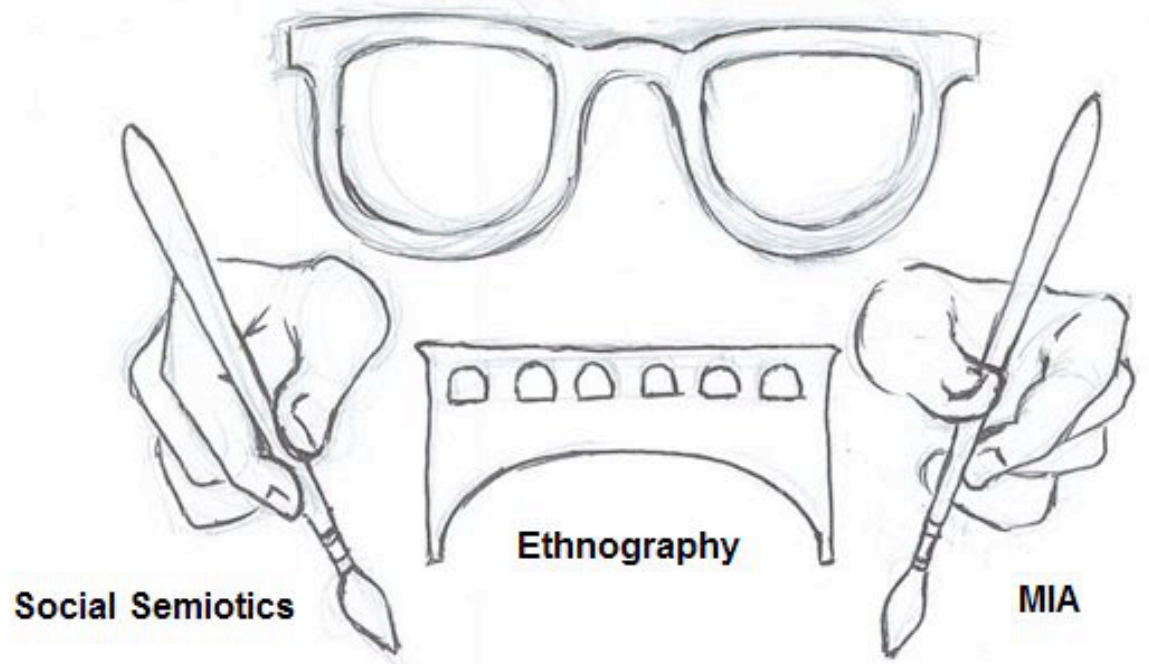

Artefacts

Interviews

Figure 3.11: Methodologies and Theoretical Approaches

Here I conceptualise Social Semiotics and MIA as brushes which, when applied through analysis, can help build a multi-layered picture of meaning. At the same time, my ethnographic insights form a bridge, helping me to interpret the Discourses found in artefacts and interviews. As discussed in Chapter 2, this is all viewed through my critical, ethnographic, and multimodal lenses.

I can further expand my analytical scope by drawing upon these interlocking theoretical, methodological, and analytical frameworks. In the following chapters, I operationalise my research questions by examining the many multimodal ways in which Discourses are appropriated, resisted, and entextualised in two specific case studies. 


\subsection{Analytical Design}

Unconventional fossil fuel extraction has led to resistance from locals living on the land proposed for mining in both Canada and Aotearoa/New Zealand. In Canada, much of the resistance has come from Indigenous groups in cohort with Settlers in solidarity, while in Aotearoa/New Zealand resistance has come primarily from anti-mining advocates in support of local farmers. However, activists recognise the economic benefits that mines bring while problematising their environmental footprints. Similarly, while highlighting the economic potential of mining, industry representatives concede that there is concern for environmental damage. Since this (seemingly) dichotomous situation is recognised by all parties, in both cases it forms the foundation for the appropriation and resistance of further Discourses.

However, using an approach based in ethnography where theory is built through the collection and analysis of data (Blommaert \& Jie, 2010), I have identified a number of Discourses which extend beyond the environmental and economic dichotomy. This thesis thus explores Discourses of regional, Indigenous, and even queer identities. I have chosen these themes because they clearly emerged as highly relevant during my interviews and their significance is supported by accompanying artefacts. Through the following analyses, I comment upon the ways in which these Discourses are appropriated, resisted, and entextualised multimodally.

In Chapter 5 I discuss my theoretical approach to identity, which draws upon the concepts of indexicality, relationality, and authentication (e.g. Bucholtz, 2000). I then analyse a variety of interviews and artefacts to illustrate the ways in which regional identities are appropriated and resisted in relation to the mines in both Alberta and Southland. Chapter 6 deals with the appropriation of Indigenous identities in the Athabasca tar sands, as well as subsequent resistance to that appropriation. In Chapter 7 I introduce the theoretical concept of 'intersectionality', whereby multiple oppressive systems intersect (e.g. through race, class, gender, 
etc.). As a crucial component to climate justice activist work, intersectionality plays a large role in my Canadian case study. I demonstrate this through an examination of how LGBTQ+ Discourses are appropriated and, combined with islamophobia, used to justify tar sands expansion. I also examine the ways that a local queer activist group subsequently resists the appropriation of their struggle while simultaneously linking other Discourses of oppression to the tar sands. In Chapter 8 , I discuss wider issues of appropriation and resistance by comparing the two case studies. First, I consider how activists and industry actors refer to their opposition and what implications this might have for who is heard and who is silenced in the wider debate. I then examine how activist actors multimodally utilise humour and satire in their representation of industry actors, both in conversation and through artefacts. Finally, I discuss some of the wider implications for each case study and what conclusions we might be able to draw from such an investigation. In Chapter 9, I reflexively examine my own positioning as an activist researcher by analysing various instances of discomfort recorded in my field notes. In doing so, I aim to illuminate some of the wider resources I drew upon in the field and to underline the importance of a reflexive stance in critical research (cf. Chouliaraki \& Fairclough, 1999, p. 62). However first, in the following chapter, I consider the 'Environment v. Economy' Discourse discussed above. By analysing interviews with two actors in particular (one in Canada and one in Aotearoa/New Zealand), I explore some of the ways that the tensions of the 'Environment $v$. Economy' Discourse which lie at the heart of this debate are embodied through multimodal action. 


\section{Environment v. Economy: An Embodied Discourse}

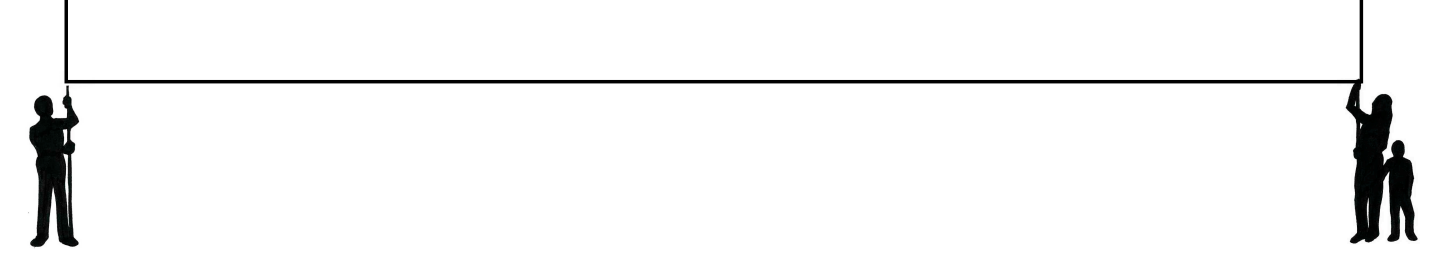

$\mathrm{R}$ esearch on resource development tends to find two major opposing Discourses: concerns for the environment weighted against concerns for economic progress (Davidson \& Gismondi, 2011; Long, Roberts, \& Dehm, 2010; McElhinny, 2006). From an industry perspective, mining projects are marketed as an economic imperative, where development equals jobs (Davidson \& Gismondi, 2011, p. 70) and nature is often viewed as a resource (Gordon, 2011). On the other hand, there are concerns about how the pace of development is affecting ecological systems (e.g. Kelly et al., 2009) and, increasingly, the human rights dimensions of such projects (Hayward, 2007).

These two competing Discourses (the environment and the economy) appear to have led to a number of articulations on either side of the debate. On the industry side, attempts to reconcile the two have often resulted in a sort of 'greenwash', where environmental issues are folded into a 'business as usual' orientation (e.g. Silverstone, 2010). Even on a wider level, however, this approach has been integrated into high-level negotiation tactics in the form of 'green capitalism' (Bäckstrand \& Lövbrand, 2007). This means that business interests tend to form the basis for many climate change solutions, which have the veneer of environmental change while in actuality allowing a capitalist system to continue using resources at an unsustainable rate (Rising Tide North America \& Carbon 
Trade Watch, n.d.). The response to this has been the (re)formation ${ }^{1}$ of the climate justice movement, a movement which, at its core, sees the capitalist system as the root of the climate change problem (Long et al., 2010). Climate justice also recognises the structural imbalances which result in minority groups (Indigenous communities, people in poverty, women, etc.) facing harsher climate realities (Di Chiro, 2011).

However, Discourses in the mainstream environmental movement have also incorporated economic concerns. The 'green economy', complete with 'green jobs', has become a rallying call that seeks to bring the economic system into harmony with ecological concerns (e.g. Royal Society of New Zealand, 2014). For the most part, this means phasing out fossil fuel development in favour of more sustainable resources, such as wind and solar (e.g. Greenpeace New Zealand, 2013). Yet, these proposed solutions have been criticised, most often by industry interests, as economically unfeasible (e.g. Levant, 2010).

These two, arguably competing, Discourses are visible in debates surrounding the controversial mining projects analysed in this thesis. For example, artefacts taken from the Athabasca tar sands case (Figure 4.1) show the 'Environment v. Economy' Discourse expressed on both industry and environmental sides.

\footnotetext{
1 The climate justice movement has been ongoing as a land-based peoples movement before its current widespread recognition in the West.
} 


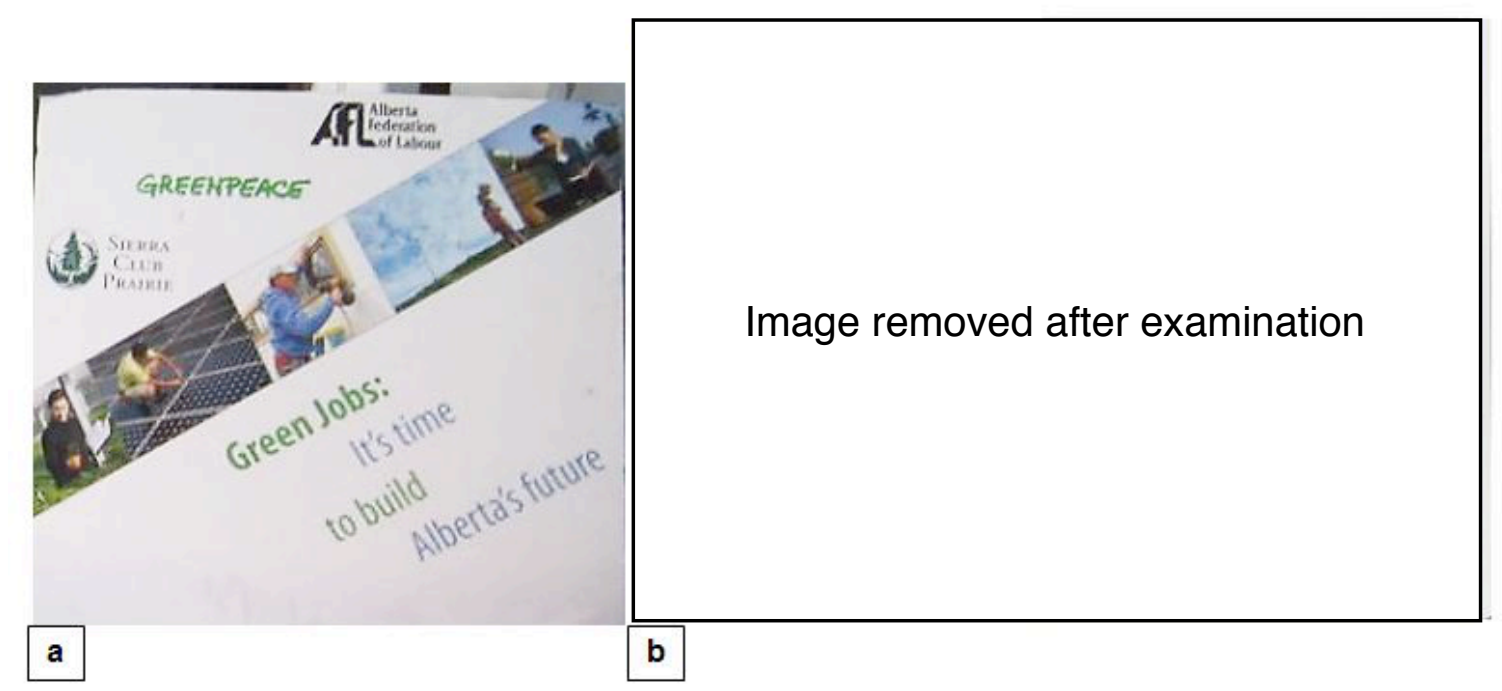

Figure 4.1: 'Environment v. Economy’ Artefacts²

We might view the Green Jobs campaign (a), as an appropriation of economic Discourses, calling for alternative work that builds infrastructure for renewables as opposed to fossil fuels. Alternately, the fossil fuel industry uses its own appropriation of environmental Discourses (b), in an attempt to deal with criticisms and appeal to conservationist concerns (Devauld \& Green, 2010). Here, the dichotomy is perhaps most explicitly visible, where we can see two chapters from a Facts About the Oil Sands handbook produced by an industry organisation which are titled Economy and Environment.

\subsection{Environment v. Economy in Interviews}

The 'Environment v. Economy' Discourse was oriented to in all my interviews as well. While this dichotomy may be representative of each of the opposing extremes - the conservation concerns of the environmental justice movement and the financial imperative of the mining businesses - this is not to say that individuals from either side do not recognise the concerns of their opposition. Many activists acknowledged the reliance of both Aotearoa/New Zealand and Canada on mining economies and both of the industry representatives interviewed

\footnotetext{
2 Figure $4.1 \mathrm{a}$ used with permission. Image in Figure $4.1 \mathrm{~b}$ can be viewed at http:// www.capp.ca/UpstreamDialogue/OilSands/Pages/default.aspx
} 
identified environmental destruction as cause for concern. The competing concerns of the 'Environment v. Economy' Discourse were perhaps best embodied by two individuals in particular.

Alanis works with a government representative from the National Party ${ }^{3}$ in Southland. National's policies encourage resource development particularly in the areas of oil and coal exploration (John Key - Exploring Our Resource Potential, 2013) ${ }^{4}$. Alanis identifies herself, however, as a conservationist (Excerpt 4.1).

\section{Excerpt 4.1: Alanis}

1 A in THIS role i'll just be talking + from my own personal point of view? + um i am very interested in + conservation and the environment of course and $i$ have + been the past + um chairperson for conservation 4 SOUTHLAND conservation board

While recognising that she speaks only from her own point of view (1), Alanis lists her credentials as an environmentally concerned citizen (i am very interested in conservation, $i$ have been the past chairperson for conservation southland, 2-4). Additionally, she positions herself as an environmentalist/conservationist in part by drawing on a national environmental ethic (Excerpt 4.2).

\section{Excerpt 4.2: Alanis}

1 A but + like + when you go to queenstown now and you see neon lights

2 an: + signs flashing and things like that it's + it's + a little bit like um +

3 a very small + gold coast? <laughs> +

$4 \mathrm{~N} \quad \mathrm{hmm}$

5 A different + everyone has different ideas about what looks good and $\mathrm{i}$

$6 \quad$ and i DO see some overseas visitors CASINOS and LIGHTS and

$7 \quad$ everything is + lovely but + for a new zealander? //i think $\$ we + cling to

$8 \quad$ um + to the natural +

${ }^{3} \mathrm{~A}$ centre-right party in government at the time of writing.

${ }^{4}$ Prime Minister John Key recently announced a number of drilling and mining block offers, promoting overseas investment in New Zealand's "untouched natural resources" (John Key - Exploring Our Resource Potential, 2013). 
9

$/ \mathrm{mm} \mathrm{hmmll}$

10 A environment

$11 \mathrm{~N} \quad \mathrm{hm}$

When discussing Queenstown and the ways in which it has become a tourist haven (a very small gold coast ${ }^{5}, 3$ ), Alanis describes a New Zealand aesthetic as one that clings to the natural environment (7-10). Her position in relation to mining is thus constrained by this wider national Discourse of New Zealand identity (see Blommaert, 2007b for a discussion of powerful Discourses as a constraining device).

The ways in which Alanis multimodally positions herself in between environmental and economic issues are expanded upon below. By analysing her multimodal actions in tandem with her discursive positioning, we can gain an understanding of how she embodies the 'Environment v. Economy' Discourse. About forty five minutes into her interview, Alanis begins talking about the local anti-mining group (Figure 4.2).
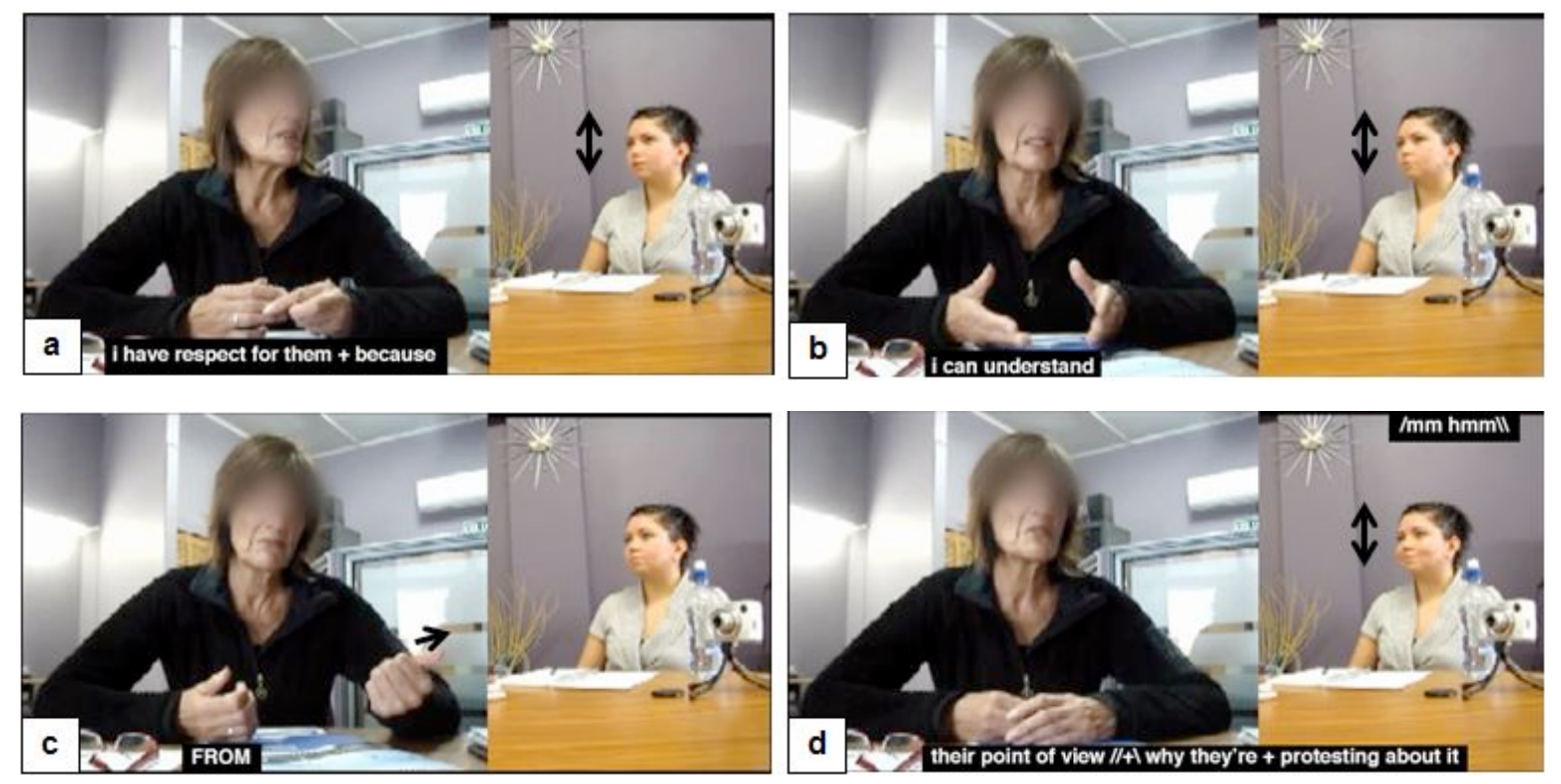

5 This is presumably in reference to the Australian tourist spot. 

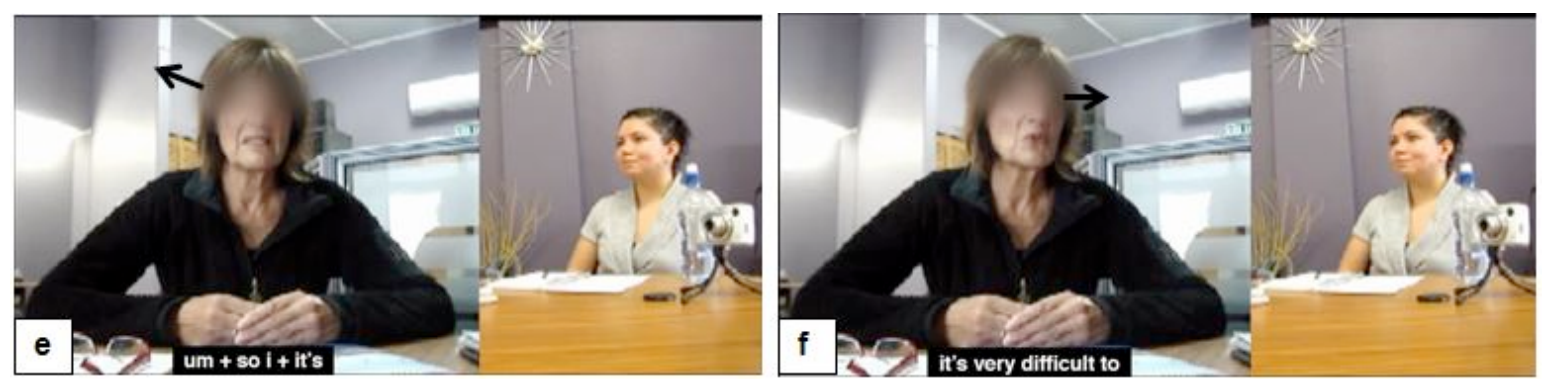

Figure 4.2: Alanis

Alanis admits that she does understand the anti-mining group's point of view (a-d), however, she positions herself as separate from the group through her pronoun choice (e.g.their, d). Pronouns are often used to "conceptualise group identity, coalitions, parties and the like, either as insiders or outsiders" (Chilton \& Schaffner, 2002, p. 30). In this way, social actors may engage in 'Othering' in order to distance themselves from groups or individuals (e.g. Van Dijk, 2000) or in order to position themselves in alignment or association with people (e.g. Liebscher, Daily-O'Cain, Muller, \& Reichert, 2010). This positioning is also achieved multimodally: Alanis' deictic thumb gesture (c) can be read as referring to the group in a space away from her body. Consequently, although she may partly align with their conservationist concerns, Alanis positions herself outside of the activist group and its work.

Next, Alanis multimodally enacts the difficulty she feels negotiating the issues as someone who is both a conservationist and has economic duties to maintain (Figure 4.3).
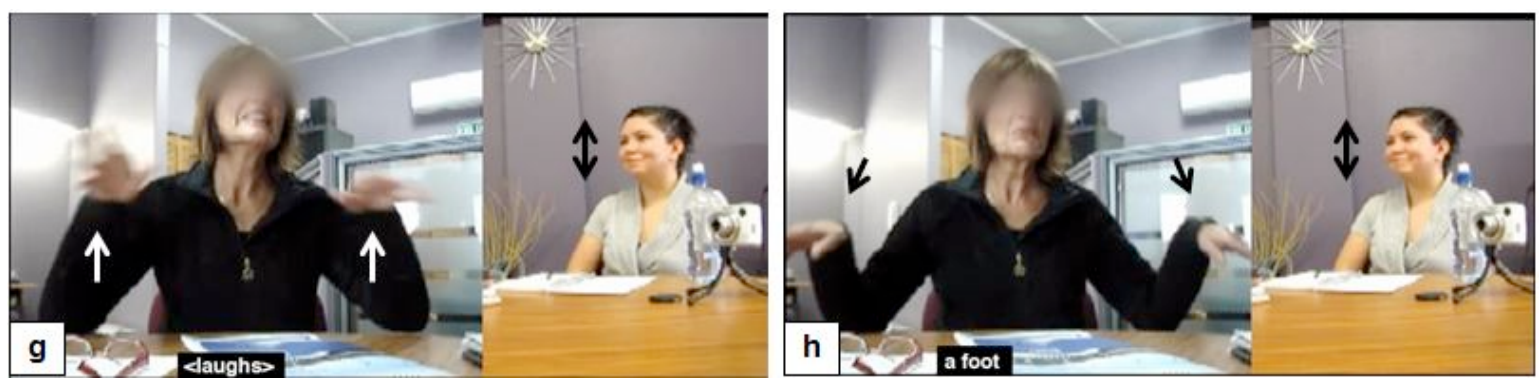

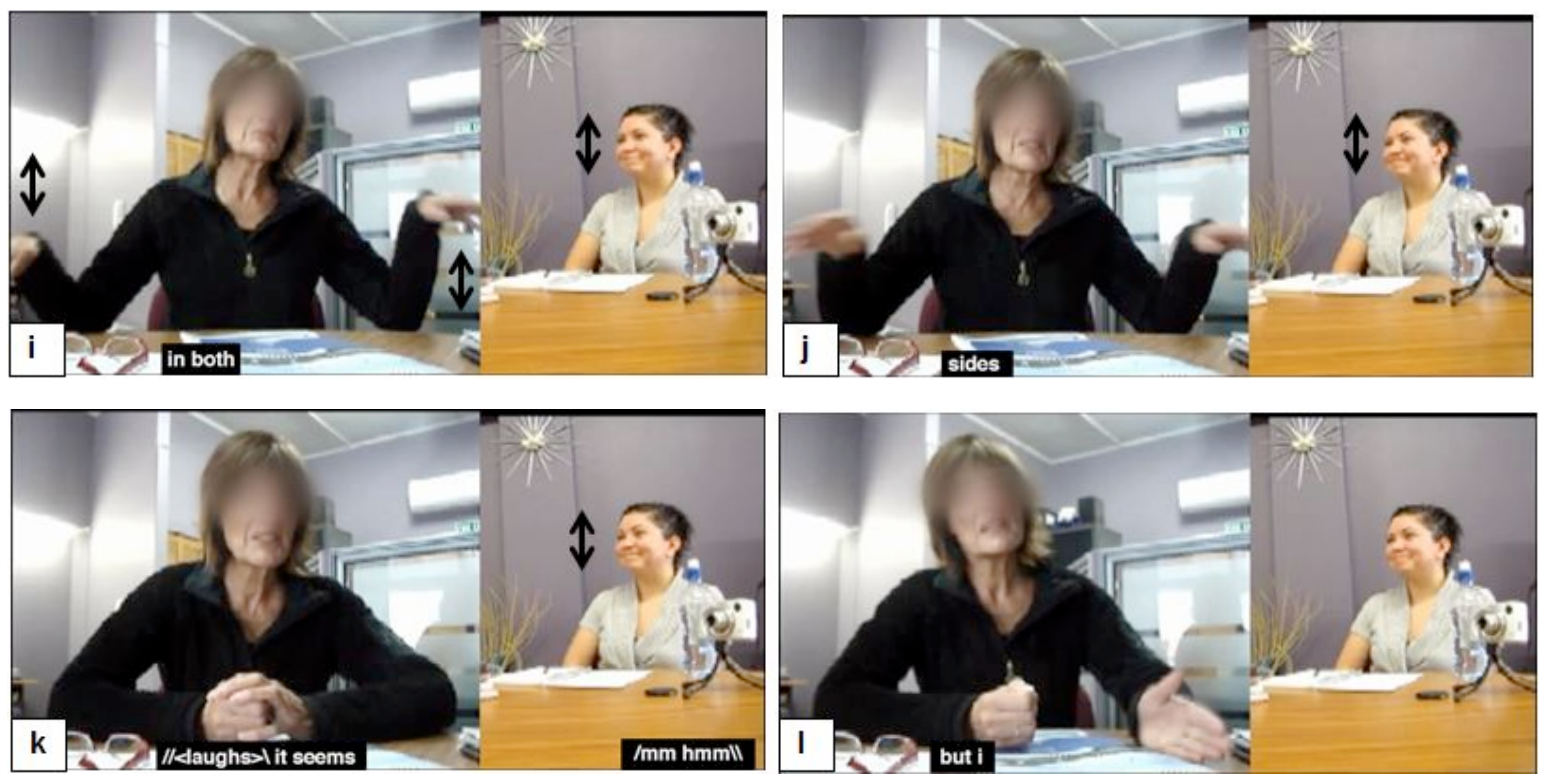

Figure 4.3: Alanis

She begins this depiction in Figure 4.2 (it's very difficult to, f) and then starts to laugh in Figure $4.3(\mathrm{~g})$. While she laughs she brings up $\mathrm{BH}^{6}$ simultaneously and leans her torso back on her chair. While describing her situation as having a foot in both sides, Alanis presents her hands on either side of her body and oscillates each up and down in an opposing motion (i.e. her $\mathrm{RH}$ is high while her $\mathrm{LH}$ is low and vise versa) (h-i). This metaphoric gesture (see Chapter 2.3.1) presents each 'side' of the issue with Alanis' body positioned in between them. Additionally, by holding her palms down, this gesture suggests that this situation is something that has happened to Alanis rather than a result of her own actions (see Kendon, 2004, p. 263). The oscillating movement might also suggest that the sides are constantly in motion, and changing in their relevance and value.

Alanis then provides an elaboration on her position and begins to align with a pro-mining stance (Figure 4.4).

${ }^{6} \mathrm{BH}$ both hands, $\mathrm{RH}$ right hand, $\mathrm{LH}$ left hand 

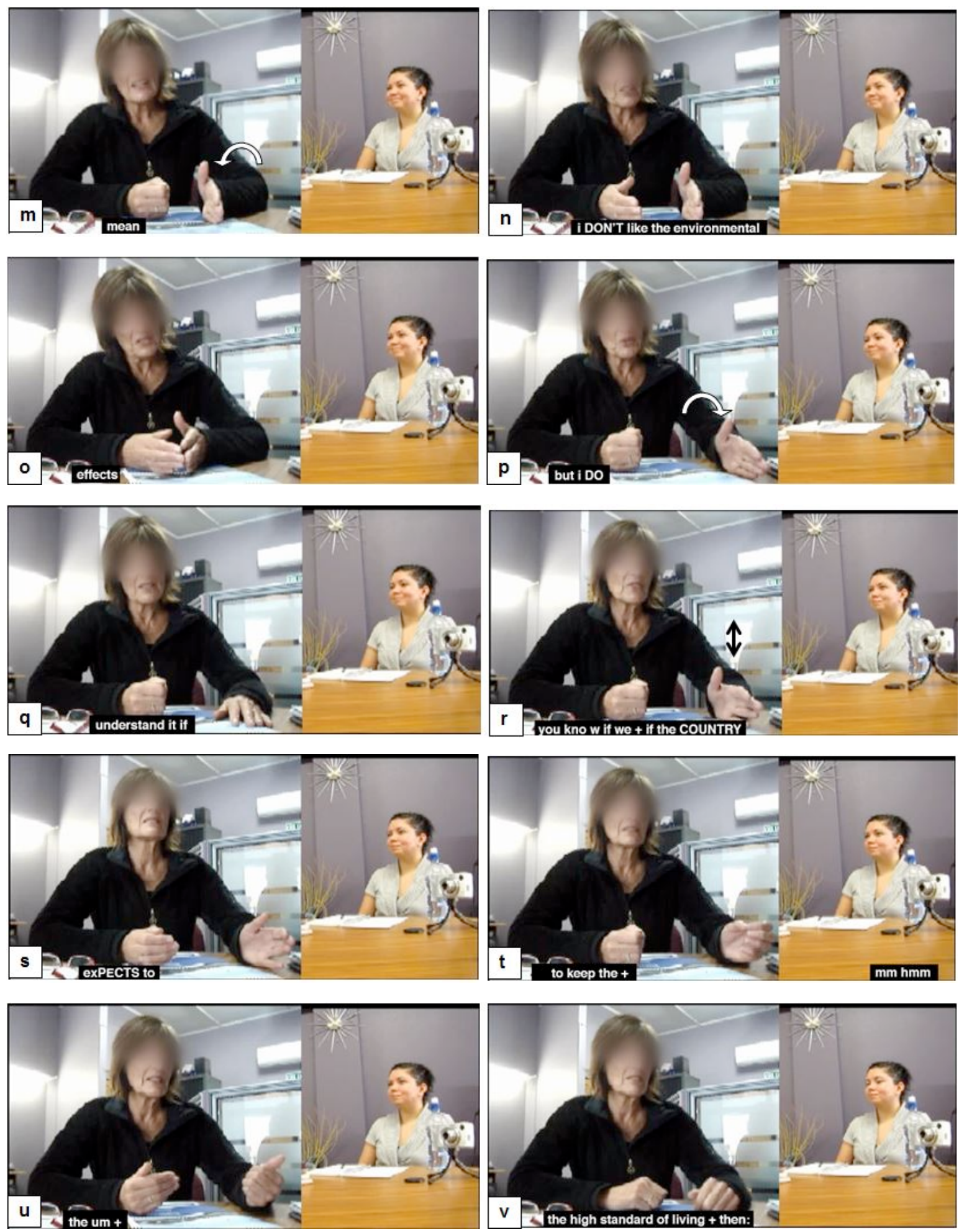

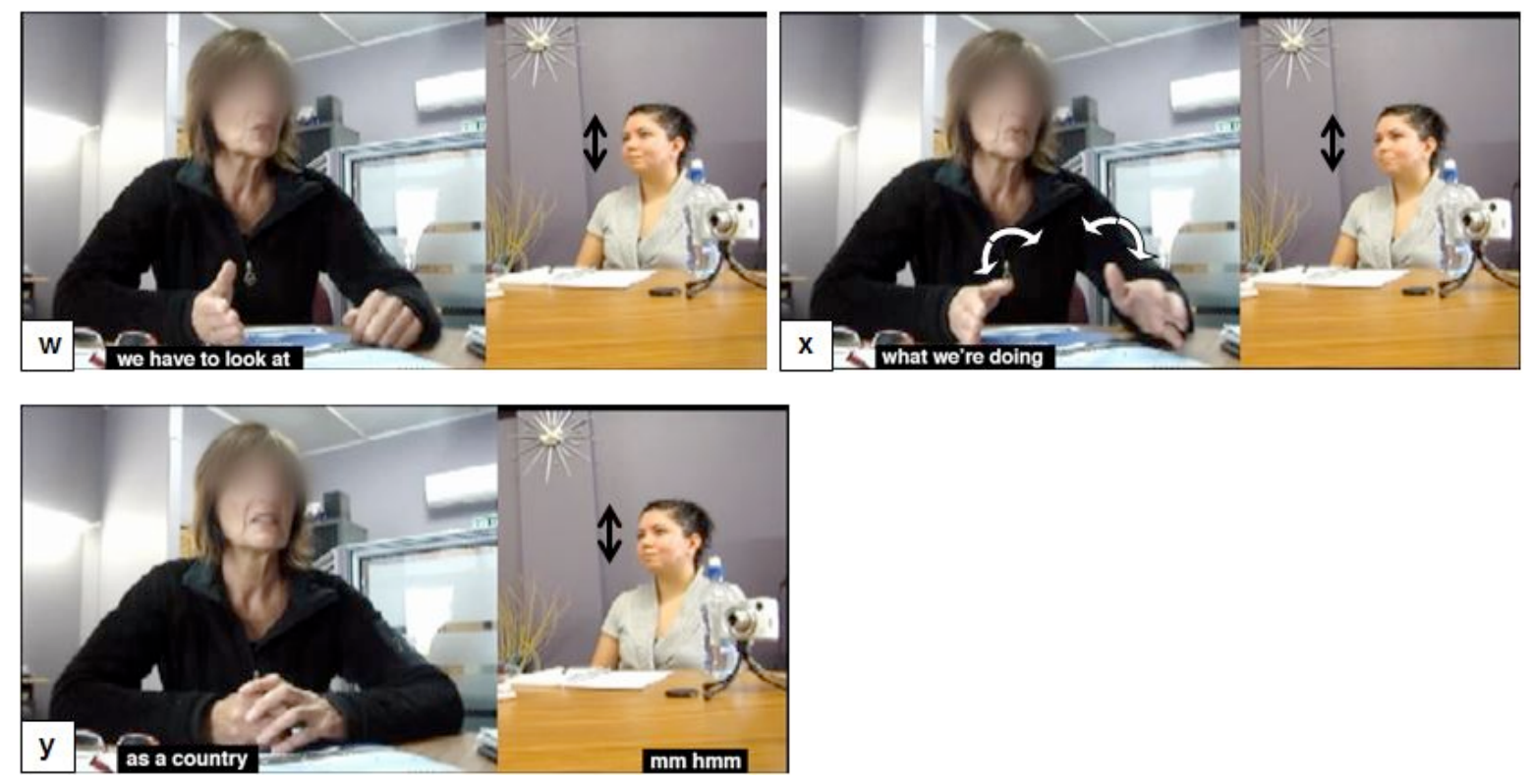

Figure 4.4: Alanis

She establishes this new explanation by forming her $\mathrm{RH}$ into a fist and placing her $\mathrm{LH}$ on its edge, palm facing inwards $(\mathrm{m})$. Her fist acts as a cohesive device that is maintained throughout the elaboration in (I-t) (McNeill, 1992). With her LH, Alanis beats on various utterances and positions each of her elaborations in relation to each other. For example, she begins by moving her hand closer to the centre of the table space $(m)$ while describing her dislike for the environmental effects of mining $(n-0)$. She then outlines the elements of mining that she does agree with by moving her hand back to the left side of her body $(p)$, separating the opinions into different locations on the table. Because this counters her previously described conservationist identity, Alanis expands upon, and possibly seeks to justify, her promining stance $(p-y)$. However, she is able to shift the pro-mining opinion away from herself and onto the country $(\mathrm{r})$. Once again using her $\mathrm{LH}$, she beats on do $(\mathrm{p})$, we, country (r), and expects (s), emphasising these words in her positioning.

In this way, Alanis draws upon her identity as a public servant who is representing common opinion to allow her to hold two seemingly opposing views: conservation is important but mining is necessary. Her switch to we, coupled with her LH lateral movement marks this change in voice, and therefore opinion, and 
positions her in the middle of both sides of the mining debate. By analysing her multimodal actions, we can see how Alanis also embodies the 'Environment v. Economy' Discourse.

Similarly, in Alberta, Christina works with an organisation which encourages responsible development of the tar sands. Although primarily an environmental group, the organisation seeks to orient to the province's economic imperative while maintaining a conservationist perspective. This was partly exemplified in my interview with Christina, where she at times referred to the Athabasca tar sands as the oil sands resource (cf. Kidner, 2012 regarding the terms oil and tar), and described her organisation's aims as critique of current development but also as providing an alternative policy recommendation.

Much like Alanis, Christina seems to negotiate the boundaries of the 'Environment v. Economy' Discourse, and she does so using both verbal and multimodal means. In Figure 4.5, Christina elaborates on a previous utterance in which she discussed the imperative for Canada to establish a green economy which does not rely on fossil fuels. She describes this as a transition and uses her hand to metaphorically enact the preferred trajectory.
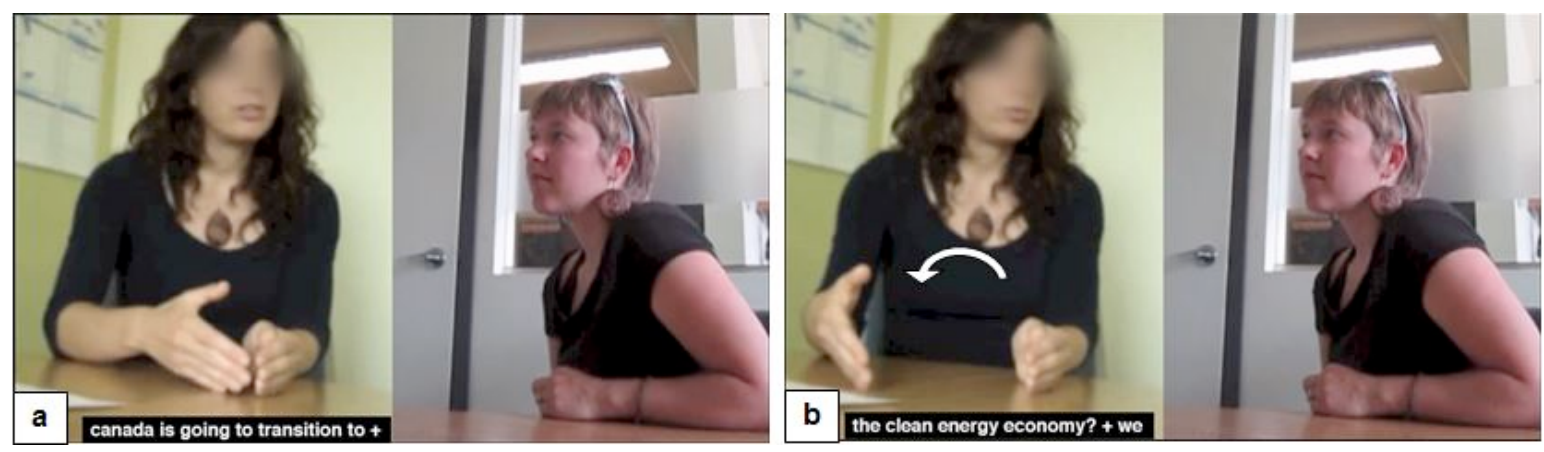

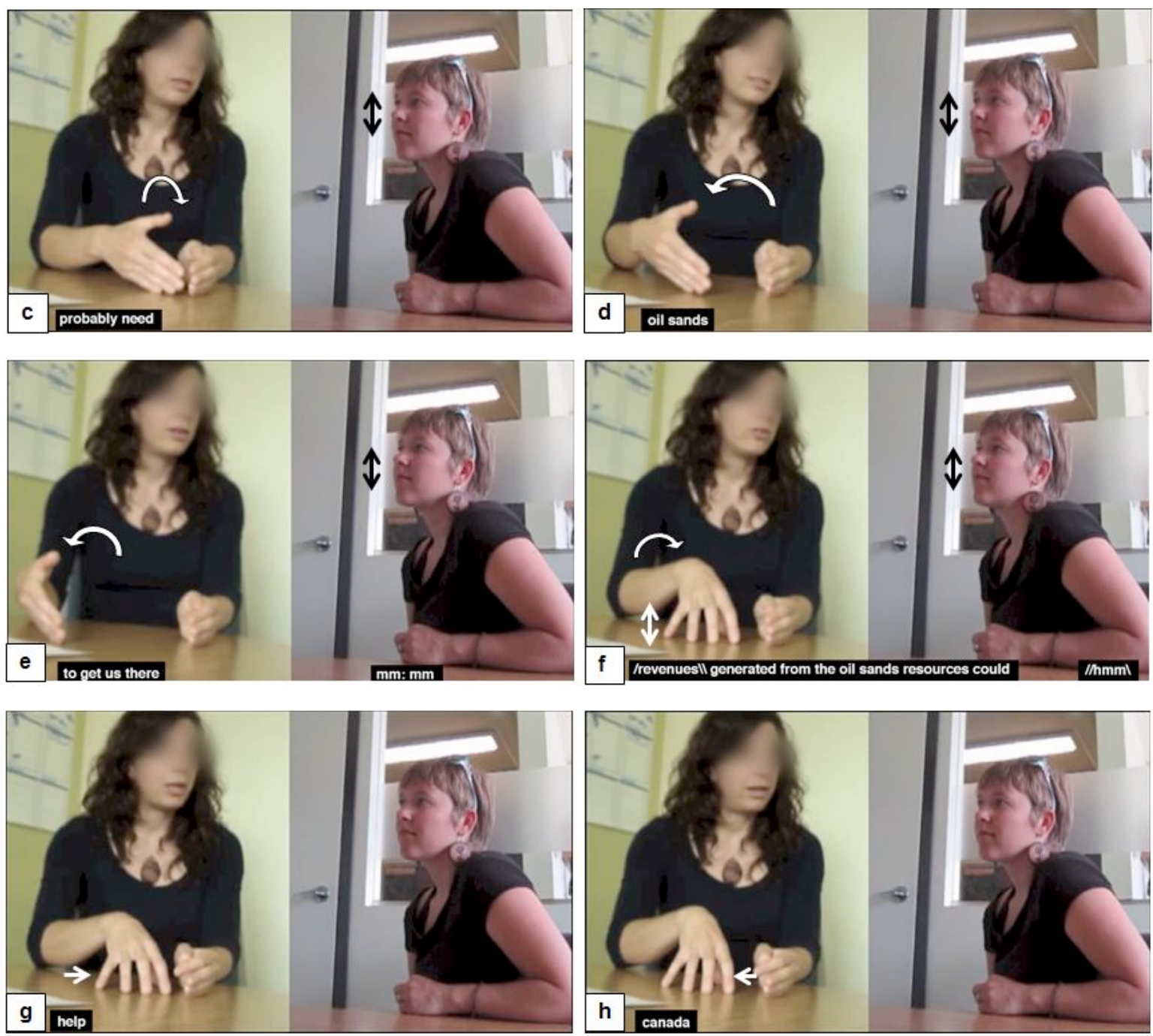

Figure 4.5: Christina

First, she establishes the green economy spatially on the table by moving her $\mathrm{RH}$ to the side, palms inwards (a-b). Next, she goes back to the centre and re-enacts the movement with another stop on the way to the pre-established point (c-e). This stop coincides with oil sands, showing a more gradual shift than simply jumping from one location to the other. With this basic, gradual trajectory established, Christina next elaborates on the ways in which the oil sands can help Canada achieve a green economy. Moving back to the centre (f), she spreads her fingers and beats in time with her utterance, marking "help with a lateral movement (g). Because oil sands and a green economy appear as opposing interests, Christina 
seems to highlight help as the verbal link uniting the two sides. In other words, it is through resources from the oil sands that Canada might be able to invest in a new economy and thus, the oil sands can actually be 'helpful' in this sense.

In Figure 4.6, Christina expands upon the ways in which transition can be used in the oil sands debate.
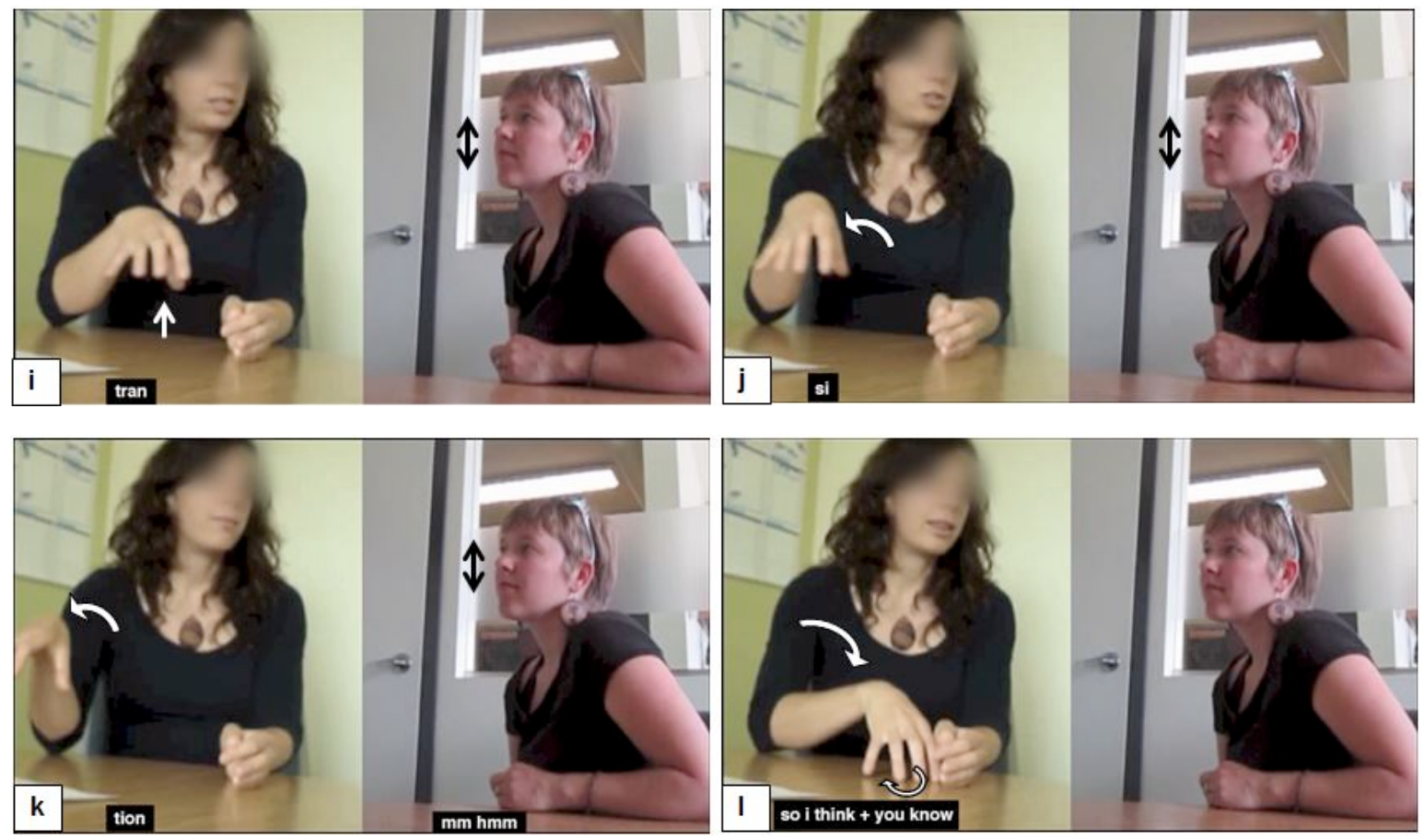

Figure 4.6: Christina

She repeats an adapted version of the gradual transition gesture (4.5, c-e) while saying transition (4.6, i-k). As before, she pauses at a point in between, suggesting a cohesive link between the two concepts of transition. Next, Christina comes back to discussing her organisation (so i think you know, I), establishing the group's position with a gesture: fingers spread with her hand circling on the table in front of her (I). In Figure 4.7 she further discusses the organisation's stance in comparison to the stance of other groups. 

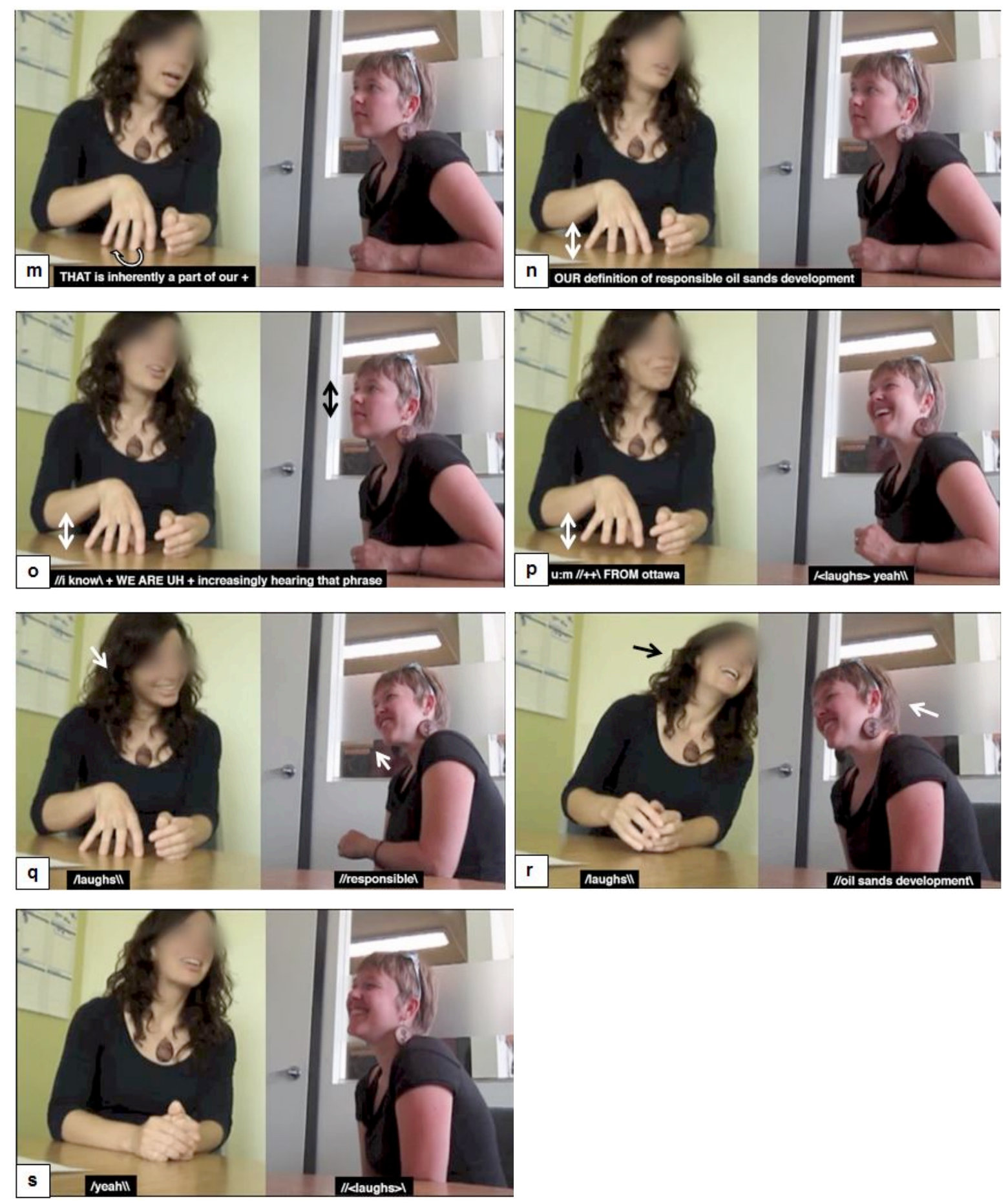

Figure 4.7: Christina

Once she has begun the circling gesture, she switches pronouns ( $i$ to our, we), marking her opinion as shared by the organisation she represents and 
simultaneously positioning the organisation in opposition to other groups (cf. Chilton \& Schaffner, 2002, p. 30). Her circling gesture might metaphorically suggest a collective idea, which she marks by pausing when she first switches to our $(m)$. Next, Christina leans in, pauses, and raises her voice before she explains the way the phrase responsible oil sands development has been taken up by others, most notably in Ottawa (i.e. the Canadian government) (o-p). This positions her in opposition to government voices who have been pushing mining projects with little concern for environmental effects. She thus makes clear that, despite shared use of the term responsible oil sands development, Christina's prodevelopment stance does not align with that of Ottawa. She further marks this point with laughter to which I respond by laughing and repeating the phrase ( $p-r)$. Finally, we align with each other by leaning forward and mirroring each other's movement (see Giles, Coupland, \& Coupland, 1991) while continuing to laugh (q-r).

In this excerpt, we can see how Christina positions mining as a means to achieve a more sustainable future by using the concept of transition (revenues generated from the oil sands resource could help canada transition, $\mathrm{f}-\mathrm{k})$. Much like Alanis above, Christina draws upon her institutional identity as a representative of the organisation to hold a pro-environmental and pro-economic stance simultaneously. By describing the tar sands as a resource that can be used to move to a more sustainable economy, she reflects the mandate of the organisation to provide alternative policy ideas while being critical of environmental issues in the province. This is further enacted multimodally by using gestures to show a transitional trajectory for development that is in alignment with environmental and economic goals (i.e. the "green economy"). Additionally, she is sure to position herself (and her organisation) in opposition to the government stance (which is considered pro-mining) by criticising their use of the shared term responsible oil sands development. In this way, Christina not only linguistically negotiates the 'Environment v. Economy' Discourse, but also multimodally embodies it. 


\subsection{Conclusion}

In the previous analyses, we have seen how the 'Environment v. Economy' Discourse is embodied by social actors on either side of the debate in both Canada and Aotearoa/New Zealand. During my interviews, every participant oriented in some way to this Discourse, recognising the importance of conservation as well as the economic imperatives. Many of these orientations have found a manifestation in artefacts as well (as seen in Figure 4.1).

Although the 'Environment v. Economy' Discourse is embodied by both Alanis and Christina, and finds manifestation in artefacts produced by either side, it is the economic imperative which appears to hold greater weight. This is perhaps due to the neoliberal framing of the mining projects which seems to privilege individualism over collectivism, and extends the "economic rationale beyond the economic sphere to saturate all aspects of life" (Bilge, 2013, p. 408). Consequently, financial concerns within this frame tend to be valued above all else (see Blommaert, 2005 on Discourses of differing values) and this uneven discursive dichotomy has been shown to impact other mining projects (e.g. Fougère, 2013). In fact, the Southland project which forms this thesis' case study was recently halted, not due to valid environmental concerns but rather the financial impacts of falling coal prices on Terra Resources. This left the community of resistance in an uneasy state of celebration: the project was indeed halted, but not because of their resistance work.

As much as the 'Environment v. Economy' Discourse is oriented to, and embodied by, social actors on either side of the mining debate, it is not the only Discourse that becomes relevant. The following analyses show how other Discourses, such as regional identities, Indigenous identities, and even LGBTQ+ identities, are brought into the discussions and marketing of the projects. In this way, the appropriation and resistance of Discourses in mining go beyond greenwash, and begin to colonise (Chouliaraki \& Fairclough, 1999; Fairclough, 2006, p. 26) other aspects of social life as well. 


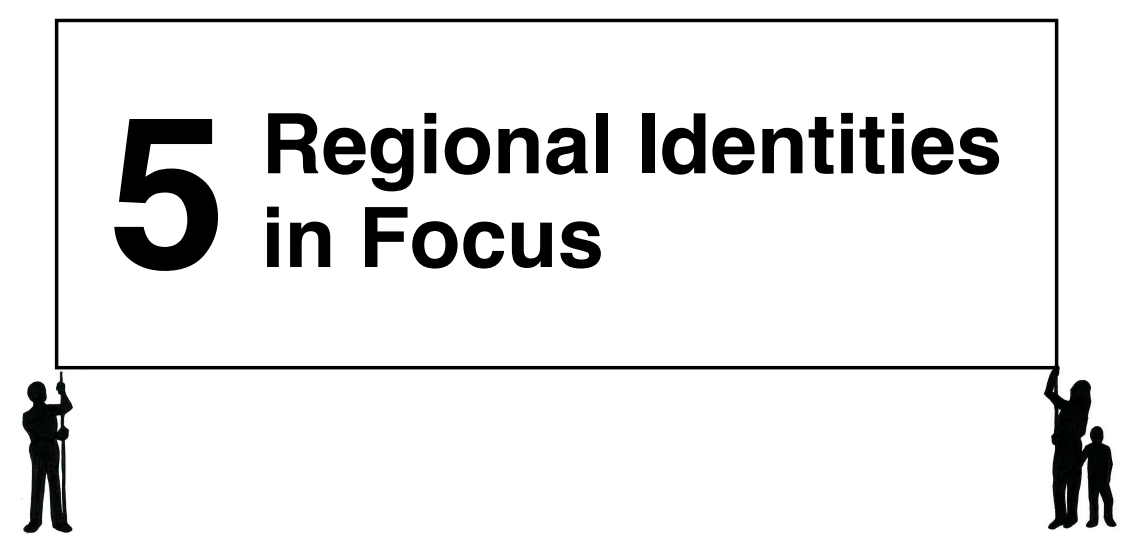

$\mathrm{T}$ here is a vast field of literature dealing with the ways identity is constructed and negotiated through discourse. At its core, identity is "the social positioning of self and other" (Bucholtz \& Hall, 2005, p. 586), or "a meeting point where the discourses of the society meet the voices of the mind" (Pietikainen \& Dufva, 2006, p. 205). It is not something that is possessed but rather something that is enacted (Blommaert, 2005, p. 205) and necessarily partial due to the everchanging contextual landscapes in which individuals find themselves (Blommaert \& Varis, 2011, p. 12; Bucholtz \& Hall, 2005, p. 607). In the case studies analysed in this thesis, activist and industry identities become relevant in terms of their opposition to each other and their potential alignment with other entities. For example, by constructing themselves as different from industry entities, activists might in turn highlight their similarities with other actors, such as political individuals or even fictional characters (e.g. Starosielski, 2011). Additionally, social actors in mining debates may construct their identities based on attitudes towards a specific concept or entity (e.g. the 'climate justice movement', or 'economic development'). Here, they might use communicative signs to guide their interlocutors' interpretations (e.g. a shirt displaying solidarity with communities resisting resource extraction on their lands). By using these 'indexicals' (Johnstone, 2010), social actors can, for example, indicate exactly what type of environmentalist they identify as, and which ideas they align with or against. Yet, these claims may be contested, and so social actors must make their identity 
constructions authentic. It does little good to construct an identity as a 'green capitalist' or an 'environmental justice advocate' if it is not made believable (cf. Johansson, 2011). This also highlights the co-constructed nature of identities, as well as the processes of negotiation which occur in identity construction (Bucholtz \& Hall, 2005).

In the analyses which follow, I draw upon the principles of indexicality, relationality, and authentication, which are adapted from Bucholtz and Hall's seminal paper (2005). However, I recognise that approaching identity is a complicated process and that my analyses will also necessarily be partial accounts which make salient certain aspects and not others, as "identity in all its complexity can never be contained within a single analysis" (Bucholtz \& Hall, 2005, p. 607).

Indexicality is concerned with the ways that a semiotic form becomes linked to meaning "by virtue of co-occuring with the thing it is taken to mean" (Johnstone, 2010, pp. 30-31). Indexical work can be explicit (naming categories), implicit (implicatures, presuppositions), or accomplished through the use of interactional footings, or language that links ideologically to persons or groups (Bucholtz \& Hall, 2005 , p. 594). Through stance, described as a "display of evaluative, affective, and epistemic orientations" (Bucholtz \& Hall, 2005, p. 595), larger identity categories can be built which social actors subsequently index, evoke, and construct (Johnstone, 2010, p. 31). When a group of indexicals are seen as related, they form a register which can enregister further semiotic forms (Johnstone, 2010).

However, missing from these ideas is a wider discussion of the role of power and domination in stance and indexicality. From a critical perspective, we might consider how different indexical features are valued or rejected (Blommaert, 2010). Blommaert introduces the concept of orders of indexicality, whereby indexical meanings are ordered via "a higher plane of social structuring" (2007b, p. 117). This makes indexical meanings "susceptible to a politics of access" (Blommaert, 2007, p. 117) based in the authority of perceived centres (Blommaert, 2007b, p. 118). It is through this stratification that indexicalities are given different values, 
depending on their context and even on their mode of semiotic formation (Blommaert, 2007b, p. 120).

Identities can also be considered in terms of relationality, where groups or individuals may be positioned as alike (adequated) by highlighting similarities and downplaying difference (Bucholtz \& Hall, 2005, p. 599). The opposite, positioning groups as dissimilar (distinction), can be achieved by downplaying similarities and highlighting difference (Bucholtz \& Hall, 2005, p. 599). Positioning can also occur at different levels: the macro structural, the local discursive, and the micro interactive (Bucholtz \& Hall, 2005, p. 592). In addition, positions might accumulate ideological associations with broader identities while simultaneously being constrained by them (Bucholtz \& Hall, 2005, p. 591). Similar ideas have also been approached from cognitive psychology, conceptualised as the ways in which "rights and duties are distributed in the course of an episode of personal interaction" (Harré, Moghaddam, Cairnie, Rothbart, \& Sabat, 2009, p. 9).

Speakers can also "make claims to realness" through authentication (Bucholtz \& Hall, 2005, p. 601). In contrast, denaturalisation involves subverting this process by highlighting instead the "ways in which identity is crafted, fragmented, problematic, or false" (Bucholtz \& Hall, 2005, p. 602). Authorisation is another way of affirming identity, by relying on institutionalised powers and ideology, whereas illegitimation "addresses the ways in which identities are dismissed, censored, or simply ignored by these same structures" (Bucholtz \& Hall, 2005 , p. 603). Individuals may only need to orient to very few specific features or resources to index authentic identities (Blommaert \& Varis, 2011).

Despite the agency of social actors in their identity constructions, there is still an element of pretextuality, where "identities can be there long before the interaction starts" and thus impact what can be accomplished (Blommaert, 2005, p. 206). In addition, micro constructions of identity are affected by macro social structures, while at the same time contributing to such structures (Blommaert, 2005; Bucholtz \& Hall, 2005, p. 607). Like indexicalities (Blommaert, 2010), and 
positionings (Harré \& Langenhove, 1991, p. 406), authenticity is also subject to wider constraints: identities "must be recognised by others" in order to function socially (Blommaert, 2005, p. 205).

Many of the above concepts have been recognised as applying to modes beyond language. For example, Johnstone describes how indexicalities may involve modes such as "dress, carriage, or gesture" and that using "a particular form while looking a particular way can link the linguistic form to the look" (Johnstone, 2010, pp. 33-34). One need only think on the indexical links of modes such as hairstyle (e.g. a shaved head) to realise that indexicalities extend beyond language. In addition, positioning can be "implicit in various modes of presentation" (Harré et al., 2009, p. 10) and authentication may draw on resources such as colour, symbol, or even font (Blommaert \& Varis, 2011). Identity construction has also been studied multimodally at the interactive level using the concepts of foregrounding and backgrounding (Kuśmierczyk, 2013; Norris, 2011). The micro focus of MIA has also recently been extended to encompass wider identity categories and the ways they are indexed in institutional settings (Kuśmierczyk, 2013).

Consequently, identity can be conceptualised less as a stable entity and more as a repertoire of potential semiotic features (Blommaert, 2005, p. 232) which can be used to construct identities in different ways depending on context (Holmes \& Marra, 2002). Additionally, identity is constructed multimodally through action that takes place "in intersubjective relations of sameness and difference, realness and fakeness, power and disempowerment" (Bucholtz \& Hall, 2005, p. 608). Drawing upon the concepts outlined above (indexicality, relationality, authenticity), the following analyses examine how regional identities are made relevant in the debate over mining projects in Alberta and Southland. 


\subsection{Alberta is Oil}

Regional identities in Alberta tend to take a variety of forms (Evans \& Garvin, 2009), one of the most prominent of which being related to oil and gas (see Chapter 1). This was reflected when interviewing Tina, an American visitor from DC. After our return from the tar sands, she described her impressions of Alberta as a place based on oil: it is in the air that you breathe here. Her description demonstrates some of the issues that will be discussed in this chapter: namely the ways in which Alberta is constructed as oil and how locals struggle to contest this identity Discourse. It is through this contestation that we see the dominant Discourse appropriated and entextualised multimodally as a form of resistance.

In the 'Alberta is oil' Discourse (see section 1.1.5), the message is that the exploitation of the tar sands are not to be slowed - they represent the lifeblood of the Albertan, and Canadian, economy: "indeed, the world is depending on the people of Fort McMurray" (Davidson \& Gismondi, 2011, p. 69). Ultimately, it is claimed that the development of the tar sands equals jobs (Davidson \& Gismondi, 2011, p. 70). Alberta has been named a "petro state", characterised by political apathy, a lack of transparency, and a decline in freedom and democracy (Davidson \& Gismondi, 2011; Nikiforuk, 2008). The Alberta state thus struggles, it is proposed, to maintain legitimacy by using Discourses to hide and obscure inequalities created by state policies and to promote its own ideologies and authority (Davidson \& Gismondi, 2011, pp. 7-8). Both industry and government use these Discourses to position those who question oil sands development as the opposition (HaluzaDelay, 2012, p. 2). Even in primary school, children are exposed to these narratives as the curriculum "focuses upon Alberta's resource abundance without word of environmental consequences." (Haluza-Delay, 2012, p. 3; see also Ibrahim, 2014).

The dominant Discourse of the tar sands tends to characterise freedom as capital and nature as resource (Gordon, 2012, p. 2). Environmental disturbance is justified as necessary for prosperity and the common good while nature exists to 
be used by humans (Gordon, 2012, pp. 4, 6). The world's growing energy demand is construed as justification for tar sands development: "Albertans, by extension, should feel proud of their tar, but also need to embrace their responsibility to produce this global treasure" (Davidson \& Gismondi, 2011, p. 158). It is in this identity space that locals, and visitors to Alberta, must negotiate their own provincial and political identities. These macro Discourses are evident in many of the artefacts I collected, and construct the discursive background upon which the mining debates occur.

For example, in popular provincial culture, Albertan citizenship is explicitly equated with oil, as is visible in Figure 5.1.

Images removed after examination

Figure 5.1: 'Alberta is Oil'1

Edmonton's ice-hockey team, the Edmonton Oilers, make extensive use of the provincial oil Discourse in their marketing (and other local sports teams include the

\footnotetext{
${ }^{1}$ Images can be viewed at www.oilers.nhl.com, www.ilovealbertaoil.com.
} 
Oil Kings and Oil Barons). Even in the Oilers logo, we see the ubiquitous oil drop and the extension of the lower half of the 'Oilers' font gives the impression that the words are rising out of the ground. Additionally, through the purchase of the above pullover, individuals can literally construct themselves as Alberta oil2. This design also indexes a popular Molson Canadian beer campaign by mimicking its font and the I am construction. The fact that such items can be purchased and displayed strongly reinforces the prevalence of the 'Alberta is oil' Discourse in the province.

At the Oil Sands Discovery Centre in Fort McMurray, visitors can purchase a souvenir sample of bitumen-soaked sand in the form of a small plastic bag stapled on the inside of an information card. The card copy describes the tar sand as a little piece of Alberta (Figure 5.2). Here, it is claimed that tar sands are literally what the geographical place is made from and Alberta as a province is equated with the resource itself.

Image removed after examination

Figure 5.2: Piece of Alberta

2 This may also refer to Alberta beef, a campaign developed to reinvigorate the declining beef market after the BSE or 'mad cow scare' in 1993. During that time, it was common to see items such as vanity license plates and bumper stickers declaring I love Alberta beef. It is also interesting to note that the third pullover option is I am Newfie, targeting the record number of Newfoundlanders who have left their home province to work in Alberta's oil industry. 
When visiting the tar sands region and Fort McMurray, tourists can also purchase postcards depicting the mines and mining culture (Figure 5.3). As ideological representations of place (Waitt \& Head, 2002), these items depict the region with a focus on oil and oil-related activities, proudly labeling Fort McMurray Home of the Oil Sands. Massive machinery is foregrounded and, in the last example, presented from a high angle which makes palpable the power of the object over the viewer (Kress \& Van Leeuwen, 2006, p. 140). In fact, the person on the truck is positioned in the photograph in order to make the size of the machinery more obvious. This juxtaposition of "giant equipment... with tiny humans" (Davidson \& Gismondi, 2011, p. 65) is a common visual trope in tar sands discursive constructions.

Images removed after examination

Figure 5.3: Fort McMurray Postcards

Less explicitly, a number of pamphlets produced by industry and government actors utilise possessives (i.e. Alberta's as highlighted in red circles in Figure 5.4) to position the oil sands as belonging to the province of Alberta: 
Images removed after examination

Figure 5.4: Alberta's Oil Sands

In light of the above artefacts, the 'Alberta is oil' Discourse can be considered a prominent identity that is constructed multimodally. The ubiquity of oil, from sports teams to souvenir gifts, suggests this is an identity Discourse which is cultivated throughout popular Albertan culture. As artefacts represent designed, and therefore macro, Discourses, 'Alberta is oil' forms the backdrop for political discussions in the province. This Discourse also benefits the oil and gas industry at the expense of those who wish to resist: when being Albertan means being an oil supporter, industry interests are more readily considered. The power which the oil and gas industry holds over the province has been a matter of contention in both academic and journalistic examinations (e.g. Davidson \& Gismondi, 2011; Nikiforuk, 2008) and this power was also mentioned in my interviews. For example, in discussion, Marcelo (who works for a research organisation with a critical focus), admits that because Alberta relies on the oil patch, it is therefore difficult to fight against: 


\section{Excerpt 5.1: Marcelo}

\begin{tabular}{|c|c|c|}
\hline 1 & M & so yeah i mean they're + that's that's + and and ++ i don't know how \\
\hline 2 & & much longer they'll get a free ride on it? but if the economy + \\
\hline 3 & & continues to improve and pick up? they'll continue to get a free ride on \\
\hline 4 & & it + because you can't you can't fight that that economic book \\
\hline 5 & & particularly in alberta we know + in alberta + where + more than half \\
\hline 6 & & the population is connected somehow or the other to the oil patch for \\
\hline 7 & & their money \\
\hline 8 & K & $\mathrm{mm} \mathrm{hmm}$ \\
\hline 9 & M & right? \\
\hline 10 & K & $\mathrm{mm} \mathrm{hmm}$ \\
\hline 11 & M & um + it's it's a tough one to fight + a:nd $+\mathrm{i}: \mathrm{f}+$ the person who's signing \\
\hline 12 & & your paycheck + tells you + that the people + who are arguing \\
\hline 13 & & AGAINST them + are out to make you lose your job + \\
\hline 14 & K & $/ / \mathrm{hml}$ \\
\hline 15 & M & /that \ their GOAL is to make you lose your job that's what they WANT \\
\hline 16 & & + right? they hate wealth they hate business and they want you to lose \\
\hline 17 & & your jo:b + um and then they sign your paycheck + \\
\hline 18 & K & yeah \\
\hline 19 & M & you're gonna be mu:ch much more likely to listen to what THEY have \\
\hline 20 & & to say \\
\hline 21 & $\mathrm{~K}$ & yeah \\
\hline 22 & M & than to what anybody else has to say and that's that's + the battle \\
\hline
\end{tabular}

Here, Marcelo describes the difficulties inherent in challenging oil and gas development in Alberta as a battle, because more than half the population is connected somehow or the other to the oil patch for their money (5-7). In line 12, he adopts a general you pronoun, positioning Albertans in contrast to their bosses and anti-tar sands activists (the person who's signing your paycheck, the people who are arguing against them are out to make you lose your job, 11-17). This presents the 'typical' Albertan as positioned between the two extremes of industry and activism (see previous Chapter for a similar positioning). However, the industry side has a more powerful position as they sign your paycheck $(12,17)$ and therefore have control over livelihoods. This, explains Marcelo, means that Albertans will typically listen to their bosses over anyone else (19-20), making it 
difficult for activists (that's the battle, 22). In this short excerpt, Marcelo concisely presents how he views the situation in Alberta: due to reliance on the oil patch and its accompanying identity Discourse, as well as the powerful position of industry, 'typical' Albertans are discouraged from challenging development.

Similarly, in my conversation with Jill (a representative of an environmental organisation), we both discuss the difficulties for Albertans who wish to criticise development:

\section{Excerpt 5.2: Jill}

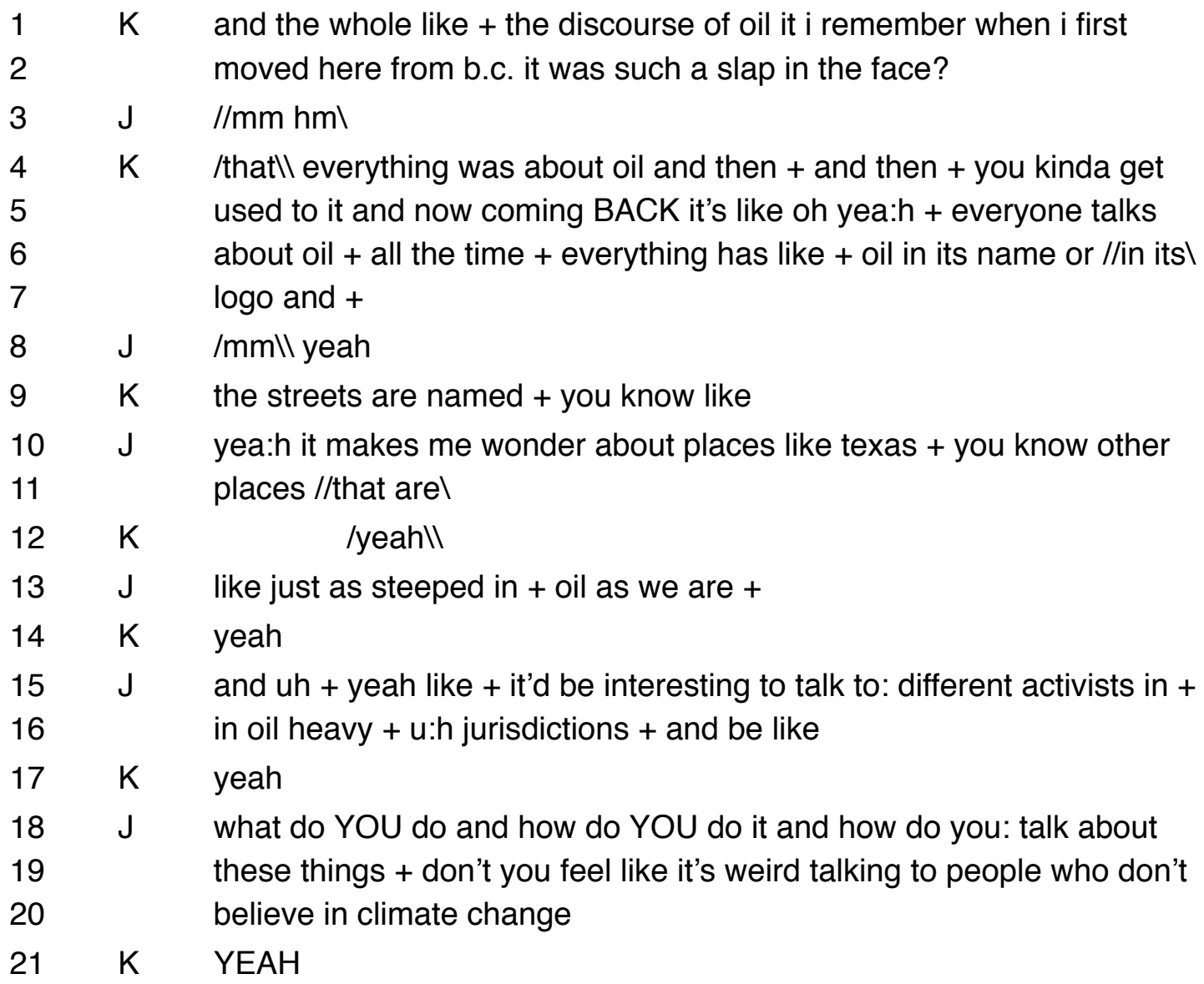

In the beginning of this excerpt, I make my identity relevant by constructing myself as an outsider from BC (1-2). This is done in alignment with Jill, who I know has also moved from Ontario to Alberta. In this way, I utilise our shared identities as 
outsiders to guide the conversation to a discussion of Alberta's regional identity. I conceptualise the Discourse of oil as a slap in the face (2), with which Jill agrees $(3,10)$. Using this metaphor, I thus present 'Alberta is oil' as something marked that 'assaults' the newcomer. After a brief agreement, Jill makes the comparison to Texas, as another place that is just as steeped in oil'(13). This lexical choice presents a different metaphorical image of Alberta as surrounded by, or even soaking in, oil. Jill thus recontextualises my concept as something less aggressive and much more enveloping. Additionally, the soaking metaphor underlines, in a similar way, the 'Alberta is oil' Discourse so explicitly presented in Figure 5.2 (the souvenir bitumen), where Alberta is presented as physically constructed of tar sand.

Jill also expresses an interest in talking to activists in other places for advice on strategies to talk about these things (15-19), highlighting the difficulty she experiences in constructing Discourses of resistance around tar sands development. These difficulties extend to her interactions with the 'everyday Albertan' which Marcelo also talks about: someone who relies on the oil patch, who identifies with the 'Alberta is oil' Discourse, and who possibly doesn't believe in climate change (20).

Both Jill and Marcelo's excerpts orient to the 'Alberta is oil' Discourse, and show the powerful position of industry in the province and the resulting difficulties for those who resist. Additionally, Jill's focus on "talk" in her last utterance suggests she recognises "the power of discourse" and "why it is worth struggling over" (Wodak \& Fairclough, 2010, p. 13). However, despite the importance of spoken or written discourse on tar sands development and resistance, other modes should be considered for their entextualising potential (Machin, 2013). In the next sections, I consider how alternative identity Discourses of resistance are articulated multimodally. 


\subsection{Resistance to 'Alberta is Oil'}

Locals find ways to position themselves in relation to identities (Bucholtz \& Hall, 2005) constructed at the macro level through designed artefacts. If we take, for example, the 'I am Alberta Oil' pullover in Figure 5.1, we can imagine that social actors might buy it and wear it or even alter it to read a different message. Depending on the interactional context, social actors may dynamically position themselves as opposed to, in alignment with, or ambivalent of larger, ideological identity categories such as the 'Alberta oil supporter'. However, the identity positions which are available are also restricted (see Blommaert, 2007b) by the strong 'Alberta is oil' identity Discourse, which has major implications for those who seek to question tar sands development. Any contesting voices are considered "contrary to the interests of the Alberta people themselves." (Haluza-Delay, 2012, p. 4) and individuals must negotiate "competing moral geographies rooted in the goodness of petroleum development" (Evans \& Garvin, 2009, p. 66). Because petrocapitalism ${ }^{3}$ is so embedded in Albertan lifestyles and politics, and controls Albertans "by our very own internalisations" (Haluza-Delay, 2012, p. 4), opposing the oil industry is also opposing the Albertan identity. Thus, there are difficult positionings at play when "taking on Alberta oil and gas as an Albertan" (Evans \& Garvin, 2009, p. 65).

For example, in their analysis of locals resisting sour gas ${ }^{4}$ development, Evans and Garvin found that people "struggled to negotiate their dual position: opposing sour gas development near their homes while simultaneously receiving direct or indirect benefits from sour gas development through employment" (2009, p. 62). To negotiate these discursive positionings, Evans and Garvin (2009) describe how community members utilised various storylines to help establish an ethical ground from which to contest the development. They accomplished this by drawing on ideas of living "the good life", while recounting "horror stories" of

\footnotetext{
${ }^{3}$ An economy reliant on oil (see Nikiforuk, 2008).

4 Natural gas containing hydrogen sulfide.
} 
development gone wrong. Through "stigma stories", individuals discussed their difficulties in managing their identity as Albertans who also oppose development in Alberta and denied labels such as 'radical' or even 'environmentalist' ( 2009, p. 61). Ultimately, these stories allowed people to present proposed development as bringing unwelcome consequences which were "incompatible with how they viewed their lives, home, and communities" (2009, p. 63). The counter Discourses that Evans and Garvin found being used by locals can be considered strategies which allow participants to simultaneously uphold an Albertan identity while questioning energy development (2009, p. 63). The authors explain that the stories helped community members construct "a type of 'ethical' subject position from which to contest oil and gas development in 'oil country"' (2009, p. 65). In provincial literature as well, alternative Discourses do exist, though they are few and far between and we must "listen for them" (Gordon, 2012, p. 28). Gordon takes hope from recent voter apathy, noting that "not voting might suggest that people have stopped listening to the "sustainable development" monologue" and "the modern contractual compromise between owing and owning is breaking" (2012, p. 28).

The environmental movement, meanwhile, seeks to position itself in active opposition to dominant identity narratives by using framing processes of its own. In their influential book which tracks the Discourses surrounding tar sands development, Davidson and Gismondi (2011) identify three tiers of opposition in Alberta. First, they describe the long-established groups who employ a collaborative approach to ensure longevity in a province hostile to tar sands criticism, such as the Pembina Institute. Second are the large-scale players like Greenpeace who frame the tar sands globally as "Dirty Oil", drawing awareness to Alberta and inspiring international action as a result. Finally, small, localised grassroots groups such as Keepers of the Athabasca tend to be far more critical and are able to better challenge state legitimacy. It is the citizens of Alberta who the authors see as most likely to succeed in their challenge, with an "acknowledgement of the rights of and responsibilities toward ecosystems and other species" (2011, pp. 179-180). By expanding the provincial identity to include 
environmental rights and responsibilities, Albertans may take on "multiple citizenships, each with differential forms and levels of influence over those in power" (2011, p. 181). Ultimately, new identity narratives of what it means to be Albertan can empower "concerned Albertan citizens to confront their state, and by doing so give citizens everywhere the encouragement to take back their own states" (2011, pp. 223-224). It is this confrontation that becomes apparent through interaction in the form of Discourses of resistance.

Missing from these discussions, however, is a textual analysis of the discursive strategies used in completing these positionings, as well as an analysis of the multimodal dimension to these interactions. It is this textual and multimodal approach that I offer in this thesis.

\subsubsection{Alternatives to 'Alberta is Oil'}

Seldom do alternatives to the 'Alberta is oil' Discourse come up, but one explicit example is found in my discussion with Tom (a representative of a large environmental organisation). Throughout our conversation, he orients to the Discourse characterising 'typical' Albertans as supportive of oil development. However, he also describes the discursive implications for those who wish to challenge the fossil fuel industry:

\section{Excerpt 5.3: Tom}

1 K <laughs > but i found that a lot + people would say like even the tour

2 operators like well OBVIOUSLY it has big environmental impact

$3 \mathrm{~T}$ yeah

$4 \quad \mathrm{~K} \quad$ but look at wapisew lookout <laughs>

$5 \mathrm{~T}$ yeah

$6 \quad \mathrm{~K}$ you know it's that //wholel

$7 \quad \mathrm{~T}$

land $\backslash i$ think like even if like and when you spend more

9 time up the:re and like + even like when we do helicopter tou:rs you know'll start off sort of like really industry line and then you'll + WILL hear like those + sort of side comments and

$$
\mathrm{K} \text { yeah }
$$




\begin{tabular}{|c|c|c|}
\hline 12 & $\mathrm{~T}$ & mu:h + and $i$ think that's the thi:ng of like + and $i$ think the most clever \\
\hline 13 & & thing that the oil industry di:d is how they + really got albertans to \\
\hline 14 & & associate + part of alberta identity is as + being like an oil suPORter \\
\hline 15 & $\mathrm{~K}$ & $\mathrm{~mm}:$ \\
\hline 16 & $\mathrm{~T}$ & and $i$ think that that's what a lot of people STRUGGLE with is that they \\
\hline 17 & & + WANNA be critical of this industry they want things to be: improved \\
\hline 18 & & but either THEY depend on it or they know people that are in //thel \\
\hline 19 & & industry \\
\hline 20 & $\mathrm{~K}$ & /yeahlI yeah \\
\hline 21 & $\mathrm{~T}$ & or they just like SEE it as + you know part of being alBERtan and so if \\
\hline 22 & & you attack it then you attack your own identity $+\mathrm{u}:: \mathrm{m}+$ and it makes it \\
\hline 23 & & really tough for people to sort of + speak out to + to GRAPPLE with all \\
\hline 24 & & that so i think that's like yeah \\
\hline 25 & $\mathrm{~K}$ & $\mathrm{i}-$ \\
\hline 26 & $\mathrm{~T}$ & the trickiest part \\
\hline 27 & $\mathrm{~K}$ & yea:h and i noticed like in the greenpeace warehouse there was $a+a$ \\
\hline 28 & & chorflute like + sign that had \\
\hline 29 & $\mathrm{~T}$ & yeah \\
\hline 30 & $\mathrm{~K}$ & it had like i'm an albertan and i'm against the //tar\ sands yeah \\
\hline 31 & $\mathrm{~T}$ & /yeahll \\
\hline
\end{tabular}

Throughout this discussion, Tom discursively presents an alternative Albertan identity in a number of ways. First, in response to my point about the way environmental concerns are dealt with by industry actors (but look at wapisew lookout, 4), he shares stories of how resistance can be found in unexpected places (even like when we do helicopter tours, you'll hear those sort of side comments, 8-10). Next, he recognises the 'Alberta is oil' identity Discourse and assigns responsibility for its construction on the industry itself (the most clever thing that the oil industry did, got albertans to associate part of alberta identity as being an oil supporter, 12-14). In his next turn, he expresses the difficult positioning which critical Albertans are forced to take (either they depend on it or they know people that are in the industry, 18-19), and the problems people have in grappling with conflicting identities (if you attack it then you attack your own identity, 22). I mention a Greenpeace artefact that I had seen (27-28), which explicitly presents this issue (Figure 5.5). 


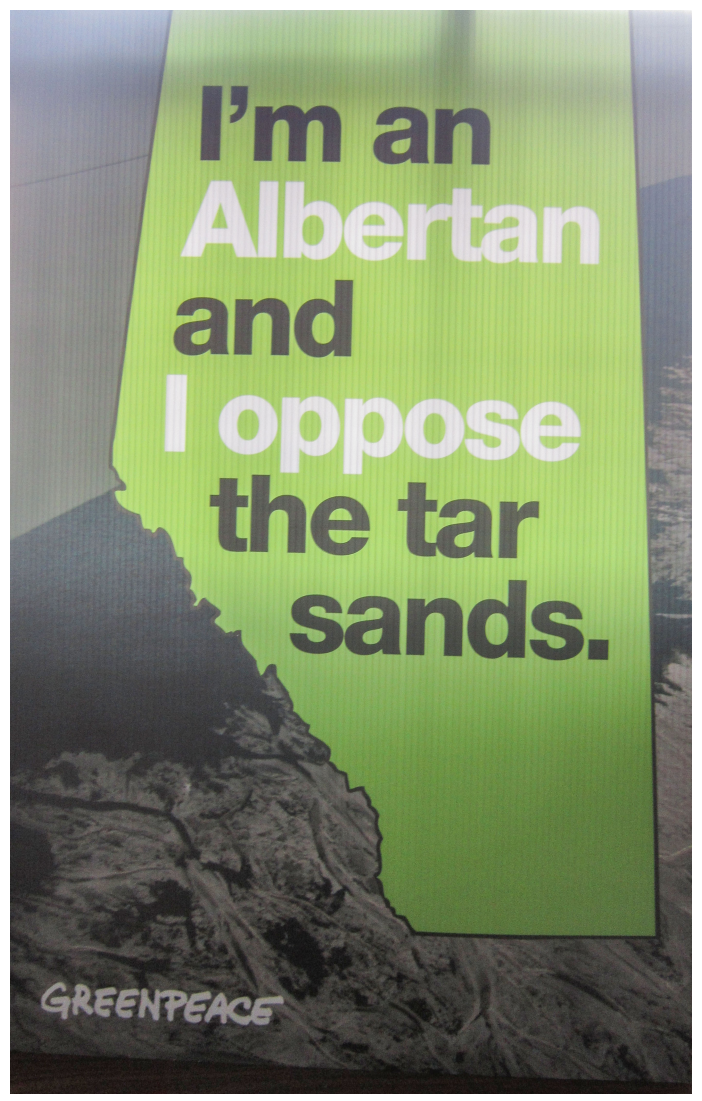

Figure 5.5: Greenpeace Artefact 5

In this artefact, there are a number of ways in which an alternative Albertan identity is constructed. First, Alberta is represented symbolically (Kress \& Van Leeuwen, 2006) through a green map outline of the province. This is literally set against the backdrop of a tailings pond (compare with Figure 1.3), creating a stark contrast through colour which is echoed in the two possible identities for Alberta presented. The green provincial icon draws upon wider cultural understandings and contemporary, localised meanings (Van Leeuwen, 2011) which may present the preferred Alberta as an environmentally responsible place. In addition, the text seems to explicitly introduce a novel regional identity which opposes instead of supports the tar sands. ${ }^{6}$ The fact that the words Albertan and I oppose are

\footnotetext{
${ }^{5}$ Artefact reproduced with permission.

6 This campaign may also be referencing a very popular bumper sticker which uses icons like the provincial outline to read "I love Alberta oil". in this case, it can be seen as a further entextualisation.
} 
encoded in white (and thus highlighted), further supports this interpretation.

\section{Excerpt 5.4: Tom}

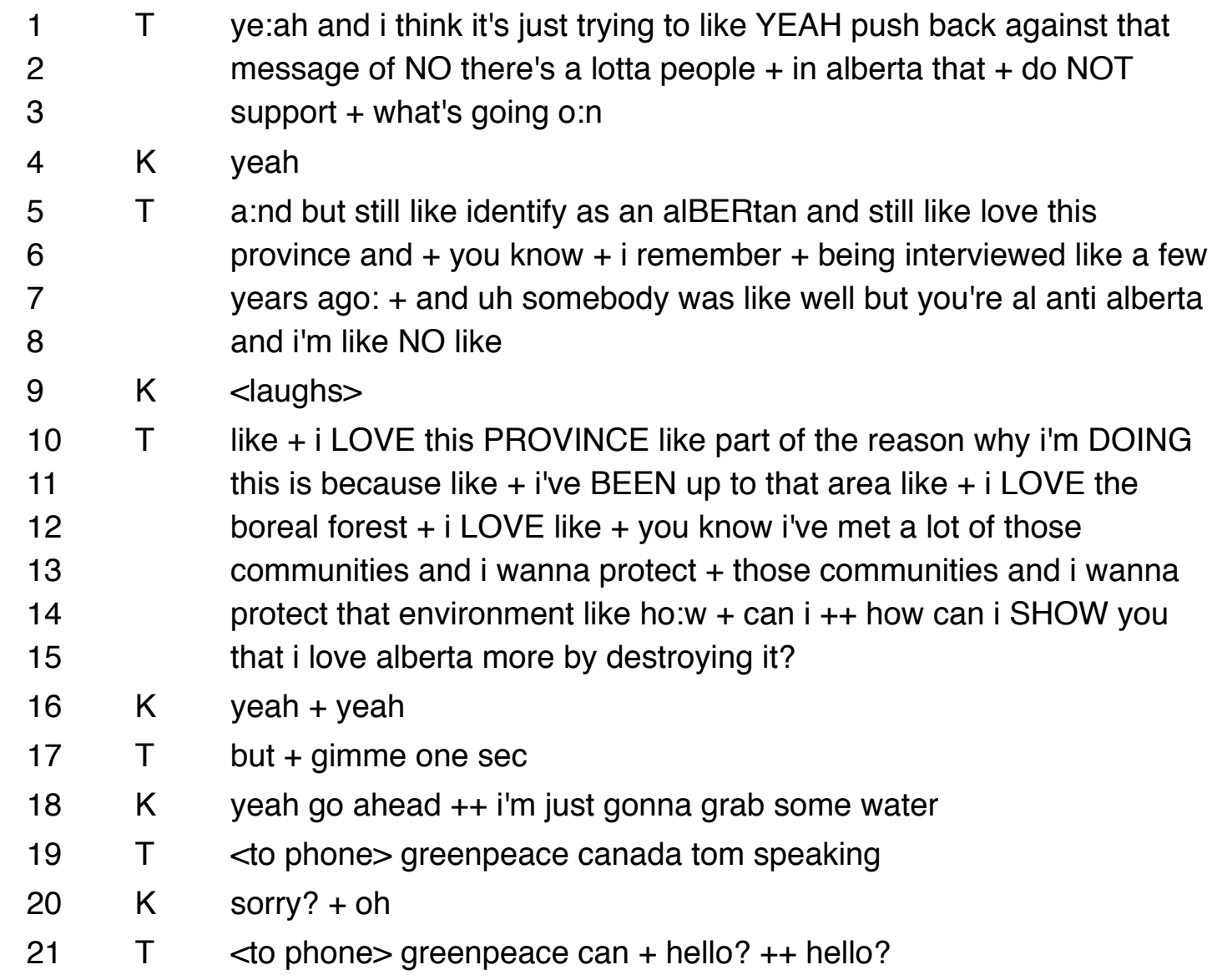

Tom expands on the motivation for using such a poster, as a way of pushing back against that message to show that there's a lotta people in alberta that do not support what's going on (1-3). He then to positions himself as an Albertan who does not support the tar sands through a personal story in which he is accused of being anti alberta during an interview (6-8). Tom then articulates an alternate Discourse of Albertan identity in lines 13-21: he challenges development because he in fact loves this province (10), because he loves the boreal forest and its people and wants them to be kept safe (10-14). In this description, Tom uses rhetorical repetition to highlight his point (cf. Fozdar, 2008). If we examine this discussion multimodally, we can see how this final statement becomes the crux of 
Tom's argument.

Throughout the exchange, Tom continuously orients to me with both his gaze and posture for agreement. I backchannel multimodally with utterances, facial expressions, and copious nodding as I listen (see Van Leeuwen, 2014). Many of Tom's gaze shifts can be interpreted as reducing cognitive load (Rossano, 2012) on some very complex statements about identity politics. For example, while explaining his love for Alberta in lines 10-15, Tom alternates his gaze between me, and the middle distance at least six times. This interpretation is strongly supported by the numerous pauses and hesitations which we see in Tom's utterances (e.g. lines 5-15).

When I met with Tom, he had just returned from an activist event and was awaiting media interviews. Because of this, his phone becomes an object which demands attention at various times during our interview. However, Tom's level of engagement with his phone varies depending on his attention to our discussion and, presumably, the importance of the call. For example, earlier in the discussion, he spent some time multi-tasking with the phone while I was talking, as illustrated in Figure 5.6. This could be due to the fact that I had the speaking floor and that Tom is better able to listen and check his phone than to speak and check it. Still, we can see that his lack of attention causes me to begin gesturing and gazing in his direction in an attempt to regain his attention (cf. Bavelas, Chovil, Lawrie, \& Wade, 1992).

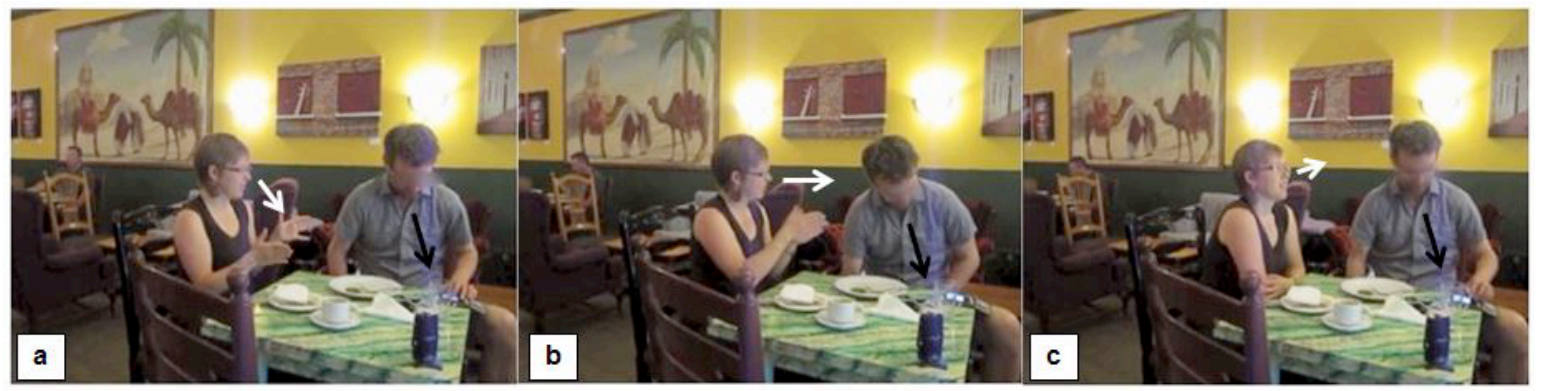

Figure 5.6: Tom 
First, Tom moves his gaze from myself to his phone, which has just lit up. In an attempt to regain Tom's attention, I begin gesturing widely, while also gazing at the phone (a). After 9 seconds, Tom returns his gaze to me and then once again engages with his phone. Next, we can see through his body posture that he is leaning in to me while reading the phone screen (b). I am now directly engaging with Tom, both my gaze and gestures are oriented to him in another attempt to regain his gaze. Finally, Tom presses a button on his phone to disengage it before returning his gaze back to me and thus returning to the conversation (c). This small sequence shows how Tom's phone becomes important in the interaction early on and forces him to avert his attention.

In line 12 of Excerpt 5.4, Tom's phone lights up and distracts him momentarily from his utterance. However, he continues to speak while simultaneously checking the phone:
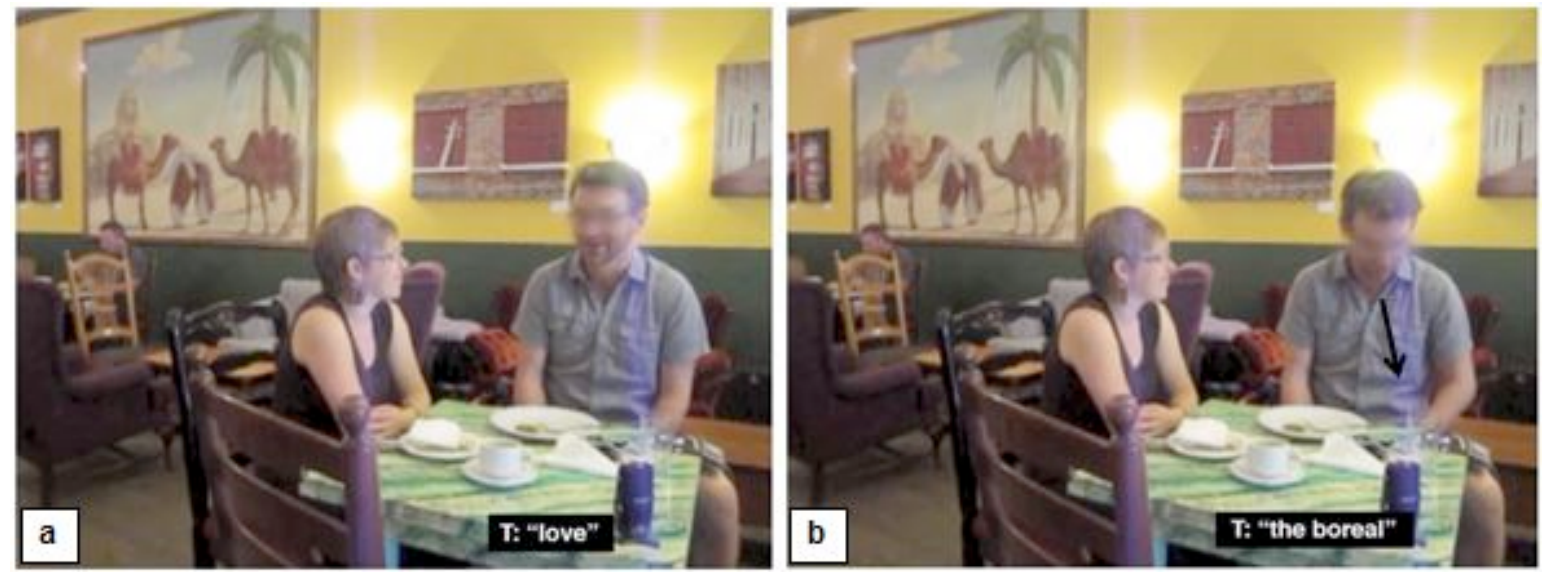

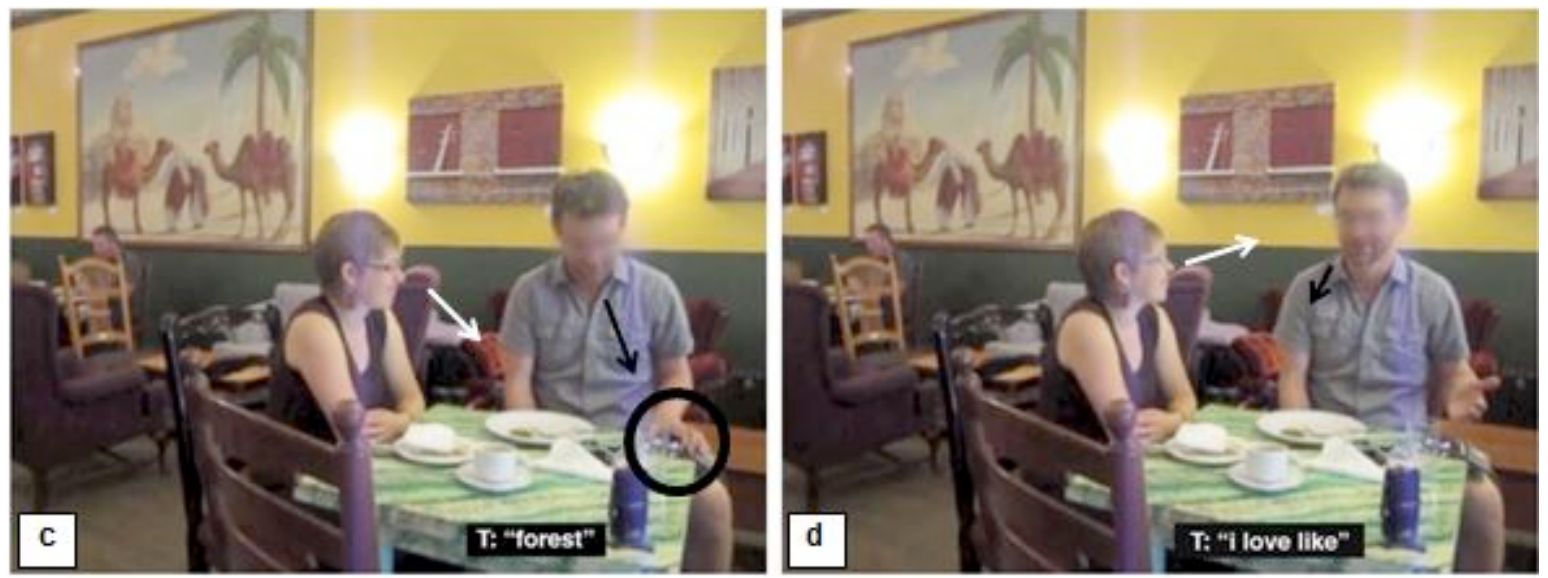

Figure 5.7: Tom

While speaking, Tom momentarily looks to his phone (b) and presses a button (c), presumably deferring a call or text. The fact that Tom stopped the interruption in order to finish his point allows him to focus attention on his argument, bringing it into the foreground of our interaction (Norris, 2011). At this point, Tom has moved his hand up on to the table (d) and he begins to gesture with it in the next few lines. These gestures are mostly emphatic beats, however, he utilises a performative iconic gesture (Kendon, 2004; McNeill, 1992) in line 14 when he says how can I show you. This is preceded by a pause and a shift of gaze to the middle distance, presumably in contemplation of the utterance (Figure 5.8).
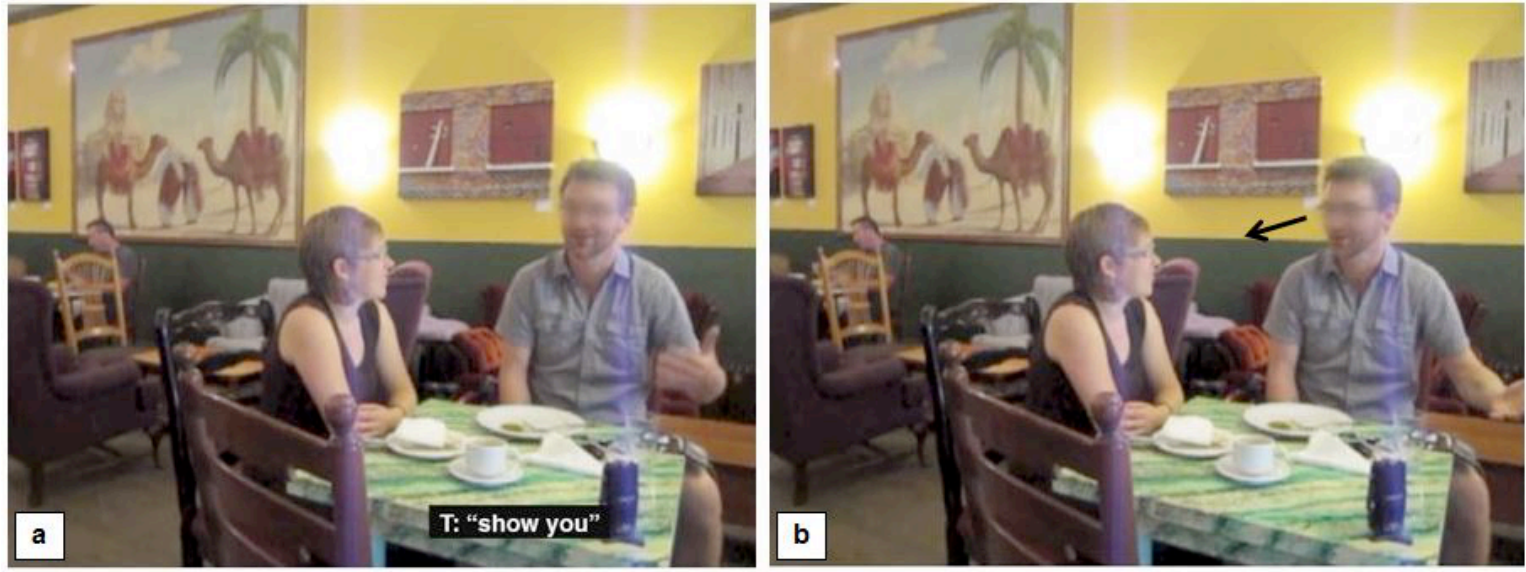

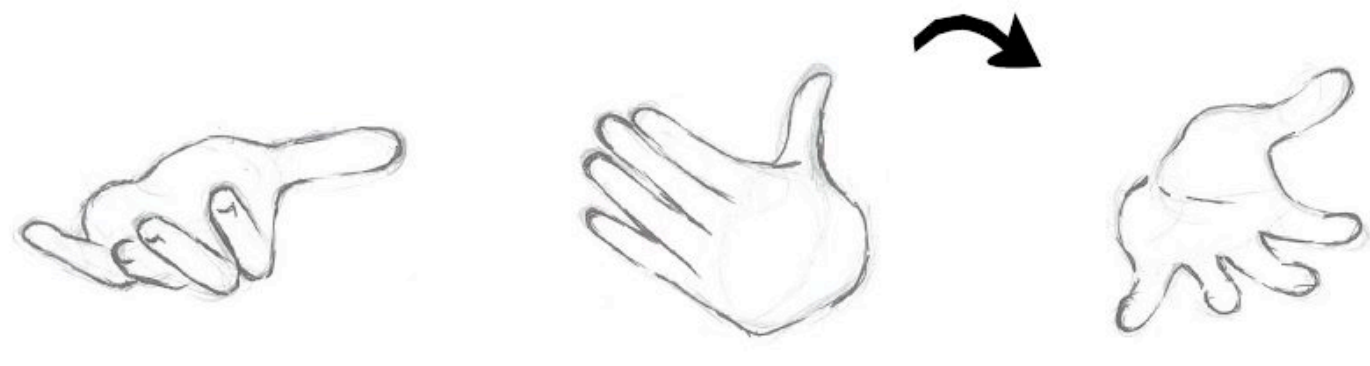

how

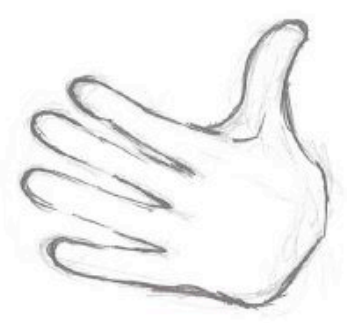

can i

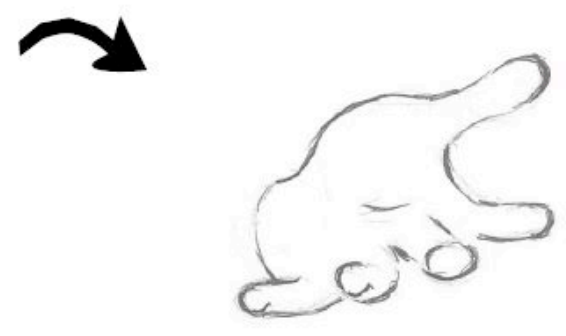

show you

Figure 5.8: Tom

The gesture accompanying show uses an open hand (Kendon, 2004) to metaphorically present to me the love for Alberta that Tom is discussing. Through the gesture and the word choice (how can i show you that i love alberta more, by destroying it?, 14-15), Tom demonstrates how he feels he must show his love in some way. This suggests that, for Tom, supporting oil development which destroys the land and people is the wrong way to display love for the province. In this short example, Tom seems to embody an understanding of his alternative regional identity (that of an Alberta who resists tar sands), which is held in opposition to the dominant identity (that Alberta is oil).

Finally, as Tom finishes his utterance in line 21 , he re-orients to his phone and takes the call that he had turned down a few seconds before (Figure 5.9, a-b). 
As he gets up to take the call, I also get up to replenish our water (c).
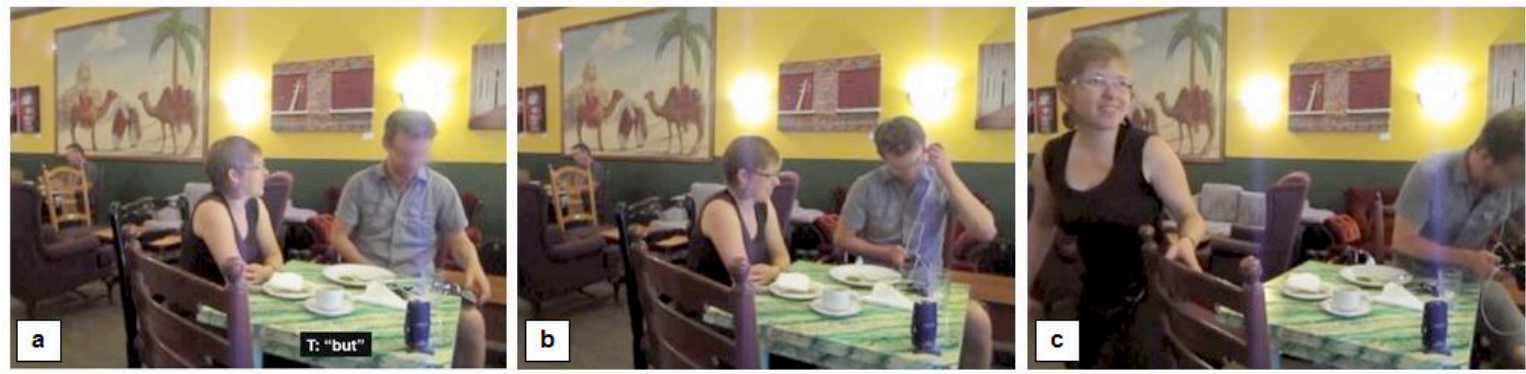

Figure 5.9: Tom

This short series of excerpts demonstrates the alternative identity

Discourses which Tom constructs. He seems to suggest that a 'true' Albertan is one who loves the land and the people and who therefore wants to protect them, as opposed to continuously supporting the oil industry. This is not to say that Tom rejects individuals who take up the dominant 'Alberta is oil' identity. On the contrary, he shows great understanding and compassion for people who are struggling to negotiate their wishes and the difficult identity positions they are forced to take (it makes it really tough for people to speak out, to grapple with all that, Excerpt 5.3, 23-24). Like Marcelo, Tom highlights the uneven power distribution in the province which allows industry actors to work in their own self interest, leaving the 'typical' Albertan caught between supporting oil development and wanting to resist it (they wanna be critical, but either they depend on it or they know people that are in the industry, Excerpt 5.3, 17-19). Tom's final utterance in lines 10-15 of Excerpt 5.4 ( $i$ love this province...) present an alternative Albertan identity that does not rely on oil support but that instead allows citizens to embrace a love for the land and people. In this way, Tom recognises the 'Alberta is oil' Discourse and rejects it, providing in its place a new version of what it means to be Albertan.

\subsection{Multimodal Entextualisation: Purely Albertan}

As we have seen, 'Alberta is oil' is a Discourse which has been oriented to by activists in my interviews, with Tom even providing an alternative identity Discourse in resistance. Yet, if we consider Excerpts 5.1 and 5.2 with Marcelo and 
Jill, it is apparent that 'Alberta is oil' is also oriented to without explicit discussion of alternatives. It would be folly, however, to assume that this equals a tacit endorsement. As in the previous example, if we extend our analysis to include the accompanying multimodal features, we can better understand what is happening when people mention 'Alberta is oil'. Using a variety of modes, speakers can contextualise an utterance to be interpreted a certain way and may encourage a critique of the Discourse, rather than simply repeating it (Blommaert, 2005): in other words, they multimodally entextualise 'Alberta is oil'.

This is exemplified in discussion with Andrea (who operates a community art organisation). Tina, Andrea and I are discussing Andrea's idea for an art exhibition that would feature pieces painted with bitumen collected from oil spills around the province (referred to earlier in section 3.4):

\section{Excerpt 5.5 Andrea and Tina}

\begin{tabular}{|c|c|c|}
\hline 1 & A & whatever then we'd either have the pieces that we keep in our \\
\hline 2 & & collection with everything else or we'd try and sell them for an actual \\
\hline 3 & & fundraiser cus i mean + e.s.p.a. needs the money the ar the ARTISTS \\
\hline 4 & & i know need like you know everybody's starving right now right? \\
\hline 5 & $\mathrm{~T}$ & uh //hu:hl \\
\hline 6 & A & $\begin{array}{l}\text { /soll you could just do it as a joint fundraiser and it's also like + } \\
\text { purely albertan + right? }\end{array}$ \\
\hline 8 & A & I+ so <laughs $>11$ \\
\hline 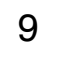 & $\mathrm{K}$ & /yeah <laughs> yeah purely albertanll \\
\hline $\begin{array}{l}10 \\
11\end{array}$ & $\mathrm{~T}$ & $\begin{array}{l}\text { /that's a great idea }+ \text { yeah }+ \text { I'm } \backslash \text { i'm imagining the smell in the gallery } \\
\text { though? }\end{array}$ \\
\hline 12 & A & I/+ well + well \\
\hline 13 & $\mathrm{~T}$ & Iof all that oil cus it\\
STINKS \\
\hline 14 & A & well hey \\
\hline 15 & $\mathrm{~T}$ & and you could USE that \\
\hline 16 & A & yeah //exactlyl \\
\hline $\begin{array}{l}17 \\
18\end{array}$ & $\mathrm{~T}$ & $\begin{array}{l}\text { /you could youll you could you this is what this is what it smells // } \\
\text { like + it smells like a gas station }\end{array}$ \\
\hline$y$ & A & /exactly + that should be exploited \ \\
\hline
\end{tabular}


Andrea first presents her thoughts on the exhibition and how it could be used as a fundraiser for under-funded activist groups and artists (1-4). Then, she describes the exhibition as purely Albertan (7). By using this phrase, Andrea highlights the 'Alberta is oil' Discourse in a similar way as Jill through her metaphorical 'steeped' construction. In other words, because the defining feature of the exhibition is its materiality (see section 3.4 and also Figure 3.7), it is this materiality (i.e. oil) that becomes defined as purely Albertan. Yet, her spoken utterance does not entirely account for the reaction from Tina and myself (9-10) and, in order to understand what has happened we must examine her multimodal actions. In the following analysis, we can see how Andrea builds up modal density through her head movement, gaze, and facial expression (Norris, 2011) during the pause directly before she says purely Albertan.

For most of the excerpt, Andrea is in the conversational position visible in Figure 5.10 , addressing both myself and sometimes shifting her gaze to Tina (who is sitting across the room and silhouetted by the lighting).

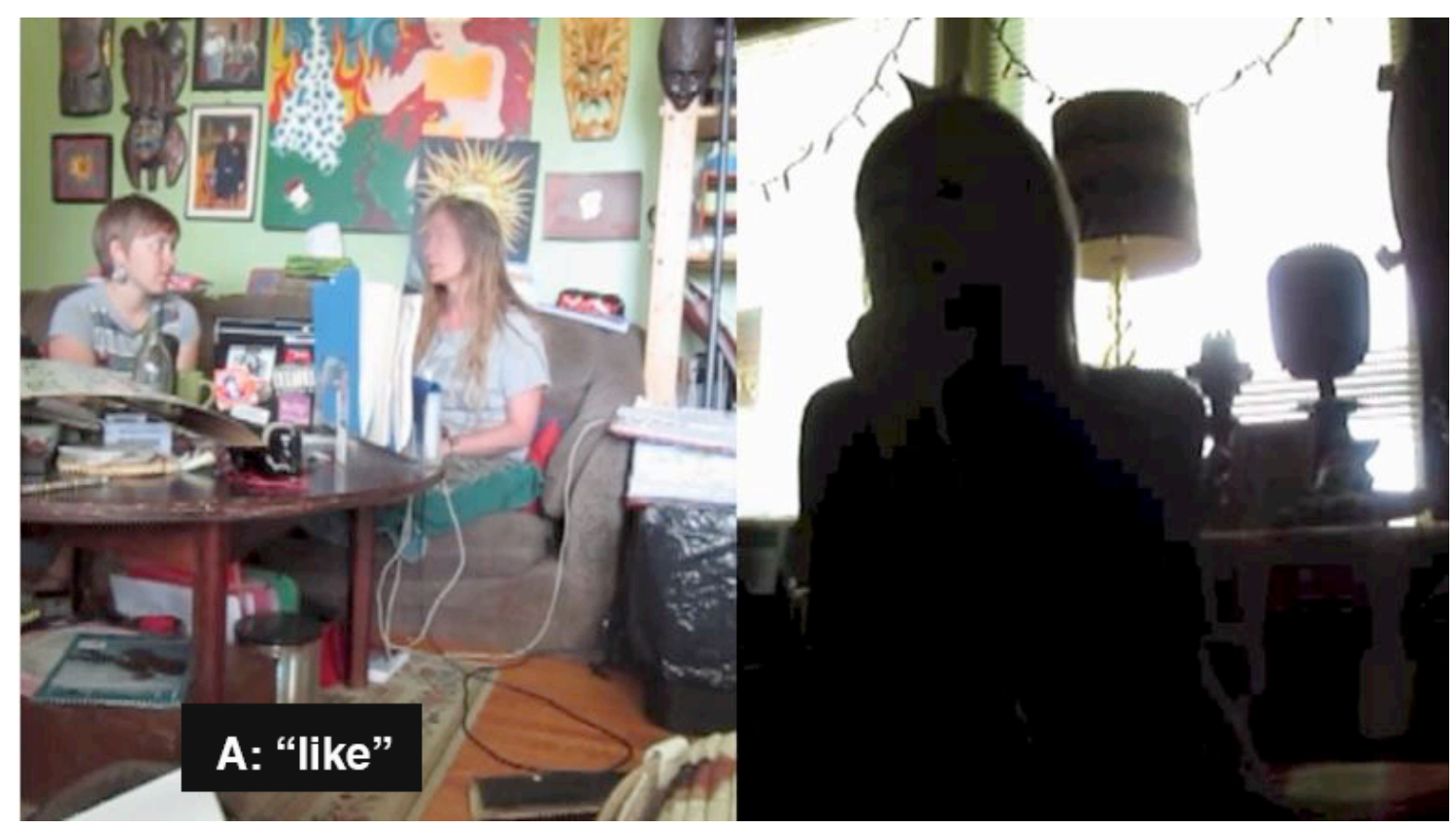

Figure 5.10: Andrea 
After a long turn, Andrea says like and then pauses (6) (see Figure 5.11).

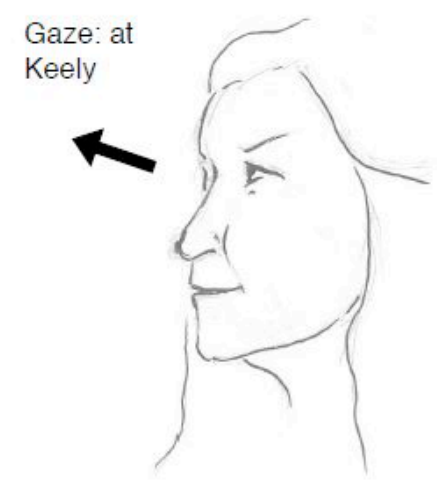

like
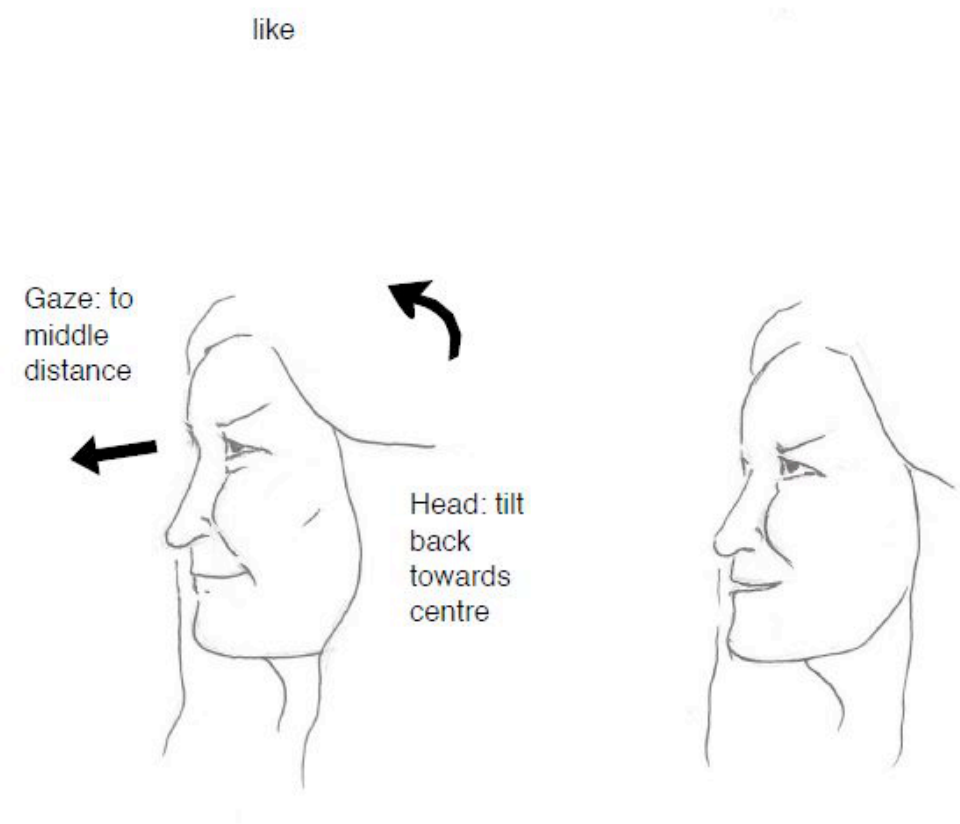

purely albertan

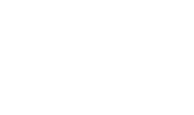

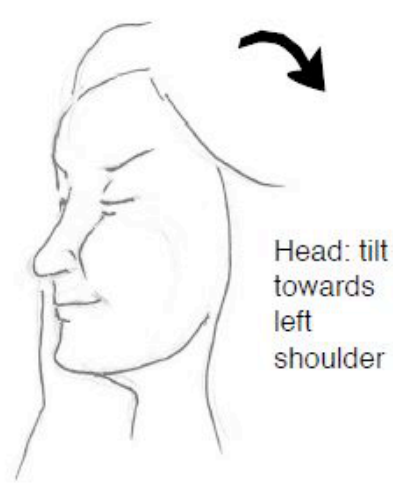

towards

eft

houlder

\section{Figure 5.11: Andrea}

During the pause, Andrea shifts her gaze away from me and to the middle distance. She simultaneously pulls in her chin, tilts her head down and slightly to the right, and smiles with her lips together. Andrea brings her head back up to where it was, but her chin is still pulled in slightly and she continues to gaze to the middle distance. She then says purely Albertan before shifting her gaze back to me. After adjusting back to the original conversational position, she says right? 
In this short pause, Andrea uses a number of communication devices, such as gaze, head movement, and facial expression. By layering modes and increasing the modal density (Norris, 2004b) before the phrase purely Albertan, Andrea draws special attention to it. First, by gazing into the middle distance, she allows for possible thinking time, while also directing attention away from Tina or myself. We might read this as acknowledging a more general idea, as if the Discourse she is about to reference is present as a fourth interlocutor. Her facial expression provides clues as to how she evaluates it: her smile is tight-lipped, closed, and narrow and she draws in her chin and tilts her head slightly. This facial expression seems to be emotionally presented in order to index a stance of disapproval or distaste (Bucholtz \& Hall, 2005). These subtle movements all co-construct an interpretation for her phrase, as if she is orienting to an unpleasant idea.

Andrea's multimodal ensemble (Kress, 2011) provides additional clues as to how she wishes this phrase to be interpreted, and as a result both Tina and I respond with laughter and praise (lines 8-9). This is not a simple repetition of the 'Alberta is oil' Discourse, but seems to be a comment about it. We might consider how this utterance would be interpreted without the silent pause, and therefore without the contextualising multimodal features: you could just do it as a joint fundraiser and it's also like purely albertan, right?. The critique of 'Alberta is oil' is not as strong, as it misses the more explicit features that seem to tell us how to interpret what she says: her gaze to the middle distance, her tight-lipped half-smile, and the slight nod with chin drawn in. Additionally, the reaction from myself and Tina suggest we have interpreted Andrea's potential evaluative meaning, as we both simultaneously erupt into laughter and praise. In fact, I even repeat the phrase while nodding and smiling (see Figure 5.12). 


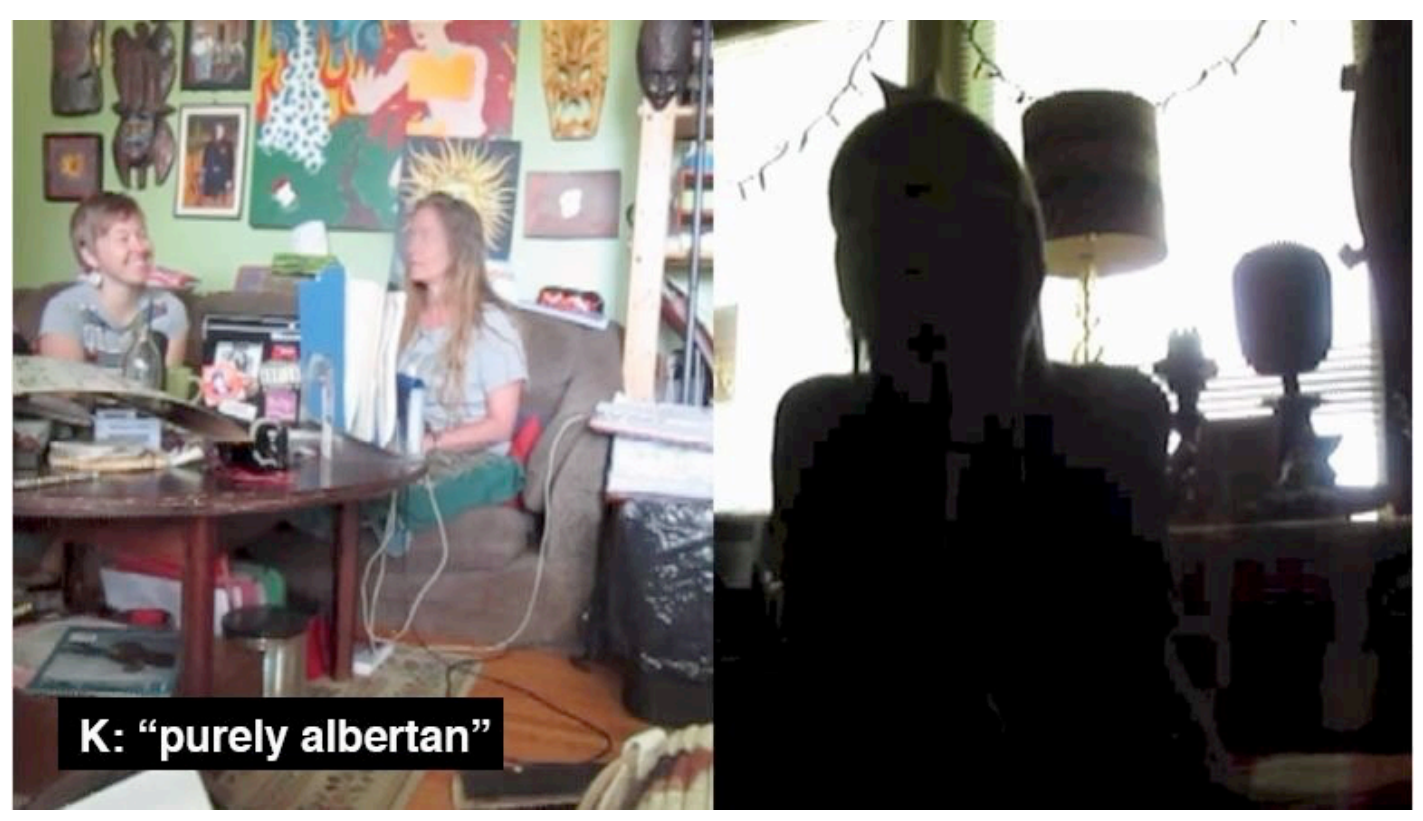

Figure 5.12: Andrea

In this short example, we can see how multimodal actions might be used to provide interpretation clues for an utterance. Within the context of Albertan identity Discourses present in both collected artefacts and previous interviews, Andrea references 'Alberta is oil' and arguably provides a critique on it. She in fact appropriates and re-contextualises the Discourse through her multimodal actions. In this way she uses a dominant, restrictive identity construction to create a multimodal Discourse of resistance.

\subsection{Southland Identities: Close-knit, Rural Farmers}

The multimodal appropriation and resistance of regional identity Discourses is also evident in Southland. As an outsider, I approached the community with little knowledge of local identities, and my development from a place of ignorance to a stance of understanding is documented through my field notes (Blommaert \& Jie, 2010 , p. 23). There are a number of aspects of the Southland identity which slowly became clear to me as I engaged in work and life amongst the community and, after four months of traveling to and from the area, I was able to articulate 'Southlandness' to some degree. Below, I outline various Discourses of Southland 
identity; as hard-working rural farmers in opposition to urban regions, and as communities characterised by dense social networks. I end with a discussion of 'tall poppy syndrome' and its relevance to communities of resistance.

First, Southland is a decidedly rural place, embedded in a "cultural tradition that associates nature and the rural with authenticity" (Law, 1997, p. 25). Like many areas in Aotearoa/New Zealand, this region relies mostly on farming for its economic progress. This was described in an interview with Alanis, a local government representative: we're a farming community, we thrive off farming, without farming southland wouldn't be the region that it is.

Fittingly, my first interaction with the community took place on a sheep farm where I was tasked with constructing and maintaining composting waste facilities (see section 3.2). Following ethnographic practice (Blommaert \& Jie, 2010), I endeavoured to help in any way I could. This meant that I was cooking dinners, setting up for events, digging gardens, and even at times swinging a hammer:

There's a sense of regularity to the work day all over Southland - morning work and then tea, work and then lunch, work and then tea, work and then dinner. (April 26, 2012, FN)

\section{Dawn}

@ThisPhD

\section{I love returning from research trips with dirt beneath my fingers \#awyiss}


I soon recognised that this work was a core community value:

There is a value placed on hard workers. Because I am willing to roll up my sleeves and do whatever job is asked of me, without complaint and to the best of my ability without dawdling around, I am taken much more seriously. I could read from Mark pretty early on that he values hard work over much else, and my time spent working on the toilets (though exhausting) was not unnoticed. He constantly brings it up... I've learned early on that fitting in and becoming part of a community often involves just being a pair of hands. I feel my willingness and ability to do physical labour counter-acts my perceived "laziness" of being an academic - Mark often remarks about the lack of usefulness of student life, or I guess the lack of application and practicality. Hard work also seems to be a Southland cultural value, where my ability to interact with Southlanders somewhat relies on my ability to do work with them, as one of them. (April 26, 2012, FN)

By applying myself to this work and by being willing and able to do physical labour, I was quickly welcomed by my Southland hosts. This became apparent in subsequent discussions with farmers in the region, who remembered well my work as the 'toilet lady'. For example, Mark described how he really expected a couple guys or three guys that have a bit of experience in, knowing how to use saws and hammers and stuff like that to knock together a decent set of toilets. However, he found that there were not enough people to do physical work, and that many people feel it's almost as if it's beneath them. He then said it was great to see you come down here and get so involved in the toilets.

In addition to Southland's rural identity, there is an accompanying regional aesthetic (Law, 1997). Described as a region made up of conservative, national voting farmers, and jokingly as rural hicks, by some of my (Southland) participants, Southland identity partly draws upon wider Discourses of political preference and independence as a region. In addition, many Southlanders I talked to expressed a distrust, and sometimes hatred, of urban New Zealanders. This was most notable 
in the case of Aucklanders ${ }^{7}$ who, for many, represent quintessential 'city folk', and tend to be brought up in opposition to rural farmers. This is exemplified in my interview with Justin, a campaigner from outside the region who agrees that outside voices are often dismissed, but it is particularly aucklanders with anyone anywhere in the country. He then tells a story about being labeled from auckland during an interview, which put him in an awkward position (i'm quite aware of how that's perceived to people watching it).

I personally experienced this attitude towards Auckland during a fieldtrip to the region. I asked the bus driver to let me off at the corner of the road to the farm where I was staying. As it turns out, this was the very same driver who was working when anti-coal activists came from around the country for the festival on Mark's property:

You wanna go to the lignite then. I dropped all them off further up the road. They come down here from Auckland and I say do you know much about what we do down here? No. Well, what are you doing here? Protesting. Go back to Auckland and protest. (March 17, 2012, FN)

Southland identity is in part constructed in opposition to the urban, business identity symbolised by Auckland. In the above example, Aucklanders are presented as ignorant of southern rural lifestyles and meddling in issues they do not understand (see also Grant, 2012, p. 171), highlighting the differences with Southlanders (see Bucholtz \& Hall, 2005, p. 599).

Like many rural areas, Southlanders construct their regional identity based upon the values of small, tight-knit community networks (Milroy \& Margrain, 1980, p. 48). During an interview with Molly (a local in the anti-mining group), she discusses how she first joined the opposition group and describes some of the early conversations they had about organising the anti-mining festival:

\footnotetext{
${ }^{7}$ Auckland is the largest city in New Zealand, and is stereotypically considered the central business hub of the country (cf. Nielsen \& Hay, 2005).
} 


\section{Excerpt 5.9: Molly}

1 M and then they started talking about the camp and they had all these

2 high () ideas about what we're gonna do and everything and i kept

3 saying but this is southland + you know + and we'll have to hire

4 marquees and we'll have to but i said but this is southland we can get

5 all this stuff for free

$6 \quad \mathrm{~K} \quad$ //uuhl

7 M /there's thell scouts and + you know + <laughing $>$ they didn't beLIEVE

8 me i'm sure <laughs>

$9 \quad \mathrm{~K} \quad / / y e a: h$ you were amazing

$10 \mathrm{M} \quad$ /and i spent a:III this time //networking \with people that i knew + that would give us stuff for nothing

$12 \quad \mathrm{~K}$

/<laughs $>11$

Molly explains that the organisers had all these high ideas about sourcing items and that she kept saying but this is southland (1-3). She then repeats the organisers' voice (we'll have to hire marquees, 3-4), and her point (but this is southland, we can get all this stuff for free, 4-5), suggesting that her advice was initially ignored. Molly then begins listing resources (there's the scouts and you know, 7), which in effect demonstrates to me that she does in fact have contacts for such items. She laughs and exclaims that they didn't believe me i'm sure (7-8) to which I reply that she did an amazing job (9). In the last utterance, Molly describes how she was able to draw upon her extensive networking to get stuff for nothing (10-11). In this way, her local knowledge and Southland connections aided the national organisers.

This 'neighbourliness' is oriented to discursively, but also through action. This was most noticeable to me when staying with Molly and witnessing the interaction work she does. For example, Molly not only talks about these myriad interactions with people in the region, she also enacts them during our conversations. Our interviews were continually interrupted by emails and phone calls as she sorted her schedule. During my day with Molly we attended the local sheepdog trials, helped a school group plant a garden, tutored maths in a 
community education centre, attended a concert, and stopped by a friend's house for tea. My time spent in her company exemplifies the ways in which being a 'Southlander' seems partly to be constructed in an embodied way through networking and relationships (cf. Norris, 2011).

Dawn

This trip so far: gardens, log splitting, crutching, sheepdog trials, school permaculture, homemade toasties, art gallery, trains \#research?

4:34 PM - 26 Apr 2012

In common with wider New Zealand culture, Southlanders also orient to the 'tall poppy syndrome', a concept based on egalitarian values where individuals avoid demonstrations of power or influence (Holmes, Marra, \& Vine, 2012, p. 1067). In my data, the tall poppy syndrome is conceivably indexed (Bucholtz \& Hall, 2005) by a local farmer explaining that southlanders don't like to create waves.

Southlanders, he argues, will avoid giving an opinion: rather than sit and say this person's talking a load of crap, they don't, that's what needs to be said but they won't say it.

In my interview with Justin (Excerpt 5.10), he also describes the tall poppy syndrome as a hesitation to stick your head out (3).

Excerpt 5.10: Justin

$1 \quad \mathrm{~J} \quad$ i think particularly + southland $++<$ brushes mouth with hand $>$ possibly

2 more + well + no + probably anywhere + rural or provincial + new zealand ++ to kinda stick your head out <head moves up $>+$ is a bit + is quite difficult so + you know $+\mathrm{i}$ imagine down there it's + particularly so 
Here, Justin points out that this is common all over New Zealand in rural or provincial areas (2), but that it is especially so in Southland (4-5).

Although we might also interpret this as avoiding conflict with co-workers and neighbours, Justin embodies the tall poppy idea during his utterance (stick your head out, 3) (Figure 5.13):
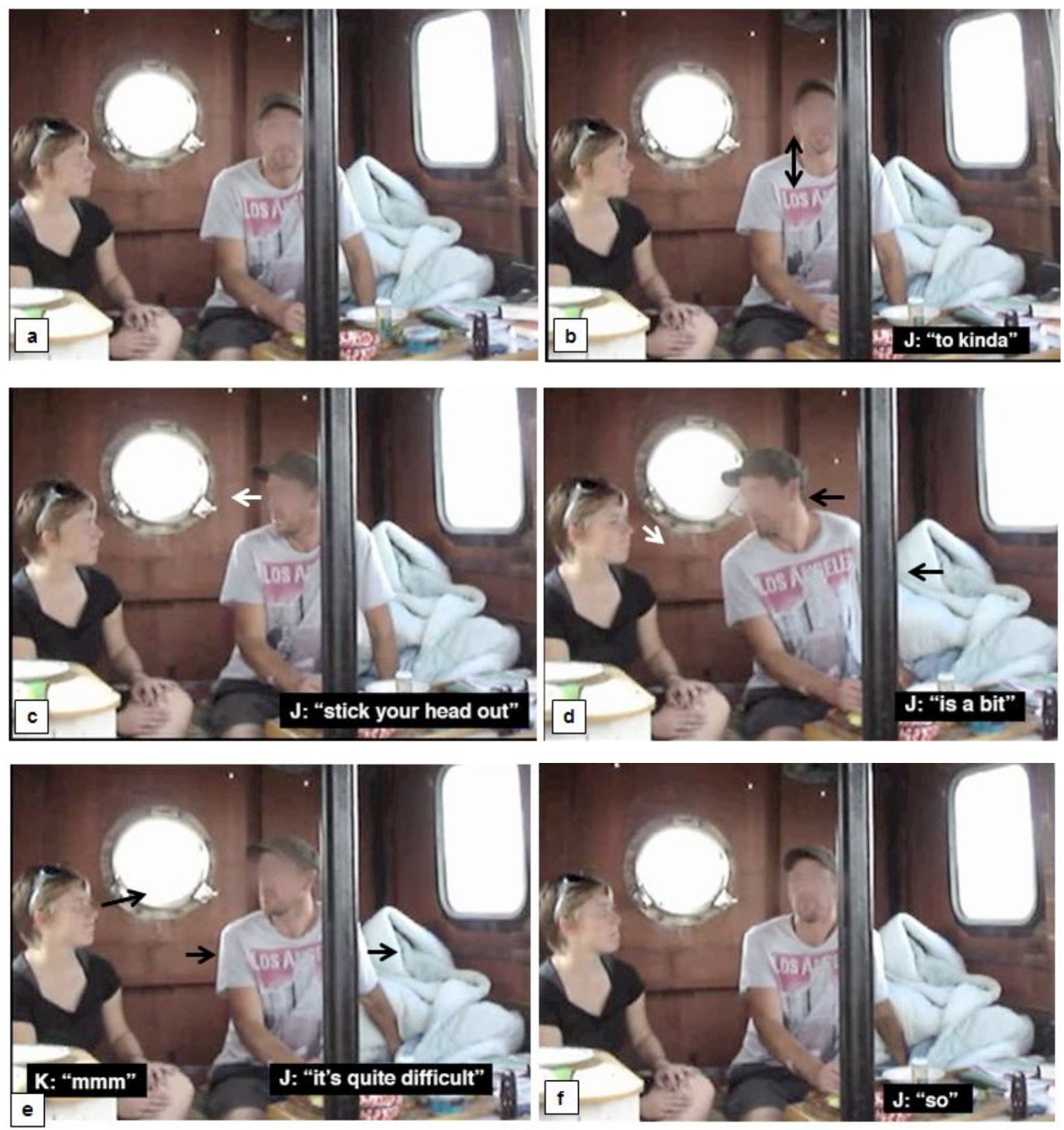

Figure 5.13: Justin 
Here, Justin briefly shrugs his shoulders (a) and then mimics sticking his head up as an iconic movement that helps illustrate his metaphorical point (b). Here is a possible representation of the tall poppy in action: the act of becoming conspicuously 'taller' than others (see Holmes et al., 2012). In keeping with McNeill's observations, the iconic movement precedes the utterance (a-b), thus anticipating speech (McNeill, 1992). Justin then gazes in my direction and leans in to me briefly (c-e) as I verbally backchannel $(\mathrm{mmm}, \mathrm{e})$. In this way, Justin uses posture and proximity, building up modal density to highlight the concept (Norris, 2004b).

I also discussed this issue at length with Amy, an American ex-pat living in the region with whom I stayed during fieldwork. Amy expressed frustration with the lack of directness from locals when it came to political issues such as the lignite debate and, during my stay, I witnessed an interaction in which the tall poppy syndrome seemed to be played out. Amy's husband Jeremy, who normally does not wish to 'stick his head out', engaged with a neighbour regarding the lignite issue:

It was interesting: Jeremy got a ride to the field days on Thurs. from a neighbour. When the neighbour came in, Amy introduced me and tried to give them each a protest button ${ }^{8}$ and the neighbour started in about how he's on the fence and Jeremy said, uh oh, here goes Amy, she'll convince him otherwise. Amy asked what he was unsure about and the neighbour started explaining his stance. Then, Jeremy actually jumped in and took over convincing him - it was the fact that the lignite would be creating urea that got him. Jeremy took the button and put it on and the neighbour's wife did too but the neighbour didn't. Jeremy left for the field days with the button on his shirt. My analysis is that Jeremy uses Amy's outspoken personality (and American cultural traits) to hide behind when he is unsure in these tense situations and allows Amy to "open the door" to the conversation so to speak. Once Amy has approached the subject and warmed up the issue, Jeremy feels free to jump in and take over, becoming more confident as he goes. (Feb. 14, 2012, FN)

\footnotetext{
${ }^{8}$ See Figure 3.6
} 
I remember feeling that Jeremy jumping into the conversation with his neighbour felt very marked (perhaps I was also picking up on the interlocutors' reactions to help me realise this). It is worth noting that Jeremy's embodied action of putting on the button felt very impactful, as well as the fact that the neighbour's wife also took a button. In addition, Jeremy left the house wearing the button (whether he took it off later or not is unknown), which shows a level of commitment and public advertising of his stance on the issue which I had been led to believe was rare in the region. In further discussions with Amy, it came out that this was noticed by her as well.

In conceptualising the tall poppy syndrome, Amy also used the analogy of sheep farming, further indexing the Southland farming identity described above. She described how sheep being herded into a small space will simply continue circling until the right individual is found to lead them. This, explained Amy, was what needed to happen in Southland, as most people would not risk standing out amongst their peers.

My own identity as an Albertan becomes relevant in these interactions as well. There are many instances where I compare the situation in Southland to Alberta as a way to make sense of what is happening. Additionally, this identity presentation helped me to align with my interlocutors and create shared understanding (Bucholtz \& Hall, 2005). It was also quickly apparent that, upon first contact with local environmental activists, my previous work as an Albertan afforded me a level of 'activist prestige'. Due to recent campaigns (e.g. Davidson \& Gismondi, 2011, p. 179), the Athabasca tar sands have become an internationally known example of contemporary resource extraction conflicts. As an activist who has worked with tar sands-affected communities, it seemed that my entry into new environmental justice communities was met with a higher level of respect. Consequently, I felt it was somewhat easier to integrate as an outsider, due to the resulting legitimacy I brought from my experiences in Alberta. 
When we moved here, one day we went to the library for information on housing. We stumbled across a demonstration in Civic Square - it was the International Day of Action Against Extraction...I chatted with a guy about the tar sands (my first experience with the widespread tar sands fame). (Jan 16, 2012, FN)

In summary, the above discussion illuminates how the Southland regional identity is constructed. First, Southland is a rural region which relies on farming and its accompanying value of physical labour (actions which perhaps facilitated my opportunity to 'become a Southlander'). This is further constructed in opposition to Auckland as a place symbolic of urban New Zealand and ignorance of land-based lifestyles (Grant, 2012, p. 171). Additionally, like many rural places, Southland identity seems to be constructed through close networks and embodied as such through enacting relationships with others in the community. Finally, the 'tall poppy syndrome' was apparent in many of my interactions, where individuals avoid 'sticking their necks out' or standing out from the crowd. This has implications for those who seek support in their resistance to mining development.

\subsection{Multimodal Entextualisation: Wolves in Sheep's Clothing}

In this section, I discuss how these strong regional identity Discourses become appropriated as a discursive strategy to market the mine expansion to locals and how this appropriation is subsequently resisted. As a company that is not based in Southland, Terra Resources seeks to position themselves locally by appropriating aspects of the regional Southland identity. For example, in Figure 5.14 , the company linguistically positions itself amongst locals: 
The footprint of a new mine in Southland to support a coal-to-fertiliser processing plant would be about the same size as $11 / 2$ average Southland dairy farms. It would include a buffer zone between the mine and our neighbours. Three hundred hectares of pasture would be out of operation at any one time. Mining would be progressively followed by rehabilitation, returning the land to as near a condition or even better than it was before.

Figure 5.14: Mining Footprint

Here, the proposed mine is described in terms of an average Southland dairy farm. This arguably indexes the farming aspect of Southland regional identity and locates the mine with dairy farms in the region. Its impact then becomes comparable to what is already there. In the following sentence, a buffer zone is described that would separate the mine from our neighbours. The pronoun and lexical choice (our neighbours) not only helps position the mine amongst other Southlanders as a regional inhabitant, it also seems to index the close networks that characterise Southland identity.

The appropriation of a local identity is also accomplished through multimodal means as in Figure 5.15 (with close-up). Taken from the same document, the mining process, from initial exploration through to rehabilitation, has been presented here as a drawing, with photos underneath. 
Images removed due to copyright

Figure 5.15: Mining Process

This layout takes advantage of the horizontal axis, positioning the drawing in the Ideal position (Kress \& Van Leeuwen, 2006) with a selection of photographs from each stage presented beneath in the Real position. Frames separate the images as they are aligned with the varying stages presented in the process above, implying vectorality and progression from left to right (Kress \& van Leeuwen, 2006). As viewers, we can see how the land is transformed from its original state presented far left, subsequently explored, mined, backfilled, replanted, and finally returned to a state of productivity (complete with sheep). The use of photography here increases its modality, arguably bringing authenticity (Kress \& van Leeuwen, 2006) to these actions - actions which can be proven through documentation. At each end of the progression in the drawing and the photographs we are presented with a before and after image, which present grazing cattle and sheep and thus further index the Southland rural, farming identity. In this case, what distinguishes the before and after image in the drawing is the presence of lignite which has been subsequently removed and replaced. Even the horizon has not changed and the landscape is left the same as it was before mining began: a Southland farm. 
Terra Resources also positioned itself as a local in a much more embodied way by holding a stall at the local Field Days. ${ }^{9}$ The stall was set amongst a variety of other organisations and companies (e.g. farming equipment, refreshments, government representatives, etc.) in a large field over a number of days. Visitors were greeted by representatives in suits, and the interior included leather chairs, wood paneled flooring, refreshments, and information panels about the company's activities (see Figure 5.16). In addition, a sandbox complete with digging toys was supplied for children (c), and visitors were encouraged to sign up and participate in a mining tour.

Terra Resources' Field Days stall appears distinct in comparison to other stalls in the event, with many consisting of hay bale flooring and fold up chairs. To describe the higher-level actions which have led to the layout of the stall and the accompanying clothing of the representatives, I propose the concept of a multimodal register, combining linguistic register with a multimodal enactment.

Through the use of business attire, leather chairs, flooring, and other items (Figure 5.16), Terra Resources uses a higher multimodal register to index an accompanying professional identity. This is in comparison with the other multimodal registers that are present at the Field Days, such as informal tents, casual dress (e.g. jeans and woolen shirts), and farming equipment displays (e.g. tractor pulls). At the risk of appearing out of place, or less 'authenticly' local (Blommaert \& Varis, 2011), Terra Resources instead multimodally invokes a higher order of indexicality (Blommaert, 2007b) to present itself as a professional authority.

\footnotetext{
${ }^{9}$ An outdoor farming exposition.
} 

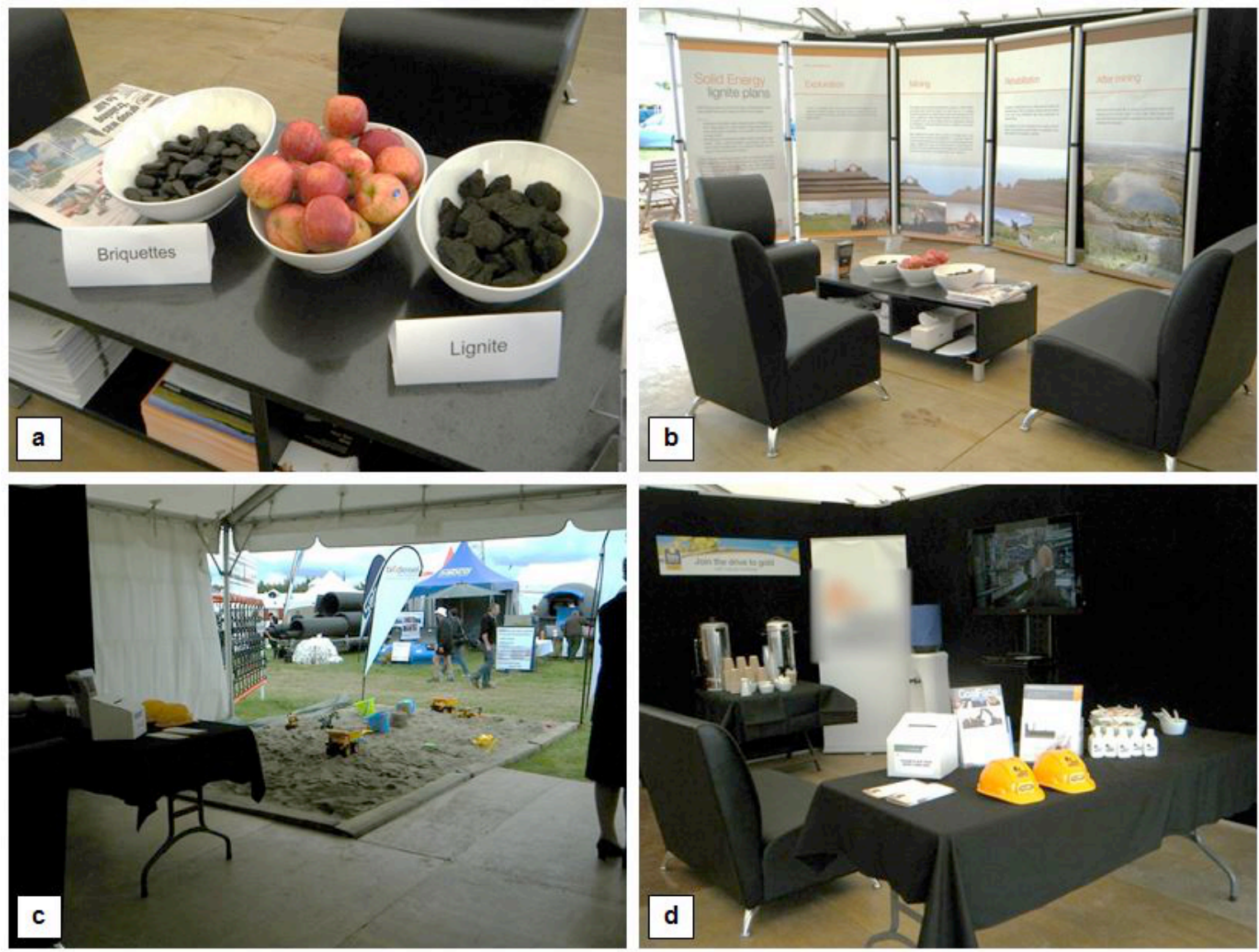

Figure 5.16: Field Days

During my visit to the stall, I was told that the company's presence was needed to counteract misinformation that was being spread by anti-mining individuals. In addition, I was told the stall represented a direct line to locals without filtration through media. The very presence of Terra Resources at the Field Days is an embodied positioning amongst Southlanders, which perhaps helps to mitigate the local inauthenticity of the multimodal display. Indeed, one of the few items to index a Southland farming identity is the bowl of apples (agriculture) which divides the two lignite samples (a): perhaps a token attempt at integrating into the Field Days aesthetic.

These identity constructions are not lost on locals who oppose the mine. In discussions with Amy, she expressed her concern that the mine might become a part of the local identity, as once this happened, the case for resistance would be 
lost. Locals also resisted the appropriation of local identity through the production of their own artefacts. Figure 5.17 shows two in a series of artefacts created by activists for dispersal at the Southland Field Days.
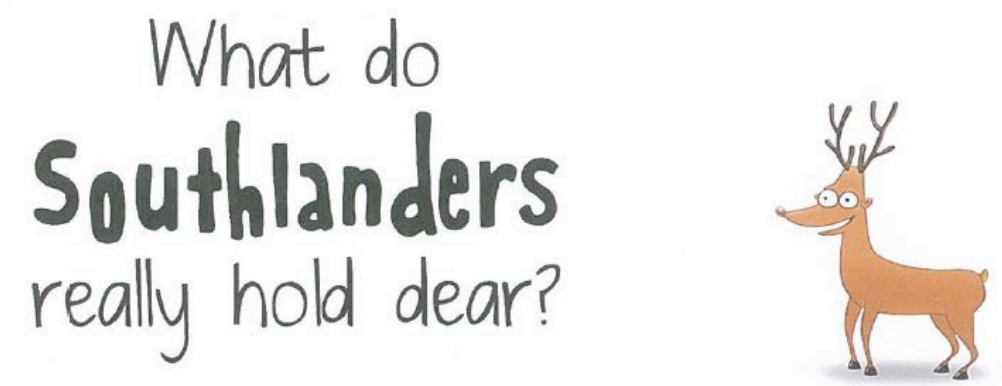

Do we really love the land? The 4,000 ha of good farmland already purchased by Terra Resources is clearly only a start - much more will be required to mine the billions of tonnes they are projecting. Crown Minerals calculate there is economically recoverable lignite under 61,000 ha of Southland.

Do we actually appreciate the wealth we have right now? Clean air. Clean water-and an ample supply of it! Friendships that have lasted for generations. Not much traffic. A wide variety of sporting opportunities. Low unemployment. If Southland becomes the largest mining operation in New Zealand, ALL of that will change.

Do we really value the security we have? We pretty much know what will happen tomorrow. We are not surrounded by uncertainty....except for the weather. We know our neighbours. There's not much crime. But when greed is disguised as progress and corporate ownership is disguised as opportunity, a family community is no longer secure. http://www.orataiao.org.nz/wiki/changes
http://www.pce.parliament.nz/assets/Uplads/PCE-Lignite-LGE-18-Aug-11.pdf
http://coalactionnetworkaotearoa.wordpress.com/ 

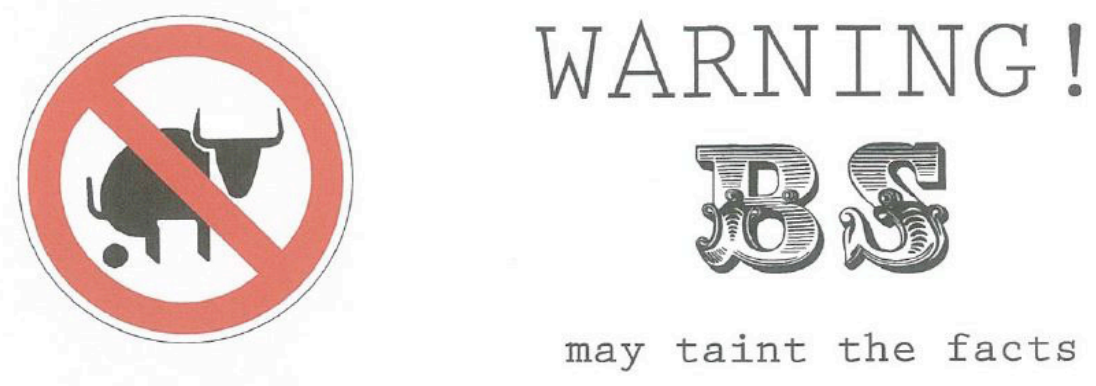

Once lignite mining occurs, the fertility and quality of the soil cannot be returned for over a hundred years. The seams of lignite can be 200 metres deep! Terra Resources (and its future partners) will earn their profits from tearing the land up, not replacing it. It would be a Bit Stupid to think everything was going be just like it was when they are done.

Our standard of living will decrease. We won't feel prosperous when we are worried about the quality of the water we drink and the air we breathe. It would be a Bit Stupid to imagine we'd feel "better off" when we are surrounded by constant noise. enveloped in constant dust, and silenced by the destruction of a once beautiful landscape.

Our community will be crippled. Families live on farmland. The wealth of the land is shared amongst those families. Those families employ local contractors and support the local businesses and schools. It would be a Bit Stupid to imagine that none of that will change when the land becomes a lignite mine operated by individuals who have little need for a community.

Figure 5.17: Southland Pamphlet ${ }^{10}$

Here we can see how Southland identity is constructed in a number of ways. First, the rural farmer identity is indexed through linguistic choices (Families live on farmland, wealth of the land, Do we really love the land?) and multi modally through the inclusion of livestock mascots ${ }^{11}$. Both artefacts make use of linguistic animal puns in the title accompanied by images to build up the modal density (cf. Norris, 2011) of the farming identity. For example, What do Southlanders really hold dear? relies on the homonym of deer, while Warning! BS may taint the facts references 'bullshit' as deception and misinformation as well as the excrement of cattle. In addition, Southlanders' close community networks are mentioned (We know our neighbours, a family community, Our community, the wealth of the land is shared amongst those families, local contractors support the local businesses and

\footnotetext{
${ }^{10}$ Artefacts reproduced with permission.

${ }^{11}$ Deer is commonly farmed in Southland in addition to cattle and sheep.
} 
schools), indexing another aspect of local identity. Amongst these constructions, Terra Resources is positioned in opposition (Bucholtz \& Hall, 2005) by highlighting the ways in which the company does not respect the rural farming lifestyle (The 4,000 ha of good farmland already purchased, the fertility and quality of the soil cannot be returned, will earn their profits from tearing the land up, the destruction of a once beautiful landscape, the land becomes a lignite mine) nor the community (a family community is no longer secure, our community will be crippled, operated by individuals who have little need for a community). This oppositional positioning is also evident visually in Figure 5.18:
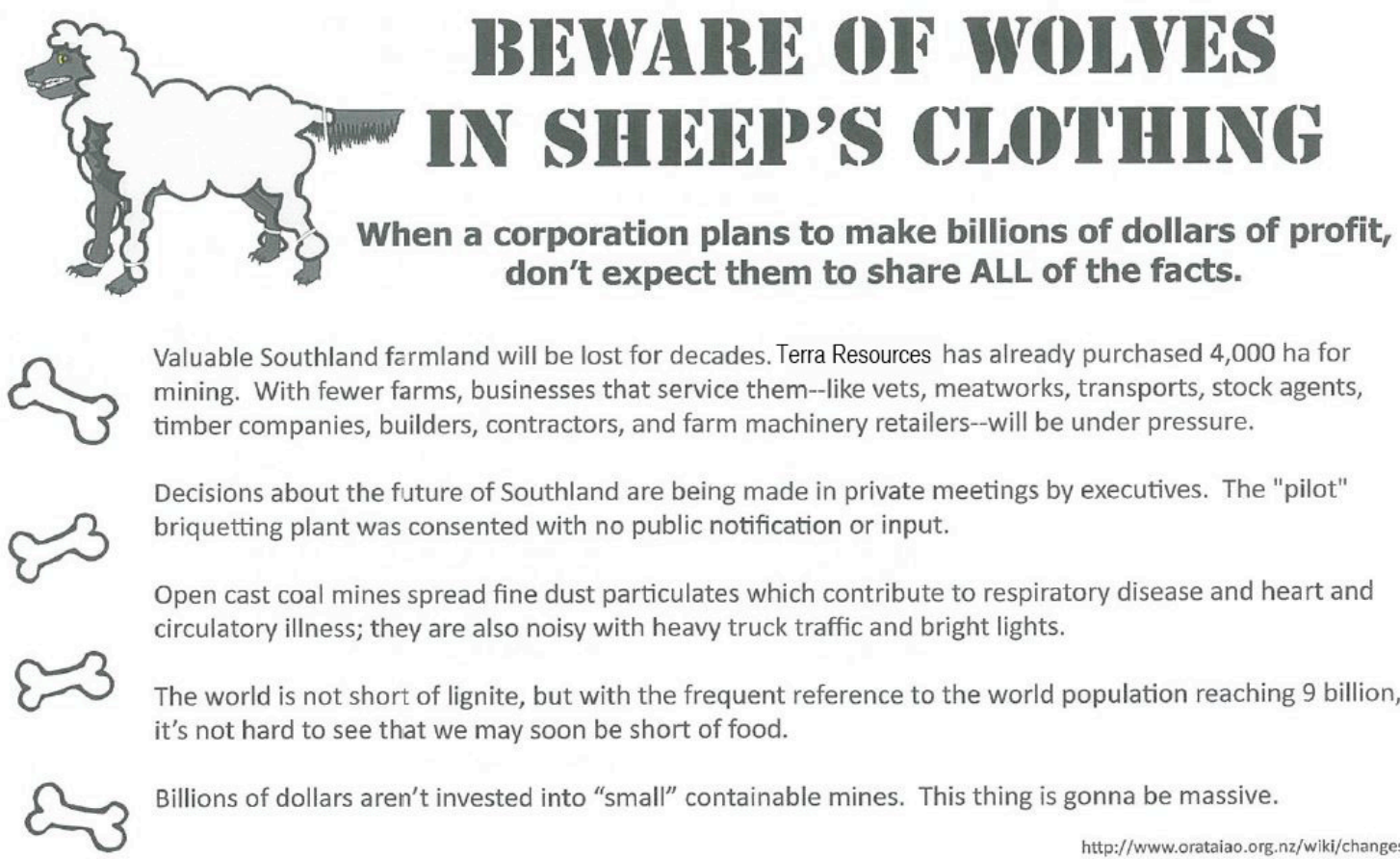

Valuable Southland farmland will be lost for decades. Terra Resources has already purchased 4,000 ha for mining. With fewer farms, businesses that service them--like vets, meatworks, transports, stock agents, timber companies, builders, contractors, and farm machinery retailers--will be under pressure.

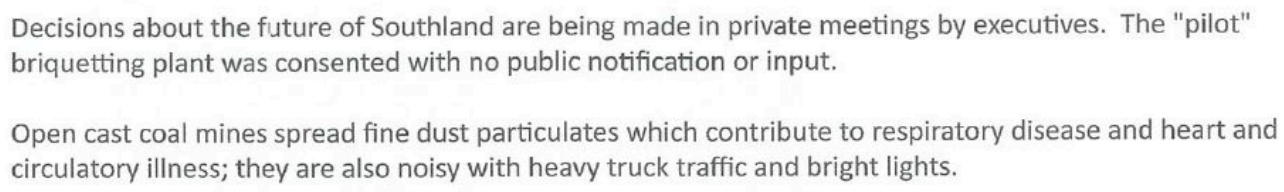

The world is not short of lignite, but with the frequent reference to the world population reaching 9 billion, it's not hard to see that we may soon be short of food.

Billions of dollars aren't invested into "small" containable mines. This thing is gonna be massive.

Figure 5.18: Southland Pamphlet ${ }^{12}$

Here, in addition to linguistic constructions similar to those outlined in Figure 5.17 (Valuable Southland farms will be lost, Decisions about the future of Southland are being made in private meetings by executives), the animal mascot

12 Artefact reproduced with permission. 
multimodally presents a visual metaphor (Forceville \& Urios-Aparisi, 2010). In the image, a wolf is dressed in sheepskin, complete with visible leg bands. The wolf's eye-line creates a vector over its back, leading the viewer to the title. It is in fact the title and subtitle which guide us in the interpretation of this image: the plural wolves indicates a group of individuals, who are part of a corporation. The subtitle assumes a local audience (Bell, 1984) who understands which corporation is implied (and it is only in the first line that the company name is used). Using these modes in tangent, the designers of the artefact build up modal density to construct a preferred reading. In fact, not only does this design position the company in direct opposition to the community, it also recognises Terra Resources' attempts to present themselves as a part of the community (represented by the sheepskin) and denaturalises the claims to authenticity (Bucholtz \& Hall, 2005, p. 602). Drawing upon ideas of the wolf and sheep as cultural symbols (Kress \& van Leeuwen, 2006), as well as the symbolic meaning associated with black and white (Van Leeuwen, 2011), this image also provides an evaluation of the situation: Terra Resources is dangerous and not an authentic member of the community. Thus, the appropriation and resistance of Southland identity becomes multi modally entextualised as a wolf in sheep's clothing.

We might also consider the overall multimodal register in this artefact, compared to the designs in Figure 5.15 and the display in Figure 5.16. This is partly due to differences in materiality, as the artefact in Figure 5.15 is printed in colour on glossy paper as a professionally produced and cut pamphlet. In contrast, Figures 5.17 and 5.18 are printed from a home machine on matte paper and cut by hand. This becomes relevant when we consider the ways in which the accompanying identities become authenticated ( Blommaert \& Varis, 2011; Bucholtz \& Hall, 2005). For example, how might the identity presentation of a professional company change if pamphlets were printed on a matte finish and cut by hand? What identities would glossy, professionally cut paper index for activists wishing to resist the mine? Indeed, a 'homemade look' may be advantageous and in alignment with the rural Southland identity that is claimed in Figures 5.17 and 
5.18, whereas a professional image (Figure 5.15) may be more advantageous in promoting the mine, even at the risk of seeming locally inauthentic. The materiality of the artefacts also reveals information about financial resources, access, and relative power (Van Dijk, 1996). In certain contexts, the use of inexpensive materials can serve to highlight the lack of power the community holds when confronting the company, positioning them as worthy of sympathy and support.

\subsection{Appropriation, Resistance, and Entextualisation}

In the previous analyses, I have shown how regional identities are in part constructed and appropriated by industry actors in an attempt to promote mining activities. Most explicitly, in Alberta, the 'Alberta is oil' Discourse is actively and multimodally constructed, while Southlanders are multimodally constructed as rural, farming, tight-knit communities. In both cases, regional identity is a strong discursive resource for both industry actors and activists.

What then, does this mean for the appropriation, resistance, and entextualisation of Discourses? As evidenced by the artefacts in section 5.2, we can see how Albertan identity has been appropriated using the 'Alberta is oil' Discourse. This identity construction and its accompanying constraints (Blommaert, 2007b), arguably benefit the oil and gas industry by framing support for development in the province as something that is quintessentially Albertan. This then forces critical Albertan citizens to formulate arguments against the oil and gas industry, which is seen as a part of their own provincial identity. However, locals do find ways to resist, as exemplified in Tom's excerpt where he provides alternatives to the 'Alberta is oil' Discourse identity. This new construction highlights a love for land and people and an ethic of protection and conservation. This partly draws on a less prominent Discourse of Albertan identity that highlights 'the good life' that is available to those who enjoy an outdoor lifestyle (Evans \& Garvin, 2009).

Discourses of resistance are also visible multimodally in the ways in which 'Alberta is oil' is taken up by activists. This is most prominent in Andrea's example 
where she utilises a number of modes (such as gaze, head movement, facial expression, and silence) to recontextualise the phrase purely Albertan. By building modal density (Norris, 2011), Andrea uses the 'Alberta is oil' Discourse in order to critique it. This demonstrates how dominant Discourses may be entextualised as resistance in interaction, and how these subtle flashes of discursive resistance are more visible when including multimodality in an analysis of Discourse.

In Southland, Discourses of a rural lifestyle, farming, and dense social networks are appropriated by Terra Resources as a way to appear authentically local. Indexing these identities, the company positions itself amongst Southlanders as a neighbour and community member. In addition, the company embodies this positioning through its participation in the Field Days. Here, decisions must be made about how a professional or a local identity can be presented, as both these identities operate through very different multimodal registers. Ultimately, Terra Resources constructs a professional identity in its display, drawing upon more powerful orders of indexicality (Blommaert, 2007b). Locals, however, are aware that there is a danger in letting the mine become associated with their regional identity, and seek to resist this appropriation. This is accomplished with designed artefacts which recognise and negatively evaluate the appropriation of regional identity before reclaiming it (Figures $5.17,5.18$ ). This struggle over Discourses is further entextualised in the animal images, such as the wolf in sheep's clothing.

As we have seen through the previous examples, Alberta is considered a place where oil is inevitable, where oil is relied upon, and where oil permeates the sociocultural atmosphere. It has become an aspect of regional identity which is authenticated through claims to a historical legacy of resource development (cf. Bucholtz \& Hall, 2005, p. 302), making resistance of the tar sands more difficult for activists. Conversely, in Southland, we can see how Terra Resources struggles in its attempts to establish mining as a part of the regional identity. The fact that activists are able to explicitly and effectively highlight the appropriation of their regional identity is an indication that it has not yet become naturalised. In fact, 
positioning the company as a dangerous outsider seeking entry into the community (i.e. wolves in sheep's clothing) is an effective strategy for Southland anti-mining activists. In both cases, Discourses of regional identities are appropriated and resisted multimodally and therefore become important resources in the debate about how and if these controversial projects should go forward. In Alberta, however, further Discourses are appropriated by industry actors in a bid to gain legitimacy. I examine these in the following chapters. 


\section{Indigenous Discourses 0 in Focus}

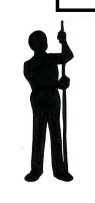

$A \begin{aligned} & \text { s evidenced by the last chapter, regional identity Discourses are a useful } \\ & \text { resource for both industry actors and activists in Southland and Alberta. }\end{aligned}$ However, additional Discourses, such as Indigenous identities, also become relevant in the Athabasca tar sands debate. As discussed in section 1.5, the tar sands are located in Treaty 8 territory, where mining and other developments threaten the ability for many Indigenous communities to live traditionally (Fumoleau, 2004). In their attempts to legitimise expansion, industry actors must manage concerns about environmental degradation and the impacts this might have on the rights of local Indigenous communities. Because stakes are so high for industries operating in these controversial locations, companies make use of more 'unconventional' discursive resources in their communications. These include the appropriation of Indigenous Discourses, which I explore in this chapter along with their subsequent resistance.

As an example, let us consider the ways the wood bison is used as an iconic marketing symbol in the area surrounding Fort McMurray. Known as the Wood Buffalo ${ }^{1}$ region, the animal is present in city emblems and tourist items (Figure 6.1)

\footnotetext{
${ }^{1}$ Although buffalo is commonly used, the animal found in North America is scientifically known as bison (plains and wood).
} 
Image removed after examination

Figure 6.1: Wood Bison Toy²

However, the bison is also an iconic symbol in Canadian consciousness, intimately tied to First Nations who sustainably hunted and relied on the animal for generations (Fumoleau, 2004). When European settlers arrived, they slaughtered herds almost to extinction, destroying the most valuable resource of 'Plains Indians'3 (see Isenberg, 2000). One might also draw connections between the mass slaughter of bison and the (attempted) genocide of Aboriginal communities (Fontaine \& Farber, 2013). It is within this colonial history that the wood bison of northern Alberta is used as a symbolic cultural icon.

As discussed previously, many First Nations communities are economically reliant on, and surrounded by, oil and gas development. While development does provide economic opportunities, the ways in which communities become

2 A version of this item can be viewed at: http://www.qualitylogoproducts.com/stress-balls/ buffalo-stress-reliever.htm

${ }^{3}$ Although the term 'Indian' is used in the United States, I use it here as it is a frequent collocation with 'Plains'. In Canada, however, more common terms include Aboriginal, Indigenous, Native, and First Nations. Following other researchers (e.g. Buhr, 2012), I capitalise these terms in recognition of their reference to nationhood and as a sign of respect. 
dependent on the oil and gas sector is contested. Resistance to unwanted industrial processes are ongoing and part of a hundreds-year long history of Indigenous resistance to Canadian colonialism (Usher, Tough, \& Galois, 1992). Local, Aboriginal resistance to tar sands expansion takes many forms, from constitutional challenges (McDermott, 2012) to direct action (The Canadian Press, 2013). In this chapter, I discuss only a few acts of opposition, although I wish to be clear that they exist within a wider culture of Indigenous resistance that encompasses all of North America and forms part of a history of struggle dating back to the signing of the Treaties (Usher et al., 1992).

I am also aware that my own 'Settler' status (see Barker, 2009 for a discussion of the term "Settler") potentially limited my access to Indigenous activists for interviews. I am therefore grateful to Denise (a member of Athabasca Chipewyan First Nation, or ACFN) for her availability and willingness to share with me stories which she has undoubtedly told countless times. Because my data set includes just one, albeit rich, interview, I also draw upon some of the wider First Nations social movements which address the re-appropriation of Indigenous Discourses in Alberta.

Similarly, my industry perspective is limited to one interview with Brandon, a representative of the Canadian Association of Petroleum Producers (CAPP). This is due in part to the refusal of individuals from companies to participate in my research (for more on this issue, see the discussion in Chapter 9). Again, to help manage this limitation, I include examples from tourist sites which are operated by major oil companies located in the tar sands (such as reclamation sites, as discussed in section 1.5.1).

\subsection{Discourse Appropriation}

Companies operating in the tar sands utilise the symbolic potential of bison and other Indigenous Discourses in their advertising, in order to construct both the image of successfully reclaimed land, and of a beneficial and supportive industry/ 
Indigenous partnership. This is accomplished at public sites of 'reclamation' (see section 1.5.1). Here I discuss three: Wood Bison Viewpoint, Gateway Hill, and Wapisew Lookout. Industry actors typically present these partnerships in terms of employment and other economic opportunities for Indigenous communities, to the extent that the oil and gas sector represents one of the largest employers in the region.

\subsubsection{Appropriating Bison}

In keeping with the regional use of the bison (e.g. Figure 6.1), tar sands companies appropriate the animal for use in marketing sites which were once part of mining operations but have since been 'reclaimed'. The bison imagery is most prevalent at Wood Bison Viewpoint, which consists of a small hill off the highway with a lookout for tourists (Figure 6.2). From the top, the mines, tailings ponds (b), replanted forest (c), and a small herd of wood bison (d) can all be seen.
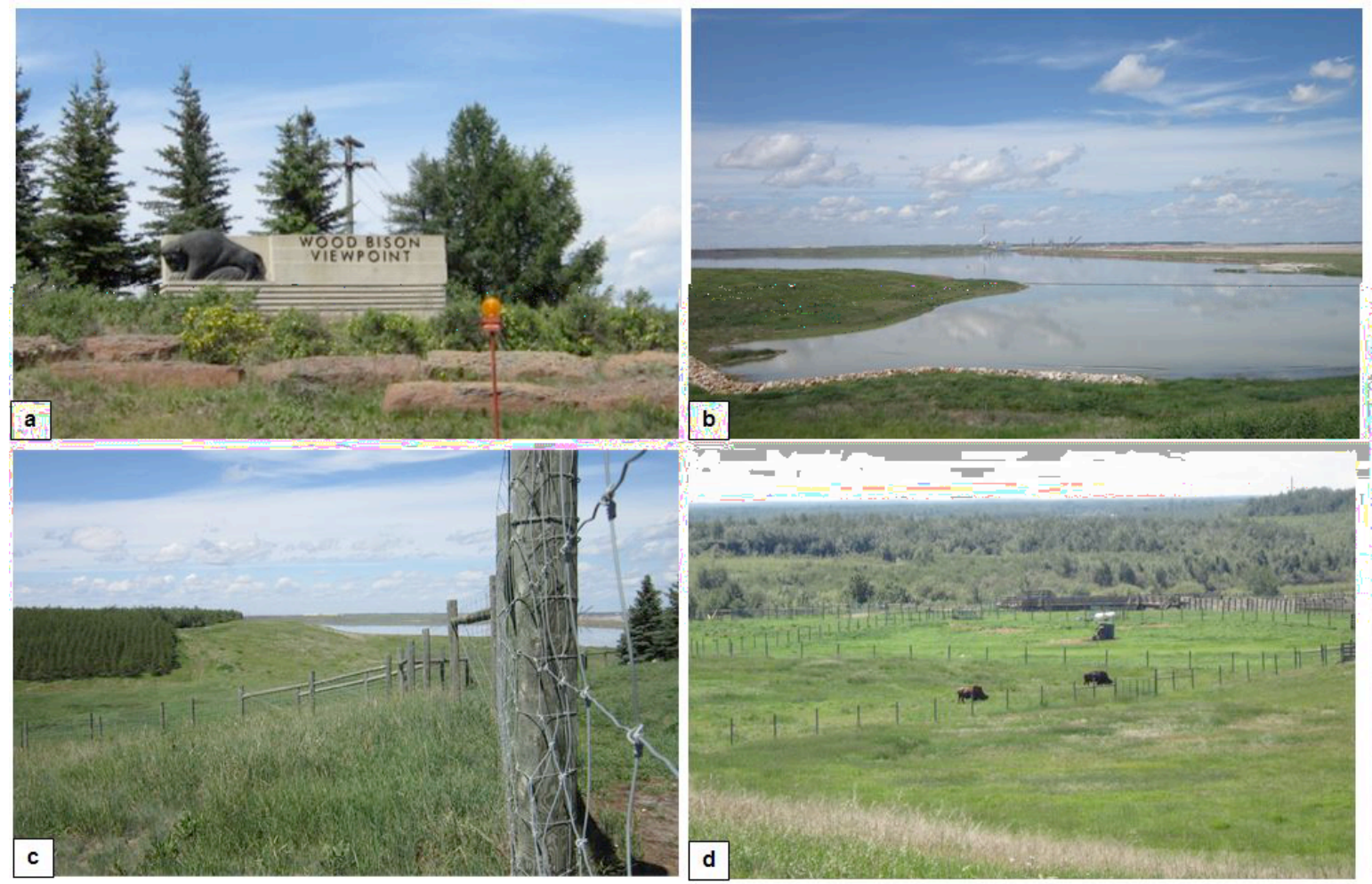

Figure 6.2: Wood Bison Viewpoint 
As is evident in the place name, the wood bison plays a central role in the presentation of this reclaimed land: it is prevalent in the signage, on the nameplate (a), in logos, and even physically present in a paddock that is visible from the lookout (d). At the view point, a series of signs describe the location's history and reclamation plans, and establish the symbolic links between bison and Indigenous people more explicitly (Figure 6.3):

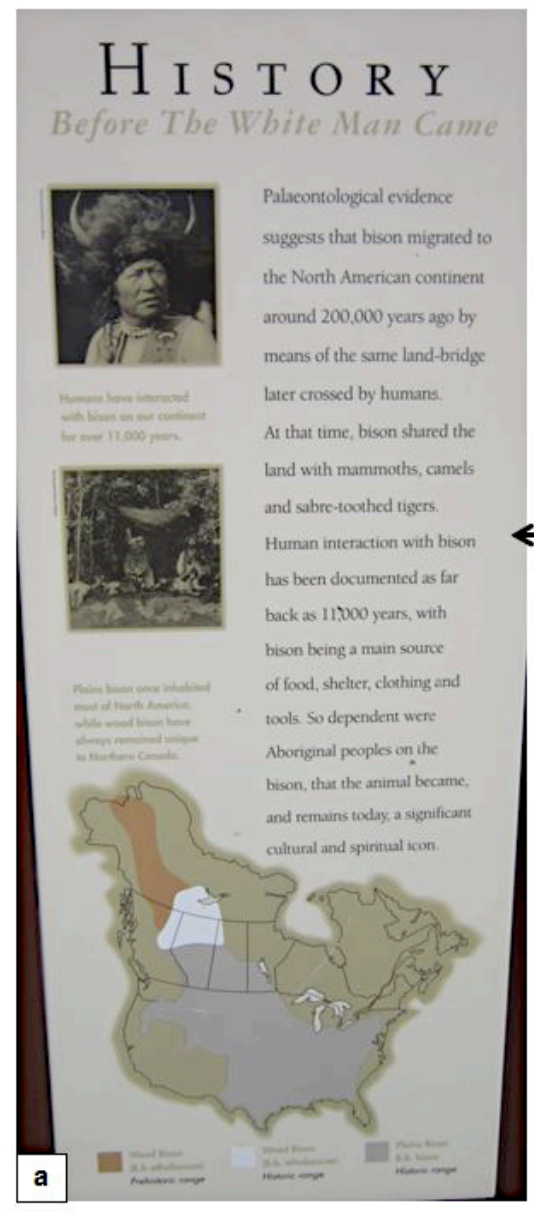

"Paleontological eviden ce suggests that bison migrated to the North American continent around 200,000 years ago by means of the same land-bridge later crossed by humans. At that time, bison shared the land with mammoths, camels and sabre-toothed tigers. Human interaction with bison has been documented as far back as 11,000 years, with bison being a main source of food, shelter, clothing and tools. So dependent were North American Aboriginal peoples on the bison, that the animal became, and remains today, a significant cultural and spiritual icon"

"Humans have interacted with bison on our continent for over 11,000 years."

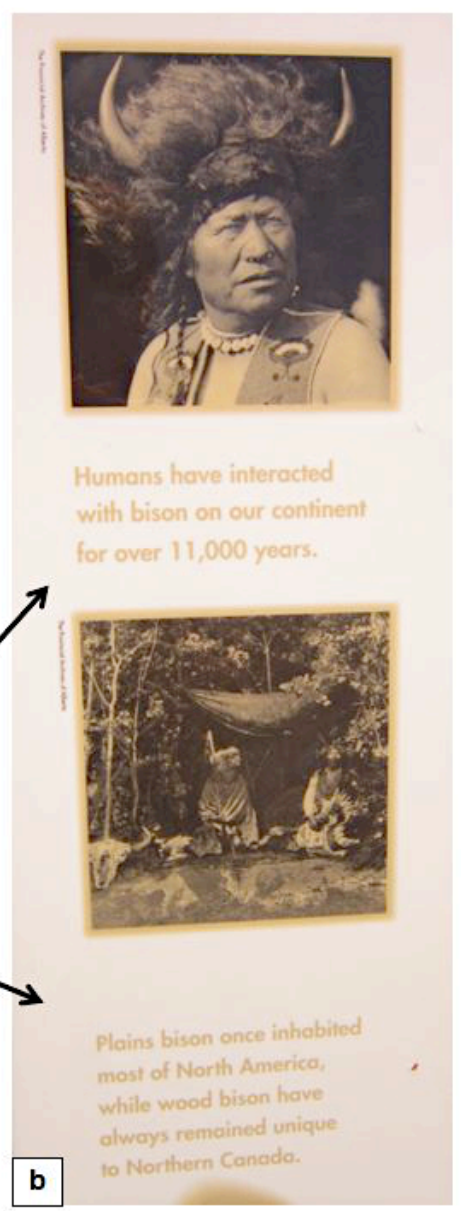

"Plain s bison once in habited most of North America, while wood bison have always remained unique to Northern Canada."

Figure 6.3: Wood Bison Viewpoint

Historical photographs of First Nations people using bison (6.3b) are presented alongside text which discursively positions the bison as an Indigenous symbol (the animal became, and remains today, a significant cultural and spiritual icon). It is 
this bison-as-icon which is used to do further discursive work for the company's reclamation marketing (i.e. creating the appearance of respectful involvement with First Nations communities).

Another sign in the series presents the bison's uneasy survival in the area (Figure 6.4).

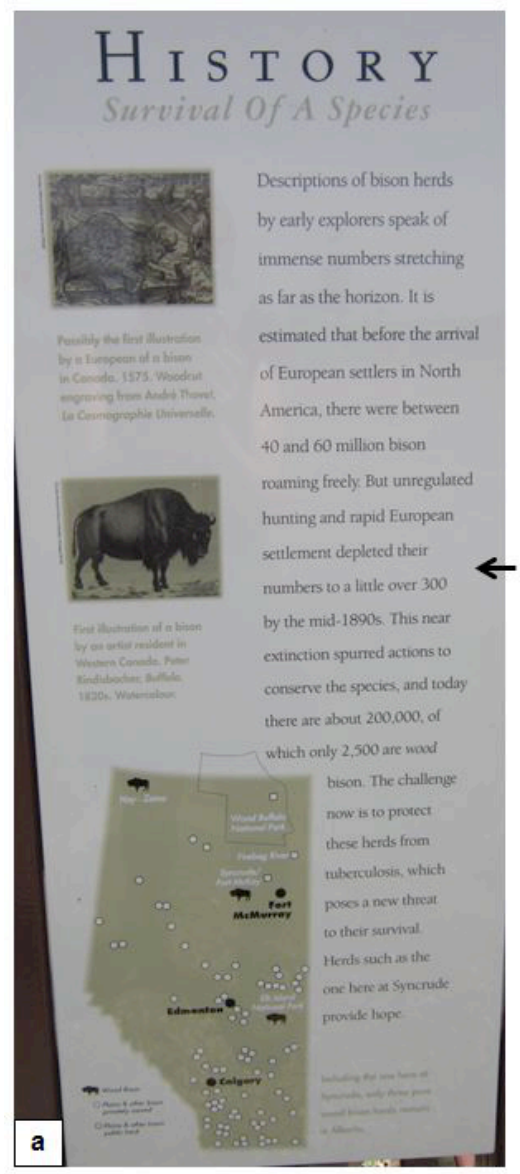

"Descriptions of bison herd by early explorers speak of immense numbers stretching as far as the horizon. It is estimated that before the arrival of European settlers in North America, there were between 40 and 60 million bison roaming freely. But unregulated hunting and rapid Eu ropean settlement depleted their numbers to a little over 300 by the mid-1890s. This near extinction spurred action s to conserve the species, and today there are about 200,000 of which only 2,500 are wood bison. The challenge now is to protect these herds from tuberculosis, which poses a new threat to their survival Herds such as the one here at (Company) provide hope."

"Possibly the first illustration by a European of a bison in Canada, 1575. Woodcut engraving from André Thevet, La Cosmographie Universelle."

"First illustration of a bison by an artist resident in Western Canada. Peter Rindisbacher, Buffalo. 1820s. Watercolour."

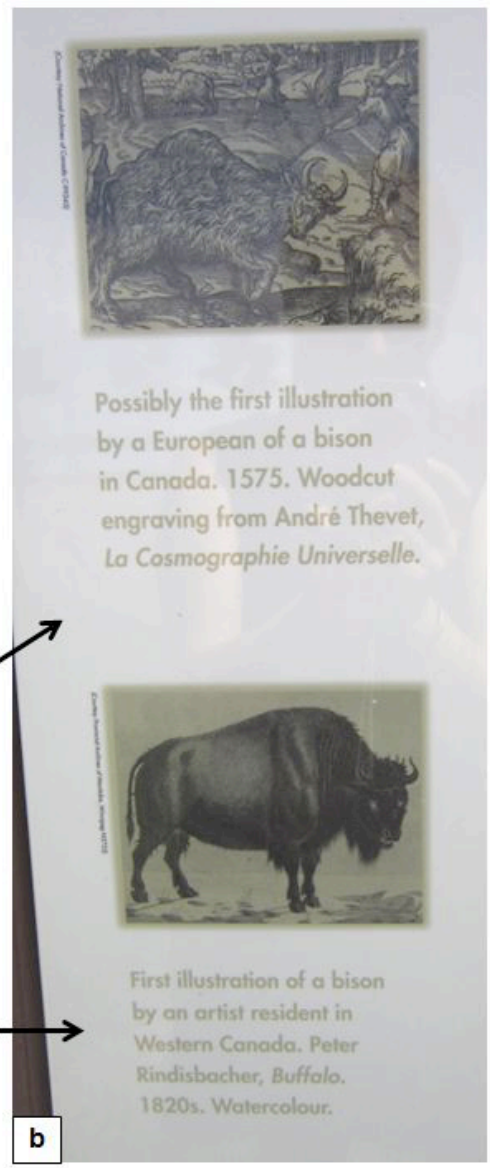

Figure 6.4: Wood Bison Viewpoint

The sign references the historical mass slaughter (unregulated hunting and rapid European settlement) and presents early European drawings of the animal (b). In contrast to the images in Figure 6.3, these are not photographs, which arguably lowers their modality, or "general impression of reality, naturalness, or truth" (Kress \& Van Leeuwen, 2006, p. 163). However, they represent the first illustrations by European hands, perhaps lending an authenticity (cf. Blommaert \& Varis, 2011) 
that mitigates their low modality.

Having established the bison's history as a victim of slaughter and as an icon of Indigenous identity, additional signs elaborate on the bison's behaviour and statistics. The Indigenous link is strengthened through the subtitles on these (Figure 6.5), where the words used to describe bison (noble, strong, silent type) also have wider intertextual meanings related to Indigenous people (consider the collocation 'noble savage') (Binnema \& Hutchings, 2005).

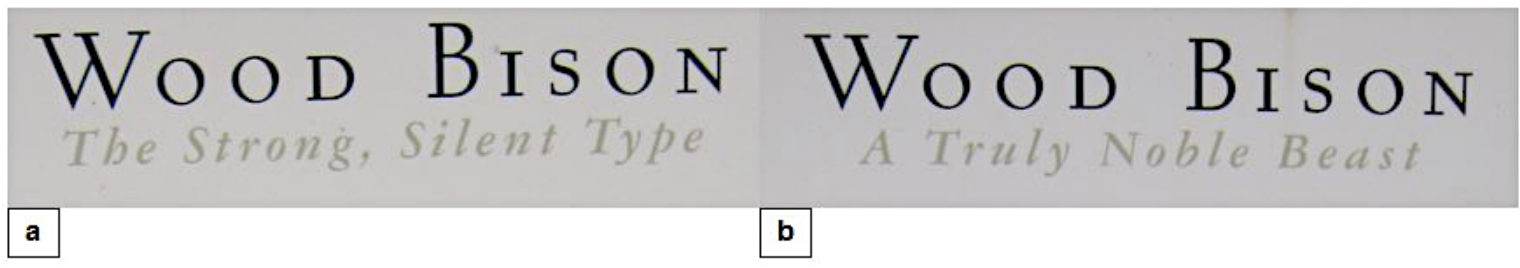

Figure 6.5: Wood Bison Viewpoint

Yet more signs further the Indigenous/bison discursive link, by entextualising the animal as a symbol of reclamation and First Nations partnership (cf. Friedel, 2008). In another sign, we are told how the bison are a focus of partnership and reclamation (Figure 6.6). 


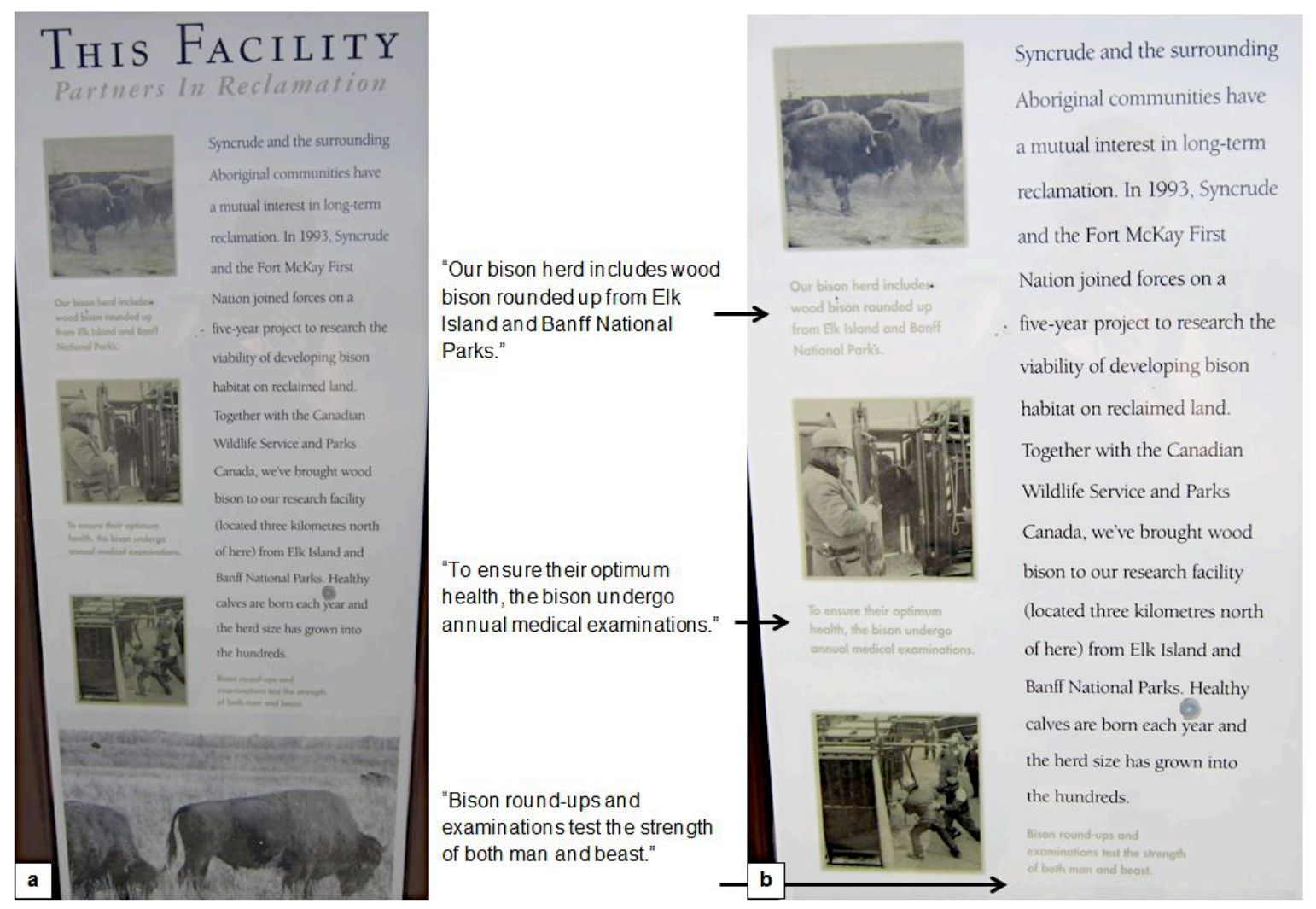

Figure 6.6: Wood Bison Viewpoint

Here, we can see how First Nations communities are discursively positioned in alignment with industry through textual choices such as mutual interest, joined forces, together, as well as pronouns (we, our). These constructions present both the company and Indigenous communities as sharing goals. Through working with industry to re-populate the land with wood bison (a potent symbol of Indigenous identity), local Aboriginal communities such as Fort McKay are suggested as full partners. In fact, Fort McKay is one of the only communities that could engage in such a supportive partnership with industry, arguably because it is surrounded by mines. This interpretation is echoed by Denise in our interview, where she describes how residents don't have much access to their lands anymore, there's political turmoil, and they're just in a really tough place. In such a situation, partnering with the oil industry may in fact become one of the only viable economic options for people (see Davidson \& Gismondi, 2011). This may be considered a 
case of "orthopraxy", where hegemonic practices are performed simply because there are no other options for individuals who are unable to challenge the system (Blommaert, 2005, p. 169).

Having established communities like Fort McKay as partners, the wood bison next becomes a measurement of successful land reclamation (Figure 6.6: healthy calves and growing herds). Here, the bison arguably represent "Nature's vitality" (Davidson \& Gismondi, 2011, p. 124), becoming indicators of a healthy landscape, and therefore of successful reclamation. Consequently, the wood bison is discursively linked as a symbol of Indigenous/industry partnership and also of successful reclamation. The clever use of this symbol thus helps the oil industry to manage their reputation in the face of ongoing challenges about impacts on the environment as well as their influential role in ignoring treaty rights (e.g. The Canadian Press \& Global News, 2014).

The use of bison as a symbol culminates in the presentation of real live wood bison living in a fenced area that is visible from the lookout (Figure 6.7a).

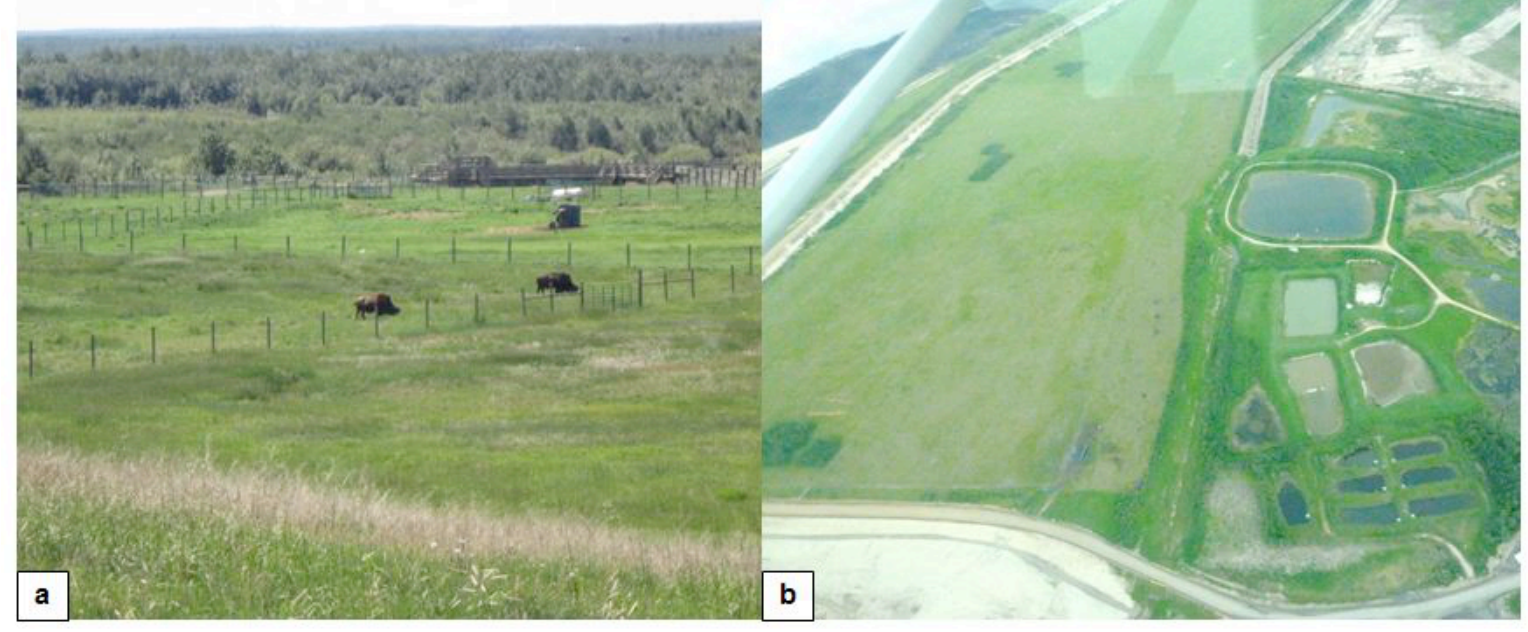

Figure 6.7: Wood Bison Viewpoint

These are in fact 'show' bison which the company keeps on site, visible so that tourists might watch them from the lookout. The rest of the herd live on a range 
that the company owns, where they are raised and brought to graze on the reclaimed land. However, aerial footage of one such range shows that it is limited in size, and even surrounded by mines, tailings ponds, and highways (b).

Wood bison also play a large role in the presentation of the Gateway Hill reclamation site, operated by the same company as Wood Bison Viewpoint. Gateway Hill is the only officially recognised reclaimed land that has been returned to the Alberta government (Alberta, 2010) and it consists of replanted hiking trails on a small hill surrounded by highways, mines, and tailings ponds. Heralded as an example of successful reclamation (see Davidson \& Gismondi, 2011), the site was actually reclaimed from its use as an overburden ${ }^{4}$ dump. In discussions with Christina (representing a local environmental organisation), she explains it was originally a storage for the rocky layer that exists between the muskeg and trees. In other words, the reclamation site at Gateway Hill was never mined.

At Gateway Hill, once again, visitors are greeted with bison symbols when entering the reclaimed area (Figure 6.8).

${ }^{4}$ The top layer of vegetation and soil that is removed before mining commences. 


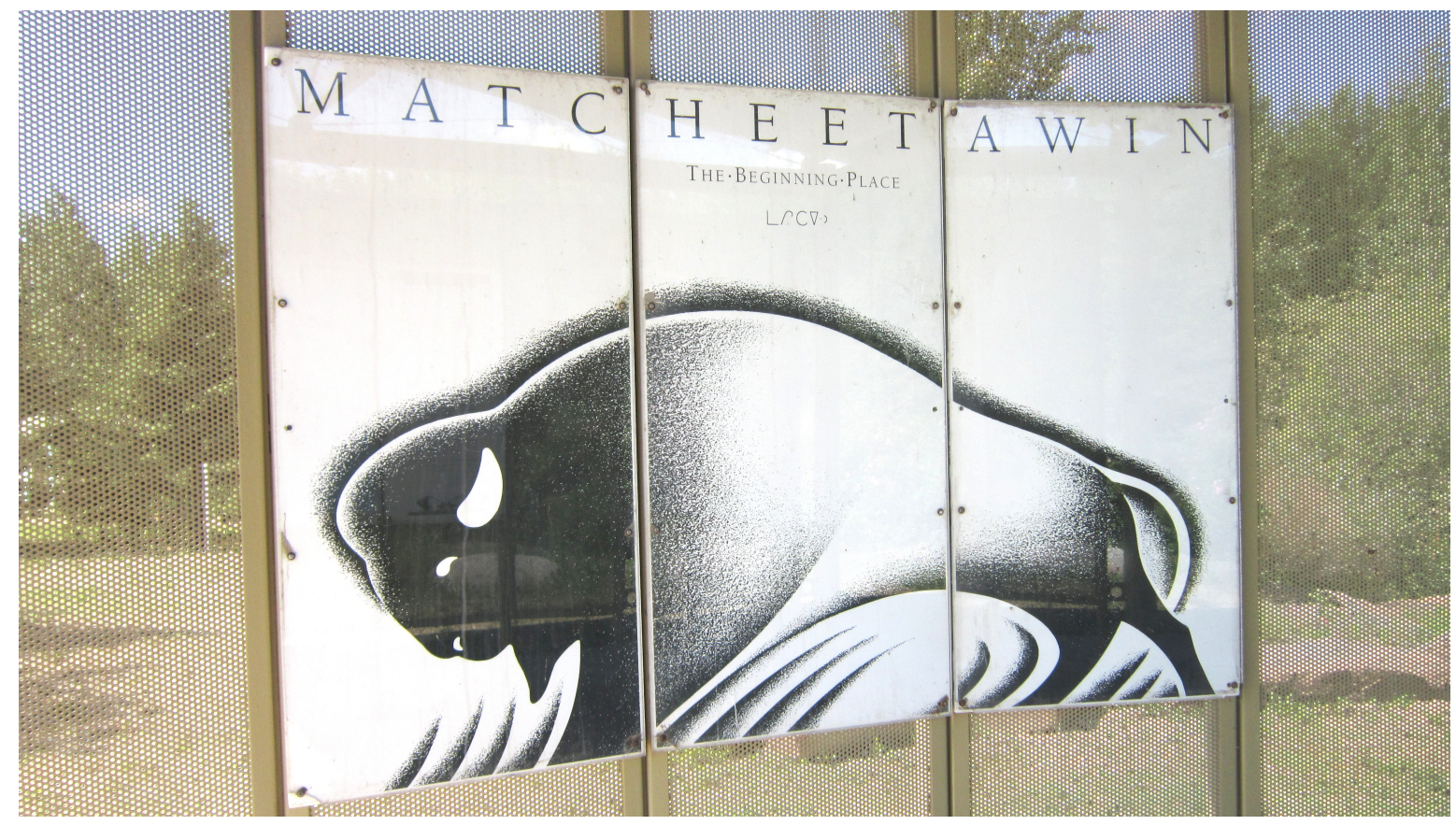

Figure 6.8: Matcheetawin

First, large bison statues adorn the entrance from the highway ${ }^{5}$ and visitors next see a prominent sign announcing the name of the reclaimed area (6.8). This sign features a heavily stylised illustrated bison and the words Matcheetawin, The Beginning Place, with a further translation in the Cree script (6.9).

The drawing itself is monochromatic and uses sweeping lines and a distinct style of shading reminiscent of cave paintings (cf. Lawson, 2012). This suggests a Discourse of primitivity, which casts both bison and Indigenous people as ancient relics of the past (see also Smith, 1999). Within a neocolonial space where Indigenous people are encouraged to assimilate into industrial progress (cf. Friedel, 2008), this suggestion of Aboriginal people as relics might serve to erase contemporary Indigenous people who live traditionally. At the same time however, this Discourse seems to position the reclaimed land itself as ancient, and, along with the name given to the site (The Beginning Place), suggests it has been

\footnotetext{
5 Unfortunately these statues were being renovated during my fieldtrip so I was unable to photograph them.
} 
restored to its original state. The cave painting bison thus imprints an 'authentic' Indigenous presence onto the reclaimed land, while simultaneously locating both in a distant past.

In these ways, the wood bison becomes a potent symbol, which the company has made use of discursively, graphically, and even physically. Industry actors are then able to manage their controversial presence through the appropriation of Indigenous Discourses, such as the bison, representing partnership with Indigenous people.

\subsubsection{Appropriating Language}

Additional aspects of Indigenous identity are also used in these constructions, most notably language. Alongside the bison in the Matcheetawin sign at Gateway Hill is the overt use of the Cree language. The sign presents Matcheetawin using the English alphabet, followed by an English translation (The Beginning Place), followed by the Cree script (Figure 6.9)

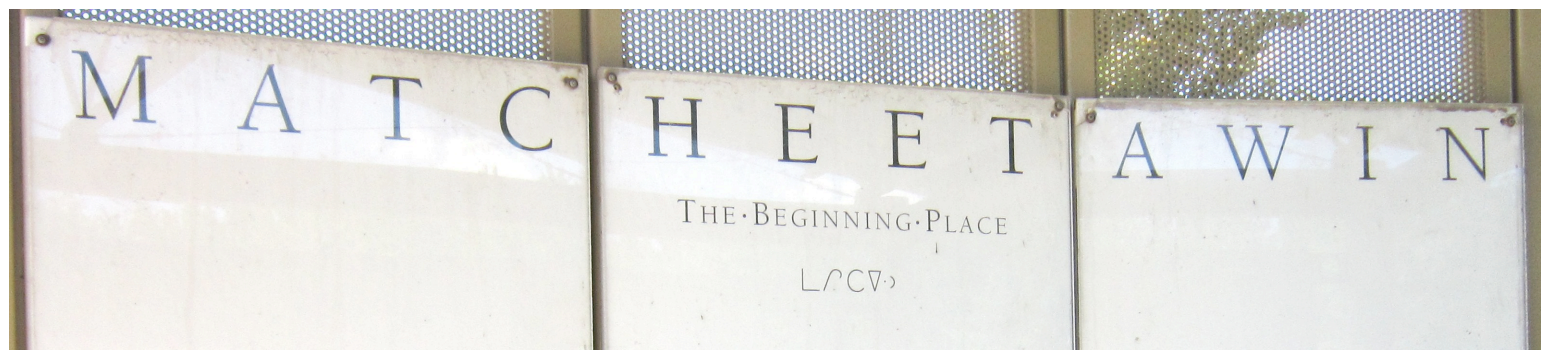

Figure 6.9: Matcheetawin

Although the sign makes use of an Indigenous language, it appears not to be designed for a Cree-speaking audience (Bell, 1984). The largest and most prominently placed script is in English, although it is used to present a non-English word (Matcheetawin). The Cree script is given the lowest hierarchical level (see Kress \& Van Leeuwen, 2006), placed below the English. In this case, it is the prominent position of Matcheetawin which suggests an appropriation of Indigenous Discourses. By presenting the Cree word in English, the designers simultaneously 
assume an English-speaking audience while constructing an Indigenous presence. This audience design is echoed in other signs (for instance around the welcome area which are presented solely in English).

At Gateway Hill visitors can walk along a path winding around the hill, interspersed with lookouts. Introducing the path as the Sagow Pematosowin Trail is a sign in English, Cree, and Dene, another Indigenous language (Figure 6.10).

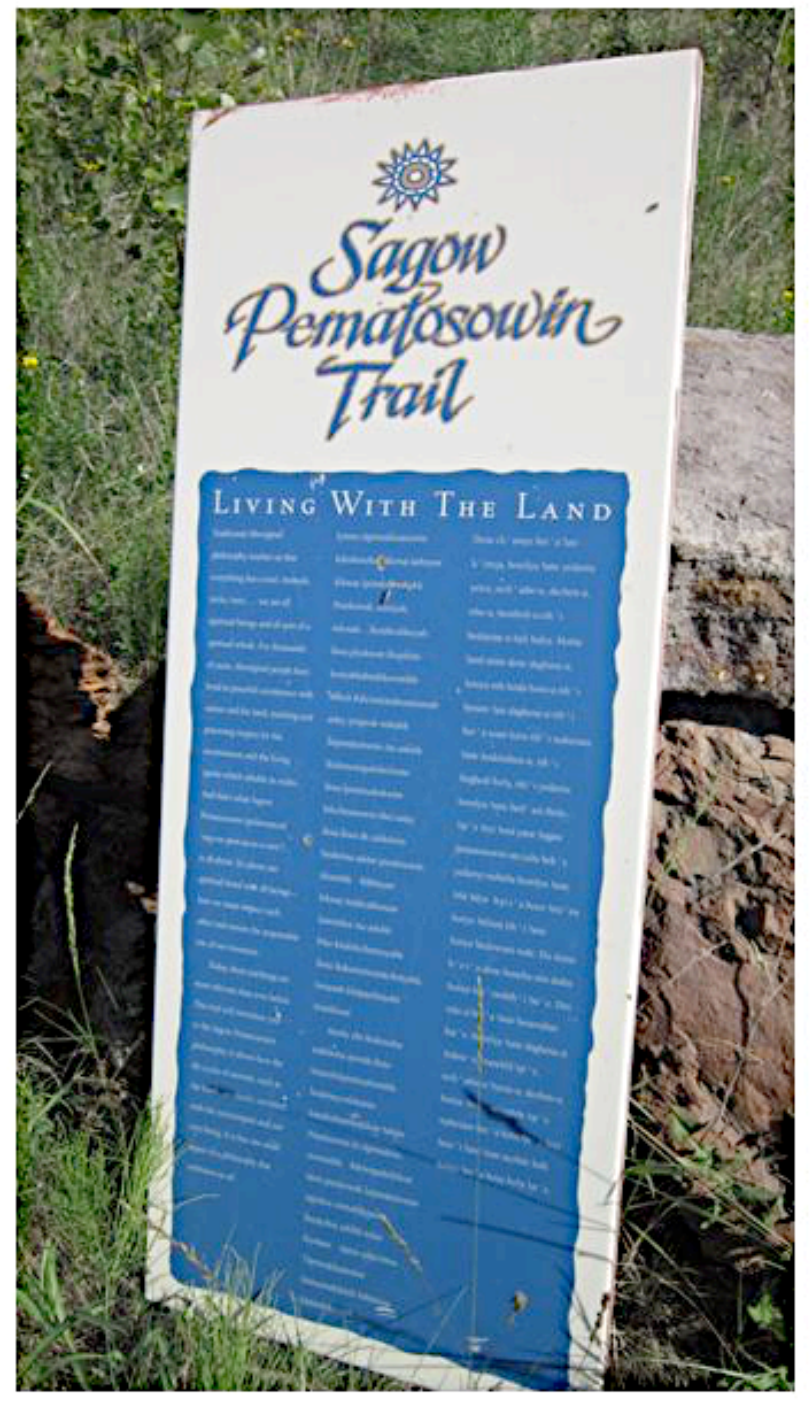

\begin{abstract}
"Traditional Aboriginal philosophy teaches us that everything has a soul. Animals, rocks, trees...we are all spiritual beings and all part of a spiritual whole. For thousands of years, Aboriginal people have lived in peaceful coexistence with nature and the land, teaching and practising respect for the environment and the living spirits which inhabit its realm. And that's what Sagow Pematosowin (pron ounced seg-ow pem-at-os-o-win) is all about. It's about our spritiual bond with all beings - how we must respect each other and ensure the responsible use of our resources. Today, these teachings are more relevant than ever before. This trail will introdu ce you to the Sagow Pematosowin philosophy. It shows how the life cycles of animals, such as the hawk, are closely entwined with the environment and ourvery being. It is but one small aspect of a philosophy that embraces us all."
\end{abstract}

Figure 6.10: Sagow Pematosowin 
Once again, English occupies a privileged position (for left to right-reading cultures) as the most prominent (Kress \& Van Leeuwen, 2006). Additionally, the subtitle Living With The Land spans across all three texts, uniting them under an Englishlanguage banner. The text goes on to explain the principles of Sagow Pematosowin as a traditional Aboriginal philosophy where everything has a soul and requires respect. The trail promises to introduce this philosophy and show how the life cycles of animals, such as the hawk, are closely entwined with the environment and our very being. Near the end of the walk, one comes across an installation representing the various life cycles of animals arranged in a circle (Figure 6.11a). 


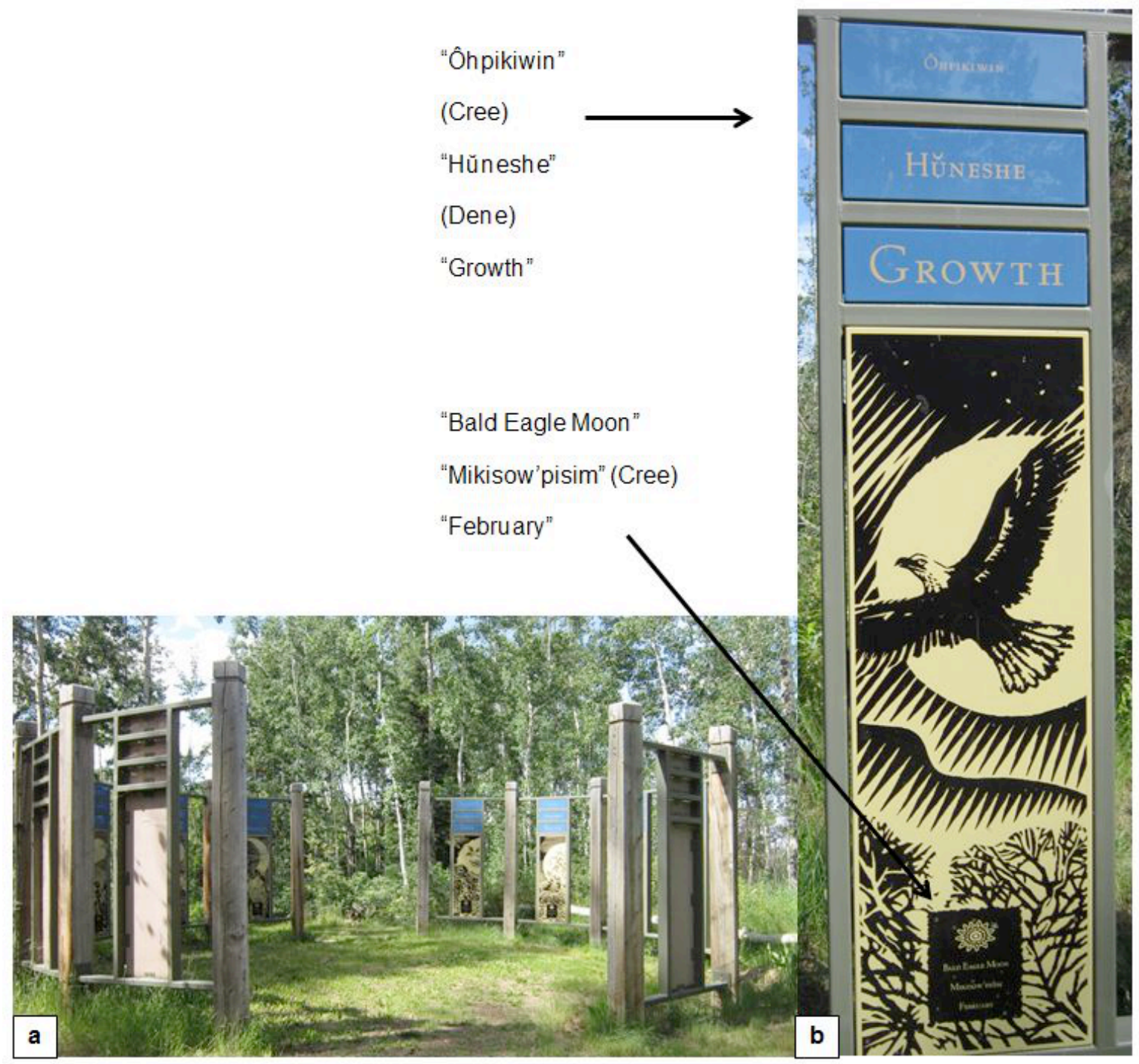

Figure 6.11: Sagow Pematosowin

Cree and Dene language choices are again used in the signs to present an Indigenous presence for an English-speaking audience. Although English is not at the top, it is the largest (and, considering the height of the installation, most likely the closest to eye-level) (b). Cree (in English script) adorns the top of each sign, followed by Dene and then the English translation. Below the image is a box describing each moon in English, followed by a Cree translation, and finally, the corresponding month is written in English at the bottom (b). 
Both the Matcheetawin sign and Sagow Pematosowin Trail make use of Indigenous language and imagery to imprint an Indigenous presence on the reclaimed land. However, word locations and sizes still privilege English, or at least assume an English-speaking audience.

In this case, we might consider what alternate motivations have encouraged the inclusion of First Nations Discourses for an (assumingly) non-Indigenous audience. As discussed above, we can interpret the incorporation of the bison and Dene and Cree language as suggesting Indigenous partnership in the reclaimed land project. It also casts a local historical 'authenticity' on the project's aims of returning land to its original state (see Blommaert \& Varis, 2011; Bucholtz \& Hall, 2005). These symbolic processes are also explicitly mentioned at another reclaimed site: Wapisew Lookout.

Wapisew Lookout is the 'flagship' reclaimed area for one of the major companies. Previously a tailings pond located beside the river, the tailings were moved to another pond and the original site was filled and replanted. After extensive work, the site was opened in 2010 with the name Wapisiw Lookout, the choice of which is explained on signs ${ }^{6}$ at the lookout:

What's in a name?

Pronounced "wah-p-su", this reclaimed site, Wapisiw Lookout, is named after a Cree trader who purportedly brought a sample of oil sands to the Hudson's Bay Company in 1719. The name was chosen by Suncor to pay tribute to the history of this region, and to honour its Aboriginal peoples.

By referencing the first Indigenous person to introduce the resource to a company, the choice of name again suggests the idea of Indigenous/industry partnership. Additionally, the name was chosen to symbolise the process of reclamation itself, as is explained by the company's President upon its opening:

6 Due to privacy restrictions, I am unable to reproduce any photographs from my visit onsite. 
The new name - Wapisiw Lookout, - is intended to reflect the transformation of the site. Wapisiw means 'swan' in the Cree language and is also close to Wapasun, the name of the first person to bring a sample of oil sand to a Hudson's Bay Company outpost in 1719.7

The choice of 'swan' in this case relies on (Western) cultural knowledge of the 'Ugly Duckling' story, where an entity once considered unattractive transforms into something beautiful. Similar to the signs on the Sagow Pematosowin Trail (Figure 6.10), Cree lexical items are used, however the intended audience would need to be familiar with Western fairytales to gain the full meaning. Once again, we see the use of a First Nations language to show both the 'success' of the reclamation (e.g. transformation from 'ugly duckling' to swan) and a supportive partnership with First Nations (e.g. the name of the first person to bring oil sands to 'white men').

\subsection{Aboriginal 'Opportunities'}

From an industry perspective, relationships with Indigenous people also tend to focus on employment and other economic opportunities as partnerships. Interviewee Brandon works for the Canadian Association of Petroleum Producers (CAPP), an organisation which represents companies operating in the tar sands. In discussion with Nicole, he presents this work of doing business with Aboriginal people (Figure 6.12).

\footnotetext{
${ }^{7}$ Retrieved from: http://www.suncor.com/en/newsroom/2470.aspx?id=3728.
} 

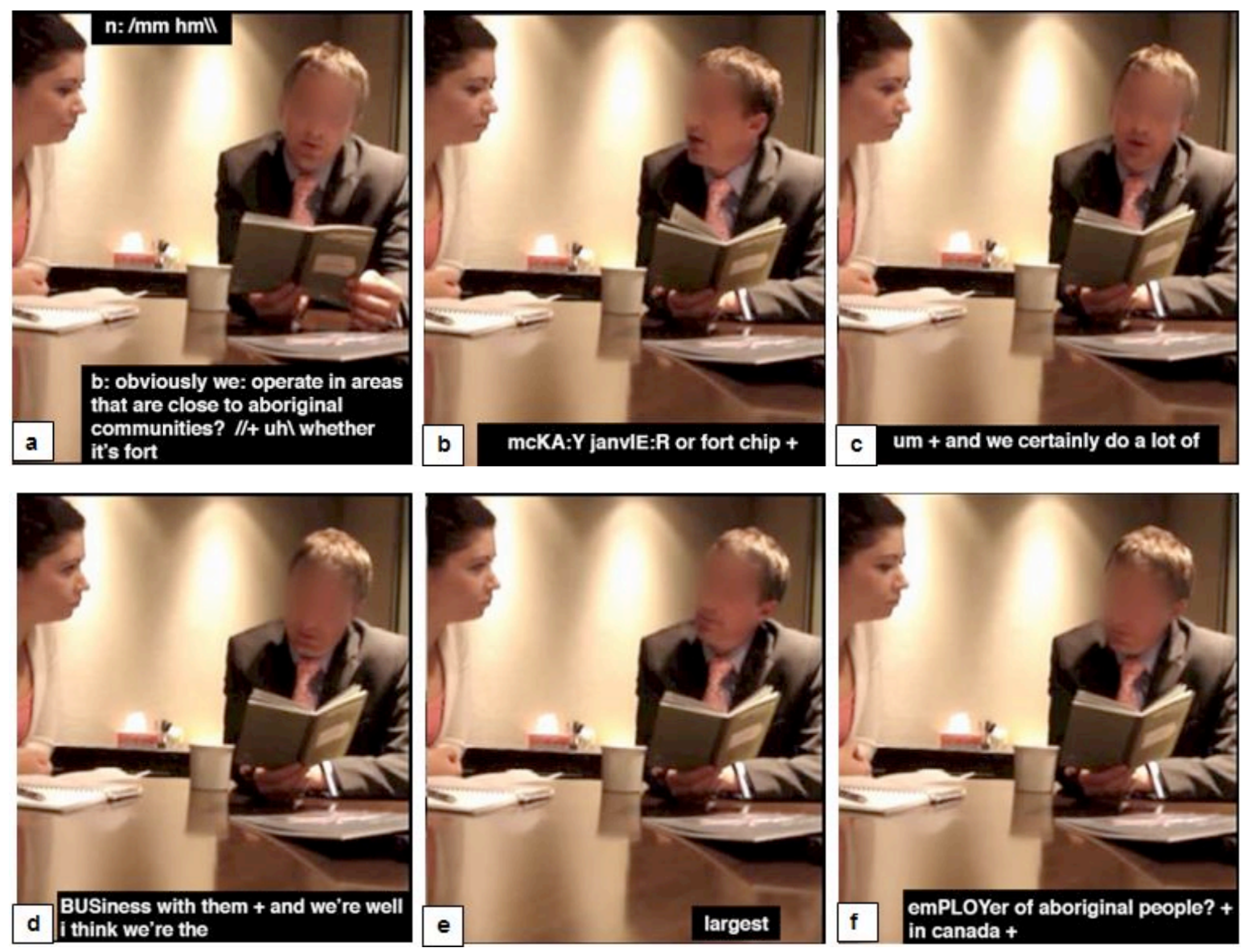

Figure 6.12: Brandon

Brandon first explains that CAPP-represented companies work in regions inhabited by Indigenous people (we operate in areas that are close to aboriginal communities: a). He prefaces this with obviously, establishing the fact as presumably common knowledge (see Lee, 2001). Next, he shifts his gaze to Nicole and begins listing various communities (b). This can be interpreted as a presentation of professional identity by displaying local knowledge of the area and the surrounding communities (cf Bucholtz \& Hall, 2005). Returning to the booklet, Brandon then explains that CAPP does a lot of business with these communities (c-d), and goes on to claim that the companies which CAPP represents are the largest employer of aboriginal people in canada (d-f). This is marked with a glance to Nicole while saying largest (e), which may help to emphasise the importance of the claim. 
Next, he elaborates on exactly how this business interaction is accomplished (Figure 6.13).
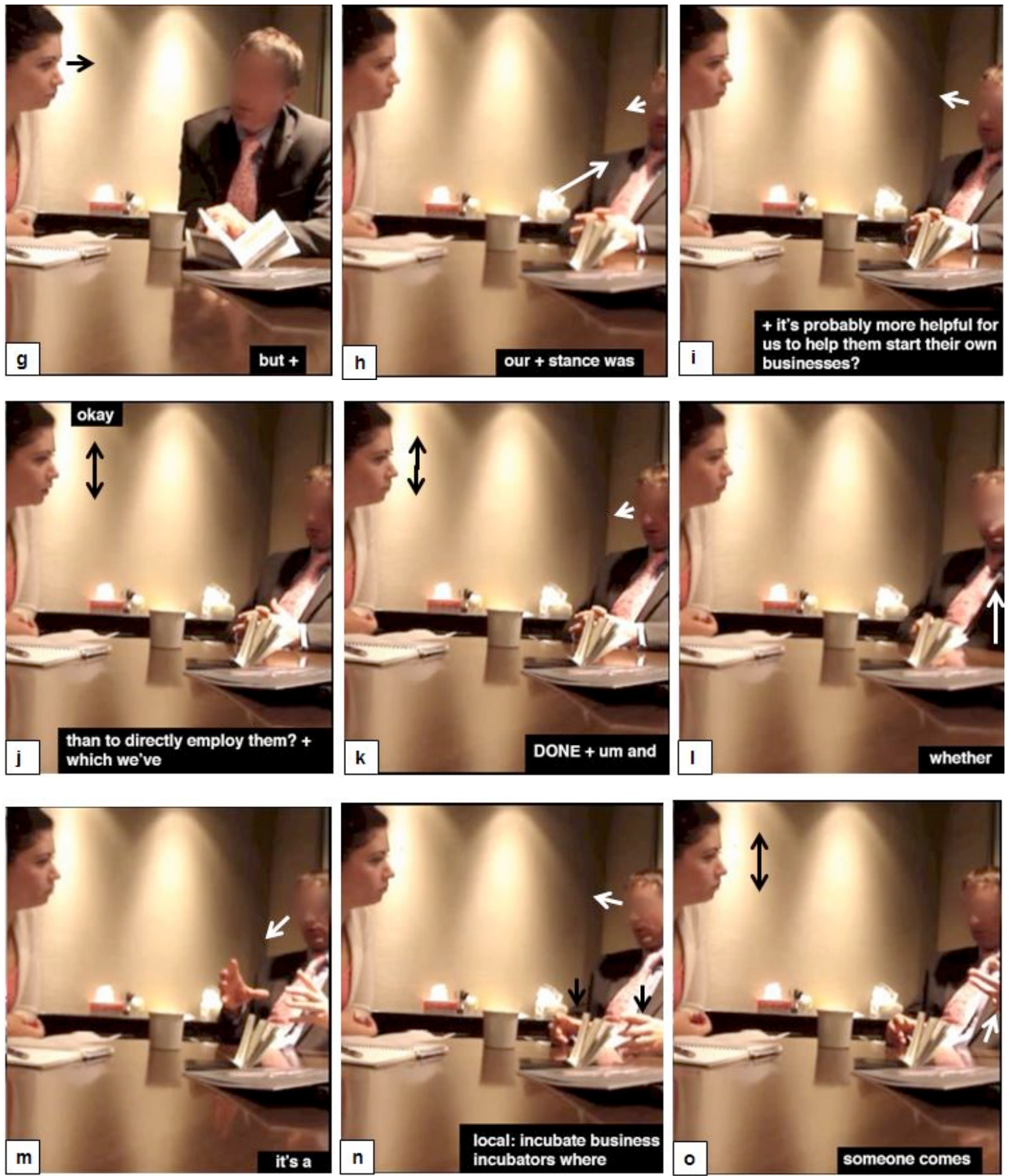

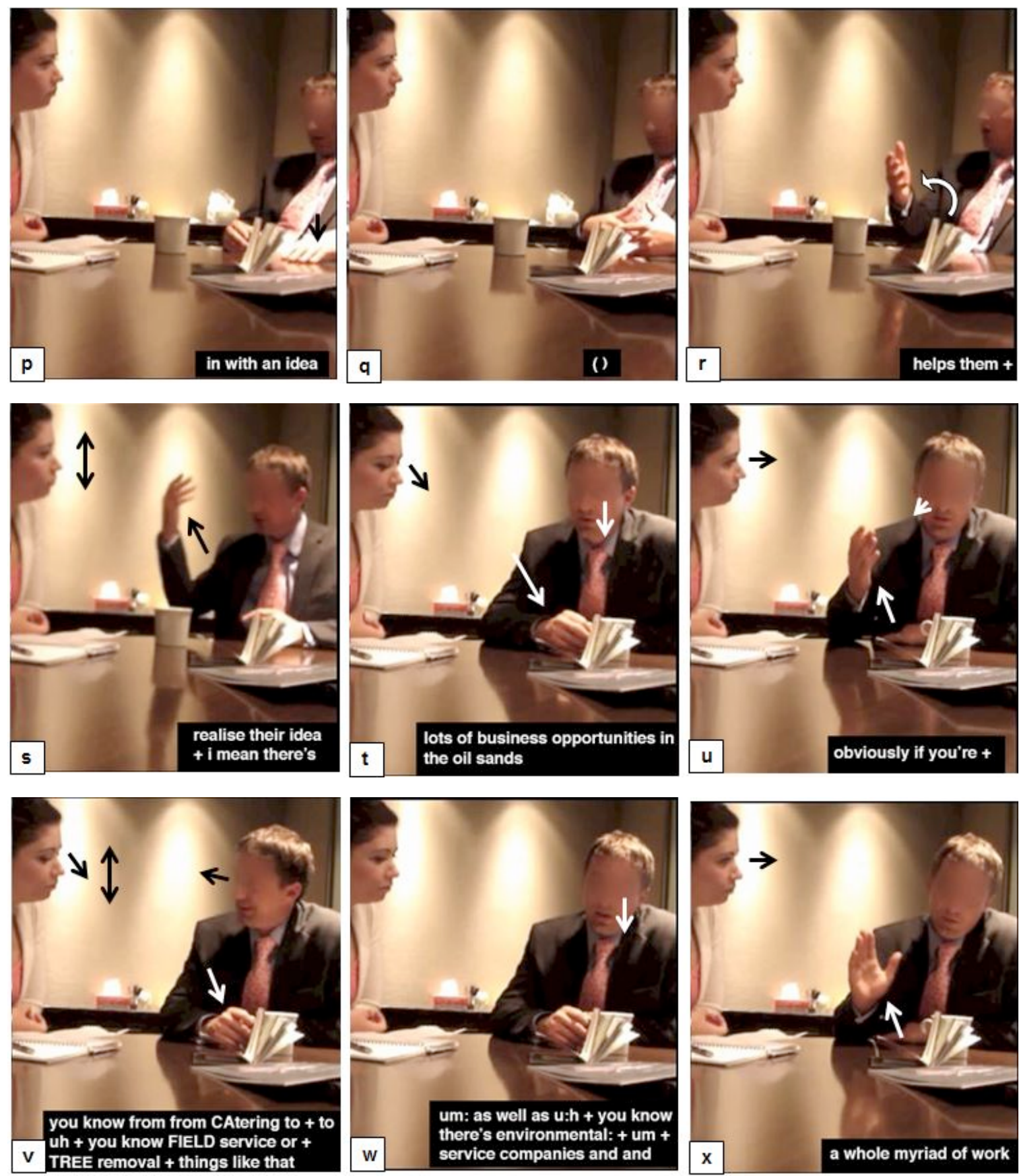

Figure 6.13: Brandon

Brandon drops the book, leans far back in his chair, and averts his gaze to the middle distance (but our stance was: $\mathrm{g}-\mathrm{h}$ ). These actions are multimodally dense (cf Norris, 2009), working to mark the change to an aside or elaboration on his statement. He then recounts the organisation's consideration about what would be 
most helpful for local communities (to help them start their own businesses, than to directly employ them?: $\mathrm{i}-\mathrm{j}$ ). His high rising terminal is backchanneled by Nicole with a nod, and he continues (which we've done: $\mathrm{j}-\mathrm{k}$ ). This concept is elaborated even more through examples (whether it's, business incubators: $n$ ). During this explanation, Brandon places $\mathrm{BH}$ on the table in front of him in a metaphoric gesture, suggesting a conceptual object which represents the business incubator of which he speaks $(n)$. He then explains how this works (someone comes in with an idea: o-p) and he raises and lowers his LH, possibly in an iconic gesture to show the hypothetical person with an idea. He then uses a gesture where $\mathrm{BH}$ are presented palm out (() helps them: q-r). With his $\mathrm{RH}$ he then makes a circular motion while leaning forward as he searches for the word realise (s) (Goodwin \& Goodwin, 1986). Next, Brandon brings his RH hand up and down as a beat while exclaiming the large number of business opportunities available in the oil sands (tv). The palm up orientation, coupled with the slight lateral movement might suggest that these opportunities are obvious (Kendon, 2004, pp. 264-265). Indeed, Brandon makes this explicit by saying obviously (u), and then he lists examples of business ideas (you know from catering, field service, tree removal, environmental um service companies: $\mathrm{v}-\mathrm{w}$ ). He concludes that there are many opportunities (a whole myriad of work: $\mathrm{x}$ ) while raising his $\mathrm{RH}$ palm out in a gesture which suggests that he has finished listing (Kendon, 2004, pp. 248-249).

Brandon re-orients to the book as he describes the end result of this engagement with local business (Figure 6.14). 

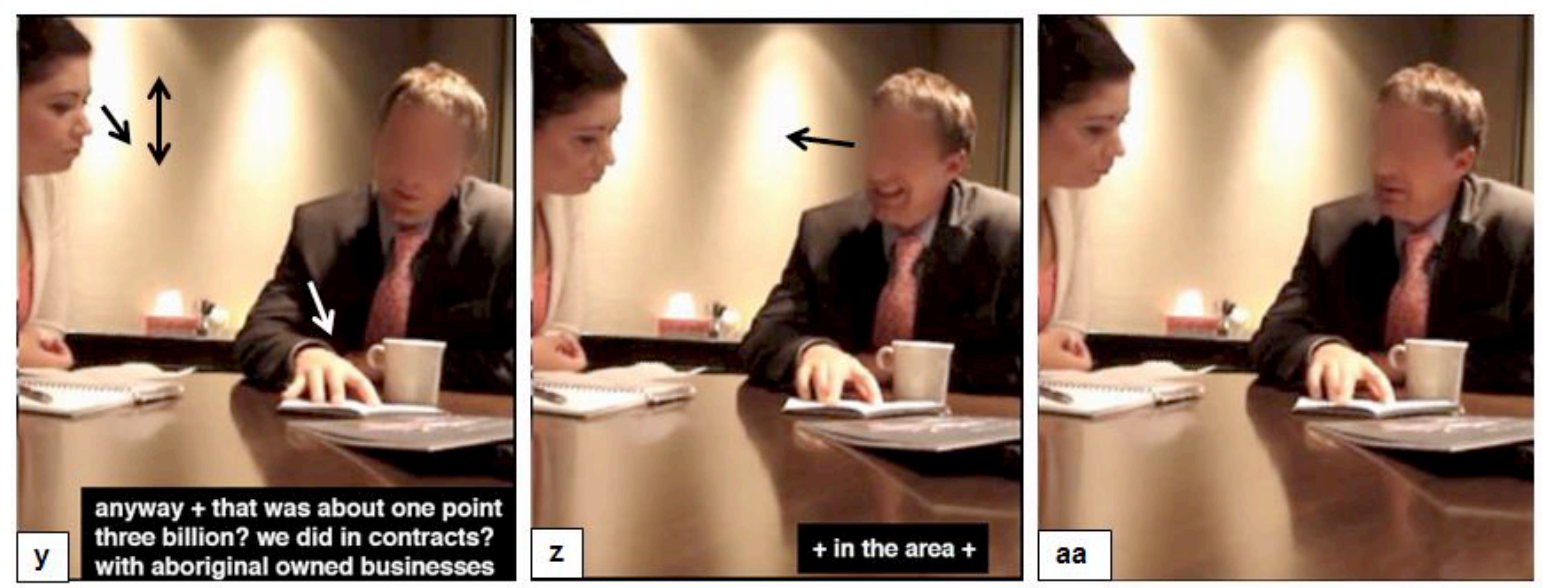

Figure 6.14: Brandon

He marks this shift by saying anyway and moving his $\mathrm{RH}$ onto the book, directing Nicole's attention to it (y). Using the page in the book, he announces the financial sum given to Indigenous businesses (about one point three billion? we did in contracts? with aboriginal owned businesses: $y$ ). He also uses high rising terminals (HRTs), in a possible attempt at more interlocutor engagement (cf. Warren \& Britain, 2000), however Nicole maintains her gaze on the booklet (y). By using the published book, Brandon is thus able to draw upon an institutional authority (i.e. CAPP) to back up his claim. He then glances at Nicole, raises his eyebrows and smiles as he comments upon this statement (in the area: $\mathrm{z}$ ). This seems to indicate he is specifying for Nicole that this is only for the region around the mines in Alberta, which makes the sum even more impressive.

The relevant page in the book from which Brandon draws is reproduced below (Figure 6.15). 
Image removed after examination

Figure 6.15: CAPP Booklet ${ }^{8}$

Here we can see there are a number of subtitle phrases which are made salient through colour and size (see Kress \& Van Leeuwen, 2006). Taken together, these words (Aboriginal opportunities, $\$ 1.3$ billion, Jobs, Community) construct a series of keywords. Notably, the sum is linked to the chapter title (Economy) through colour, and opportunities is given a bigger size than Aboriginal, suggesting a higher level of importance (Kress \& Van Leeuwen, 2006). Relationships with communities are described as solid which have, in turn, created employment and business opportunities. We are told that the $\$ 1.3$ billion which Brandon cites represents the amount contracted from 2010. This is even cited with a source (Source: OSDC 2011), indexing a stance of authority and academic practice (cf. Mondada, 2013).

\footnotetext{
${ }^{8}$ Image can be viewed at http://www.capp.ca/UpstreamDialogue/OilSands/Pages/ default.aspx
} 
Next, the jobs awarded to First Nations are cited below the contract paragraph. This layout suggests that the jobs are in fact less important, a point which Brandon has already highlighted (our stance was it's probably more helpful for us to help them start their own businesses: 6.3, i). Finally, we are told the total sum that companies contributed to community programs (presumably through sponsorship), once again backed with a source.

Brandon thus explains CAPP's relationship with Indigenous communities in a way that closely aligns with the official document from which he draws. Companies, he argues, develop helpful relationships with local communities through the provision of business opportunities, jobs, and sponsorship. This helps construct the companies' relationships with Indigenous communities as a partnership, much in the same way appropriating bison or languages does (see section 6.1.1, 6.1.2). In this way, Brandon is very much in alignment with individual company marketing strategies. Additionally, by making use of economic Discourses (employment, business opportunities, $\$ 1.3$ billion), these strategies cast the oil and gas industry as 'giving' rather than 'taking'. This results in the skillful subversion of criticisms about industry's problematic use of Indigenous lands for development, instead casting companies in the role of 'supporter'.

\subsection{Aboriginal Opportunities: Another View}

However, the provision of these seemingly beneficial financial opportunities are considered somewhat differently inside the communities which are directly affected by development. Denise, who is a member of Athabasca Chipewyan First Nation (ACFN) and works in media, is experienced in the processes of negotiation with government and industry representatives. In our discussion of industry relationships with First Nations communities, she talks about how industry 'partnerships' with Indigenous communities are actually strategic relationships built ultimately for financial gain. She introduces me to Aboriginal Youth Task Force (AYTF) teams, which are initiatives designed to bring Indigenous communities like hers onside with industry interests (Excerpt 6.1). 


\section{Excerpt 6.1: Denise}

1 D these sectors have what they call aboriginal youth task force + and

2

3

4

5

6

7

8

9

10

11

12

13

14

15

16

17

18

19

20

21

22

23

24

25

26

27

28

29

30

31

32

33

34

35

36

37 they are HIGHly funded + and HIGHly slick they get CURRICULUM developers to come in and they hire curriculum developers usually aboriginal curriculum developers so they make sure that it's culturally sensitive <quotation gesture > + materials um + and then they take these basically TEAMS to: small first nations communities that are either going to be impacted by + or given opportunities to work in certain sectors so make deals with or + to be impacted either environmentally or like

$\mathrm{K}$ huh

D right there + um they go into these communities with these aboriginal youth task force usually + WELL before their projects or applications are put in + um they + usually through their philanthropic arm $<$ quotation gesture $>$ uh offer some sort of funding TO the education program + either new + new gym new + new

$\mathrm{K}$ yeah

D equipment //new $\backslash$

K lokayll

D computers uh + and then: through that they're like we just wanna give them + some information to your student body about the type of + fields that exist for employment within our sector + and they start as young as grade three and four

K wha::t

D + three and four + WE:LL before projects come in + INundating these children with + the possibilities of working in: in: uranium mining: in DIAMOND mining: + in: potash mining in oil and gas + in TAR sands this happens in chip this happens in mckay this happens in ALL those //communities around fort chipl

K /wo::wll

D so: you talk about the p r ar:m like + the stuff that WE see as the public? + that doesn't even necessarily GO to these small communities because they're so small and rural + you take it one step further they HA:VE + slick teams + aboriginal youth task force teams that are + their sole job is to get the youth + who are the next leaders the largest growing demographic //in canadal

K /yeah truell yeah
D to be onSIDE with industry 
Denise introduces the AYTF with an emphasis on their resources (highly funded and highly slick: 1-2). While describing their use of Aboriginal curriculum developers, Denise uses air quotes with her hands (Figure 6.16) when she says the phrase culturally sensitive (4-5).
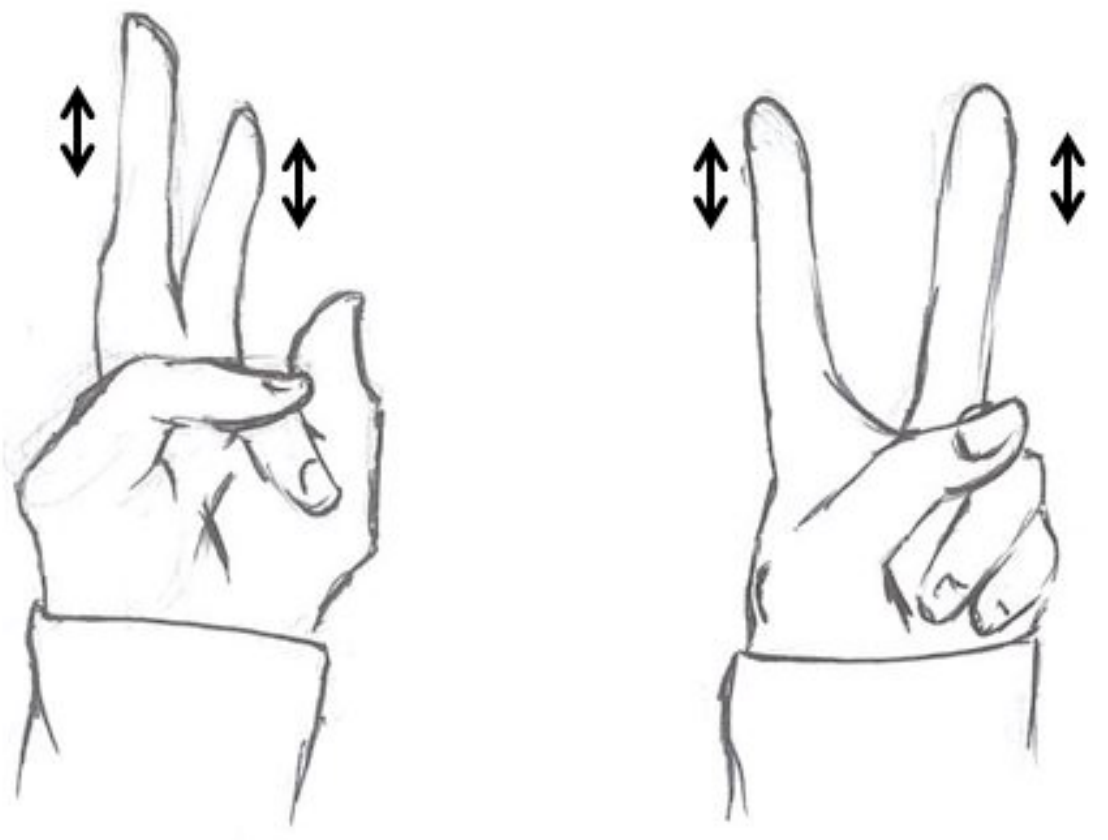

Figure 6.16: Quotative Gesture

As a performative gesture (Kendon, 2004), this marks the phrase as one used by industry actors, effectively quoting them. Additionally, Denise uses a mocking tone which helps present her quotation as sarcastic (e.g. Capelli, Nakagawa, \& Madden, 1990). She then explains that the teams begin interacting with First Nations communities early on (well before their projects or applications are put in:12-13) and that they bring offers of funding (new gym, new equipment, new computers: 15-19). This is done through the company's philanthropic arm, a phrase which Denise once again marks with air quotes (Figure 6.16). In this way, Denise might also be displaying her awareness of industry practices, establishing herself as 
knowledgeable on the subject. Next, she takes on the voice of industry by switching pronouns (we just wanna give them: 19-20), enacting a sort of performance of industry actors (see Chapter 8 for more discussion on this phenomenon). In this way, she demonstrates how schools are approached by the AYTF teams (19-21). This, she exclaims, happens very early (as young as grade three and four: 22) which causes me to answer in surprise (what: 23). Denise then repeats (three and four well before projects come in: 24), which seems to reassure me as to the truth of this statement. She next describes the effects of this in terms of a flood metaphor (cf. Baker et al., 2008, p. 287) (inundating these children:24), which may construct such marketing strategies as unstoppable and capable of leaving communities feeling hopeless. She explains how the teams present children with job opportunities in various mining industries (uranium mining, diamond mining, potash mining, oil and gas: 25-26) and how this occurs throughout the region (27-28). Denise then summarises this discussion by describing what she sees as the ultimate purpose of the AYTF teams: they use these techniques to gain support from community members (their sole job is to, be onside with industry: 34,37$)$. She explains that the goal is to strategically garner support from a specific subset of the community (get the youth who are the next leaders the largest growing demographic in canada: 34-35). In short, Denise describes the AYTF in terms of the problematic way that they are used by industry to solicit approval of development from small, rural First Nations communities. We might consider how this positions industry actors as using communities for their own marketing (and workforce) goals: in effect, appropriating them for a wider purpose.

Indeed, the way in which these teams behave when visiting communities suggests a more strategic goal. Denise discusses how AYTF teams, and companies in general, elicit sponsorship opportunities through (branded) gift-giving (Figure 6.17). 

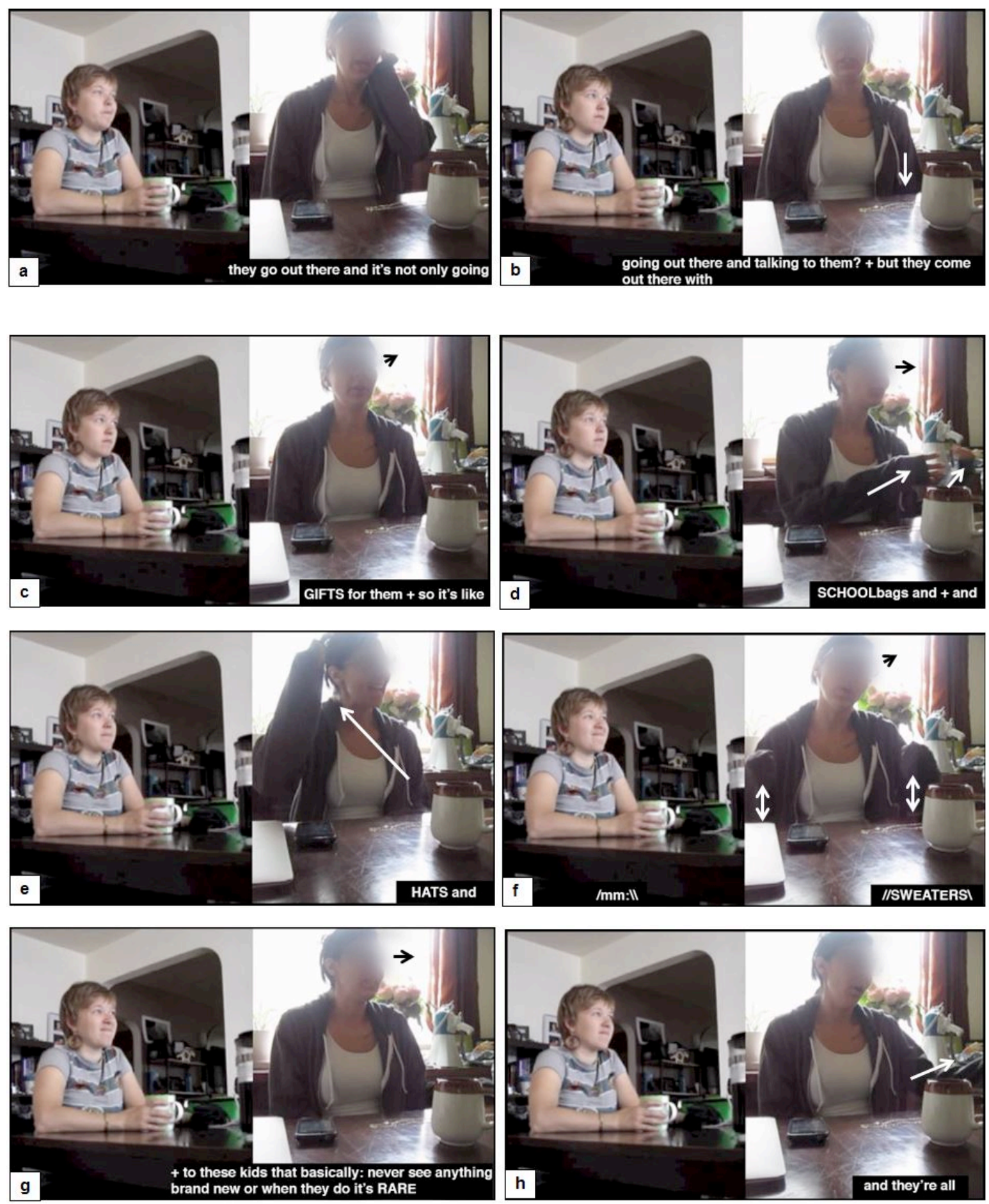

Figure 6.17: Denise

Denise explains that groups going to communities will also bring gifts for students $(b-c)$. While she says gifts, Denise increases her volume and establishes mutual 
gaze, arguably highlighting the word (Norris, 2009). She then elaborates on the kinds of gifts given (schoolbags, hats, sweaters: $d-f$ ) while iconically performing the items. Next, she explains why she finds this practice so problematic: that they are in fact branded with company names (Figure 6.18).
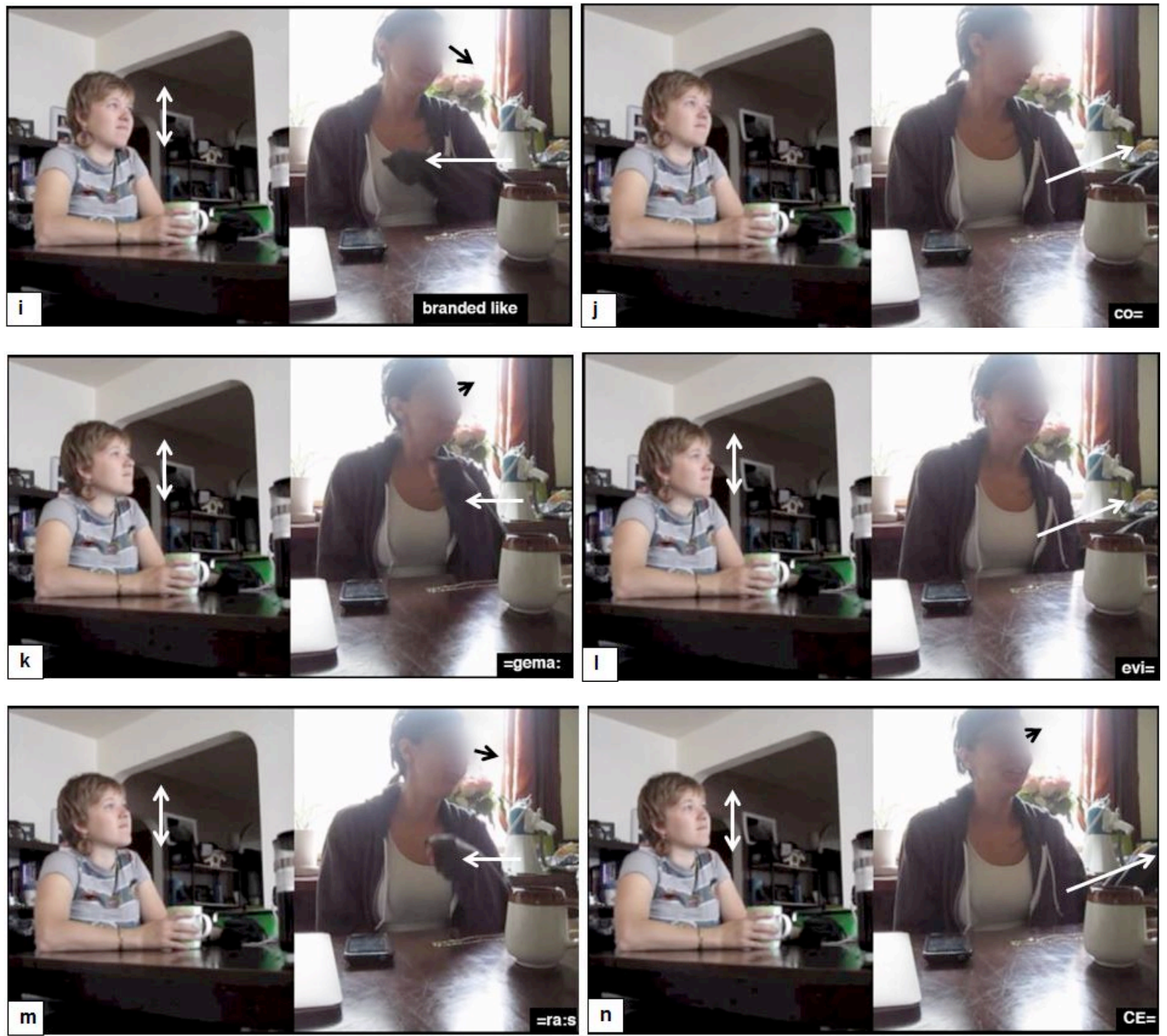

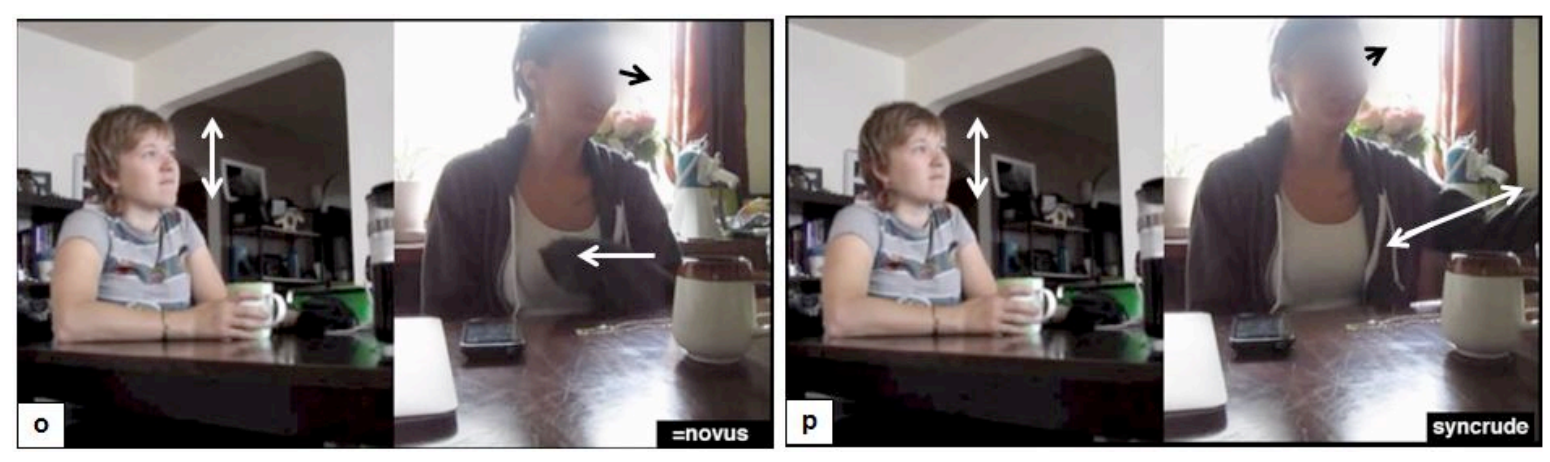

Figure 6.18: Denise

As she makes this point, Denise also moves her LH from the side and swipes it across the front of her body (i), as if mimicking the left to right motion of writing text (cf. Kress \& van Leeuwen, 2006). She then lists the names of various oil and gas companies while simultaneously repeating the branding gesture and establishing mutual gaze at the onset of every new name (j-q). In this way, Denise appears to highlight the vast number of companies that engage in this practice, thus emphasising the overwhelming nature of their sponsorship. She finishes this critique by explaining how it affects her own hometown as a whole (Figure 6.19).
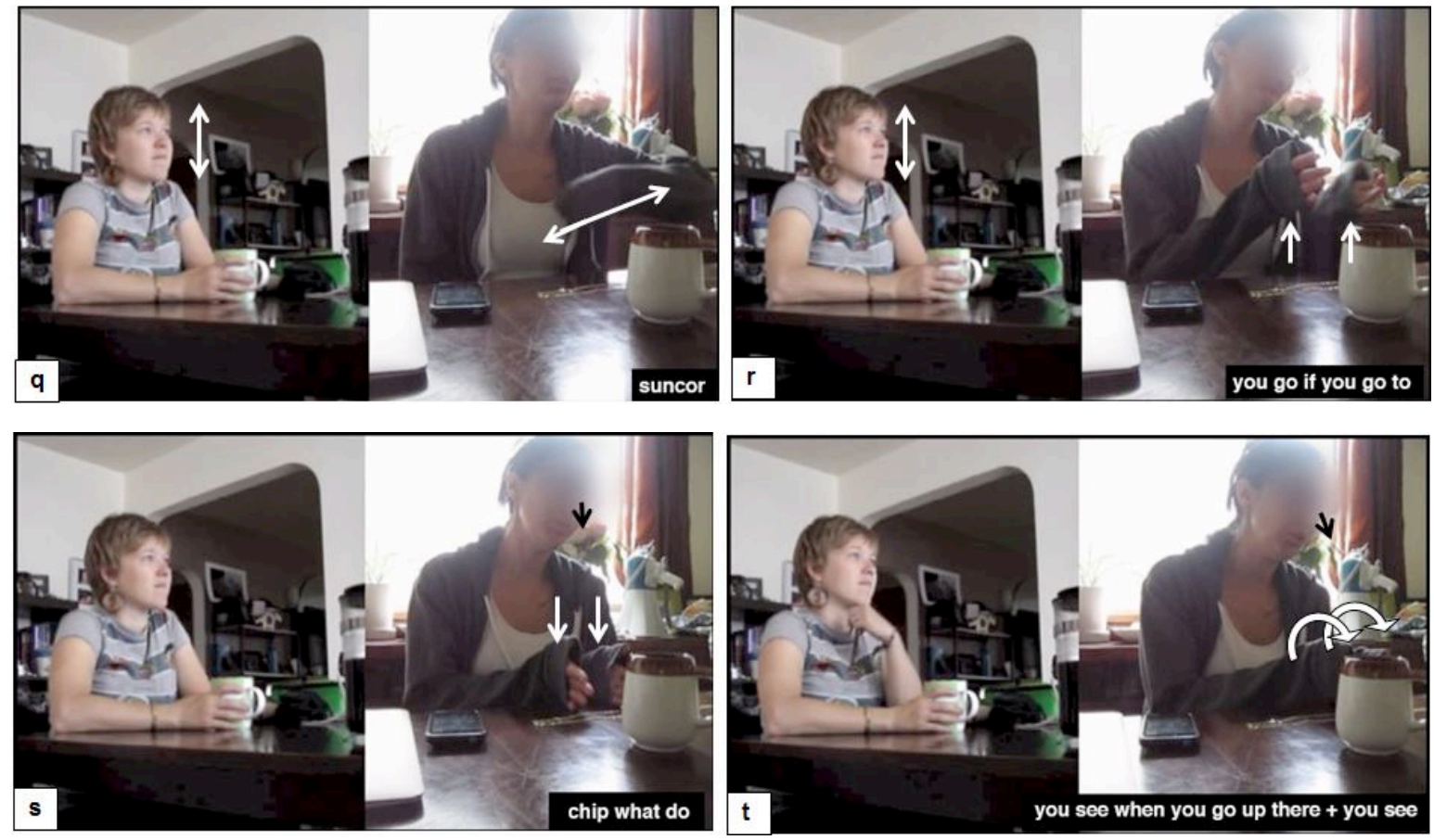

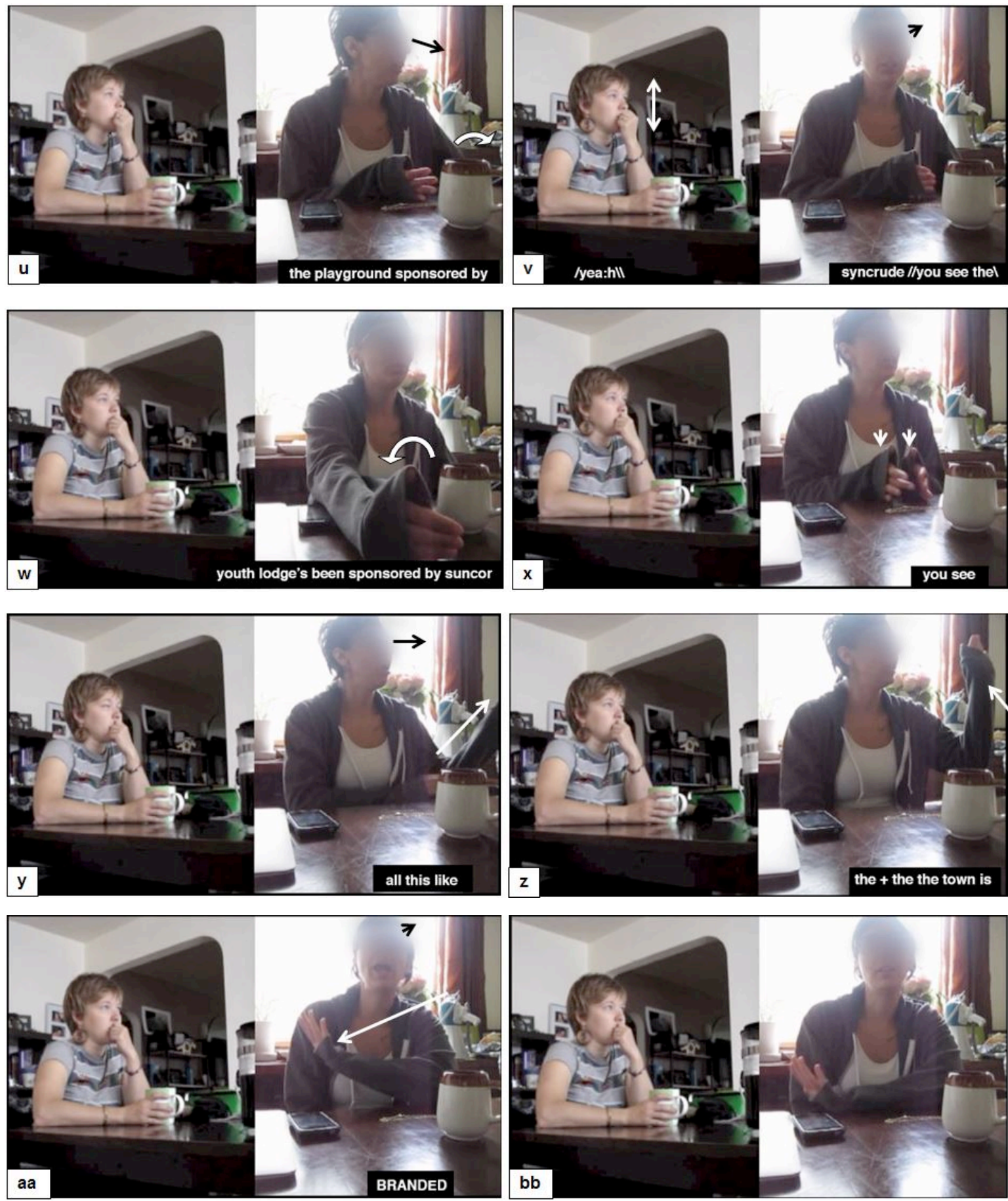

Figure 6.19: Denise

She describes how a visit to Fort Chip will show the evidence of this branding (if you go to chip what do you see: r-t). Here, Denise uses the shortened form (chip) for Fort Chipewyan, drawing upon our shared knowledge of the region and 
seeming to position me as a local (see Mondada, 2013). While she says this, she places $\mathrm{BH}$ palms facing inwards in a metaphoric gesture which establishes the hypothetical you as a visibly delineated space on the table (s). Next, she moves this gesture unit slightly to the left, perhaps mimicking the transitory action of traveling (when you go up there: $\mathrm{t}$ ). Denise then shifts her gaze to the left where her LH moves out, conceivably presenting the playground she speaks of (the playground sponsored by syncrude: u-v). Next, she leads with her gaze to the middle distance and moves her $\mathrm{RH}$ in front of her onto the table, leaning into the camera (the youth lodge's been sponsored by suncor: v-w). Much like her LH, her $\mathrm{RH}$ movement can be interpreted as a figurative depiction of the youth lodge of which she speaks and, by placing these items around her body, she also enacts the idea that they surround her, in keeping with her previous flood description (Excerpt 6.1, inundating these children: 24-25). Finally, Denise concludes her point by returning to the you with $\mathrm{BH}$ palms facing inwards on the table in front of her (you see: $\mathrm{x}$ ). She then moves once again into the space to her left, as if she is about to elaborate on more items that are branded in the town (all this like: $y$ ). She brings up her LH and repeats the original branding gesture, swiping her arm across her body while saying the town is branded (z-bb). By repeating this previously established gesture, Denise not only cohesively links this concept to what she said before (i-q), but she alters it slightly (see McNeill, 1992, for more about cohesive gestures with alterations). Where before her hand was held with her fingers together, here she spreads her fingers wide and places her palm outwards, which suggests that the branding of the town is more dramatic, or occurring to a greater extent.

It is here that Denise seems to articulate a wider invasion of her community by industry Discourses. No longer a matter of appropriation, here the dialectic turns and company Discourses colonise community spaces (Chouliaraki \& Fairclough, 1999). Denise's branding example shows the explicit nature of this colonisation as occurring through text. Additionally, from an industry perspective, branding of this nature helps companies financially: from reputation management to mere brand 
repetition (Santulli, 2011), sponsorship is "advertising plus" (Allori, 2011, p. 80).

These practices take on a more problematic dimension when we consider them within the wider context of Aboriginal communities in Canada. By claiming the right to name community spaces, companies in fact locate themselves within a colonial history of re-naming Indigenous spaces in general (e.g. Smith, 1999, p. 51). This kind of direct industry sponsorship within Aboriginal communities can thus be read as a neocolonial activity. Thus, what is described as a partnership ${ }^{9}$ by industry actors, takes on a much more nefarious and disingenuous nature when considered from a First Nations' perspective.

The neocolonial behaviour of the oil and gas industry can have seemingly subtle results. Denise explains how this sponsorship leads to communities like hers becoming economically dependent on the oil and gas industry. In Excerpt 6.2, she discusses how this discursive colonisation helps industry representatives secure support for development projects.

\section{Excerpt 6.2: Denise}

1 D because + when + the industry comes up there they're like oh no no

2 this is this has NO:thing this is not about making an impact benefit

3 agreement + we just want to show you that we are coming here in

4 GOOD faith to begin our discussion and we really wanna + help your

5 community GROW so we're gonna sponsor a new YOUTH centre +

6 and then you know three months four months one year down the road

7 they come in and they're like oh we'd like to make an impact benefit

8 agreement we have a new proposal + on the table

$9 \mathrm{~K} \quad \mathrm{hm}$

10 D so let's let's sit down and talk you know we've had a REALLY good

11 relationship //in the last yearl

$12 \mathrm{~K} \quad / \mathrm{mm}: \$

${ }^{9}$ See Catenaccio, 2011 for a discussion on corporate philanthropy and the term 'partnership'. 
13 D let's begin to discuss how we're gonna move forward with our project

14 + so you lay they lay have laid the foundation to make them seem like

15 they are the good guy + they are the employer + they're the people

16 that give our kids things + um: you know our children are gonna

17 WORK in this industry because NO other industry has gone there to

18 tell them about like +

Denise explains that the industry's work in her community is prefaced with an expression of good faith (this is not about making an impact benefit agreement, we are coming here in good faith:2-4). She adopts the industry's voice through the use of quotative like and a shift in pronouns (1-3), and outlines their approach with a hypothetical example (we really wanna help your community grow so we're gonna sponsor a new youth centre: 4-5). She then reverts back to her narrative voice (you know: 6) and explains that months later the companies will return to the community (6-7). Once again, Denise adopts the industry voice and describes how they then request consent for development (and they're like oh we'd like to make an impact benefit agreement we have a new proposal, let's sit down and talk:

7-10). She emphasises how industry actors leverage their previous work with the community (we've had a really good relationship, let's begin to discuss how we're gonna move forward: 10-13) and summarises this strategy by reverting back to her own voice (they lay have laid the foundation to make them seem like they are the good guy: 14-15). Here, Denise seems to suggest that industry is only coming to the community to build and invest in a positive reputation which will yield financial gains through community support for oil and gas projects. She elaborates on how this reputation is cultivated (they are the employer, they're the people that give our kids things, our children are gonna work in this industry: 15-16). By shifting pronouns, Denise takes on the voice of the community itself (our kids, our children: 16), perhaps relating the internal discussion within the community about whether or not to support the project.

She then draws attention to the power discrepancy in this negotiation by explaining that the industry's influence is due to its considerable financial resources 
(Figure 6.20).
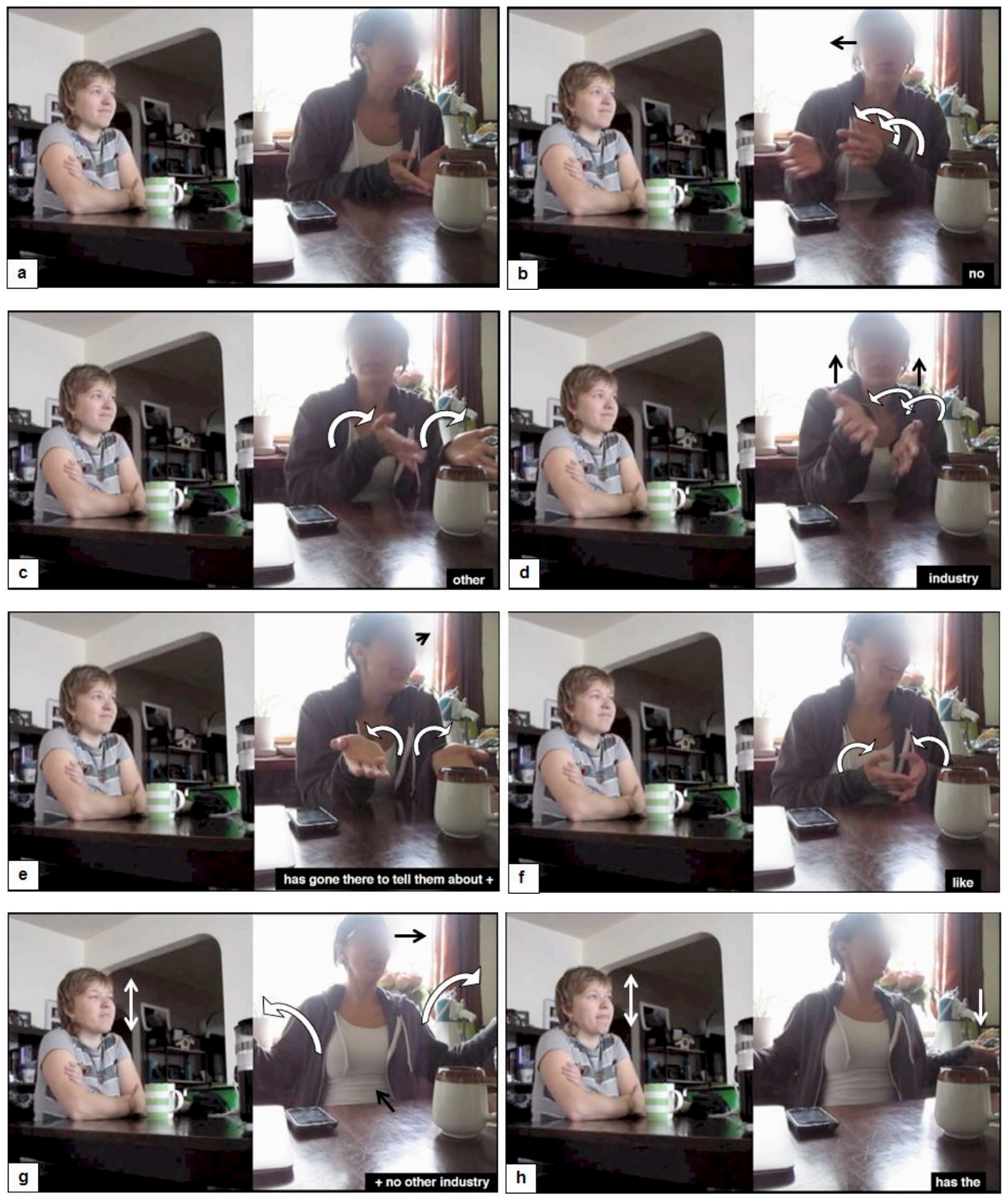

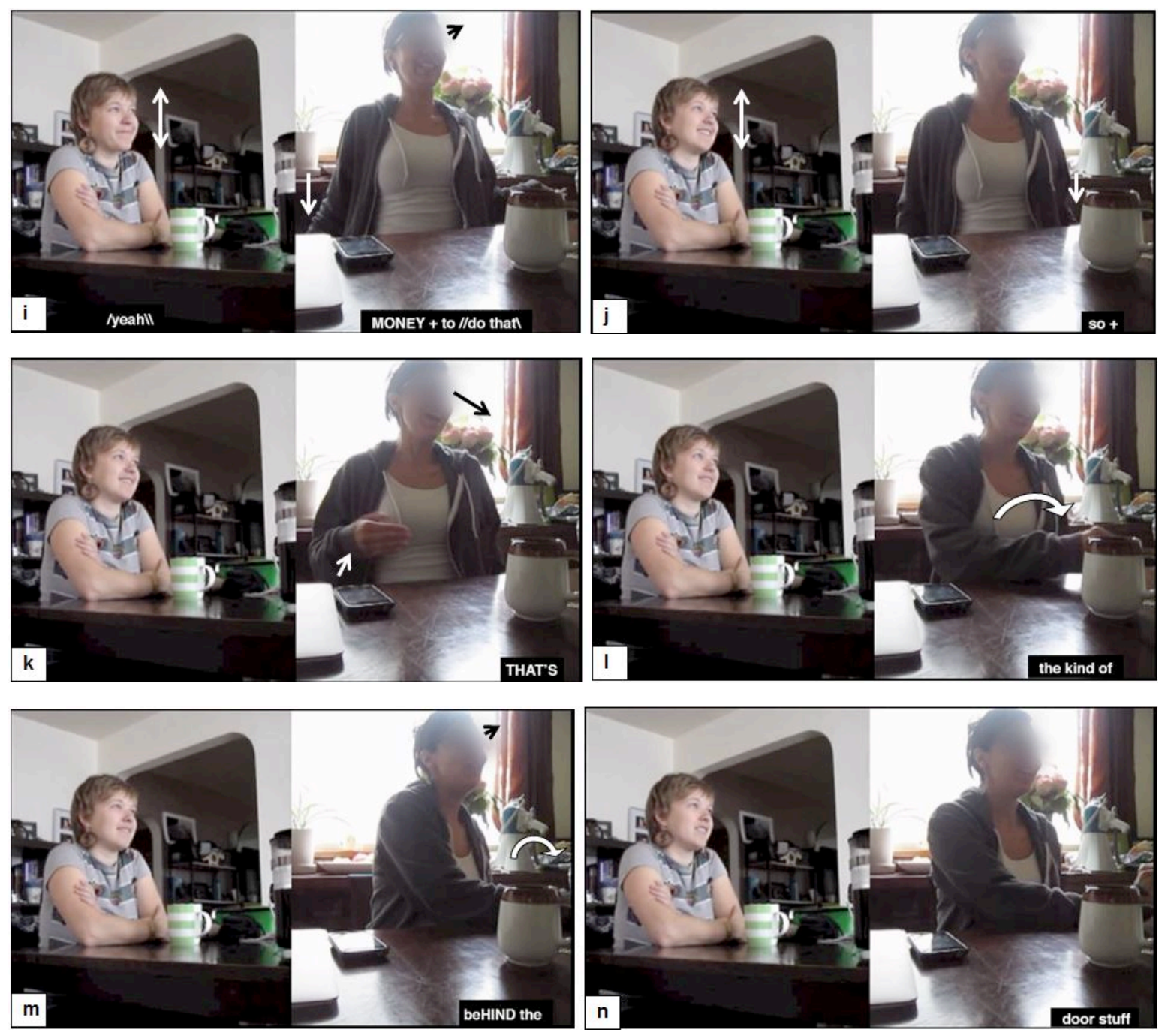

Figure 6.20: Denise

Denise explains that the oil and gas industry has gained support in communities like hers because they are the only companies who have approached them (no other industry has gone to tell them about: (a-e). She enacts this situation by holding up $\mathrm{BH}$, palms up and tilted slightly inwards in a palm presentation gesture which suggests an expectation of receiving something (Kendon, 2004, pp. 271272). She then moves her hands to the right, left, and centre (b-d), which might depict her community's action of searching. The last movement is accompanied by a shrug, which suggests a stance of disengagement or "letting go" (Streeck, 2009, p. 168), possibly highlighting the helplessness felt by residents. She then 
completes the shrug by twisting her wrists to open her palms in a presentation gesture (e) (see Streeck, 2009). Next, Denise meets both her hands together (f), which ends the gesture unit before spreading her hands out in a wider and more exaggerated gestural shrug while leaning back in her chair $(g)$. She explains that the reason for the oil industry's advance into communities is because no other industry has the money ( $\mathrm{g}-\mathrm{i})$. This explanation is accompanied by a slight lowering and hold of her palms, before dropping them in quick succession (h-j). By emphasising money (i) and leaning back while holding the shrug position, Denise intensifies her earlier shrug, suggesting a corresponding intensification in her stance that the community is unable to counteract such advances. By dropping her hands and ending the gesture unit (j), Denise marks the end of her exclamation (McNeill, 1992) and then summarises what she has said. She brings up her RH and shifts her gaze to the table, foreshadowing her next gestural trajectory (see Streeck, 2009). She then places her $\mathrm{RH}$ on the table, pausing to beat along the trajectory while she explains that these strategies are enacted behind the door (In). By beating on the table, Denise may be establishing the door of which she speaks before moving past it. This gesture phrase suggests that industry sponsorship campaigns go beyond what most of the public knows (see also Excerpt 6.1 you talk about the pr arm, the stuff that we see as the public: 30-31).

The result of these sponsorship strategies is that communities are placed in difficult situations. As Denise explains in our interview, because first nations people have a huge ability to stop these projects and because industry knows this, industry actors must invest in good relations in order to develop a positive reputation. As a result, community members will not assert their rights to halt projects because they have become reliant on them. Denise puts this in no uncertain terms: why would you want to bite the hand that feeds you?

The oil industry's AYTF teams even develop this economic reliance in their school visits. Denise explains their approach (Excerpt 6.3). 


\section{Excerpt 6.3: Denise}

1 D and and and then also you + just this like whole BRAIN washing tactic

2 of going into their schools over and over again + and telling their youth

3 that this is + this is the way to go ++ you //wanna bel a part of the +

$4 \quad \mathrm{~K} \quad / \mathrm{mmll}$

5 D you wanna be a part of the modern world + do you want an ipad two

6 do you want a //ce:Il pho:nel do you want a big truck do you want a flat

7 screen tv well you can HAVE ALL of that if you work in our INdustry

$8 \quad \mathrm{~K} \quad / \mathrm{mm} \backslash$

9 D a:nd and so we're inundating + these children in these communities

10 with like + um + <laughing > you know the american drea:m

$11 \mathrm{~K}$ ye//a:hl

12 D land $\backslash$ telling them the only way that's gonna be possible is through

13 this industry or through like this and + and like oh don't worry we're

14 doing our best to ensure that the wa:ter is protected and you know we

15 have some of the BEST technologies to //make sure that you'll STILL

16 be able to swim in your lakes and your streams and your river

17 syste:ms and +

$18 \mathrm{~K} \quad$ /yeahll

19 D you'll have this for your future generations

She characterises the strategy as brainwash (this whole brain washing tactic of going into their schools over and over again: 1-2). This is accompanied by a gesture where she repeatedly extends her hand out to her side and brings it back to her body (Figure 6.21).

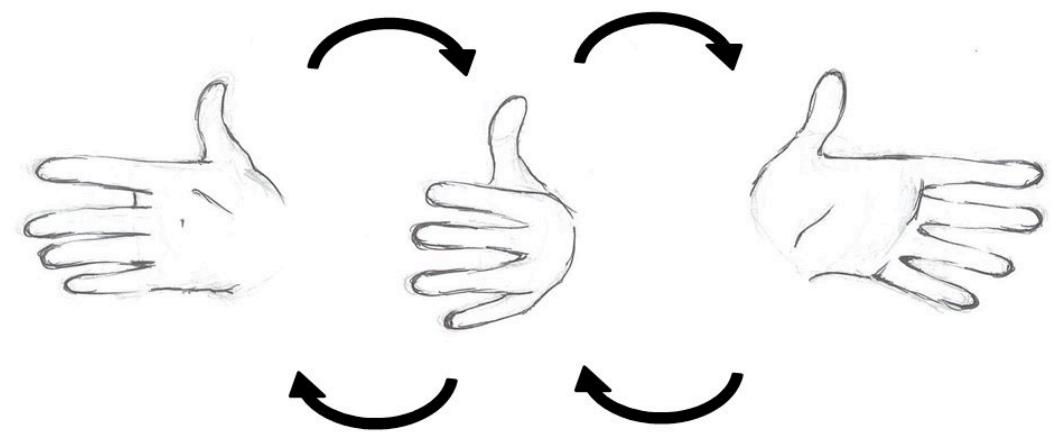

Figure 6.21: Brainwash Gesture 
This repeated gesture seems to reference the repetition of entering the schools (over and over again: 2). Next, she once again adopts the voice of industry through a quotative and pronoun shift (telling their youth, you: 2-3). In the next utterance, Denise describes the ways in which industry sells jobs to youth: by promoting financial mobility as a way to enter the modern world (do you want an ipad two do you want a cell phone do you want a big truck do you want a flat screen tv well you can have all of that if you work in our industry: 5-7). At the same time, children are reassured that their environment will be protected through the help of technology (ensure that the water is protected, we have some of the best technologies: 13-17). Throughout this example, Denise argues that the oil and gas industry is invading the community and targeting children (brainwash tactic of going into their schools), enticing them with economic gains (e.g. ipad, cellphone, big truck). Her lexical choices (modern world, american dream) suggest there is pressure to conform and move away from traditional livelihoods or, in other words, to assimilate. I take up Denise's point and summarise it as explicit neocolonialism (Figure 6.22).
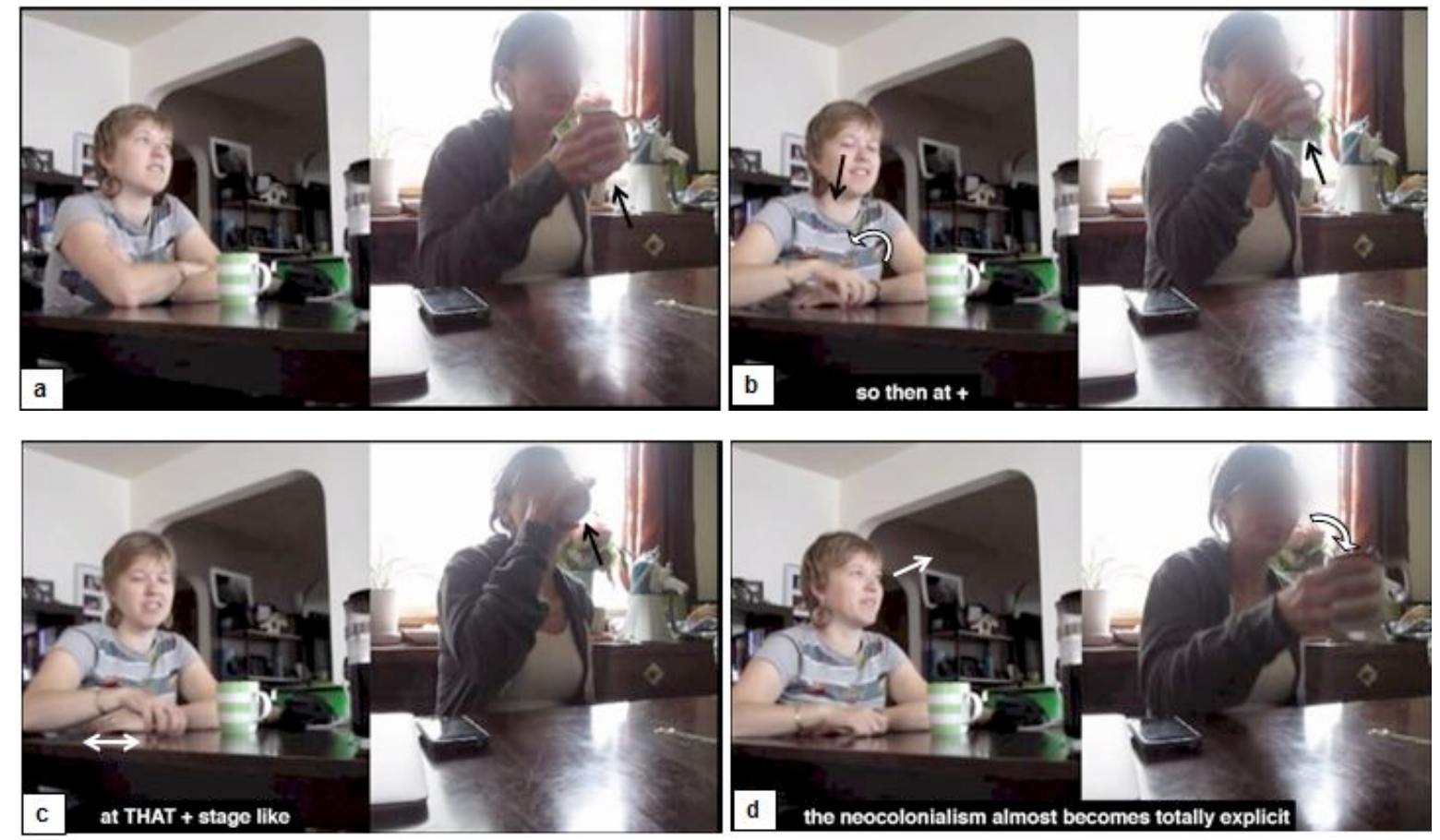

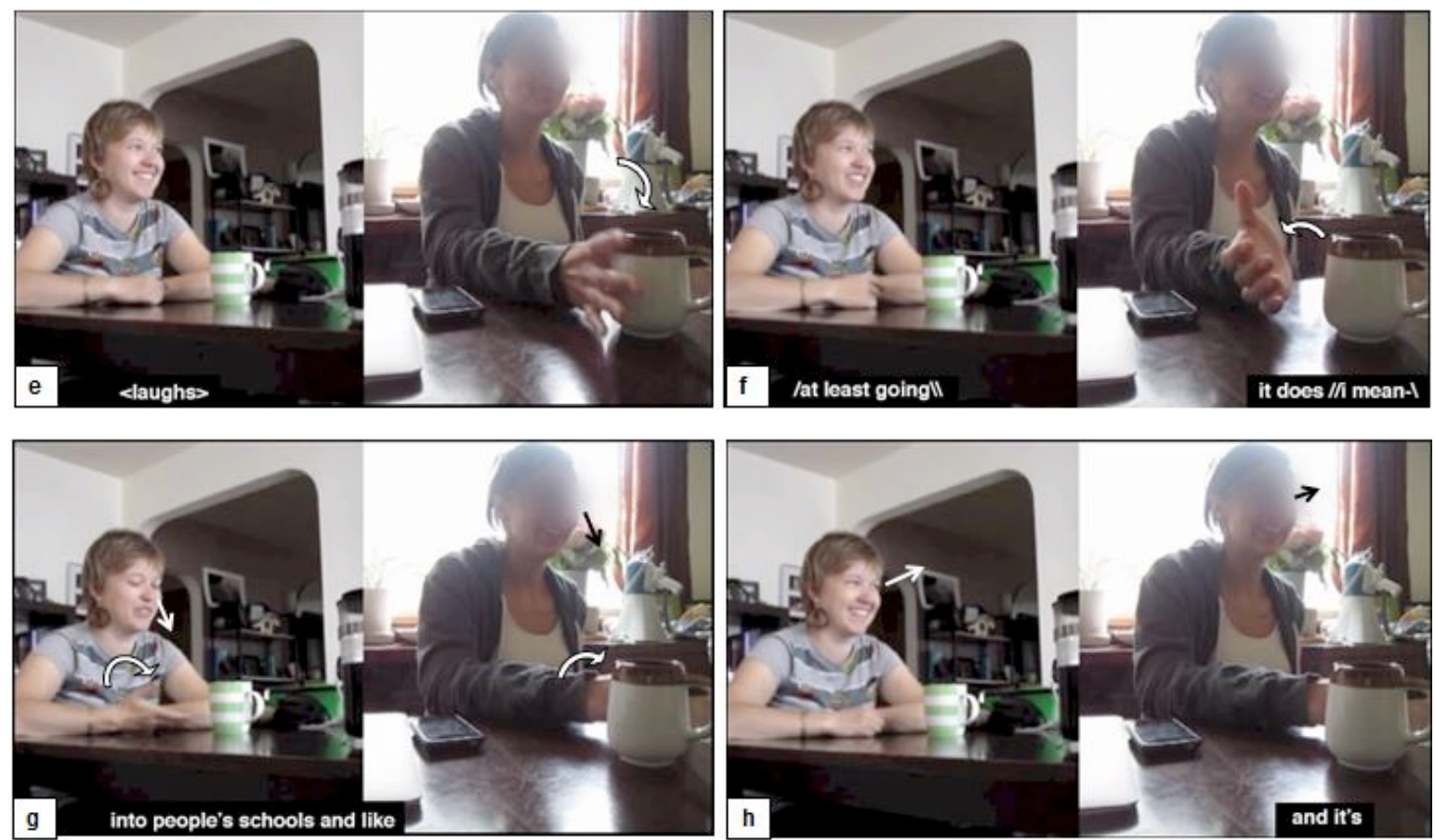

Figure 6.22: Denise

While summarising Denise's explanation (so then at that stage like the neocolonialism becomes totally explicit: $\mathrm{b}-\mathrm{d}$ ), I place my $\mathrm{RH}$ onto the table in front of me and shift my gaze towards it (b). I then move it back and forth repeatedly on the table, similar to Denise's motion when discussing the industry teams going into schools (Figure 6.21). By mirroring her earlier gesture, I suggest a cohesive link between my own utterance and hers (McNeill, 1992). I then begin to laugh and Denise puts down her mug (e), and uses her $\mathrm{RH}$ to gesture to the side with her palm up, which suggests she is commenting upon this idea (Kendon, 2004, pp. 265-266) (it does I mean: f). However, I interrupt her to further explain why I consider this neocolonialism, and I mark my interruption by repeating her palm presentation (Kendon, 2004) gesture with my own $\mathrm{RH}$ (at least going into people's schools: g). By repeating this gesture, I present a comment upon my earlier idea (Kendon, 2004) and most likely align with Denise through my gestural mimicry (cf. Kuśmierczyk, 2013). Additionally, the expansion of my neocolonialism idea directly repeats the comment Denise had made earlier when she enacted the original hand gesture in Figure 6.21 (brain washing tactic of going into their schools over and 
over again). By comparing both our gestures and utterances, we can see that they are indeed thematically linked and that my gesture recontextualises Denise's brainwash gesture as one of neocolonialism. As such, both Denise and I discuss the dynamics of the oil and gas industry and local Indigenous communities within a frame of colonialism (be a part of the modern world, neocolonialism).

Denise's recounting of community experiences with industry programs like the AYTF teams gives a very different view of the solid relationships discussed by Brandon and the CAPP document (Figure 6.15). Denise constructs local First Nations communities' reliance on the oil industry as a strategy planned by industry and backed by considerable resources (e.g. the branding of Fort Chip, and the use of AYTF teams). Additionally, Denise and I co-construct the oil and gas industry's early influence on Indigenous schoolchildren via AYTF teams as problematic (neocolonialism becomes totally explicit, inundating these children, brainwashing tactic). We align in our criticism of these industry strategies as invasive (going into their schools over and over again).

Viewed from a wider lens, we might consider how this strategic reliance on a fossil fuel economy which destroys traditional lands joins with a neo-colonial agenda of assimilation. The negative effects on land and water resources caused by industrial development (Kelly et al., 2009) mean that traditional economies and subsistence practices are threatened, undermining community self-determination. As long as traditional practices in First Nations communities provide economic independence, resistance to fossil fuel development can be expected. It is therefore in the industry's best interest to cultivate reliance, so that community members are left with few economic options but to support oil and gas projects on their land. Until this happens, local communities constitute an obstacle to development, much in the same way Indigenous Nations are viewed as obstacles to the Canadian State (see Regan, 2010 for a critical discussion of the "Indian problem"). By encouraging the assimilation of Indigenous communities into a fossilfuel economy, industry actors thus align themselves with the wider, neo-colonial 
goal of assimilating Indigenous communities into the Canadian State. In this light, the Indigenous partnerships constructed through the appropriation of symbolic imagery (such as bison) is contested as a partnership that is constructed through unequal access to powerful resources. In other words, the partnerships between industry and First Nations communities seem to be a result of carefully managed marketing and engagement strategies, which are designed to leave residents economically dependent on the very companies who are destroying their lands.

\subsection{Multimodal Resistance: Alternative Economies in Fort Chip}

In situations like this, where economic reliance leaves few other options, and systems of oppression run deep (i.e. to the singing of the Treaties as discussed in section 1.5), resistance may be very subtle. Additionally, groups are diverse and may be divided, or coming to terms with the realities faced by other communities (e.g. Fort McKay). Speaking out against livelihoods can result in backlash from both community members working in the tar sands and industry actors themselves (consider Denise's statement, why would you bite the hand that feeds you?). However, many First Nations communities do recognise the problematic nature of their reliance on oil and gas and, in resistance, have instead begun investing in sustainable resources (Excerpt 6.4).

\section{Excerpt 6.4: Denise}

1 D like + it's not like our community is sitting there waiting for money: + 2 from industry to support our community like our + our chief is looking 3 at independent ventu:re like doing they're exploring green energy in in 4 fort chip right now

$5 \mathrm{~K} \quad$ rea://ly: what kind of things?

6 D /yeah um they're building- 11 Denise lists project examples

7 D but they're doing different projects to see what what's like VIABLe up 8 there for getting people more off the grid because it's REA:lly 9 expensive

$10 \mathrm{~K} \quad<$ sigh $>$ 
11 D to live //+like like people run out of fuel EVERY winter

$12 \mathrm{~K}$ /i can't even imagine + yeahll

13 D ++ because they can't aFFORD it + //and then-I

$14 \mathrm{~K} \quad$ land likell + what's happening up + right now in NUnavut and stuff with

15 the + expenses that people you kno:w just to get foo:d //it's justl

16 D lexACTly\ so if people //can\save on their energy costs by //having

17 like so:lar or geothermal heating or whatever it is-

$18 \mathrm{~K} \quad /$ yeah \\/yeahlI and can keep themselves warm and feed themselves 19 yeah

Denise constructs her community as active (it's not like our community is sitting there waiting for money from industry: 1-2) and investigating alternatives to fossil fuels (our chief is looking at independent venture, exploring green energy: 2-4). This is possibly in response to contemporary constructions of Indigenous peoples as passive victims (Chappell, 2000). After I prompt her (5), Denise lists off various project examples. She then explains the reason for this as primarily financial (it's really expensive, people run out of fuel every winter because they can't afford it: 8-13). She emphasises this problem with a dramatic shrug (Figure 6.23).

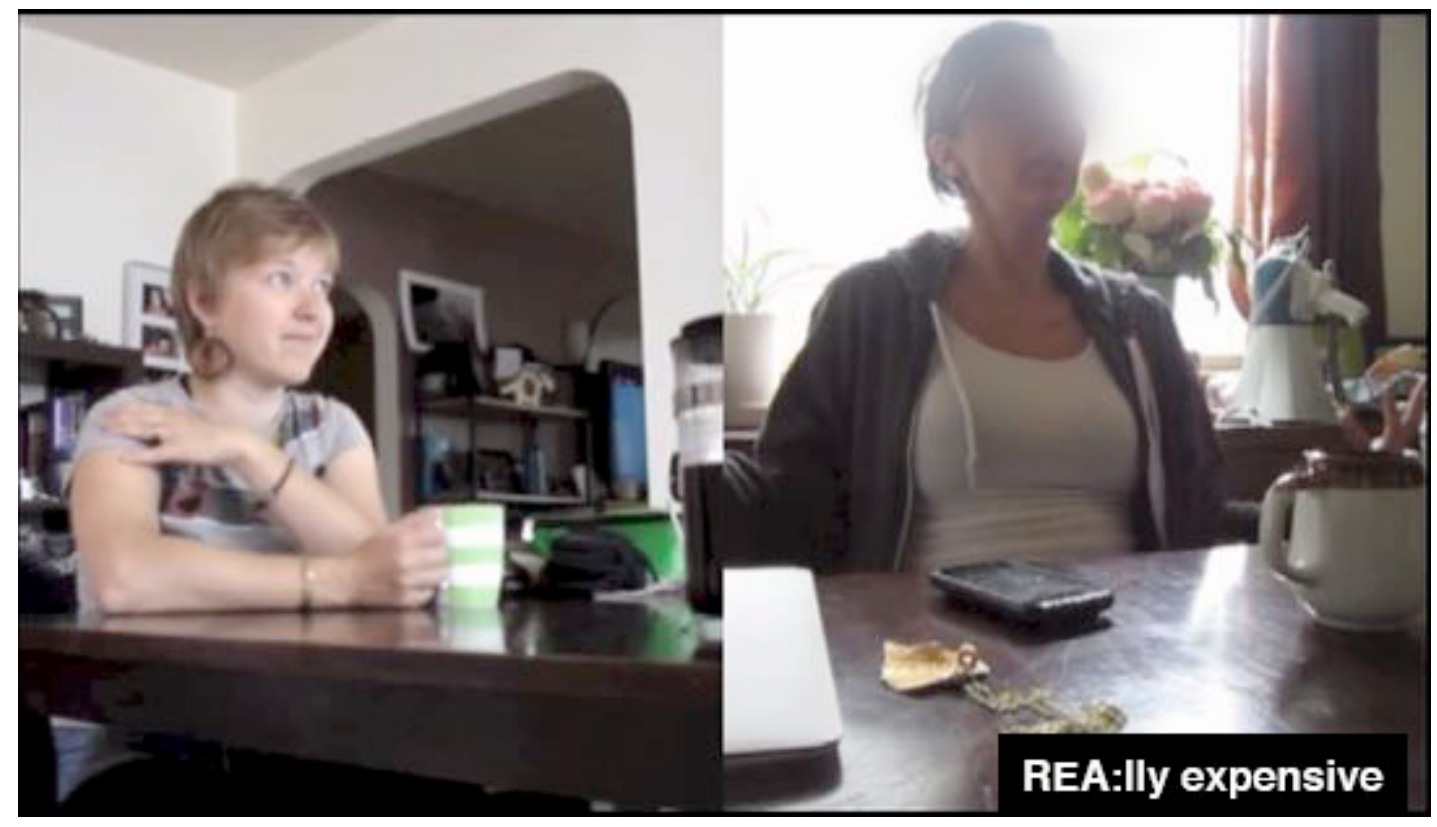

Figure 6.23: Denise 
Here, Denise leans back in her chair, spreads her arms out to either side, and places her palms up. Much like her previous shrug (see Figure 6.20: h), this suggests an attitude of retreat (Streeck, 2009), and multimodally builds up her point (Norris, 2004b).

Denise lists a number of other projects which are helping to move the community away from fossil fuel reliance and how these are part of the larger story of resistance (Figure 6.24).
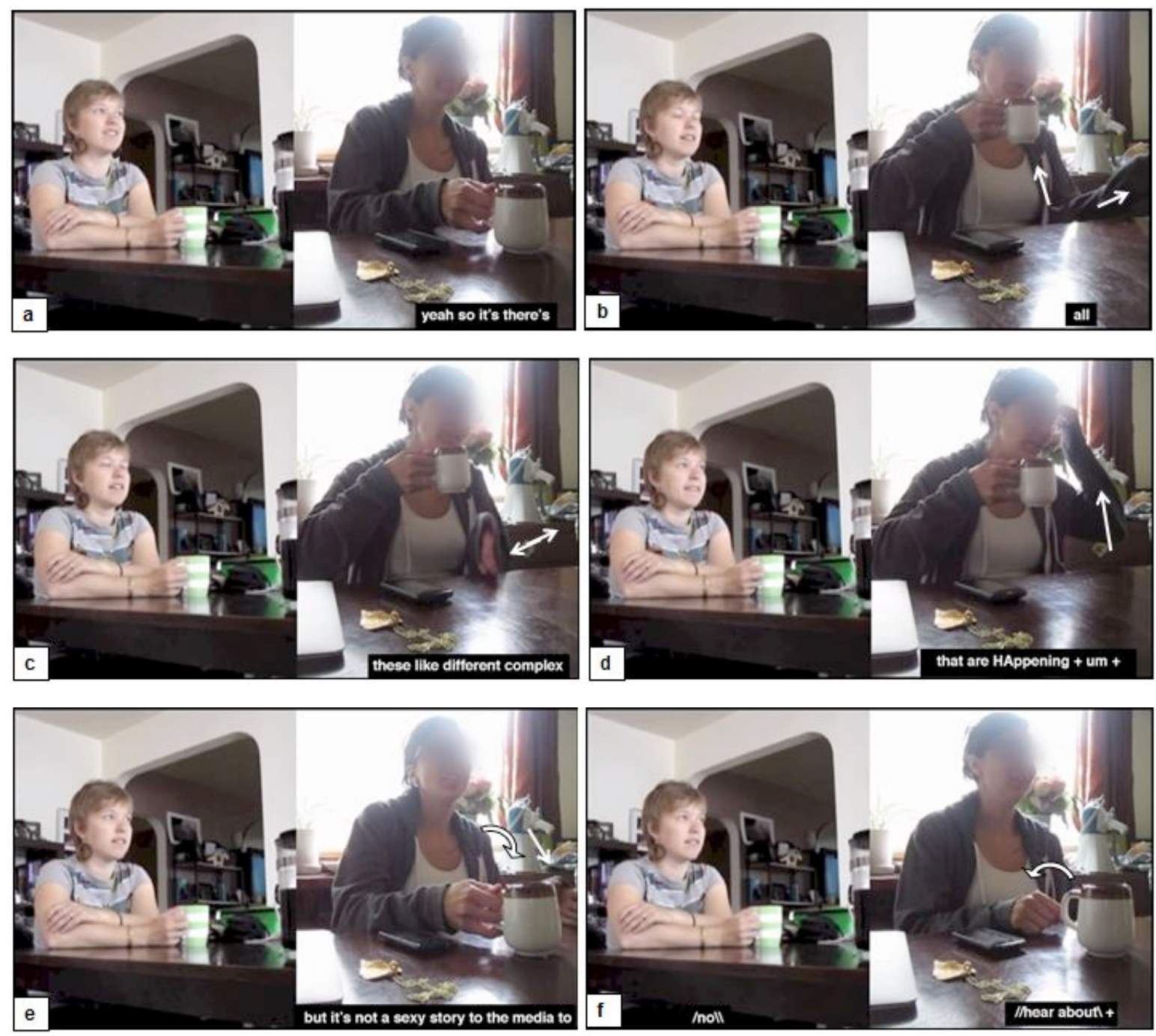

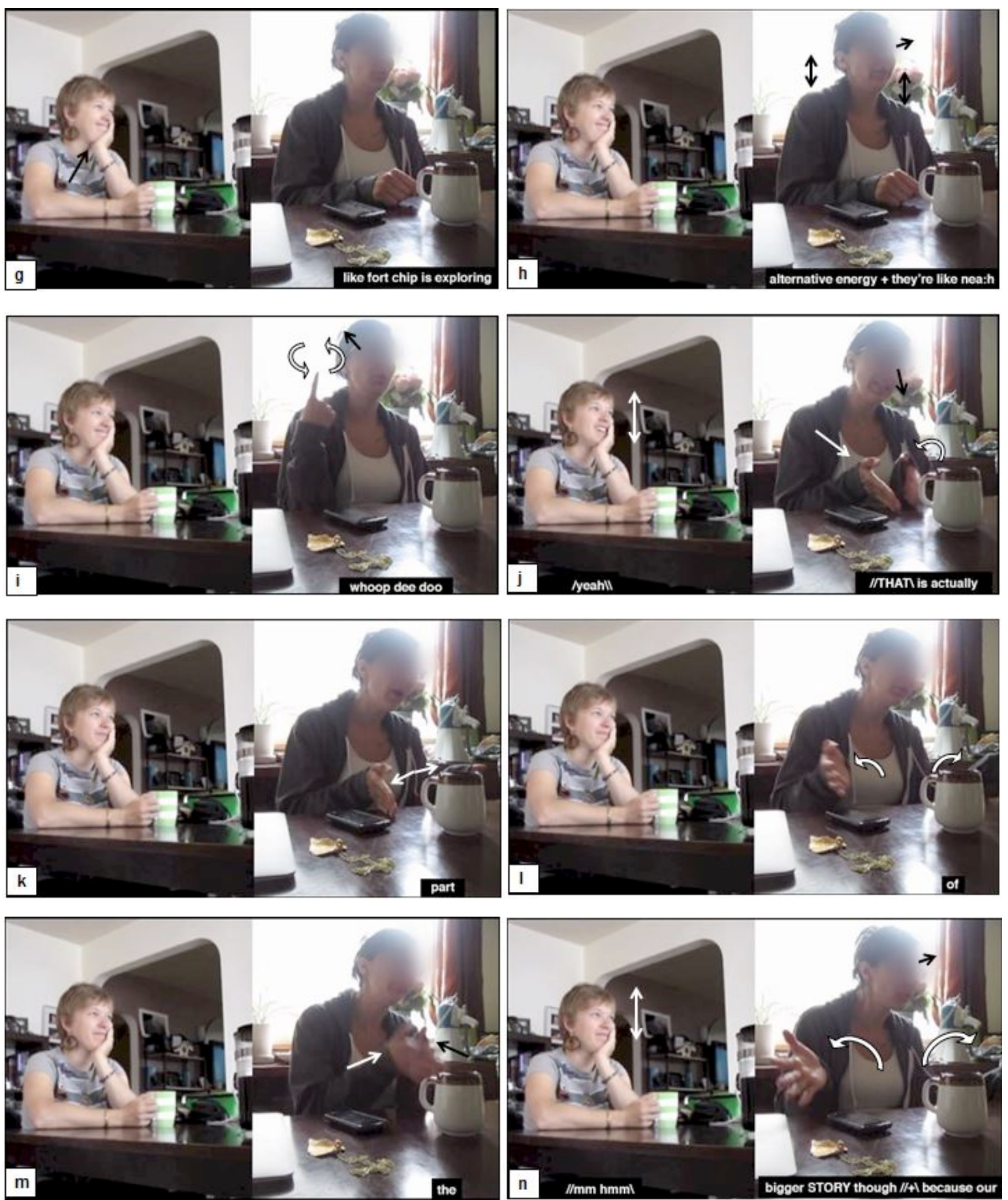

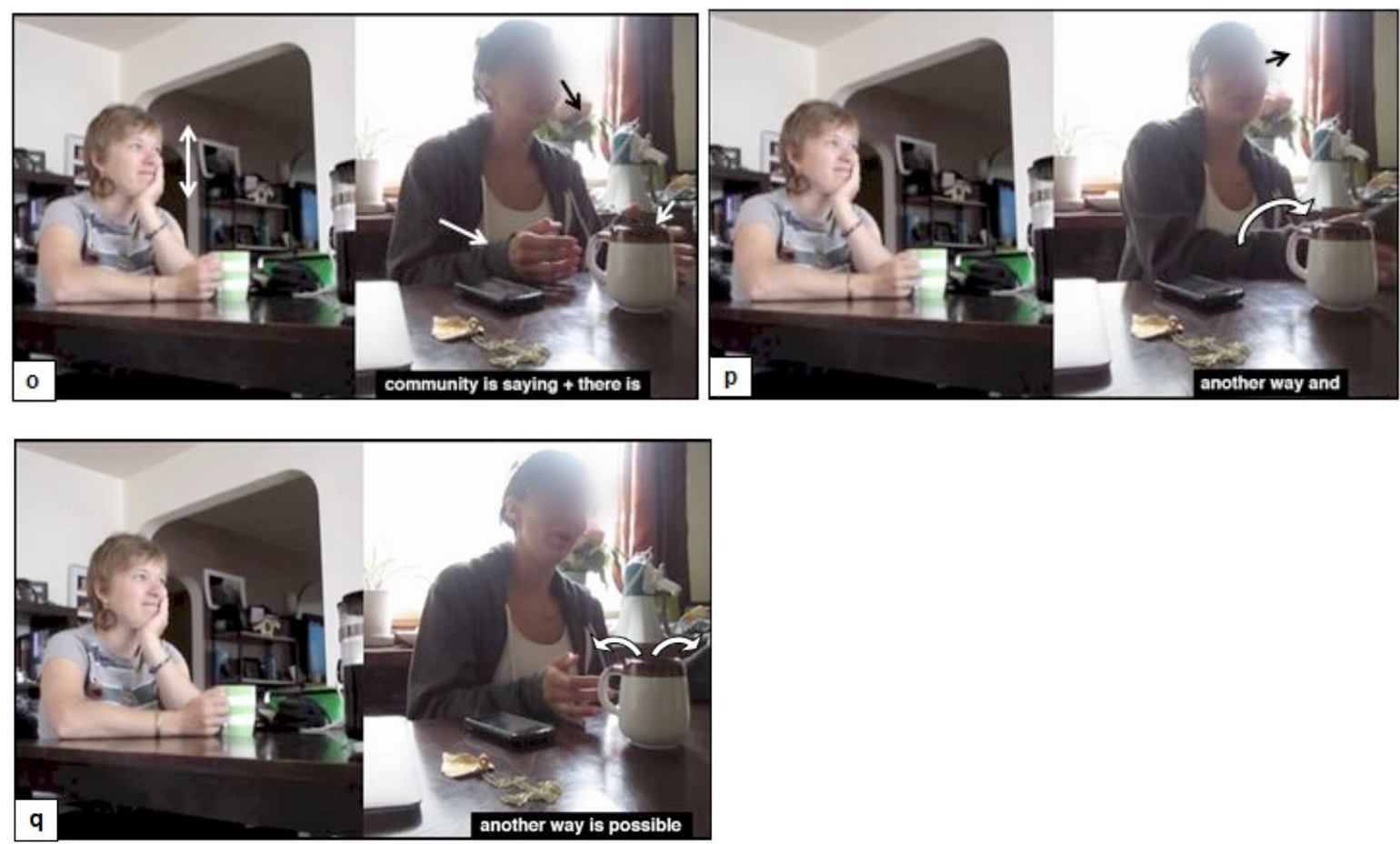

Figure 6.24: Denise

First, she summarises the examples (there's all these like different complex things that are happening: a-d) and waves her LH laterally in front of her (c): a metaphoric gesture apparently referring back to the examples she previously listed. While explaining this, Denise lifts the mug to her mouth but holds it there while she takes the turn $(b-d)$. She places it back on the table and brings her hand back while explaining that these projects are not discussed in the media (it's not a sexy story to the media: e-f). She then enacts the voice of the media through a quotative like and by lowering her voice (like fort chip is exploring alternative energy: $\mathrm{g}$-h). She gives commentary on this statement by quoting, in a mocking tone, the media reaction as one of indifference (they're like neah whoop dee doo: $\mathrm{h}-\mathrm{i}$ ). Denise also shifts her gaze up, raises her $\mathrm{RH}$ to shoulder-level in a deictic gesture, and begins circling it in the air beside her right ear (i): an iconic gesture which might suggest sarcasm. Next, she gazes to the table and brings her hands down together (j) before spreading them apart $(\mathrm{k}-\mathrm{l})$. This gesture suggests she is enacting the bigger story of which she speaks (that is actually part of the bigger story though: $\mathrm{j}-\mathrm{n}$ ). This 
gesture phrase is then repeated less dramatically on the left side of the table as she describes the alternative (our community is saying that there is another way and another way is possible: $\mathrm{m}-\mathrm{q}$ ). By locating the gesture in another space on the table, Denise arguably refers to the ways in which her own community is metaphorically beginning to operate in another economic space. Here, Denise clearly positions Fort Chip's exploration of green energy as part of the bigger story of community opposition to fossil fuel reliance. Considering how she has previously described the oil and gas industry's involvement in communities like hers as an invasive force, developing alternatives can then be read as a form of resistance.

Denise also connects these community-led development projects to wider resistance to oil and gas in terms of independence (Figure 6.25).
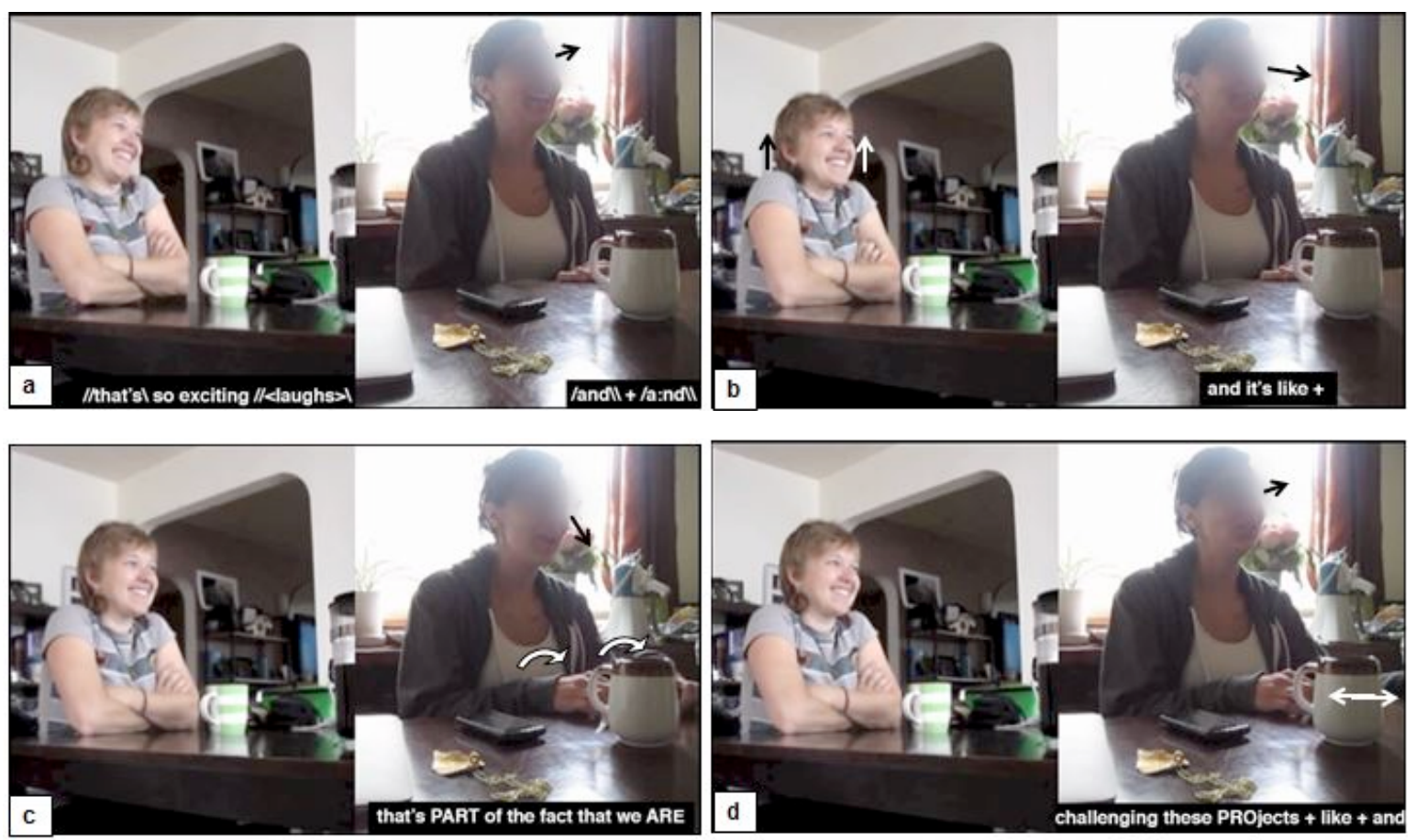

Figure 6.25: Denise

First, I express my excitement for this news that Fort Chip is becoming a more independent sustainable community (that's so exciting: a). Denise describes this once more as a form of resistance to oil and gas development (that's part of the 
fact that we are challenging these projects: $\mathrm{c}-\mathrm{d}$ ). She simultaneously places $\mathrm{BH}$ to the left and moves them laterally apart (c-d), suggesting a gestural return to the previously discussed alternative path (see Figure 6.24 p). Denise then explains exactly how such green projects in her community can help them achieve more independence (Figure 6.26).
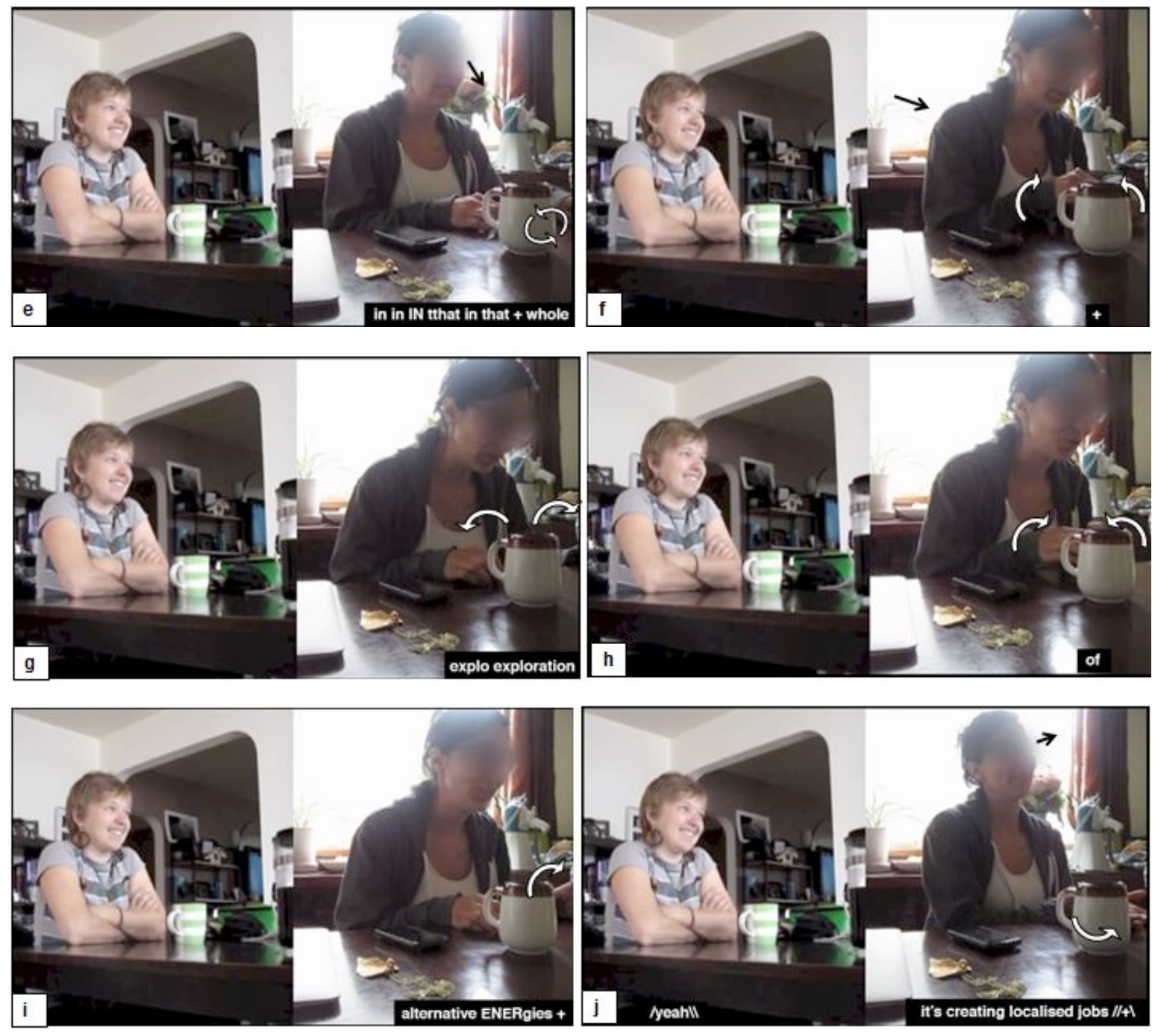

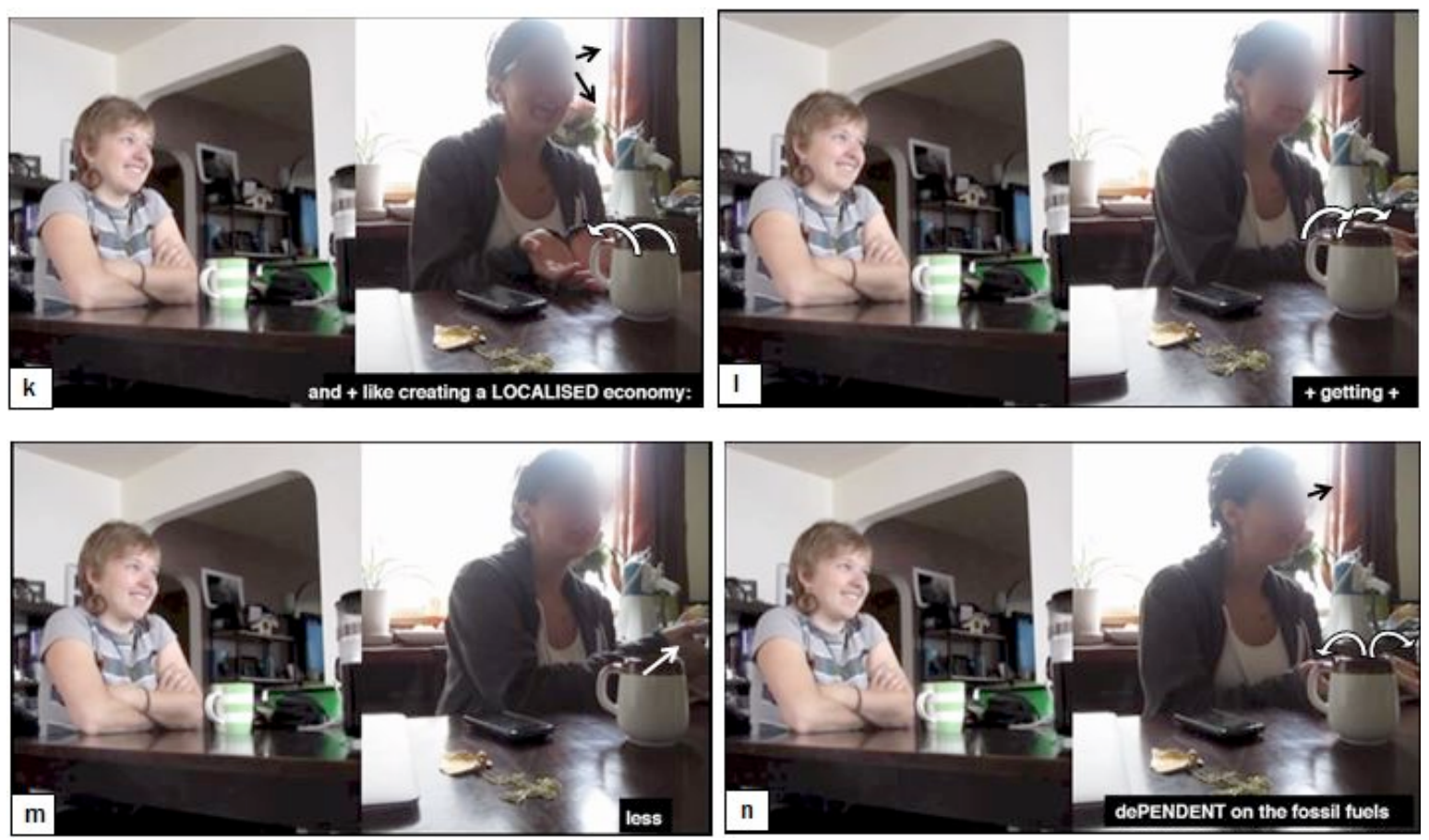

Figure 6.26: Denise

Denise places her LH onto the table and begins circling it around (e), possibly in an attempt to find the word she is searching for (in that whole explo exploration: $\mathrm{e}-\mathrm{g}$ ) (e.g. Bavelas, Chovil, Lawrie, \& Wade, 1992). She then brings her hands together and apart, leaning in over the table (f-g). Denise places her LH palm up to her left side once again as she further explains her argument (alternative energies: i). With her $\mathrm{RH}$, she joins her $\mathrm{LH}$ and brings the cupped gesture to the centre (creating localised jobs, a localised economy: j-k). This metaphoric gesture presents this localised economy to me almost as an object that can be held (McNeill, 1992). The way she addresses this gesture to me might be interpreted as an offering (Kendon, 2004, pp. 271-272), which is then moved once again to her left (I). Similar to the previous example (see Figure 6.25: c-d), Denise repeats the cupped gesture to the side (less dependent on fossil fuels: $m-n$ ), which seems to represent the economy moving to a different conceptual space.

After making this claim, Denise appears to hedge it by explaining that it is unlikely her community will be completely independent of the oil and gas industry. 
She recognises that everyday items (such as food, computers, phones) mean that some level of reliance is necessary. However, the aim is to diminish part of that dependence by taking away one portion.

Throughout the conversation, Denise recognises the ways that her community has become dependent on the oil and gas industry economically. However, as can be seen in the above examples, this reliance is contested and resisted through community-based alternatives which include a localised, renewable energy economy. These alternatives are enacted multimodally through gestures which locate them in a separate space from the current fossil fuel economy and thereby help communities to gain more economic independence. In this way, economic independence can be read as a form of subtle resistance to the fossil fuel industry's appropriation of Indigenous Discourses (and, to some extent, of communities themselves).

\subsection{Public Relations}

Like many contemporary industries, companies involved in the tar sands use public relations (PR) to manage their reputations and appear accountable (e.g. Degano, 2011; Garzone, 2011; Malavasi, 2011). Described as a technique which is "at its most powerful when it is invisible" (Burton, 2008, p. ix), PR activities take many forms. We might consider the oil and gas industry's sponsorship of Fort Chip as a form of PR, which would imply another intended audience (cf. Bell, 1984): the Alberta public. As Denise points out, companies approach the community in good faith, and lay the foundation to make them seem like they are the good guy (Excerpt 6.2). In the event of a publicised act of resistance to tar sands development, this might help companies counter criticisms by referencing the community spaces they have funded (cf. Burton, 2008). In this way, the branding of Fort Chip and its people can be seen as a sort of insurance investment against retaliation from residents (i.e. why would you bite the hand that feeds you?), and also the wider public. Much as the reclamation signs make use of Cree or Dene but still orient to an English-speaking audience (e.g. Figure 6.9), we might see industry 
sponsorship/partnership as using Indigenous communities to orient to a (predominantly) non-Indigenous, public audience (cf. Friedel, 2008). This leaves First Nations communities like Fort Chip in a difficult position, where the realities for residents are often hidden from wider public view (the kind of behind the door stuff, Figure 6.20) (cf. Van Dijk, 1993).

Even when there is resistance to community dependence on the fossil fuel industry, it is often ignored by the media (it's not a sexy story, Figure 6.24). For this reason, First Nations communities seek to publicise their resistance in other ways. In our interview, Denise discusses how her nation is compelled to engage in a 'public relations battle' with industry actors (Figure 6.27).
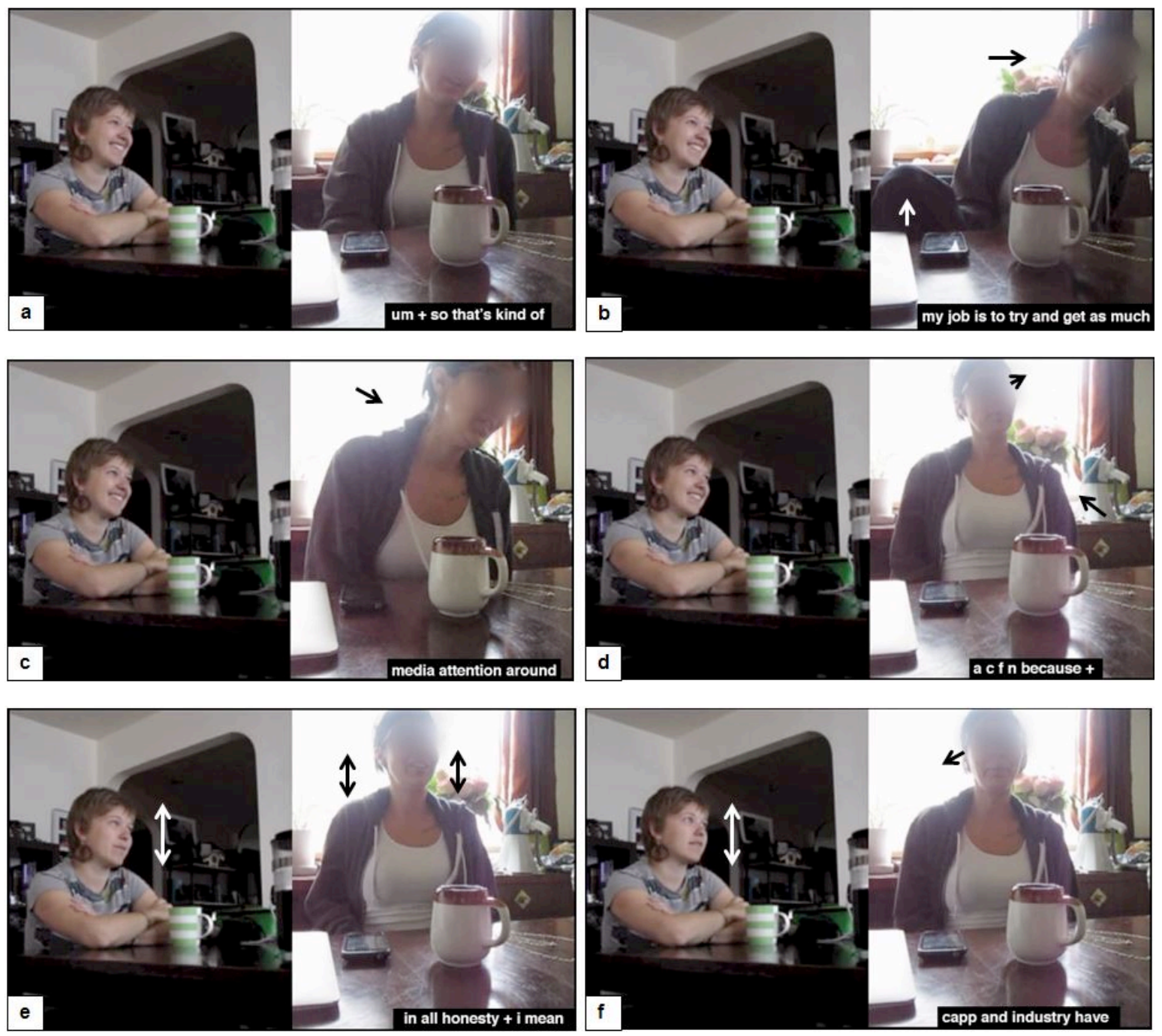

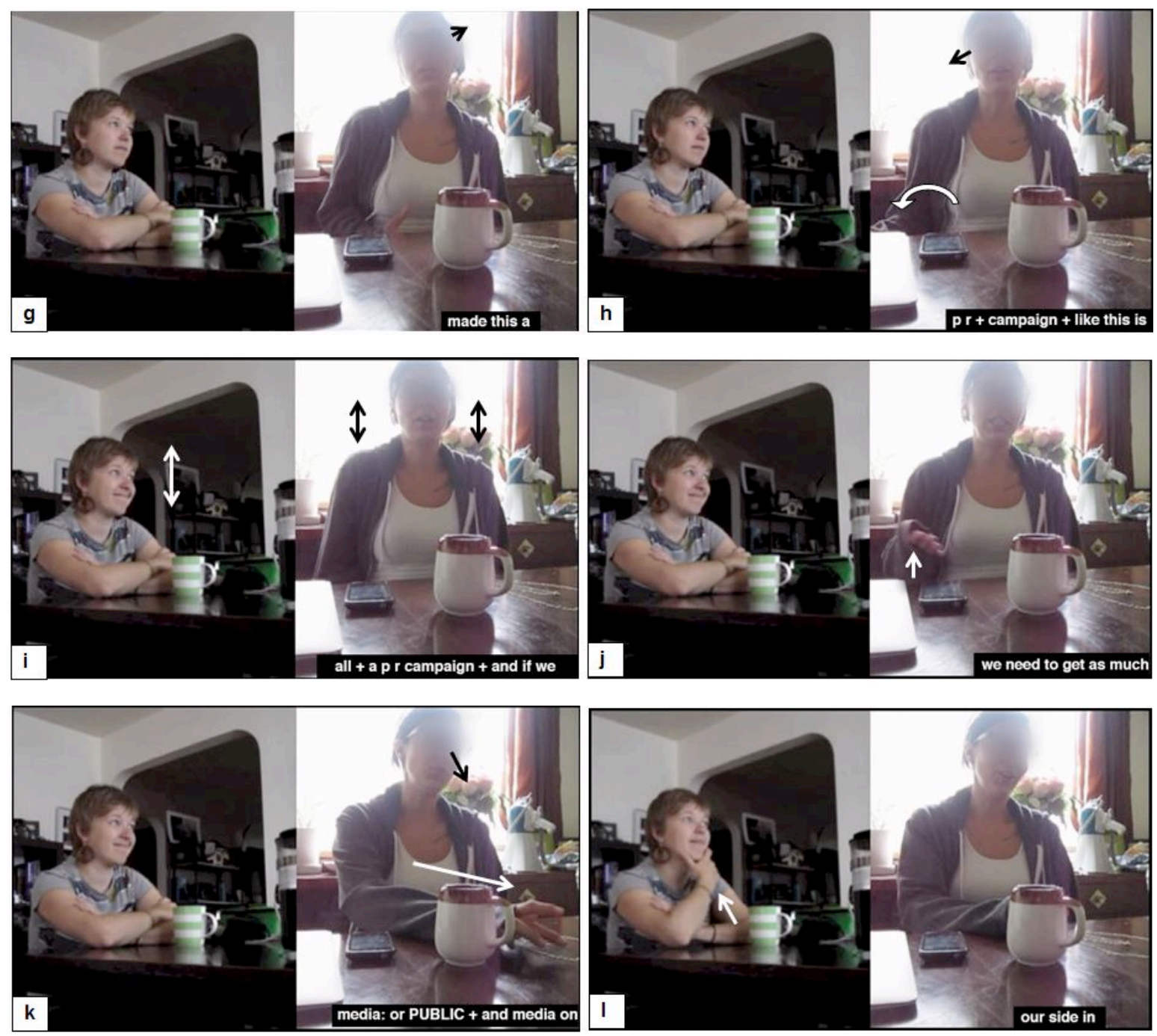

Figure 6.27: Denise

Denise begins by explaining her role as someone who seeks to attract media attention to her nation's cause (a-d). This is due to the fact that capp ${ }^{10}$ and industry have made this a pr campaign (f-h). In introducing this concept, Denise shrugs her shoulders (e), a possible embodiment of her stance of disengagement (Streeck, 2009, p. 168). Her shoulder shrug precedes the admittance that the situation has become a pr campaign, which Denise underlines with a metaphoric palm presentation gesture (Kendon, 2004, p. 266) to introduce the concept (h). Next, she repeats both the phrase ( $p r$ campaign) and the shrug simultaneously (i) and I

10 The organisation for which Brandon (discussed in section 6.2) works. 
begin to nod and smile in agreement. Denise then orients to the necklace on the table in front of her $(\mathrm{k})$. This gaze shift to an inanimate object might allow her a visual focus to reduce cognitive load (see Rossano, 2012).

Denise expands upon the pr campaign and re-contextualises it as a battle (Figure 6.28).
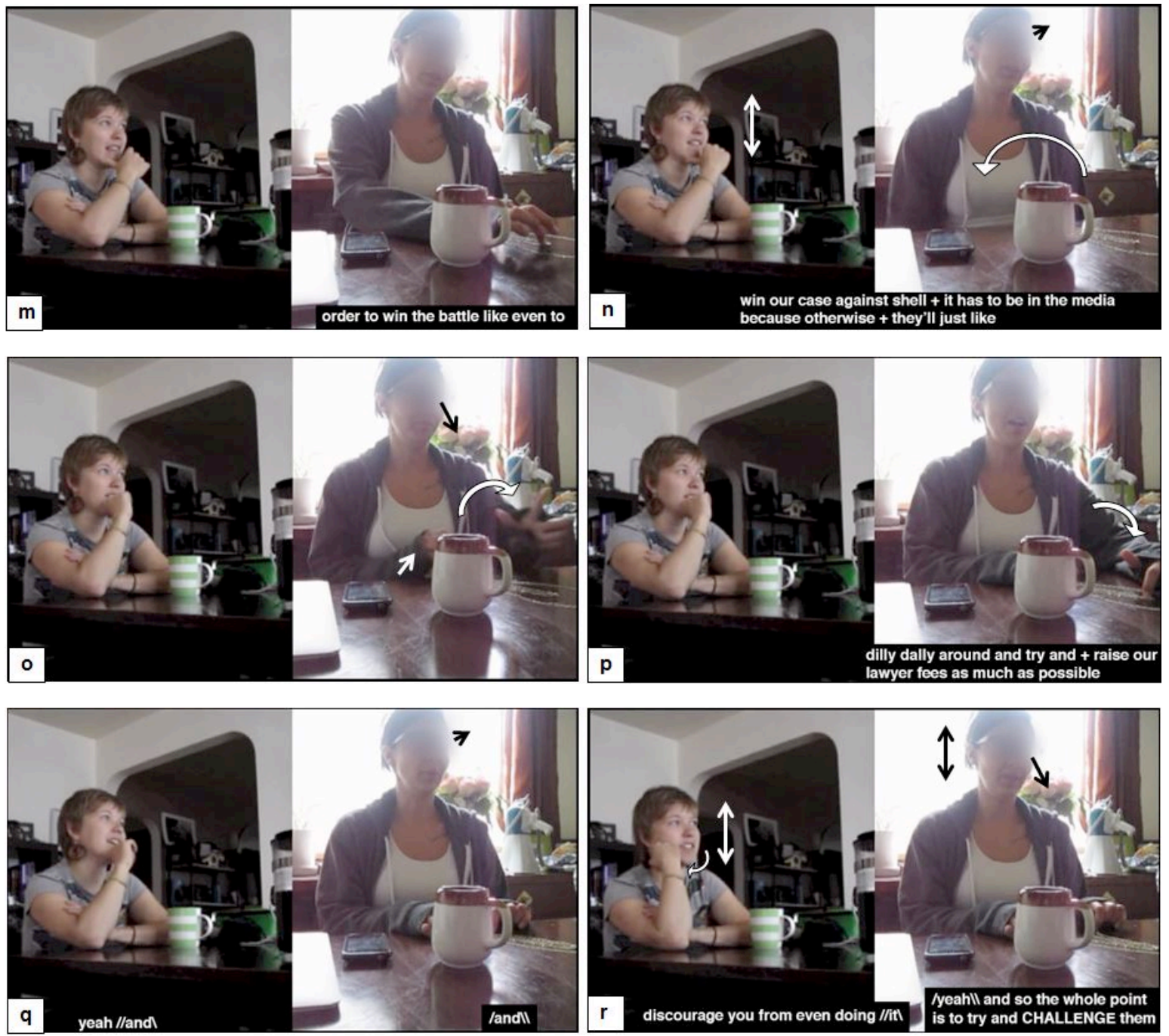

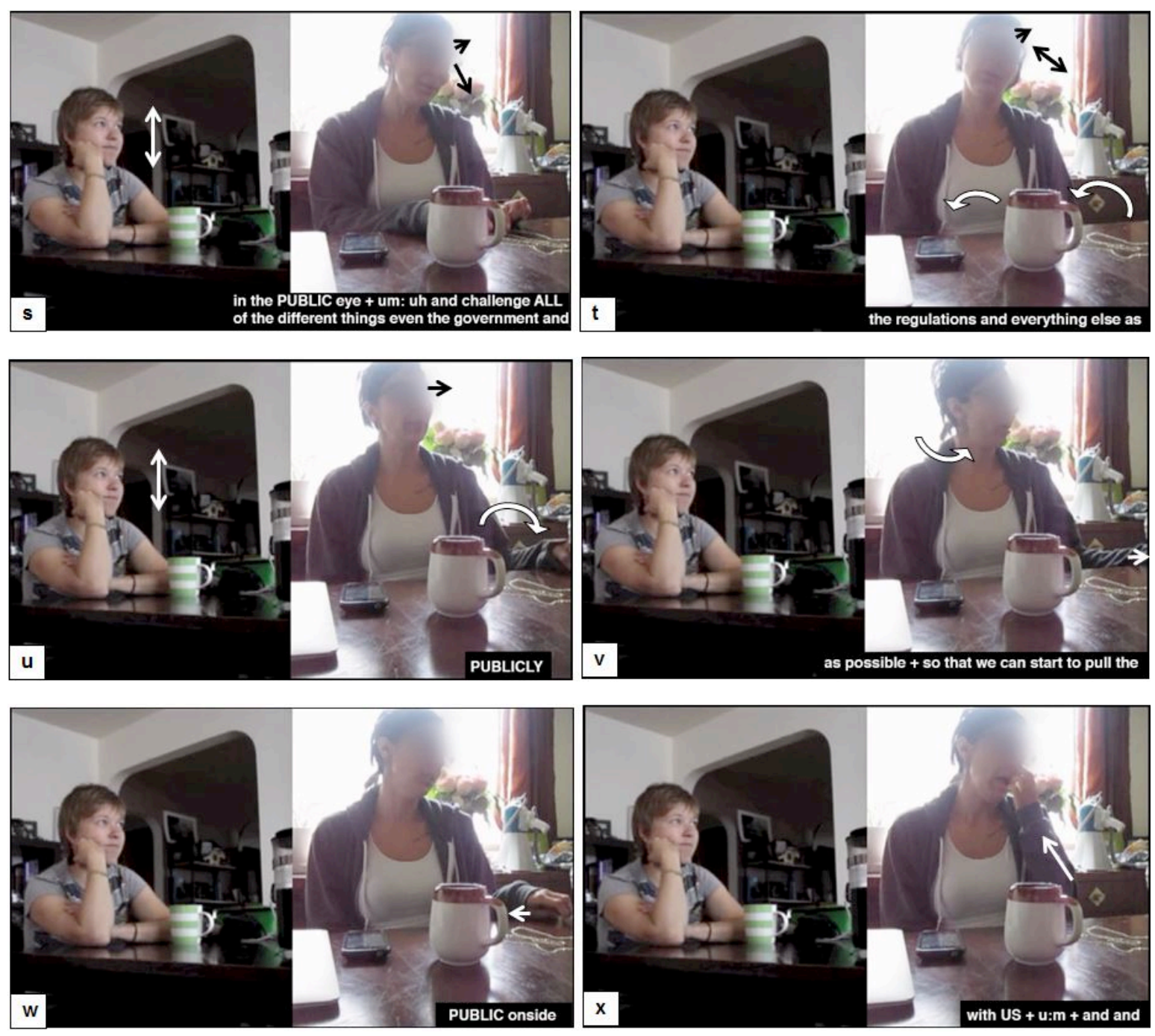

Figure 6.28: Denise

She specifies this with the case of her nation against Shell as an aside, marked by retracting her hand and establishing mutual gaze $(n)$. She sets up a description of what will happen without a media presence (otherwise they'll just like) by pausing, moving her hands and her gaze to the necklace (0). Denise then talks about the industry tactic of raising lawyer fees and I complete this thought with the consequence for her community (discourage you from even doing it: q-r). Denise agrees with this formulation by backchanneling verbally and by nodding before outlining the tactic which her community takes in countering industry's strategies (the whole point is to try and challenge them, $r$ ). In her description, Denise meets 
my eye when she says public and then gazes down again to her hands (s). This brief shift acts as a beat (McNeill, 1992) presumably highlighting the focus on the public for her nation's campaign. She retracts her hands behind the table and establishes mutual gaze again before shifting to the left and placing her $\mathrm{LH}$ fist on the table while saying publicly $(\mathrm{t}-\mathrm{u})$. Like before, this beat marks public as an important part of her work. Denise then places her LH on the table and pulls it in towards her body while saying so that we can start to pull the public onside ( $\mathrm{v}-\mathrm{w})$. The pulling action occurs on public, once again highlighting the concept. This continual co-occurrence seems to suggest that, in the pr war, it is the public which plays a crucial role. Indeed, Denise makes this point explicitly in Figure 6.29.
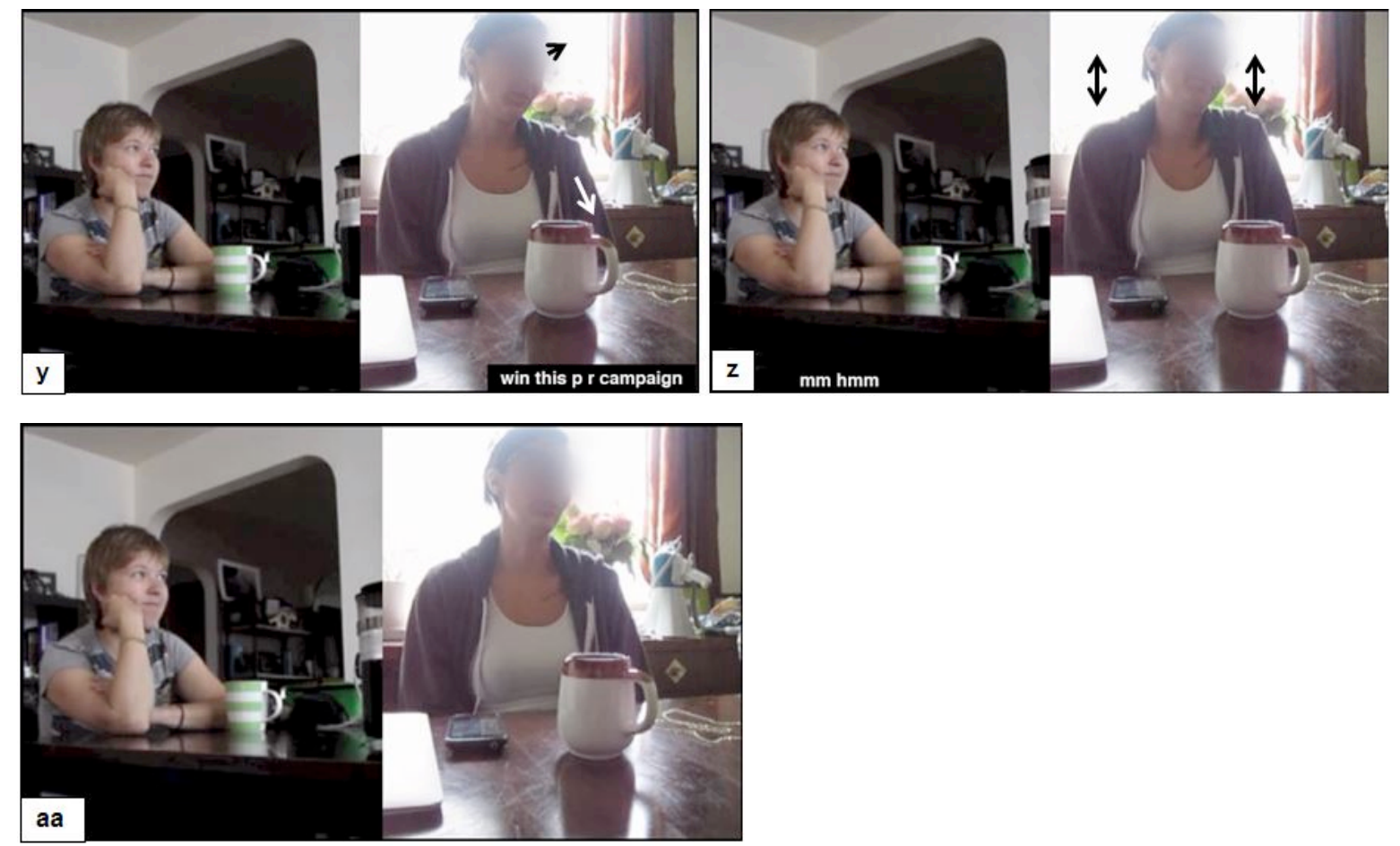

Figure 6.29: Denise

The action of pulling the public onside $(v-x)$ is the necessary move which will allow Denise's community to win the pr campaign (y). She then finishes with a shrug $(z)$, which serves to cohesively link the topic from beginning to end through its repetition (McNeill, 1992) and once again display Denise's stance of 
disengagement with the entire process (Streeck, 2009, p. 168). Indeed, Denise's copious shrugs during the interview seem to indicate a stance of hopelessness throughout (e.g. Figure 6.23).

Throughout this interaction, Denise introduces the necessity of media relations that is as public as possible: this is continuously highlighted with beats and gaze shifts as well as an increase in volume. To further resist and reappropriate their image and identities as local Indigenous communities, Denise and others strategically cultivate a public presence that challenges development. The Tar Sands Healing Walk is one of these visible, public acts of resistance.

The Healing Walk is a walk along Highway 63 (through the tar sands mining area) which was initiated in 2009 by the Keepers of the Athabasca. Led by local community members, the walk is not a protest (Leah, 2014), but a chance to publicly pray for the healing of the land and the people. Additionally, it provides a visual presence of First Nations concerns with development (Figure 6.30).

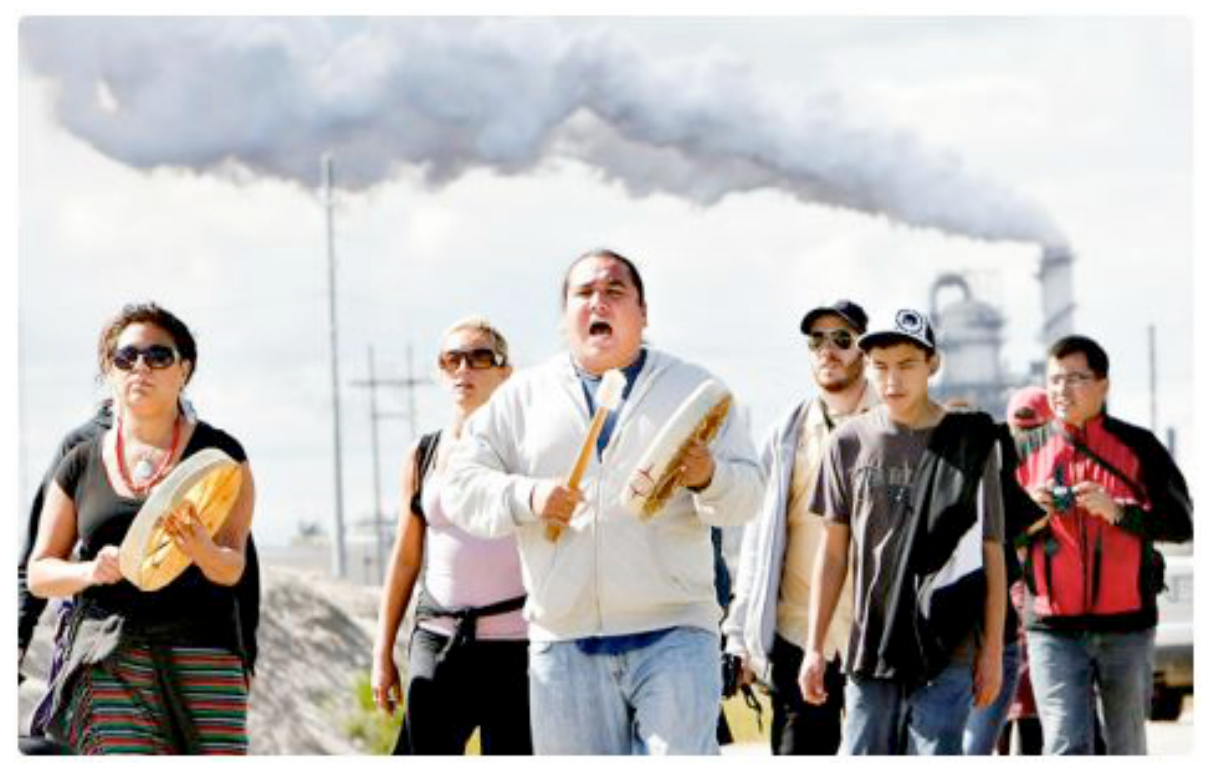

Figure 6.30: Healing Walk ${ }^{11}$

\footnotetext{
11 Image from Flickr user Velcrow Ripper.
} 
Through the use of cultural and ceremonial items (such as feathers, signs, and drums), First Nations walkers proudly display their Indigenous identities, accompanied by Settlers walking in solidarity. The Healing Walk is thus a public way of re-appropriating Indigenous Discourses of identity while resisting tar sands expansion, presenting an alternative to the Indigenous/industry partnership constructed at reclaimed sites (e.g. section 6.1.2). Since its inception, the Healing Walk has grown exponentially, with walkers traveling from other nations along various pipeline routes (e.g. Northern Gateway, Keystone XL), joined by allies and even celebrities (Leah, 2014). As an action, the walk creates a very visible First Nations presence along the highway which produces reactions amongst local workers. In discussions with another activist, Jill, she admits that it is really surprising the walk gets such support. In fact, there's a lot of workers who honk in support, which, she argues, is due to the fact that they are aware of the environmental and social impacts of their jobs, as well as the quality of their own working conditions. This suggests that, even in Fort McMurray, there is public support for Indigenous resistance.

In addition to the Healing Walk, Canada has seen more public displays of Indigenous Discourses being re-appropriated by Indigenous people through the IdleNoMore Movement. The movement began with a group of women in Saskatchewan holding teach-ins (workshops) about government policy bills which would further erode Indigenous sovereignty as well as environmental protection, some of which related directly to the tar sands (www.idlenomore.ca). IdleNoMore has since grown across the rest of Canada, with First Nations holding local and national events relating to Treaty rights, missing and murdered Aboriginal women, and environmental struggles (Barrera, 2013). In April 2014, an alliance of ranchers and Indigenous people camped on the National Mall in Washington DC to protest the Keystone XL pipeline (Khan, 2014), which would bring tar sands oil to the Gulf of Mexico. Dubbed the 'Cowboys and Indians Alliance', the event indexed wider cultural Discourses of Settlers and Indigenous people as natural enemies, but instead flipped the 'Cowboys and Indians' Discourse by presenting them as 
partners in resistance (Figure 6.31).
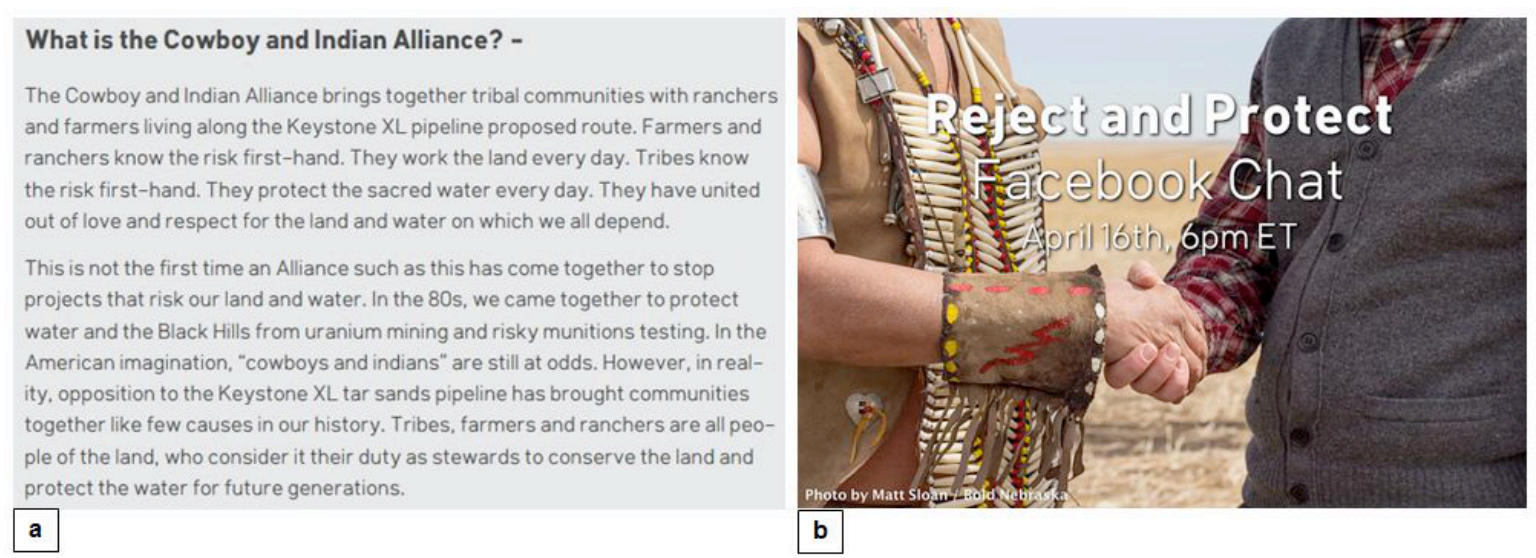

Figure 6.31: Cowboys and Indians Alliance ${ }^{12}$

On the FAQ portion of the event's website, this Discourse is elaborated upon (a). Farmers and Indigenous communities are compared, highlighting the ways in which their identity positions are alike (Bucholtz \& Hall, 2005, p. 599). This is achieved through syntactic repetition (know the risk first-hand, They...every day) and we are told they have united out of love and respect for the land and water. The 'Cowboys and Indians' Discourse is referenced explicitly (In the American imagination, "cowboys and indians" are still at odds) and subsequently presented as untrue (however, in reality). This new understanding of the 'Cowboys and Indians' Discourse is further presented through images of the event, which feature Indigenous and Settler individuals riding together on horseback onto the Mall or even shaking hands (b).

Although this example is admittedly geographically distant from the tar sands in Alberta, it shows how Indigenous Discourses are re-appropriated and used to resist projects across national borders. With the clever subversion of the 'Cowboys and Indians' Discourse, activists multimodally entextualise Indigenous, and subsequently Settler, identities.Ultimately, this creates a new Discourse of

12 Image used with permission viewable at http://rejectandprotect.org/facebook-chat/, Photo by Matt Sloan/Bold Nebraska. 
empowerment, as groups conventionally considered to be at odds unite under a banner of shared resistance.

\subsection{Conclusion}

The importance of images and icons in the appropriation of Discourses becomes relevant when we consider the wood bison (where the chapter began) as representing Aboriginal people and successful reclamation. Much like traditional sponsorship, the marketing and advertising of reclaimed land uses carefully chosen semiotic items to facilitate positive transfer from the social action (e.g. the inclusion of Indigenous peoples) to the company itself (cf. Allori, 2011). In other words, companies appropriate Discourses in order to construct an ideal image, with the ultimate goal of financial gain. Through the previous analyses, we can see how successfully reclaimed land is symbolically established in both a physical and metaphorical sense: for example, bison physically become indicators of "Nature's vitality" in the flesh (Davidson \& Gismondi, 2011, p. 124) while also performing these roles metaphorically for marketing purposes.

We might also consider how the land which is being 'reclaimed' has been subject to dispute between First Nations groups and the Government of Canada (Usher et al., 1992), making its appropriation and subsequent 're-claiming' by industry problematic. In a country built on the dispossession of Indigenous land and people (Hill, 2009), who has the right to claim and re-claim? And from whom? These issues seem to be skillfully managed by constructing relationships with Indigenous people as positive, supportive partnerships, with the reclamation of disturbed land at the centre of this alliance. Through the appropriation of Indigenous Discourses, reclamation takes on a wider metaphorical meaning, representing not only the 'healing' of the land, but also the 'healing' of hundreds of years of strained relationships with Aboriginal peoples. Consequently, companies can subvert concerns about the effects of industrial expansion on treaty rights into carefully managed partnerships. 
The inclusion of Indigenous communities in the oil economy also appears to be a strategy for establishing their reliance upon it. The use of Aboriginal Youth Task Force (AYTF) teams which encourage children to eventually work in the sector, as well as sponsorship within communities themselves, are examples of sophisticated marketing techniques used by industry actors. As the above analyses suggest, they are also problematic in that they align with wider colonial goals of assimilating Indigenous communities into the modern world. Community members like Denise identify and contest these activities, and some First Nations communities are resisting by seeking alternatives to an oil-based local economy. In addition, these communities are put in the position where they need to make their resistance visible to the public in an attempt to gain support, leading to overt displays such as the Healing Walk and the Cowboy and Indian Alliance. Indigenous Discourses are thus appropriated but also resisted and re-appropriated in creative, multimodal ways.

Indigenous communities are forced to continuously adjust their interactions with industry and government actors, while resisting strategies of assimilation. Increasingly, communities find themselves in the difficult situation of protecting their lands and rights while attempting to establish local, sustainable economies. The recent upswell in Indigenous resistance sweeping the country (e.g. IdleNoMore) is a hopeful sign that opposition is becoming more pronounced. As Indigenous nations unite and as Settlers begin to work with them in solidarity, perhaps the wider public will begin to engage in a much-needed discussion about the connections between First Nations rights, neocolonialism, and industrial development.

It is evident that Indigenous Discourses are combined with various other Discourses in the tar sands debate (economic, environmental, social justice, educational, etc.) in ways that are not evident in Southland. It is worth noting that, although I attempted to discuss the issue of Māori rights relating to the lignite mine, I had difficulties gaining access to local communities. The apparent absence of 
Māori Indigenous Discourses in both the marketing and resistance of the Southland mine could be therefore due to my own cultural inabilities to see such Discourses (cf. Smith, 1999, also King, 2011). However, in comparison with the explicit use of Indigenous identity in Canadian reclamation sites discussed here, it appears that Indigenous Discourses in Southland do not feature in the mine's marketing strategies.

The way these various Discourses interact is complex and every-changing (Blommaert, 2010), and at times difficult to see. As the tar sands have become more controversial through continued resistance, even more Discourses have been brought into the debate, creating a complex myriad of identities that are woven together. In the next chapter, I discuss this concept of 'intersectionality', and track a number of these Discourses through a group of queer activists responding to the appropriation of LGBTQ+ identities. 


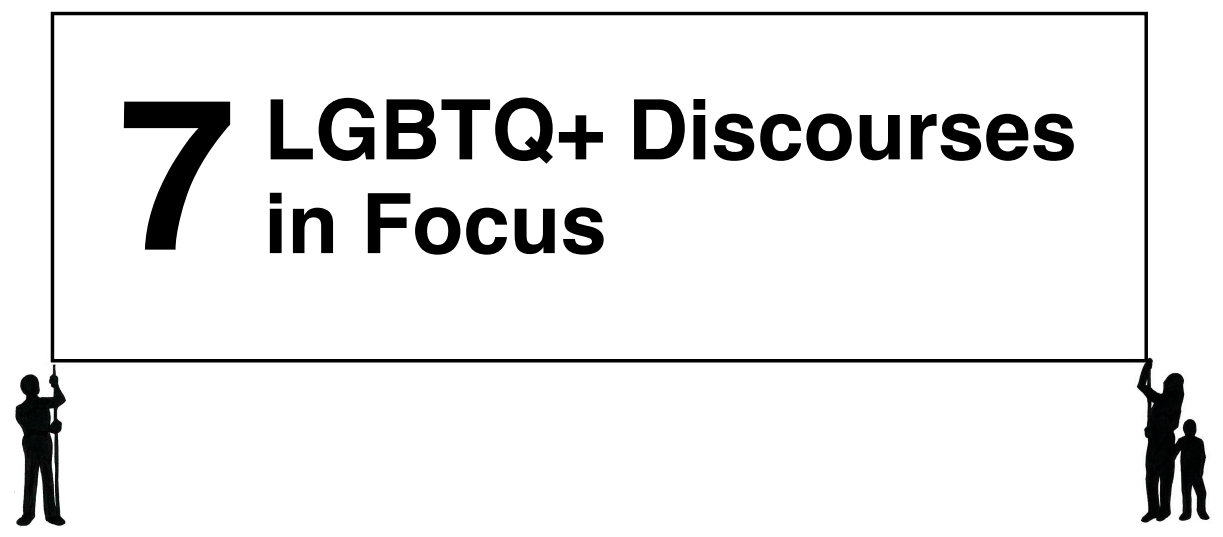

$\mathrm{n}$ the previous chapter, I discussed the ways in which First Nations Discourses have become entangled with mining projects in Treaty 8 Territory and beyond. Many individuals involved in these debates must negotiate multiple identity positionings, such as being Albertan but also a member of a First Nation that is resisting colonial assaults on Treaty rights. In this chapter, I discuss an instance where a variety of identities and oppressive forces intersect around mining debates. In this case, industry marketers have made use of LGBTQ+ rights as well as Islamophobia, encouraging queer social justice groups to engage in tar sands resistance.

\subsection{Intersectionality: a Theory From the Grassroots}

As social movements come together to confront oppression, there is a greater awareness of the ways these oppressions might intersect for certain groups. In other words, "recognizing that both power and identity are complex and interrelated, intersectionality offers a systemic and structural analysis of both, while recognizing the variability, fluidity, and contingency of specific manifestations of subordination" (Cho, 2013, p. 385). Like other critical approaches, intersectionality not only seeks to recognise these dynamics, but also to "transform them" (Carbado, Crenshaw, Mays, \& Tomlinson, 2013, pp. 311-312). It is thus a theory, an analytical tool, but also a practice for activist communities (Bilge, 2013, p. 410; Gleeson, 2014), by offering a structure through which groups might build 
coalitions with each other instead of competing under a neoliberal regime which frames social life as individualistic (Cho, 2013, p. 407).

For example, if we take the case of Black ${ }^{1}$ feminists in the mainstream feminist movement, it becomes apparent that they face different obstacles than their white counterparts (cf. Crenshaw, 1991). Without an awareness of these issues, Black women risk being subjugated through misogyny in anti-racist movements and racism in feminist movements, further marginalising an already marginalised group (Bilge, 2013, pp. 406-407; Crenshaw, 1991, pp. 1244, 1280). Black women are therefore forced to split their political energies between two different groups, who may, in fact, be in opposition at times (Crenshaw, 1991, p. 1252). This creates tension between movements (Crenshaw, 1991, p. 1242) and also leads to an entrenchment of the power structures each seeks to dismantle: in other words, "the failure of feminism to interrogate race means that the resistance strategies of feminism will often replicate and reinforce the subordination of people of color, and the failure of antiracism to interrogate patriarchy means that antiracism will frequently reproduce the subordination of women" (Crenshaw, 1991, p. 1252). This dynamic is exemplified in the case of 'Slutwalk', a protest march which began in North America encouraging women to reclaim the word 'slut' and counteract the idea that a woman is partly responsible for rape because of the clothing she wears. However, 'slut' has a very different history for Black women (namely the oversexualisation of Black women's bodies) and any reclamation of the term would further validate racist ideas of the 'promiscuous Black woman' (see Bilge, 2013). Intersectionality is a way to foreground the multiple and oppressive positionings which social actors, such as Black women in the 'Slutwalk', experience (Cho, 2013, p. 393; Crenshaw, 1991; Phoenix \& Pattynama, 2006, p. 187).

Intersectionality has arisen from the direct experiences of oppressed groups (Bilge, 2013; Cho, 2013, p. 387; Gleeson, 2014; Phoenix \& Pattynama, 2006, p.

\footnotetext{
1 Following Crenshaw, I capitalise Black as a proper noun which refers to a specific cultural group (Crenshaw, 1991, p. 1244).
} 
187) and was brought into the academy at the junction of Critical Race Theory (CRT), Black feminism, and Law (Carbado et al., 2013; Crenshaw, 1991).

However, intersectionality is a theory that "can and does move" (Carbado et al., 2013, p. 306), and it has since expanded into new geographies and new disciplines (Carbado et al., 2013). It has also been used to interrogate issues besides race and gender, including sexuality (Cho, 2013), and colonialism (Bilge, 2013). However, like many theories which travel and are translated beyond their origins, "intersectionality falls prey to widespread misrepresentation, tokenization, displacement, and disarticulation" (Bilge, 2013, p. 410). For example, Bilge describes what she terms ornamental intersectionality, where social actors appropriate the concept without addressing its core issues (Bilge, 2013, p. 408). This is similar, in a way, to phenomena like greenwash (see section 2.2) in that it allows groups to appear progressive while maintaining problematic power structures. Additionally, it shows how the tendency to appropriate Discourses in this fashion is not only limited to institutionally powerful actors but also occurs within activist communities themselves.

Bilge also comments on how intersectionality has become 'whitened' in that its historical roots (in academia) have been continuously linked to feminism but less to Black feminism and CRT (Bilge, 2013). This, she argues, "effectively erases a landmark oppositionality from which intersectionality emerged: feminists of color confronting racism within feminism" (Bilge, 2013, p. 420). She also laments that intersectionality risks becoming "an overly academic contemplative exercise" (Bilge, 2013, p. 411) which ignores its grassroots origins before academia, as a way of interrogating oppression within social movements themselves (Cho, 2013, p. 387; Gleeson, 2014; Phoenix \& Pattynama, 2006, p. 187). These issues have given rise to new calls for intersectional work to reconnect with its mandate of social struggle (Bilge, 2013, p. 411; Carbado et al., 2013, p. 312; Gleeson, 2014) and to centre those most marginalised in its analysis (Cho, 2013, p. 392). In this way, intersectionality can "also promote collective action by linking structures of subordination and compounded subjectivities, thereby refusing 
compartmentalization" (Cho, 2013, p. 392). In other words, using a "coalitional strategy" based on the oppressions faced by the multiply-subordinated, will also achieve justice for those struggling against singular oppression (Cho, 2013, p. 392).

In the same way that many projects have moved the theory across disciplines (Carbado et al., 2013, p. 307), this thesis brings intersectionality into the realm of resource development and sociolinguistics. However, at the same time, I take up an intersectional analysis based on work already being done at the grassroots level, thus recognising the theory's aim to be "animated by the imperative of social change" (Carbado et al., 2013, p. 312). This mirrors my own exposure to intersectionality as a grassroots activist first and academic second. Thus, my perspective is grounded in my own experiences working with communities of struggle and the ways in which intersectionality is deployed in their own analyses of oppression. Consequently, I adopt an intersectional approach because the activists with which I work also use it to deal with the realities of their oppressions. The following analysis will elaborate upon and interrogate the ways in which the appropriation and resistance of Discourses relate to intersectional oppression in queer ${ }^{2}$ activist spaces in Alberta and beyond.

\subsection{Pinkwashing the Tar Sands}

Upon my return to Edmonton,for my field visit I began interacting with activists involved in one of the many LGBTQ $+{ }^{3}$ activist communities (see section 9.1.5). Because these activists also work on various issues around environmentalism, colonialism, racism, homophobia, transphobia, misogyny, etc, I was soon able to track tar sands Discourses through its intersection with a local group that is part of Edmonton's annual Pride Parade. In its organising, the group makes use of the term 'queer' to describe the LGBTQ+ activist community (Figure

\footnotetext{
2 See below for a discussion of my use of the word 'queer'.

${ }^{3}$ This is a term encompassing the range of sexualities and nonbinary gender identities.
} 


\begin{tabular}{|c|c|}
\hline "queer" is used simulkanoouxly & *In this particular context, "queer" \\
\hline as an umbrellatern for the & is used simultaneously as an \\
\hline GI $B T T I Q Q 2 S A A$ & umbrella term for the \\
\hline $\begin{array}{l}\text { community and as a political } \\
\text { iderity. }\end{array}$ & $\begin{array}{l}\text { GLBTTIQQ2SAA community and as a } \\
\text { political identity }\end{array}$ \\
\hline
\end{tabular}

Figure 7.1: Terminology

We can see that 'queer' is used to denote both an LGBTQ+ and a political identity. In Excerpt 7.1, William (a local queer activist), discusses some of the ways the term is being reclaimed and used:

\section{Excerpt 7.1: William}

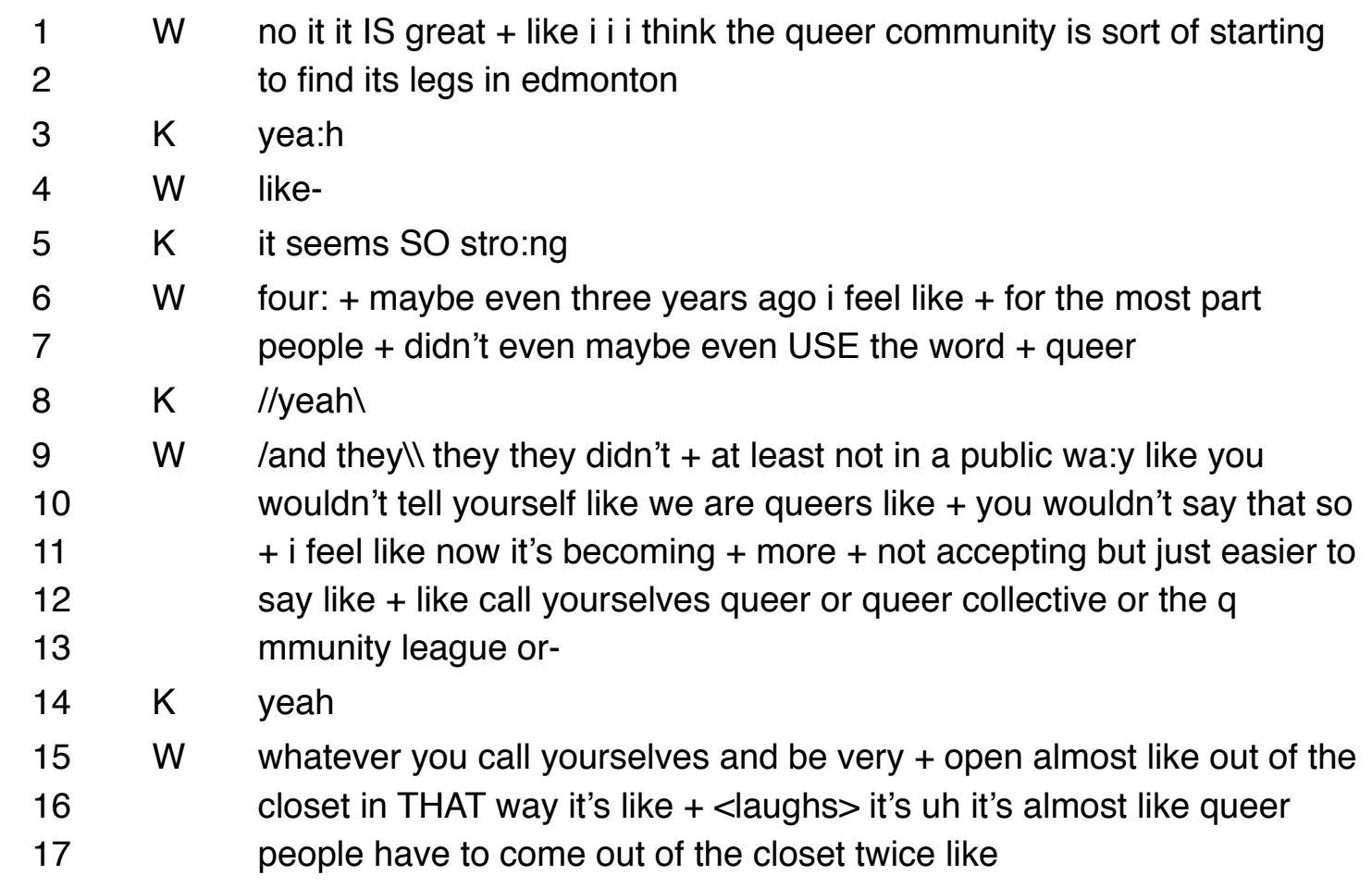

4 Figure 7.1 and 7.2 , as well as Figures 7.7-7.10 are taken from the pamphlet analysed in Section 7.3 and reproduced with permission. 


\begin{tabular}{|c|c|c|}
\hline 18 & $\mathrm{~K}$ & yeah $/ /<$ laughs $>1$ \\
\hline $\begin{array}{l}19 \\
20\end{array}$ & W & $\begin{array}{l}\text { /likell like oh i'm gay oh and i'm political too: //you know } \backslash \text { ? like not } \\
\text { to ruffle any of your feathers }\end{array}$ \\
\hline 21 & $\mathrm{~K}$ & /yeahII \\
\hline 22 & W & //maybe you $\backslash$ can accept the fact that i'm gay but not that i'm political \\
\hline 23 & $\mathrm{~K}$ & |<laughs $>\| 1$ yeah \\
\hline 24 & W & you know like that seems to be almost the ha:rder door to //openll \\
\hline 25 & $\mathrm{~K}$ & /yea:hll \\
\hline
\end{tabular}

First, he explains how the word queer is new in the Edmonton community (6-7) and that there is a change in the way the term is being used (now it's becoming more not accepting but just easier to say, 11-12). He describes how the word denotes an LGBTQ+ identity that also includes a political identity, and he even likens this to coming out of the closet twice (17). In line 19, William adopts the voice of a hypothetical queer person in the act of coming out: oh i'm gay oh and i'm political too). He describes this dual identity as a difficult one for people to accept (you can accept the fact that i'm gay but not that i'm political, 22), showing how the political part of an LGBTQ+ identity can often be more difficult to negotiate (that seems to be almost the harder door to open, 24).

Following these community practices, I will use 'queer' to denote the community and activist activities while using LGBTQ+ to denote the (often depoliticised) Discourses regarding sexuality and gender which circulate throughout wider society.

\subsubsection{EQUAIA}

Built upon a foundation of intersectionality, radical queer groups like the one in Edmonton engage with politically charged issues. Edmonton Queers Against Israeli Apartheid (EQUAIA) is a collective ${ }^{5}$ organised to act in solidarity with Palestinian queer activists. EQUAIA, like similar groups in Toronto and in New

\footnotetext{
${ }^{5}$ Collective is used here to refer to a style of organising based on anarchist principles of non-hierarchy and, very often, consensus-based decision making.
} 
York, draws attention to the struggle for Palestinian nationhood and the ways in which the state of Israel seeks to legitimise itself through the appropriation of LGBTQ+ Discourses ${ }^{6}$ (see Figure 7.2a).

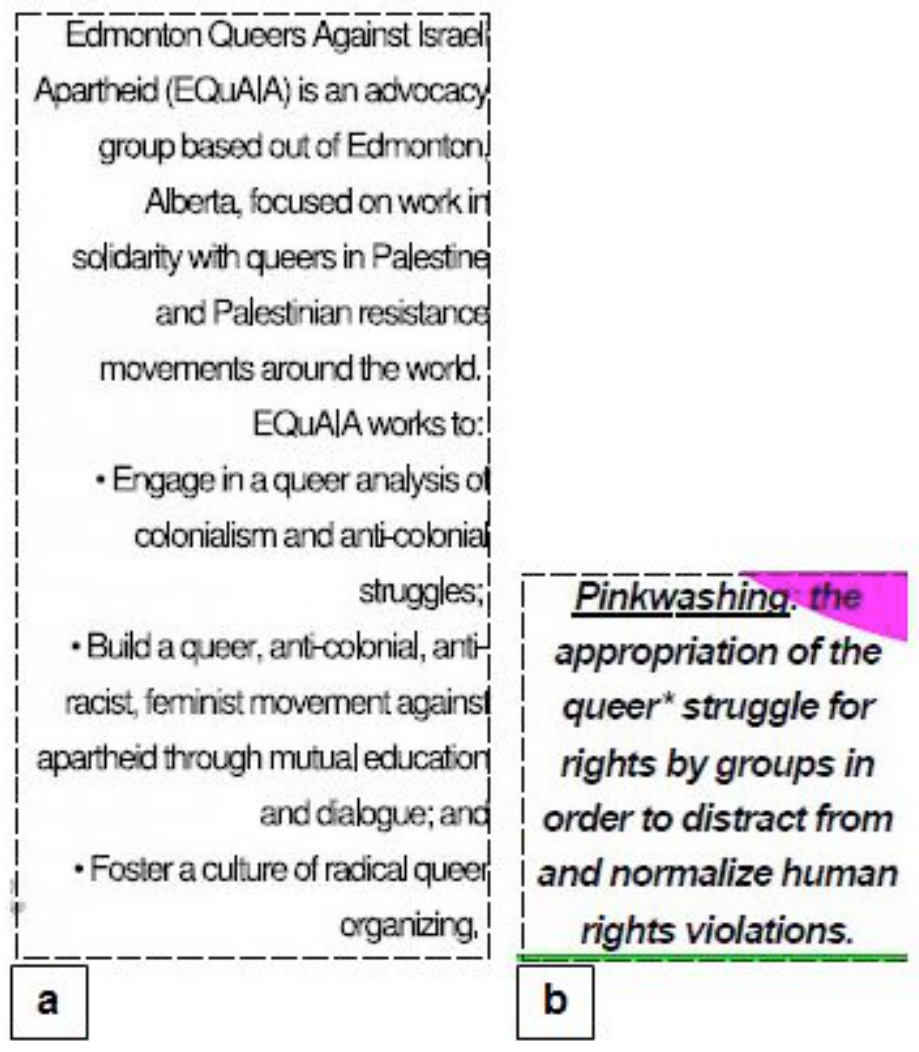

Figure 7.2: EQUAIA

We can see in this description of the group that the intersectionality is foregrounded: they seek to bring a queer perspective to issues of colonialism and also build a movement based on multiple struggles, including anti-colonialism, feminism, and anti-racism. Consequently, EQUAIA's existence as a collective is based around this recognition of intersectionality between queer rights and Palestinian sovereignty and the ways in which wider LGBTQ+ Discourses are appropriated in the name of colonialism. This concept is referred to as

${ }^{6}$ This refers to the government's presentation of Israel as a safe haven for LGBTQ+ people (see Schulman, 2011). 
'pinkwashing': "a deliberate strategy to conceal the continuing violations of Palestinians' human rights behind an image of modernity signified by Israeli gay life" (Schulman, 2011). However, as can be seen in the definition given by EQUAIA in Figure $7.2 \mathrm{~b}$, the concept is not uniquely applied to the Middle East.

This takes on a wider dimension when we consider how other situations can be pinkwashed. In Canada, the Ethical Oil Campaign (see section 1.7) also makes use of LGBTQ+ Discourses in one of its ads (Figure 7.3). This ad appeared as one in a series which juxtaposes Canada with other oil-producing nations. Following a consistent design, the ads present two images under the headlines conflict oil and ethical oil against a red and green background. Uniting both images along the bottom against a green background is the phrase Ethical oil. A choice we have to make., followed below with a logo and information about the campaign's website.

Image removed after examination

Figure 7.3: ‘Ethical Oil'8

\footnotetext{
7 Not to be confused with the same term which refers to the use of pink to connote support for breast cancer awareness for capitalist ends (see Lubitow \& Davis, 2011).

8 Image can be viewed at http://www.theguardian.com/environment/blog/2011/jul/28/oil-tarsands-canada-ethical
} 
The ad presents images representing two different realities for gay couples. The image on the left shows two men about to be hanged with the word persecution on a red background. On the right is a cropped image of two men holding hands while wearing rainbow wristbands with the word pride superimposed on a green background. Like the others in the series, this ad makes use of colour and layout to present a visual narrative (Kress \& Van Leeuwen, 2006). First, the design utilises the horizontal axis: the persecution image is presented as the point of departure (Given, see Figure 3.6 for another example of this layout) and the pride image as the element which draws attention (New) (Kress \& van Leeuwen, 2006).

Additionally, colour plays an important role in the interpretation of this ad. Drawing upon cultural understandings of red and green (Van Leeuwen, 2011), we might read the red image as a reference to stop and green as go or even as blood and growth. The colours therefore not only provide contrast and salience, but also give additional guides to interpretation (van Leeuwen, 2011).

The images themselves also provide additional meanings. First, they are colour photographs which bring a level of apparent truth, or increased modality (Kress \& Van Leeuwen, 2006, p. 159). The persecution image features dark-haired, brown skinned men in opposition to the pride image which features white skinned hands. The persecution image also depicts an imminent execution while, in contrast, the two hands on the right proudly and publicly sport rainbow wristbands: a salient symbol (Kress \& van Leeuwen, 2006) of LGBTQ+ identity. The images alone thus present two versions of reality: a 'backwards' society of brown skinned people who are restricted from freely displaying their sexuality versus a 'progressive' society of white skinned people who are not so restricted.

Created for a Western audience, this ad also draws the eye through a reading trajectory, presenting a visual narrative (Kress \& van Leeuwen, 2006). From top left to right we are shown two societies: one in which LGBTQ+ identities are outlawed and one in which they are supported ('pride' here also refers to the very visible Pride Parades which are staged in most Canadian cities). We are told 
that persecution of minority groups in oil-producing countries marks them as conflict oil regions and that, alternatively, ethical oil comes from places like Canada which support minority groups. Next, we are drawn to the green band at the bottom where ethical oil is presented as Given, followed by a choice we have to make. Here, the complexities of intersectional struggles are reduced to a simple dichotomy: conflict oil or ethical oil. The carefully chosen images further encourage one choice over the other, aimed at an audience sympathetic to the LGBTQ+ cause but also willing to believe in the islamophobic stereotype presented in the first image. Finally, we are encouraged to learn more about Canada's oil through the Ethical Oil website.

Thus, the trajectory presents a problem (conflict oil), suggests an alternative (ethical oil), simplifies the issue to a dichotomous choice, and finally leads us to the campaign's website. The story presented draws upon progressive ideals of support for minority groups as well as Canadian nationalism, using LGBTQ+ Discourses and islamophobic Discourses to sell Canada's oil. Through the cohesive repetition of certain elements (e.g. layout) and the contrast of others (e.g. colour), the ad both linguistically and visually positions Canada in opposition to other oil-producing nations (e.g. the Middle East). Thus, the ad's designers orient to a progressive 'Fair Trade' Discourse (Low \& Davenport, 2005), exploiting LGBTQ+ struggles in order to position Canada as an alternative source for 'ethical oil'.

The blatant appropriation of LGBTQ+ Discourses, coupled with islamophobic Discourses, was understandably very upsetting to members of EQUAIA. Having formed as a group to protest the pinkwashing of Israeli national policies against Palestinians, the group suddenly found their struggle being appropriated to pinkwash tar sands development while also contributing to nationalistic, islamophobic Discourses in Canada. As only one in a number of minority groups to find themselves in this situation (the ethical oil ads also feature women and First Nations people among others), there was much discussion about whether the campaign should simply be ignored. This was a common thread in 
many of my interviews where activists suggested that engaging with the campaign might only draw more attention to it. However, in my interview with William, an organiser with EQUAIA, he describes the dynamics of this particular appropriation and the need for resistance (Figure 7.4). Not only does he explain the issue using language, he also uses gesture to multimodally enact what he describes.
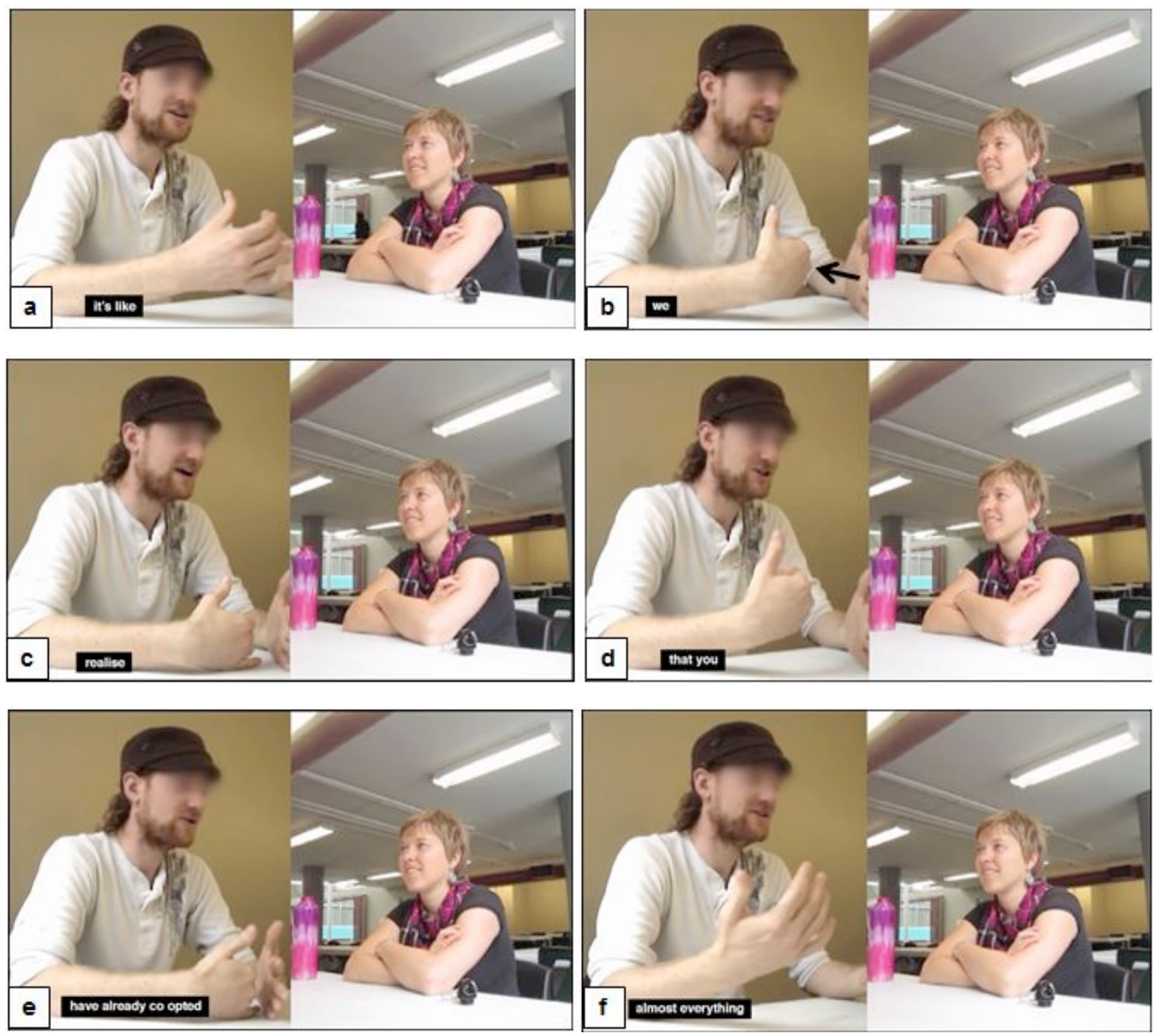

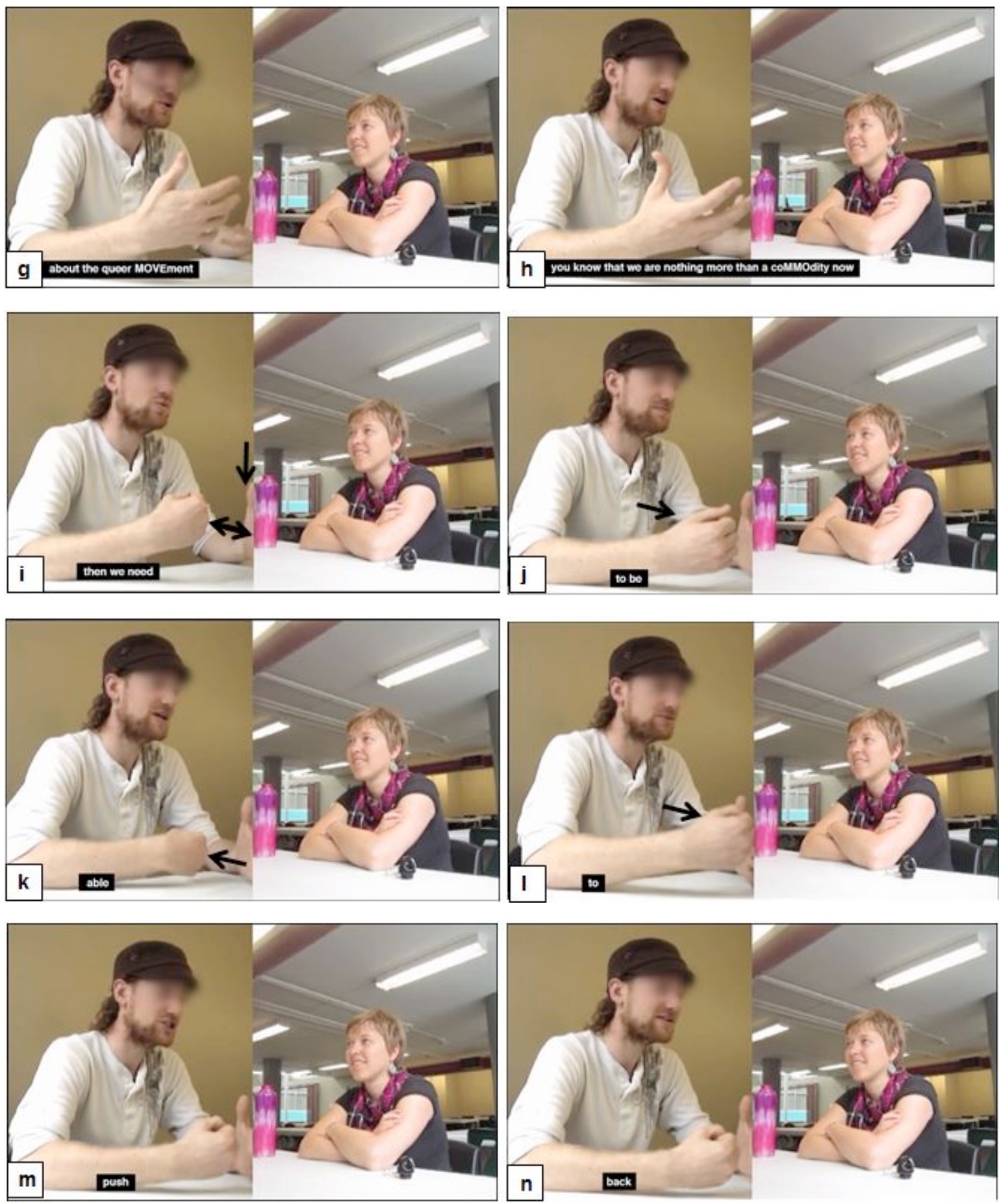

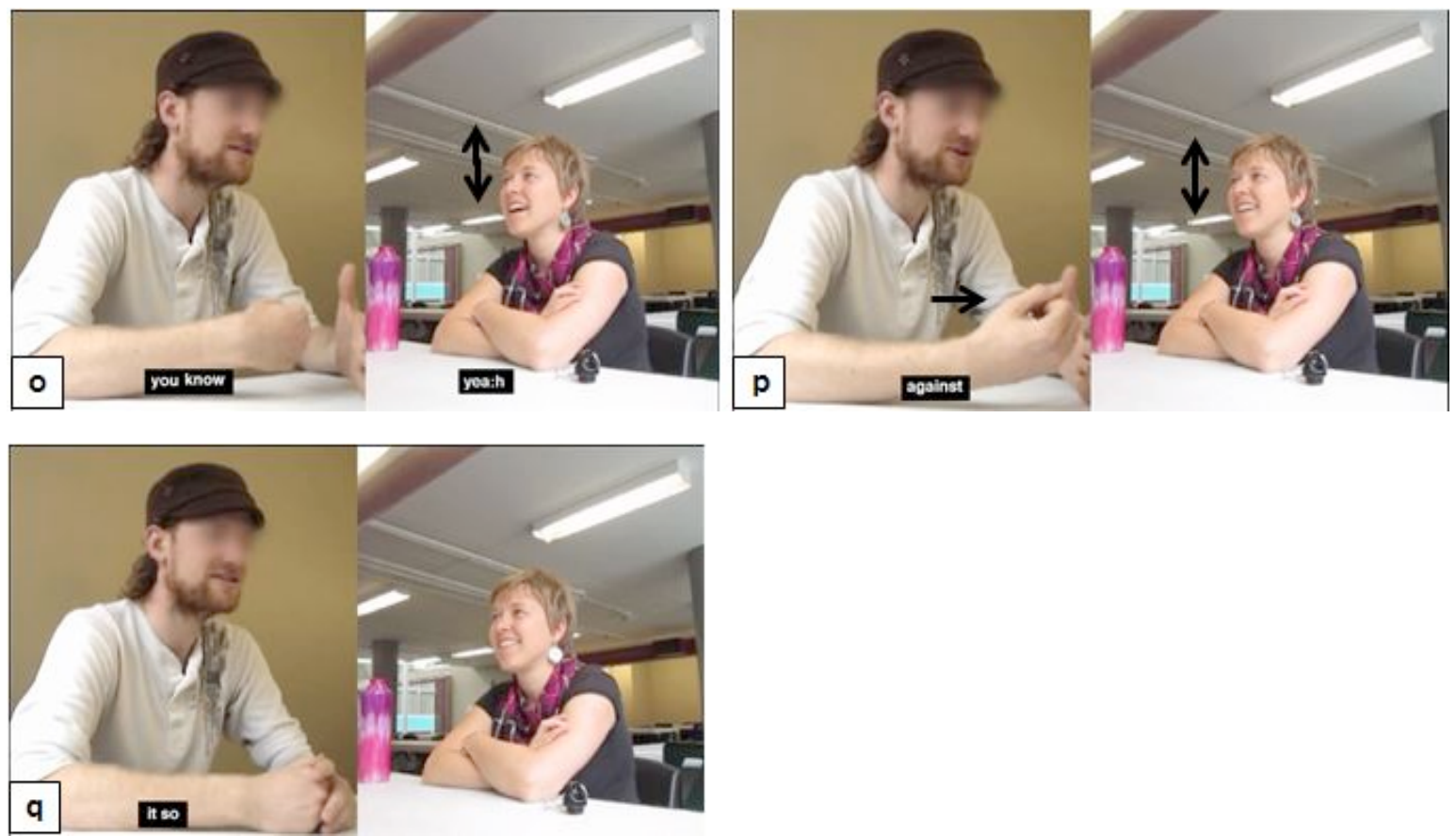

Figure 7.4: William

William begins by positioning himself as a member of the LGBTQ+ community through his use of we coupled with a deictic gesture towards himself with his $\mathrm{RH}$ (b). This establishes his right hand as a symbol representing the queer community. Next, he illustrates the process of appropriation with a metaphoric gesture where his $\mathrm{RH}$ (the queer community) comes up against his $\mathrm{LH}$, which is placed open palmed on its side on the table (d-e). This gesture elaborates on his utterance, showing the effects of the appropriation: the community is obstructed in its ability to achieve its goals. William then explains that almost everything about the queer movement has been co opted (f-g). Here, he presents a metaphoric gesture display with both hands palms up (Kendon, 2004, p. 265), showing that there is nothing left. This seems to further position himself with the queer movement, as he gestures from their point of view, presenting the loss they experience instead of the gain acquired by appropriating actors (see McNeill, 1992 for more on gestural viewpoint). He then alters this gesture slightly by bending his fingers and tensing his thumb (h), while asserting that the queer movement is nothing more than a commodity now. This adapted gesture presents the queer movement as an object 
that can be held (McNeill, 1992), possibly underlining the objectification expressed in his utterance. Next, William re-forms his LH as an obstruction (i), providing a cohesive link (McNeill, 1992) with his previous depiction of the appropriation (b-e). $\mathrm{He}$ also changes the handshape representing the queer community to a closed fist (i) and begins moving it forward towards the obstruction (j-l) in a possible display of power (Schubert, 2004). This enactment of resistance precedes his narration of what is happening (McNeill, 1992) and finally, he explains that the community must push back $(m)$. As William elaborates on this resistance $(n-p)$, his $\mathrm{RH}$ fist breaks

through his obstructing hand $(p)$ and I offer my support by verbally backchannelling and nodding my head (o-p).

In summary, William skillfully deploys his hands as symbols representing the queer community and the groups who are appropriating this Discourse. Throughout the explanation however, he maintains a position within the community through his pronoun choices (we, you) but also multimodally in the way his gestures move from his body outwards. He also uses gesture to elaborate upon his utterance (McNeill, 1992) by showing actions which go beyond what he says (for example, in $m-p$ he talks about 'pushing back' while his fist in fact pushes through the obstruction). William thus understands and explains in an embodied way, the dynamics of appropriation and resistance that the queer community faces.

\subsection{Complicated Intersections: Pride, Palestine and the Tar Sands}

EQUAIA decided to respond to the Ethical Oil campaign by featuring a 'Green Bloc' in the Edmonton Pride Parade, possibly in reference to the anarchist 'black bloc' tactic found in many protest marches. This group would march as part of EQUAIA, wearing green to protest the pink washing of the tar sands alongside those protesting the pinkwashing of Palestine. Upon discovering the plans for a Green Bloc in Edmonton's Pride Parade, I asked to march with the group. I made this decision partly for data collection reasons, but I also felt strongly that I should show my support for the group's struggle (See Chapter 9 for more discussion on this decision). 
Resistance to the 'persecution/pride' advertisement took a number of forms within the parade. First, a group of marchers wore green to differentiate themselves from the larger EQUAIA group and mark themselves as the 'Green Bloc'. The choice of green here references the environmental Discourse which the marchers oriented to, and served to create a cohesive identity. ${ }^{9}$ All participants were given either pink or green bandanas with the words my pride is political stenciled in front (Figure 7.5b).
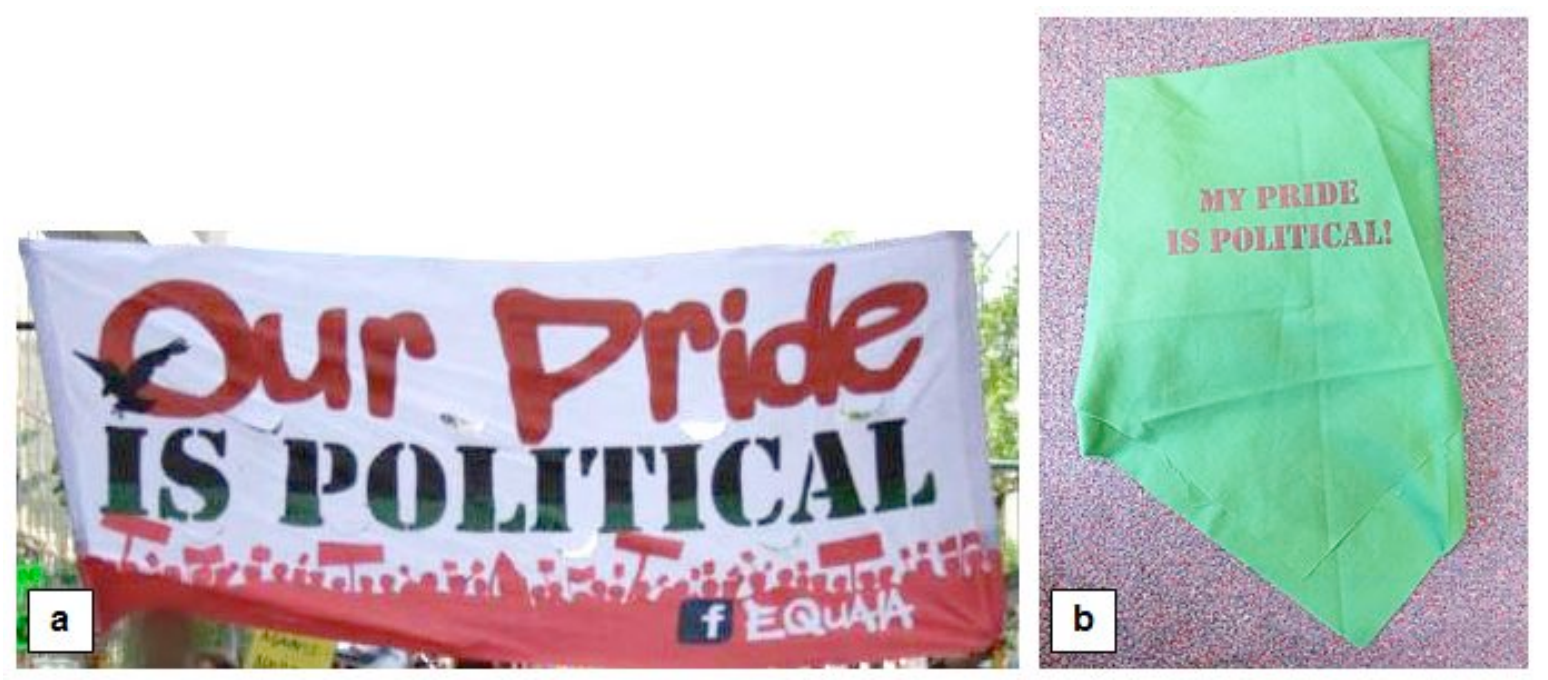

Figure 7.5: Our Pride is Political10

My pride is political also formed the broad discursive idea under which the group marched (in this case quite literally, see 7.5a). This phrase had been chosen to encompass the variety of intersecting Discourses (see section 7.4) and also to resist the perceived de-politicisation of the broader LGBTQ+ movement, especially in Pride Parades. In fact, William uses the concept of pinkwashing to describe what has happened to the Pride movement in general (Excerpt 7.2):

\footnotetext{
9 It should be noted that most of those marching were involved in many activist groups: queer, anti-racist, and environmental among them.

${ }^{10}$ Artefacts reproduced with permission.
} 


\section{Excerpt 7.2: William}

1 W i mean you could call + really the entire appropriation of the queer 2 movement like + what pride is considered today //is nothing $\backslash$ more 3 than a big party a celebration you know

$4 \quad \mathrm{~K} \quad$ /yeahll yeah

$5 \quad W$ the struggle for FREEDOM and LIBERATION + and that's been you

$6 \quad$ know a a very gradual very innocuous $+u: h+$ development over you

7 know probably twenty + years or so + fifteen twenty years or //sol

$8 \mathrm{~K} \quad$ /yea:hll

9 W um most of the people who are marching nowadays + it just seems so:

10 + you know + it it like it's taken for ge- taken for granted that that you

11 know + it's always been like this

$12 \mathrm{~K} \quad / / \mathrm{yeahl}$

13 W /butll you know it's + it's not //it was a PROtestl + you know?

$14 \mathrm{~K}$ land it kind of yeahll yeah

Having just defined pinkwash before the excerpt began, William describes the Pride festival as part of a wider appropriation of the queer movement (1-2) and laments that it is nothing more than a big party a celebration (2-3). Pride began, he explains, as a struggle for freedom and liberation (5) and has been de-politicised over time (6-7), such that its origins have been forgotten (it's taken for granted that it's always been like this, 10-11).

EQUAIA sought to re-politicise the parade space multimodally, with participants wearing bandanas over their faces in the style of Black Bloc anarchists, and some marchers even going topless as an act of resistance against body policing. ${ }^{11}$

Participants were also given hand-painted signs to hold with slogans linking environmental concerns with indexicals of LGBTQ+ Discourses (see Figure 7.6).

11 This later resulted in EQUAIA's expulsion from the Edmonton Pride Parade. 

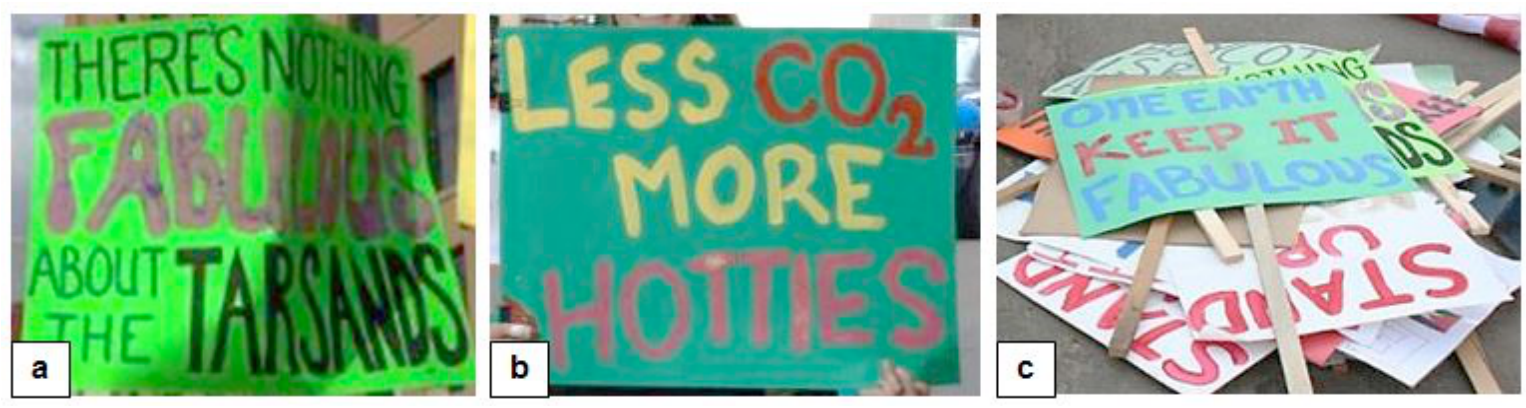

Figure 7.6: Parade Signs ${ }^{12}$

Many of these indexicals are linguistic (fabulous, hotties) and are further highlighted multimodally through the use of glitter or the colour pink (7.6a, b) (Stasi \& Evans, 2013). The signs also make use of colour to symbolically link the queer movement with the environmental movement by combining pink or purple with a green background. The wider effect is that queer struggles and environmental concerns are connected. Exactly how they are connected was further explained through a pamphlet distributed to parade viewers (Figure 7.7, front and back).

12 Artefacts reproduced with permission. 

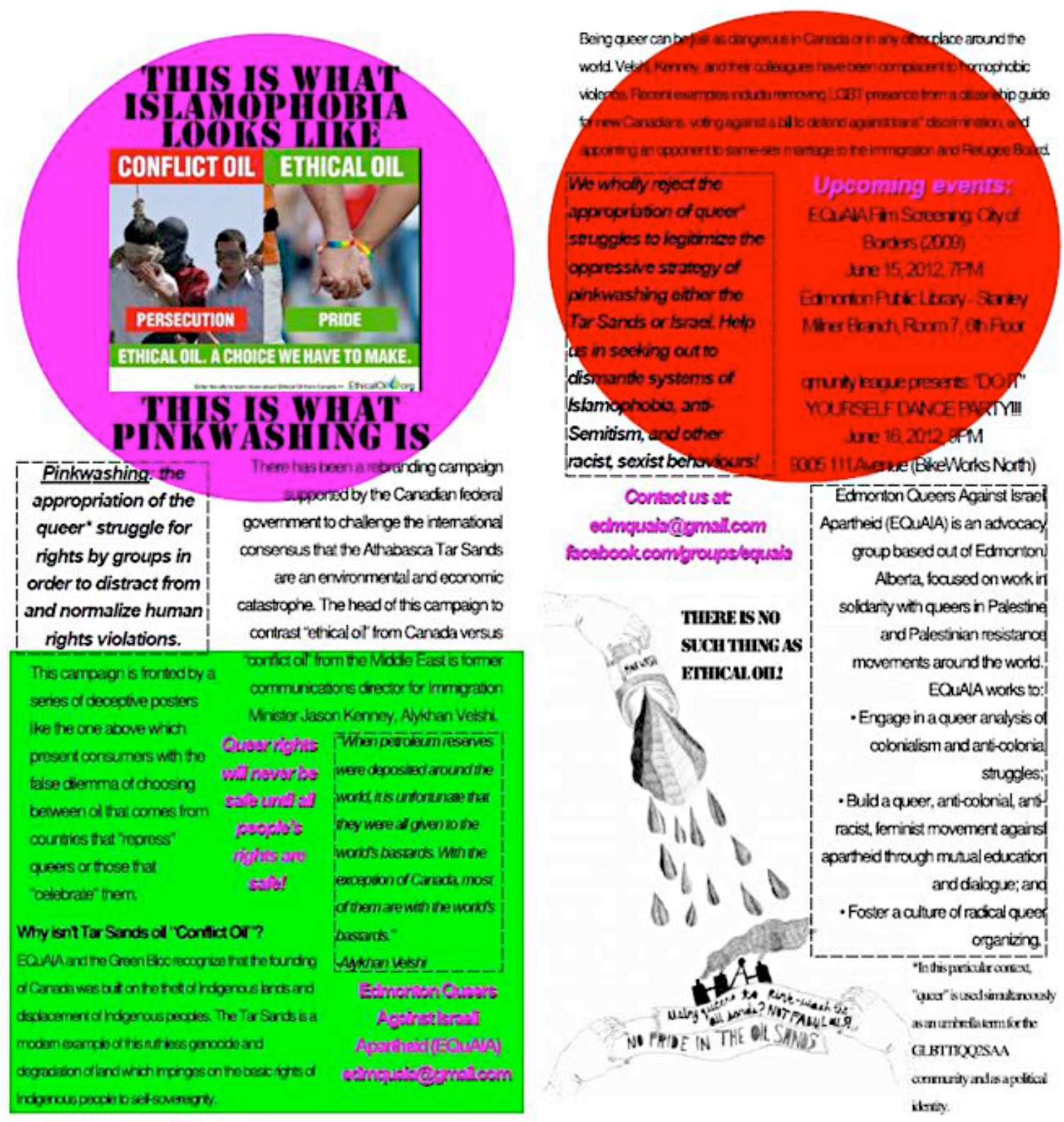

Figure 7.7: Pamphlet

Here, we see how the designer(s) seek to make sense of, and critically comment upon, the various intersecting Discourses. To begin, the offending ad is reproduced against a large, pink circle with the text this is what Islamophobia looks like above and this is what pinkwashing is below. Here, the two major Discourses (Islamophobia and LGBTQ+) are introduced and critiqued through evaluative word choice (Islamophobia, pinkwashing). Coupled with the image of the ad, these 
phrases concisely summarise the issue EQUAIA is protesting. However, elaboration is needed in order to understand just what these concepts mean, and what the tar sands have to do with Pride and Palestine. First, the pamphlet designer provides a definition of pinkwashing (see Figure 7.8) in the assumption that this is a new term for this audience. Next, an elaboration of the 'ethical oil' campaign is presented below the ad on a neon green background.

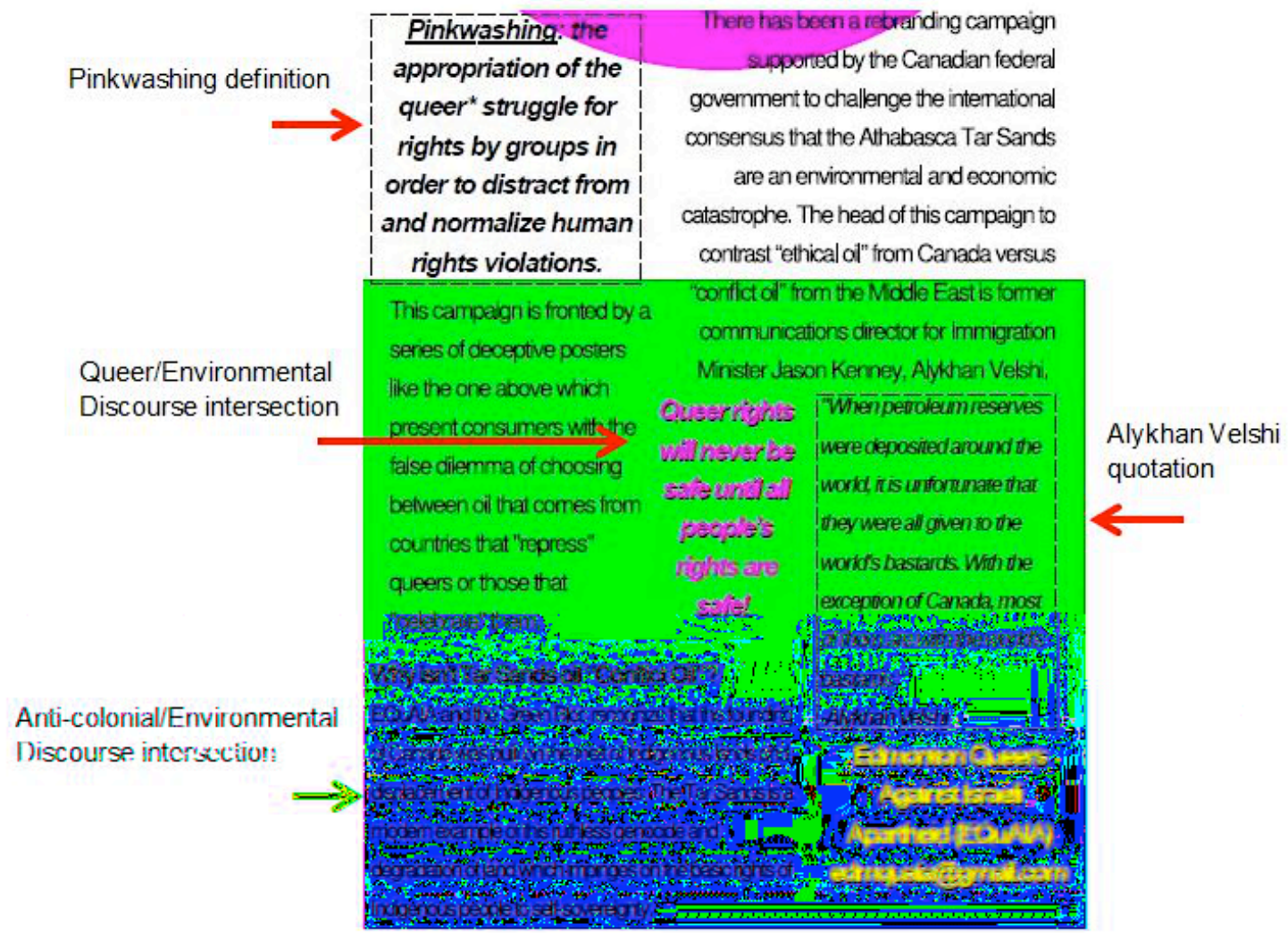

Figure 7.8: Pamphlet

Also included is a quotation from the ad's campaign organiser Alykan Velshi, in which he characterises non-Canadian oil-producing nations as the world's bastards. This is arguably in reference to dictatorships in many oil-producing countries, however it also demonstrates Velshi's practice of 'othering' entire nations while holding Canada in a spotlight of moral superiority (cf. Lams, 2010). Finally, in the bottom left is a paragraph (Why isn't Tar Sands Oil 'conflict Oil'?) which introduces an anti-colonial critique (Canada was built on the theft of Indigenous 
lands and displacement of Indigenous peoples). The tar sands are further characterised as a modern example of colonial practices (ruthless genocide and degradation of land), thus linking colonialism and environmental destruction as two intersecting Discourses. Finally, connecting this established environmental/anticolonial Discourse to queer rights, is the phrase Queer rights will never be safe until all people's rights are safe! in pink against the green background. Similar to the original ad (Figure 7.3), the group's contact information is presented in the bottom left, also in pink. Once again, we can see the use of colour to index LGBTQ+ Discourses and environmental Discourses (pink and green) and link them by using the colours together.

On the other side of the pamphlet, there is further elaboration of the intersecting Discourses (Figure 7.9).

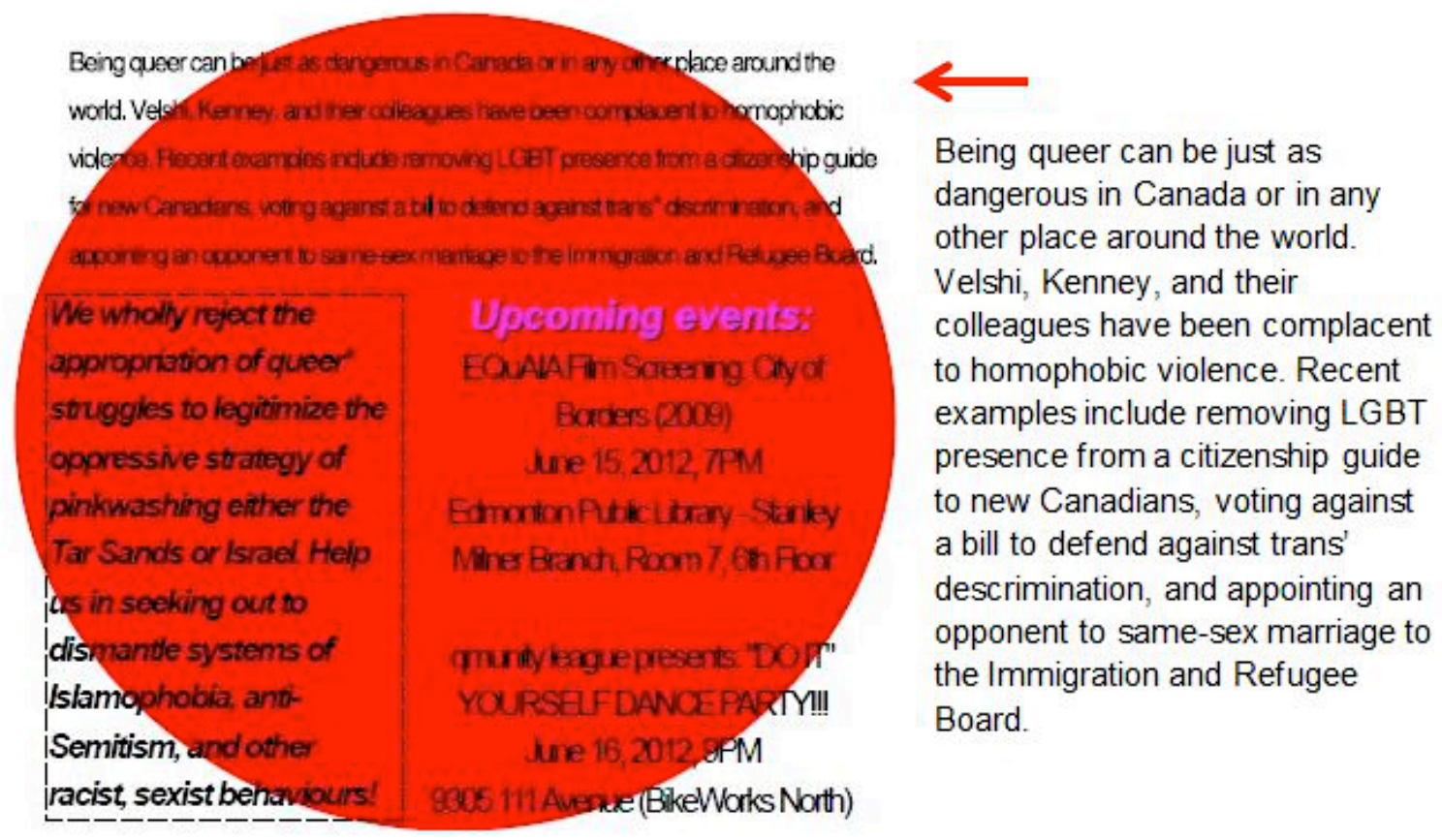

Figure 7.9: Pamphlet

We are told that being queer can be just as dangerous in Canada and that Velshi (who was quoted on the previous page) has been involved in policies of discrimination against LGBTQ+ people, challenging his apparent championing of 
queer rights. His true motivations (appropriating queer rights) are summarised in the boxed manifesto (we wholly reject the appropriation of queer struggles). This also links Palestine and the tar sands through their both being subject to pinkwashing (pinkwashing either the Tar Sands or Israel). The manifesto also urges participation in dismantling systems of Islamophobia, anti-Semitism, and other racist, sexist behaviours, naming more intersecting Discourses (including the first mention of anti-Semitism). Finally, readers are given a list of upcoming events. These texts are all presented against a red background which mimics the pink circle from the other page. The significance of the choice of colour is not clear; however a possible interpretation could be the indexing of danger (blood) which queer people face in Canada.

In the bottom half of the second page, we are presented with more information about EQUAIA itself. Contact information and another manifesto fill most of the space (Figure 7.2a), as well as a footnote elaborating the use of the word 'queer' (Figure 7.1). Also included is a black and white pencil drawing with the text THERE IS NO SUCH THING AS ETHICAL OIL! (Figure 7.10). 


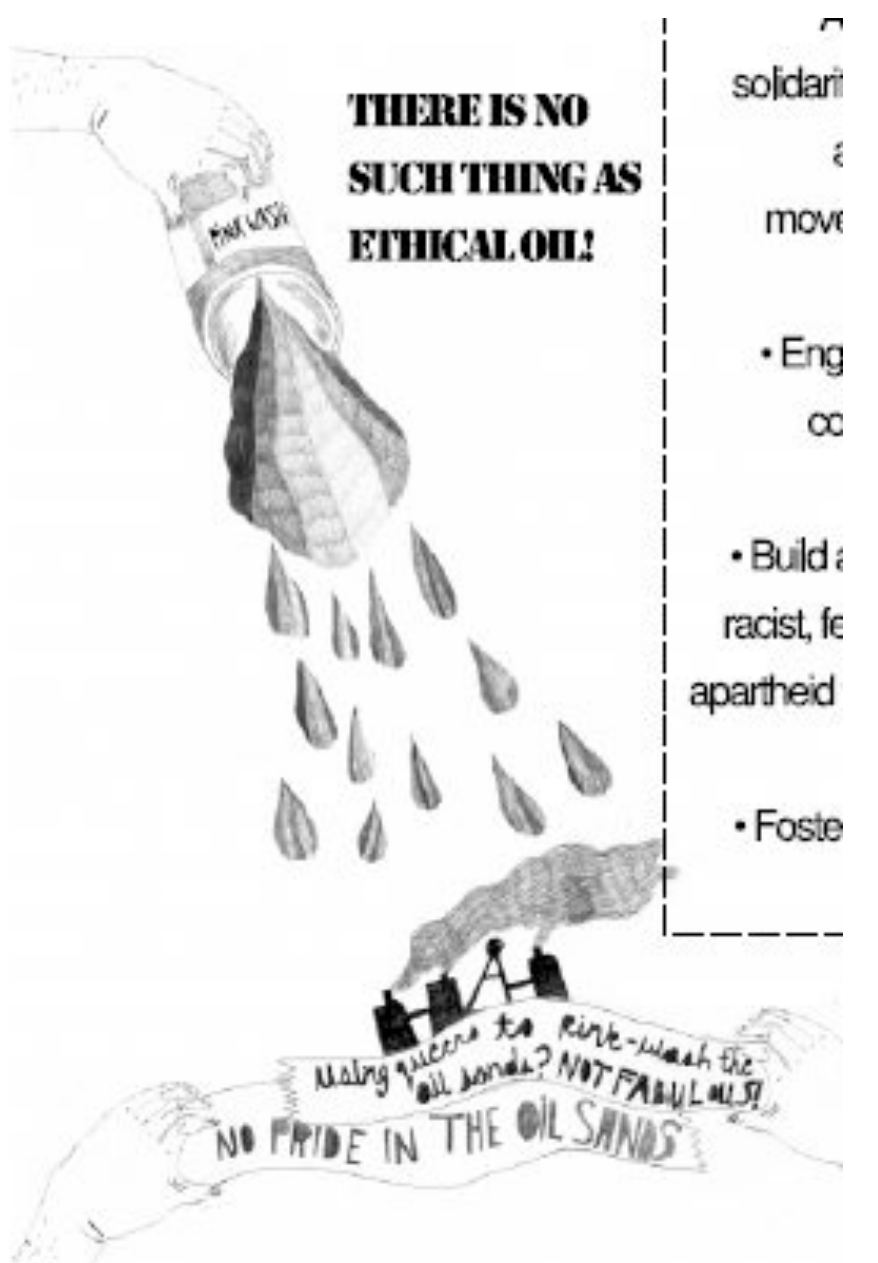

Figure 7.10: Pamphlet

The drawing uses symbolic imagery (cf. Kress \& Van Leeuwen, 2006) to summarise the pinkwashing of the tar sands. A hand is shown spilling 'pinkwash' from a paint tin, and the liquid substance which flows out is (presumably) rainbowcoloured. Much like the wristbands in Figure 7.3, the rainbow indexes LGBTQ+ Discourses, and is used to cover the environmental destruction depicted below. The drops fall onto small iconic representations of machinery billowing dark smoke while two hands hold banners reading using queers to pink-wash the oil sands? NOT FABULOUS! and NO PRIDE IN THE OIL SANDS. It is interesting to note the use of the term 'oil sands' as opposed to 'tar sands' here, which tends to position the mines in a positive way (Kidner, 2012). Once again, LGBTQ+ Discourses are 
indexed through lexical choice (fabulous, Pride) and discursively linked to the environmental anti-tar sands movement (e.g. no Pride in the oil sands).

In summary, this pamphlet explains the complexity of the pinkwashing issue and seeks to link it back to the tar sands. We are presented with the goals of the EQUAIA group and introduced to the concept of pinkwashing and the issue of Palestinian nationhood. Additionally, we are shown the Islamophobic aspect of the ethical oil ad and its subsequent use of pinkwashing to justify tar sands development. Finally, Indigenous sovereignty is connected to environmental destruction, and Israel and Canada are linked as two nation states which use pinkwashing to cover up colonial oppression. This is achieved both through explicit textual references but also through the use of colour and symbols. The artefact thus summarises a very complex web of interconnected and competing Discourses, which can subsequently be tracked through their appropriation and resistance. We might also consider the differing multimodal registers (see section 5.5) present between this resistance artefact and the original Ethical Oil ad, which relies on a professional design and commercial production. In contrast, the EQUAIA pamphlet is printed in matte finish on hand cut paper with a number of intersecting and overlapping design elements visible, suggesting it uses a lower, and more informal multimodal register.

\subsection{Multimodal Entextualisations}

The situation which EQUAIA wished to get across to Pride Parade viewers is a very complex one. The intersecting Discourses which move back and forth between Ethical Oil and EQUAIA are tracked and summarised in Table 7.1: 
Action

LGBTQ+ struggle used to legitimise Israeli apartheid

Resistance of Israeli pinkwash

LGBTQ+ struggle and Islamophobic

Discourses used to sell oil

LGBTQ+ struggle reclaimed and used to highlight environmental destruction
Actors

Israeli state

EQUAIA

Ethical Oil

EQUAIA
Means

Israeli pinkwash

past Pride Parades

Persecution/Pride ad

Pride Parade artefacts

(e.g. pink/green)

Table 7.1: EQUAIA Timeline

However, EQUAIA not only highlighted their resistance to the appropriation of LGBTQ+ Discourses but also made a wider comment on intersectionality in general. This was done by drawing together the seemingly separate plights of people in Canada and Israel to comment on shared oppression. William summarises this in Excerpt 7.3:

\section{Excerpt 7.3: William}

1 W it was kind of difficult how we would-i mean + it was easy to see the

2 connection with the whole intersectionality of the issue

$3 \mathrm{~K} \quad / / \mathrm{yeahl}$

$4 \quad$ W $\quad$ /you knowll? like it's i mean + speaking PERsonally $+i$ see that there's no difference + in the apartheid state that canada + has + CREATED

6 and and the apartheid state ISRAEL has created by appropriating

7 la:nd a:nd + basically + creating + genocidal + you know + u:h

$8 \mathrm{~K}$ yeah

9 W POLICIES //and + and policy DIRECTIONS

$10 \mathrm{~K}$ /yeahll

11 W that + forcibly remove people from their lands and you know destroy

12 homes and + create impoverished populations

$13 \mathrm{~K}$ yeah

14 W you know based on racist ideologies

$15 \mathrm{~K}$ yeah 


\begin{tabular}{|c|c|c|}
\hline $\begin{array}{l}16 \\
17\end{array}$ & W & $\begin{array}{l}\text { within their own borders + you //know like } \backslash \text { they're they're they're the } \\
\text { eXACT same situation }\end{array}$ \\
\hline 18 & K & /yeahll \\
\hline $\begin{array}{l}19 \\
20\end{array}$ & W & $\begin{array}{l}\text { a //at least } \backslash \text { in my MIND but um }+ \text { we wanted to find } a+a+u m \\
<\text { clears throat }>\end{array}$ \\
\hline 21 & K & /yeahII \\
\hline $\begin{array}{l}22 \\
23\end{array}$ & W & $\begin{array}{l}\text { we wanted to find an }+ \text { easily }+ \text { uh }+ \text { communicative }+ \text { language to } \\
\text { use //with } \backslash \text { crowds and with the audience and to }\end{array}$ \\
\hline 2 & $\mathrm{~K}$ & $/ \mathrm{mmll}$ \\
\hline $\begin{array}{l}25 \\
26 \\
27 \\
28\end{array}$ & W & $\begin{array}{l}+ \text { to sort of }+ \text { make them see HOW these two seemingly really }+ \\
\text { different }+ \text { very }+ \text { um }+ \text { uh }+ \text { very different in their }+ \text { i guess } \\
\text { motivations or mandates }+ \text { you know their GOALS whatever that that } \\
\text { they + work together }\end{array}$ \\
\hline 29 & $\mathrm{~K}$ & //yeah\ \\
\hline $\begin{array}{l}30 \\
31 \\
32\end{array}$ & W & $\begin{array}{l}\text { /you know } \backslash \text { like like it was kind of }+ \text { we were working }+ \text { to see how we } \\
\text { could use language to actually make people SEE that you know this is } \\
\text { a natural + alliance }\end{array}$ \\
\hline 33 & $\mathrm{~K}$ & $/ / \mathrm{hmm} \backslash$ \\
\hline 34 & W & /that $\backslash$ you know that + we're working together for the same purpose \\
\hline 35 & $\mathrm{~K}$ & $\mathrm{~mm} \mathrm{hmm}$ \\
\hline & W & um + and because + you know the ACTORS in ONE party are are \\
\hline & & trying to + uh + aPPROpriate + the people from another party and + \\
\hline $3 \varepsilon$ & & $\begin{array}{l}\text { you know so anyway }+ \text { u::m so we WANTED to make it really simple } \\
\text { and we thought vou know we iust + savina that we're + poLltical like }\end{array}$ \\
\hline 40 & & $\begin{array}{l}\text { that that that + that our pride is political and that what we believe in is } \\
\text { political }\end{array}$ \\
\hline
\end{tabular}

William begins by admitting that it may be difficult to present the connections between Canada and Israel (1-2), but that these connections are clear to him (speaking personally i see that there's no difference, 4-5). He then elaborates on the ways in which he sees the Discourses connecting, that is, through the link of apartheid and genocidal policies (5-9). Both countries forcibly remove people from their lands, destroy homes, create impoverished populations based on racist ideologies (11-14) and can then be seen as the exact same situation (16-17). In this way, William brings Canada and Israel together as two colonial entities founded on the oppression of First Nations and Palestinian people respectively. 
However, he hedges this strong statement (the exact same situation) by personalising it as his opinion (at least in my mind, 19). While recognising that these connections may not be so clear to others (19), he recounts how the group sought to find a way to communicate these issues to the specific Pride audience (22-23). William describes the difficulties in bringing the two struggles together using language as a tool to illuminate the connections (make them see how these two...work together, use language to actually make people see that this is a natural alliance, we're working together for the same purpose, 25-34). In lines 36-37, he describes another connection (actors in one party are trying to appropriate the people from another party), adding to the apartheid/colonial link he has already established (4-17). Perhaps realising how complicated the situation has become, William hesitates and hedges (you know so anyway, um, 38) before stating that the group wanted a simple message (38). This message, (our pride is political, what we believe in is political, 40-41) reiterates his earlier concern that Pride has become de-politicised (see Excerpt 7.1) and shows how the group has considered how its messaging might re-politicise the space. Using the idea of a political Pride, William can then draw upon a shared Discourse of anti-apartheid/anti-colonialism, simultaneously support Palestinian and Indigenous sovereignty, and engage with a queer identity.

These intersections were further entextualised multimodally through t-shirts the group made for participants to wear (Figure 7.11), as the phrase we march on occupied land could apply to either Israel or Canada. 


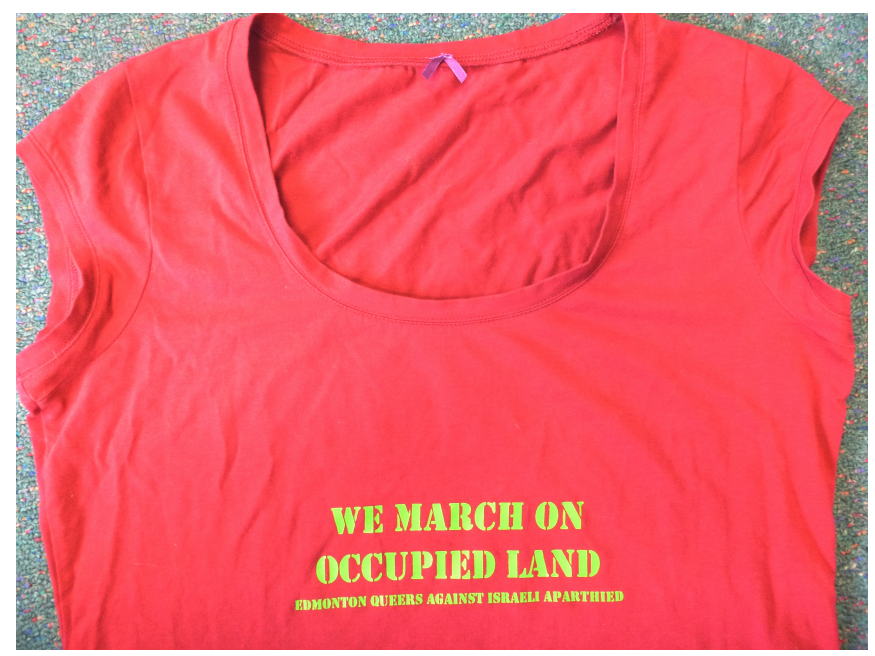

Figure 7.11: T-shirt ${ }^{13}$

Because the t-shirts were worn in Canada and produced by a Canadian-based group, the occupied land firstly indexes First Nations struggles against colonialism as the most immediate, local case. However, the presence of the group's name (Edmonton Queers Against Israeli Apartheid) in smaller font also recontextualises the phrase in respect to Palestine, thus bringing both struggles together through one textual presentation. ${ }^{14}$ This political stance is further framed through the generalised banner our Pride is political in an attempt to simplify and encapsulate the intersecting Discourses (Excerpt 7.3, lines 38-41).

This bringing together of Discourses into one overarching concept is also multimodally presented through gesture when William discusses his approach to intersectionality (Figure 7.12).

${ }^{13}$ Artefact reproduced with permission.

14 This shirt in particular also makes use of the pink/green links established in section 7.3, however the fabric colour in this case formed one of several choices. 

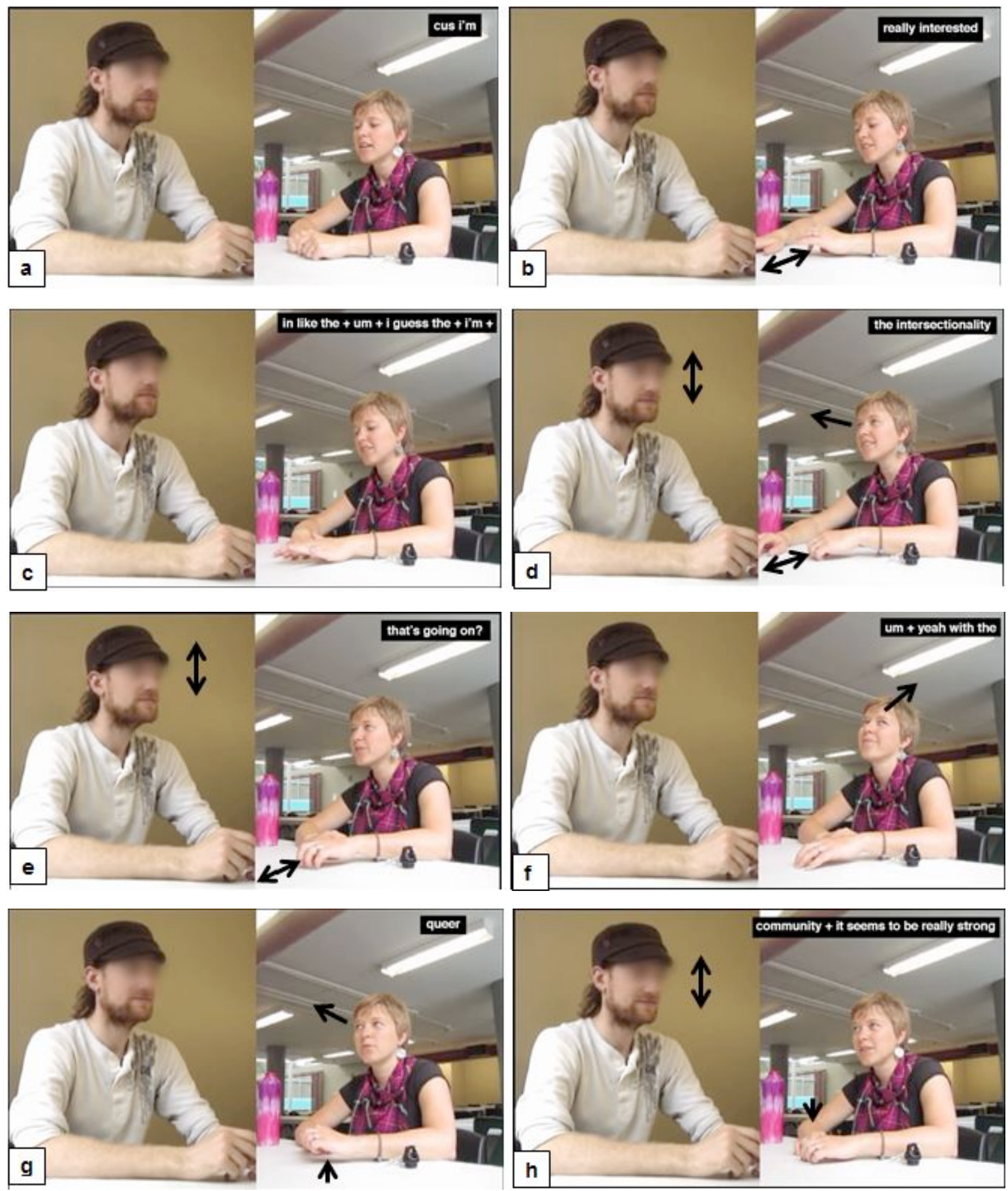

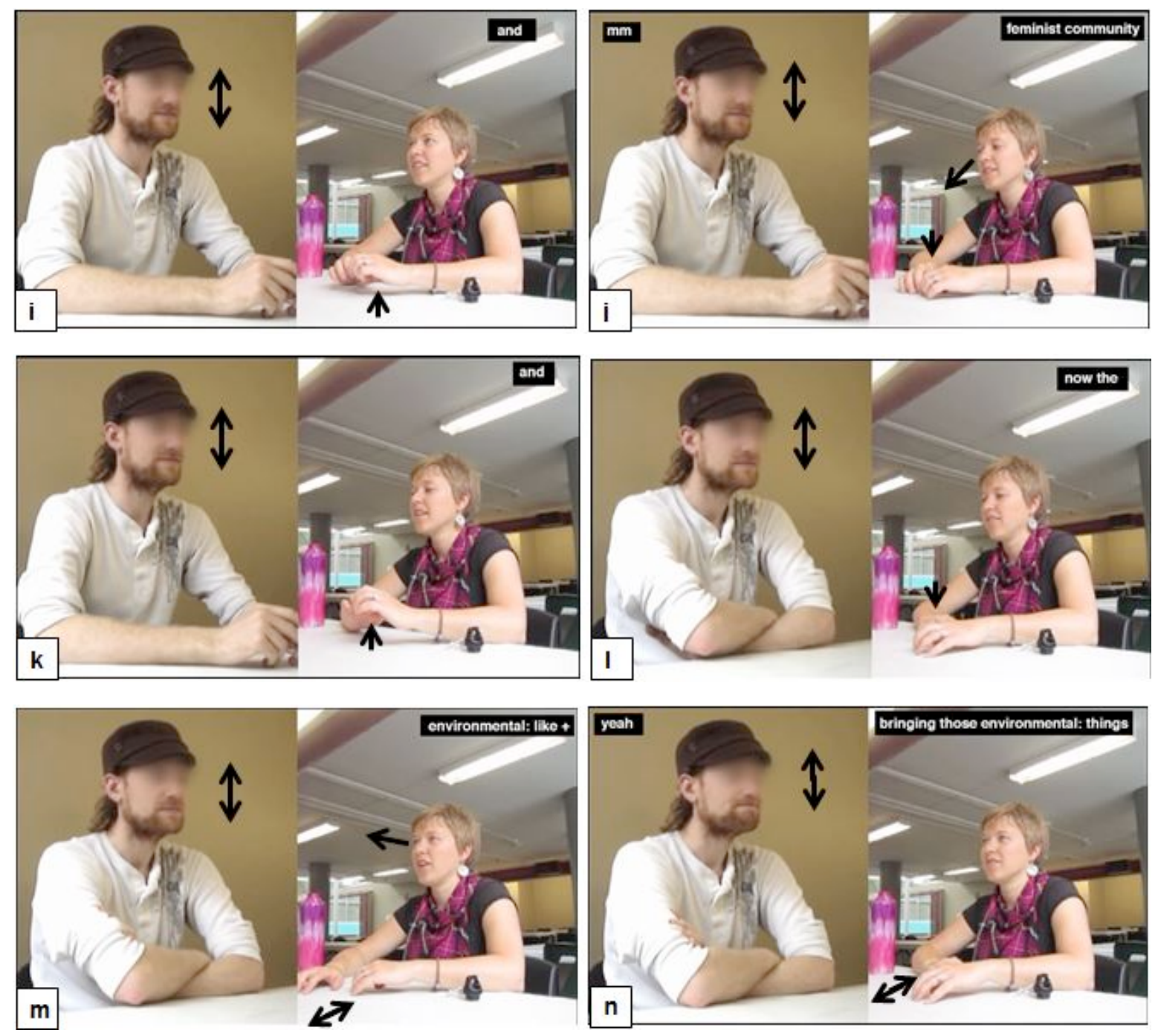

bringing those onvironmontal: things
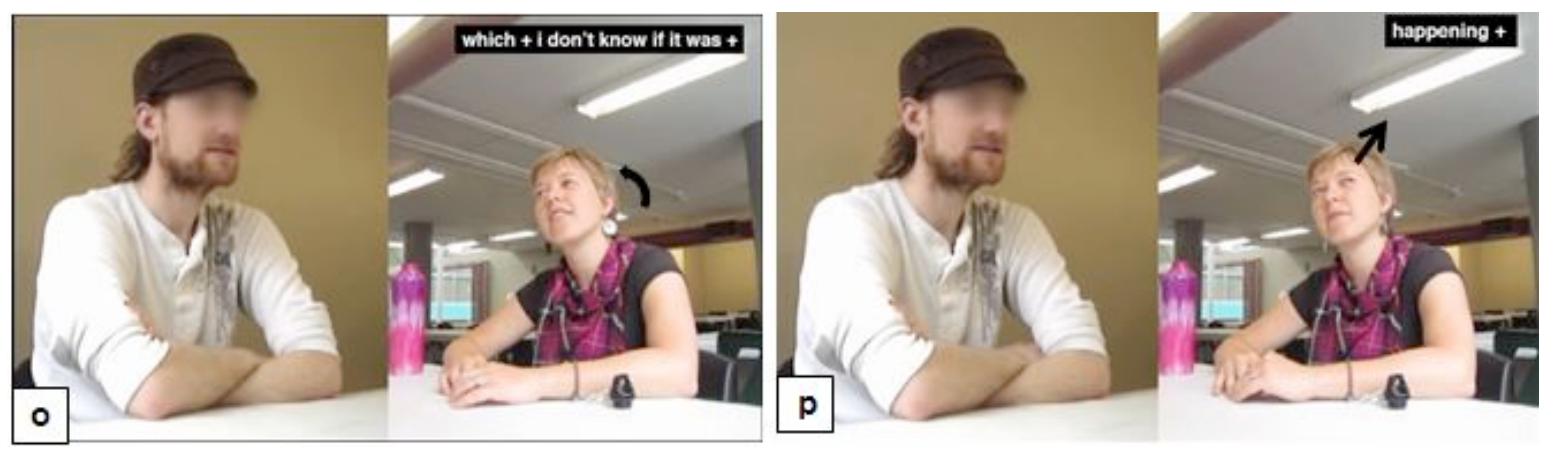

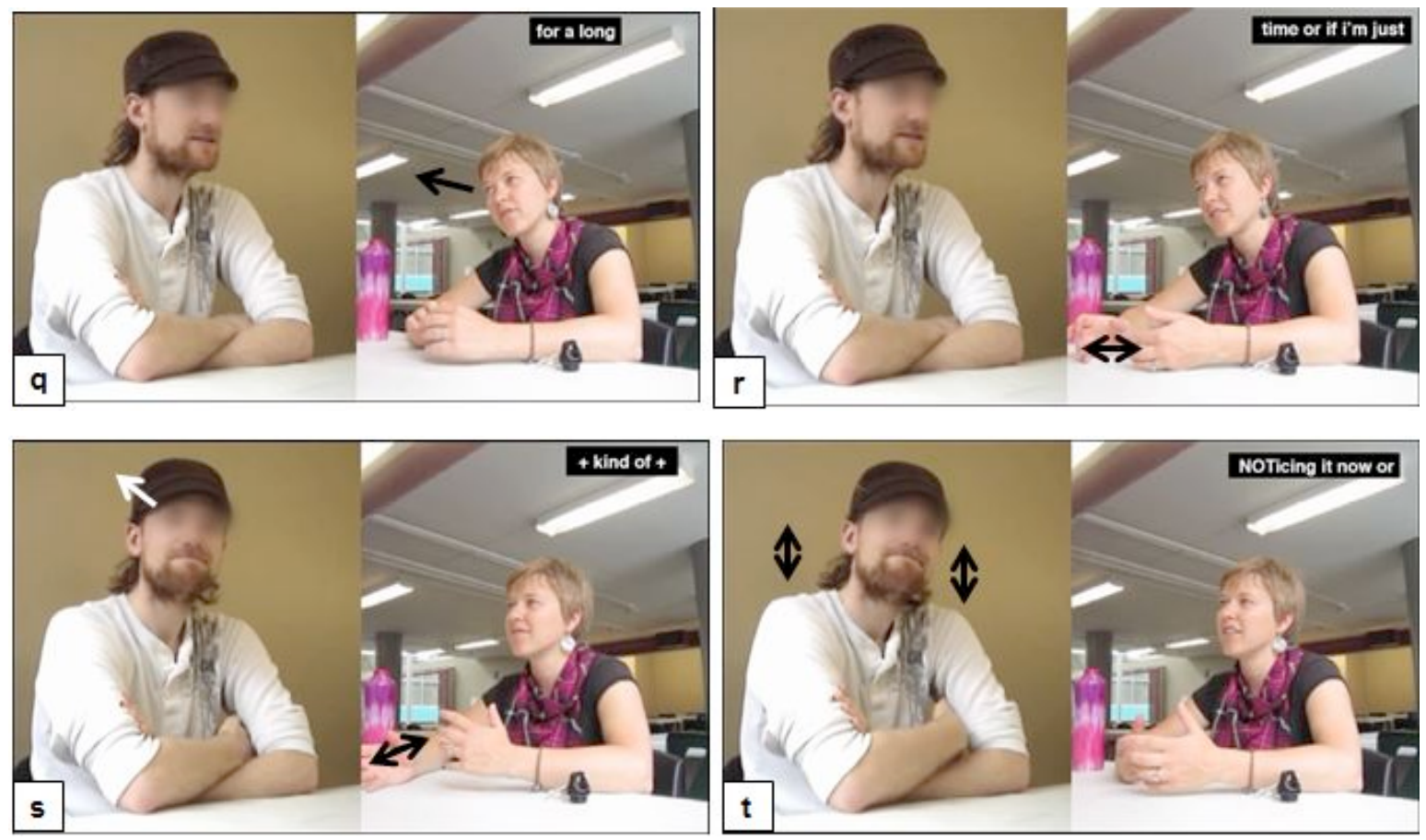

Figure 7.12: William

First, I bring up the concept of intersectionality (d) and elaborate on what I mean (fn). Already, before I have used the term, I make an iconic gesture which seems to depict two entities intersecting on the table (b). I repeat this again when saying the word (the intersectionality) in d-e. I then emphasise the groups that I perceive are working together with beats $(\mathrm{g}-\mathrm{I})$ before repeating the intersectional gesture, which suggests I am multimodally enacting the crossing of the listed groups (m-n). I next tilt my head in William's direct (o) and lean in (q) before repeating an adapted form of the intersectional gesture (s). This adaptation moves the gesture into our shared interactive space (see Kendon, 2004 on interactive gestures), and can be read as an invitation for William to take the floor, which he does (Figure 7.13).

In this example, we can see how the idea of intersectionality has been introduced multimodally by me as separate entities which are traveling in perpendicular motion and thus cross paths. In the next section of the conversation, William takes this concept of separate, but intersecting groups and changes it into a single entity (Figure 7.13 ). 

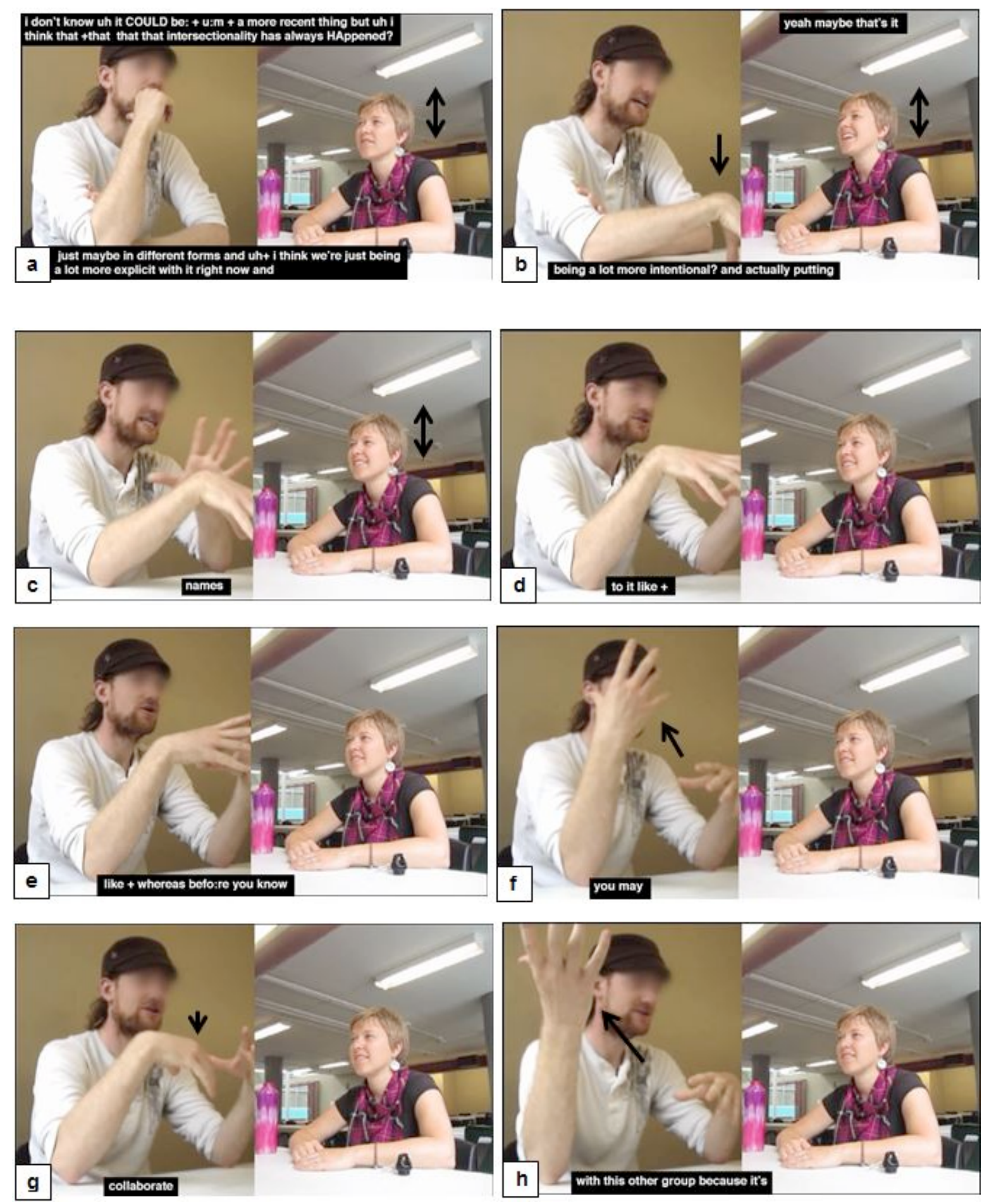

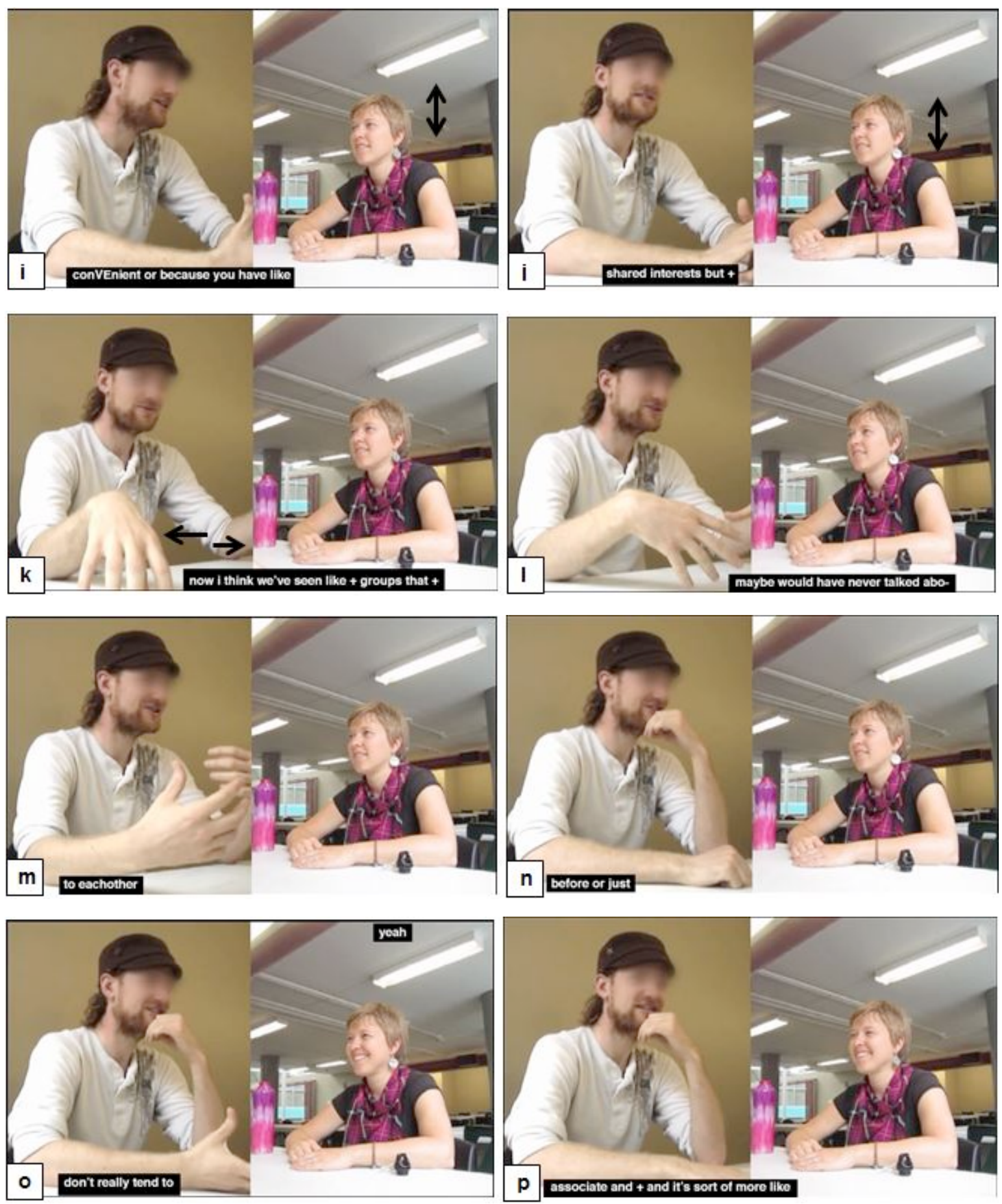

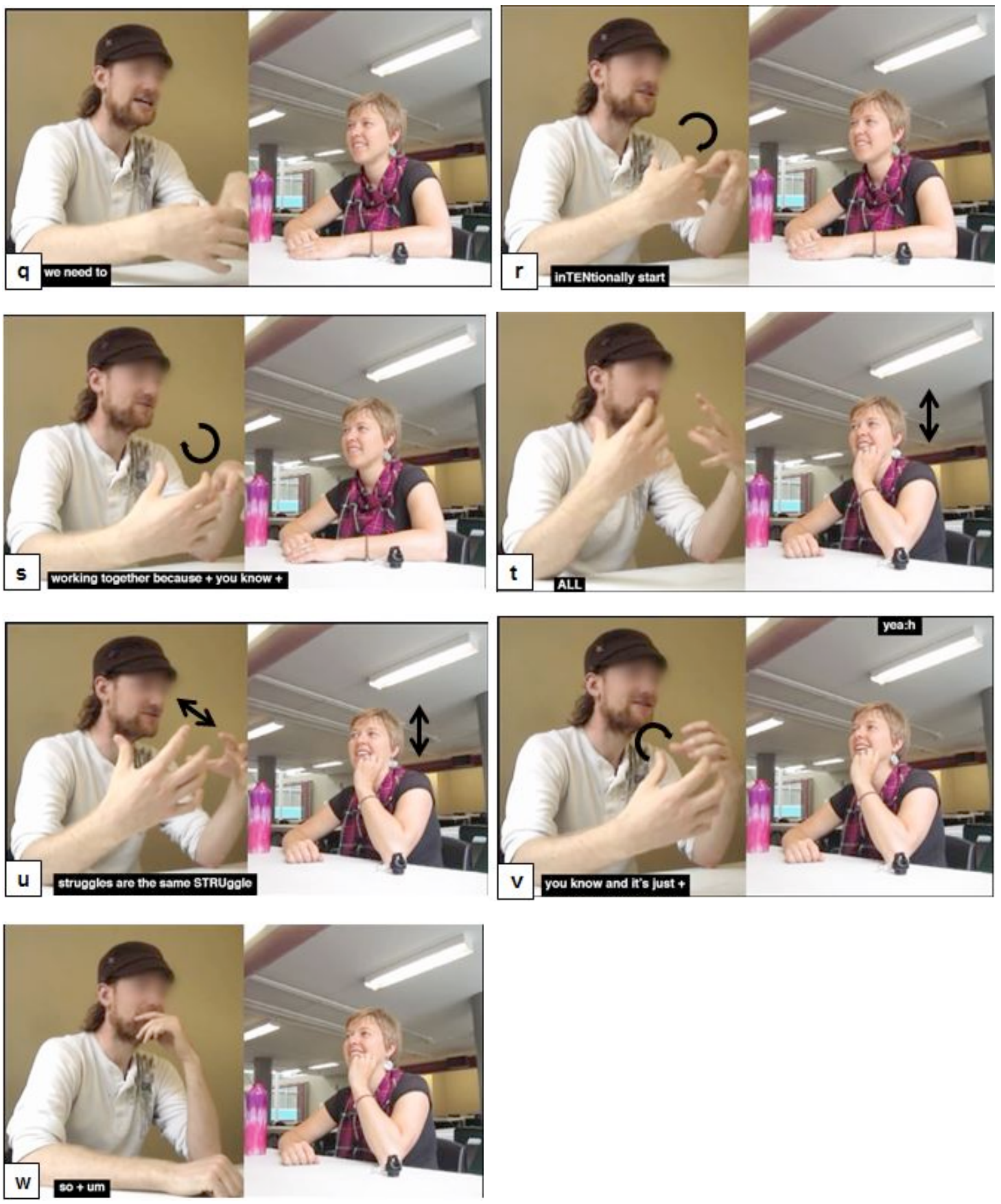

Figure 7.13: William

William begins his turn with a description of the history of intersectionality in Edmonton (a) before asserting that it has now become more explicit (b-d). This is 
accompanied by a metaphoric gesture (palms in, hands spread, as if clutching something, c-d), which arguably presents intersectionality as an object that can thus be 'named' (c). Next, William contrasts this current situation with the past, when groups would work with each other only due to convenience or shared interests (e-j). To illustrate this further, he gestures with his palm up to the right side, which presents this other group for display (Kendon, 2004) while also locating it in a separate space away from himself. After his hands have come together in shared interests (j), William spreads them apart again in an iconic gesture of separation, possibly showing the groups' lack of interaction ( $k$ ), by locating them on either side of the table space in front of him. Then, while discussing groups that maybe would have never talked before, he brings his hands together. which seems to show the groups interacting with each other (I-n), before dropping his $\mathrm{RH}$ to the table and touching his $\mathrm{LH}$ to his chin (n). The next few utterances are an elaboration on how these groups wouldn't interact (don't really tend to associate) and then William talks about the need to work together intentionally (q-s). He once again brings both hands together as he did before $(m)$, which suggests a cohesive link to his previous utterance before the elaboration (groups that maybe would have never talked to eachother). William then describes the need to intentionally start working together ( $\mathrm{q}-\mathrm{s}$ ) and he conceivably enacts this with a 'digging' motion using both hands, presenting two entities which mirror each other's actions and work in cohort. Finally, William comes to the main point of his argument, that all struggles are the same struggle $(\mathrm{t}-\mathrm{u})$. Here, he uses both hands to arguably present the struggle as one object which can be delineated and held. He then uses this struggle-as-object gesture to beat on struggle and same, which suggests he is highlighting their integration even further (u) (McNeill, 1992, p. 169). In effect, William seems to bring separate, intersecting issues together into one metaphorical object that presents them as the same struggle $(\mathrm{u})$.

The discussion of intersectionality with William shows how we multimodally co-construct the concept. In Figure 7.12, I introduce intersectionality as separate entities which cross paths. In Figure 7.13, William elaborates on his understanding 
of the concept, moving from separate entities which might interact at various times, to a singular, generalised entity which encompasses each individual struggle.

\subsection{Conclusion}

Through the above analysis, I have shown the complex ways in which Discourses are appropriated and resisted in Alberta. Through the use of layout, colour, and image, the Ethical Oil campaign appropriates LGBTQ+ Discourses and, coupled with a Discourse of Islamophobia, seeks to legitimise tar sands oil as 'ethical' (see Figure 7.3). This can be read as an example of 'pinkwashing', where LGBTQ+ rights are used to cover other oppressions. The dynamics of appropriation and resistance are also multimodally enacted through gesture, as is shown in Figure 7.4 where William uses his hands to symbolically construct the queer community and the appropriating actors in opposition to each other. With their 'Green Bloc' resistance in the Pride Parade, EQUAIA seeks to link various Discourses multimodally through colour, layout, and symbolic images. In this way, the group creates linguistic and multimodal connections between pinkwashing and Islamophobia, environmental destruction and colonialism, Israel and Canada, and queer rights and Palestinian/Indigenous struggles. By linking these Discourses, EQUAIA highlights the intersectional oppressions these various groups face.

This intersectionality is also co-constructed multimodally through gesture by William and myself (Figures 7.12, 7.13), showing the concept first as separate but intersecting entities which eventually come together under one struggle. This mirrors, and gesturally enacts, the collaborative potential of an intersectional approach to activism (i.e. Cho, 2013, p. 407).

The case discussed in this chapter suggests industry actors are also drawing partly upon intersectional understandings to legitimise the oil industry. For example, the ads in the Ethical Oil campaign use minority Discourses (e.g. LGBTQ+ rights, women's rights, Indigenous sovereignty, etc.) to juxtapose Canada's treatment of such communities against that of other oil-producing 
nations. This encourages the ad's audience to contemplate how oppression is manifested by the State (e.g. by denying or allowing same sex marriage). The solution proposed to consumers is to withdraw support from these regimes of power by refusing to buy their oil. Thus, consumers of Canadian oil can show their support for communities of struggle (e.g. those identifying as LGBTQ+, First Nations, women) through their purchasing decisions. However, by suggesting Canadian oil as an 'ethical' alternative, the campaign fails to consider the ways in which similar oppressions occur in tar sands development (cf. Davidson \& Gismondi, 2011). This is precisely what EQUAIA seeks to make visible by introducing anti-colonial Discourses in their presentation: Canada has its own issues of (Indigenous) oppression which must be recognised. Additionally, using the term 'pinkwashing', EQUAIA calls in to question the genuineness of Ethical Oil's support for the LGBTQ+ movement, likening it to yet another appropriation in an attempt to sell oil.

As a result of this complex constellation of positionings, the tar sands debate has become intersectional on both sides: industry actors have brought in seemingly intersectional Discourses in order to sell oil, while community activists resist these appropriations and simultaneously introduce additional intersectional Discourses. In what may well be a novel case of "ornamental intersectionality" (Cho, 2013), industry actors orient to progressive and intersectional Discourses to legitimise their expansion without addressing the intersectional oppression involved in the tar sands. However, activist groups respond with their own analyses which focus on an end to oppression of all peoples through intersectional activism. Thus, this is perhaps more than a case of Discourse appropriation, but rather a case of appropriating entire practices (like intersectionality). This makes it all the more insidious and difficult to counteract, especially when we consider how the' Alberta is oil' identity construction discussed in section 5.1 adds yet another layer of difficulty for queer activists in Alberta resisting the tar sands. How then, do activists deal with these difficulties and how do they approach their messages about the fossil fuel industry? In the next chapter, 
I will begin to unpack some of the broad strategies used by both industry actors and activists when discussing the opposition. 


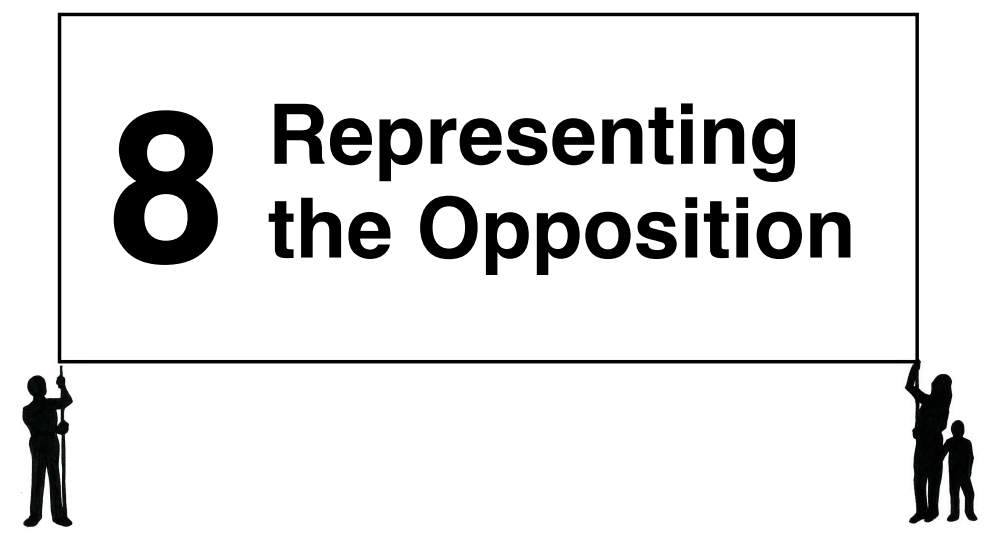

s discussed in the previous chapters, various Discourses are multimodally
appropriated in the discussion of mining debates: environment, economy, regional identity, Indigeneity, and even LGBTQ+ identities. At the same time, the appropriation of these Discourses is multimodally resisted by activist communities, whether it is through the production of artefacts (e.g. the wolf in sheep's clothing pamphlet in section 5.5), the use of gesture or facial expressions (e.g. Andrea's use of purely Albertan in section 5.3), or the public display of opposition (e.g. EQUAIA's Green Bloc in Chapter 7). Because these positions represent two extremes of the debate (i.e. the industry and the activists), their opinions and approaches are in opposition. Additionally, each side's stance tends to be wellpublicised and known to the wider population (consider Denise's characterisation of her community's mining negotiations as a $P R$ campaign, Figure 6.27). It follows, that each stance is therefore known to the opposing side: that, for example, Terra Resources is aware of the local anti-mining group or that CAPP (Canadian Association of Petroleum Producers) are informed about local resistance groups. How then, in this context, might one side talk about the other? Who recognises the opposition and how is the opposition discussed? In other words, how are industry actors or activists made present or invisible in each other's discussions?

The discursive positioning of social actors can have implications for how they are perceived by others. Fairclough (2003) and Van Dijk (1993) present a 
number of textual choices that individuals may make when discussing others. First, we might consider whether social actors are included in the text at all, and, if they are included, how they are represented (e.g. as a participant). Another important representational choice is the level of activation or passivation that a social actor may have as this has implications for how they are represented: "where social actors are mainly activated, their capacity for agentive action, for making things happen, for controlling others and so forth is accentuated, where they are mainly passivated, what is accentuated is their subjection to processes, them being affected by the actions of others, and so forth" (Fairclough, 2003, p. 150). Representing social actors in generalised terms (as opposed to specific, i.e. naming), serves to dehumanise them and "take the focus away from them as people" (Fairclough, 2003, p. 150). In this way, they instead become elements of structural processes, helping to undermine their agency (Fairclough, 2003, pp. 144, 150). The use of vagueness may also be a strategy to avoid criticism or challenges to what is said (Fairclough, 2003, p. 48), and can erase and suppress differences (Fairclough, 2003, p. 144). This can affect how knowledge is displayed, as preferred information might be presented in detail, while dispreferred information tends to be described less completely (Van Dijk, 1993, p. 275). Thus, the classification and categorisation of social actors help to "shape how people think and act as social agents" (Fairclough, 2003, p. 88). This work is constant, where social actors are put in opposition, in equivalence, in differentiation, etc. (Fairclough, 2003, p. 88) and positioned in various ways.

The discussion of opposition is also affected by pretextualities which impose conditions on what people can accomplish (Blommaert, 2005). In other words, the wider context affects who can say what to whom and how. Because discursive resources are historically loaded (Bakhtin, 1981), they are not equally appreciated in all contexts. This can lead to a loss of voice, where some social actors are ignored or even prevented from speaking. Such inequalities occur in what Blommaert terms "pretextual gaps", characterised by differences between what someone is able to do and the expectations of the situation (Blommaert, 2005, p. 
77).

In both industry and activist cases, discussion of the opposition tends to follow a distinct pattern: industry actors generalise about activist groups while positioning themselves as passive, while activists specifically name industry representatives and position them as active. In fact, many activists openly mock industry actors in an effort to name and shame. For example, Al is an activist organiser in Aotearoa/New Zealand and, during our interview, he begins to discuss the company's media strategies (Excerpt 8.1).

\section{Excerpt 8.1: Al}

1 A but if I was terra resources $+\mathrm{i}$ would ride out the small stuff + ah but 2 the:y just react react react react react + so it's really easy to push their 3 buttons?

$4 \mathrm{~K} \quad \mathrm{~mm}$ :

Al explains how he would run the company, naming them in the process (if I were terra resources, $i$ would ride out the small stuff: 1). He then describes their behaviour as simply reaction (2), which he repeats five times, helping to emphasise the regularity and predictability of the company's response. This predictability, he explains, makes it easy to frustrate the company by pushing their buttons (2-3). $\mathrm{Al}$ elaborates on how this happens through challenges to the company's CEO, Jack Fischer (Figure 8.1).
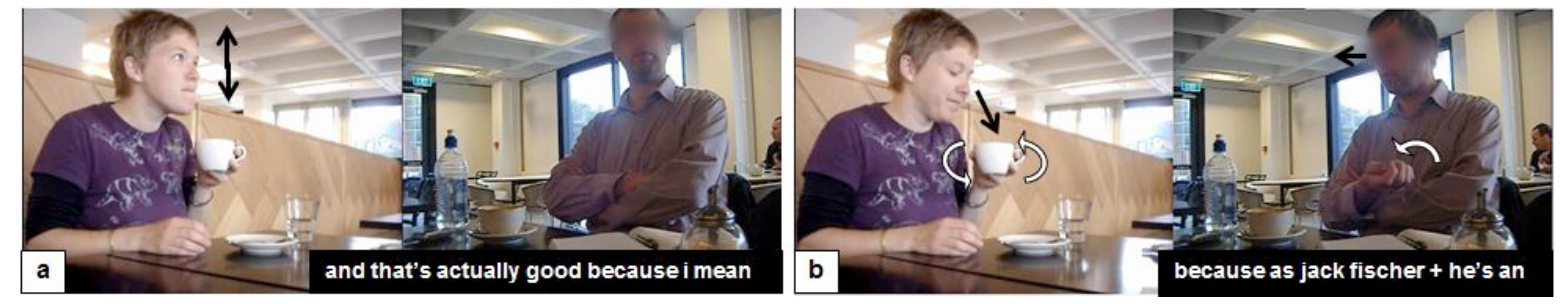

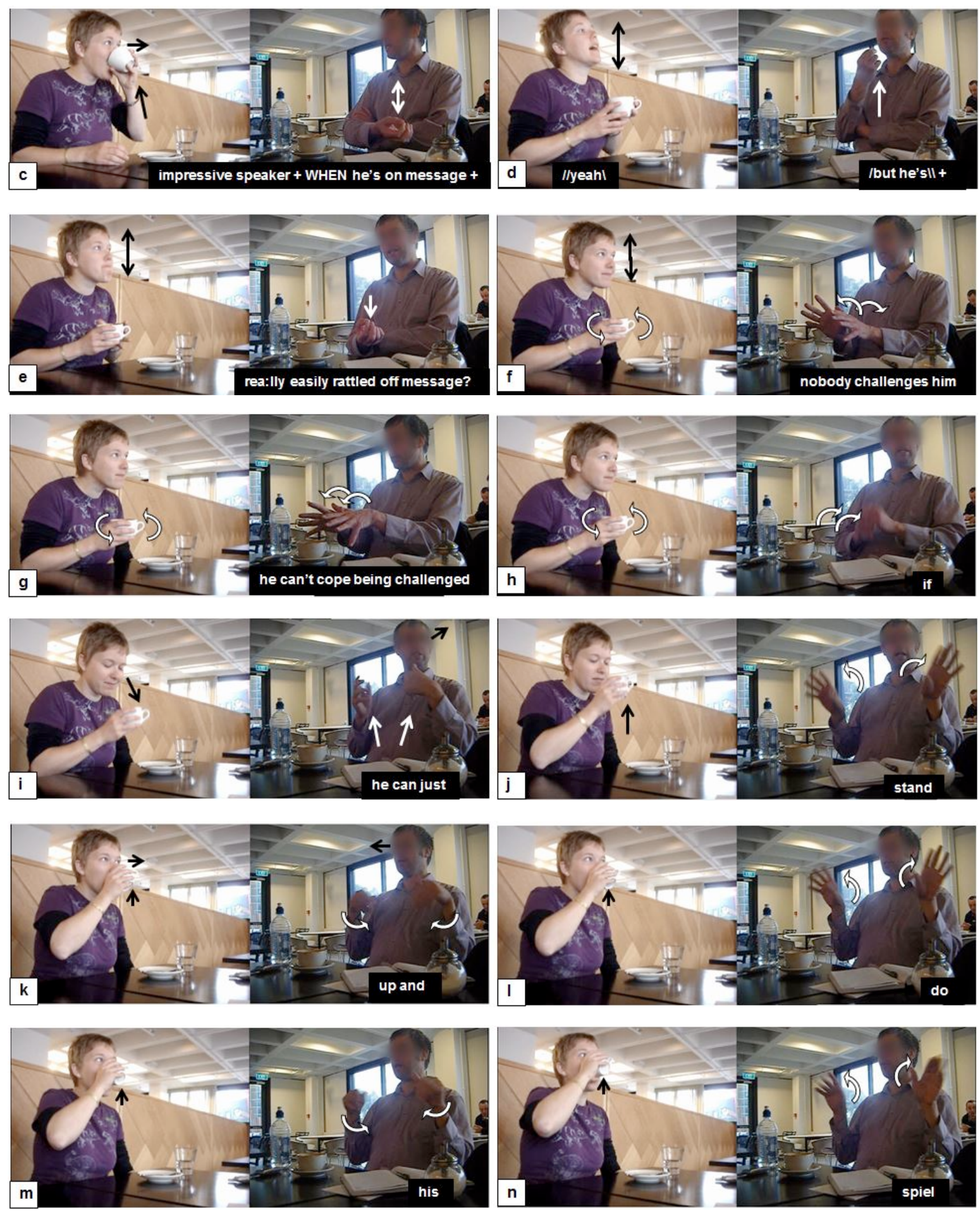

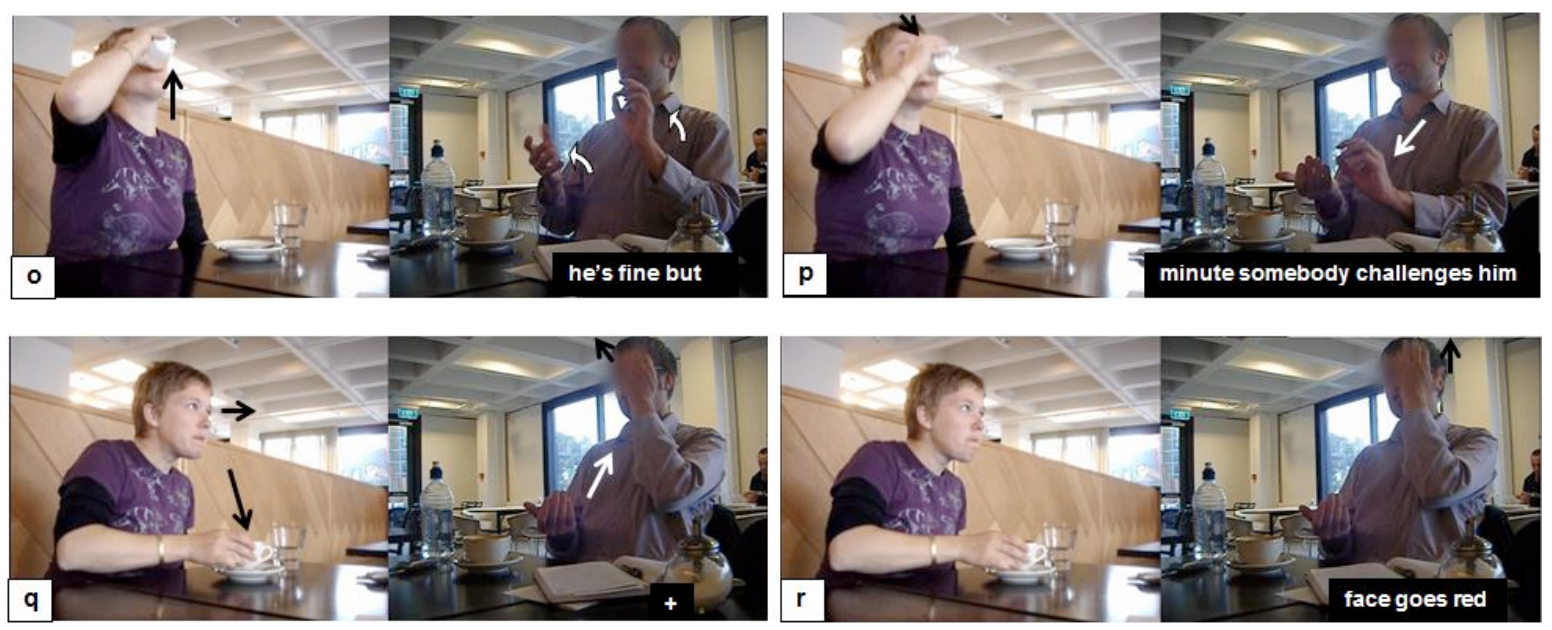

Figure 8.1: Al

Al explains that being a reactive company is actually good for the activists (a), because Jack Fischer is easily rattled off message (b-e). Here, Al refers to the CEO by name, and moves his LH in a palm presentation gesture, which serves to introduce Jack Fischer as the new topic (Kendon, 2004, pp. 265-266). Additionally, Al uses a 'ring hand shape' (Kendon, 2004) (index finger and thumb touching), to beat throughout his utterance (c-e). This gesture suggests clarification (Kendon, 2004, p. 241), and indeed, Al begins by describing Jack Fischer as an impressive speaker, but then qualifies this statement (when he's on message, but he's easily rattled off message: c-e). Next, he specifies (if nobody challenges him: $\mathrm{f}$ ), by holding up BH with palms down in a possible self-interruption (Kendon, 2004, pp. 248-249). He then clarifies this (he can't cope with a challenge: $\mathrm{g}$ ) by moving the gesture slightly forward, appearing to mark it as an aside. Al then returns to his demonstration of the speaking strengths of Jack Fischer and gestures with $\mathrm{BH}$, palms forward from his chest in a circular motion (h-n). This continuous looping action appears uninterrupted, iconically enacting Jack Fischer's speaking style while the word spiel suggests a set of memorised lines ("Spiel", 2010). However, next $\mathrm{Al}$ re-forms the ring hand shape with his $\mathrm{LH}$ and places it onto his $\mathrm{RH}$, which has been turned up into a cupping gesture (o-p). This 'precision grip' (Kendon, 2004 ) beats while he says minute ( $p)$, suggesting that his is a very precise analysis 
and cohesively links it to his previous point (d-e). Meanwhile, I have been drinking my coffee (i-o) and at this point I put the cup down and look at Al as he begins to enact Jack Fischer (q). Al brings his LH up to his face and spreads his fingers in a possible iconic representation of blushing (face goes red: $r$ ). He then mocks Jack Fischer, critiquing his lack of improvisational speaking ability (Figure 8.2).
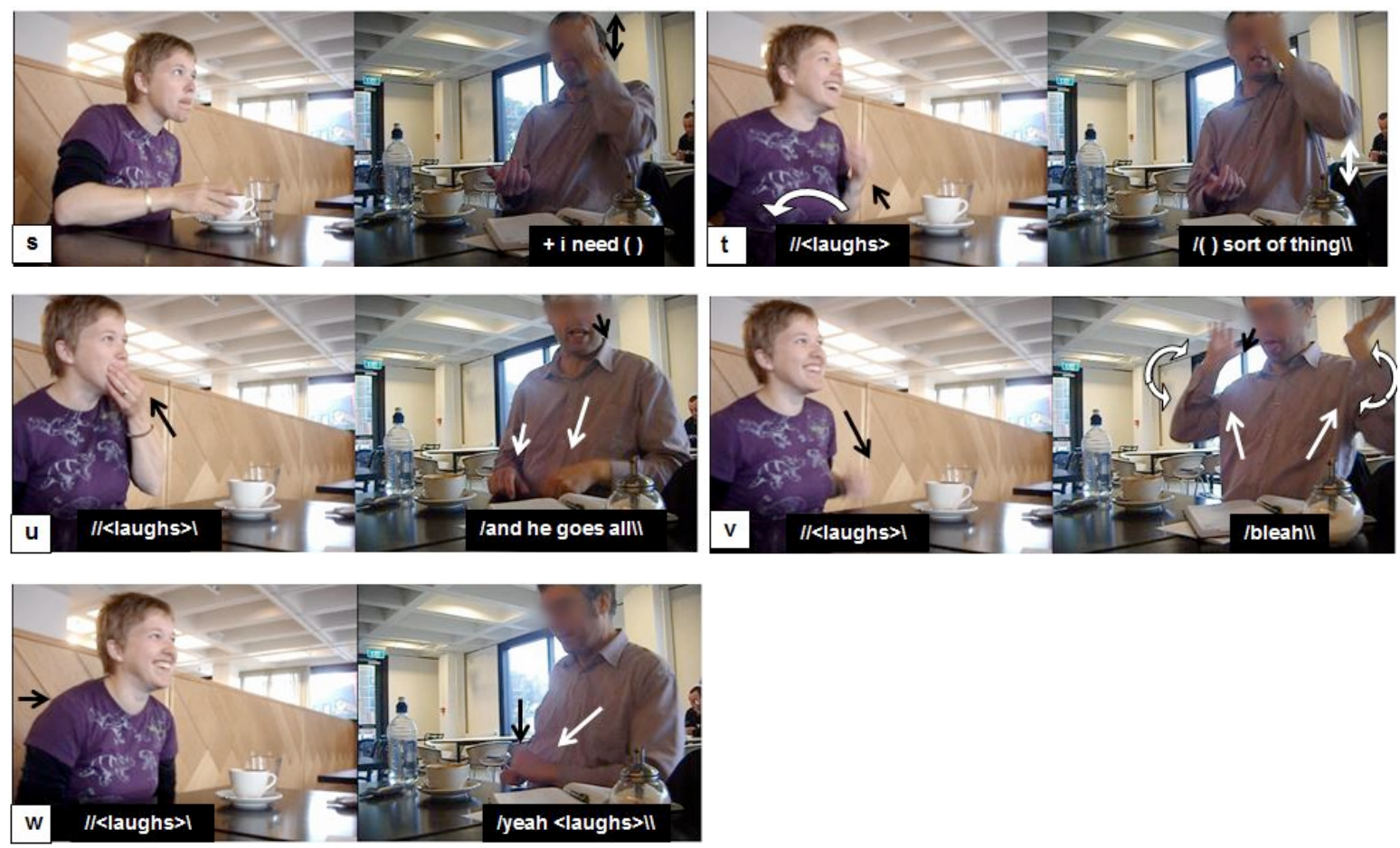

Figure 8.2: Al

In order to satirise Jack Fischer, Al switches pronouns ( $i$ need), effectively taking on his voice (s). He holds up his thumb and moves his hand up and down in a deictic gesture while exclaiming what he needs (which is, unfortunately unintelligible on the recording) (s-t). This gesture suggests that Al-as-Jack Fischer is reaching for something, or possibly asking for assistance by raising his hand as if he were in school. The combined effect of the gesture, the gaze shift up, and the verbal enactment of Jack Fischer might serve to infantilise him or portray him as a puppet who is unable to think for himself. I respond to this performance by laughing and leaning in towards $\mathrm{Al}(\mathrm{t}-\mathrm{w})$, thus co-constructing the interaction as a humorous 
presentation. Having portrayed Jack Fischer's tendency to stumble when challenged in speeches, Al looks down, lowers his hands and sets up a new portrayal by quoting him (and he goes all: $\mathrm{u}$ ). However, in this case, Al does not represent Jack Fischer through his voice but rather through his actions. He raises both hands with palms out and waves them back and forth while gazing down and sticking out his tongue (v). While he does this, Al utters a nonsense word (bleah), suggesting through his multimodal ensemble (Kress, 2011) that Jack Fischer becomes incomprehensible and out of control.

As a typical example of activists discussing the opposition, we can see how industry actors are overtly referenced by name and even mocked through satirical mimicry. Additionally, activists tend to construct industry actors as active agents and sometimes, like $\mathrm{Al}$, adopting them as characters to be performed.

By contrast, industry actors very seldom mention activist groups, and when they do it tends to be as vague categories or general classifications. This is exemplified in an interview with Brandon (discussed in detail in Chapter 6), a representative of CAPP (which in turn represents oil companies in the tar sands). Here, he discusses the impacts of development on downstream communities (Figure 8.3).
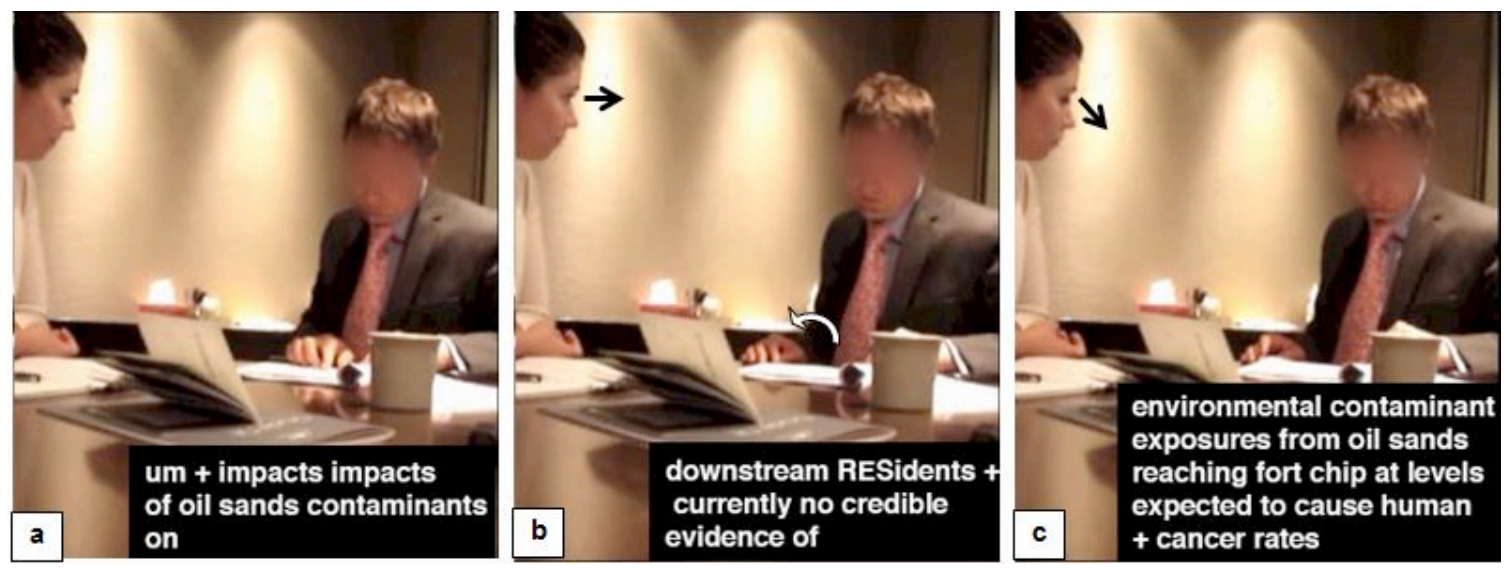

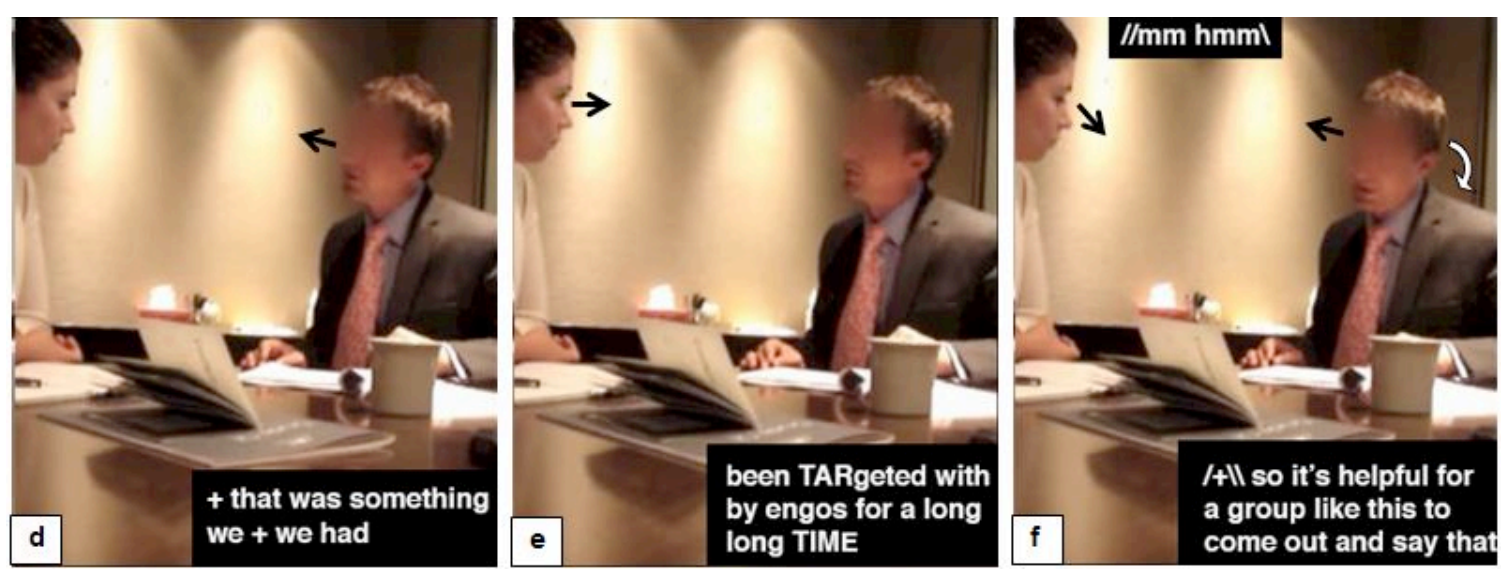

Figure 8.3: Brandon

Brandon is reading from an artefact documenting a study on water contamination, which claims there is no evidence for cancer-causing effects on residents (a-c). He then looks up at the interviewer and explains that his organisation has faced accusations of cancer (that was something we had been targeted with by engos for a long long time: $\mathrm{d}-\mathrm{e}$ ). Brandon's lexical choice of targeted is a passive construction with an inserted agent (engos is short for 'environmental nongovernmental organisations'), and serves to position industry actors as passive subjects in the debate (Fairclough, 2003). This, in turn, positions the activists as active agents who are targeting industry and, as a result, casting them as victims (cf. Harré \& Langenhove, 1991). Additionally, Brandon does not specify which groups are acting this way but instead opts to classify them broadly as engos, possibly in an attempt to avoid blaming specific individuals. He then tilts his head and explains that it's helpful for industry that the study has found no evidence of cancer (f). In possible anticipation of an argument, Brandon emphasises that further study should be done (Figure 8.4). 

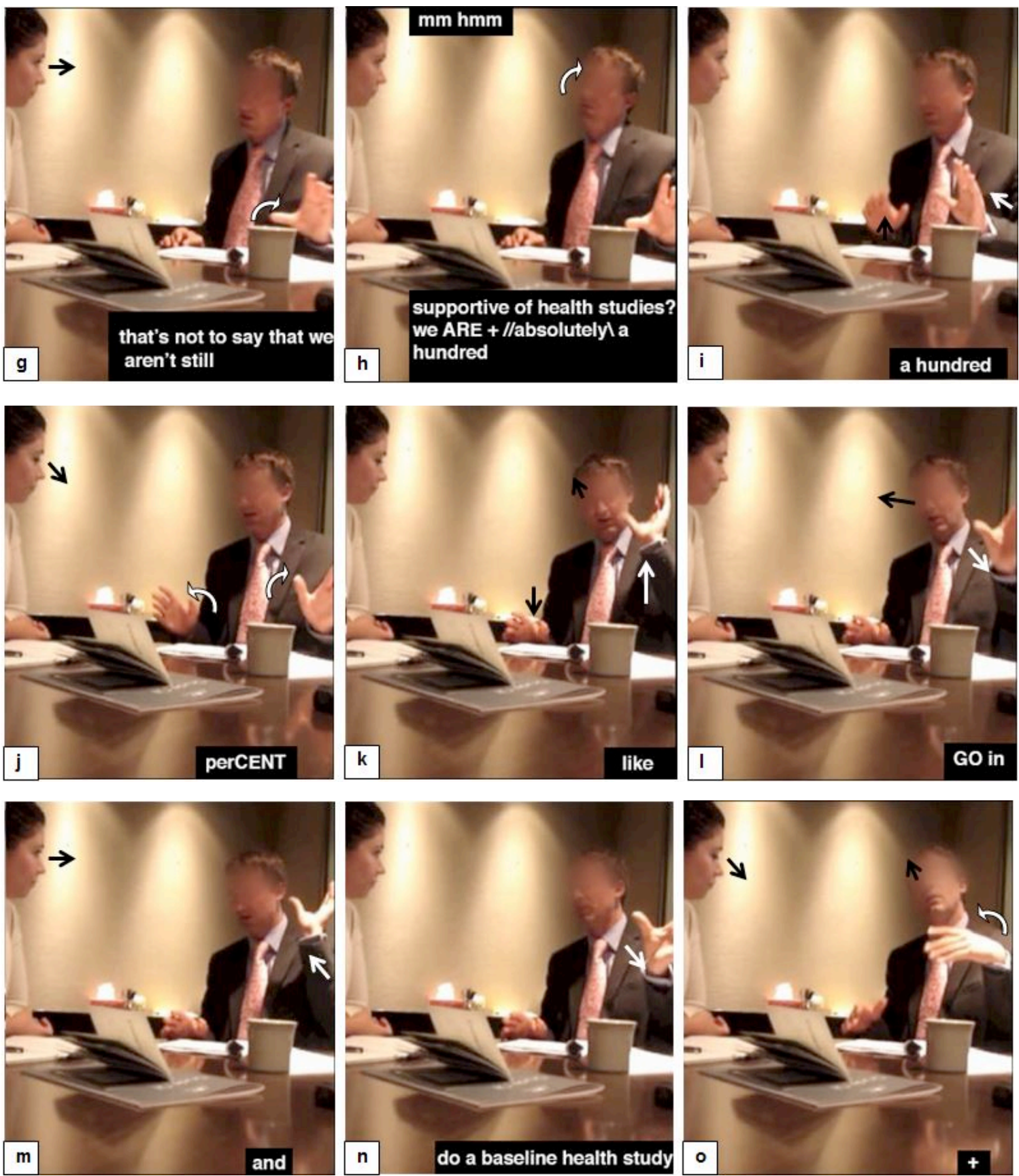

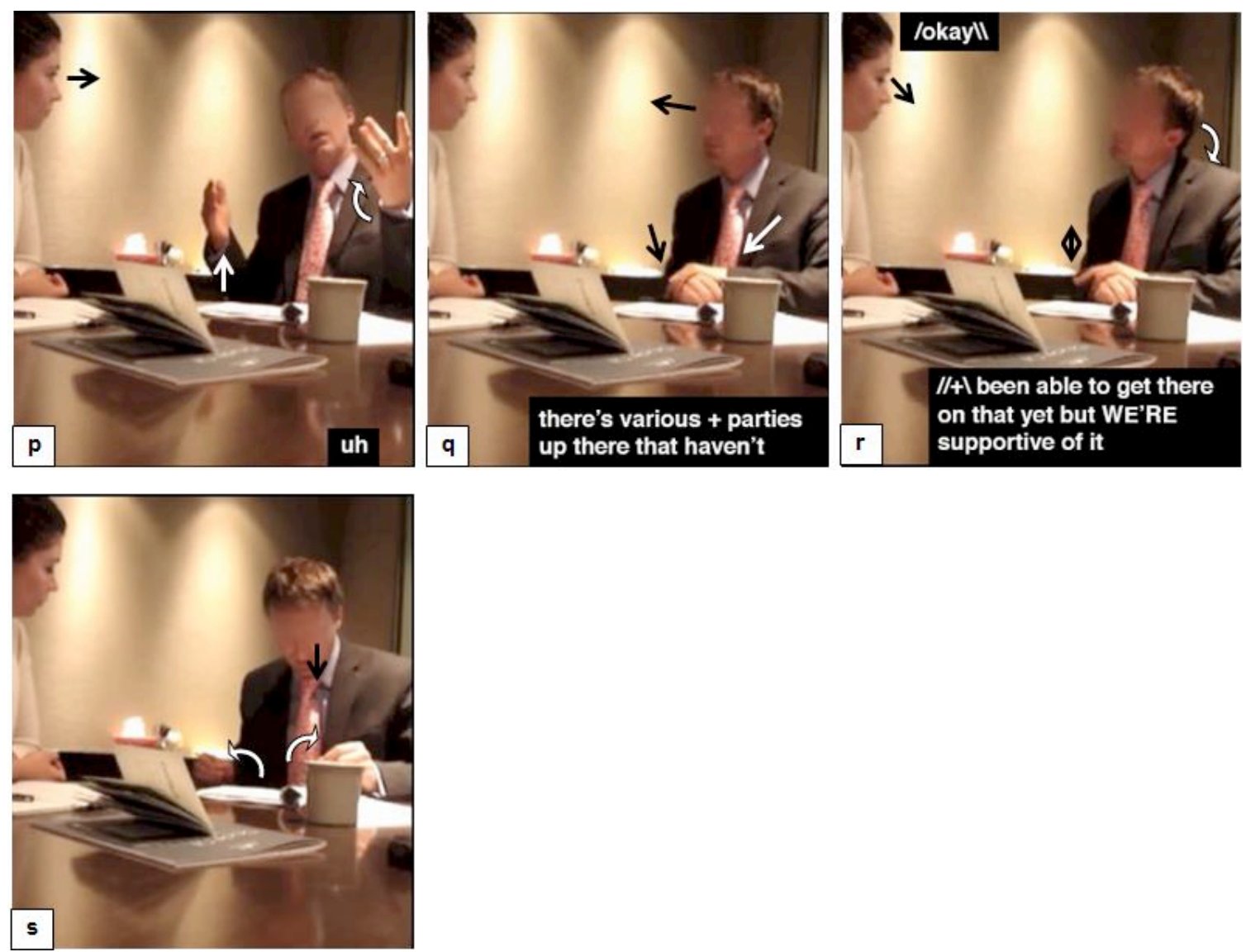

Figure 8.4: Brandon

Holding up his LH in a gesture recognised as signaling interruption (Kendon, 2004), Brandon clarifies that CAPP is supportive of health studies (g-h). He then holds up both hands, possibly as a means to intensify the level of support expressed through his utterance (a hundred percent: $\mathrm{i}-\mathrm{j}$ ). Brandon then moves his $\mathrm{LH}$ in an open-palm deictic towards his left side, almost as if he is drawing attention towards an invisible interlocutor (k-n). While doing so, he offers an imperative (go in and do a baseline study: I-n). He then pauses, gazes to the middle distance and moves both his hands up in what might be an abandoned addition ( $u$ h: $p$ ) before re-establishing mutual gaze and explaining why these studies have not yet been conducted (o-p). His explanation is marked by hesitations and a tapping finger $(r)$ and once again, he uses unspecified broad categories when describing the entities which have not done the health studies (there's various parties up there that 
haven't been able to get there on that yet: q-r). It is unclear whether these various parties are oil companies, local health organisations, the provincial government, or other entities. By remaining vague on both who should be doing the studies and when, Brandon avoids assigning responsibility to anyone (see Fairclough, 2003). However, he is clear to affirm that CAPP supports the studies by emphasising we're (but we're supportive of it: $r$ ), thus positioning the organisation in an advocating role. In this way, he aligns CAPP with those who harbour concerns about the health effects of development. This puts the organisation in a seemingly contradictory position: expressing support for the communities worried about downstream health, but also for the companies who may be causing harm, as its mandate dictates.

Throughout this discussion, Brandon uses broadly classified, generalised terms to describe activist groups, as well as other industry groups. As he explained earlier in the interview, reputation is important but also a weakness for the oil industry in Alberta and so Brandon's behaviour may very well be constrained by wider social structures (Blommaert, 2005; Fairclough, 2003, p. 22; Holmes, Marra, \& Vine, 2011), such as his role as an industry representative. Additionally, Brandon positions the oil industry and CAPP as passivised subjects by constructing them as the victims who are targeted by activist groups.

These examples are part of a wider trend, whereby industry actors tend to avoid naming and remain vague when describing opposition (in Southland too, Alanis discusses the local anti-mining group rather vaguely, see section 4.1), while activists tend to name, mimic and ridicule their opposition. This could be explained by the different interlocutors in interviews. Because the activists know me, perhaps they are more comfortable naming individuals. In contrast, because the industry representatives and Nicole were virtual strangers, perhaps they were less likely to name specific groups. However, these broader tendencies are also visible in artefacts, which are designed for a much wider public audience than is afforded in interviews. Consider, for example, the image in Figure 8.5 which is taken from a 
Greenpeace information booklet.

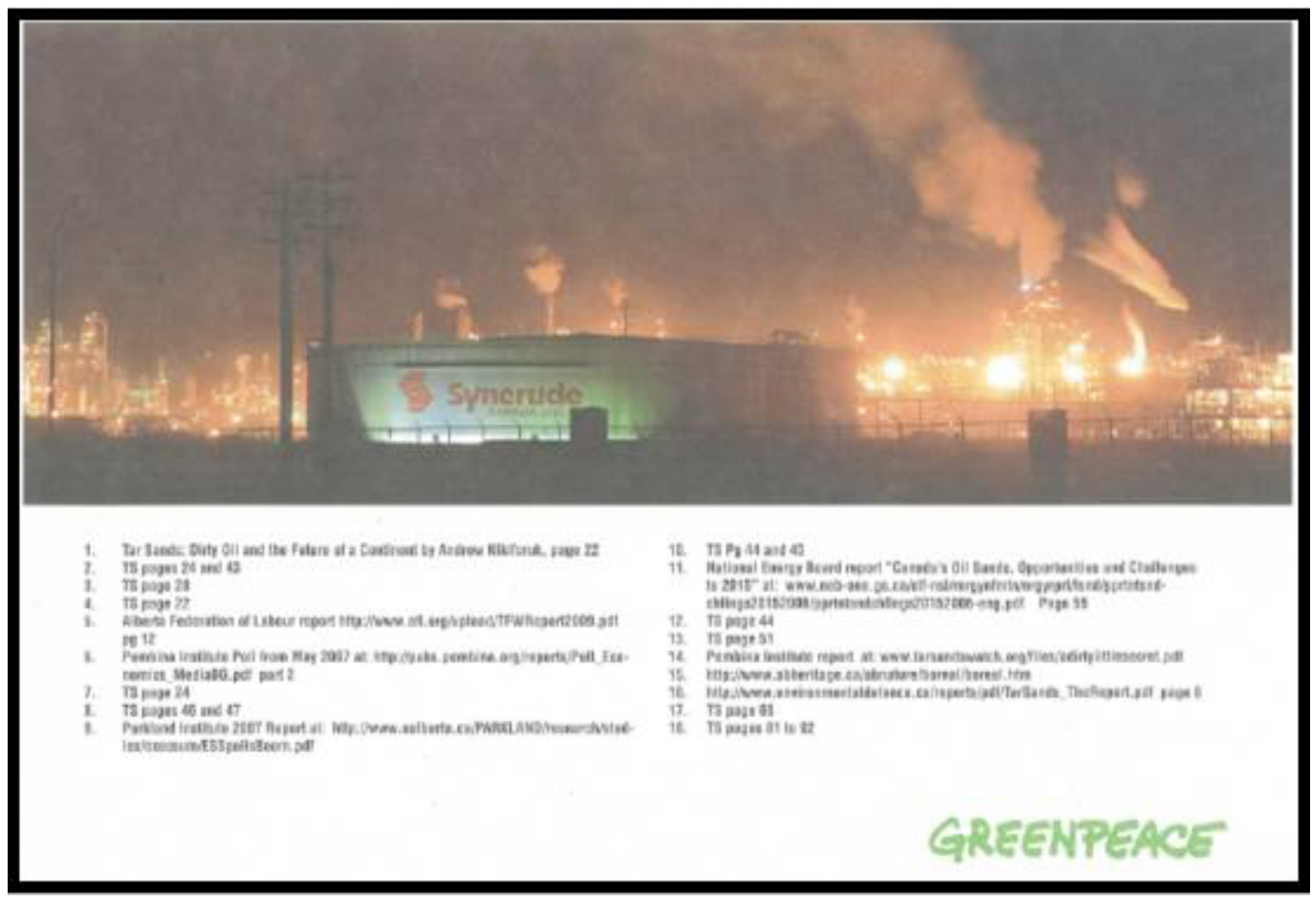

Figure 8.5: Greenpeace Booklet ${ }^{1}$

In this image, the name of the company (Syncrude) is clearly visible, and even arguably foregrounded through the composition (Kress \& Van Leeuwen, 2006). The shadows on the structure frame the company logo which is in turn lit up from below. The refinery in the background links the name to that of an oil company for any audience member that is unaware of what Syncrude means. In Figure 8.6, the strategy of naming is taken even further, with individuals being mocked.

${ }^{1}$ Artefact reproduced with permission. 


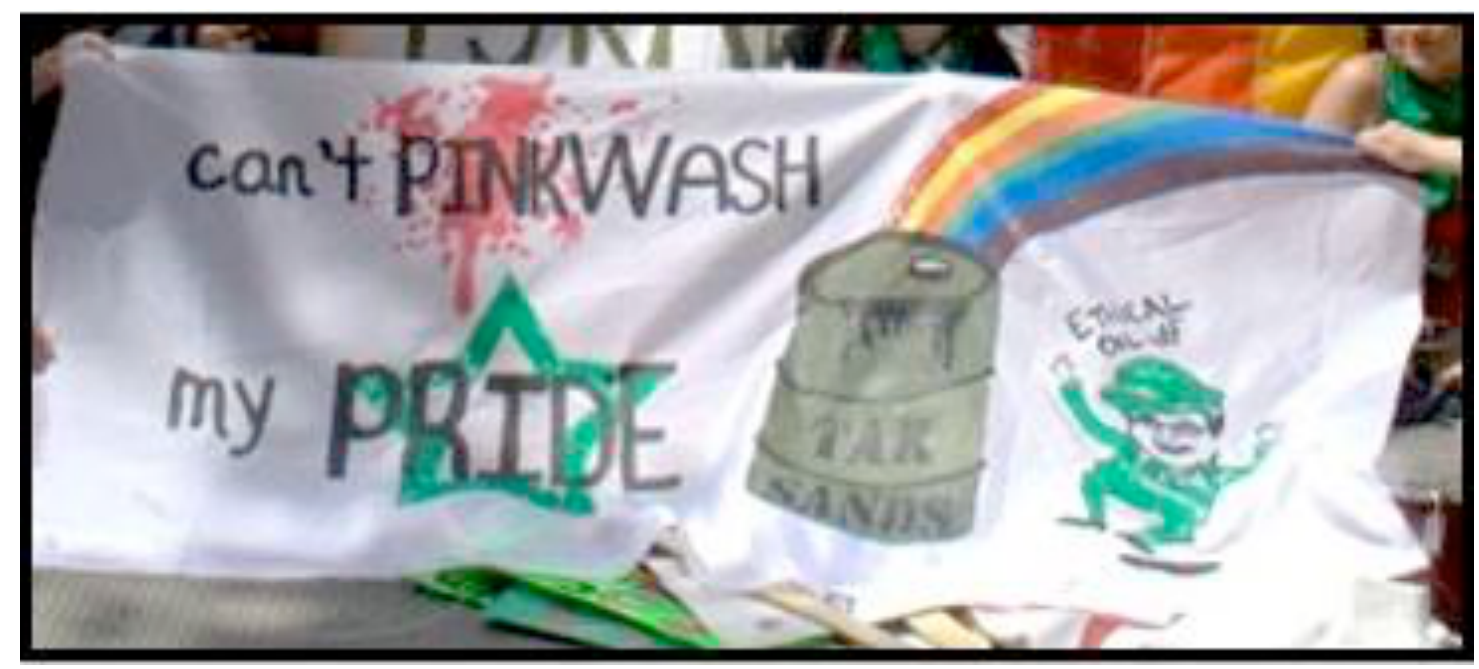

Figure 8.6: EQUAIA Banner²

Taken during the Pride Parade march described in Chapter 7, the banner features a cartoon rendering of Ezra Levant, author of the book Ethical Oil (Levant, 2010). $\mathrm{He}$ is comically depicted as a leprechaun, dancing beside a barrel of oil at the end of a rainbow. If the rainbow (presumably) represents the LGBTQ+ movement, we might interpret Ezra's gleeful presence as representing his re-direction of the LGBTQ+ movement to help encourage tar sands development. Whatever the interpretation, as a representative of the oil industry lobby, Ezra Levant is personally named and mocked multimodally.

Similarly in Aotearoa/New Zealand, activists have created depictions of industry actors and printed them onto company coal bags (Figure 8.7).

${ }^{2}$ Artefact reproduced with permission. 

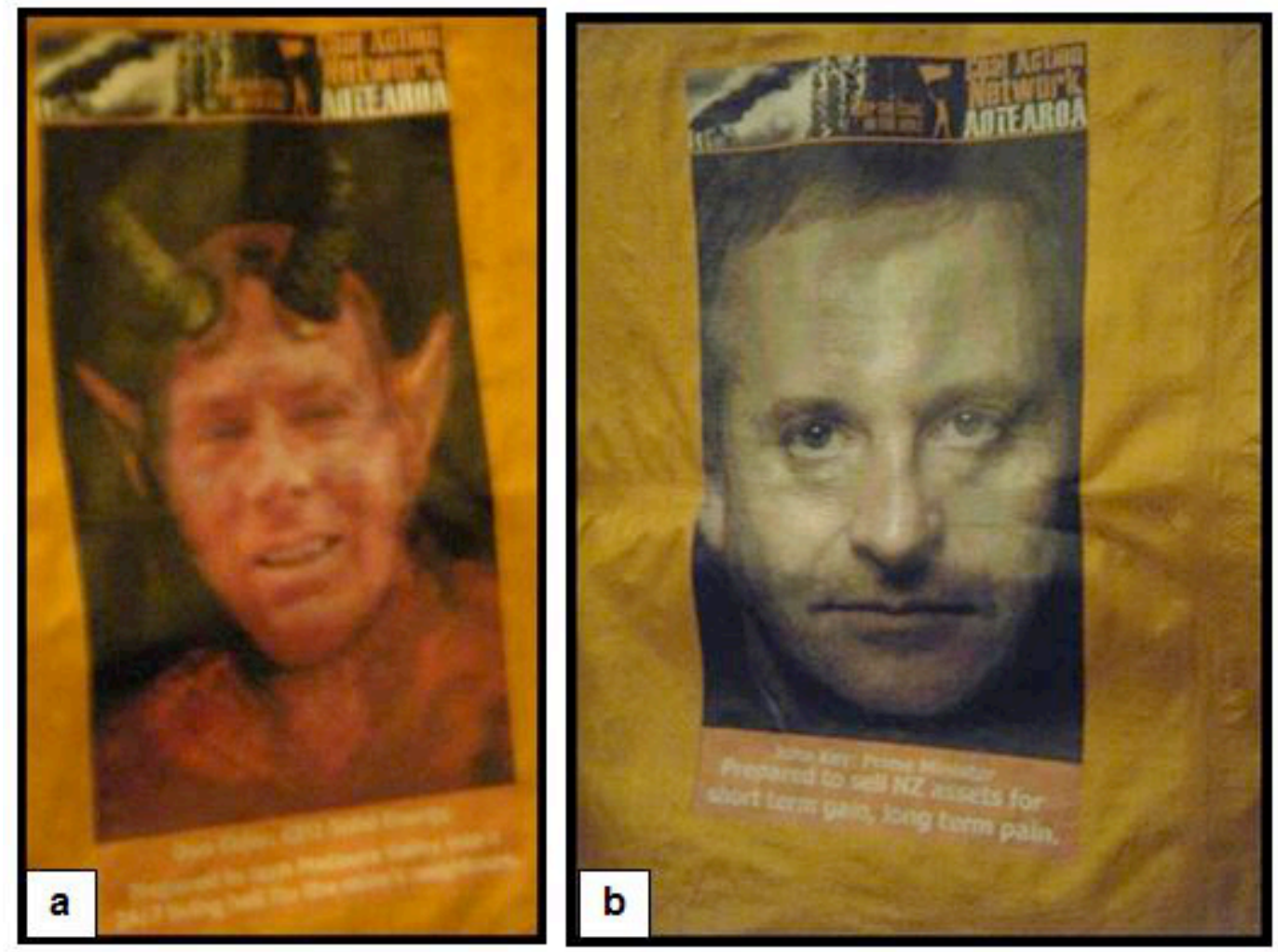

Figure 8.7: Southland Coal Bags ${ }^{3}$

Here, the coalbags very clearly feature specific individuals (including the Prime Minister) who are also explicitly named in the copy below the photos. The CEO of the mining company, Jack Fischer, is even portrayed with digitally altered red skin, extended ears, and horns (a), comparing him to a devil.

In contrast, industry artefacts very seldom refer to opposition groups. When they do, however, it tends to be very indirect. For example, Figure 8.8 shows excerpts from mining publications in Aotearoa/New Zealand and Canada.

${ }^{3}$ Artefacts reproduced with permission. 


\section{Resource use demands reasoned debate}

When it comes to the big questions like realising the value of natural resources and possible impacts, we are selling ourselves short if

a everything ets reduced to yes-or-no choices...

\section{The size of England?}

Some organizations claim the oil sands are destroying an area the size of England (approximately 130,000 km2). In fact, the total mining footprint covers an area about $0.6 \%$ the size of England and $10 \%$ of that land has

b been or is being reclaimed. The total area that could be impacted by mining is about $4 \%$ the size of England. Source: AESRD

Figure 8.8: Industry Artefacts

The excerpt from the coal mining publication (a) does not specify any opposition but rather implies it. By using phrases like reasoned debate and yes-or-no choices, the opposition is simply hinted at (e.g. a debate implies two sides). Additionally, this opposition is evaluated as unreasonable by the very fact that the article calls for a reasoned debate, lest everything gets reduced to yes-or-no choices. Similarly, in Canada (b), the information box references opposition as a general classification (some organizations claim the oil sands are destroying an area the size of England). Once again, activist groups are not named and instead only represented in vague terms.

The practices of naming or not naming can have effects on the wider debate. Representatives of industry may be limited by professional pretextual impossibilities (see Blommaert, 2005), which constrain what they are able to say and do. However, there is some discursive power gained in not naming, which helps to delegitimise or even ignore opposition voices (Fairclough, 2003). Additionally, by constructing themselves as passive, industry actors conversely position activists as the ones who are active and who have agentive power. This helps industry actors to avoid appearing responsible for their actions and to be recast as victims in the debate (Fairclough, 2003). Through such passivisation, industry actors also benefit from having themselves and their actions appear 
normalised and unquestioned or even invisible (see Van Dijk, 1993, p. 275) In contrast, activists make use of specific naming strategies and even ridicule individuals. This makes industry actors visible and, through activisation, positions them as active subjects. In the context of controversial mining development, locating industry actors as active subjects illuminates their position as powerful forces in the wider debate. In other words, choices for representing the opposition seem to be based on either shining the spotlight or seeking to avoid its glare.

From the micro textual level, it is apparent that speakers use a variety of resources in discussing their opposition (as seen in Figures 8.2 and 8.4) and that these same resources also occur on the mediated macro level in artefacts (as demonstrated in Figures 8.7 and 8.8). These practices in representing social actors can also play a role in creating pretextual impossibilities at an even wider, macro policy level. For example, during the Southland Field Days, both Terra Resources and the Invercargill Environment Centre had a stall. However, these stalls were set up very differently (Figure 8.9).
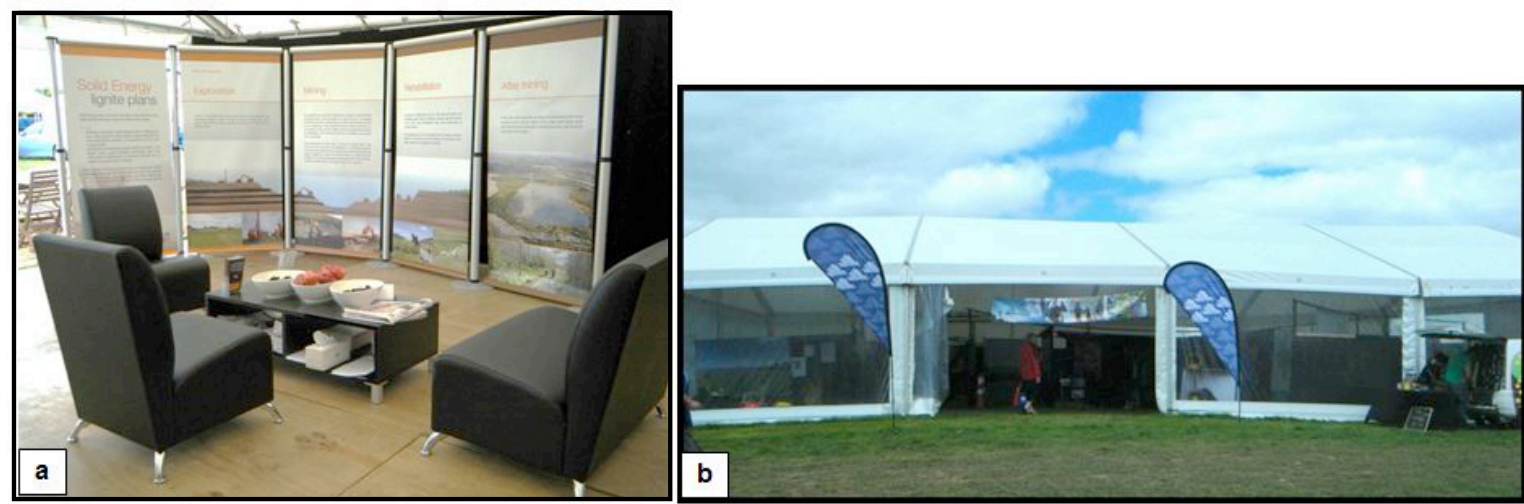

Figure 8.9: Field Days Stalls

The mining company's stall was large and easily seen, with a formal multimodal register featuring wooden floors, an open plan, a sandbox for children, prominent displays about lignite plans, and many company representatives wearing suits (a). The Environment Centre's stall, however, was hidden inside a larger tent (b), and was only accessible via a small corridor. As someone who was looking specifically 
for the Environment Centre, I had difficulty finding it and it was not until I was invited down the corridor that I came across the group. Simply by understanding the layout of the two stalls, we might consider the different levels of access that have resulted from different levels of prestige, power, and resources (Van Dijk, 1996). Furthermore, in my discussion with the Environment Centre's stall holders, I discovered that they were forbidden from using the word lignite within the larger tent. I was told that this was a condition imposed on the group for using space within the larger tent and that the tent owners wished to avoid any controversies. After explaining my reasons for visiting, I was able to hold a whispered conversation about the mine with one of the stall holders, however any reference to lignite was instead uttered as the ' $L$ ' word. The implications of this being, that visitors to the Field Days would hear one perspective only: that of the mining company. Moreover, this perspective is presented prominently and through professional resources, with no mention of oppositional groups. This is an example of policies creating pretextual impossibilities for language users on the ground, and how industry practices of avoiding naming means the opposition is effectively erased.

When discussing industry actors, however, activists use strategies of play and creativity to take back power (Shepard, 2011). As we have seen in the previous examples, industry actors are named but also openly mocked (see Figures 8.6, 8.7). Ridicule through performed satire during interviews was a common way for activists to creatively resist their opposition.

\subsection{Play and Creativity as Strategic Resources}

Playful humour features rather prominently in the way activists approach Discourses in both Canada and Aotearoa/New Zealand. Consider for example, the artefacts which portray industry actors as wolves in sheep's clothing (Figure 5.18), leprechauns (Figure 8.6), or devils (Figure 8.7). In interviews too, conversationalists create multiple voices to satirically index well-known characters. Al's enactment of Jack Fischer (Figures 8.1, 8.2) is an example of this type of 
playful performance. In this section, I consider how activists discuss their opposition by appropriating and recontextualising their voices using humour and play.

Coupland differentiates between high performance, which is "marked off from the routine flow of communicative practice" with spatial and temporal boundaries, and mundane performance, which occurs within conversational interactions (2007, p. 146) . It is the latter type which will be discussed here, where speakers adopt exaggerated styles to criticise powerful actors. Such stylisation is based on Bakhtin's ideas of intertextuality (discussed in section 2.2), where discursive actions are interpreted through the history of their use. This "Bakhtinian stylisation" then becomes "a subversive form of multi-voiced utterance, one that discredits hegemonic, monologic discourses by appropriating the voices of the powerful, and reworking them for new purposes" (Coupland, 2007 italics mine). In this way, stylised performances can be considered acts of resistance, which use appropriation and entextualisation.

The use of humour is an important aspect of the multimodal entextualisation of stylised voices. Shepard (2011) explains how ludic play can contribute to resistance communities in a number of ways. First, it helps create a sense of community culture where outsiders are invited to participate. In our interview discussing EQUAIA and intersectionality, William explained that humour is such a powerful weapon for getting across heavy messages, and that it creates an empowering message in the midst of negativity. In this way play also functions as a coping mechanism for people who are struggling against systemic oppressions. For example, in another interview with activists who were organising an 'antioppression dance party', I was told this was necessary because sometimes you just need to dance.

Play can also be subversive, inverting social hierarchies, destabilising plotlines, and challenging legitimacy and authority (Bakhtin, 1981; Shepard, 2011). During our interview, William describes an activist action whereby donuts were 
suspended from fishing poles in front of riot police, making use of the stereotype that officers enjoy eating donuts. This re-oriented the frame of the interaction into one where the activists were 'fishing for cops' instead of struggling against them. Shepard gives a similar example where activists loudly played a recording of the Imperial March from the film Star Wars (otherwise known as 'Darth Vader's Theme'), which aimed to depict the riot police squad as mindless soldiers similar to the film's Stormtroopers (Shepard, 2011). In Alberta, activists stage elaborate and humorous performances, such as a mock wedding for government and industry, highlighting their close relationship and allowing a space for the public to protest their union (CBC News, 2014). In this way, humour becomes an important resource for activists who seek to gain a voice in situations where they are often dominated.

Even in interviews, humorously stylised mundane performances were common. For example, in my conversation with Denise, we discussed the role of the provincial government in ensuring treaty rights are protected when allowing industry access to land. Before projects are approved, they must first be presented to First Nations communities with ample time for comment and negotiation. However, in our interview, Denise discusses the ways in which government actors have failed to respect this process (Figure 8.10).
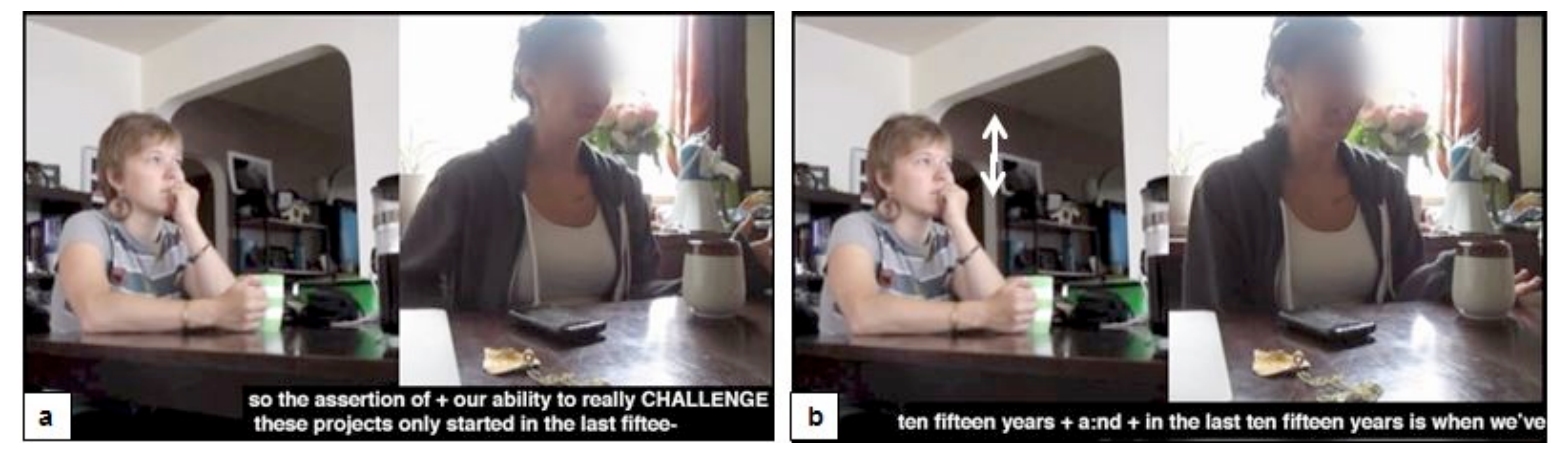

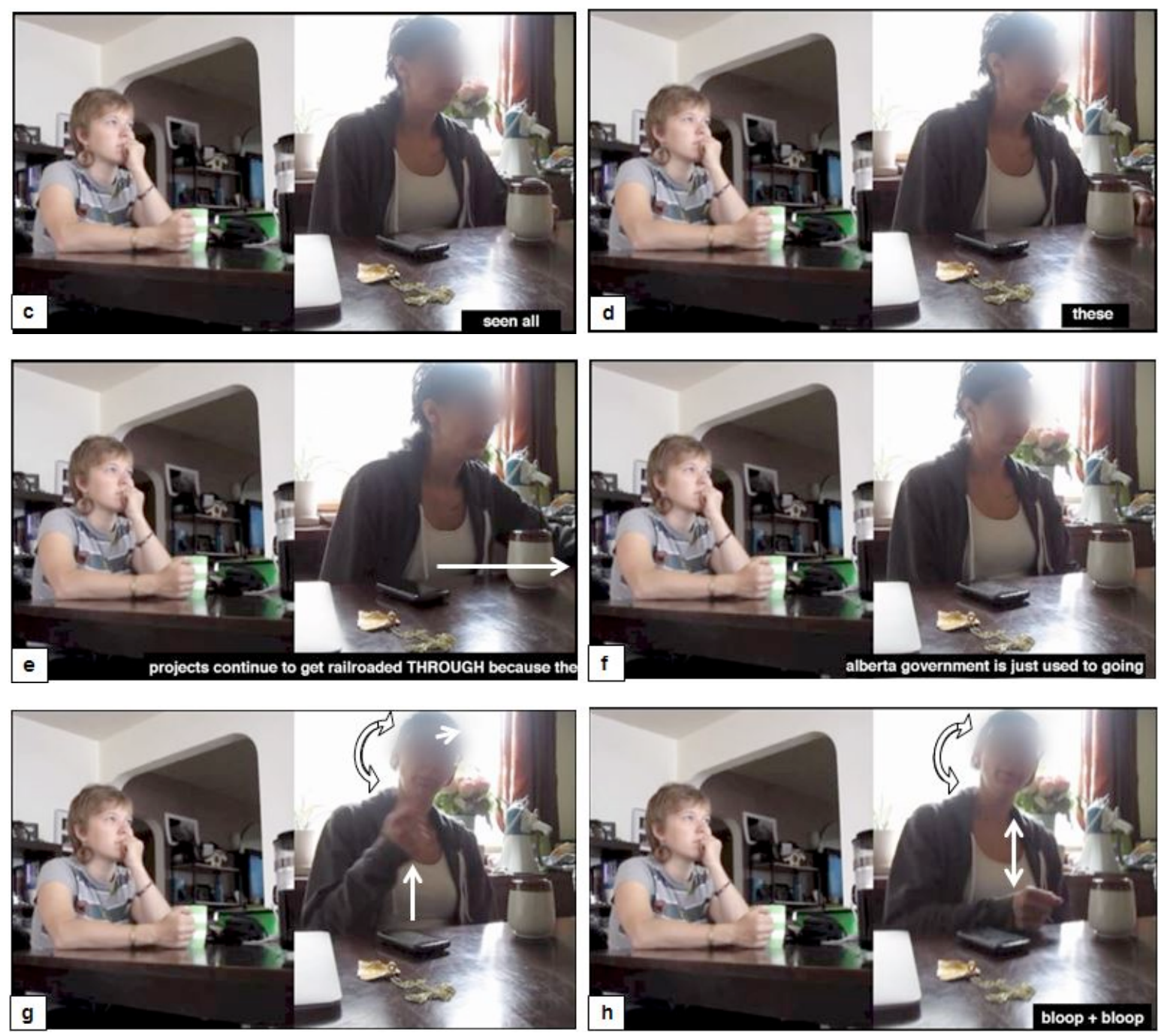

Figure 8.10: Denise

Denise explains how the rights afforded to First Nations communities to challenge development has only come into effect in the last decade (a-b), and that this has affected the continued approval of projects (e). She enacts the trajectory of approvals by placing her LH in front of her body on the table (d) and dragging it forward in a slow and steady motion (projects continue to get railroaded through: e). This iconic gesture mimics her description of the projects by using an apt metaphor which reflects the difficulty in stopping or slowing down development once it has started. Next, she expands upon why this difficulty arises: it is because the Alberta government is unable to stop its custom of approving everything which 
is proposed. To make her point, Denise becomes a government worker in a 'mundane' performance (Coupland, 2007, p. 146) and marks this with a stylisation change (adjusting her posture and raising her voice). She shifts her gaze to the middle distance, wobbles her head back and forth, and moves her $\mathrm{RH}$ in a fist in an iconic gesture as if she were stamping papers on her desk (g-h). As she brings her fist down, she tilts her head back and forth and says bloop in a high-pitched voice, effectively differentiating the onomatopoeia from her regular voice (h). Each 'stamp' onto the table is timed in a consistent rhythm much like a piston and, coupled with Denise's head wobble as a counterweight, presents her actions in an almost mechanistic manner. This creates a combined multimodal metaphor (Johnson, 2010), which seems to portray the approvals process as robotic and automatic, as a machine without agency.

Denise continues to enact the robotic government worker by stamping and wobbling her head (Figure 8.11).
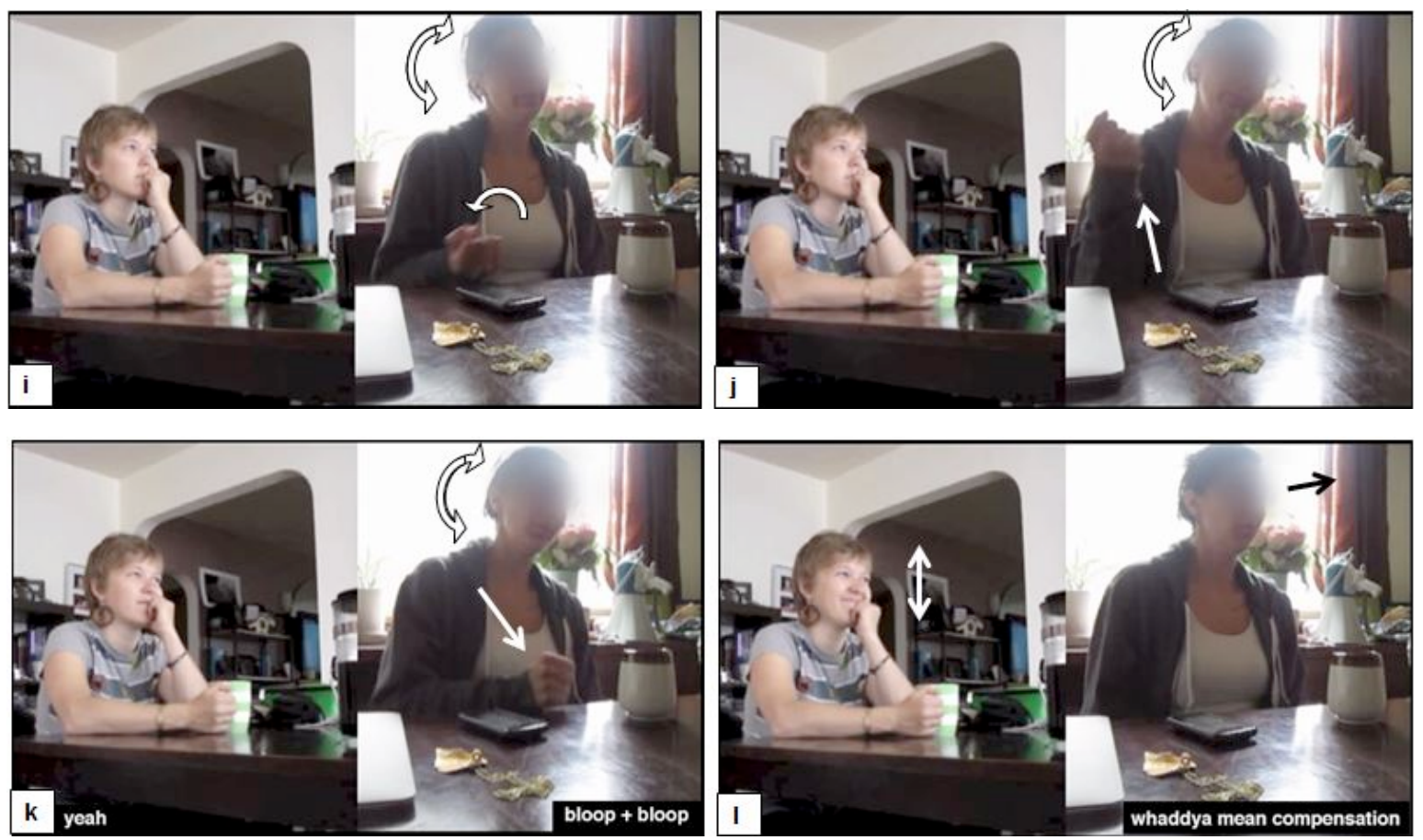

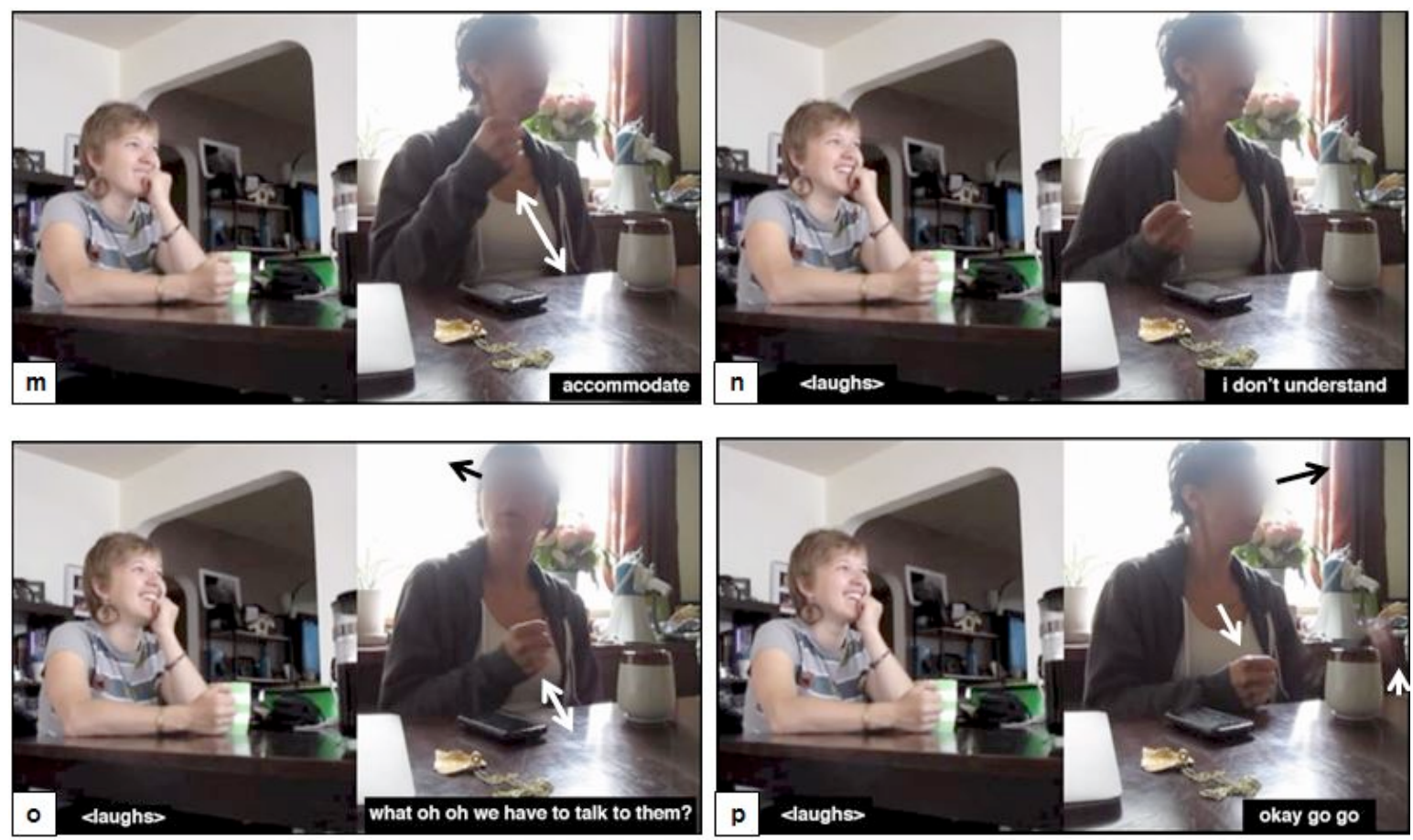

Figure 8.11: Denise

Throughout this interaction, I begin to smile, nod and laugh as I recognise that Denise is satirically performing a government official (I-p). She repeats the stamping gesture two more times (i-k repeated) before pausing suddenly and shifting her gaze to the left (I), effectively disrupting the 'machine'. Her gaze shift and address (whaddya mean compensation accommodate: I-m) constructs an imaginary interlocutor who we imagine has interrupted her to ask about government policies towards First Nations communities. After a brief pause, Denise-as-government-official continues stamping, even though she doesn't understand what has been asked of her ( $n)$. This causes me to laugh (n) and, as I adopt the audience role in the performance, Denise is encouraged to continue (Hay, 2008). She shifts her gaze to yet another imaginary interlocutor on her right (o) and her utterance (we have to talk to them?) clarifies what was meant by compensation accommodate (i.e. consulting with affected communities). She then shifts once more to her left, constructing yet another interlocutor $(p)$ who is addressed in Figure 8.12. 

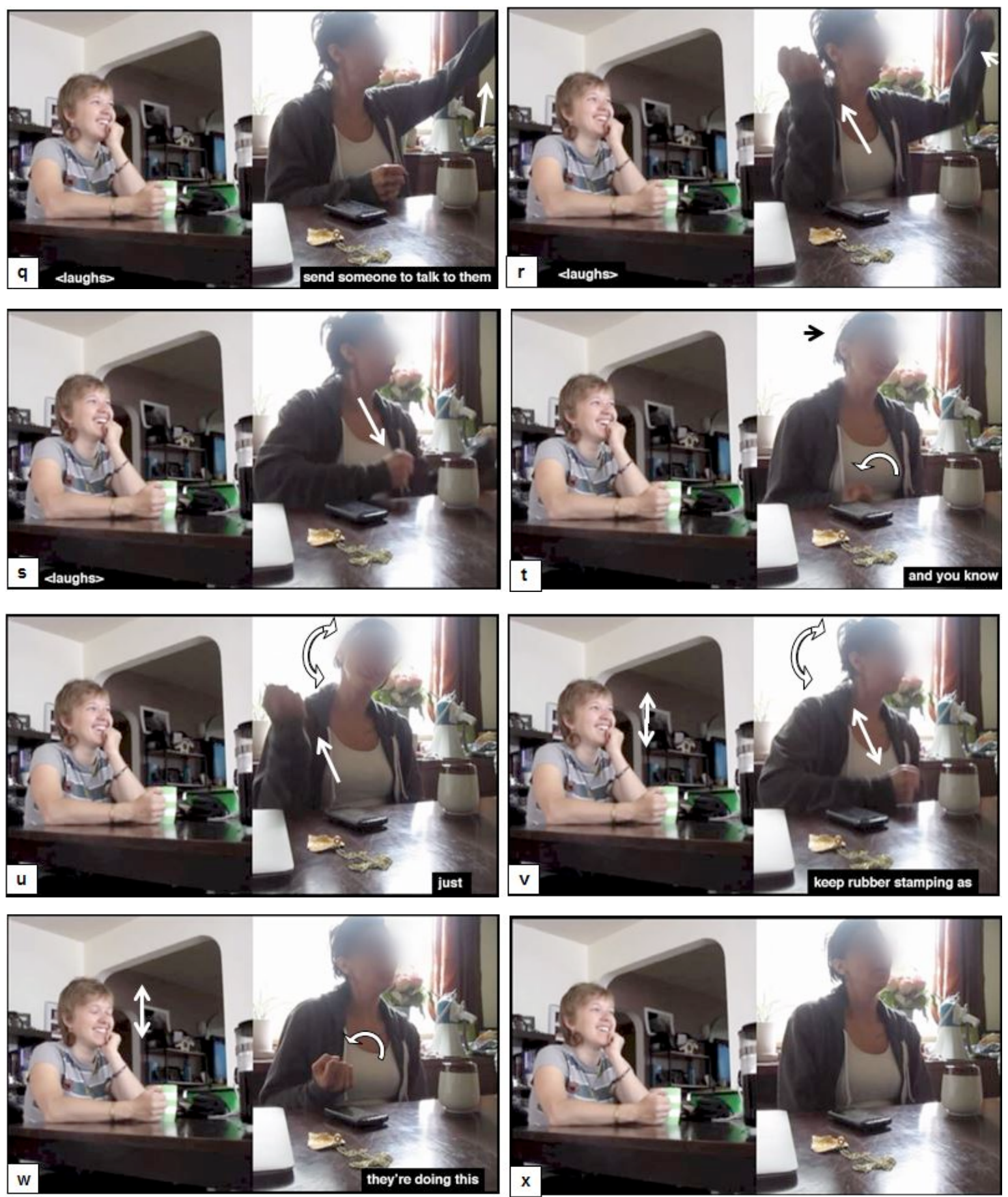

Figure 8.12: Denise

In frame (q), Denise raises her LH and uses a deictic gesture to wave into the distance, while saying send someone to talk to them. This action suggests a government worker who will not pause the approvals process (i.e. stamping) to 
carry out the government's policy (i.e. consultation). In fact, Denise may be constructing the performance to imply that the government does not even understand its own policy ( $\mathrm{n})$, and that the approvals process is a series of mindless, robotic actions requiring little attention (i.e. she never looks at what she is stamping). It is also interesting to note that Denise decides not to give the Indigenous characters a voice, but instead infers their presence (send someone to talk to them: q). We might interpret this as a representation of the ways in which Indigenous people are silenced in matters of government (see Glick, 2007; Hill, 2009; Usher, Tough, \& Galois, 1992).

Finally, Denise redirects her gaze to me, pauses her stamping gesture, and, using a discourse marker (you know: $\mathrm{t}$ ), seems to signal the end of her performance (Fox Tree \& Schrock, 2002). I nod (v), as if to accept the repositioning of myself as interlocutor once again. However, Denise maintains her head wobble and stamping gesture ( $\mathrm{u}-\mathrm{w}$ ) while she explains her main point (just keep rubber stamping as they're doing this), highlighting what she considers problematic about the process: projects are approved with little thought. She then retracts both hands back under the table $(\mathrm{x})$, marking the end of the gesture unit and therefore the end of her performance. The repeated stamping gesture works as a cohesive device (McNeill, 1992) to frame her performance and mark its onset and completion. By performatively becoming a government official, Denise is able to ridicule the social actors responsible for problems in her community, and thereby take back some agency (cf. Shepard, 2011). Here, she multimodally entextualises Discourses of government/Indigenous policy and simultaneously provides an evaluation of their ineffectiveness through her gestures and gaze.

A similar 'mundane performance' (Coupland, 2007, p. 146) occurs in my interview with Jill. We are discussing Ezra Levant, a popular right-wing author and television personality who is responsible for inspiring the 'Ethical Oil' campaign. As a television host, Levant also interviews activists, and Jill explains his interviewing style to me (Figure 8.13). 

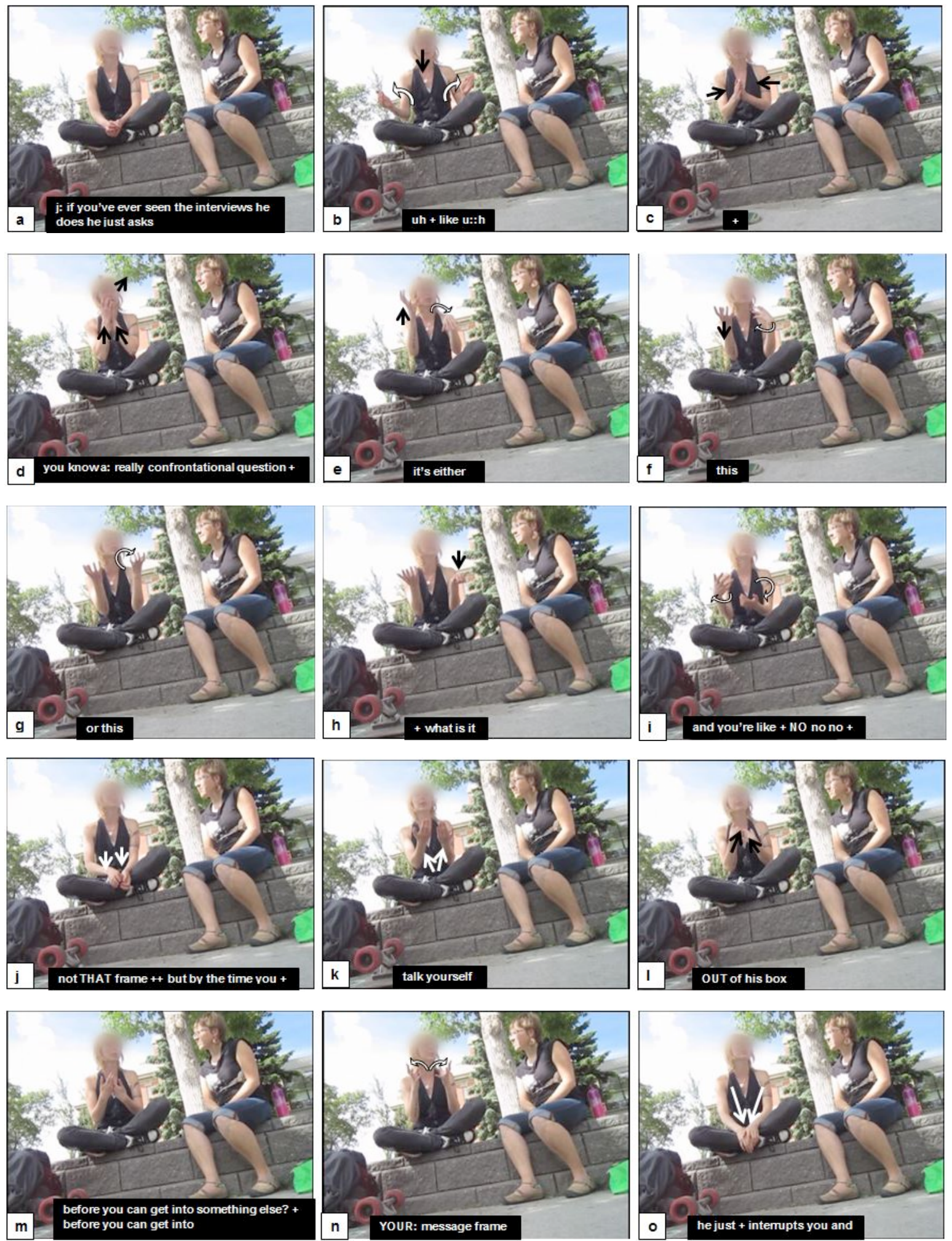

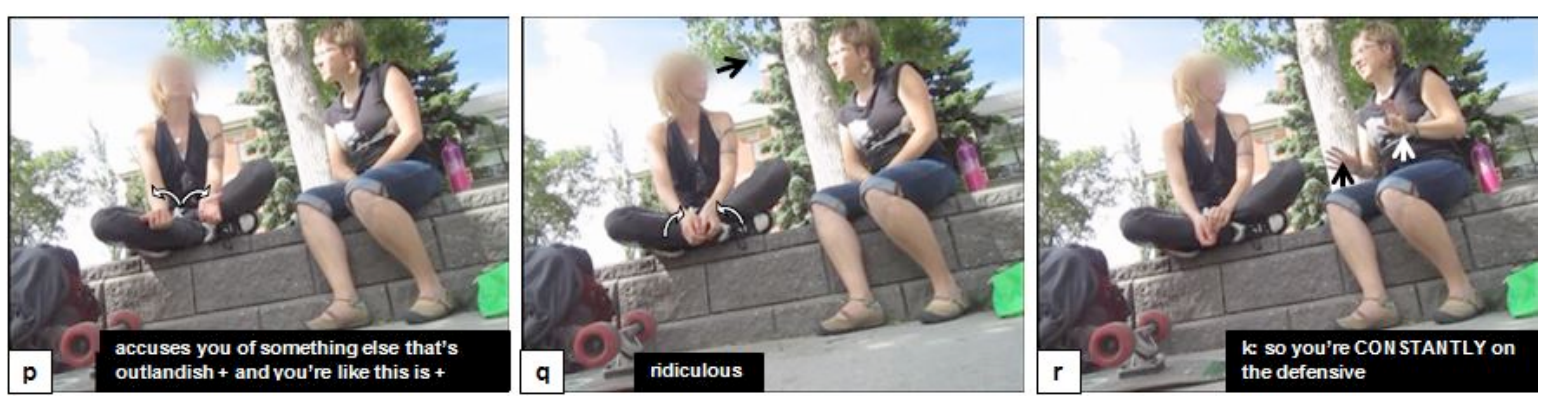

Figure 8.13: Jill

First, Jill describes the confrontational way that Levant begins an interview: by asking a dichotic question (it's either this or this, what is it: $\mathrm{d}$-h). While doing so, she uses a palm presentation gesture (Kendon, 2004) to introduce the two options (e-h). She then explains a typical interviewees' resistance to this questioning approach (you're like no, not that frame: $\mathrm{i}-\mathrm{j}$ ). Jill explains that this type of questioning 'traps' a person into orienting to certain Discourses and conceptualises it as a box (j-l). She visually depicts this box by raising her hands up in front of her (k) before moving them towards her chest (I). This echoes her spoken point that interviewees must talk themselves out of the box and re-orient to their own message frames (m-n). To illustrate, Jill places her hands out as if holding something $(\mathrm{n})$, possibly conceptualizing the message as an object that may be presented in the interview. She then drops her hands, dissolving the message-asobject in the process, and explains that Levant will simply interrupt the interviewee at that point (he just interrupts you and accuses you of something else that's outlandish: o-p). While explaining this, Jill presents her palms up in what is presumably a shrug, suggesting an "attitude of disengagement" (Streeck, 2009, p. 168) (as discussed in Chapter 6). She then retracts her hands and looks to me (q) and I summarise my understanding of her explanation (so you're constantly on the defensive: r). While doing so, I raise my hands with palms out in a gesture of defense (see Kendon, 2004, pp. 248-249 for more on stopping gestures). Next, Jill suddenly adopts the persona of Ezra Levant to illustrate his interviewing style to me in more detail (Figure 8.14). 

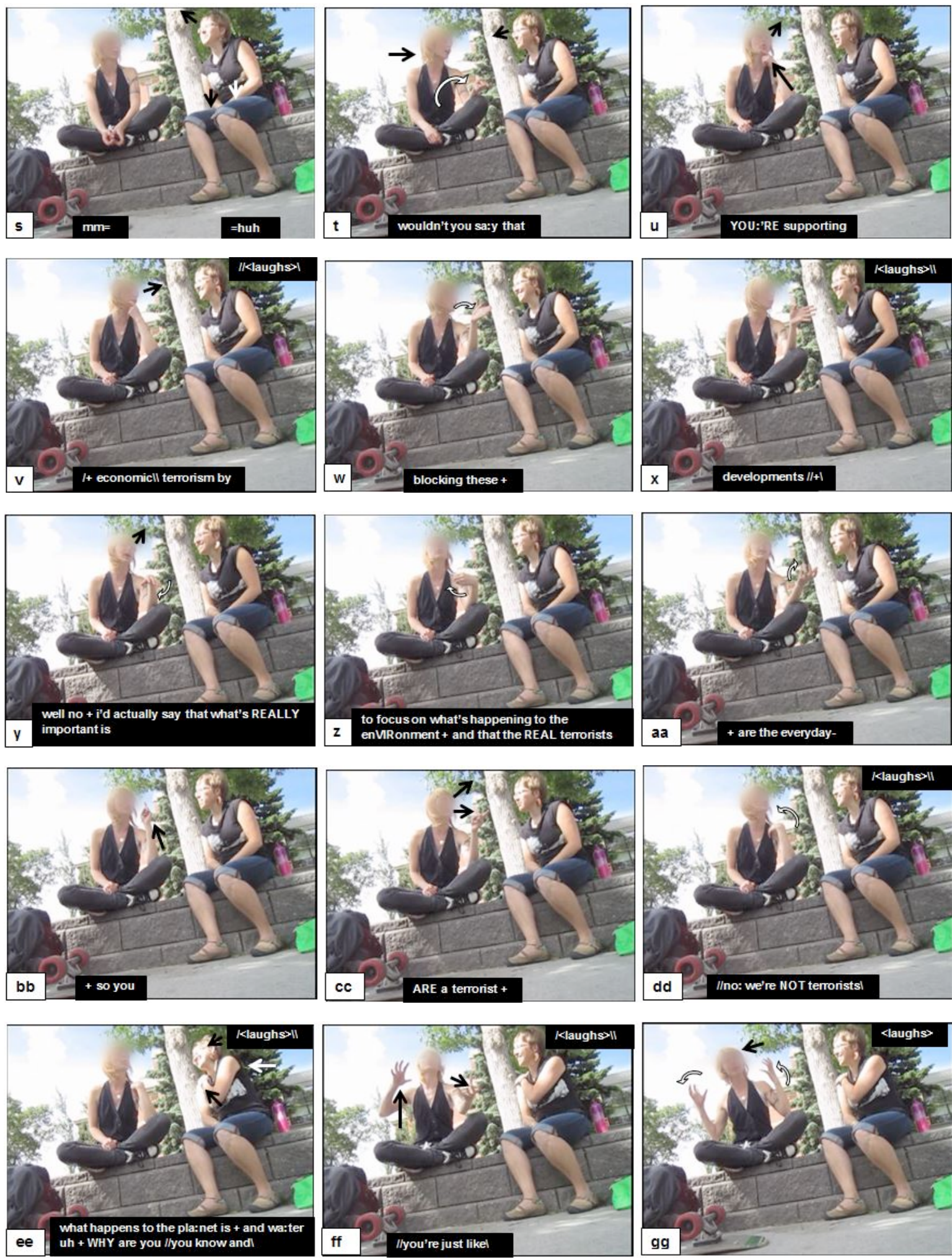

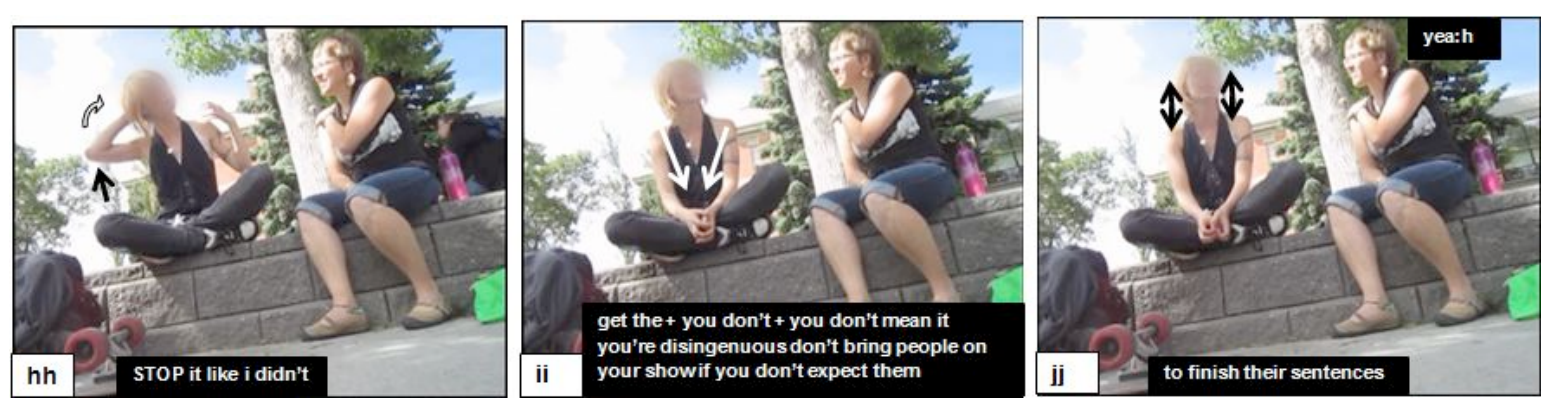

Figure 8.14: Jill

After I have dropped my hands and averted my gaze (s), Jill suddenly leans in and gestures with a LH deictic in my direction $(\mathrm{t})$. She lowers her tone of voice and adopts an accent that indexes 'American' (rather than 'Canadian') English, by drawing out vowels (sa:y, you:re) and substituting [E] with [I] (economic) (cf. Luhman, 1990). The postural shift, coupled with the change in voice, help to mark a new character. Jill moves her hand to her chin in a gesture symbolic of 'thinking' and then moves it back in an open-hand deictic gesture towards me ( $\mathrm{v}-\mathrm{x})$. I begin to laugh in the interactive space where I am meant answer her question, essentially declining to engage in the role as co-performer but encouraging her to continue (x) (Hay, 2008). Jill then gazes to the middle distance and answers her own question $(\mathrm{y})$, thus relieving me from adopting the role of interviewee in her performance and instead positioning me as overhearer (i.e. audience). As Jill becomes a new character, she raises her voice's pitch and reverts to a more Canadian English pronunciation. Additionally, she changes the style of her gesture, moving from the wrist as opposed to the entire arm (compare w and $z$ ). While answering the question, she interrupts herself once more as Ezra Levant by lowering her voice and gesturing once again with a deictic (bb-cc). Simultaneously, Jill averts her gaze to the middle distance, which prevents me from adopting any sort of interviewee character. In her performed interaction, Jill thus illustrates what she has previously described: Ezra asks a confrontational question (wouldn't you say that you're supporting economic terrorism by stopping these developments: t$\mathrm{x}$ ), interviewees struggle to orient to their message (well no, l'd actually say that what's really important is focusing on the environment: $\mathrm{y}-\mathrm{z}$ ), and Ezra interrupts 
with an accusation (and that the real terrorists are the everyday-, so you are a terrorist: $\mathrm{z}-\mathrm{cc})$.

Jill begins the cycle again and answers the question, this time in her own voice, but accompanied by the gestural style already established for the interviewee character (dd). I laugh and lean in as she expands on her answer, which is characterised by false starts and hesitations (what happens to the planet is, and water uh: ee). Jill may be using these resources to portray the discursive difficulties that activist interviewees experience when interviewing with Levant (i.e. talking themselves out of his box). She marks the end of the performance with the discourse marker you know (ee), and begins to comment upon the enactment. She describes how interviewees are left feeling (you're just like), and brings her hands up as if they are grasping and rotating a large object (ff-gg). While doing so, she tilts her body and head to the right and holds this posture briefly with body askew (gg). Here, Jill might be depicting the major obstacles which interviewees must negotiate when engaging with this style of interviewer. The gestural hold beside her head, coupled with her tilted body, is suggestive of the way that interviewees may feel dazed or disoriented after such an experience. Jill then brings her hands down and summarises how she feels about the entire situation (don't bring people on your show if you don't expect them to finish their sentences: ii-jj). This marks the end of the gesture unit and thus the end of her explanation.

Both Denise and Jill mark their performances with repeated gestures which cohesively link and mark their characters. Additionally, they use discourse markers (such as you know) to re-align with me at the end of the enactment. It is evident from my responses (e.g. laughing and leaning in) that their use of humour helps to build rapport with me as a conversation partner (Hay, 2008). In taking on the characters they perform, both women have the power to determine exactly how they will portray powerful social actors. And so, by presenting government workers as mindless robots, or Ezra Levant as an overly aggressive interviewer, Denise and Jill are able to exert some level of control in a situation of institutional 
dominance.

By using humour, they are able to create and defend a space for critique and ridicule (cf. Holmes, 2000; Schnurr \& Rowe, 2008). Jill and Denise skillfully manipulate a variety of modes (gesture, gaze, posture, speech) to create meaning and it is the entire multimodal ensemble (Kress, 2011) that makes up the performance. Although it is possible that these mundane performances (Coupland, 2007) are conducted for the benefit of my recording device, satirical depictions of industry and government actors are also visible in artefacts (e.g. Figure 8.6). This suggests that playful humour is a strategy that many activist groups orient towards.

The use of humour within activism is expanded upon by Shepard's analysis of ludic protest in New York through the 90's and 2000's (2011). He chronicles social movements through interviews with activists working on issues from AIDS to community gardens to the wider peace movement. In doing so, he finds that humour plays important roles for communities of resistance as a way to cope with oppression, as a method of engaging with outside actors, and also as a subversive force.

The power of humour is explicitly recognised by many activists in my interviews. For example, William characterises humour as a powerful weapon (as discussed above) and Justin explains that it can be a way to find a common point, even if it's just laughing at yourself. When Tom and I discussed the humour he uses in activism, he described it in terms of the three functions as presented in Shepard (2011): humour as coping mechanism, as subversion, and as engagement strategy (Excerpt 8.2). 


\section{Excerpt 8.2: Tom}

$1 \quad \mathrm{~T}$ it's super important + because definitely working in this environment + against sort of like the: + obstacles that you're working against because you're working against like the biggest companies on the face of the planet + you know heavily backed by the two governments that are supposed to + help represent the public interest that are + just abdicating their responsibility and that + have become the public relations mouthpiece for those industries + and so it can be like + fairly depressing

$\mathrm{K} \quad / /<$ laughs $>$ yeah

$\mathrm{T} \quad \mathrm{u}$ :h and so $\mathrm{i}$ think a lot of times we use like humour and creativity + you know partially for ourSELVES because it + feels really nice to do that type of + action when you use that type of creativity + and then also for other people + uh you know + like we talked about beFORE you know the fact that the oil industry is so + entWINED with people's sense of identity

$\mathrm{K}$ yeah

that sometimes humour is a way to sort of + break that open a little bit $\mathrm{K}$ huh

$\mathrm{T}$ and like when we can start to laugh at ourselves + and laugh at this sort of like culture that we've suddenly + somehow identified with we can start to critique it more and + ask ourselves is that you know is that who i really am or? just ( ) be able to look at this industry + um + and so i think it's partially for that and then + partially that we do: live in like a very + you know visual: media driven society //tool and so a lot of times + creative activities are more visual and more engaging and more entertaining and so they + they do draw people in a lot more than + potentially other ( )

K /yeahll yeah

Tom first describes the difficult environment in which activists in Alberta work, which can be fairly depressing (1-8). Humour, he argues, is used partially for ourselves, because it feels really nice to do that type of action when you use that type of creativity (10-12). This echoes Shepard's assertion that play can serve "as a coping mechanism" (2011, p. 13) and help "lighten up an awfully heavy, often very serious, and contradictory experience" as well as be an "escape from an often hostile outside world" (Shepard, 2011, p. 58). Tom then describes how humour can 
break open the public's connection to the 'Alberta is oil' identity Discourse (see section 5.2) and allow them to begin to critique it (13-22). Humour gives people the space to laugh at themselves (laugh at ourselves and laugh at this sort of like culture that we've suddenly somehow identified with: 19-20), and to question assumptions about normalised Discourses (ask ourselves is that who I really am?: 21-22). This relates to Shepard's (2011) ideas about humour and play taking on a subversive quality, where normative plotlines are destabilised. Tom also discusses the use of humour as an engagement strategy (creative activities are more visual and more engaging and more entertaining so they, do draw people in a lot more: 25-27). Similarly, Shepard describes playful protest which "invites people to participate in an expanding public conversation, in which movements and community groups interact" (2011, p. 260). It is evident from Tom's comments that creativity and humour play a large role in his approach to activism and that he is informed about the reasons for utilising humour.

Playful, humorous performances feature prominently in Alberta's tar sands debate. From mock weddings, to mock funerals, to buried treasure hunts (CBC News, 2009b), tar sands activists stage elaborate theatrics to highlight problematic actions of the government or industry. In Aotearoa/New Zealand, although playful humour is evident, it appears to be less elaborately produced. In the next section, I discuss other ways in which the mining debates in both Canada and Aotearoa/New Zealand might be compared and contrasted.

\subsection{The Discursive Arms Race in Canada and Aotearoa/New Zealand}

In consideration of the Discourses appropriated by industry actors in mining debates, it seems that Canadian industry actors draw upon a wider range. For example, tar sands advocates such as those behind the 'Ethical Oil' campaign, have used Discourses of LGBTQ+ rights (as discussed in Chapter 7) in order to come across as legitimate. There are no examples of such Discourses becoming relevant in the debate in Southland, where even Discourses of Indigenous rights are seemingly absent. In both cases however, Discourses of environment, 
economy, and regional identity are used as strategies of legitimation and resistance (Chapters 4, 5). So why are there more Discourses appropriated and resisted in the tar sands than in the Southland lignite debate?

One interpretation could be that the level of debate is further along, and that the industry is more entrenched. In Alberta, development of the tar sands has been occurring over a number of decades, and it continues to expand (Davidson \& Gismondi, 2011). Additionally, tar sands development involves some of the world's largest extraction companies and accounts for a significant portion of the local economy (Davidson \& Gismondi, 2011). As an industry with a longer presence, there has also been a prolonged history of resistance to the development. Resistance groups, such as Greenpeace Alberta and Indigenous Environmental Network, have had success in publicising the situation outside of Canada (e.g. Goldenberg, 2011). Such international publicity has invited widespread criticism (e.g. Babad, 2013; Ibrahim, 2014; Nikiforuk, 2008; Rooney, Bayley, \& Schindler, 2012), and industry actors have found themselves in a precarious position where their legitimacy is challenged from outside Alberta as well as from within (see Davidson \& Gismondi, 2011).

I have thus far discussed how industry actors appropriate Discourses from various other groups (e.g. Southlanders, First Nations, LGBTQ+ people, etc.). An alternative possibility is that this is not appropriation at all, but simply an attempt to acknowledge some of the issues brought forth (e.g. legitimate concern about environmental issues or Indigenous involvement). However, this 'acknowledgment' seems in fact to be disingenuous, as it often ignores the struggles and voices of local people. Consider for example Denise's argument, that Indigenous Discourses are used primarily for marketing purposes, whilst industry actors facilitate the dependence of local communities on the fossil fuel sector (see section 6.3). A more likely interpretation is that the use of these Discourses is a strategy to counter ongoing resistance rather than acknowledge it. By appearing to listen to the concerns of communities of resistance, industry actors can delegitimise further 
charges of wrongdoing by claiming that they have already managed them sufficiently. As might be expected, this encourages more resistance, which in turn encourages further appropriation, and so on, resulting in a sort of discursive arms race (Figure 8.15).

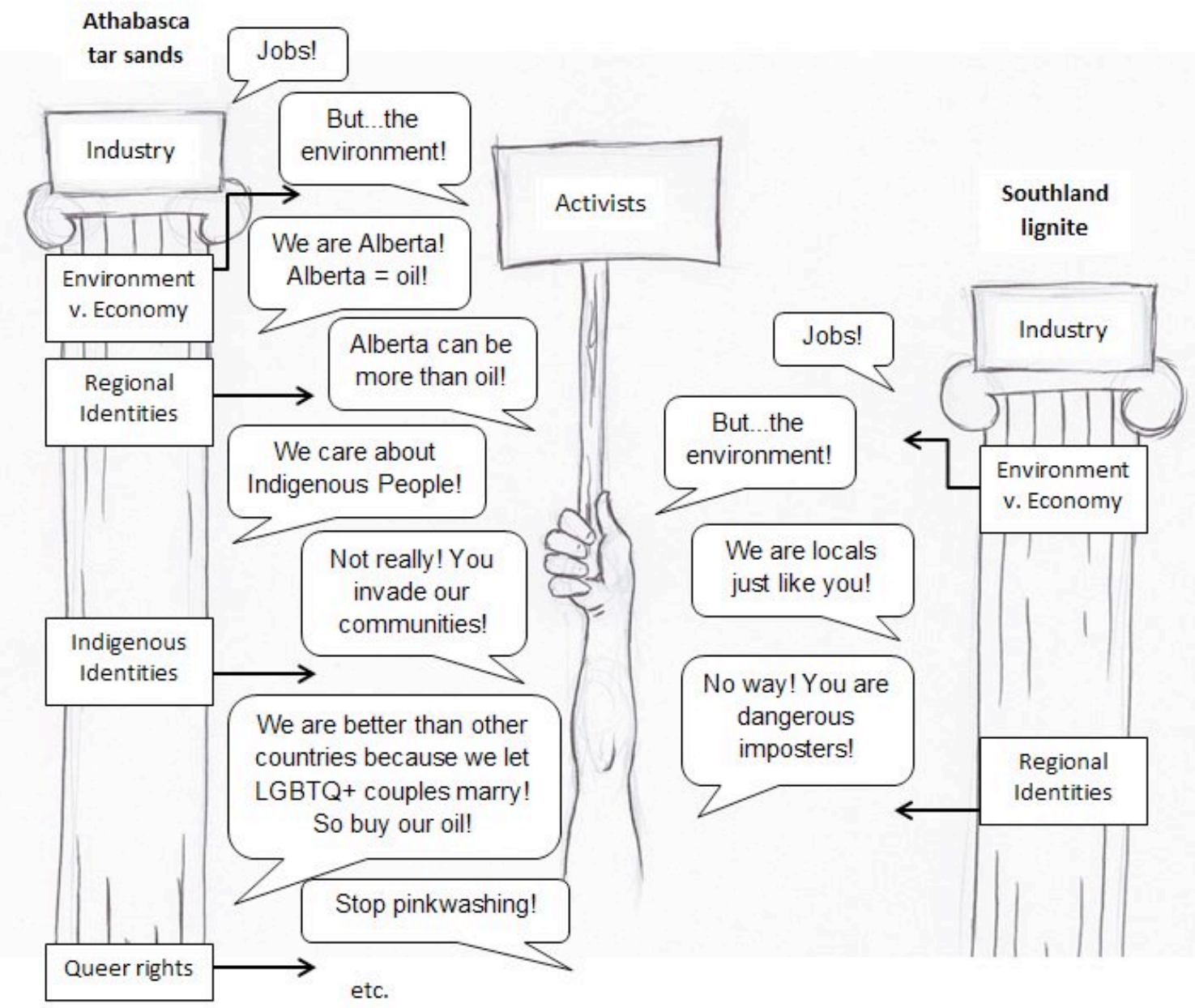

Figure 8.15: Discursive Arms Race

This might help explain the differences I have found in Alberta and Southland: because the tar sands has a longer history, this discursive arms race has had more time to develop and has thus resulted in a wider range of appropriated Discourses. 
One could argue that, ultimately the wide variety of Discourses appropriated in the tar sands is a sign of a weakening industry which must justify its legitimacy (cf. Davidson \& Gismondi, 2011). As long as these appropriated Discourses are recognised and resisted by activists, industry actors will be forced to find new ways of regaining legitimacy and justifying industrial expansion. Or, in other words, as the mining industry loses legitimacy in the face of resistance, they will be forced to reach for wider Discourses to appropriate (such as Indigenous identities, or even LGBTQ+ rights). If this is the case, we might be able to predict that this type of marketing behaviour will occur at mine sites which have a shorter history of resistance, such as the lignite mine in Southland. Luckily for local activists, this mine expansion has been halted; however these ideas may be found relevant in describing the debates surrounding other new projects as resistance to fossil fuel development builds (e.g. McCorkindale, 2014).

Additionally, it seems there is a strategic temporal order in Discourse appropriation. In both cases, industry actors legitimise expansion by appealing to a neoliberal Discourse of job creation which is, in turn, countered with concerns about environmental impacts. This leads to the 'Environment v. Economy' Discourse (discussed in Chapter 4), which tends to characterise many contemporary discussions of fossil fuel projects (e.g. Nikiforuk, 2008). Similarly, in both Alberta and Southland, Discourses of regional identity are appropriated and used by industry actors in their marketing (consider how Terra Resources positions itself amongst Southlanders, as discussed in section 5.6), and subsequently resisted by local activists (Chapter 5). It is here that each case appears to diverge however, with Albertan industry actors appropriating further Discourses, such as Indigenous identities (Chapter 6) and LGBTQ+ rights (Chapter 7). Although some of these might be regarded as extreme (consider the variety of intersecting Discourses which make up EQUAIA's resistance to 'Ethical Oil'), they still form part of, and thus influence, the wider debate (Blommaert, 2005, p. 66). In fact, the relationship between LGBTQ+ rights and oil requires a number of discursive moves (i.e. Canada is one of many oil-producing nations; individuals have a choice of 
which oil-producing nation to support; Canada allows gay marriage and other nations do not; therefore, Canada should be supported; therefore, buy Canadian oil), making the link less direct. As such, it seems that industry actors must reach further in their appropriation of Discourses as more direct links are resisted (e.g. environmental stewardship, job creation), meaning discussions of environmental debates tend to escalate to become less directly-linked to oil and mining. In other words, industry actors are forced to adopt wider arguments to legitimise their industry's expansion as major Discourses are exhausted and countered by the resistance. As Blommaert notes, "the fact that certain discourse forms only become visible and accessible at particular times and under particular conditions is in itself an important phenomenon, which tells us a lot about our societies and ourselves" (2005, p. 66). This does not mean, however, that direct Discourses no longer play a role (see Chapter 4 for examples of 'Environment v. Economy' in tar sands discussions), but rather that newly appropriated Discourses are added to the discussion, resulting in a wide variety of intersecting Discourses. From job creation to gay marriage, all Discourses lead to the tar sands.

This escalation of Discourse appropriation and resistance is also characterised multimodally. Both interaction (evident in interviews) and design (evident in artefacts) is an integral part of these dynamics. Additionally, the multimodal aspects of these mining debates reflects the different resources available to industry actors and activists (cf. Van Dijk, 1996). It is here that power becomes visible, as these resources are valued differently in different spaces (Blommaert, 2005). In interviews with me, activists can exert control over the representation of industry actors by ridiculing them. This behaviour might not be tolerated in other situations, however. In spaces where critical voices are ignored or even silenced (consider Denise's representation of Indigenous voices in her performance as a government official, or activists in Southland being forced to refer to lignite as the "L" word), resistance takes on different forms. It is therefore crucial for activists to be able to develop the skills to effectively (and engagingly) resist Discourse appropriation. As research based in a critical perspective, this thesis 
seeks to contribute to such empowerment of communities of struggle. In Chapter 10, I will expand upon the implications of these findings for both academia and activism alike. First however, I interrogate some of my own positionings as an activist researcher in the next chapter. 


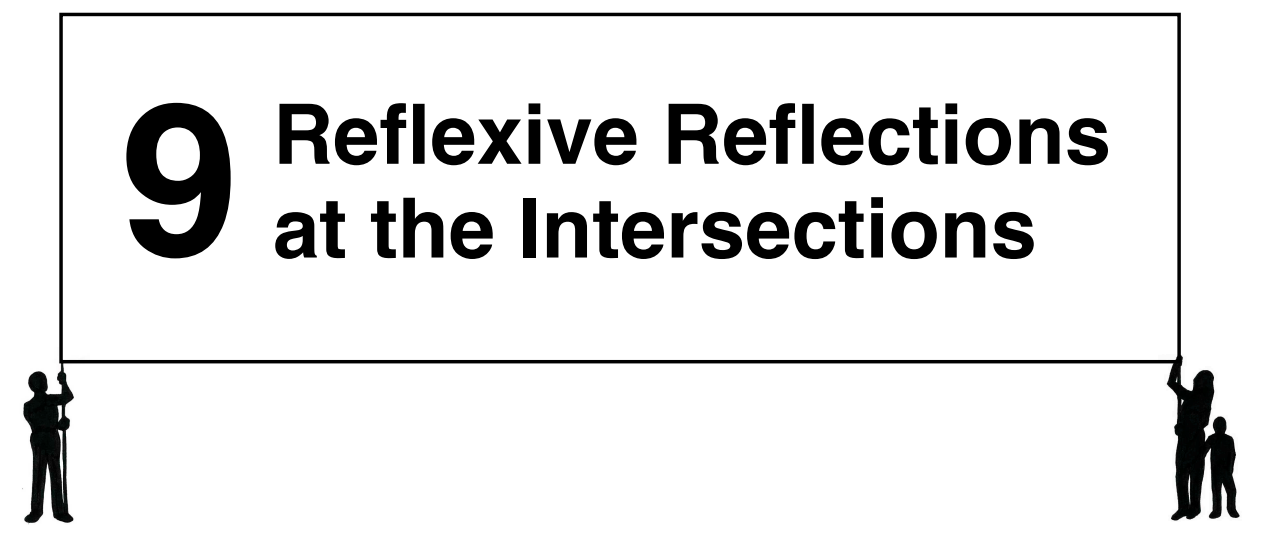

I Chapter 7, I discussed the concept of 'intersectionality' and the ways that oppressions and Discourses might intersect and be linked multimodally. The research questions with which this thesis engages have also dealt with a variety of intersections, including both activist and industry groups, as well as the two case studies in Canada and Aotearoa/New Zealand. Additionally, I have analysed the ways in which these various entities intersect through both micro and macro Discourses as seen through action in interviews and artefacts.

Before concluding this thesis, I feel it is valuable to reflect upon my role in the intersections of this thesis by focusing on the data collection experience. As discussed in sections 2.4, 3.1 and 3.2, ethnography forms one of the lenses through which I view and conduct interaction (see Figure 2.8). This has given me a number of methodological advantages: I have developed the trust necessary to gain access to people and places, integrating myself within the communities. An ethnographic approach has also allowed me to move between the micro and macro Discourses through my use of fieldnotes and intuitive knowledge of community practices. It has also provided a methodological framework for practicing critical reflexivity, while allowing the voices of my participants, and of myself as a researcher, to come through.

In keeping with this critical tradition of reflexivity (Blommaert, 2005; Sarangi \& Candlin, 2003), in this chapter I analyse my ethnographic experiences at the 
intersections discussed throughout the thesis: both activists and industry actors in Canada and Aotearoa/New Zealand. To this end, I interrogate the complex constellation of positionings in which I found myself while conducting fieldwork. The difficulties these entanglements bring may not be resolvable but, by unpacking and describing them I aim to provide useful insights into ethnographic work in general.

\subsection{Becoming a Participant: Reconsidering the Researcher ${ }^{1}$}

Because an ethnographic approach to social research is all-encompassing and more than simply a method for gathering data (Blommaert \& Jie, 2010, p. 5), immersion within a community is common practice. Yet, through this immersion and interaction, the ethnographer may find herself in unexpected and sometimes deeply uncomfortable places and situations. Moreover, her mere presence in a space changes it: the researcher is "a foreign body which causes ripples on the surface of smooth routinized processes" (Blommaert \& Jie, 2010, p. 27). Ethnographers are familiar with the (dis)comfort of acting as a participant observer, and negotiating their roles as insider/outsider (see Fincham, 2006 for a discussion on ethnographic trust and authenticity), regardless of whether these roles involve such dichotic subject positions as is evident in this thesis. In this section I wish to interrogate how I approached the tensions that arose from my presence and introduce the resources I used to negotiate the various, and often difficult, situations in which I found myself.

\footnotetext{
1 This chapter also appears as Kidner, K. (forthcoming). Activist Ethnography: Becoming the 'toilet lady', Navigating roles in the field. In e. Emerald \& R. Rinehart (Eds.), Ethnographies in Pan Pacific Research: Tensions and Positionings. New York: Routledge.
} 


\section{Dawn}

(2)ThisPhD

\section{Ethnography woes or ethnography whoas?}

\#inbetween

4:37 PM - 22 Feb 2012

Harré and Van Langenhove's theory of positioning provides a useful resource for understanding the complexities of fieldwork experiences. As an alternative to the static concept of role, they highlight how positioning may be used to locate interactionists as powerless or powerful, friend or threat, confident or apologetic (1991, pp. 395-396). Positioning recognises how participants might co-construct dynamic positions for self and other simultaneously: "Whenever somebody positions him/ herself, this discursive act always implies a positioning of the one who is addressed. And similarly, when somebody positions somebody else, that always implies a positioning of the person him/herself" (Harré \& Langenhove, 1991, p. 398). How such dynamics play out is determined in part by participants' agency and abilities, which are socially constrained by larger Discourses and power structures. Positioning also extends beyond the level of the conversation and into the act of research writing itself (1991, p. 406) where, through analysis and publication, the researcher continues to position and transform individuals. It is an ongoing and dynamic process that does not stop at the end of the interview or upon return from the field: people are given new positions and re-written through the subsequent academic work of documentation and presentation. Thus, an awareness of positioning is important to maintain during all stages of research, from fieldwork to publication. I recognise that my own writing positions me, and those with whom I worked, in an academic context. Positioning provides the ethnographer with a framework to consider her own roles and negotiations in the act of research.

If as critical scholars we aim for our research to have positive impacts and tackle injustices (Blommaert, 2005; Van Dijk, 1993; Fairclough, 1995), managing 
our levels of involvement with different communities becomes an important task. My attempts to work critically while involving both myself and my research in the lives of activist community members have brought me to a complicated arrangement of positioning involvements. Because my thesis is so politically charged, I found myself in many situations that Blommaert \& Jie term "rich points" (2010, p. 41), which show the boundaries of ethnographic understanding. By homing in on these 'rich points', coupled with an analysis of positionings, I can begin to understand how I as an observer was also being observed. I wish also to highlight that the following discussion deals with perceived positionings: they represent my own impressions of what happened, although I utilise supporting data to support my interpretations.

\section{Dawn}

@ThisPhD

\section{All these thick descriptions and rich points go straight to my hips \#ethnography}

\subsubsection{The Toilet Lady: Becoming an Organiser}

As described briefly in section 3.2, my first interaction with the Southland activist community was when I was recruited to help organise the anti coal-mining festival. My positioning as an organiser and its resulting notoriety however, gave me entry into the community in a way that I may never have achieved had I simply attended the festival as planned.

The extent of my notoriety became apparent when, on a subsequent field trip, I came across a local environmental group stall where a woman recognised me as "the toilet lady" from the month before. This positioning continued throughout my data collection: months later I conducted an interview with an 
activist who assumed I was a professional organiser who had been sought out specifically to build the festival's composting toilets. He was surprised to discover that I was simply looking for a ride to the festival and that my only qualification for building the toilets had been my previous experiences using a composting system! Thus, my designation as the "toilet lady" usefully exemplifies how positionings may extend beyond our control as researchers and force us to consider how we might be viewed by the communities with which we work (e.g. Smith, 1999).

My work as the "toilet lady" also allowed me to take on an aspect of Southland rural identity (see section 5.5), which had the effect of positioning me in alignment with Southlanders. This physical work also helped to neutralise my positioning as 'urban student' (cf. Law, 1997), something that was commented on by Mark in particular:

I feel my willingness and ability to do physical labour counter-acts my perceived "laziness" of being an academic - Mark often remarks about the lack of usefulness of student life, or I guess the lack of application and practicality. (April 26, 2012, FN)

Thus, my ability to engage in physical labour formed the foundational building blocks of a number of relationships in the region. My positioning as the "toilet lady" may have been unexpected, but the impact on my research cannot be understated.

\section{Dawn} @ishisPhD

\section{I'm definitely working on the "applied" part of applied linguistics with all this building.}




\subsubsection{The Note-taker: Forced Positionings and Resistance}

My first interaction with those involved in the mining operations was unfortunately a less positive experience. I had an alarming interaction while attending a mining tour run by the company a few weeks after the festival had ended.

After introducing myself to Kalena (one of the company representatives) and gaining permission to photograph and take notes, I waited for a tour of the working mine with a busload of other attendees. At one point Don, a large man in a dark suit who was standing with the group, loudly presented me by name and said:

\footnotetext{
"You better take good notes Keely so when you get back if anyone wants to know what you did on the tour they can read your notes". I don't remember meeting him! But maybe he overheard me being introduced? I laughed it off and said I'm learning ethnography and my notes are all over" (Feb. 15, 2012, FN)
}

By making me an object of interest and drawing attention to my action of notetaking, Don engaged in a powerful move meant to mark me as a threat. Unfortunately it is difficult without a recording to identify exactly what Don did that made me feel this way, but his behaviour can still be explored in retrospect. By using my name when I had not been introduced to him, Don took advantage of an unequal distribution of knowledge (see Mondada, 2013 for more on the negotiation of epistemic authority): he could name me but I could not name him. As someone with obvious institutional backing (evidenced through his suit and company label), Don was able to utilise his authority to point me out to the rest of the crowd. It should also be noted that I am only $155 \mathrm{~cm}$ tall while Don stood quite a bit taller and bulkier. By standing directly beside me and using my name, he made me feel both physically and discursively under control and subject to surveillance (see Carney, Hall, \& LeBeau, 2005 on nonverbal actions of individuals perceived as powerful; also cf. Goodwin, 2000, p. 1499). My reaction to such a powerful move was to laugh it off: literally to defuse the situation with dismissive humour (see 
Holmes \& Marra, 2002, pp. 377-378). Because of my discomfort with being identified so publicly, I decided to codify some of my notes in Swiss German² as a way of maintaining privacy. As it turns out, this decision was very well-timed.

Upon my return from the tour, I continued to wander around with my notebook. As I was inspecting a chunk of coal, Don once again approached me and took my notebook from my hand. My reaction was to laugh nervously and make a comment about my messy handwriting while he quickly flipped through my notes. After a few seconds of this, he handed me the book without a word and I quickly found Kalena and said goodbye. I kept calm and nonchalantly walked away from the tent. However, as I turned a corner, panic overcame me and I jogged away, hid myself from view, and attempted to calm down:

"I can't shake this creepy violated feeling - I thought later on that I may see that Don guy spying on me...I wish I could have said something. What would have been the best course of action? I don't want to create a scene but I want to stand up for myself' (Feb. 15, 2012, $\mathrm{FN})$

The event caused me distress at the time and in retrospect, it is clear that I felt I was positioned as a threat in a way that was also threatening to me. The seizure of my notebook was an explicit attempt to take control of the situation and claim a right to access my writing (Van Dijk, 1996):

"The way he flipped thru my notebook makes me think it was more a display of power than serious investigation as he wouldn't have been able to read much that fast" (Feb. 15, 2012, FN).

Once again, my reaction was to laugh and make light of a very tense situation, for fear of drawing attention to, and potentially escalating, the confrontation. My own embodied behaviour and the act of codifying my notes may also have helped to co-

2 In 2001, I lived for a year in Solothurn, Switzerland where I learned to speak and write a dialect of Schwiizertüütsch. 
construct the encounter. Perhaps by behaving in a somewhat hesitant and conciliatory manner, I inadvertently presented myself as potentially deceptive and therefore threatening. In other words, my body language possibly reinforced Don's perception of me and so my positioning was in fact co-constructed by us both (cf. Carney, Hall \& LeBeau, 2005).

“Eep! Don het mini Notes gno! Der hat die eifach uus mini Haende gno! Und duure flipt und glaese. Ig fuehle mi vou violatiziert. Ibi froh ig ha aagfange uuf schwiizerduetsch zum schriibe"

"Eep! Don took my notes! He just took them right out of my hands! And flipped through and read them. I feel totally violated. I'm so glad I started writing in Swiss German" (Feb 15, 2012, FN)

Additionally, by codifying my notes in another language, I was able to gain back some level of control and power by potentially limiting access to my writing. The choice of Swiss German was also strategic: as a user of a variety of languages (e.g. Italian, French, Standard German), I elected to write in a dialect I felt would have a more limited readership. In this way, my decision to use Swiss German allowed me to reassert my positioning as a researcher with a right to privacy. However, my attempts to maintain control of my data collection were further hindered when I began to interview industry representatives.

\subsubsection{The Student: Claiming Control}

After scheduling an interview with Terra Resources, I discovered that there was a chance I would be asked to sign a legal document. My co-researcher Nicole (see section 3.6) and I agreed beforehand that we would not sign anything without the University's legal approval and so we arrived at the headquarters on the appointed date. Amidst much security fanfare, we were escorted into the interview room by an assistant and casually given a legal waiver to sign. The document contained four clauses, some of which were straight forward (such as sighting and 
approving transcripts). However, two clauses in particular were problematic in that they involved the company sighting and approving any writing as a result of the interview (i.e. this thesis) and limiting my analysis to only positive portrayals of the company. In addition, it was unclear to me how these agreements would restrict my actions outside my formal role as a research student, should I attend a protest or rally in the future. ${ }^{3}$

We politely declined our signatures and other company representatives were subsequently brought into the room. While they continued to request our signatures, at one point Kalena (the representative I had contacted first) asked me to ring my supervisors, even attempting to take my phone to ring them herself. Nicole remarked that we needed to discuss the document with the University Ethics Committee before signing and with that the matter seemed to be settled. We organised a different interview date subject to the document being signed and Nicole and I were escorted out of the building. At a café close by, we recorded a discussion debriefing what had happened (Excerpt 9.1).

\section{Excerpt 9.1: Nicole}

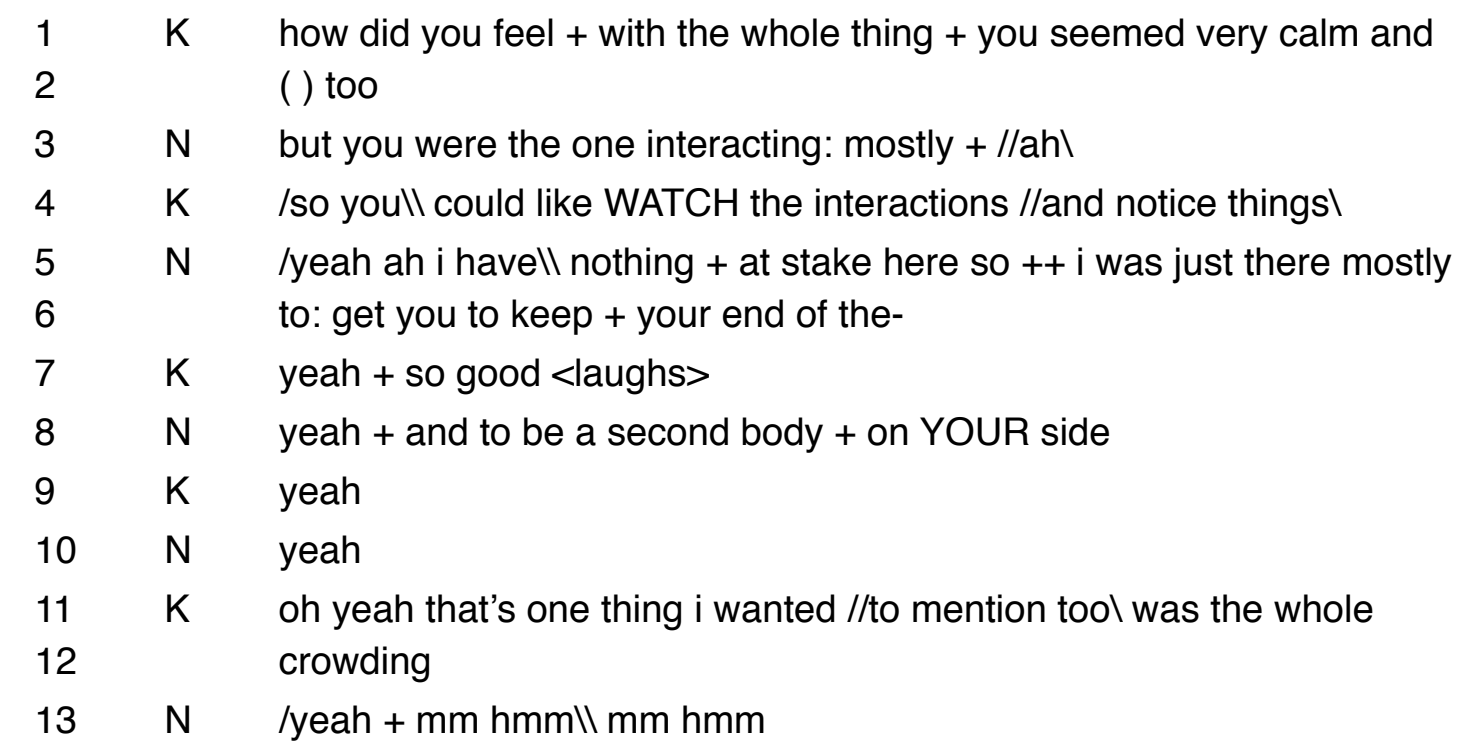

\footnotetext{
${ }^{3}$ It should be also reiterated here, that had there been no such problematic clauses, I still would have felt uncomfortable signing a legally binding document with such short notice.
} 


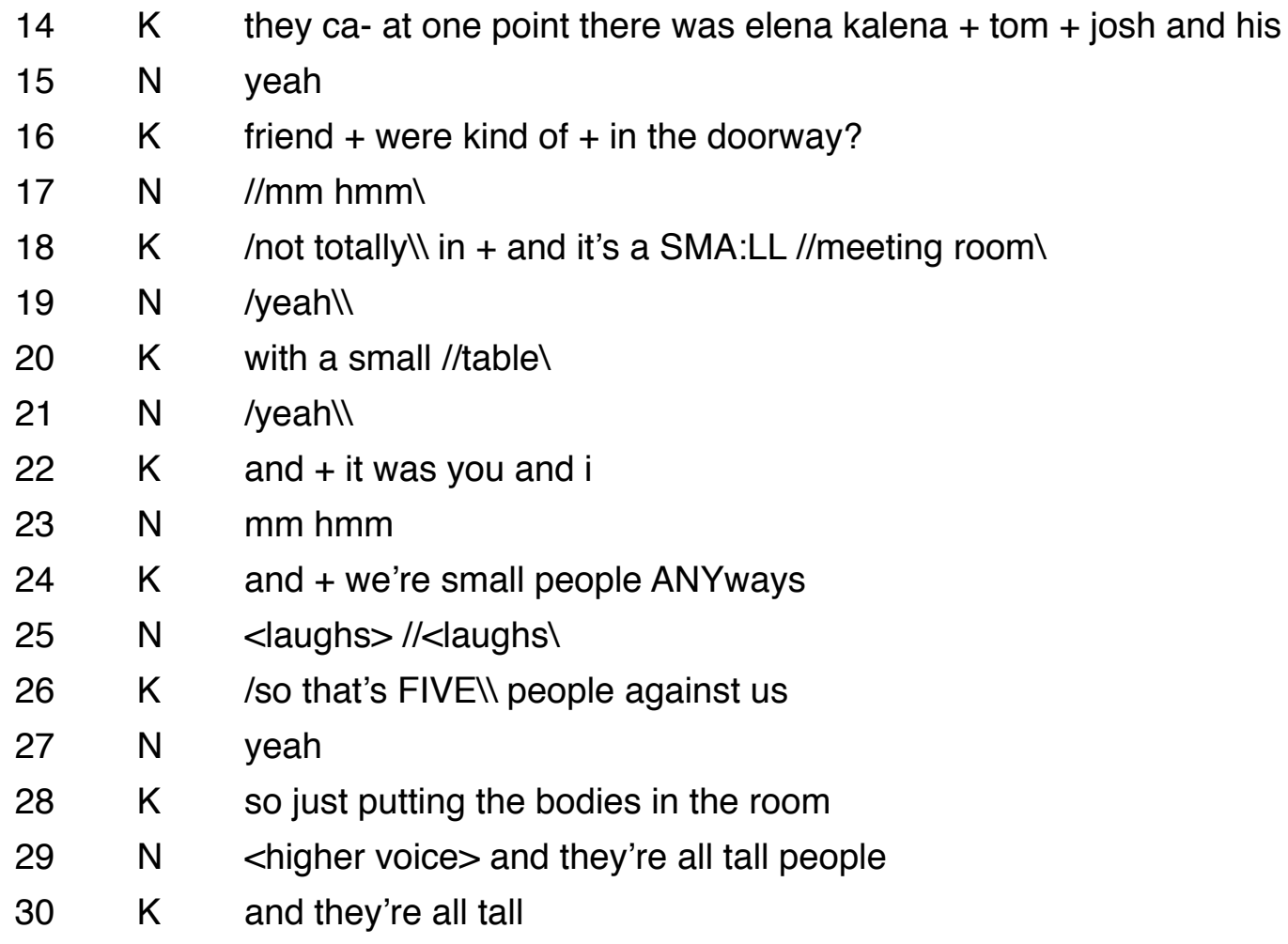

Nicole brings up very explicitly the fact that she felt she was able to support me simply through her presence, by being a second body on my side (8). The nature of those bodies also becomes important with the acknowledgment that both Nicole and I are short in stature compared to the others in the room (4-30). Additionally, Kalena's request to have me contact my supervisors immediately did offer us a solution, but not one I was comfortable with. As she moved to take my phone from my hands, I suggested that I send a text message instead. In this way, I was able to regain some sort of control over the situation although the interaction still caused me some distress (Excerpt 9.2):

\section{Excerpt 9.2: Nicole}

$1 \quad \mathrm{~K} \quad$ her getting me to text + my supervisor?

$2 \mathrm{~N}$ your supervisor yeah

$3 \mathrm{~K}$ that's when i + felt really //uncomfortablel?

$4 \quad \mathrm{~N}$ /yeahll

$5 \quad \mathrm{~K}$ because i didn't know how + //tol 


$\begin{array}{lll}6 & \mathrm{~N} & \text { /yeahll } \\ 7 & \mathrm{~K} & \begin{array}{l}+ \text { it wasn't a scenario i'd gone over + //in my } \backslash \text { head so i didn't know } \\ \text { how to react }\end{array} \\ 9 & \mathrm{~N} & \text { /yeahll but the rest you had + gone over } \\ 10 & \mathrm{~K} & \text { i'd gone over it }+ \text { and over it and over it and <laughing }>\text { over it }\end{array}$

As is evidenced in the excerpt, I had rehearsed various outcomes of the situation beforehand (7-10), carefully going over my options before I was forced to act (Holmes, Bell, \& Boyce, 1991). The request that I contact my supervisors immediately while in a room full of industry office workers was not a scenario for which I had prepared ${ }^{4}$. Our decision to postpone the interview was a rejection of our positions as powerless students. In fact, the entire interaction was rife with contested and negotiated positionings, from the moment we stepped into the building until the moment we left (Excerpt 9.3):

\section{Excerpt 9.3: Nicole}

\begin{tabular}{|c|c|c|}
\hline $\begin{array}{l}1 \\
2 \\
3\end{array}$ & $\mathrm{~K}$ & $\begin{array}{l}\text { you mentioned something while we were sitting there about how }+ \text { um } \\
+ \text { this document is trying to subvert the power dynamics that i've } \\
\text { established? being a researcher? }\end{array}$ \\
\hline 4 & $\mathrm{~N}$ & $+\mathrm{mm}:$ \\
\hline 5 & $\mathrm{~K}$ & or something like that? \\
\hline 7 & $\mathrm{~N}$ & $\begin{array}{l}\text { no actually } i+i \text { mentioned that }+ \text { you refusing to sign right away and } \\
\text { invoking the university as was a source of authority for you? }\end{array}$ \\
\hline 8 & $\mathrm{~K}$ & ah //yeah\ \\
\hline 10 & $\mathrm{~N}$ & $\begin{array}{l}\text { /that could } \backslash \text { count sort of counteract what the:y + the power that they } \\
\text { were invoking? to make you sign immediately? }\end{array}$ \\
\hline 11 & $\mathrm{~K}$ & //yeah\ \\
\hline 12 & $\mathrm{~N}$ & /by being $\backslash \backslash$ in their building and their: top + powered people \\
\hline 13 & $\mathrm{~K}$ & $\begin{array}{l}\text { true and putting us through this whole song //and dance of like + } \\
\text { signing in }\end{array}$ \\
\hline & $\mathrm{N}$ & $/ \mathrm{mm} \mathrm{hmm} \mathrm{++} \mathrm{mm} \mathrm{hmmll}$ \\
\hline
\end{tabular}

\footnotetext{
${ }^{4}$ My supervisors were not available by phone at this precise time in any case.
} 
Inviting us to the company headquarters, having us sign in and display our names and organisations, escorting us to a small meeting room to wait (12-14) - these actions accumulated to make the company appear powerful and in control of individuals entering the space (Vale, 1992). Such gatekeeping encounters "provide an ideal site for the covert, systemic exercise of power" (Holmes, 2007, pp. 19951996) and Nicole and I were positioned in relation to this power, as subject to the agency of the company ${ }^{5}$. Our refusal to sign the waiver contested this view and, by invoking the University Ethics Committee, Nicole and I successfully positioned ourselves as part of an authoritative institution (invoking the university as a sense of authority, to counteract the power they were invoking: lines 6-10).

The complicated interactions involved in our refusal to sign shows just how difficult and complex positionings can become. It is often only through subsequent reflection that we fully understand how intensely the issues of power and control play out (see Van Dijk, 1996). However, during the interaction itself, Nicole and I had to improvise and make decisions with little time for reflection (Blommaert \& Jie, 2010). These difficult situations helped prepare me for the continuation of my fieldwork in Alberta, Canada.

\subsubsection{Returning 'Home'}

Reintegrating into my old activist community in Canada brought with it different challenges. During my eight years living in Edmonton, I had become a core member of a number of activist groups. Despite engaging with different issues, these groups tended to have the same people at their core, with an everchanging constellation of outer-level individuals. When I left Edmonton, this activist community carried on and I assumed the core would be maintained as it had been over the last five years. However, returning after a year away, I noticed a number of

\footnotetext{
5 So powerful was this company intimidation, that while we were waiting alone in the meeting room, Nicole and I both assumed we were being recorded and moderated our discussion topics accordingly. This assumption was also influenced by experiences with others who have interacted with large mining companies and been subject to surveillance.
} 
changes. I chose to refrain from contacting people so that my presence wouldn't affect their participation in events (cf. Labov, 1972). In this way, I could begin to gauge the level of political involvement. To my dismay, I recognised very few of the activists who were present and I soon discovered that the atmosphere had changed dramatically with the rise of the Occupy movement. 6

Individuals in this movement, a number of them new to activist work, had been exhibiting problematic behaviour entrenched in misogyny and racism during meetings. This resulted in many core members feeling alienated or even at risk, causing them to retreat into other communities. Additionally, some key activists had left town and moved to other provinces to continue their work and some had even succumbed to fatigue and depression, forcing them to withdraw from the movement entirely. Internal conflicts had divided the community further and the Canadian election with its resulting Conservative majority and cuts to social programs had affected life on the ground for many. This combination of changes meant that the community I had left was no longer as I had assumed it would be. Its core members seemed to be scattered in other directions and it wasn't until I reintegrated with cycling advocates and queer communities that I found them again.

This intersectionality was nicely exemplified by an event run by queer advocates that was held in a community cycle shop warehouse. The 'DIY' dance party was organised by a group seeking to educate community members on antioppression while (re)building relationships.

\footnotetext{
6 Occupy, a resistance movement developed partly in response to the economic crisis, began in New York with the occupation of Gezi Park and subsequently spread internationally.
} 
On Saturday evening I went to the dance party - which was the event that Leeane and Jason have been preparing for. The event's function was to help create a fun, close-knit community that is also working to eliminate oppressive spaces. I saw most of my activist friends at the dance party which was really great. It seems there's a lot of work being done now on community-building and resilience. (June 17, 2012, FN)

In this case, my ethnographic practice allowed me to rediscover the local situation, while affording me the analytical distance (Hammersley, 2007) to recognise the changes that had occurred. Approaching my own community from the outside was in a way an ideal positioning: I had access as someone who had once been a core group member, but I also had distance as someone who was reentering from time away (cf. King, 2011).

\subsubsection{The Researcher: Stepping Back}

However, my re-entry as researcher brought with it difficult issues. In the past I had also been positioned as a student but this time the role was much more formalised as it represented the official reason for my return. Additionally, because my work was ethnographic, I was perceived to be always researching, whether video recorders were present or not. This made many of my interactions awkward at best and I had constantly to negotiate and even compensate for my newfound researcher identity. This was exemplified one evening when out cycling in a large group event. I had recently heard about a 'Green Bloc' that would be appearing in the Edmonton Pride Parade march to counter the use of LGBTQ+ Discourses by the Ethical Oil campaign (see Chapter 7):

I had gone to the symphony ride the night before and seen Caroline. I told her I was coming and it was great for my research and she said "oh...so you're gonna study us?" I was like, "well, yes, but also march with you". I felt very awkward (June 11, 2012, FN)

Here, my interaction with an old friend brought my researcher identity to the foreground. By 'accusing' me of studying people, my new outsider role was made 
explicit, as well as the historical academic practices which make vulnerable groups uncomfortable (Smith 1999). By expressing interest in the Green Bloc as something relevant to my work, I may have subtly positioned myself on the outside looking in. Caroline picked up on and explicitly showed this positioning through her accusation, in a way 'calling me out' on my action of othering my colleagues. This created an uncomfortable situation for me, as I had to quickly negotiate my place in relation to the group, essentially choosing whether I was in or out. My reply shows that I positioned myself as a researcher but also a community member, by deciding to march with the group. Although in some situations, such behaviour might be considered less analytical in terms of 'objectivity' (Cameron, Frazer, Harvey, Rampton, \& Richardson, 1993, p. 86), the deeper relationships which must be negotiated are an important part of such decisions (Fincham, 2006).

When seeking individuals to interview, I had some issues despite the fact that my relationships with most in the community were very solid. In fact, it was these previous relationships which stopped me from pushing for access and following up on failed contacts.

I've emailed Denise twice and heard nothing and, even though I have her phone number, I am afraid to bother her. I've also emailed Adriana and not heard back. I feel more comfortable bugging someone like Tom because he is not an impacted community member who has been made to tell his story over and over and he also expressed interest in the project ages ago. I think I've done well for interviews so far but at the moment all my interviewees are white. This is not good. But I am having access issues in both directions up to industry and down to impacted communities. I have to remember that these are people, they are my friends, and they have lives that are impacted by what I am doing. It may cause disturbances in the relationship I do have if I push this too far (June 27, 2012, FN)

Again, I felt uncomfortable that there was little ethnic diversity in the interviews I had done already. Had I not known the contacts before my visit to Canada, I may have been more direct in my request for interviews. However, as mentioned, these 
potential interviewees were also my friends and I was very aware that my behaviour as an academic could spill over and affect our relationships (see Jones \& Jenkins, 2008 for more on the colonising nature of demanding knowledge). My behaviour as an academic no doubt has affected our relationships, but it was the potential negative effects which were a constant worry and thus influenced my actions.

Being accountable to a host or home community adds another layer of positioning difficulty (Cameron et al., 1993; Emihovich, 2005; O'Connor, 2007; Smith, 1999). I knew I would interact with participants again as a non-researcher and so my behaviour as an academic needed to be kept in check at times. Because I was always 'on', I also needed to balance my expressions of genuine research interest with expressions of genuine relationship interest, which would often overlap. And so, although re-entering an old community brings advantages of access, it also brings its own issues of positioning.

\subsubsection{The Activist: Going Undercover}

Negotiating my academic identity took on new challenges when I traveled to Fort McMurray for a tour of the mines. I brought with me a newfound colleague, Tina, who traveled up to Alberta from Washington DC. She had been involved in nonviolent civil disobedience surrounding the Keystone $\mathrm{XL}$ pipeline protests at the White House and was keen to see the mines and surrounding area for herself. She had had trouble finding people to travel with her and had been told by a local First Nations activist that it was not a tourist destination but rather a depressing, upsetting and tremendously expensive trip. When Nicole decided not to come north because of the poor prospects for interviews, I asked Tina to join me. This was a useful decision as she provided me with a fresh perspective and a safe traveling partner. We camped together in Gregoire Lake outside of town and rented a minivan which we used to travel in and out of Fort McMurray and north towards the mines. 
The mine tour which we joined was led by Fort McMurray Tourism in partnership with mining companies and there were about forty people on our bus. Each bus seat had an individual pamphlet for the tourists to read: the CAPPproduced Upstream Dialogue (as discussed briefly in section 6.2). The vast majority of the tourists were Canadian (as was revealed by the tour operator's first question) and many had family members working in the mines. We were taken into the mining area where we could see various processes including the removal, extraction, and upgrading of bitumen. The tour finished with a visit to reclamation sites, where companies' environmental values and practices are presented (see section 6.1.1 and 6.1.2). In one of these reclaimed areas, Tina began conversing with an older couple:

Someone asked Tina why we were taking notes and she told him that we were doing research and that "they don't show you everything on these tours". She also used the word tar sands ${ }^{7}$ and I felt really worried. I asked her what had happened and told her that I wanted to remain low key so as not to draw attention to ourselves. She apologised for "outing" us and I explained some of the reasons why I was worried. I think my experience in New Zealand has made me extremely wary of these companies and what l'm doing. Also, we were surrounded by "petro tourists" who probably would not take kindly to our criticisms. I had neither the energy nor the confidence to challenge the incredible machine and resources being brought to bear on this issue here (June 24, 2012, FN)

My reaction was to pull Tina aside and explain that I didn't want to be 'outed' in this place. My past experience with discussing the Athabasca tar sands had almost always resulted in the dreaded question "which side are you on?" and I was hesitant to position myself amongst industry actors while physically standing on mined ground. In fact, so strongly did I feel about this that I adapted my own language use, avoiding the term tar and instead using oil sands (see section 1.5.1). Tina immediately understood my concerns and from that point onwards we managed to safely and successfully interact without forcing our positions. In fact,

\footnotetext{
${ }^{7} \mathrm{~A}$ term which conveyed a specific political position, as discussed in section 1.5.1.
} 
Tina very skillfully maneuvered through this discursive territory when we were driven by the car rental company back through town to the bus station:

The man who drove us there began asking us questions about why we were visiting. He was surprised to learn we had been camping and wouldn't believe we were up in Fort Mac just to camp. Tina said she was here to see the oil sands and he asked if we were anti or pro oil sands. Tina said she wasn't sure and was just interested and he asked if he could "educate" us and said "they're actually really clean" (June 27, 2012, FN)

In this situation, I felt the need to manage both mine and Tina's positioning, lest she draw unwanted attention to our presence by arguing against the mining tour's presentation. In remaining neutral, we were both able to elicit local feedback and gain a better understanding of the state of mining attitudes in Fort McMurray.

\subsection{Resources for Positioning}

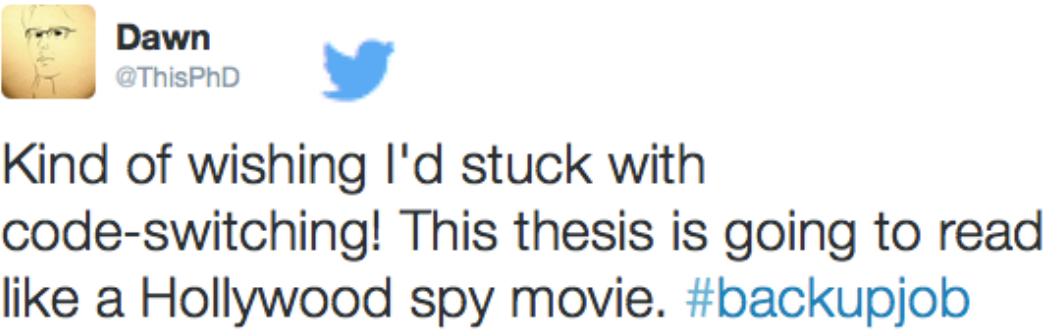

2:31 PM - 15 Mar 2012

Through the above narratives, I have illuminated some of the challenges I faced in my own fieldwork in terms of taking up and negotiating various positions. As researchers, we should be aware of the academic roles we embody, while also managing feelings of ignorance when entering a community of participants (Sarangi \& Candlin, 2003). Because ethnographic work means approaching a community as we find it, researchers should ultimately give up a level of control, and make carefully considered decisions when in the field (Blommaert \& Jie, 2010). 
Throughout my fieldwork experience, I was forced to balance various roles and alignments and was made (sometimes painfully) aware of my own positioning in relation to my participants. As ethnographers, we often draw upon non-academic resources from other aspects of our lives in order to manage these difficult positionings (e.g. Fincham, 2006). Additionally, because I bring a multimodal and CDA orientation to data collection, I became aware of and developed skills based on those approaches. Consequently, I feel it is important to recognise the various embodied ways we 'do data collection'. For example, sitting comfortably within discomfort (Blommaert \& Jie, 2010) is a crucial skill that I have developed (and continue to practice) during this research. My physical presence in many of the spaces I found myself was often controversial and there were times I felt nervous and worried about how I was perceived (see hooks, 2003, p. 114 for a discussion on space and privilege). I have also used skills I learned living in other countries as an outsider, including my ability to speak and write in a dialect of Swiss German.

"I think my exchange year was extremely helpful in preparing me for ethnographic fieldwork. The practice of blending in, following others around... always saying yes to opportunities to spend with participants, not hesitating to engage, these are all skills I developed in my year in Switzerland. I hadn't realised until recently that such ethnographic skills seem to come naturally to me, because l've actually done ethnography before! My entire year living abroad can be seen as a pilot study to prepare myself for just such a project as this...l learned on that exchange year that to understand a culture and a community properly, you must engage and become involved - even if it is outside your comfort zone" (April 29, 2012)

I am also able to read others and think and act quickly on my feet, possibly due to years of improvising as a jazz pianist and interacting with other performers. Additionally, my time spent in meditation training has helped me develop my skills of observation and self-awareness. Even my co-researcher Nicole has been an important resource for me, acting as (embodied) support during fieldwork. Although not typically considered part of academic work, these resources are not trivial. In 
fact, because all ethnographic work involves the unexpected (Blommaert \& Jie, 2010), it is necessary for ethnographers to use what tools are available to them at the time. Above all, I found my fieldwork to be exhausting in part due to the fact that as an ethnographer, one is 'always on' in the sense that data collection is continuous (Blommaert \& Jie, 2010; Fincham, 2006). Whether I was cycling with friends, swinging a hammer, walking through a mine, or dancing at a community event, I was constantly negotiating my positioning as researcher, student, activist, or friend. Chaos and learning are essential parts of ethnographic work, where individuals slowly begin to understand the world around them in a way that makes patterns more clear and logical (Blommaert \& Jie, 2010). Within this sense of chaos, one should be able to improvise, make quick decisions, and, to a certain extent, give up some control. Where to draw these lines between chaos and control, researcher and participant, is a skill that is learned over time. 


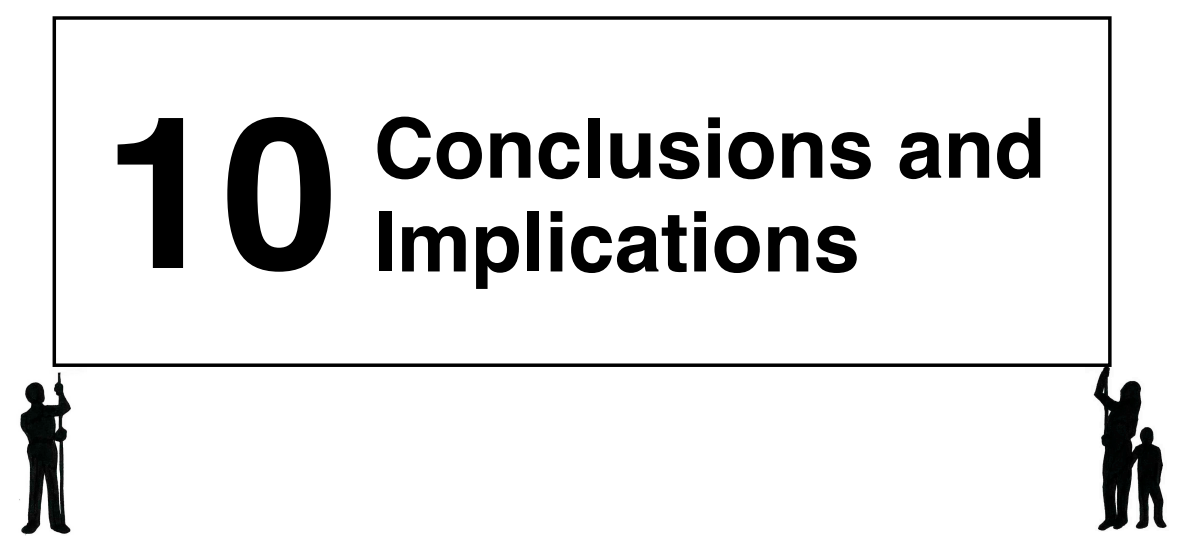

s demonstrated in this thesis, the Athabasca tar sands and the Southland
lignite mine both go 'beyond greenwash' in the appropriation and resistance of Discourses. These dynamics are reflective of wider power structures and so I have examined these controversial mining projects as sites of inequality and struggle. My aim was to track the appropriation and resistance of Discourses between industry interests and activist actors from a multimodal perspective. Throughout the analysis, I have shown how Discourses of the environment, the economy, regional identities, Indigenous rights, and LGBTQ+ struggles are appropriated, resisted, and further entextualised.

I have adopted a Critical Discourse Analysis (CDA) approach, in order to investigate the negotiation of power (Van Dijk, 1993) in mining debates. To this end, I have videorecorded 19 interviews with both industry actors and activists, and collected artefacts (pamphlets, newsletters, etc.) relevant to each case. As a critical analyst, I have sought to 'denaturalise' the natural (Fairclough, 1995, p. 36) and have taken into account the ways that Discourse both affects, and is affected by, wider sociopolitical structures (Blommaert, 2005). Additionally, I have considered input from Indigenous research agendas (Denzin, Lincoln, \& Smith, 2008; Smith, 1999) and adopted an ethnographic approach of reflexivity (Blommaert \& Jie, 2010; Sarangi \& Candlin, 2003) (Chapter 9). This has also allowed me to engage with the complexity of each case study (Blommaert \& Jie, 2010) and to link 
language and action to larger sociocultural structures through my interpretations (Rampton, 2007).

Additionally, this thesis has built upon theories of CDA by including multimodal data in the form of interviews and collected artefacts. In order to examine these, I conceptualised my wider approach as a combination of overlapping lenses which highlight the multimodal, ethnographic, and critical perspectives I adopt (see Figure 2.8). Using these lenses, I investigated the concepts of multimodal entextualisation and creativity in the Discourses surrounding controversial mining sites in Canada and Aotearoa/New Zealand, interrogating the following questions:

\section{What types of Discourses are appropriated in the marketing of the fossil fuel industry and how is this accomplished? \\ 2. How is Discourse appropriation by the fossil fuel industry creatively resisted by the climate justice movement?}

\section{Within environmental Discourses, how do the dialectics of appropriation, recontextualisation, and resistance play out multimodally?}

Through the use of Multimodal Interaction Analysis (MIA) and Social Semiotics (SS), I have shown the ways that Discourses are entextualised multimodally through action as a unit of analysis (cf. Norris, 2011). By interviewing both activists and industry representatives in Canada and Aotearoa/New Zealand, as well as collecting artefacts at each site, I have analyzed both micro actions in interaction and macro Discourses through design. Using these methodological tools, I have responded to the first research question by showing how various Discourses are appropriated in the marketing of the fossil fuel industry. In both case studies, Discourses of the environment and the economy are used on either side of the debate, which leaves many individuals feeling as if they are trapped in between two opposing Discourses (Chapter 4). Discourses of regional identity (both Alberta and Southland) are also appropriated by industry actors in attempts 
to legitimise expansion and are subsequently resisted and re-contextualised (Chapter 5). These identity Discourses are thus strong resources for both industry actors and activists. In Alberta, further Discourses are appropriated, including Indigenous and LGBTQ+ identity (Chapters 6 and 7). It also seems that industry actors (most notably those behind the 'Ethical Oil' Campaign), have begun appropriating wider Discourses of intersecting oppressions in a case of "ornamental intersectionality" (Bilge, 2013) (as discussed in Chapter 7).

However, the responses to these appropriations are both skillful and creative. In addressing the second research question, I have shown how activists in Canada and Aotearoa/New Zealand resist and re-appropriate Discourses of economy, and regional, Indigenous, and LGBTQ+ identities. This has been accomplished with the extensive use of creativity and ludic play (Bakhtin, 1981; Shepard, 2011) through naming and mocking individual industry actors (Chapter 8 ). In both cases, the continuous resistance to appropriated Discourses suggests that industry actors have been forced to appropriate new Discourses in attempts to regain legitimacy in the face of opposition. This 'discursive arms race' has resulted in the use of Discourses which link less directly to oil, such as the struggle for LGBTQ+ rights in Canada (Chapter 7). Although the case in Southland did not develop quite so far, similar Discourses were appropriated and resisted, suggesting a wider temporal order to such marketing strategies. Comparing the two case studies, we may be able to predict which Discourses might be appropriated in other environmental struggles (Chapter 8). Ultimately, the attempts to appropriate these wider Discourses can be read as a weakening of the fossil fuel industry's legitimacy.

Additionally, the appropriation and resistance of Discourses has been decidedly multimodal. To answer the final research question, I have shown how both industry actors and activists make use of designed artefacts and draw upon ideas relating to colour, layout, font, etc. to further their arguments and link Discourses together (Chapter 7). In interaction also, social actors entextualise wider Discourses through densely connected lower-level actions such as gaze, gesture, and postural shifts. Most notably, activists make skilled use of a variety of 
multimodal actions to adopt industry and government personas in 'mundane performances' (Coupland, 2007) which allow for humorous critique of powerful actors. Importantly, these multimodal meanings are collaboratively achieved by all interlocutors.

The unique approach of this thesis has resulted in a number of implications for further research. These include theoretical and analytical implications, as well as contributions to discussions surrounding multimodal data collection, presentation, and community outreach. These are summarised below.

\subsection{Theoretical Implications}

Through the analyses in Chapters 4-7, I have shown how multimodal features may add, or even change, meaning (consider Andrea's facial expression accompanying her phrase purely Albertan in Figure 5.11). This recognition is not new (cf. Norris, 2011), but its application to environmental debates is, to the best of my knowledge, a novel undertaking. Additionally, a multimodal approach has allowed me to see how speakers may use modes in interaction to help conceptualise ideas (such as William's gestural conception of intersectionality in Figure 7.13) or emphasise a point (e.g. building modal density to co-occur with spoken utterances). This approach has also allowed me to analyse the ways that social actors construct their opposition through a variety of modes, whether it is through colour and digital alteration (e.g. Jack Fischer as a devil in Figure 8.7) or the complicated, interactive gestural depiction of satirical characters (e.g. Denise's robotic government worker in Figures 8.10, 8.11, 8.12).

Conversely, approaching multimodal analyses based on a critical perspective helps shed light on how actions might influence and be influenced by wider social structures. MIA has been useful in illuminating how modes help construct more isolated interactions (Kuśmierczyk, 2013; Norris, 2011), however, this thesis has expanded this scope to analyse interaction within the larger context of Discourse appropriation and resistance. This has helped to illuminate links 
between the micro action and the wider macro Discourse (e.g. Alanis' 'weighing' gesture, which suggests she is stuck between the 'economic' and the 'environmental' in Figure 4.3).

\subsection{Analytical Implications}

This thesis integrated a novel combination of analytical approaches. Polarised environmental debates occurring around controversial mining projects like the cases presented in this thesis, tend to be characterised by the production of designed artefacts. Both sides create pamphlets, buttons, information sheets, etc. to further their arguments and the inclusion of these was therefore necessary to gain a broader understanding of Discourse appropriation and resistance in each case. Moreover, both recorded interviews and collected artefacts helped me to multimodally navigate the micro-level of interaction and the macro-level of design. However, I struggled to conceptualise how I might analyse these two very different data sets within a unifying multimodal paradigm. MIA is ideally suited to analyse the typical dyad interaction of interviews (cf. Kuśmierczyk, 2013), however, it is less than ideal for interrogating the designed nature of produced artefacts. Similarly, Social Semiotics is an exemplary tool for understanding visual communication in the form of artefacts (cf. Kress \& Van Leeuwen, 2006), but has a less developed focus on bodily interaction (McDonald, 2013). I therefore used both MIA and Social Semiotics as analytical tools, the combination of which has allowed for a deeper understanding of multimodal meaning-making at various discursive levels. Further research in areas where designed artefacts play a large role in framing interactions (such as political or classroom discourse) might consider utilising such a multimodal methodological approach. In light of the ways in which contemporary communication is becoming increasingly multimodal with the incorporation of technologies and online social networks (see Blommaert, 2012), an analytical approach that integrates designed artefacts and embodied interaction may become more common. 


\subsection{Implications for Data Collection and Presentation}

Due in part to the polarising nature of the mining debates in each case study, collecting data for this research often required an ability to 'sit comfortably in discomfort' and to carefully consider my own behaviours. In the previous chapter (9), I discussed the difficulties and ways in which I managed the various positionings I experienced during fieldwork. Unpacking and discussing these (cf. Harré \& Langenhove, 1991) has helped me to further engage in a reflexive analysis of my own work. It is apparent that I drew upon unconventional resources (such as language skills, and even other researchers) in order to navigate the complex myriad of positionings in which I found myself. Additionally, it became clear to me that I myself was also being observed and problematised by my participants, whether they were industry actors or activists.

This thesis also builds upon processes for the presentation of multimodal data. Transcription as a presentation tool has been discussed in this thesis (section 3.5.2) as well as elsewhere (Bucholtz, 2000; Jenks, 2011; Ochs, 1999), and many methods of representation have been proposed (see Bezemer \& Mavers, 2011; Jenks, 2011). In this thesis, I have presented interview data using a split-screen method, overlain with arrows and spoken transcripts (cf. Kuśmierczyk, 2013). Additionally, because a number of my recordings were completed in less than ideal conditions where gestures or facial expressions were difficult to re-produce as video stills, I supplemented these transcripts with hand-drawn renditions (e.g. Figure 5.8) (cf. Kendon, 2004). In this way, I was able to portray movement or expressions which would be otherwise illegible as stills, while still protecting the anonymity of my participants. This combination of transcription practices means I could make use of the various affordances that different modes of representation carry (cf. Bezemer \& Mavers, 2011). With the addition of ethnographic fieldnotes, Twitter updates, and conceptual drawings, I was able to extend my representational 'reach' (cf. Kress, 2011, p. 249) to further echo the complexity and richness of my data. 


\subsection{Implications for Activists}

Adopting a CDA approach, means that I have conducted this study with an aim to empower communities of struggle who are resisting mining on their lands. Critical analysts are encouraged to do research which will have social impact (Blommaert, 2005; Wodak \& Fairclough, 2010) and the work is then "measured by its effectiveness and relevance, that is, by its contribution to change" (Van Dijk, 1993, p. 253). As a result, the implications of this research for environmental justice advocates are an important aspect of this work, in part because "what can be told depends on how one can tell it" (Blommaert, 2005, p. 60). However, as critical scholars we must also be vigilant about who is using our resulting analyses and for what purpose (Fairclough, 1995, pp. 82, 83). Consequently, the results of this research may be appropriated by systems of power and used to further the legitimation of the fossil fuel industry (cf. Eades, 2004). However, this analysis has uncovered a potential weakness in the mining industry's discursive armour; namely, the need for marketers to appropriate Discourses from further afield in order to legitimise development. In consideration of this, it seems that making available this thesis' remarks about the 'discursive arms race' in mining debates would be better shared than withheld. As Fairclough notes, such analysis "can therefore be an important political resource" (Fairclough, 1995, p. 209), especially for communities of resistance.

It is also important, however, to leave agency in the hands of those most affected (Fairclough, 1995), and to adapt the genre and structure of information to be relevant to community needs (Cameron, Frazer, Harvey, Rampton, \& Richardson, 1993; Smith, 1999). I will therefore aim to make this research available in the form of workshops based in theories of social liberation and anti-oppression (cf. Freire, 1970; hooks, 2003), which many of the activist communities with which I have worked employ. Such an approach practices democratic pedagogy, where teaching and learning occur constantly, are available to all, and are "never confined solely to an institutionalized classroom" (hooks, 2003, p. 41). By rejecting the 'banking method' approach to pedagogy, students and teachers co-create 
knowledge through dialogue (Freire, 1970, pp. 61-62), and education becomes a "profound human transaction" (hooks, 2003, p. 43). CDA practitioners can make use of such pedagogical theories in order to facilitate Critical Language Awareness (CLA), helping others develop the capacity for reflexive language critique (Fairclough, 1995, p. 221). This capacity should be built from existing abilities through experiential learning where the possible social causes of individual and group experiences can be further explored (Fairclough, 1995, p. 226). Preliminary discussions about the potential for workshop materials based on this thesis with activist participants, both during and after data collection, have been met with enthusiasm. However, I do not present such a syllabus here, as the development of workshops should be carried out in collaboration with communities and according to their needs (Cameron et al., 1993; Fairclough, 1995, p. 232; Jones \& Jenkins, 2008; Smith, 1999).

The need remains, however, to present the work of this thesis in an accessible way. Based on practices common in activist communities, I plan to create a 'zine' to distribute amongst environmental justice groups in both Canada and Aotearoa/New Zealand. Typically self-made, small format publications, 'zines' provide a financially accessible outlet for critique (see Anderson \& Herr, 2007). Additionally, as a genre situated within Do-it-Yourself (DIY) culture and activism, 'zines' are an ideal method for distributing the results of this thesis to communities who work on the front lines of environmental debates. Such a project also presents a new opportunity to further multimodally entextualise this thesis into a format that is community-specific, inexpensive, and engaging.

\subsection{Further Research}

As this thesis has shown, debates surrounding controversial mining projects go beyond greenwash, as wider Discourses of social struggles and identities are both appropriated and resisted multimodally by activists and industry actors. A possible next step in this research would be an examination of Discourse appropriation and resistance amongst other actors (e.g. the 'public'). As a group 
that is often the implied audience for those struggling to both legitimise and resist expansion (see Denise's comments about getting the public onside in section 6.5), further research is needed to understand how the multimodal communication strategies outlined in this study might be (un)successful. Incorporating different social actors would illuminate more of the complexities in these situations.

Research in this area also has practical implications. Understanding of, and engagement in, discussions about resource development will become more important as climate change becomes more intense, and as fossil fuel industries lose legitimacy. Critical voices are needed to question assumptions and illuminate the roles that power and domination play in these debates (cf. Van Dijk, 1993). Hence, the future study of controversial resource projects provides a valuable opportunity for critical scholars to engage with communities of struggle and contribute to positive social change (Blommaert, 2005).

There is also great potential for further research into the extent of Discourse appropriation/resistance in other cases, be they mining projects, oil drilling, or newer controversial technologies such as fracking (Rising Tide North America \& Carbon Trade Watch, n.d.). Another avenue for research may involve the investigation of Discourses surrounding more conventional extraction practices (e.g. traditional pump-jack oil drilling in Alberta), and it may be fruitful to compare such a study with the non-conventional fossil fuel projects explored in this thesis. Newer, more 'sustainable' energy production case studies (e.g. wind turbines, solar panels) may also provide insights into the dialectics of Discourse appropriation and resistance between opponents.

\subsection{Closing Remarks}

On a personal note, this research has allowed me a deeper understanding of the sociopolitical issues surrounding fossil fuel development in general. As an affected participant in these debates, I have at times needed to step back from the controversies and allow myself time and space to recover. For this, I am most 
grateful to my activist community in Alberta, who have highlighted the need to care for others, but also ourselves, in difficult times. Reflecting on how my fieldwork unfolded, I see that it has also had a profound impact on myself and the subsequent writing of this thesis. Above all, on both sides of the debate and on both sides of the world, industry representatives and activists have been welcoming, and many have opened their homes to me as well. I am indebted to their hospitality and also to their willingness to engage with such difficult issues in my presence.

This thesis has investigated the ways that Discourses are appropriated and resisted in controversial mining debates in Canada and Aotearoa/New Zealand. More specifically, I have examined how various Discourses are multimodally entextualised by industry and activist actors through analysis of both interviews and collected artefacts. In this enterprise, I have used a critical, multimodal perspective coupled with Multimodal Interaction Analysis and Social Semiotics as analytical tools. The findings of this thesis suggests that these debates go 'beyond greenwash' to incorporate a number of wider Discourses, resulting in a 'discursive arms race' in attempts to both extend and challenge the fossil fuel industry's legitimacy. Ultimately, this thesis has implications for researchers and environmental justice activists alike, and may be applied in the pursuit of positive social change. 


\section{References:}

Adam J. Barker. (2009). The contemporary reality of Canadian imperialism: Settler colonialism and the hybrid colonial state. The American Indian Quarterly, 33(3), 325351. doi:10.1353/aiq.0.0054.

Ählström, J., Macquet, M., \& Richter, U. (2009). The lack of a critical perspective in environmental management research: Distortion in the scientific discourse. Business Strategy and the Environment, 18(5), 334-346. doi:10.1002/bse.592.

Reclaiming Alberta's Oil Sands. (2010). Retrieved April 25, 2014, from http:// www.environment.alberta.ca/02012.html.

Alexander, R. (2008). Framing discourse on the environment: A critical discourse approach. Routledge.

Allori, P. E. (2011). Corporate identity and image promotion through sponsoring international sports events. A view from the web. In G. Garzone \& P. E. Allori (Eds.), Discourse, identities and genres in corporate communication: Sponsorship, advertising and organizational communication (pp. 75-97). Peter Lang.

Anderson, G. L., \& Herr, K. G. (Eds.). (2007). Zines. In Encyclopedia of activism and social justice (Vol. 3, pp. 1513-1515). Thousand Oaks, CA: SAGE Reference.

Babad, M. (2013). Neil Young on oil sands: "Fort McMurray looks like Hiroshima." The Globe and Mail. Retrieved February 5, 2014, from http://www.theglobeandmail.com/ report-on-business/top-business-stories/neil-young-on-oil-sands-fort-mcmurray-lookslike-hiroshima/article14213233/.

Bäckstrand, K., \& Lövbrand, E. (2007). Climate governance beyond 2012: Competing discourses of green governmentality, ecological modernization and civic environmentalism. In M. E. Pettenger (Ed.), The social construction of climate change: Power, knowledge, norms, discourses (pp. 124-147). Ashgate.

Baker, P. (2010). Sociolinguistics and corpus linguistics. Edinburgh University Press.

Baker, P., Gabrielatos, C., KhosraviNik, M., Krzyzanowski, M., McEnery, T., \& Wodak, R. (2008). A useful methodological synergy? Combining critical discourse analysis and corpus linguistics to examine discourses of refugees and asylum seekers in the UK press. Discourse \& Society, 19(3), 273-306. doi: 10.1177/0957926508088962.

Bakhtin, M. (1981). The dialogic imagination : Four essays. Austin: University of Texas Press. 
Barnard, I. (2006). Anti-ethnography? Composition Studies, 34(1), 95-107.

Barrera, J. (2013). Idle No More, Defenders of the Land form alliance, call for "Sovereignty Summer." APTN National News. Retrieved from http://aptn.ca/news/ 2013/03/18/idle-no-more-defenders-of-the-land-form-alliance-call-for-sovereigntysummer/.

Battiste, M. (2008). Research ethics for protecting indigenous knowledge and heritage: Institutional and researcher responsibilities. In N. K. Denzin, Y. S. Lincoln, \& L. T. Smith (Eds.), Handbook of critical and indigenous methodologies (pp. 497-509). Sage.

Bavelas, J. B., Chovil, N., Lawrie, D. A., \& Wade, A. (1992). Interactive gestures. Discourse Processes, 15(4), 469-489. doi:10.1080/01638539209544823.

Bell, A. (1984). Language style as audience design. Language in Society, 13(02), 145204. doi:10.1017/S004740450001037X.

Berman, T. (2006). The rape of mother nature? Women in the language of environmental discourse. In P. Muhlhausler \& Fill, Alwin (Eds.), Ecolinguistics reader: Language, ecology and environment (pp. 258-269). Continuum.

Bezemer, J., \& Mavers, D. (2011). Multimodal transcription as academic practice: A social semiotic perspective. International Journal of Social Research Methodology, 14(3), 191-206. doi:10.1080/13645579.2011.563616.

Bilge, S. (2013). Intersectionality undone: Saving intersectionality from feminist intersectionality studies. Du Bois Review, 10(2), 405-424. doi:10.1017/ S1742058X13000283.

Billig, M. (1999). Conversation analysis and the claims of naivety. Discourse \& Society, 10(4), 572-576. doi:10.1177/0957926599010004005

Biloslavo, R., \& Trnavcevic, A. (2009). Web sites as tools of communication of a "green" company. Management Decision, 47(7), 1158-1173. doi:

10.1108/00251740910978359.

Binnema, T., \& Hutchings, K. (Kevin D. (2005). The emigrant and the noble savage: Sir Francis Bond Head's romantic approach to Aboriginal policy in Upper Canada, 1836-1838. Journal of Canadian Studies/Revue D'études Canadiennes, 39(1), 115138. doi: 10.1353/jcs.2006.0002.

Biofuelwatch. (2011). Biochar: A critical review of science and policy. Retrieved from http://www.biofuelwatch.org.uk/wp-content/uploads/Biochar-Report3.pdf. 
Blay, J. (2011). Alberta's woodland caribou now endangered, scientists say. Peace River Record Gazette. Retrieved from http://www.prrecordgazette.com/2011/08/23/ albertas-woodland-caribou-now-endangered-scientists-say.

Blommaert, J. (2005). Discourse: A critical introduction. Cambridge University Press.

Blommaert, J. (2007a). On scope and depth in linguistic ethnography. Journal of Sociolinguistics, 11(5), 682-688. doi:10.1111/j.1467-9841.2007.00346.x.

Blommaert, J. (2007b). Sociolinguistics and discourse analysis: Orders of Indexicality and Polycentricity. Journal of Multicultural Discourses, 2(2), 115-130. doi:10.2167/ md089.0.

Blommaert, J. (2010). The Sociolinguistics of globalization (1st ed.). Cambridge University Press.

Blommaert, J. (2012). Supervernaculars and their dialects. Dutch Journal of Applied Linguistics, 1(1), 1-13.

Blommaert, J., \& Jie, D. (2010). Ethnographic fieldwork: A beginner's guide. Bristol ; Buffalo: Multilingual Matters.

Blommaert, J., \& Varis, P. (2013). Enough is enough: The heuristics of authenticity in superdiversity. In Duarte, J. \& Gogolin, I (Eds.), Linguistic superdiversity in urban areas: Research approaches (pp. 143-160). John Benjamins. doi: 10.1075/hsld. 2.10blo.

Briggs, C. L. (1986). Learning how to ask: A sociolinguistic appraisal of the role of the interview in social science research. Cambridge: Cambridge University Press.

Bucholtz, M. (2000). The politics of transcription. Journal of Pragmatics, 32(10), 14391465. doi:10.1016/S0378-2166(99)00094-6.

Bucholtz, M., \& Hall, K. (2005). Identity and interaction: A sociocultural linguistic approach. Discourse Studies, 7(4-5), 585-614. doi:10.1177/1461445605054407.

Buhr, N. (2012). Indigenous Peoples: Accounting and accountability. Social and Environmental Accountability Journal, 32(2), 59-63. doi:10.1080/0969160X. 2012.718897.

Burton, B. (2008). Inside spin: The dark underbelly of the PR industry. Allen \& Unwin.

Cameron, D., Frazer, E., Harvey, P., Rampton, B., \& Richardson, K. (1993). Ethics, advocacy and empowerment: Issues of method in researching language. Language and Communication, 13(2), 81-94. doi: 10.1016/0271-5309(93)90001-4. 
Cannella, G. S., \& Manuelito, K. D. (2008). Feminisms from unthought locations: Indigenous worldviews, marginalized feminisms, and revisioning an anticolonial social science. In N. K. Denzin, Y. S. Lincoln, \& L. T. Smith (Eds.), Handbook of critical and indigenous methodologies (pp. 45-59). Sage.

Capelli, C. A., Nakagawa, N., \& Madden, C. M. (1990). How children understand sarcasm: The role of context and intonation. Child Development, 61(6), 1824-1841. doi:10.1111/j.1467-8624.1990.tb03568.x.

Carbado, D. W., Crenshaw, K. W., Mays, V. M., \& Tomlinson, B. (2013).

Intersectionality: Mapping the movements of a theory. Du Bois Review: Social Science Research on Race, 10(02), 303-312. doi:10.1017/S1742058X13000349.

Carney, D. R., Hall, J. A., \& LeBeau, L. S. (2005). Beliefs about the nonverbal expression of social power. Journal of Nonverbal Behavior, 29(2), 105-123. doi: 10.1007/s10919-005-2743-z.

Carvalho, A. (2005). Representing the politics of the greenhouse effect: Discursive strategies in the British media. Critical Discourse Studies, 2(1), 1-29. doi: 10.1080/17405900500052143.

Catenaccio, P. (2011). Representations of corporate philanthropy: A linguistic approach. In G. Garzone \& P. E. Allori (Eds.), Discourse, identities and genres in corporate communication: Sponsorship, advertising and organizational communication (pp. 121-142). Peter Lang.

CBC. (2009a). Fort Chip cancer rates higher than expected. Retrieved August 23, 2011, from http://www.cbc.ca/news/health/story/2009/02/06/edm-fort-chip-cancer.html.

CBC News. (2009b). Greenpeace buries $\$ 600$ to protest carbon capture spending. Retrieved May 13, 2014, from http://www.cbc.ca/1.779351.

CBC News. (2014). Mock wedding for National Day of Action held at legislature steps. Retrieved May 12, 2014, from http://www.cbc.ca/1.2638773.

Chappell, D. (2000). Active agents versus passive victims: Decolonized historiography or problematic paradigm? Voyaging through the Contemporary Pacific, 205-28.

Chase, S. (2011). Harper's embrace of 'ethical' oil sands reignites "dirty" arguments. The Globe and Mail. Retrieved August 23, 2011, from http://www.theglobeandmail.com/ news/politics/harpers-embrace-of-ethical-oil-sands-reignites-dirty-arguments/ article1862499/.

Chastko, P. (2004). Developing Alberta's oil sands (1st ed.). University of Calgary Press. 
Chilton, P., \& Schaffner, C. (2002). Politics as text and talk: Analytic approaches to political discourse. Amsterdam/Philadelphia: John Benjamins.

Cho, S. (2013). Post-intersectionality: The curious reception of intersectionality in legal scholarship. Du Bois Review, 10(2), 385-404. doi:10.1017/S1742058X13000362.

Chouliaraki, L., \& Fairclough, N. (1999). Discourse in late modernity: Rethinking critical discourse analysis. Edinburgh: Edinburgh University Press.

Climate Justice Taranaki. (n.d.). About Us « Climate Justice Taranaki. Retrieved September 5, 2011, from http://climatejusticetaranaki.wordpress.com/about/.

Coates, J., \& Thornborrow, J. (1999). Myths, lies and audiotapes: Some thoughts on data transcripts. Discourse \& Society, 10(4), 594-597. doi:

$10.1177 / 0957926599010004015$.

Coupland, N. (2007). Style: Language variation and identity. Cambridge University Press.

Crenshaw, K. (1991). Mapping the margins: Intersectionality, identity politics, and violence against women of color. Stanford Law Review, 1241-1299. doi: $10.2307 / 1229039$.

Cresse, A., \& Blackledge, A. (2010). Towards a sociolinguistics of superdiversity. Zeitschrift Für Erziehungswissenschaft, 13(4), 549-572. doi:10.1007/ s11618-010-0159-y.

Davidson, D. J., \& Gismondi, M. A. (2011). Challenging legitimacy at the precipice of energy calamity. New York: Springer.

Degano, C. (2011). Linguistic perspectives on image construction and moral identity. The case of banks. In G. Garzone \& P. E. Allori (Eds.), Discourse, identities and genres in corporate communication: Sponsorship, advertising and organizational communication (pp. 235-260). Peter Lang.

Denzin, N. K., \& Lincoln, Y. S. (2008). Introduction: Critical methodologies and indigenous inquiry. In N. K. Denzin, Y. S. Lincoln, \& L. T. Smith (Eds.), Handbook of critical and indigenous methodologies (pp. 1-20). Sage.

Devauld, C., \& Green, L. (2010). "Don't throw anything away”: Greenwashing in public relations. Media Democracy and Change: Refereed Proceedings of the Australian and New Zealand Communications Association Annual Conference.

Di Chiro, G. (2011). Acting globally: Cultivating a thousand community solutions for climate justice. Development, 54(2), 232-236. doi:10.1057/dev.2011.5. 
Dicks, B., Soyinka, B., \& Coffey, A. (2006). Multimodal ethnography. Qualitative Research, 6(1), 77-96. doi:10.1177/1468794106058876.

Djonov, E. (2007). Website hierarchy and the interaction between content organization, webpage and navigation design: A systemic functional hypermedia discourse analysis perspective. Information Design Journal, 15(2), 144-162. DOI: 10.1075/idj.15.2.07djo.

Dorow, S., \& O'Shaughnessy, S. (2013). Fort McMurray, Wood Buffalo, and the oil/tar sands: Revisiting the sociology of "community". Canadian Journal of Sociology, 38(2), 121-140.

Duff, P. A. (2008). Language socialization, participation and identity: Ethnographic approaches. In Encyclopedia of language and education (pp. 860-872). Springer US.

Dunbar Jr., C. (2008). Critical race theory and indigenous methodologies. In N. K. Denzin, Y. S. Lincoln, \& L. T. Smith (Eds.), Handbook of critical and indigenous methodologies (pp. 85-99). Sage.

Eades, D. (2004). Understanding Aboriginal English in the legal system: A critical sociolinguistics approach. Applied Linguistics, 25(4), 491-512. doi:10.1093/applin/ 25.4.491.

Edelsky, C. (1981). Who's got the floor? Language in Society, 10(03), 383-421. doi: 10.1017/S004740450000885X.

Emihovich, C. (2005). Fire and ice: Activist ethnography in the culture of power. Anthropology and Education Quarterly, 36(4), 305-314. DOI: 10.1525/aeq. 2005.36.4.305.

Erickson, F. (2010). The neglected listener: Issues of theory and practice in transcription from video in interaction analysis. In J. Streeck (Ed.), New adventures in language and interaction (pp. 243-256). Amsterdam ; Philadelphia: John Benjamins Pub. Co.

EthicalOil.org. (2014). Listen to the Neil Young Radio Ads. Retrieved from http:// neilyounglies.ca.

Evans, J., \& Garvin, T. (2009). "You"re in oil country': Moral tales of citizen action against petroleum development in Alberta, Canada. Ethics, Place \& Environment, 12(1), 49-68. doi:10.1080/13668790902753070.

Fairclough, N. (1995). Critical discourse analysis: The critical study of language. England: Longman. 
Fairclough, N. (2003). Analysing discourse: Textual analysis for social research. London; New York: Routledge.

Fairclough, N. (2006). Semiosis, ideology and mediation: A dialectal view. In I. Lassen, J. Strunck, \& T. Vestergaard (Eds.), Mediating ideology in text and image: Ten critical studies (pp. 19-35). John Benjamins Publishing Company.

Fincham, B. (2006). Back to the "old school": Bicycle messengers, employment and ethnography. Qualitative Research, 6(2), 187-205. doi:10.1177/1468794106062709.

Flewitt, R., Hampel, R., Hauck, M., \& Lancaster, L. (2009). What are multimodal data and transcription? In C. Jewitt (Ed.), The Routledge handbook of multimodal analysis (pp. 40-53). London; New York: Routledge.

Fontaine, P., \& Farber, B. (2013). What Canada committed against First Nations was genocide. The UN should recognize it. The Globe and Mail. Retrieved May 18, 2014, from http://www.theglobeandmail.com/globe-debate/what-canada-committed-againstfirst-nations-was-genocide-the-un-should-recognize-it/article14853747/.

Fontana, A., \& Frey, J. H. (2005). Interviewing: The art of science. In N. K. Denzin \& Y. S. Lincoln (Eds.), The SAGE handbook of qualitative research (3rd ed., pp. 361-376). Sage Publications, Inc.

Forceville, C. \& Urios-Aparisi, E. (Eds.). (2010). Multimodal metaphor. Berlin: Mouton de Gruyter.

Foucault, M. (1980a). Truth and power. In C. Gordon (Ed.), Power/knowledge: Selected interviews and other writings (pp. 109-133). New York: Pantheon Books.

Foucault, M. (1980b). Two lectures. In C. Gordon (Ed.), Power/knowledge: Selected interviews and other writings (pp. 78-108). New York: Pantheon Books.

Fougère, L. (2013). Democracy in the face of disagreement: Environmentalist opposition to Escarpment Mine on the Denniston Plateau. Unpublished master's thesis, Victoria University of Wellington, Wellington, New Zealand.

Fox Tree, J. E., \& Schrock, J. C. (2002). Basic meanings of you know and I mean. Journal of Pragmatics, 34(6), 727-747. doi:10.1016/S0378-2166(02)00027-9.

Fozdar, F. (2008). Duelling discourses, shared weapons: Rhetorical techniques used to challenge racist arguments. Discourse \& Society, 19(4), 529. doi:

10.1177/0957926508089942.

Freire, P. (1970). Pedagogy of the oppressed. New York: Herder and Herder. 
Friedel, T. L. (2008). (Not so) crude text and images: Staging Native in "big oil" advertising. Visual Studies, 23(3), 238-254. doi:10.1080/14725860802489908.

Fumoleau, R. (2004). As long as this land shall last: A history of Treaty 8 and Treaty 11, 1870-1939. University of Calgary Press.

Garzone, G. (2011). Multiple sponsorships and advertising in the discursive construction of corporate identity. In G. Garzone \& P. E. Allori (Eds.), Discourse, identities and genres in corporate communication: Sponsorship, advertising and organizational communication (pp. 51-74). Peter Lang.

Gee, J. P. (1999). An introduction to discourse analysis: Theory and method. Psychology Press.

Geertz, C. (1973). The interpretation of cultures: Selected essays. Basic Books.

Giles, H., Coupland, J., \& Coupland, N. (1991). Contexts of accommodation: Developments in applied sociolinguistics. Cambridge University Press.

Gleeson, J. J. M. E. (2014). Is intersectionality a theory? The North Star. Retrieved February 7, 2014, from http://www.thenorthstar.info/?p=11928.

Glick, D. J. (2007). Some performative techniques of stand-up comedy: An exercise in the textuality of temporalization. Language \& Communication, 27(3), 291-306. doi: 10.1016/j.langcom.2007.01.003.

Goldenberg, S. (2011, August 19). Massive protest at White House against Alberta tar sands pipeline. The Guardian. Retrieved September 5, 2011, from http:// www.guardian.co.uk/environment/2011/aug/19/protest-white-house-tar-sands.

Goodwin, C. (2000). Action and embodiment within situated human interaction. Journal of Pragmatics, 32(10), 1489-1522.

Goodwin, C., \& Goodwin, M. H. (1986). Gesture and coparticipation in the activity of searching for a word. Semiotica, 62, 51-75. doi: 10.1016/S0378-2166(99)00096-X.

Gordon, J. (2012). Displacing oil: Towards "lyric" re-presentations of the Alberta oil sands. In D. Coleman, E. G. Glanville, W. Hasan, \& A. Kramer-Hamstra (Eds.), Countering displacements: The creativity and resilience of Indigenous and refugee-ed Peoples (pp. 1-30). The University of Alberta Press.

Government of Alberta. (2014). Reclamation Process. Alberta Environment and Sustainable Resource Development. Retrieved May 5, 2014, from http:// esrd.alberta.ca/focus/state-of-the-environment/land/response-indicators/oil-sandsmining-development-and-reclamation/reclamation-process.aspx. 
Graham, C. (2009). Accounting and subalternity: enlarging a research space. Accounting, Auditing \& Accountability Journal, 22(3), 309-318. doi: 10.1108/09513570910945633

Grande, S. (2008). Red pedagogy: The un-methodology. In N. K. Denzin, Y. S. Lincoln, \& L. T. Smith (Eds.), Handbook of critical and indigenous methodologies (pp. 233254). Sage.

Grant, L. E. (2012). Culturally motivated lexis in New Zealand English. World Englishes, 31(2), 162-176. doi:10.1111/j.1467-971X.2012.01738.x.

Greenpeace New Zealand. (2013). The Future is here: New jobs, new prosperity and a new clean economy. Retrieved from http://www.greenpeace.org/new-zealand/en/ campaigns/climate-change/The-Future-is-Here/.

Guggenheim, D. (2006). An inconvenient truth. Documentary.

Gwiazda, W. (2014). Truth and Reconciliation Commission faces huge new pile of documents. Radio Canada International. Retrieved from http://www.rcinet.ca/en/ 2014/04/22/truth-and-reconciliation-commission-faces-huge-new-pile-of-documents/.

Hager, N., \& Mussen, D. (2007, May 27). "I was paid to betray protesters." Sunday Star Times. Retreived from http://www.nickyhager.info/i-was-paid-to-betray-protesters/.

Halliday, M. a. K. (1967). Notes on transitivity and theme in English: Part 2. Journal of Linguistics, 3(02), 199-244. doi:10.1017/S0022226700016613.

Haluza-Delay, R. (2012). Giving consent in the petrostate: Hegemony and Alberta oil sands. Journal for Activism in Science and Technology Education, 4(1), 1-6.

Hammersley, M. (2007). Reflections on linguistic ethnography. Journal of Sociolinguistics, 11(5), 689-695. doi:10.1111/j.1467-9841.2007.00347.x.

Hammersley, M., \& Atkinson, P. (1995). Ethnography: Principles in Practice. Psychology Press.

Hansen, A. (2011). Communication, media and environment: Towards reconnecting research on the production, content and social implications of environmental communication. International Communication Gazette, 73(1-2), 7-25. doi: 10.1177/1748048510386739.

Hansen, A., \& Machin, D. (2008). Visually branding the environment: Climate change as a marketing opportunity. Discourse Studies, 10(6), 777-794. doi:

$10.1177 / 1461445608098200$. 
Harré, R., \& Langenhove, L. V. (1991). Varieties of Positioning. Journal for the Theory of Social Behaviour, 21(4), 393-407. doi:10.1111/j.1468-5914.1991.tb00203.x.

Harré, R., Moghaddam, F. M., Cairnie, T. P., Rothbart, D., \& Sabat, S. R. (2009). Recent advances in positioning theory. Theory \& Psychology, 19(1), 5-31. doi: $10.1177 / 0959354308101417$.

Harvey, K. (2013). Medicalisation, pharmaceutical promotion and the Internet: A critical multimodal discourse analysis of hair loss websites. Social Semiotics, 23(5), 691-714. doi:10.1080/10350330.2013.777596.

Hay, J. (2008). The pragmatics of humor support. Humor - International Journal of Humor Research, 14(1), 55-82. doi:10.1515/humr.14.1.55.

Hayward, T. (2007). Human rights versus emissions rights: Climate justice and the equitable distribution of ecological space. Ethics \& International Affairs, 21(4), 431450. doi: 10.1111/j.1747-7093.2007.00117.x.

Hill, G. (2009). 500 years of Indigenous resistance. PM Press.

Holmes, J. (2000). Politeness, power and provocation: How humour functions in the workplace. Discourse Studies, 2(2), 159-185. doi:10.1177/1461445600002002002.

Holmes, J. (2007). Monitoring organisational boundaries: Diverse discourse strategies used in gatekeeping. Journal of Pragmatics, 39(11), 1993-2016. doi: 10.1016/ j.pragma.2007.07.009.

Holmes, J., \& Bell, A. (1988). Learning by experience: Notes for New Zealand social dialectologists. Te Reo, 31, 19-49.

Holmes, J., \& Marra, M. (2002). Humour as a discursive boundary marker in social interaction. In A. Duszak (Ed.), Us and others: Social identities across languages, discourses and cultures (pp. 377-400). John Benjamins Publishing Company.

Holmes, J., Bell, A., \& Boyce, M. (1991). Variation and change in New Zealand English: A social dialect investigation: Project report to the Social Sciences Committee of the Foundation for Research, Science and Technology. Department of Linguistics, Victoria University.

Holmes, J., Marra, M., \& Vine, B. (2011). Leadership, discourse, and ethnicity. Oxford University Press.

Holmes, J., Marra, M., \& Vine, B. (2012). Politeness and impoliteness in ethnic varieties of New Zealand English. Journal of Pragmatics, 44(9), 1063-1076. doi: 10.1016/j.pragma.2011.11.006. 
hooks, bell. (2003). Teaching community: A pedagogy of hope. Psychology Press.

Howlett, M., \& Raglon, R. (2006). Constructing the environmental spectacle: Green advertisements and the greening of the corporate image, 1910-1990. In P. Muhlhausler \& Fill, Alwin (Eds.), Ecolinguistics reader: Language, ecology and environment (pp. 245-257). Continuum.

Hudema, M. (2010). Put a CAPP on Tar Sands Greenwashing. Greenpeace Canada. Retrieved August 23, 2011, from http://www.greenpeace.org/canada/en/Blog/put-acapp-on-tar-sands-greenwashing/blog/28380/.

Humphries, M. (2008). North American oil sands: History of development, prospects for the future. Retrieved from fas.org/sgp/crs/misc/RL34258.pdf.

Ibrahim, M. (2014). Critics raise concerns over oil industry involvement in Alberta curriculum redesign. Edmonton Journal. Retrieved March 12, 2014, from http:// www.edmontonjournal.com/news/edmonton/Critics+raise+concerns+over+industry +involvement+Alberta/9606253/story.html.

IEN. (2011). Indigenous Environmental Network ---- What Are the Tar Sands? Retrieved August 23, 2011, from http://www.ienearth.org/what-are-tar-sands.html.

Inuit Tapiriit Kanatami. (2013, May 14). Press Release - Canadian Inuit Leaders Reject Environmentalist Campaign Pitting Indigenous Peoples Against Arctic Resource Development. Retrieved February 5, 2014, from https://www.itk.ca/media/mediarelease/press-release-canadian-inuit-leaders-reject-environmentalist-campaign-pitting

Isenberg, A. C. (2000). The destruction of the bison: An environmental history, 1750-1920. Cambridge University Press.

Jenks, C. J. (2011). Transcribing talk and interaction: Issues in the representation of communication data. John Benjamins Publishing Company.

Jewitt, C. (2009). An introduction to multimodality. In C. Jewitt (Ed.), The Routledge handbook of multimodal analysis (pp. 14-27). London; New York: Routledge.

Johansson, A. (2011). Constituting "real" cutters: A discourse theoretical analysis of self-harm and identity. In A. E. Sjolander \& J. G. Payne (Eds.), Tracking discourses: Politics, identity and social change (pp. 197-224). Nordic Academic Press.

John Key - Exploring Our Resource Potential. (2013). Retrieved from http:// www.youtube.com/watch?v=qQrBly7xMjs\&feature=youtube_gdata_player.

Johnstone, B. (2010). Locating language in identity. In C. Llamas \& D. J. L. Watt (Eds.), Language and identities (pp. 29-36). Edinburgh University Press. 
Jones, A., \& Jenkins, K. (2008). Rethinking collaboration: Working the indigenecolonizer hyphen. In N. K. Denzin, Y. S. Lincoln, \& L. T. Smith (Eds.), Handbook of critical and indigenous methodologies (pp. 471-486). Sage.

Jones, R. H. (2010). Creativity and discourse. World Englishes, 29(4), 467-480. doi: 10.1111/j.1467-971X.2010.01675.X.

Katz-Rosene, R. (2012). Materiality informs subjectivity informs materiality: An environmental history of Alberta's bituminous sands. Presented at the Canadian Association of Geographers' Annual Meeting, Wilfrid Laurier University.

Kelly, E. N., Short, J. W., Schindler, D. W., Hodson, P. V., Ma, M., Kwan, A. K., \& Fortin, B. L. (2009). Oil sands development contributes polycyclic aromatic compounds to the Athabasca River and its tributaries. Proceedings of the National Academy of Sciences of the United States of America, 106(52), 22346-22351. doi:10.1073/pnas. 0912050106.

Kendon, A. (2004). Gesture: Visible action as utterance. Cambridge University Press.

Khan, N. (2014). Cowboys and Indians ride into U.S. capital to protest Keystone pipeline. Al Jazeera America. Retrieved April 30, 2014, from http:// america.aljazeera.com/articles/2014/4/22/keystone-xlprotestcowboysindiansranchers.html.

Khasnabish, A., \& Haiven, M. (2012). Convoking the radical imagination: Social movement research, dialogic methodologies, and scholarly vocations. Cultural Studies $\leftrightarrow$ Critical Methodologies, 12(5), 408-421. doi:10.1177/1532708612453126.

Kidner, K. (2012, May 30). Tar sands or oil sands: What these words really mean in Alberta. Presented at the Environmental Studies Association of Canada (ESAC), Kitchener-Waterloo, Ontario.

King, B. W. (2011). Linguistic negotiations of sexual agency in sexuality education. Unpublished doctoral dissertation, Victoria University of Wellington, Wellington, New Zealand.

Know Your Meme. (2010). I Want to Believe. Know Your Meme. Retrieved from http:// knowyourmeme.com/memes/i-want-to-believe.

Kowalsky, N., \& Haluza-DeLay, R. (2013). Homo energeticus: Technological rationality in the Alberta tar sands. In H. M. Jerónimo, J. L. Garcia, \& C. Mitcham (Eds.), Jacques Ellul and the technological society in the 21st century (pp. 159-175). Springer Netherlands. 
Kress, G. (2009). What is mode? In C. Jewitt (Ed.), The Routledge handbook of multimodal analysis (pp. 54-67). London; New York: Routledge.

Kress, G. (2011). "Partnerships in research": Multimodality and ethnography. Qualitative Research, 11(3), 239-260. doi:10.1177/1468794111399836.

Kress, G., \& Van Leeuwen, T. (2001). Multimodal discourse: The modes and media of contemporary communication. London; New York: Arnold; Oxford University Press.

Kress, G., \& Van Leeuwen, T. (2006). Reading images. Routledge.

Kuśmierczyk, E. (2013). "The only problem is finding a job": Multimodal analysis of job interviews in New Zealand. Unpublished doctoral dissertation, Victoria University of Wellington, Wellington, New Zealand.

Kwon, W., Clarke, I., \& Wodak, R. (2009). Organizational decision-making, discourse, and power: Integrating across contexts and scales. Discourse \& Communication, 3(3), 273 -302. doi:10.1177/1750481309337208.

Labov, W. (1972). 13. The social stratification of (R) in New York City department stores. In Labov, W. Sociolinguistic patterns. Philadelphia, PA: University of Pennsylvania Press, 43-69.

Lams, L. (2010). Linguistic tools of empowerment and alienation in the Chinese official press: Accounts about the April 2001 Sino-American diplomatic standoff. Pragmatics, 20(3), 315-342.

Law, R. (1997). Masculinity, place, and beer advertising in New Zealand: The southern man campaign. New Zealand Geographer, 53(2), 22-28. doi:10.1111/j.

1745-7939.1997.tb00495.x.

Lawson, A. J. (2012). Painted caves: Palaeolithic rock art in Western Europe. Oxford University Press.

Leah, D. (2014). June 28th: Final "Tar Sands Healing Walk" Simply a New Beginning, Say Organizers. DeSmog Canada. Retrieved May 22, 2014, from http://desmog.ca/ 2014/05/08/june-28th-final-tar-sands-healing-walk-simply-new-beginning-sayorganizers.

Lee, B. P. H. (2001). Mutual knowledge, background knowledge and shared beliefs: Their roles in establishing common ground. Journal of Pragmatics, 33(1), 21-44. doi: 10.1016/S0378-2166(99)00128-9.

Levant, E. (2010). Ethical oil: The case for Canada's oil sands. McClelland \& Stewart. 
Lewis, J. (2014). Group vows to hinder Otago oil drill. New Zealand Herald. Retrieved from http://www.nzherald.co.nz/business/news/article.cfm?c_id=3\&objectid=11185432.

Liebscher, G., Daily-O'Cain, J., Muller, M., \& Reichert, T. (2010). Negotiating identities through pronouns of address in an immigrant community. Pragmatics, 20(3), 375-400.

Long, S., Roberts, E., \& Dehm, J. (2010). Climate justice inside and outside the UNFCCC: The example of REDD. Journal of Australian Political Economy, The, (66), 222-246.

Low, W., \& Davenport, E. (2005). Postcards from the edge: Maintaining the "alternative" character of fair trade. Sustainable Development, 13(3), 143-153. doi: 10.1002/sd.275.

Lubitow, A., \& Davis, M. (2011). Pastel injustice: The corporate use of pinkwashing for profit. Environmental Justice, 4(2), 139-144. doi:10.1089/env.2010.0026.

Luhman, R. (1990). Appalachian English stereotypes: Language attitudes in Kentucky. Language in Society, 19(3), 331-348. doi:10.2307/4168150.

Machin, D. (2013). What is multimodal critical discourse studies? Critical Discourse Studies, 10(4), 347-355. doi:10.1080/17405904.2013.813770.

Machin, D., \& Mayr, A. (2013). Personalising crime and crime-fighting in factual television: An analysis of social actors and transitivity in language and images. Critical Discourse Studies, 10(4), 356-372. doi:10.1080/17405904.2013.813771.

Malavasi, D. (2011). The multifaceted nature of banks' annual reports as informative, promotional and corporate communication practices. In G. Garzone \& P. E. Allori (Eds.), Discourse, identities and genres in corporate communication: Sponsorship, advertising and organizational communication (pp. 211-233). Peter Lang.

Mann, S. (2011). A critical review of qualitative interviews in applied linguistics. Applied Linguistics, 32(1), 6-24. doi:10.1093/applin/amq043.

Marra, M., King, B. W., \& Holmes, J. (2014). Trivial, mundane or revealing? Food as a lens on ethnic norms in workplace talk. Language \& Communication, 34, 46-55. doi: 10.1016/j.langcom.2013.08.004.

Martinec, R., \& Van Leeuwen, T. (2009). The language of new media design: Theory and practice. London; New York: Routledge.

McCorkindale, W. (2014). Dunedin divided over deep-sea oil drilling. Stuff.co.nz. Retrieved from http://www.stuff.co.nz/business/industries/9600471/Dunedin-dividedover-deep-sea-oil-drilling. 
McDermott, V. (2012). ACFN fights ruling on constitutional challenge. Fort McMurray Today. Retrieved from http://www.fortmcmurraytoday.com/2012/11/01/acfn-fightsruling-against-constitutional-challenge.

McDonald, E. (2013). Embodiment and meaning: Moving beyond linguistic imperialism in social semiotics. Social Semiotics, 23(3), 318-334. doi:

10.1080/10350330.2012.719730.

McElhinny, B. (2006). Written in sand: Language and landscape in an environmental dispute in southern Ontario. Critical Discourse Studies, 3(2), 123-152. doi:

10.1080/17405900600908087.

McNeill, D. (1992). Hand and mind: What gestures reveal about thought. University of Chicago Press.

Miles, C. (2010). Discursive power and the new labor force: The metamorphosis of a speech community. Language and Intercultural Communication, 10(2), 150-164. doi: 10.1080/14708470903348507.

Milroy, L. (1987). Observing and analysing natural language: A critical account of sociolinguistic method. Oxford, OX, UK; New York, NY, USA: Blackwell.

Milroy, L., \& Margrain, S. (1980). Vernacular language loyalty and social network. Language in Society, 9(01), 43-70. doi:10.1017/S0047404500007788.

Ministry for the Environment. (2001). Valuing New Zealand's Clean Green Image. Ministry for the Environment. Retrieved from http://www.mfe.govt.nz/publications/susdev/clean-green-image-value-aug01/.

Mondada, L. (2007). Commentary: Transcript variations and the indexicality of transcribing practices. Discourse Studies, 9(6), 809-821. doi:

$10.1177 / 1461445607082581$.

Mondada, L. (2013). Displaying, contesting and negotiating epistemic authority in social interaction: Descriptions and questions in guided visits. Discourse Studies, 15(5), 597-626. doi:10.1177/1461445613501577.

Morningstar, C. (2010). Eyes wide shut: TckTckTck exposé. The Art of Annihilation. Retrieved July 26, 2011, from http://theartofannihilation.com/category/eyes-wide-shutsleeping-with-the-enemy-tcktcktck-expose/.

Nielsen, D., \& Hay, J. (2005). Perceptions of regional dialects in New Zealand. Te Reo, 48, 95-110. 
Nikiforuk, A. (2008). Tar sands: Dirty oil and the future of a continent. Vancouver; Berkeley. Greystone Books.

Norris, S. (2004a). Analyzing multimodal interaction: A methodological framework. Taylor \& Francis.

Norris, S. (2004b). Multimodal discourse analysis: A conceptual framework. In P. LeVine \& R. Scollon (Eds.), Discourse and technology (pp. 101-115). Georgetown University Press.

Norris, S. (2009). Modal density and modal configurations: Multimodal actions. In C. Jewitt (Ed.), The Routledge handbook of multimodal analysis (pp. 78-90). London; New York: Routledge.

Norris, S. (2011). Identity in interaction: Introducing multimodal interaction analysis. Walter De Gruyter Inc.

NZPA. (2006). Protesters plot occupation of Happy Valley coal mine. New Zealand Herald. Retrieved from http://www.nzherald.co.nz/nz/news/article.cfm?

c_id=1\&objectid=10365214.

O'Connor, P. E. (2007). Activist sociolinguistics in a critical discourse analysis perspective. In D. G. Weiss \& P. R. Wodak (Eds.), Critical discourse analysis: Theory and interdisciplinarity (pp. 223-240). Palgrave Macmillan.

Ochs, E. (1999). Transcription as theory. In A. Jaworski \& N. Coupland (Eds.), The discourse reader (pp. 166-178). London; New York: Routledge.

ONE News. (2012a). Aussie farmer warns over lignite mining. TVNZ. Retrieved from http://tvnz.co.nz/national-news/aussie-farmer-warns-over-lignite-mining-4697211.

ONE News. (2012b). Protesters celebrate Petrobras withdrawal from East Cape. TVNZ. Retrieved from http://tvnz.co.nz/business-news/protesters-celebrate-petrobraswithdrawal-east-cape-5260016.

Parliamentary Commissioner for the Environment. (2010). Lignite and climate change: The high cost of low grade coal. Retrieved from www.pce.parliament.nz/assets/ Uploads/PCE-Lignite-Update2.pdf.

Payton, L. (2012). Radicals working against oilsands, Ottawa says. Retrieved January 28, 2014, from http://www.cbc.ca/1.1148310.

Phoenix, A., \& Pattynama, P. (2006). Intersectionality. European Journal of Women's Studies, 13(3), 187-192. doi:10.1177/1350506806065751. 
Pietikainen, S., \& Dufva, H. (2006). Voices in discourses: Dialogism, critical discourse analysis and ethnic identity. Journal of Sociolinguistics, 10(2), 205-224. doi: 10.1111/j. 1360-6441.2006.00325.x.

Pullman, E. (2011). Open Letter to Oprah Winfrey on "Ethical Oil" Ads. Retrieved August 30, 2012, from http://www.desmogblog.com/open-letter-oprah-winfrey-ethicaloil-ads.

Rampton, B. (2007). Neo-Hymesian linguistic ethnography in the United Kingdom. Journal of Sociolinguistics, 11(5), 584-607. doi:10.1111/j.1467-9841.2007.00341.x.

Regan, P. (2010). Unsettling the settler within: Indian residential schools, truth telling, and reconciliation in Canada. UBC Press.

Reynolds, M. (2004). How does Monsanto do it? An ethnographic case study of an advertising campaign. Text-Interdisciplinary Journal for the Study of Discourse, 24(3), 329-352. doi: 10.1515/text.2004.014.

Rising Tide North America, \& Carbon Trade Watch. (n.d.). Hoodwinked in the hothouse: False solutions to climate change. Retrieved from http:// www.carbontradewatch.org/publications/hoodwinked-in-the-hothouse-false-solutionsto-climate-c.html.

Rooney, R. C., Bayley, S. E., \& Schindler, D. W. (2012). Oil sands mining and reclamation cause massive loss of peatland and stored carbon. Proceedings of the National Academy of Sciences. doi:10.1073/pnas.1117693108.

Rossano, F. (2012). Gaze in conversation. In J. Sidnell \& T. Stivers (Eds.), The handbook of conversation analysis (pp. 308-329). John Wiley \& Sons, Ltd.

Royal Society of New Zealand. (2014). Facing the future: Towards a green economy for New Zealand (pp. 1-13). Royal Society of New Zealand. Retrieved from http:// www.royalsociety.org.nz/expert-advice/information-papers/yr2014/greeneconomy/.

Santulli, F. (2011). Event and sponsoring company. Presentation and linking strategies in the web-mediate environment. In G. Garzone \& P. E. Allori (Eds.), Discourse, identities and genres in corporate communication: Sponsorship, advertising and organizational communication (pp. 99-119). Peter Lang.

Sarangi, S., \& Candlin, C. N. (2003). Introduction trading between reflexivity and relevance: new challenges for applied linguistics. Applied Linguistics, 24(3), 271-285. doi:10.1093/applin/24.3.271. 
Schnurr, S., \& Rowe, C. (2008). The "dark side" of humour. An analysis of subversive humour in workplace emails. Lodz Papers in Pragmatics, 4(1), 109-130. doi: 10.2478/ v10016-008-0010-6.

Schubert, T. W. (2004). The power in your hand: Gender differences in bodily feedback from making a fist. Personality and Social Psychology Bulletin, 30(6), 757-769. doi: $10.1177 / 0146167204263780$.

Schulman, S. (2011). Israel and "pinkwashing." The New York Times. Retrieved from http://www.nytimes.com/2011/11/23/opinion/pinkwashing-and-israels-use-of-gays-as-amessaging-tool.html.

Schulz, Berth, A. (2006). Language and the natural environment. In P. Muhlhausler \& Fill, Alwin (Eds.), Ecolinguistics reader: Language, ecology and environment (pp. 109114). Continuum.

Scollon, R. (1999). Mediated discourse and social interaction. Research on Language \& Social Interaction, 32(1-2), 149-154. doi: 10.1207/S15327973RLSI321\&2_18.

Scollon, R. (2001). Mediated discourse: The nexus of practice. New York: Routledge.

Scollon, R., \& LeVine, P. (2004). Multimodal discourse analysis as the confluence of discourse and technology. In P. LeVine \& R. Scollon (Eds.), Discourse and technology (pp. 1-6). Georgetown University Press.

Scollon, R., \& Scollon, S. W. (2007). Nexus analysis: Refocusing ethnography on action. Journal of Sociolinguistics, 11(5), 608-625. doi:10.1111/j.

1467-9841.2007.00342.x.

Scollon, R., \& Scollon, S. W. (2009). Multimodality and language: A retrospective and prospective view. In C. Jewitt (Ed.), The Routledge handbook of multimodal analysis (pp. 170-180). London; New York: Routledge.

Shepard, B. (2011). Play, creativity, and social movements: If I can't dance, it's not my revolution (1st ed.). Routledge.

Silverstone, P. (2010). World's greenest oil: Turning the oil sands from black to green. Edmonton: PHS Holdings.

Smith, L. T. (1999). Decolonizing methodologies: Research and Indigenous Peoples. London: Dunedin, N.Z: Zed Books; University of Otago Press.

Starosielski, N. (2011). "Movements that are drawn": A history of environmental animation from The Lorax to FernGully to Avatar. International Communication Gazette, 73(1-2), 145-163. doi:10.1177/1748048510386746. 
Stasi, M., \& Evans, A. (2013). Glitter(foot)ball tactics negotiating mainstream gender Equality in Iceland. Men and Masculinities, 16(5), 560-578. doi:

10.1177/1097184X13511251.

Spiel. (2010). In The Oxford dictionary of English. Retrieved from http://

www.oxfordreference.com.helicon.vuw.ac.nz/view/10.1093/acref/

9780199571123.001.0001/m_en_gb0800230?rskey=J1HLoU\&result=80875.

Streeck, J. (2009). Forward-gesturing. Discourse Processes, 46(2-3), 161-179. doi: 10.1080/01638530902728793.

Tady, M. (2006). How clean, how green? Critics say New Zealand doesn't live up to its image. E: The Environmental Magazine. Retrieved September 5, 2011, from http:// findarticles.com/p/articles/mi_m1594/is_3_17/ai_n16533119/.

Taylor, A., McGray, R., \& Watt-Malcolm, B. (2007). Struggles over labour power: The case of Fort McMurray. Journal of Education and Work, 20(5), 379-396. doi:

10.1080/13639080701814257.

The Canadian Press \& Global News. (2014). Oilsands cause food contamination and higher cancer rates. Global News. Retrieved from http://globalnews.ca/news/1436636/ oilsands-cause-food-contamination-and-higher-cancer-rates-report/.

The Canadian Press. (2013). Alberta's Top Cop Says Roadblocks Not Safe. The Huffington Post. Retrieved July 15, 2014, from http://www.huffingtonpost.ca/ 2013/01/18/jonathan-denis-alberta-idle-no-more-roadblocks-not-safe_n_2507444.html.

Timoney, K. P., \& Lee, P. (2009). Does the Alberta tar sands industry pollute? The scientific evidence. Open Conservation Biology Journal, 3, 65-81. doi: $10.2174 / 1874839200903010065$.

Uechi, J. (2013). CAPP-funded Energy IQ project to tour Canadian schools this fall. The Vancouver Observer. Retrieved from http://www.vancouverobserver.com/ environment/capp-funded-energy-iq-project-tour-canadian-schools-fall.

Usher, P. J., Tough, F. J., \& Galois, R. M. (1992). Reclaiming the land: Aboriginal title, treaty rights and land claims in Canada. Applied Geography, 12(2), 109-132. doi: 10.1016/0143-6228(92)90002-5.

Vale, L. J. (1992). Architecture, power, and national identity. New Haven: Yale University Press.

Van Dijk, T. A. (1993). Principles of critical discourse analysis. Discourse \& Society, 4(2), 249-283. doi:10.1177/0957926593004002006. 
Van Dijk, T. A. (1996). Discourse, power and access. In C. R., Coulthard, Malcolm Caldas-Coulthard (Ed.), Texts and practices: Readings in critical discourse analysis (pp. 84-104). London: Routledge.

Van Dijk, T. A. (2000). New (s) racism: A discourse analytical approach. In Simon Cottle (Ed.), Ethnic minorities and the media (pp. 33-49). Buckingham, UK \& Philadelphia. USA: Open University Press.

Van Leeuwen, T. (2004). Ten reasons why linguists should pay attention to visual communication. In P. LeVine \& R. Scollon (Eds.), Discourse and technology (pp. 7-19). Georgetown University Press.

Van Leeuwen, T. (2005). Introducing social semiotics. London: Routledge.

Van Leeuwen, T. (2011). The language of colour: An introduction (1st ed.). Abingdon, Oxon; New York, NY: Routledge.

Van Leeuwen, T. (2014). Towards a semiotics of listening. In E. Djonov \& S. Zhao (Eds.), Critical multimodal studies of popular discourse (pp. 251-263). New York, NY: Routledge.

Vanderklippe, N. (2013). Alberta scans the compass for crude oil export options. The Globe and Mail. Retrieved February 13, 2014, from http://www.theglobeandmail.com/ report-on-business/industry-news/energy-and-resources/alberta-scans-the-compassfor-crude-oil-export-options/article7536306/.

Vestergaard, A. (2013). Humanitarian appeal and the paradox of power. Critical Discourse Studies, 10(4), 444-467. doi:10.1080/17405904.2012.744322.

Waitt, G., \& Head, L. (2002). Postcards and frontier mythologies: Sustaining views of the Kimberley as timeless. Environment and Planning D: Society and Space, 20(3), 319 - 344. doi:10.1068/d269t.

Warren, P., \& Britain, D. (2000). Intonation and prosody in New Zealand English. In A. Bell \& K. Kuiper (Eds.), New Zealand English (pp. 146-172). Victoria University Press.

Wilson, N. A. (2011). Leadership as communicative practice: The discursive construction of leadership and team identity in a New Zealand rugby team. Unpublished doctoral dissertation, Victoria University of Wellington, Wellington, New Zealand.

Wodak, R. (2006). Images in/and news in a globalised world: Introductory thoughts. In I. Lassen, J. Strunck, \& T. Vestergaard (Eds.), Mediating ideology in text and image: Ten critical studies (pp. 1-16). John Benjamins Publishing Company. 
Wodak, R., \& Fairclough, N. (2010). Critical discourse analysis in action. In C. Coffin, T. M. Lillis, \& K. O'Halloran (Eds.), Applied linguistics methods: A reader: Systemic functional linguistics, critical discourse analysis and ethnography (pp. 98-111). London: Routledge.

Yakura, E. (2004). "Informed consent" and other ethical conundrums in videotaping interactions. In P. LeVine \& R. Scollon (Eds.), Discourse and technology (pp. 146150). Georgetown University Press. 


\section{Appendix A: Cast of Actors}

\section{Aotearoa/New Zealand}

\section{Activists \\ Industry Actors}

Al is a Pākehā man who grew up in Southland but currently lives on the north island. He works with many

Alanis is a Pākehā woman who works with a local Member of Parliament. She is involved in political groups, including the national anti-mining organisation. volunteer projects and lives in the area surrounding the lignite mine.

An American ex-pat, Amy farms with her family in a small town in Southland. She volunteers in the community and is involved with the anti-mining group.

Kalena and Don both work for the mining company based on the South Island.

Bernadette's family farm lies close to Jack Fischer is the CEO of the the proposed mine expansion. She is mining company.

a core member the local anti-mining group.

Justin is a Pākehā man who grew up in a small town on the north island. He works with a large environmental, political organisation and is a core member of the national anti-mining group.

Mark is an older, Pākehā sheep farmer in Southland and his land lies in the path of the proposed lignite mine. He refuses to sell to the company and is heavily involved in the local opposition. 
Molly has Māori ancestry and she lives in a small town outside the lignite mine. She is heavily involved in her community through volunteer projects, including the local antimining group.

\section{Canada}

\section{Activists}

Andrea runs a local, political arts organisation. She is involved in direct democracy projects and organises art and engagement events.

\section{Industry Actors}

Brandon works as a media representative for the Canadian Association of Petroleum Producers (CAPP), an organisation which represents the interests of oil and gas companies across the country.

Ezra Levant is a Sun News anchor and author of "Ethical Oil".
Christina works for a research institute that engages with environment and energy issues in Alberta.

Denise works in media for her nation, the Athabasca Chipewyan First Nation (ACFN) in Treaty 8 territory (Northern Alberta). She organises events, speaks internationally, and is involved in many local, grassroots groups.

Jill works for a large environmental organisation in Alberta. She works closely with Indigenous activists organising events and she is a core member of many local, grassroots groups involved in a variety of issues. 


\section{Marcelo works for a provincial}

environmental research group that is affiliated with a University. $\mathrm{He}$ is also involved in mentoring local grassroots organisations.

Tina lives and works in Washington, DC and traveled to Alberta during my fieldwork. She works as an independent journalist, covering environmental events.

Tom works for a large environmental group in Alberta. He organises large events, works closely with Indigenous activists, and is a core member of many local, grassroots groups.

William is a core organiser of a local queer rights group in Edmonton. He works with many local, grassroots groups involved in a variety of issues.

Nicole is from northern Alberta and she holds a PhD from McGill University in translation studies. 


\section{Appendix B: Interviewing Confidentiality Agreement}

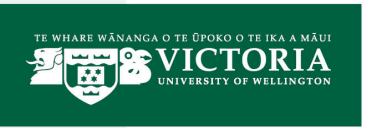

SCHOOL OF LINGUISTICS AND APPLIED LANGUAGE STUDIES

TE KURA TĀTARI REO

VICTORIA UNIVERSITY OF WELLINGTON, PO Box 600 , Wellington 6140 , New Zealand

Phone + 64-4-4635600 Fax +64-4-4635604 Email lals@vuw.ac.nz Web www.victoria.ac.nz/lals

Interview Confidentiality Agreement

Project Title: Beyond Greenwash: Environmental Discourses of Appropriation and Resistance

Principal Investigator: Keely Kidner

I , _ agree to ensure that the interviews

I conducted will remain confidential to Keely Kidner, her supervisors, and myself.

Signature:

Date: 


\section{Appendix C: Information Sheet}

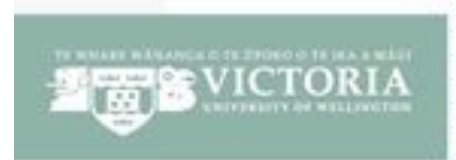

SCHDOL OF UYGUSTICS AND APRLED LANGUAGE BTUDES

TE KURA TATAR REO

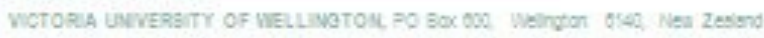

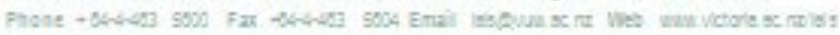

Information Sheet

Researcher: Keely Kidner: School of Linguistics and Applied Language Studies, Victoria University of Wellington

I am a $\mathrm{PhD}$ student in Applied Linguistics at Victoria University of Wellington undertaking a research project that will lead to a thesis. With this project, I am looking at how people use language and images when discussing environmental issues in Canada and New Zealand. This project has been granted ethical approval by the Victoria University of Wellington Human Ethics Committee.

I am inviting individuals representing industry interests as well as those involved in the climate justice movement to participate in a short interview that will be video recorded. The conversations will be loosely-structured, taking around 30 minutes and will be conducted by myself or a coresearcher. I will also be collecting publicly available artefacts (e.g. pamphlets, photos, songs, etc.) for my analysis. If there is an artefact I wish to use which is not publicly available, I will seek: consent from the owner creator. Should any participants feel the need to withdraw from the project, they may do 30 without question within three months from the time of data collection and I will make sure the comesponding responses/artefacts are not used. Any responses will be kept confidential and no names will be asaociated with the data. The recordings will only be viewed by myself, my co-researcher and my supervisors and will be stored in a locked cabinet and pasawordprotected file for the duration of this study. Identities will remsin anonymous at the time of writing and presentation.

The thesis will be submitted for marking to the School of Linguistics and Applied Language Studies and deposited in the University Library. I also intend to publish articles based on the data in scholarly joumals. Additionally, I will produce a summary report of the findings of the project for participants. The recordings and collected artefacts will be destroyed 5 years after the conclusion of the research.

If you have any questions or would like to receive further information about the project, please contact me at keely.kidner g vuw.ac.nz or by telephone on 044635233 ext. 8947.

Altematively, you may contact my supervisors, Professor Janet Holmes (janet.holmes (gvuw.ac.nz), and Dr. Meredith Marra (meredith.marra@vuw.ac.nz) We are all available by post at:

School of Linguistics and Applied Langugge Studies

Room 210, 2nd floor

von Zeditz Building

Kelbum Parade

Wellington 6012

Te Kura Tātari Reo

Te Whare Wänanga o te Upoko o te Tka a Māui

Poulka Poutapeta 600

Te Whanga-nui-a-Tara 6140

AOTEAROA 


\title{
Appendix D: Consent Form
}

\author{
VICTORIA \\ BCHOOL OF LIVUUSTICB AND APPLIED LANGUAE BTUDIES \\ TE KUFA TATAE RED

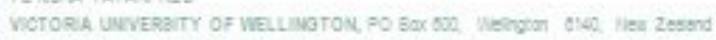

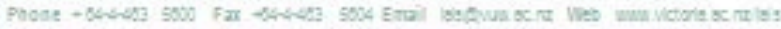

\section{Consent Form (Interviews)} \\ Thank you for considering participating in my study. My name is Keely Kidner and I am a PhD \\ student in Applied Linguistics at Victoria University of Wellington in New Zealand. I am looking \\ at how people use language when diacusaing environmental issues in Canada and New Zealand. \\ This project has been granted ethical approval by the Victoria University of Wellington \\ Human Ethics Committee. \\ To that end, I am asking you to agree to be video recordad for a short interview. Please read the \\ following carefully and sign below if you agree to the terms. \\ Please be asaured that your participation is voluntary and you do not have to participate in this \\ study if you do not want to. Anything you asy will be kept confidential and your name will not be \\ asociated with any responses. If you decide at any time that you wish to withdraw from the study, \\ you may simply let me know within three months from the time of data collection and I will not \\ use any of your responses. You do not have to answer any questions you do not want to answer. \\ Your recordings will only be viewed by myself, my co-researcher, and my supervisors and will be \\ stored in alocked cabinet and password-protected file for the duration of this study. Your name \\ will not be used and your identity will remain anonymous at the time of writing and presentation. \\ The data will be used for my $\mathrm{PhD}$ thesis a well as publication in academic joumals. At the end of \\ the project, I will produce a summary report for you. \\ If you have any questions or concems, please contact me at keely. kidner d vuw.ac.nz, or -bv \\ phone on 044635233 ext. 8947 . \\ Altematively, you may contact my supervisors: \\ Professor Janet Holmes: janet.holmes @ vuw.ac.nz \\ Dr Meredith Marra: meredith.marra@uww.ac.nz \\ I have read and understood the consent form and I agree to its terms: \\ Name (please print): \\ Signature: \\ Date:
}




\section{Appendix E: Ethics Approval}

TE WHARE WĀNANGa O TE ŪPOKO O TE IKA A MĀUI

59

MEMORANDUM

Phone $\quad 0-4-4635676$

Fax $\quad 0-4-4635209$

Email Allison.kirkman@vuw.ac.nz

\begin{tabular}{l|l}
\hline TO & Keely Kidner \\
\hline COPY TO & $\begin{array}{l}\text { Janet Holmes } \\
\text { Meredith Marra }\end{array}$ \\
\hline FROM & Dr Allison Kirkman, Convener, Human Ethics Committee \\
\hline
\end{tabular}

\begin{tabular}{l|l}
\hline DATE & 5 January 2012 \\
\hline PAGES & 1 \\
\hline
\end{tabular}

SUBJECT $\quad$ Ethics Approval: 19055

Beyond Greenwash: Environmental discourses of

appropriation and resistance

Thank you for your application for ethical approval, which has now been considered by the Standing Committee of the Human Ethics Committee.

Your application has been approved from the above date and this approval continues until 31 July 2014. If your data collection is not completed by this date you should apply to the Human Ethics Committee for an extension to this approval.

Best wishes with the research.

Allison Kirkman

Human Ethics Committee 


\section{Appendix F: Transcription Conventions}

\begin{tabular}{|l|l|}
\hline UPPER CASE & emphatic stress \\
\hline() & unintelligible \\
\hline- & interruption \\
\hline+ & pause \\
\hline$/ / \backslash$ & start and end of simultaneous speech of 'current' speaker \\
\hline$/ /$ & $\begin{array}{l}\text { start and end of simultaneous speech of 'incoming' } \\
\text { speaker }\end{array}$ \\
\hline$<>$ & paralinguistic speech (e.g. laughter) \\
\hline$:$ & elongation \\
\hline$=$ & latched utterance \\
\hline
\end{tabular}

